\author{
FINAL REPORT \\ Department of Energy \\ DE-F07-99ID13608
}

\title{
SYSTEMATIC MICROSTRUCTURAL \& CORROSION PERFORMANCE EVALUATION \\ OF \\ CK-3MCuN \& CN-3MN HIGH MOLYBDENUM STAINLESS STEEL CASTINGS
}

October 2001

\author{
C.D. LUNDIN \\ S. WEN \\ W. LIU \\ G. ZHOU
}

MATERIALS JOINING RESEARCH

MATERIALS SCIENCE AND ENGINEERING

THE UNIVERSITY OF TENNESSEE, KNOXVILLE, TN 


\section{Table of Contents}

1. Introduction 1

2. Materials 4

3. Experimental Procedures and Sample Preparation 5

3-1 Metallographic Evaluation using Optical Light Microscopy 5 and Stain- etching Technique

3-2 SEM/EDS Analysis $\quad 5$

3-3 X-ray Diffraction Analysis 6

3-4 Inclusion Study $\quad 7$

3-5 Solution Annealing $\quad 7$

3-6 Corrosion Testing 8

4. Results and Discussion 12

4-1 Microstructural Characterization of CK-3MCuN 12

4-2 Microstructural Characterization of CN-3MN 95

4-3 Results of Inclusion Study 163

4-4 Localized Corrosion Behavior of CK-3McuN and CN-3MN 171

4-5 Non-Uniform Microstructure of Cast Bar 187

5. Conclusions 203

6. Recommendation 208

$\begin{array}{ll}\text { References } & 209\end{array}$

Tables 210-

$\begin{array}{ll}\text { Appendix A } & 218\end{array}$ 


\section{INTRODUCTION}

High molybdenum austenitic stainless steel castings are widely accepted for their high strength, excellent weldability, and good corrosion resistance over a wide range of temperatures in highly oxidizing aqueous and gaseous media in chemical processing and other environments. With their desirable performance, high molybdium austenitic stainless steel castings are increasingly applied in industry in a similar manner as wrought materials.

In general, cast and wrought stainless and high alloy steels are anticipated to possess equivalent resistance to corrosive media, and they are frequently used in conjunction with each other. However, alloying element segregation usually is more evident in castings than in wrought counterparts. Segregation of alloying elements can lead to the formation of secondary phases, such as sigma $(\sigma)$. Mechanical properties and especially the corrosion resistance of castings may be affected by the formation of secondary phases [1-3]. In addition, improper heat treatment procedures can also lead to the formation of carbides and secondary phases in high alloy and austenitic stainless steels.

A previous study on the corrosion behavior of austenitic stainless steel castings [sponsored by Department of Defense (DOD)] was conducted at The University of Tennessee. A significant database was developed on corrosion behavior, which is suitable for comparison on a heat-to-heat and cast-to-wrought alloy basis. The test results were reported to the Steel Founders' Society of America (SFSA) High Alloys Technical Committee in a final report, entitled "Improved Process Procedures for Upgrading \& Repair of High Alloy \& Stainless 
Castings" [4], on the Phase I DOD Program in December 1996. However, this DOD effort did not include an evaluation of the microstructural differences between cast and wrought lots or the effect of heat treatment in terms of control of microstructure.

In order to provide a better understanding of corrosion behavior of castings, follow-on programs-"Microstructural Investigation of High Alloy Stainless and Ni-Base Castings" [Phase I study (Sept. - Dec. 1996), sponsored by Cast Metal Coalition (CMC)], and "Systematic Microstructural \& Corrosion Performance Evaluation of CK-3MCuN \& CN-3MN High Molybdenum Stainless Steel Castings" [Phase II study (Jan. 1999 - Jan. 2001), sponsored by Department of Energy (DOE) and SFSA]—have been conducted at The University of Tennessee (UT). The objectives of the study are the following: 1) to determine the microstructural characteristics of high Mo austenitic stainless steel castings in the as-cast and solution annealed condition in comparison with those of their wrought counterparts, 2) to identify the secondary phases in high Mo austenitic stainless steel castings, and 3) to understand the effect of secondary phases on corrosion behavior of high Mo austenitic stainless steel castings. In addition, another focus in the study was observing the effect of solution annealing on the microstructures of high Mo austenitic stainless steel castings as a function of solution annealing temperature and cooling conditions.

In this study, an extensive optical light microscopy (OLM), scanning electron microscopy (SEM), and energy dispersive spectroscopy (EDS) were used for characterization of the microstructures. To confirm the results, X-ray 
diffraction was also used. In addition, special stain-etching techniques were used for identifying $\sigma$ phase.

The results of microstructural evaluation and corrosion performance on high Mo stainless steel castings obtained in the Phase I and Phase II studies are summarized and discussed in this final report. The nature of the microstructure present in castings plays a key role in understanding the corrosion behavior of cast stainless steels. Through these efforts, the microstructural relationships defined provide a better understanding of the corrosion behavior and assist in defining chemistry/foundry practice changes necessary to optimize availability and performance. 


\section{MATERIALS}

Two types of high Mo austenitic stainless steel castings-CK-3MCuN and $\mathrm{CN}-3 \mathrm{MN}$ with multi-heats, provided by different foundries-were used in the study. A total of ten heats, five heats of each type, were used in the investigation. The selected heats of $\mathrm{CK}-3 \mathrm{MCuN}$ include two heats from cast bars (identified as Heats K3GAO \& K3GCO) and three heats from cast wedge blocks (Heat 2, Heat 3 \& Heat 5), as-described in the Final Report of Phase I study. The selected heats of $\mathrm{CN}-3 \mathrm{MN}$ include two heats from cast bars (identified as Heats N3GAO \& N3GBO) and three heats from cast wedge blocks (Heat 2, Heat 3 \& Heat 5) also as-described in the Final Report of Phase I study. The chemical composition was analyzed for all heats and the results for each heat, together with that of the wrought counterpart (254 SMO and AL-6XN), are presented in Tables 1 and 2 in comparison with the ASTM A743 specification. 


\section{EXPERIMENTAL PROCEDURES AND SAMPLE PREPARATION}

\section{3-1. Metallographic Evaluation using Optical Light Microscopy and Stain- etching Technique}

Specimens for metallographic evaluation (1" diameter X1/8") were extracted from cast bars in the as-cast and solution annealed conditions. All metallographic specimens were mounted and polished to $0.05 \mu \mathrm{m}$, and etched electrolytically with solute sensitive etchants. To best reveal microstructures, electrolytic etching in $10 \%$ oxalic acid (voltage: $10 \mathrm{~V}$, etching time: $10-30 \mathrm{sec}$ ) was selected for this study. However, to assess the presence of sigma $(\sigma)$ phase in Fe-Cr-Ni casting alloys, a stain-etching technique employed in a $10 \%$ sodium cyanide electrolyte (current density: $1 \mathrm{~A} / \mathrm{in}^{2}$, etching time: $5 \mathrm{sec}$ ) was used subsequent to normal etching in $10 \%$ oxalic acid. Specimens were rinsed in distilled water, cleaned using methanol, and dried in air after etching.

The microstructural evaluation was conducted using optical light microscopy at magnifications to $1000 \mathrm{X}$.

\section{3-2. SEM/EDS Analysis}

Specimens for SEM/EDS evaluation (1" diameter X1/8"), extracted from $\mathrm{CK}-3 \mathrm{MCuN}$ in the as-cast and solution annealed conditions, were prepared asdescribed above. The microstructure was characterized using SEM secondary electron imaging at a magnification of 1000X. EDS analysis was conducted at locations of interest for the as-cast and solution annealed conditions. For each 
specimen, the EDS evaluation was applied at equivalent locations. Therefore, the EDS results are comparable for each specimen.

\section{3-3. X-ray Diffraction Analysis}

An electrolytic precipitate extraction technique was used to isolate the precipitates present in $\mathrm{CK}-3 \mathrm{MCuN}$ and $\mathrm{CN}-3 \mathrm{MN}$ cast materials in both the ascast and solution annealed condition. To extract particles, a sample was dissolved in a $10 \% \mathrm{HCl}$ methanol solution for 1.5 hours at a constant voltage of 8 volts (referred to a platinum electrode). A centrifuge was used to separate the particles from the solution. The particles collected were cleaned using pure methanol and dried in air. In order to facilitate holding the extracted powder for the X-ray diffraction, the powder was mixed with Duco type cement, which is an amorphous material and the mixture was placed on glass (also amorphous). The specimens for wrought counterparts $254 \mathrm{SMO}$ and AL-6XN used for X-ray diffraction were prepared following the same procedure.

A Rigaku type X-ray diffraction apparatus was used for conducting the X-ray analysis. The conditions for X-ray diffraction were the following: i) voltage 35 [kv], ii) current - 30 [mA], iii) scan speed - 7.2 [degree/min], and iv) time constant of 0.3 [sec]. The data from X-ray diffraction studies were recorded in the form of intensity as a function of $2 \theta$ (diffraction angle). Peaks present in the X-ray spectrum were identified based on the $2 \theta$ value and peak intensity ratio. 


\section{3-4. Inclusion Study}

For inclusion evaluation, specimens (1/2"x1/2") were extracted from CK$3 \mathrm{MCuN}$ and $\mathrm{CN}-3 \mathrm{MN}$ (three heats of each) in the as-cast and solution annealed condition. Specimens were mounted and polished to $0.05 \mu \mathrm{m}$ and left in the unetched condition. Specimens from wrought counterparts 254 SMO and AL-6XN for inclusion evaluation were prepared following the same procedure.

Quantitative metallographic techniques were applied to inclusion evaluation using the Image-Pro Plug image analysis system.

\section{3-5. Solution Annealing}

To study the effect of heat treatment, solution annealing was conducted at three temperatures: $2100^{\circ} \mathrm{F} / 1150^{\circ} \mathrm{C}$ (minimum temperature per ASTM A743), $2200^{\circ} \mathrm{F} / 1205^{\circ} \mathrm{C}\left(100^{\circ} \mathrm{F}\right.$ above the lower limit per ASTM A743, within the common temperature range of foundry solution annealing: $2100-2250^{\circ} \mathrm{F} / 1150-1230^{\circ} \mathrm{C}$ ), and $2300^{\circ} \mathrm{F} / 1260^{\circ} \mathrm{C}$ (higher than common foundry solution annealing temperatures). As per ASTM A743 recommendations and common foundry practice, water quenching from solution annealing was applied to all heats. In addition, slow cooling from the $2300^{\circ} \mathrm{F} / 1260^{\circ} \mathrm{C} \mathrm{SA}$ was also applied to one heat of each cast material to study the effect of cooling rate.

Solution annealing was performed on cast bars (1" diameter X 5" with thermocouple attached) wrapped with stainless steel foil. After a one-hour heat soak at each desired temperature $\left(2100^{\circ} \mathrm{F} / 1150^{\circ} \mathrm{C}, 2200^{\circ} \mathrm{F} / 1205^{\circ} \mathrm{C}\right.$ and 
$2300^{\circ} \mathrm{F} / 1260^{\circ} \mathrm{C}$ ), the cast bar was water quenched immediately after the package was opened in the furnace.

In addition, solution annealing at $2300^{\circ} \mathrm{F} / 1260^{\circ} \mathrm{C}$ followed by slow cooling was also carried out on a cast bar (1" diameter X 5" with thermocouple attached) wrapped with stainless steel foil. After a one-hour heat soak at $2300^{\circ} \mathrm{F} / 1260^{\circ} \mathrm{C}$, the package was transferred to a furnace pre-set at $932^{\circ} \mathrm{F} / 500^{\circ} \mathrm{C}$ and approximately one hour was required to reach $932^{\circ} \mathrm{F} / 500^{\circ} \mathrm{C}$ from the solutionannealing temperature. This corresponds to a cooling rate of approximately 23 $\mathrm{F}^{\circ} / \mathrm{min}(13 \mathrm{C} / \mathrm{min})$. After equilibrating at $932^{\circ} \mathrm{F} / 500^{\circ} \mathrm{C}$, the package was air cooled to ambient temperature.

\section{3-6. Corrosion Testing}

- Pitting Corrosion Test (ASTM G 48C):

All pitting corrosion test specimens (1" diameter X 1/8"), extracted from the as-cast and solution annealed cast bars, were prepared to a 600 -grit surface finish. As recommended by ASTM G48 (Method C), $6 \% \mathrm{FeCl}_{3}+1 \% \mathrm{HCl}$ solution was used for CPT tests. The specimens were immersed in the solution for 24 hours at various temperatures to determine the critical pitting temperature (CPT: the lowest temperature at which pitting occurs). The CPT test was conducted using $5 \mathrm{C}^{\circ}$ increments. The criteria for pitting were defined such that pitting occurred when a specimen exhibited 2 or more pits examined under a magnification of 20X. Testing was replicated at the CPT and $5 \mathrm{C}^{\circ}$ below the CPT to verify the test results (per ASTM G 48C). 


\section{- Intergranular Corrosion Testing (ASTM G28 A)}

Specimens with the same heat treatments as the CPT specimens were also extracted (3-1/8" X 3/4" X 1/8") for corrosion testing. All corrosion test specimens were prepared to a 120 grit surface finish. The weight and dimensions of the specimen were measured before testing to enable calculation of corrosion rate. As recommended by ASTM G $28 \mathrm{~A}$, the corrosion test was conducted in a boiling $\mathrm{Fe}_{2}\left(\mathrm{SO}_{4}\right)_{3} / \mathrm{H}_{2} \mathrm{SO}_{4}$ solution for a 120 hour testing period. Two specimens for each condition were tested simultaneously to verify results. Weight loss was determined after testing. The corrosion rate was calculated as follows:

$$
\text { Corrosion Rate }=(\mathbf{K} \times \mathbf{W}) /(\mathbf{A} \times \mathbf{T} \times \mathbf{D})
$$

where

$$
\begin{aligned}
& \mathrm{K}=3450000 \text { (if using mpy as corrosion rate unit) } \\
& \mathrm{T}=\text { time of exposure, } \mathrm{h} \text {, to the nearest } 0.01 \mathrm{~h} \\
& \mathrm{~A}=\text { area, } \mathrm{cm}^{2} \text { to the nearest } 0.01 \mathrm{~cm}^{2} \\
& W=\text { weight loss, } \mathrm{g} \text {, to the nearest } 0.001 \mathrm{~g} \\
& D=\text { density, } \mathrm{g} / \mathrm{cm}^{3}\left(8.0 \mathrm{~g} / \mathrm{cm}^{3}\right)
\end{aligned}
$$

In addition, corrosion-tested specimens (3-1/8" X 3/4" X 1/8") were subjected to 3-point bending in a U-shaped die. The specimen was forced into the die by a plunger with a radius of $1 / 4$ " (2t radius), which provides approximately $22 \%$ surface strain. The convex surface of the specimens was examined for cracks or other open defects under a stereo macroscope. 


\section{- NORSOK Corrosion Testing}

Specimens with the same heat treatments as the corrosion test specimens were also extracted (1" diameter X 1/8") for NORSOK corrosion testing. Samples were prepared to a 600 -grit surface finish and pickled in $20 \% \mathrm{HNO}_{3}+$ $5 \% \mathrm{HF}$ solution at $60^{\circ} \mathrm{C}$ for 5 minutes prior to corrosion testing. As required per NORSOK Corrosion Testing Requirements, $6 \% \mathrm{FeCl}_{3}+1 \% \mathrm{HCl}$ (same solution as recommended by ASTM G48 C) was used for the corrosion testing. The pickled specimens were immersed into the solution at a fixed temperature of $50^{\circ} \mathrm{C}$ for 24 hours. The surfaces of the corrosion-tested specimens were examined for pit initiation under a stereo macroscope at a magnification of 20X. Weight loss was also measured after testing. Both pitting behavior and weight loss are used in the corrosion evaluation criteria. The acceptance criteria established for NORSOK corrosion test are as follows: i) No pitting shall occur at 20X magnification. ii) The weight loss shall be less than $4.0 \mathrm{~g} / \mathrm{m}^{2}$. 


\section{RESULTS AND DISCUSSION}

The potential for formation of secondary phases, such as sigma phase $(\sigma)$ and carbides ( $\mathrm{MC}, \mathrm{M}_{23} \mathrm{C}_{6}$ and $\mathrm{M}_{6} \mathrm{C}$ ), in cast high alloy austenitic stainless steels may be greater than in the wrought counterpart materials. This potential is related to alloy segregation in the cast materials. In high alloy austenitic stainless steels, $\sigma$ phase and chromium carbides are two of the detrimental secondary phases in relation to corrosion resistance.

Sigma $(\sigma)$ phase, an intermetallic compound (FeCr, FeCrMo, CrFeMoNi or CrNiMo), forms in austenitic alloys after sufficient exposure in the temperature range of $1000-1800^{\circ} \mathrm{F}\left(540 \sim 980^{\circ} \mathrm{C}\right)$ [5]. The precipitation of $\sigma$ phase leads to embrittlement and reduces the corrosion resistance of a material [6]. To avoid embrittlement and breakdown of corrosion resistance of stainless steels, the material must be water-quenched after solution annealing and carefully welded with the lowest possible heat input [7].

Chromium carbide $\left((\mathrm{Cr}, \mathrm{Fe}, \mathrm{Mo})_{23} \mathrm{C}_{6}\right)$ is another undesirable precipitate which results in reduced intergranular corrosion resistance by the creation of $\mathrm{Cr}$ depleted regions [8]. Precipitation of $(\mathrm{Cr}, \mathrm{Fe}, \mathrm{Mo})_{23} \mathrm{C}_{6}$ occurs in the temperature range of $930^{\circ} \mathrm{F}$ to $1740^{\circ} \mathrm{F}\left(500^{\circ} \mathrm{C}\right.$ to $\left.950^{\circ} \mathrm{C}\right)$; the fastest rate of precipitation takes place from $1200^{\circ} \mathrm{F}$ to $1290^{\circ} \mathrm{F}\left(650^{\circ} \mathrm{C}\right.$ to $\left.700^{\circ} \mathrm{C}\right)$ [1]. Chromium carbide is usually prevented by the addition of strong carbide formers, such as $\mathrm{Nb}$ or $\mathrm{Ti}$ [8].

It is well known that the microstructure of high alloy materials and the existence of secondary phases influence corrosion behavior [5]. In the following 
sections, the discussions concentrate on the identification of secondary phases in each casting type and their effect on corrosion behavior.

\section{4-1 Microstructural Characterization of CK-3MCuN}

\section{- Evaluation Using Optical Light Microscopy (OLM)}

$\mathrm{CK}-3 \mathrm{MCuN}$ is an austenitic stainless steel with a nominal composition of $\mathrm{Fe}-$ 20Cr-18Ni-6.5Mo. Two heats of CK-3MCuN (Heat K3GAO \& Heat K3GCO), extracted from cast bars, and three heats of CK-3MCuN (Heat 2, Heat 3, \& Heat 5) extracted from cast wedge blocks, were selected for this study. For each heat, microstructural evaluation was conducted in both the as-cast and the solutionannealed condition. Solution annealing was performed at both The University of Tennessee at Knoxville (UTK) and foundries. UTK solution annealing (SA) was conducted at temperatures of $2100^{\circ} \mathrm{F} / 1150^{\circ} \mathrm{C}$ and $2300 \mathrm{~F} / 1260^{\circ} \mathrm{C}$ followed by water quenching (WQ) for all five heats and followed by slow cooling (SC, from $2300^{\circ} \mathrm{F} / 1260^{\circ} \mathrm{C}$ only) for Heat K3GAO (from bar) and Heat 3 (from cast wedge blocks). Foundry solution annealing was conducted at temperatures of $2200^{\circ} \mathrm{F} / 1205^{\circ} \mathrm{C}(\mathrm{WQ})$ for Heat 3 and $2250^{\circ} \mathrm{F} / 1230^{\circ} \mathrm{C}(\mathrm{WQ})$ for Heats $2 \& 5$. To

simulate the foundry SA, a UTK SA was also conducted at $2200^{\circ} \mathrm{F} / 1205^{\circ} \mathrm{C}$ (WQ) for Heats K3GAO and K3GCO. Solution-annealing temperatures used by UTK and foundries for $\mathrm{CK}-3 \mathrm{MCuN}$ are listed in Table 3. Metallographic evaluation was initiated using OLM and Stain-etching techniques.

The microstructure of the as-cast $\mathrm{CK}-3 \mathrm{MCuN}$ is shown in Figures 1 though 5 for Heat K3GAO, Heat K3GCO, Heat2, Heat 3, and Heat 5, 

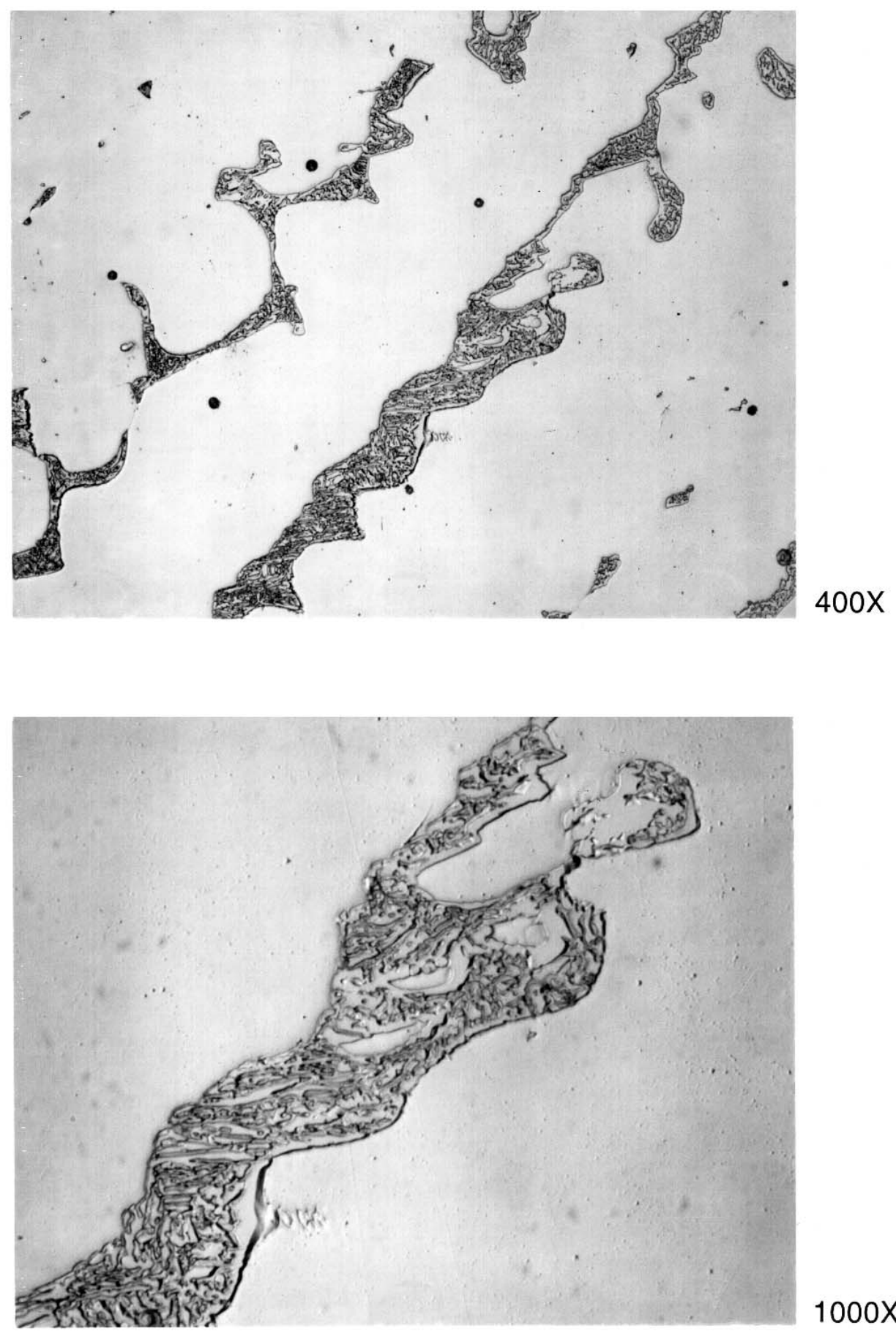

$1000 X$

Figure 1. Microstructure of as-cast CK-3MCuN Heat K3GAO 


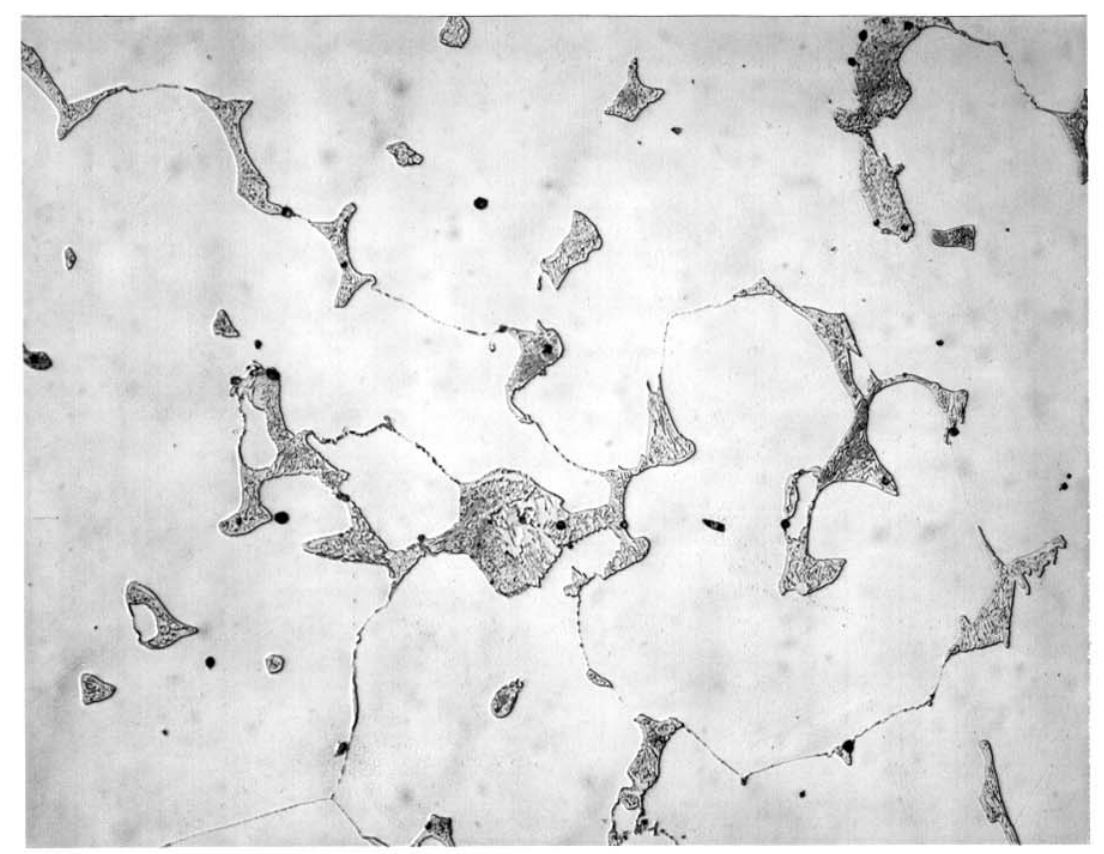

$400 x$

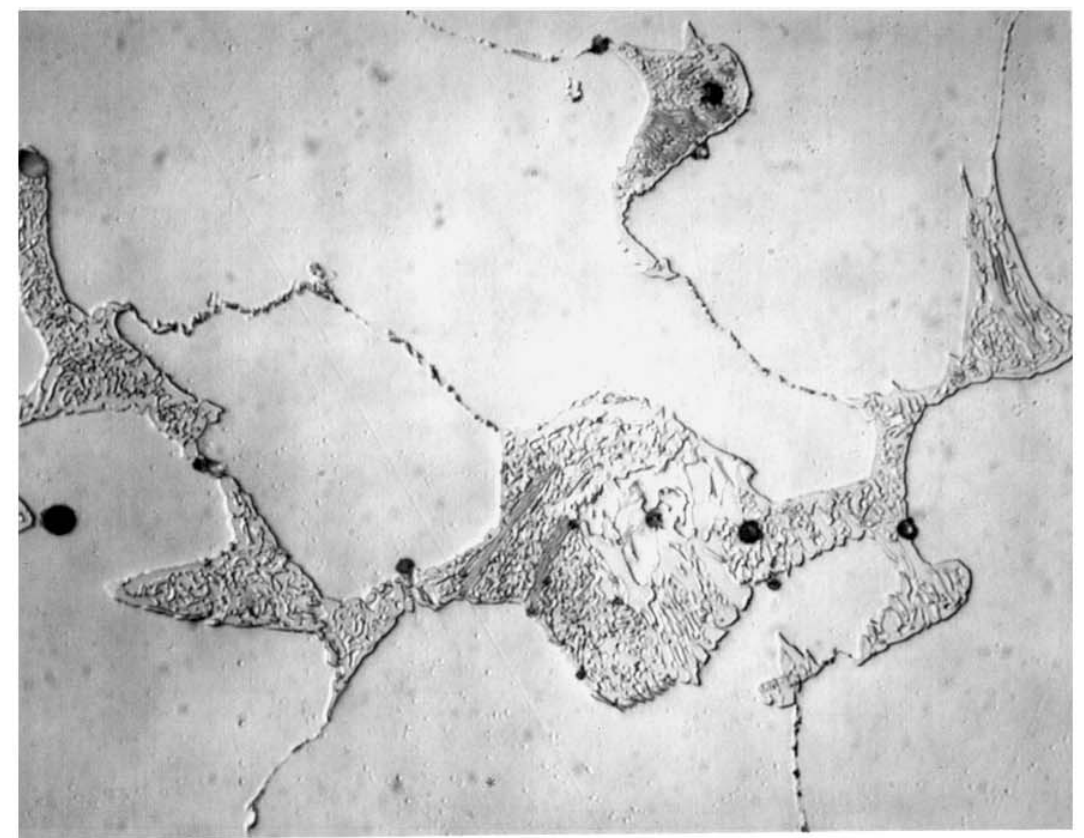

Figure 2. Microstructure of as-cast CK-3MCuN Heat K3GCO 


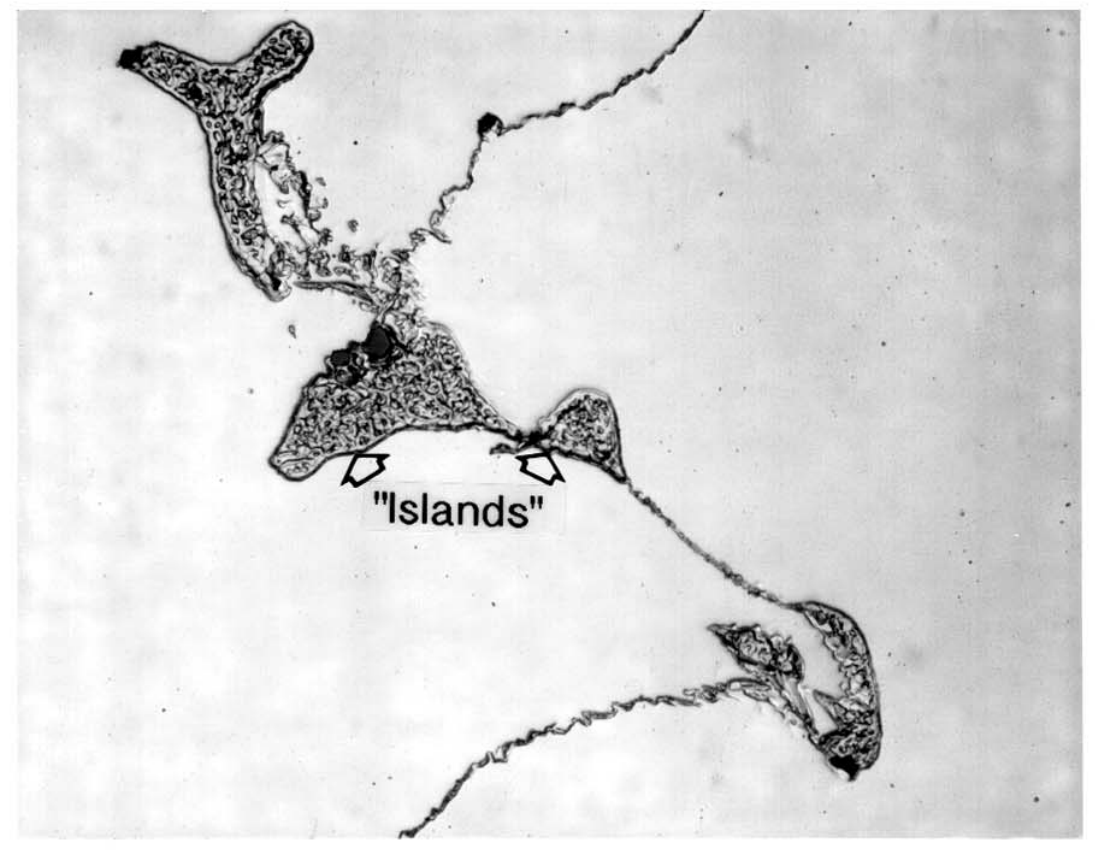

$400 x$

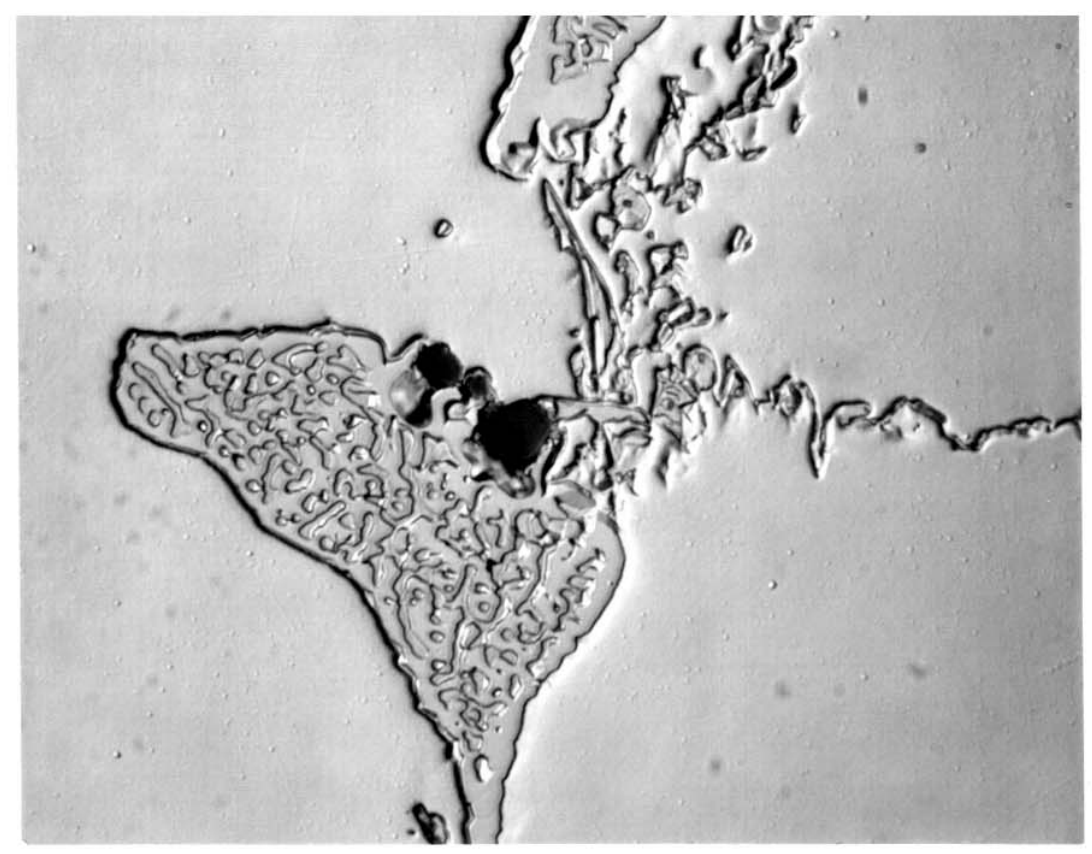

Figure 3. Microstructure of as-cast CK-3MCuN Heat 2 


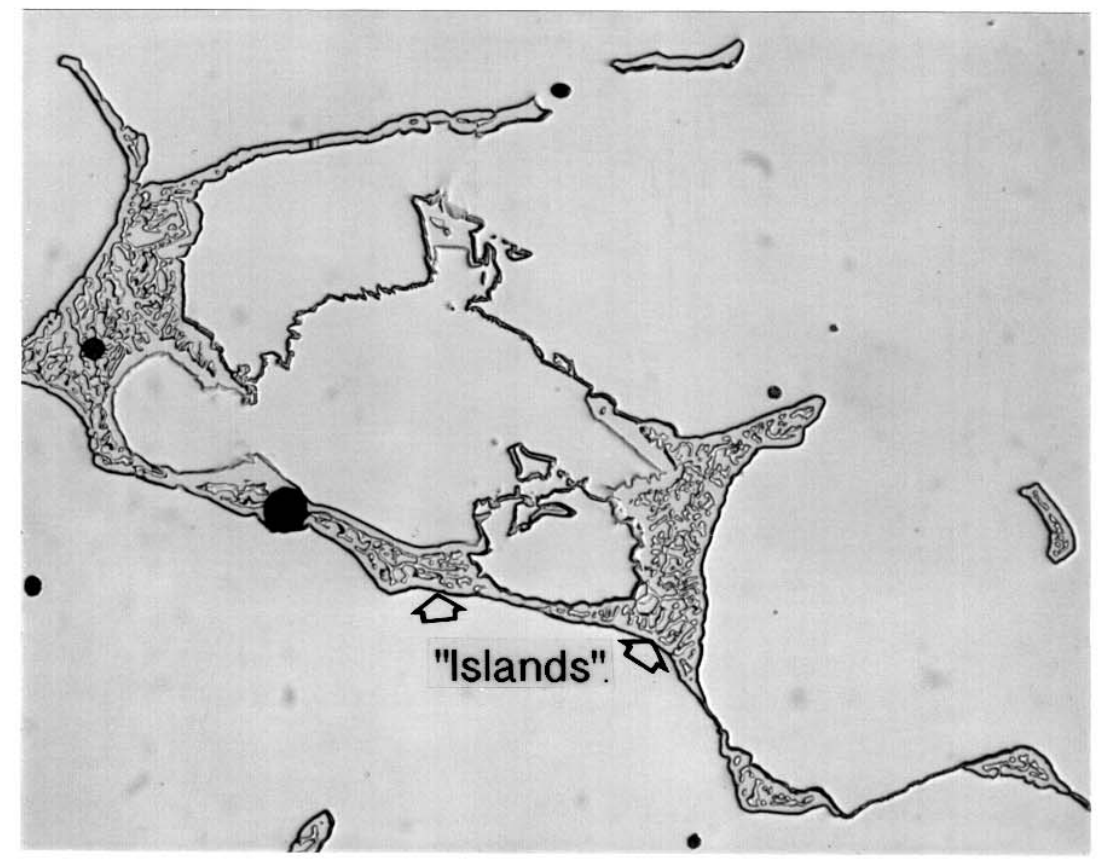

$400 X$

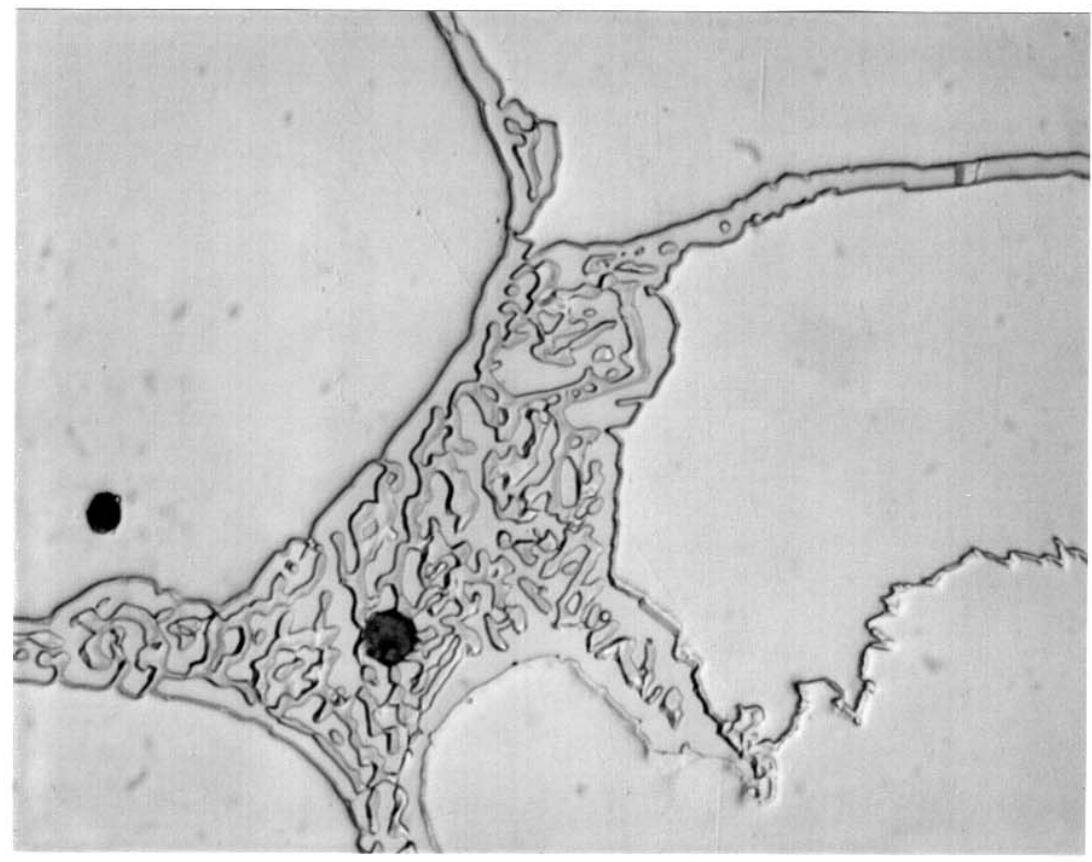

$1000 x$

Figure 4. Microstructure of as-cast CK-3MCuN Heat 3 


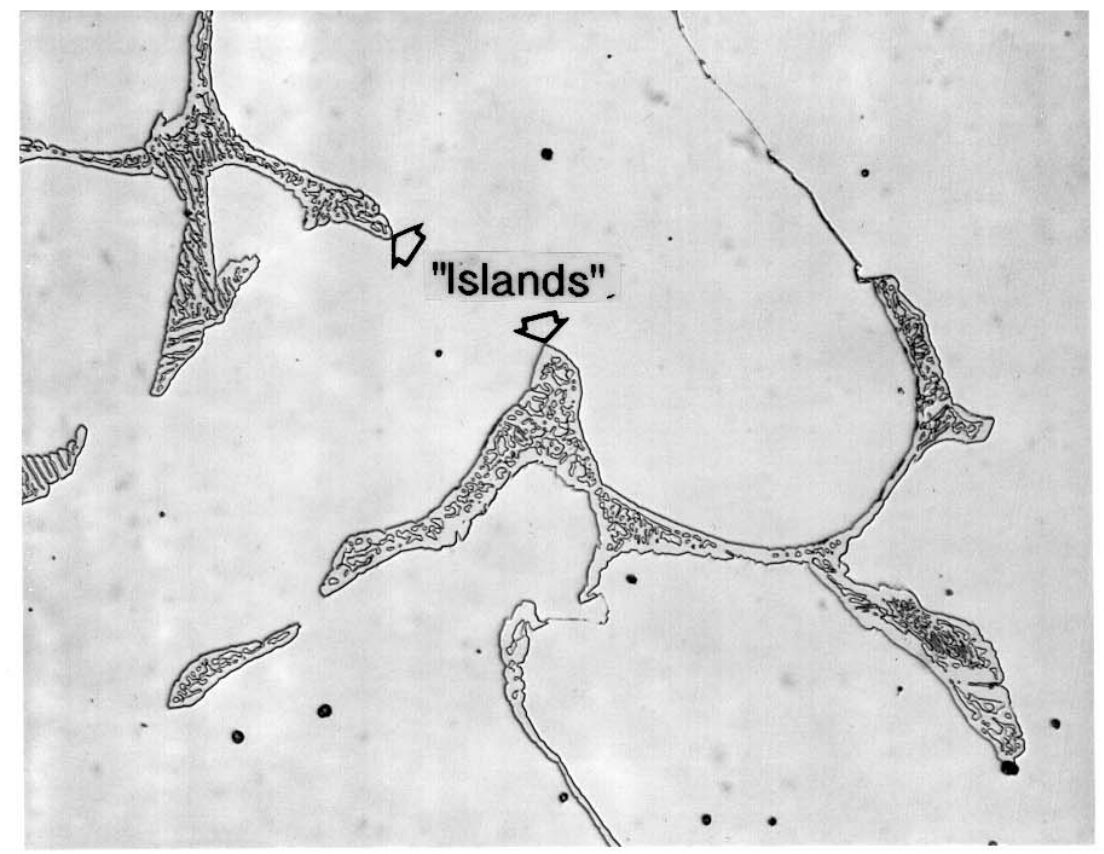

$400 X$

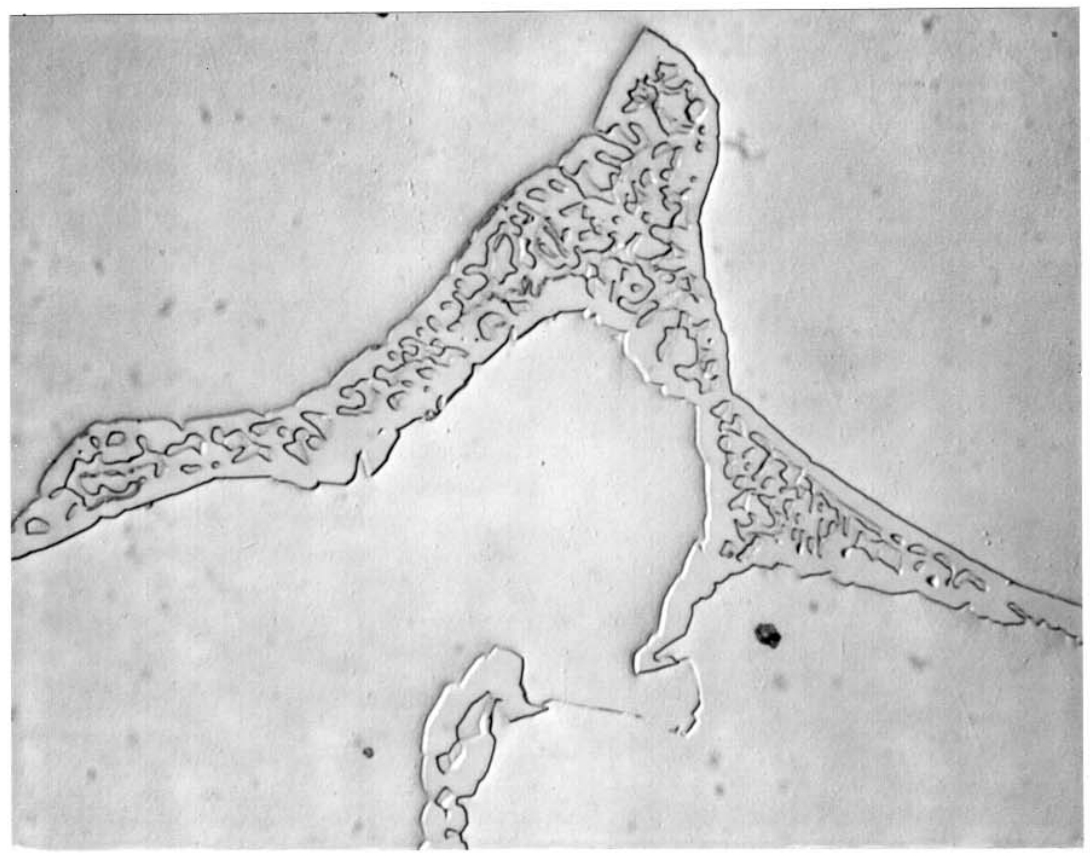

$1000 x$

Figure 5. Microstructure of as-cast CK-3MCuN Heat 5 
respectively. It is evident that the microstructures are identical for all heats in the as-cast condition. Coarse and fine irregular-shaped secondary phases within the "islands" were observed extensively in interdendritic regions and along grain boundaries. Dark globular particles in the matrix were also observed in the matrix of these heats.

Figures 6 through 10 present the OLM microstructure after SA at $2100^{\circ} \mathrm{F} / 1150^{\circ} \mathrm{C}$ (followed by WQ), while Figures 11 through 15 show the OLM microstructure after SA at $2200^{\circ} \mathrm{F} / 1205^{\circ} \mathrm{C}$ or $2250^{\circ} \mathrm{F} / 1230^{\circ} \mathrm{C}$ (followed by WQ) for the same five heats. In comparison with the microstructure of the as-cast CK$3 \mathrm{MCuN}$, the fine irregular-shaped secondary phases within the "islands" were completely dissolved during SA at temperatures in the range of 2100 to $2250^{\circ} \mathrm{F}$ $\left(1150\right.$ to $\left.1230^{\circ} \mathrm{C}\right)$. However, the coarse irregular-shaped secondary phases within the "islands" remained (see Figures 6 through 15). The dark globular particles remained unchanged in all solution annealed conditions.

After SA at a temperature of $2300^{\circ} \mathrm{F} / 1260^{\circ} \mathrm{C}$ (follow by WQ), the microstructure for these five heats is shown in Figures 16 through 20. Compared to the microstructure after SA at a temperature in the range of 2100 to $2250^{\circ} \mathrm{F}$ $\left(1150\right.$ to $\left.1230^{\circ} \mathrm{C}\right)$, the coarse irregular-shaped secondary phase within the "islands" was completely dissolved during $2300^{\circ} \mathrm{F} / 1260^{\circ} \mathrm{C}$ SA (followed by WQ) for Heat K3GAO and Heat K3GCO (extracted from the cast bars) as shown in Figures 16 and 17 . This implies that solution-annealing temperature strongly influences the microstructure of CK-3MCuN. However, after a $2300^{\circ} \mathrm{F} / 1260^{\circ} \mathrm{C}$ 


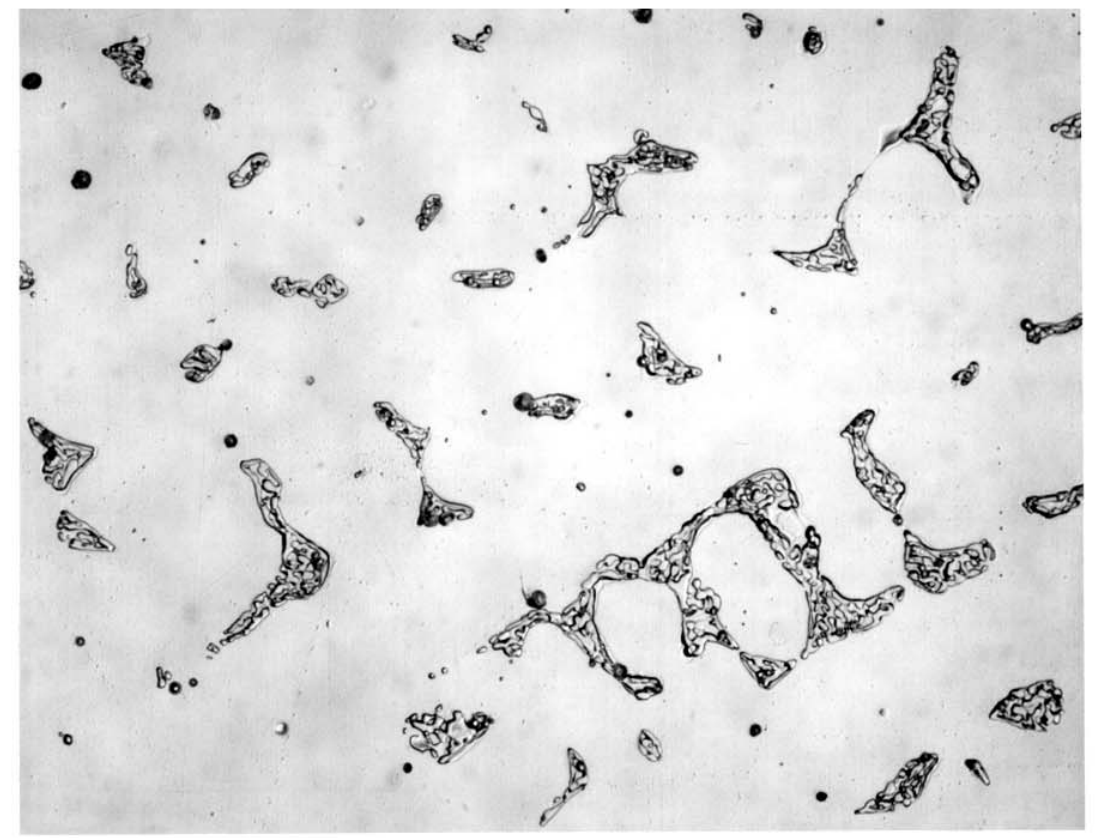

$400 X$

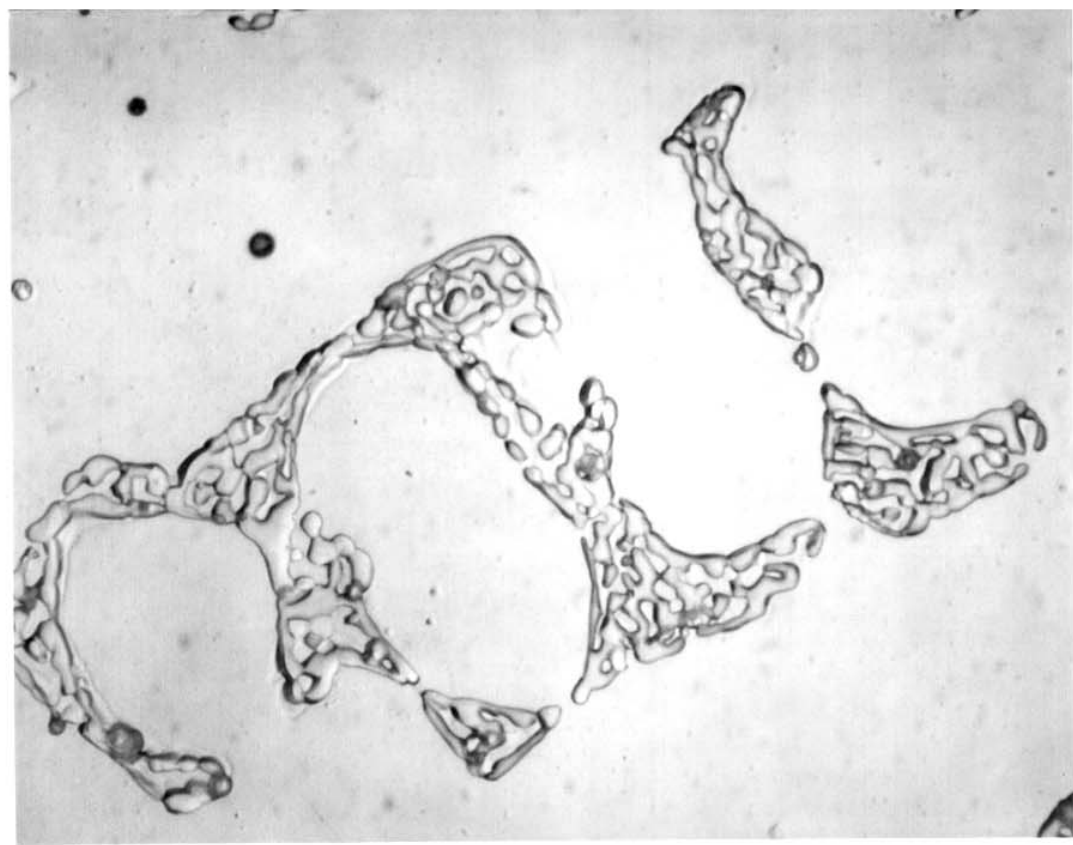

$1000 x$

Figure 6. Microstructure of UT solution annealed $\left(2100^{\circ} \mathrm{F}+\mathrm{WQ}\right)$ CK-3MCUN Heat K3GAO 


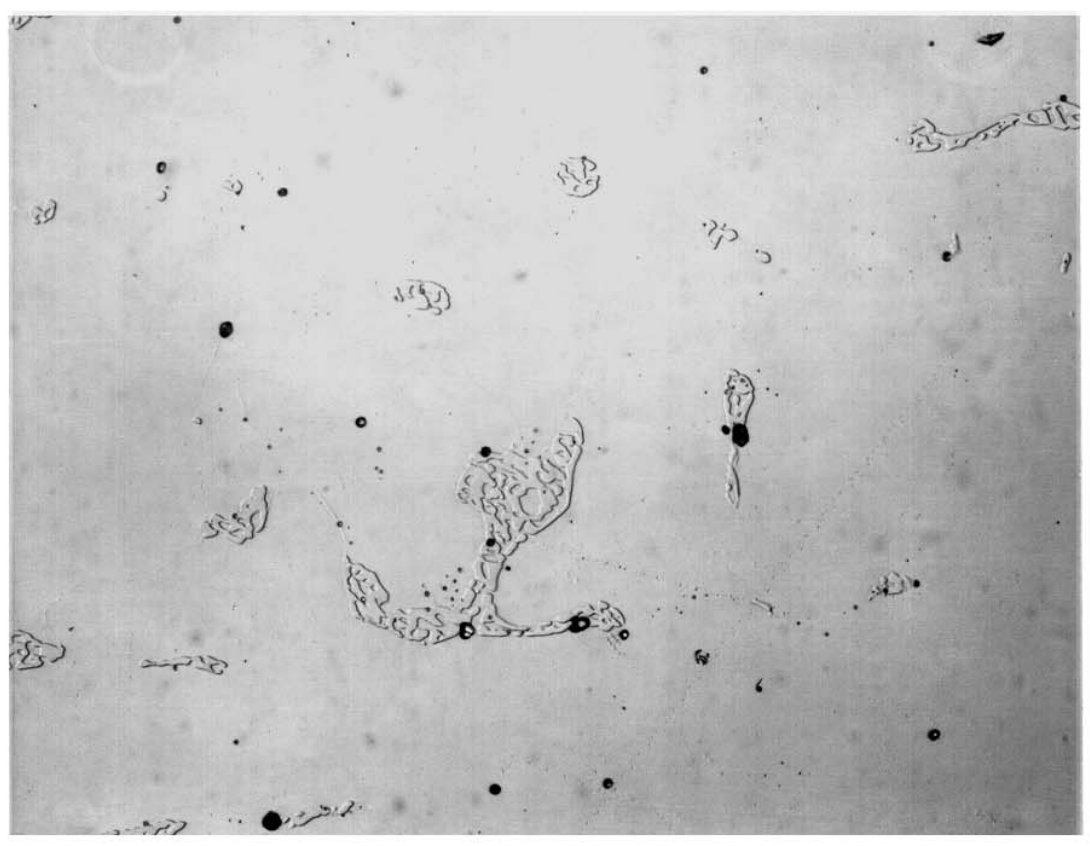

$400 X$

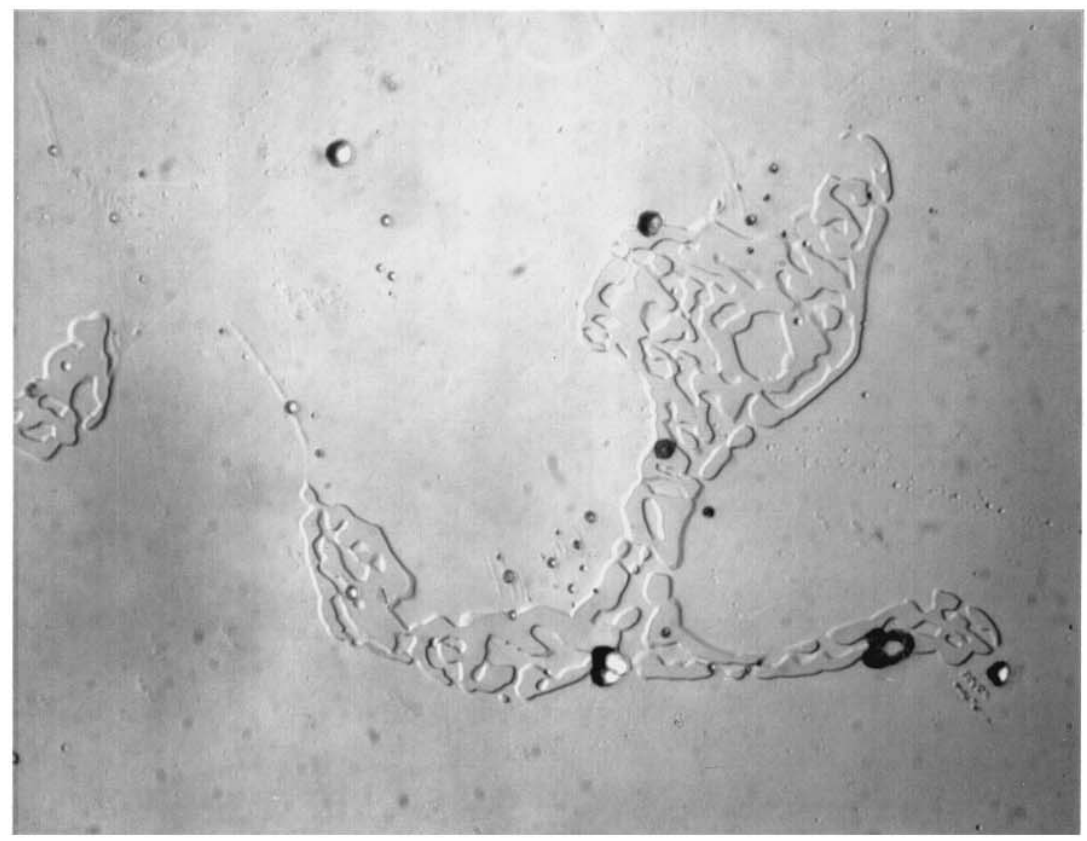

Figure 7. Microstructure of UT solution annealed $\left(2100^{\circ} \mathrm{F}+\mathrm{WQ}\right)$ CK-3MCUN Heat K3GCO 


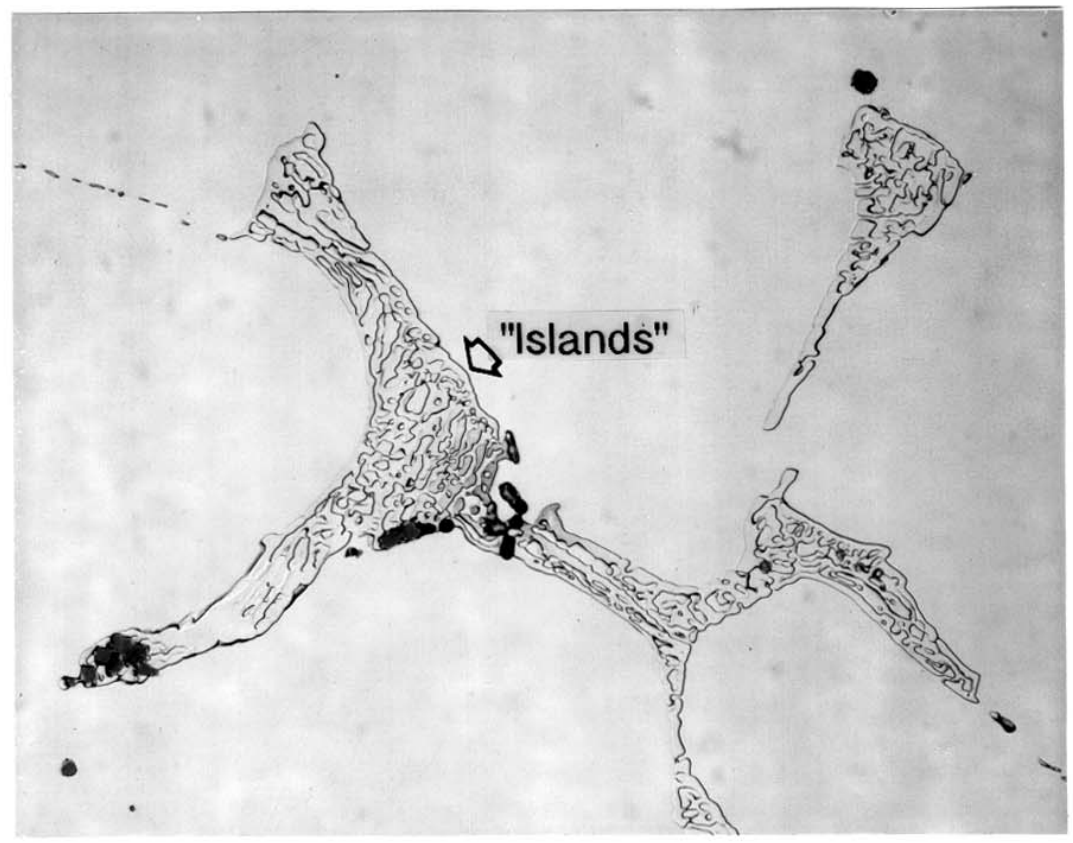

$400 x$

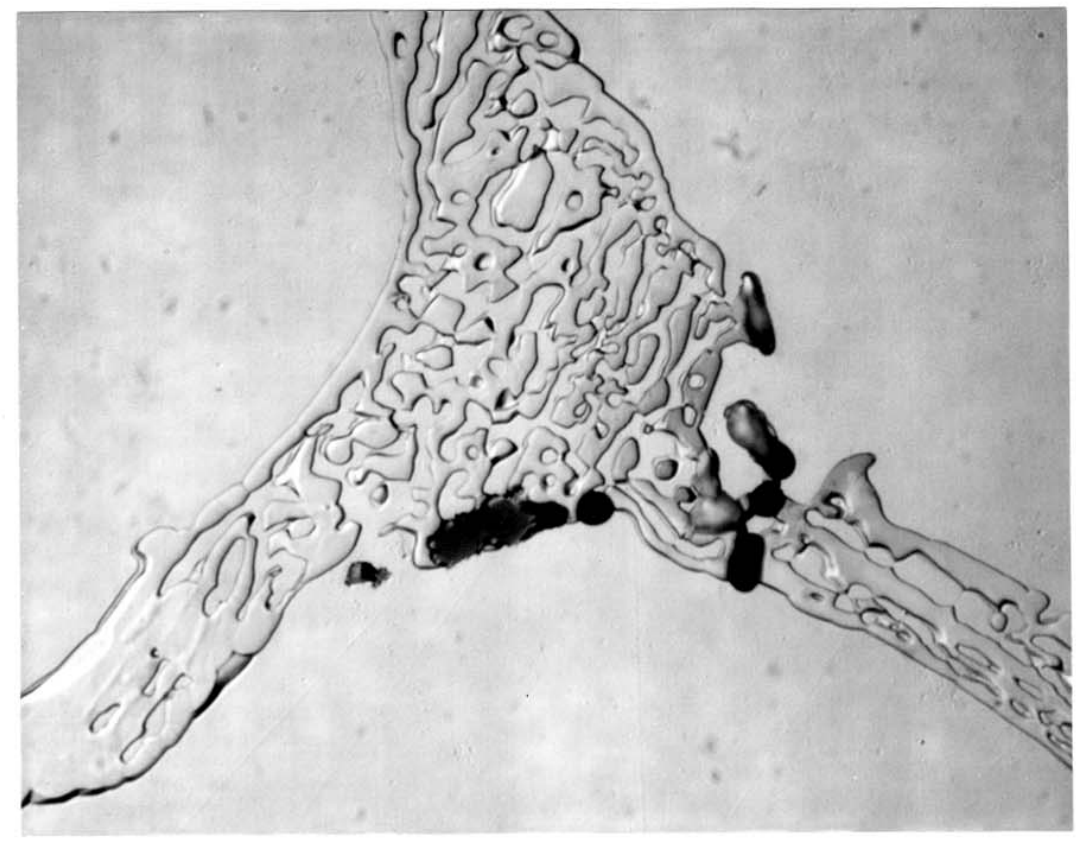

Figure 8. Microstructure of UT solution annealed $\left(2100^{\circ} \mathrm{F}+\mathrm{WQ}\right)$ CK-3MCuN Heat 2 

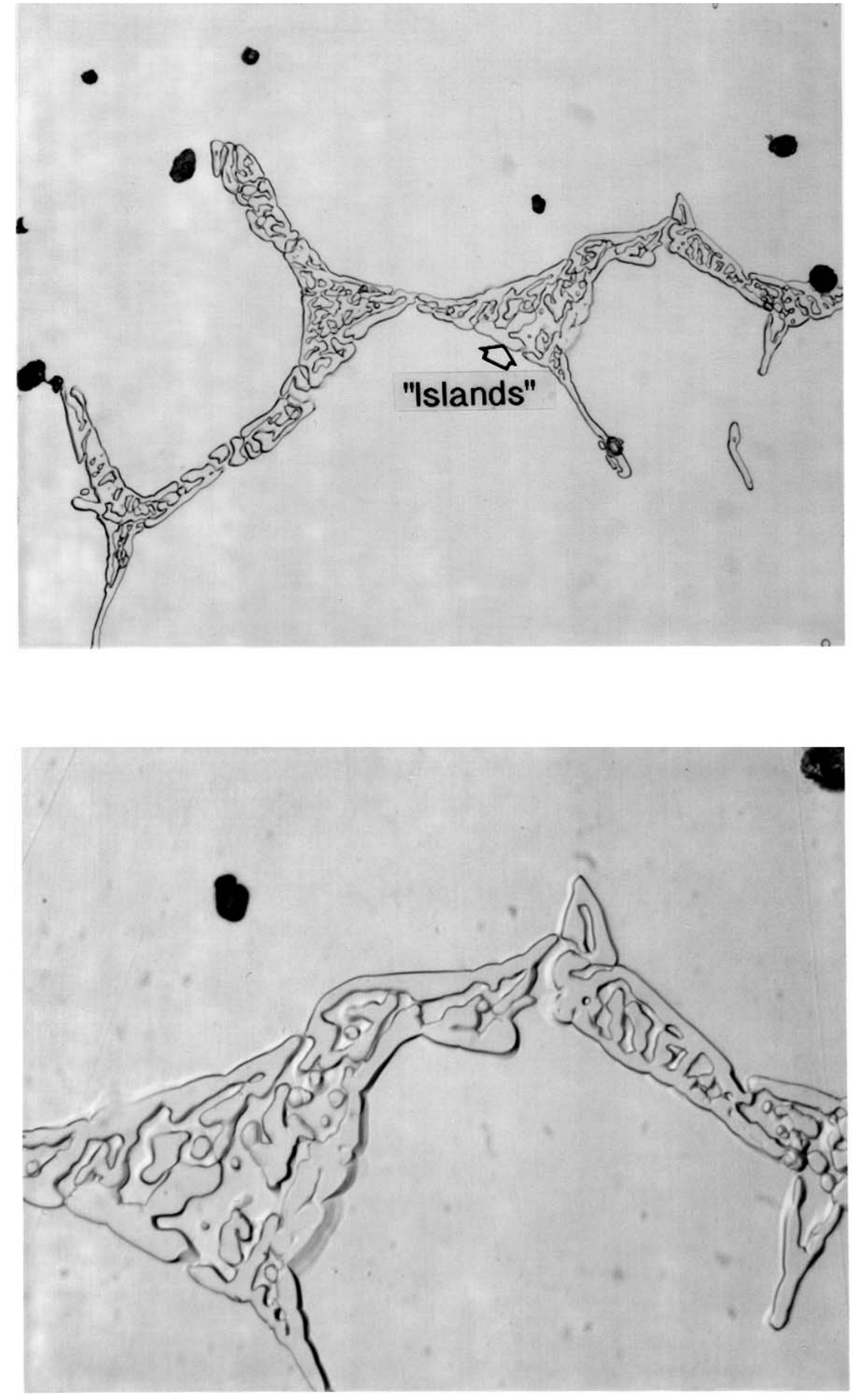

$1000 X$

Figure 9. Microstructure of UT solution annealed $\left(2100^{\circ} \mathrm{F}+\mathrm{WQ}\right)$ CK-3MCuN Heat 3 


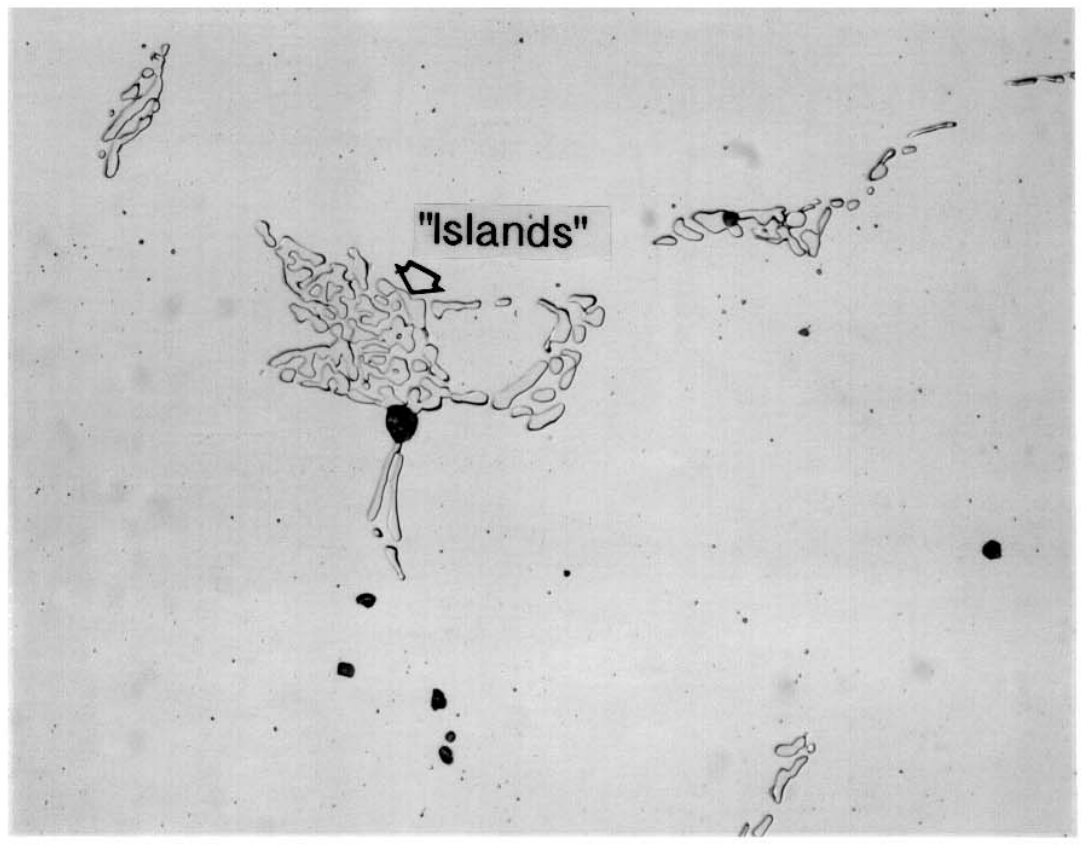

$400 X$

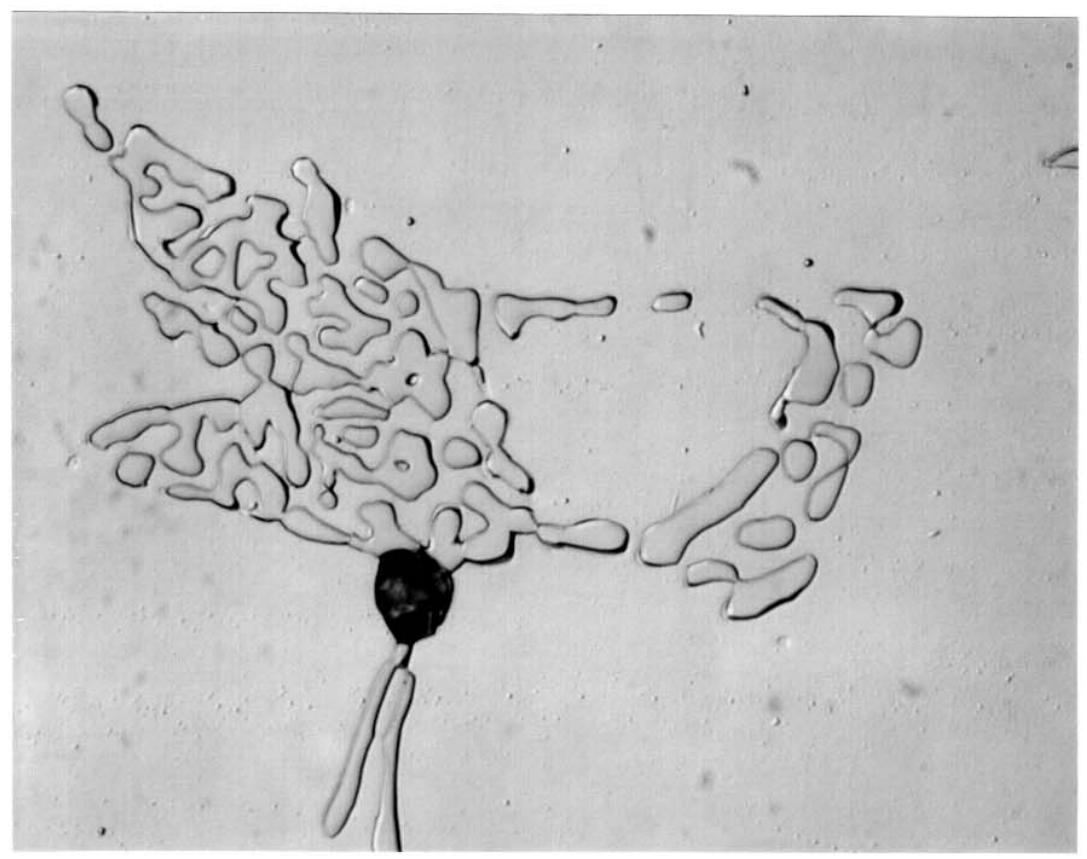

Figure 10. Microstructure of UT solution annealed $\left(2100^{\circ} \mathrm{F}+\mathrm{WQ}\right)$ CK-3MCuN Heat 5 

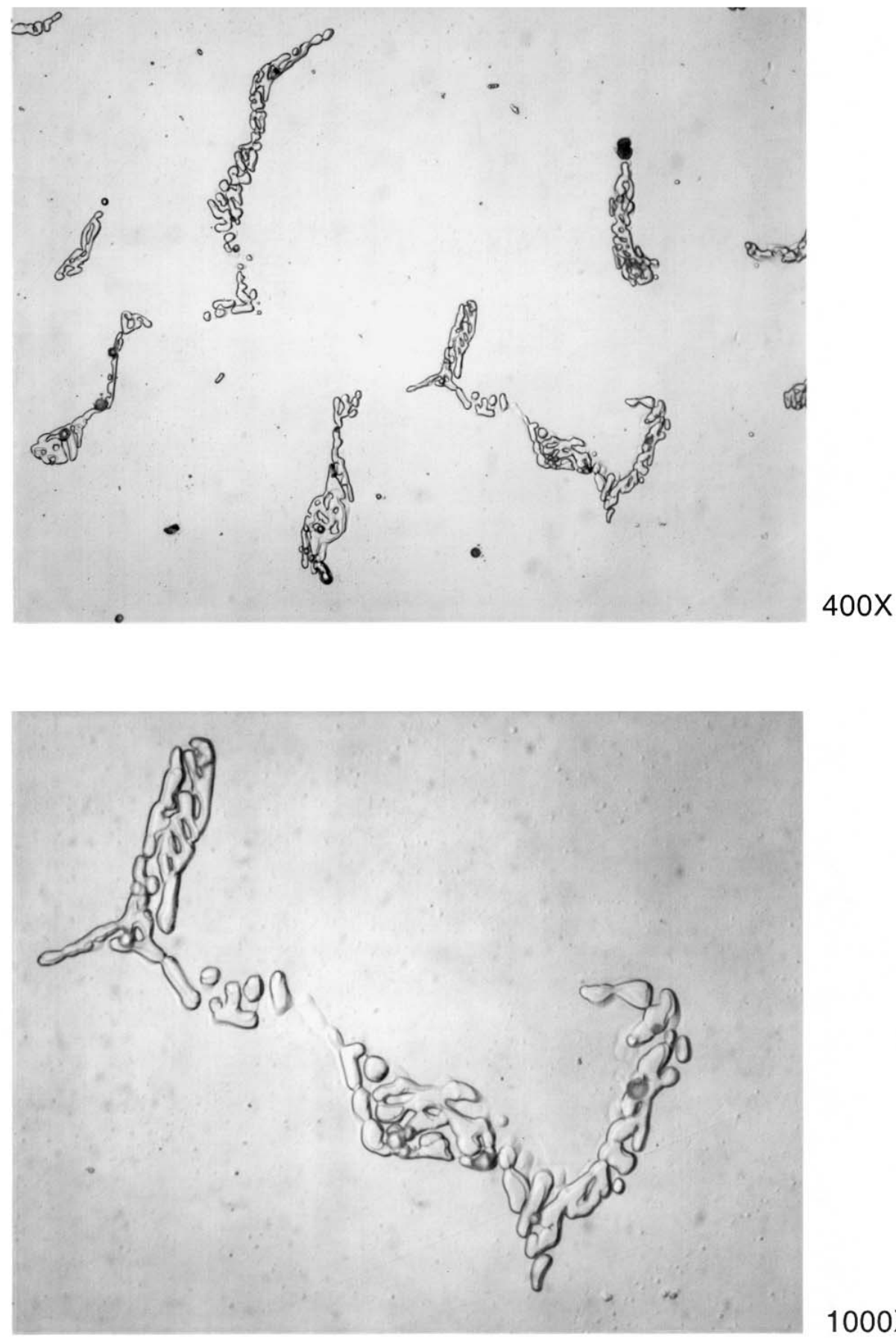

$1000 X$

Figure 11. Microstructure of UT solution annealed $\left(2200^{\circ} \mathrm{F}+\mathrm{WQ}\right)$ CK-3MCuN Heat K3GAO 


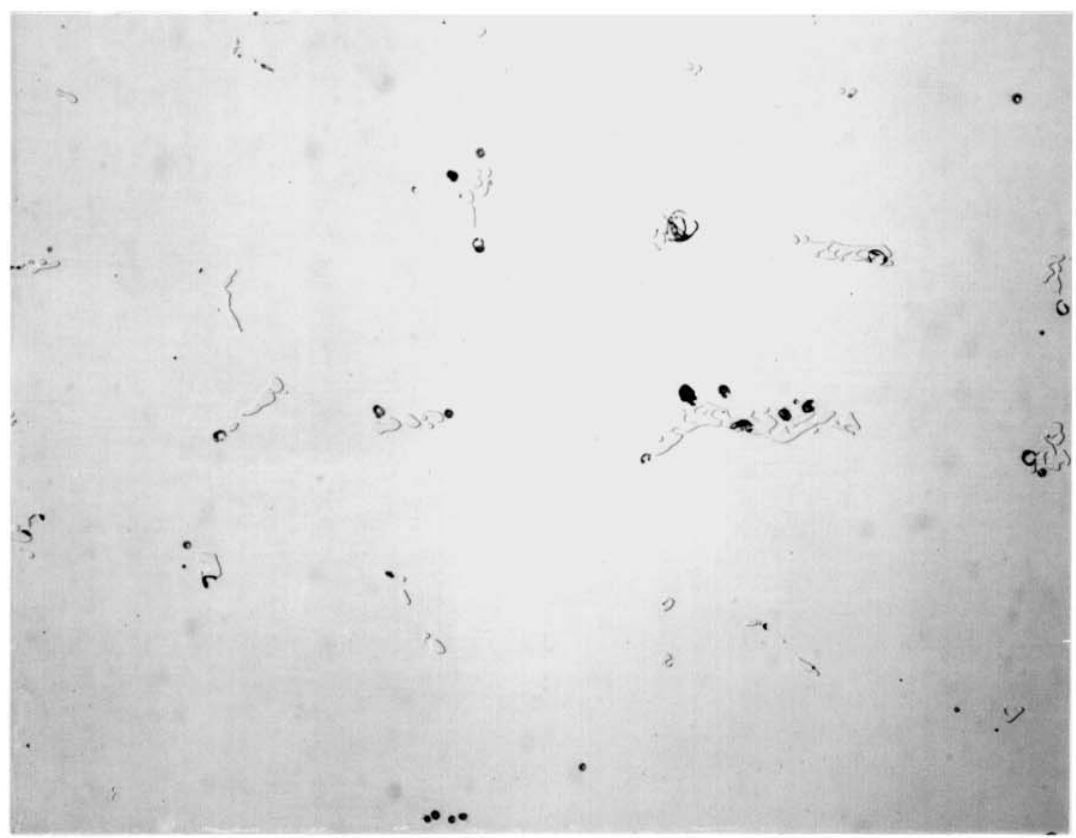

$400 X$

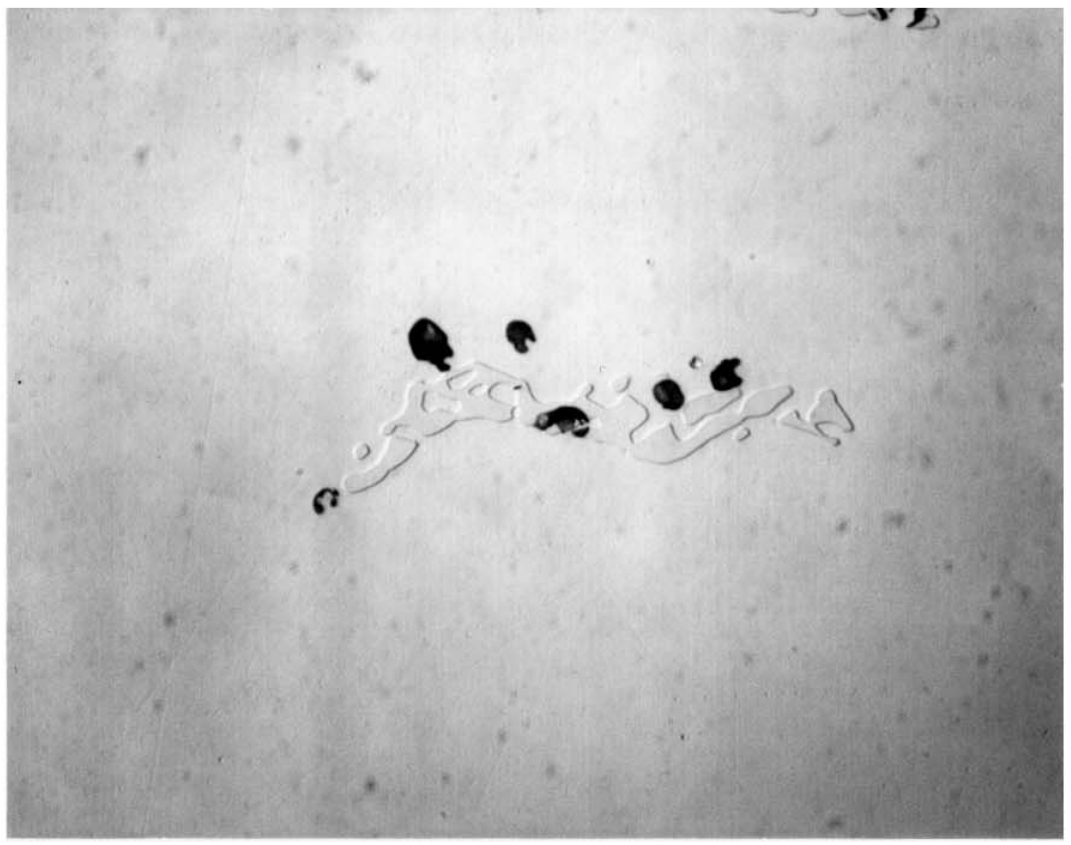

$1000 X$

Figure 12. Microstructure of UT solution annealed $\left(2200^{\circ} \mathrm{F}+\mathrm{WQ}\right)$ CK-3MCuN Heat K3GCO 


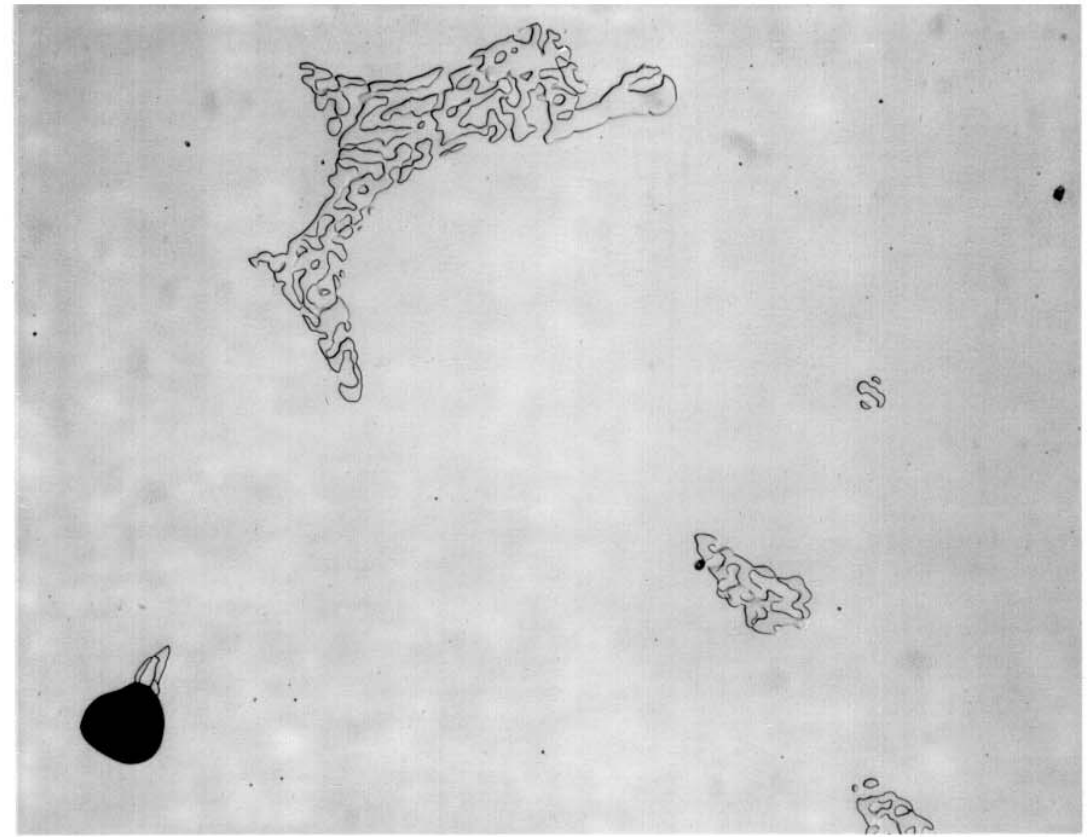

$400 X$

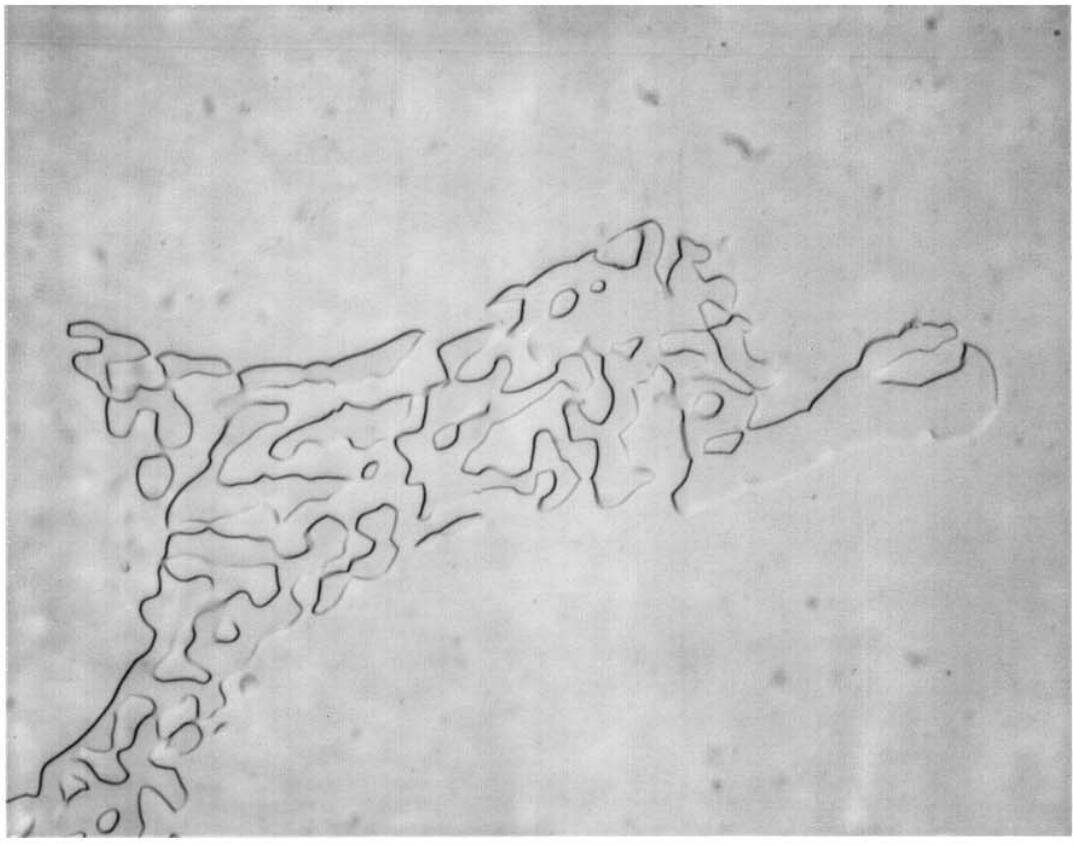

$1000 \mathrm{X}$

Figure 13. Microstructure of UT solution annealed $\left(2250^{\circ} \mathrm{F}+\mathrm{WQ}\right)$ CK-3MCuN Heat 2 


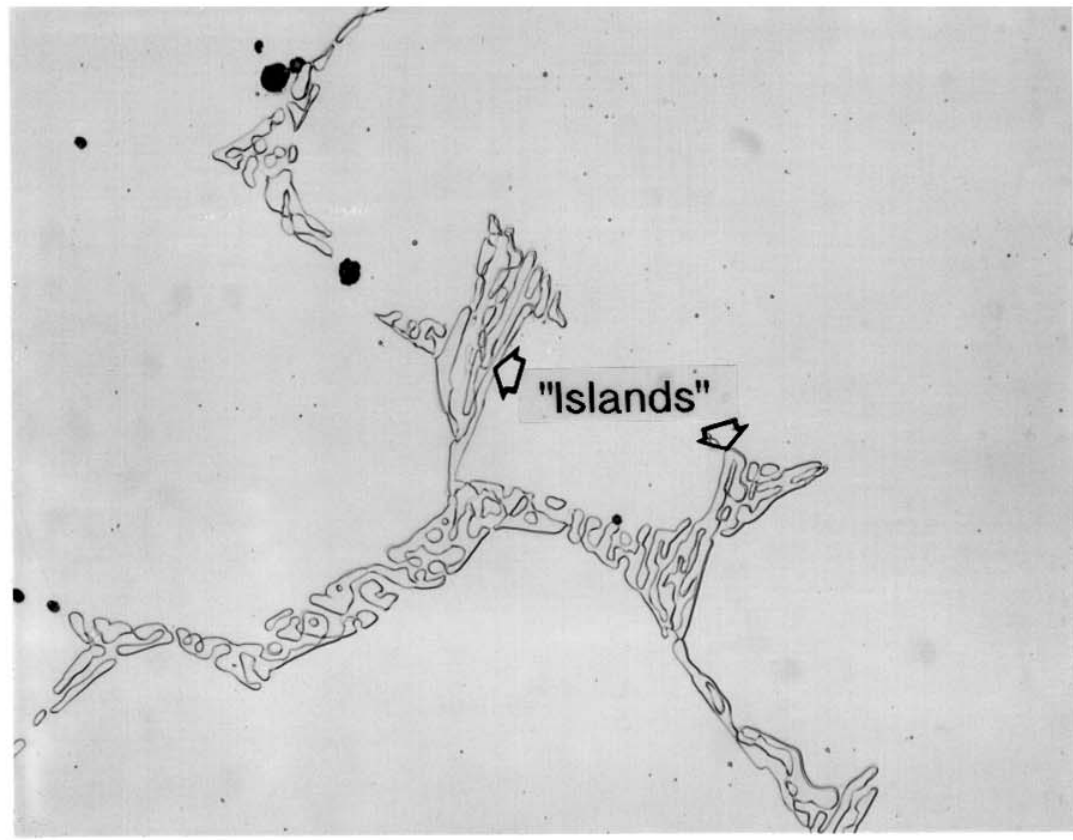

$400 x$

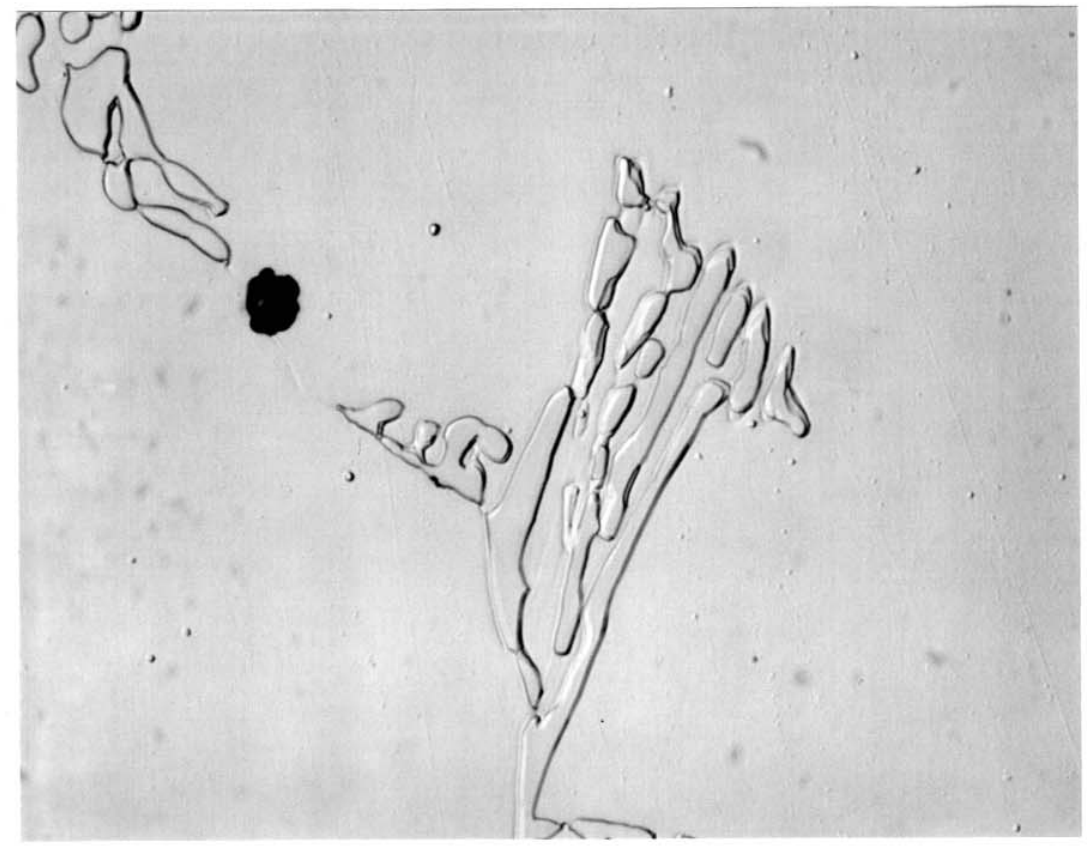

$1000 X$

Figure 14. Microstructure of UT solution annealed $\left(2200^{\circ} \mathrm{F}+\mathrm{WQ}\right)$ CK-3MCuN Heat 3 


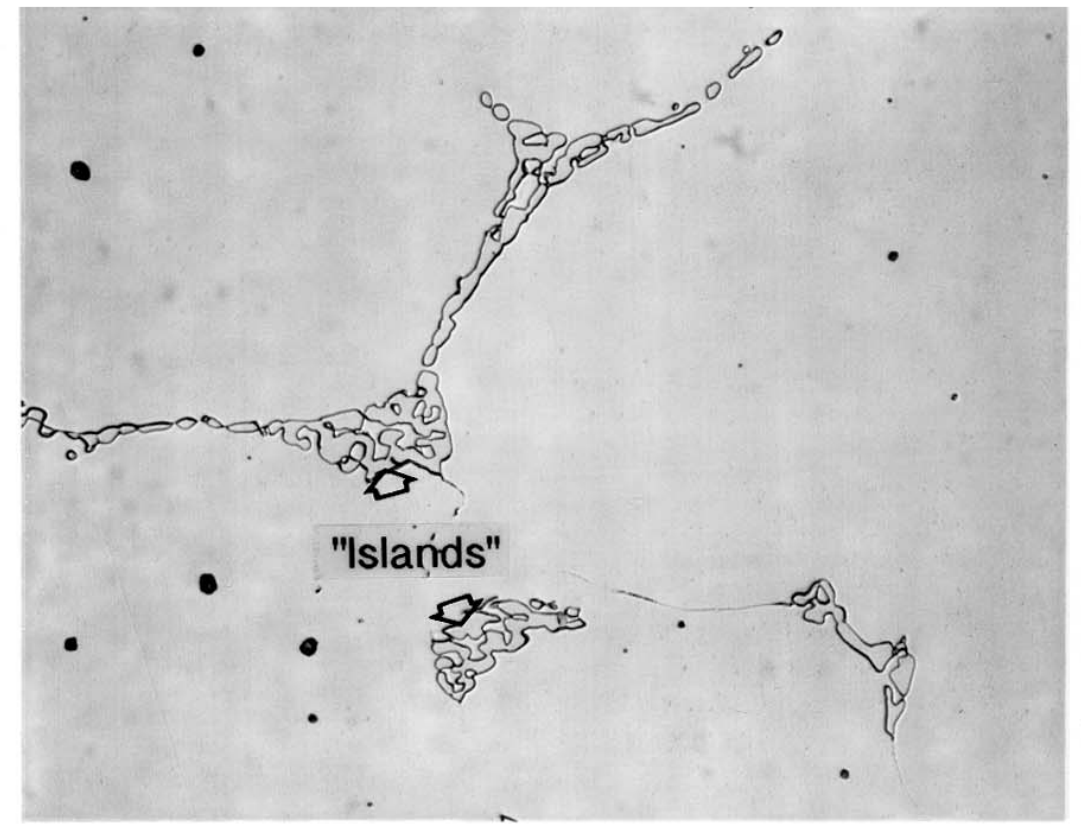

$400 x$

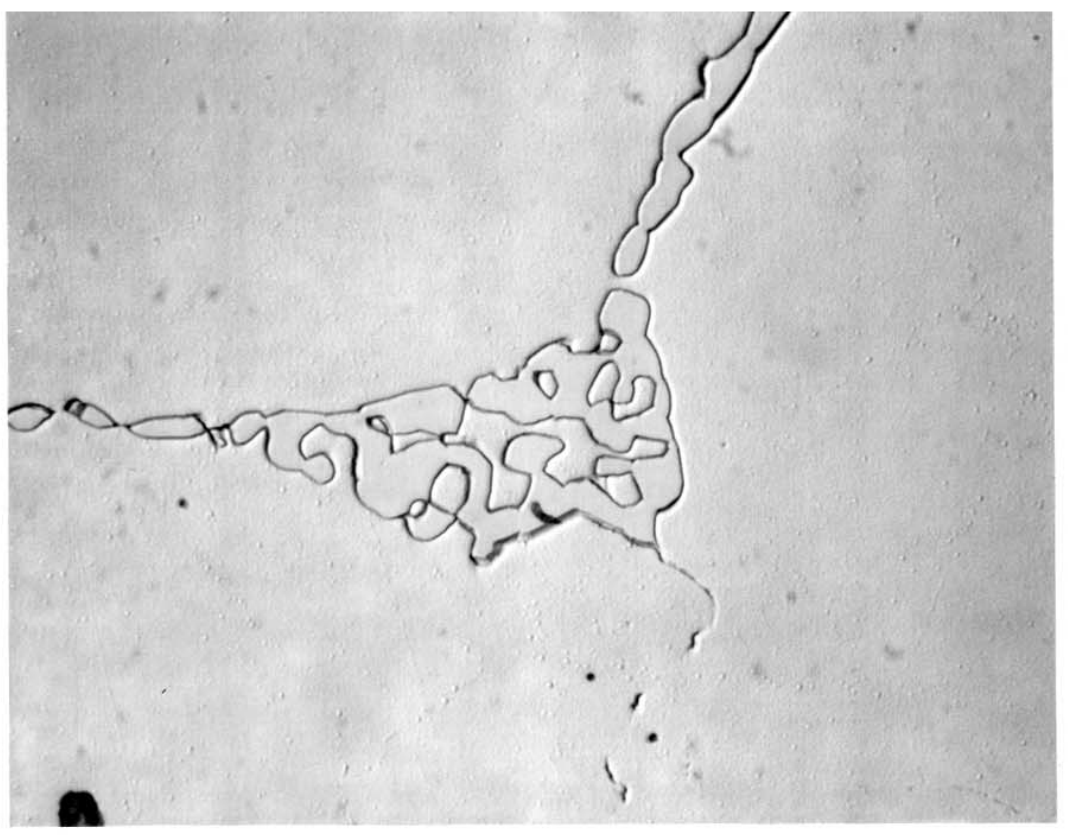

$1000 X$

Figure 15. Microstructure of UT solution annealed $\left(2200^{\circ} \mathrm{F}+\mathrm{WQ}\right)$ CK-3MCuN Heat 5 

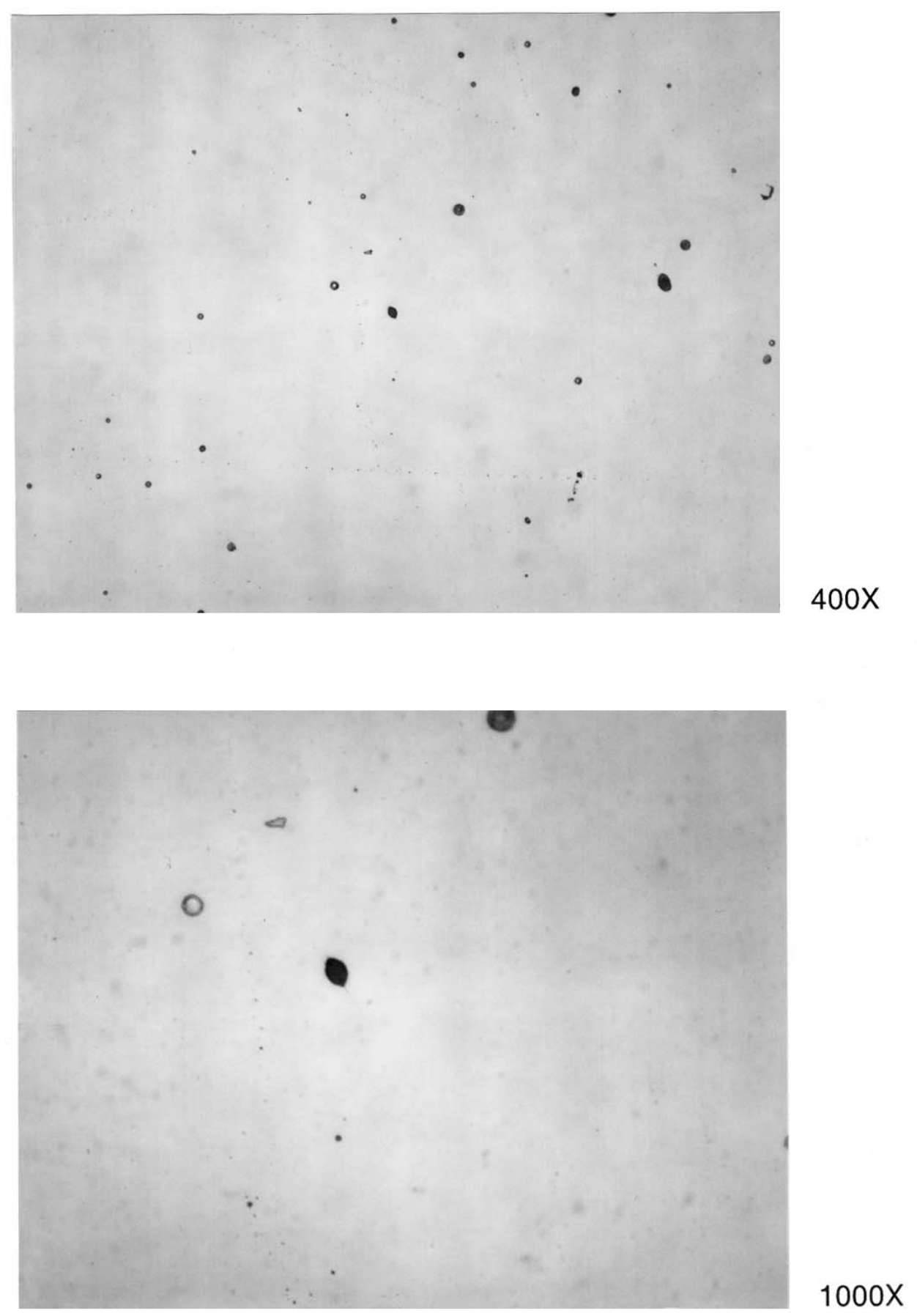

Figure 16. Microstructure of UT solution annealed $\left(2300^{\circ} \mathrm{F}+\mathrm{WQ}\right)$ CK-3MCuN Heat K3GCO 

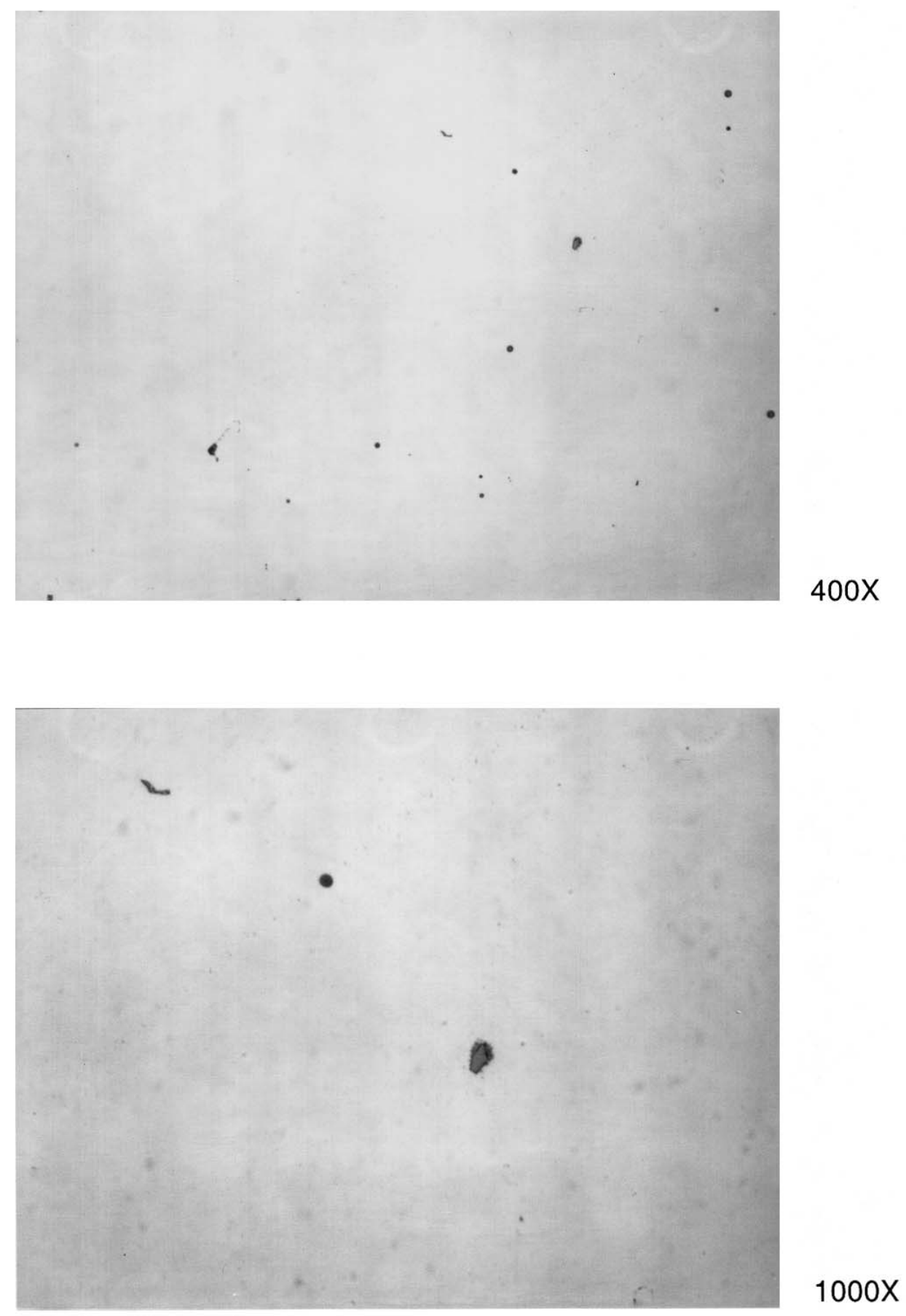

Figure 17. Microstructure of UT solution annealed $\left(2300^{\circ} \mathrm{F}+\mathrm{WQ}\right)$ CK-3MCuN Heat K3GCO 

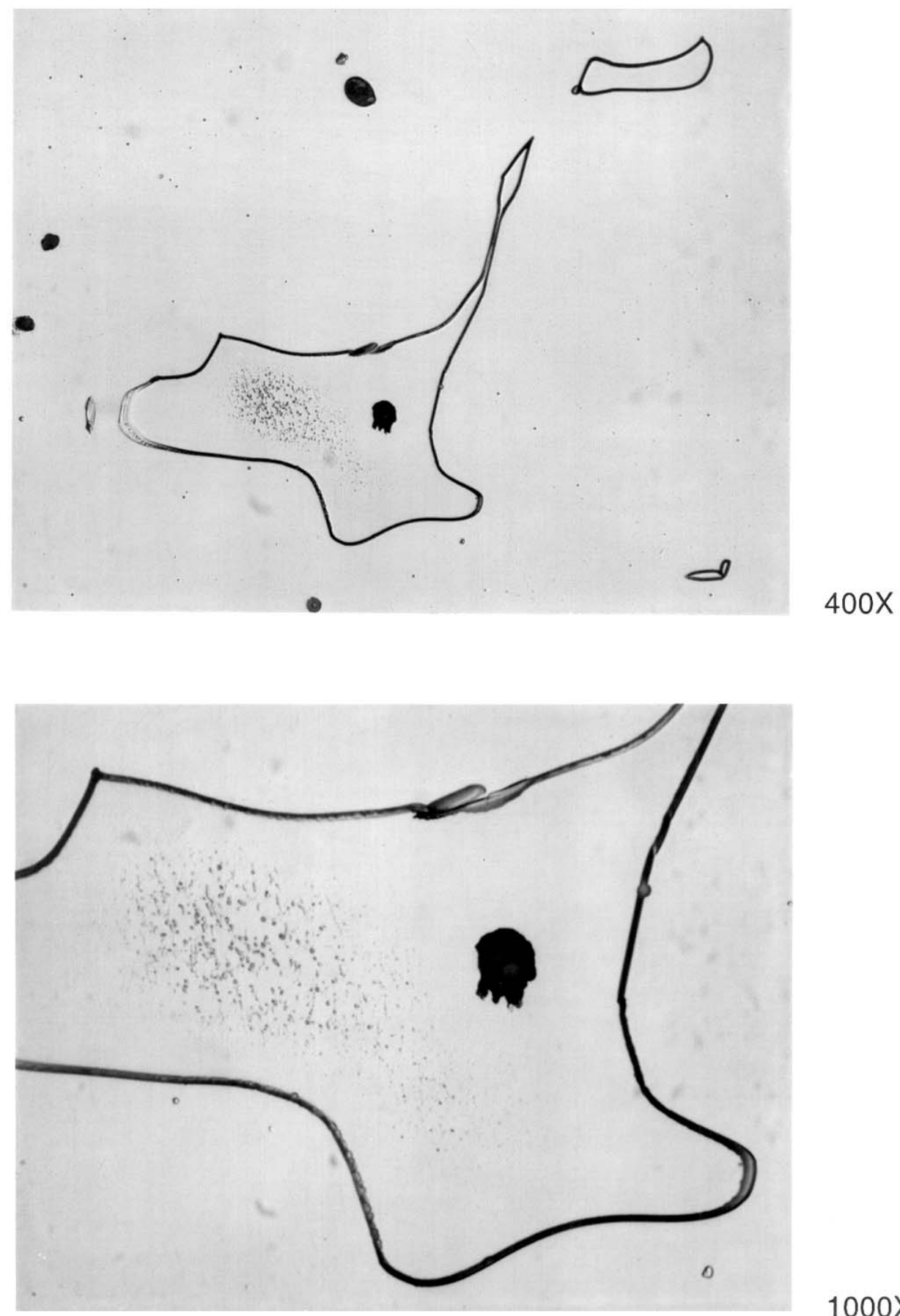

Figure 18. Microstructure of UT solution annealed $\left(2300^{\circ} \mathrm{F}+\mathrm{WQ}\right)$ CK-3MCuN Heat 2, Location 1. 


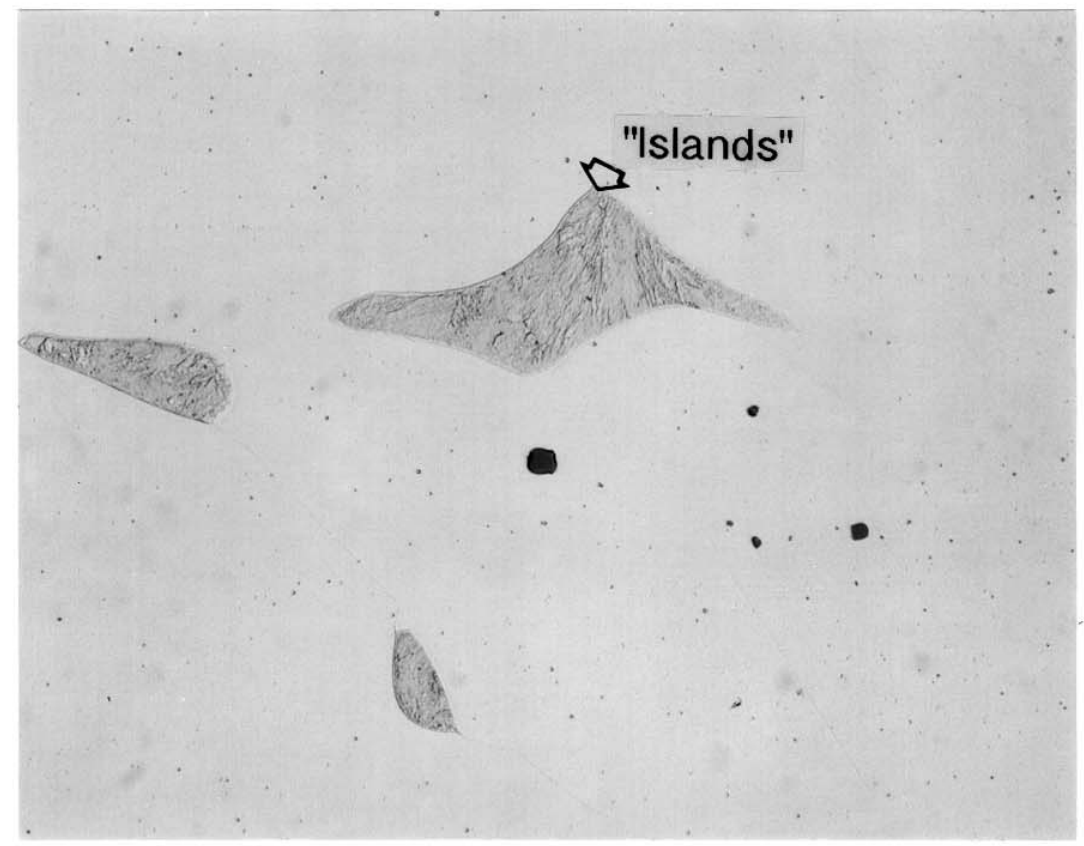

$400 x$

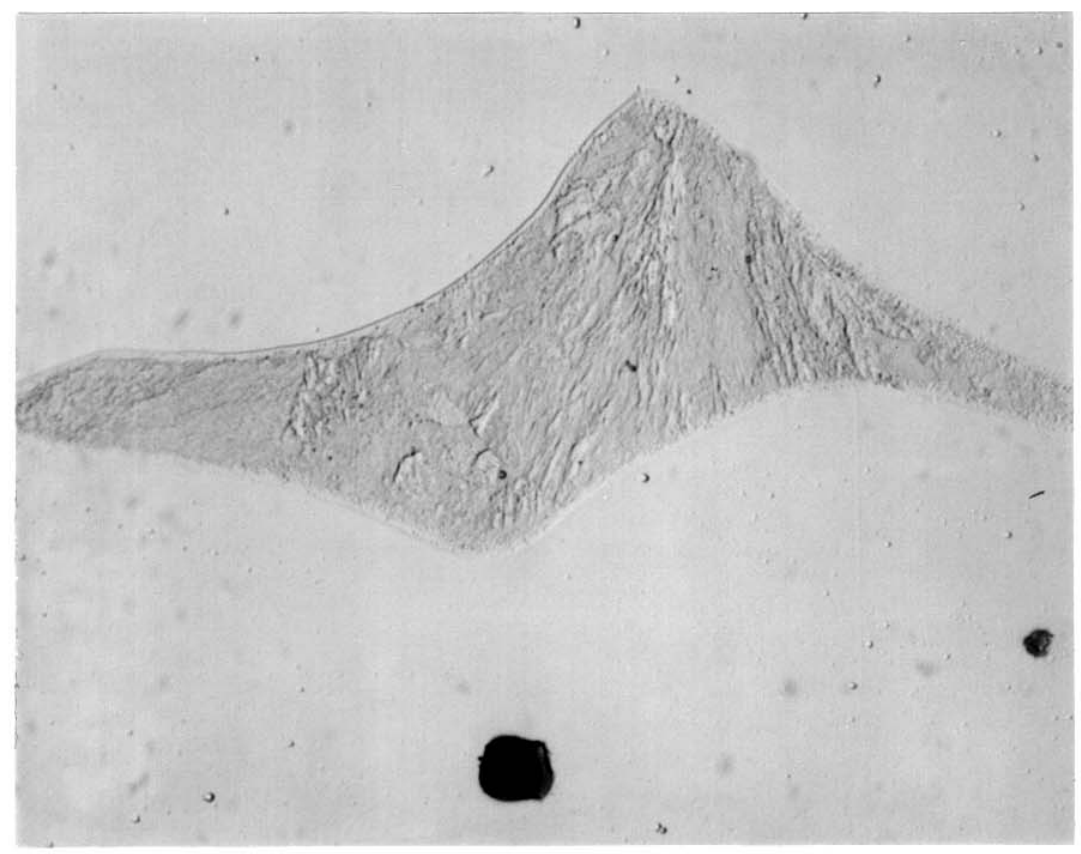

$1000 X$

Figure 18 (cont'd). Microstructure of UT solution annealed $\left(2300^{\circ} \mathrm{F}+\mathrm{WQ}\right)$ CK-3MCuN Heat 2, Location 2. 


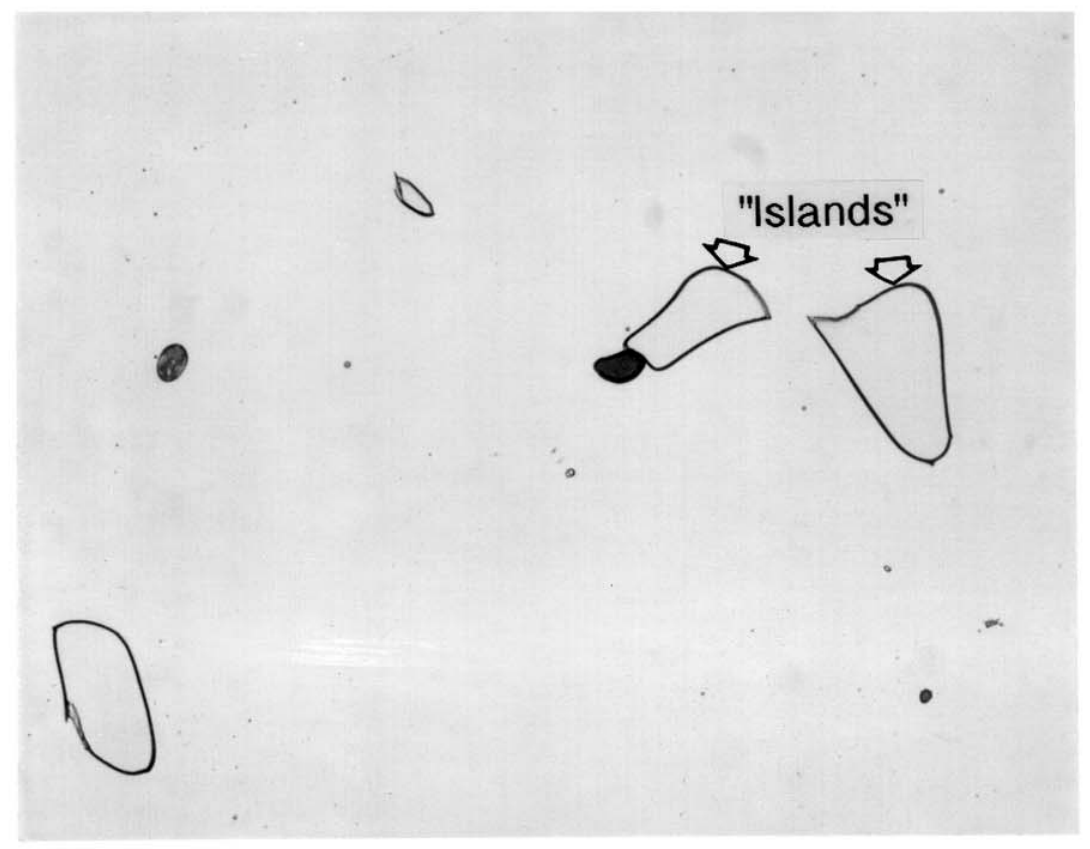

$400 x$

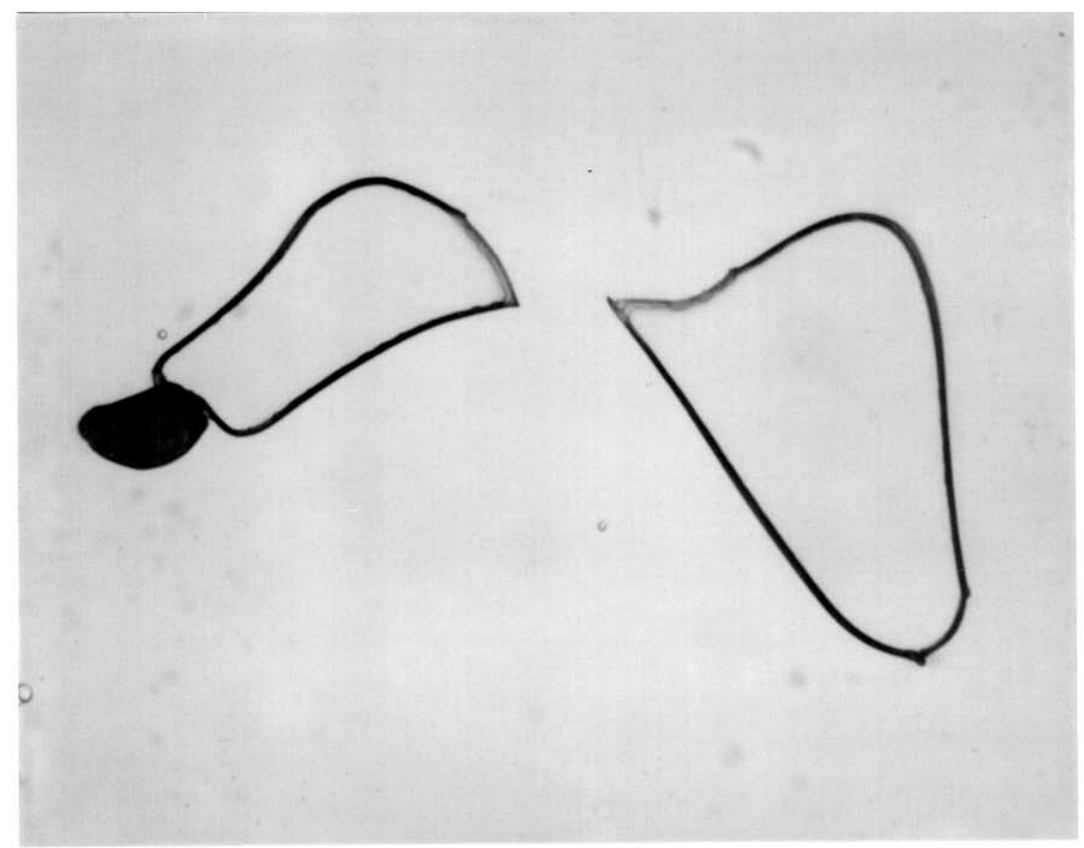

Figure 19. Microstructure of UT solution annealed $\left(2300^{\circ} \mathrm{F}+\mathrm{WQ}\right)$ CK-3MCuN Heat 3 


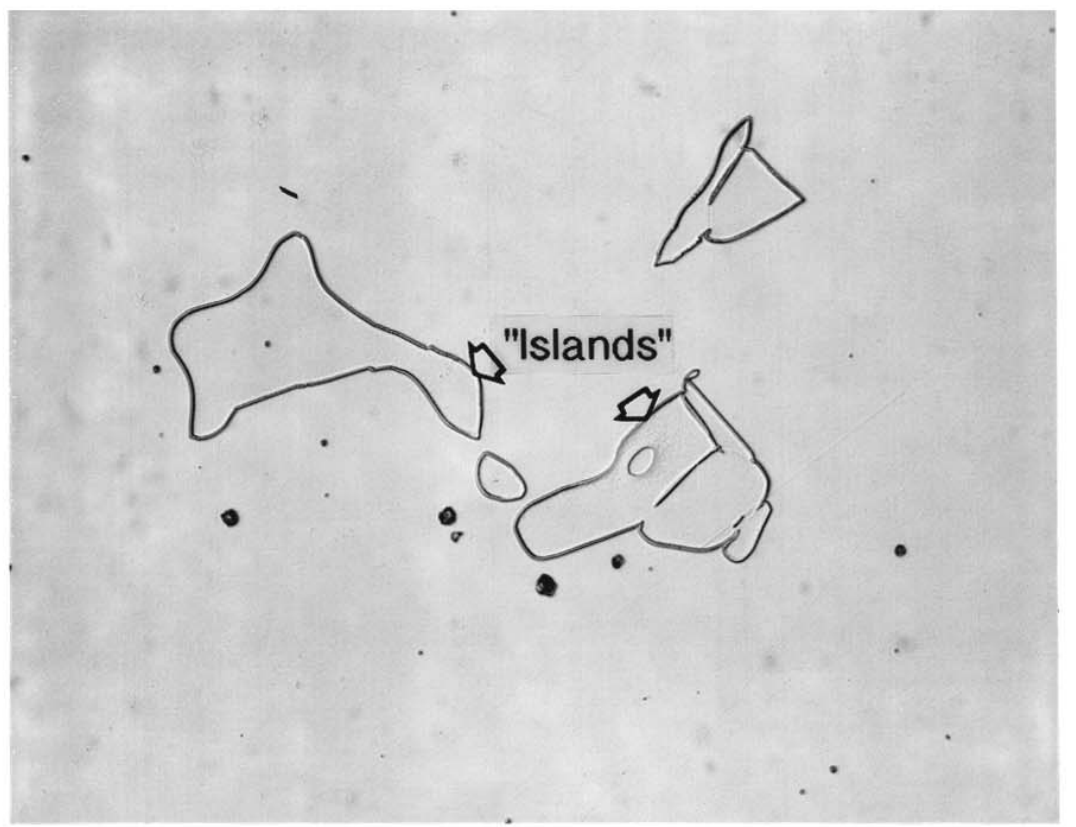

$400 x$

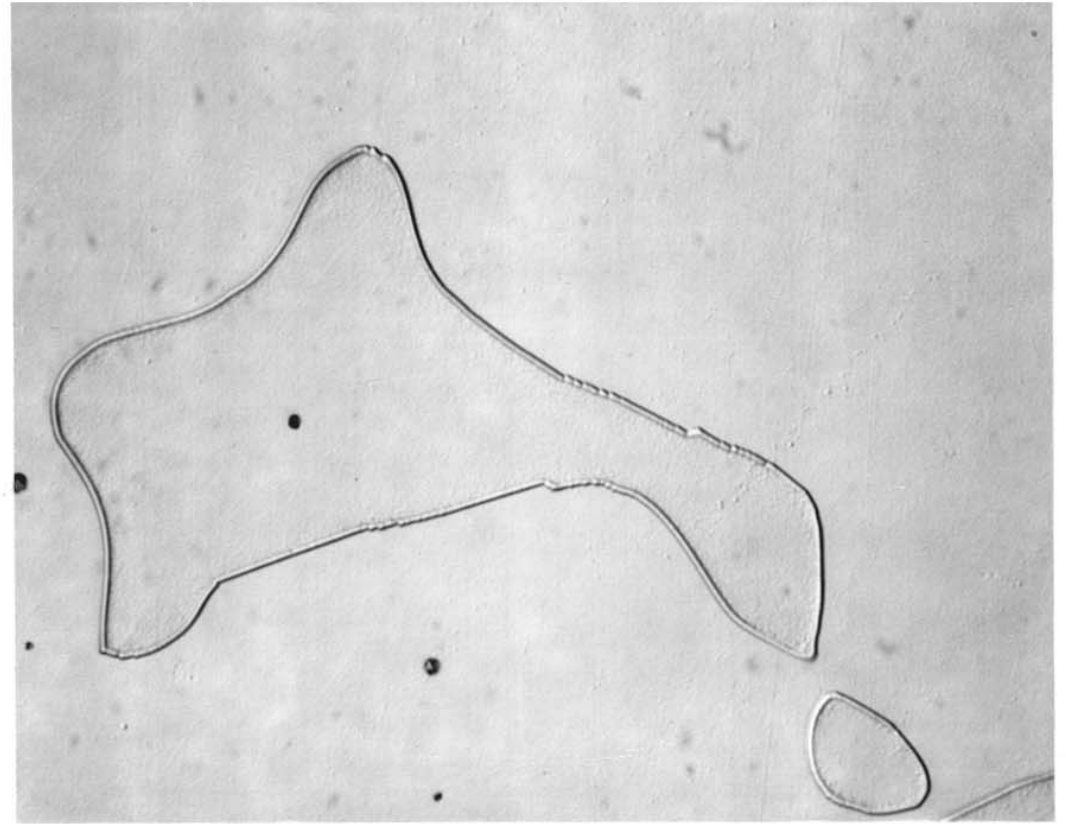

Figure 20. Microstructure of UT solution annealed $\left(2300^{\circ} \mathrm{F}+\mathrm{WQ}\right)$ CK-3MCuN Heat 5 
SA (followed by WQ), the microstructure of Heat 2 shows that some of the islands were "empty" (see Figure 18, Location 1), while some of the islands show substructure of no definitive secondary phase (see Figure 18, Location 2). For Heats 3 and 5, no irregular-shaped secondary phases were observed within the "islands" after solution annealing at $2300^{\circ} \mathrm{F} / 1260^{\circ} \mathrm{C}$, only the "empty islands" remained as shown in Figures 19 and 20. The gray globular or block-like particles remain unchanged for all samples evaluated regardless of material condition.

Ferrite measurement was conducted on all five heats in the as-cast and solution-annealed condition using the Fisher Feritscope. The results of ferrite measurement indicate $0.4 \%$ ferrite for Heat $2,1.2 \%$ for Heat 3 and $1.7 \%$ for Heat 5 after the $2300^{\circ} \mathrm{F} / 1260^{\circ} \mathrm{C}$ SA followed by $\mathrm{WQ}$, while no ferrite was detected using the Fisher Feritscope for all other conditions. Therefore, the "empty islands" remaining in Heats 2,3 , and 5 after the $2300^{\circ} \mathrm{F} / 1260^{\circ} \mathrm{C} \mathrm{SA}$ followed by WQ must be ferrite islands.

The microstructure of the wrought counterpart (254 SMO) is presented in Figure 21. It is evident that austenite (with annealing twins) is the predominant microstructural constituent for 254 SMO without the presence of any secondary phases. Ferrite measurement shows $0 \%$ ferrite in $254 \mathrm{SMO}$.

To identify sigma $(\sigma)$ phase, stain-etching techniques were applied to CK$3 \mathrm{MCuN}$ in both the as-cast and solution annealed conditions (SA at 


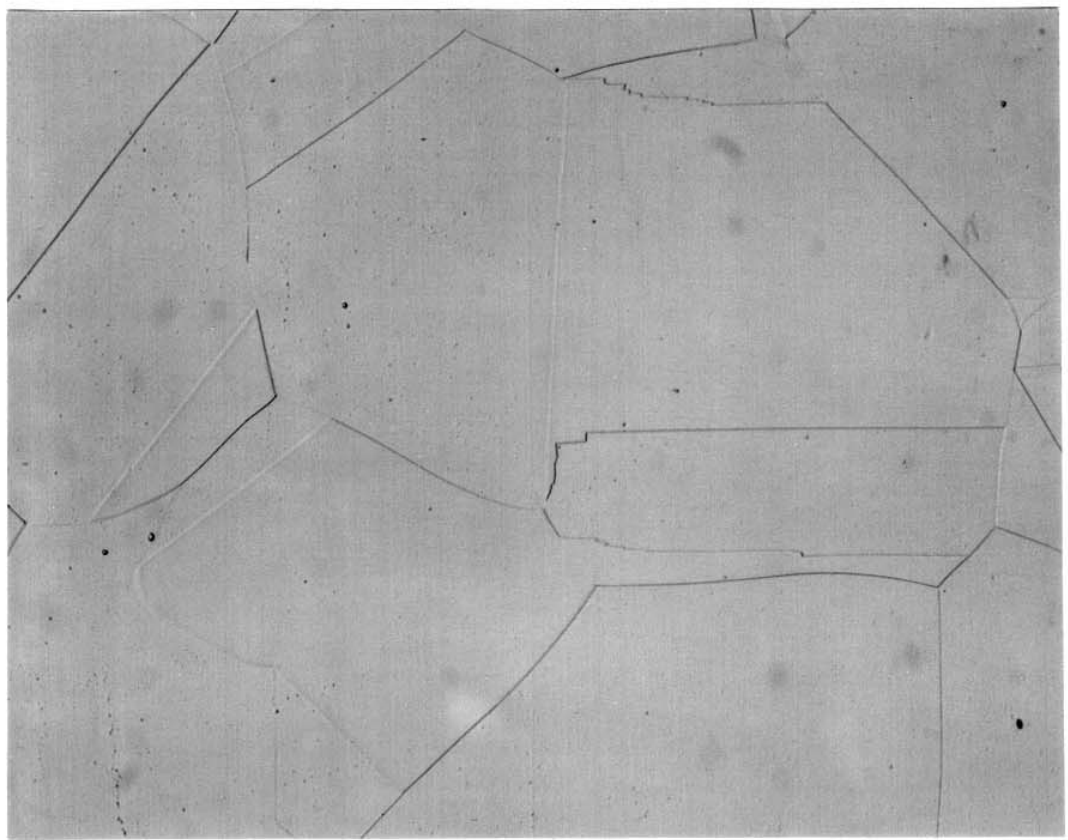

$400 x$

Figure 21. Microstructure of wrought counterpart alloy 254 SMO. 
$2100^{\circ} \mathrm{F} / 1150^{\circ} \mathrm{C}, 2200^{\circ} \mathrm{F} / 1205^{\circ} \mathrm{C}$ and $2300^{\circ} \mathrm{F} / 1260^{\circ} \mathrm{C}$ followed by WQ). Two heats-Heat K3GAO (representing the heats from cast bars) and Heat 3

(representing the heats from cast wedge blocks)—were selected for stainetching. The microstructures of stain-etched Heat K3GAO are shown in Figures 22 through 25 for the as-cast, $2100^{\circ} \mathrm{F} / 1150^{\circ} \mathrm{C}, 2200^{\circ} \mathrm{F} / 1205^{\circ} \mathrm{C}$ and $2300^{\circ} \mathrm{F} / 1260^{\circ} \mathrm{C}$ solution annealed (WQ) conditions, respectively. It is evident that only the fine irregular-shaped secondary phase within the "islands" observed in the as-cast condition by OLM was stained a blue or tan color as shown in Figure 22. The coarse irregular-shaped secondary phases within the "islands" are not stained regardless of the material condition (as-cast, $2100^{\circ} \mathrm{F} / 1150^{\circ} \mathrm{C}$, $2200^{\circ} \mathrm{F} / 1205^{\circ} \mathrm{C}$ or $2300^{\circ} \mathrm{F} / 1260^{\circ} \mathrm{C}$ solution annealed conditions) as presented in Figures 23 through 25 . These stain-etching results indicate that only the fine irregular shaped secondary phases within the "islands" in the as-cast condition are $\sigma$ phase.

Figures 26 through 29 show microstructures of stain-etched Heat 3 in the ascast, $2100^{\circ} \mathrm{F} / 1150^{\circ} \mathrm{C}, 2200^{\circ} \mathrm{F} / 1205^{\circ} \mathrm{C}$ or $2300^{\circ} \mathrm{F} / 1260^{\circ} \mathrm{C}$ solution annealed (WQ) conditions, respectively. From the stain-etching results, again, only the fine irregular- shaped secondary phases within the "islands" in the as-cast condition were identified as $\sigma$ phase. The "empty" islands observed in Heat 3 after $2300^{\circ} \mathrm{F} / 1260^{\circ} \mathrm{C} \mathrm{SA}(\mathrm{WQ})$, which are considered to be ferrite islands, are not stained and thus must reflect a ferrite phase as shown in Figure 29. 


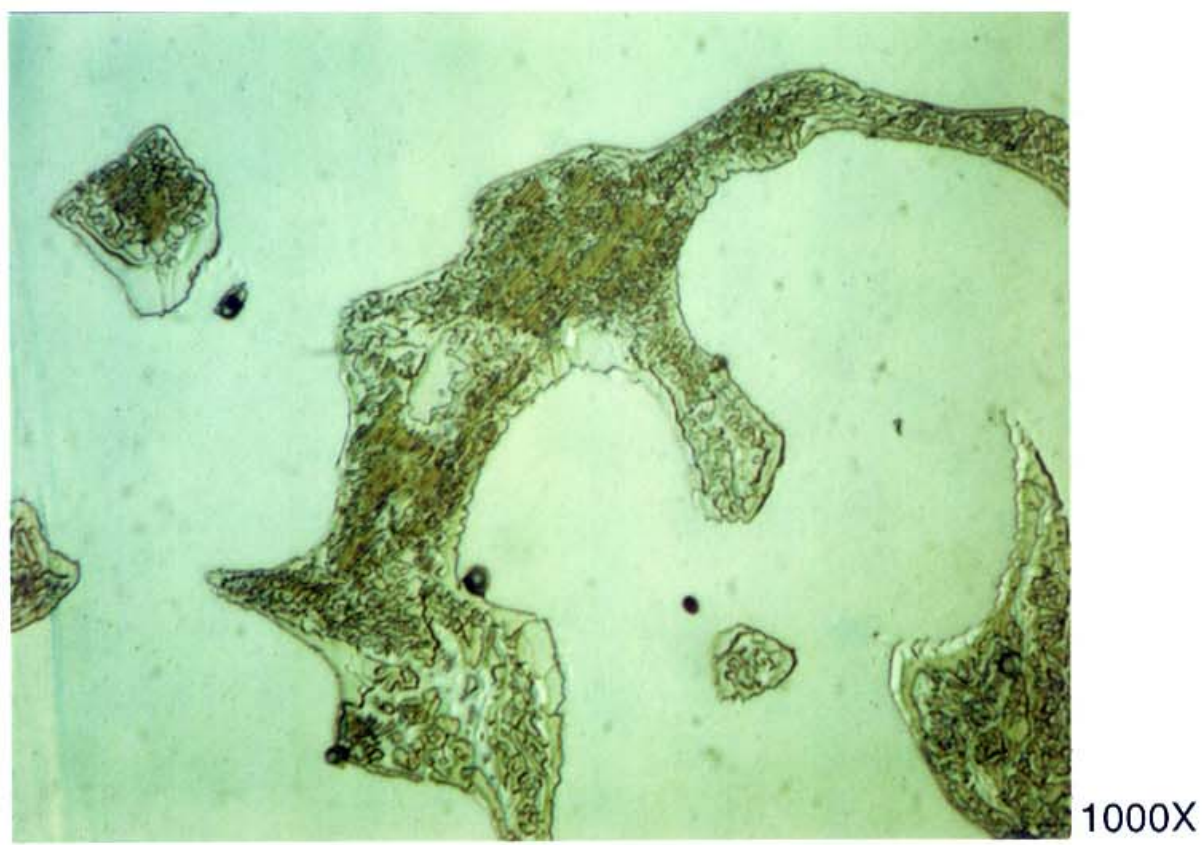

Figure 22. Microstructure of stain-etched CK-3MCuN Heat K3GAO in as-cast condition

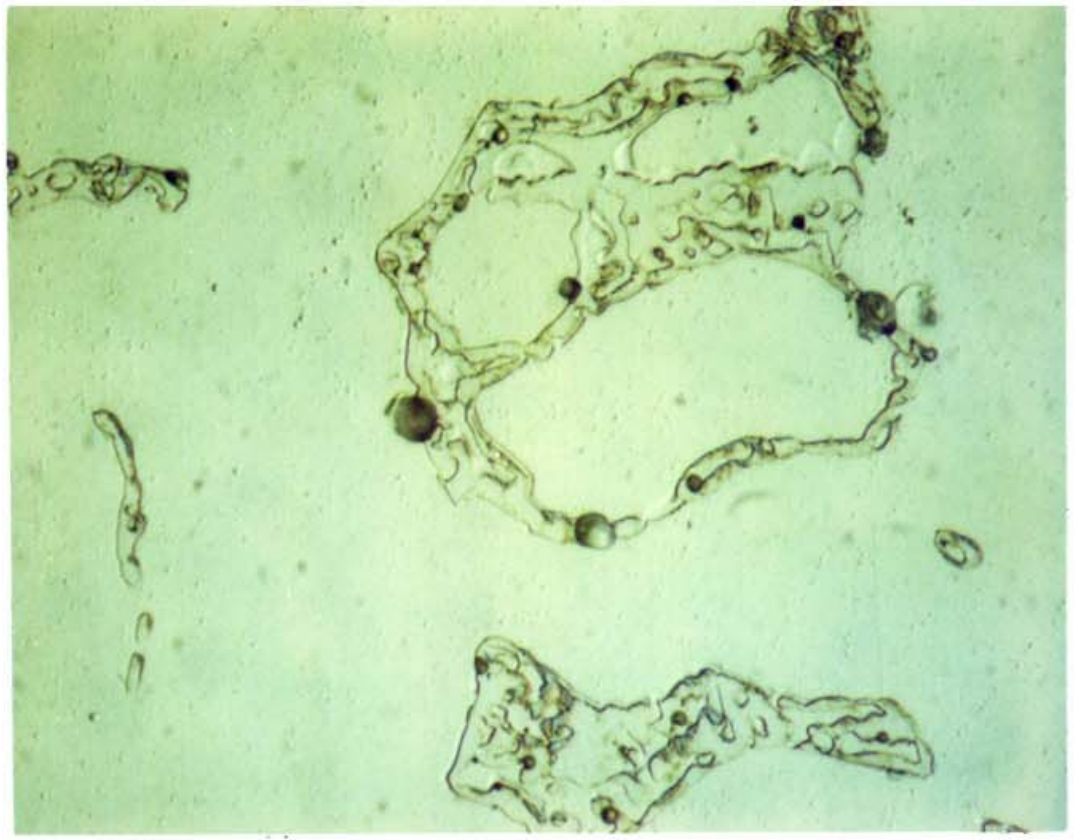

$1000 x$

Figure 23. Microstructure of stain-etched CK-3MCuN Heat K3GAO in SA condition $\left(2100^{\circ} \mathrm{F}+\mathrm{WQ}\right)$ 


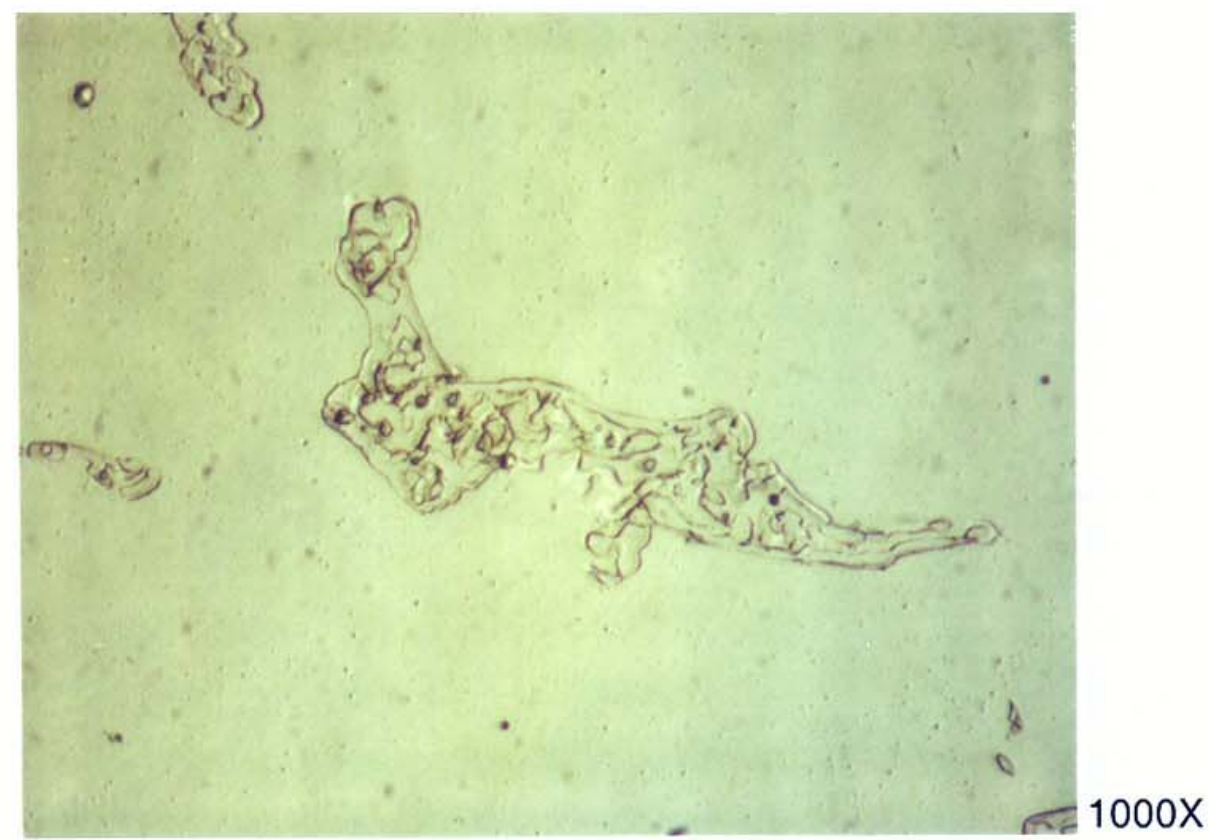

Figure 24. Microstructure of stain-etched CK-3MCuN Heat K3GAO in SA condition $\left(2200^{\circ} \mathrm{F}+\mathrm{WQ}\right)$

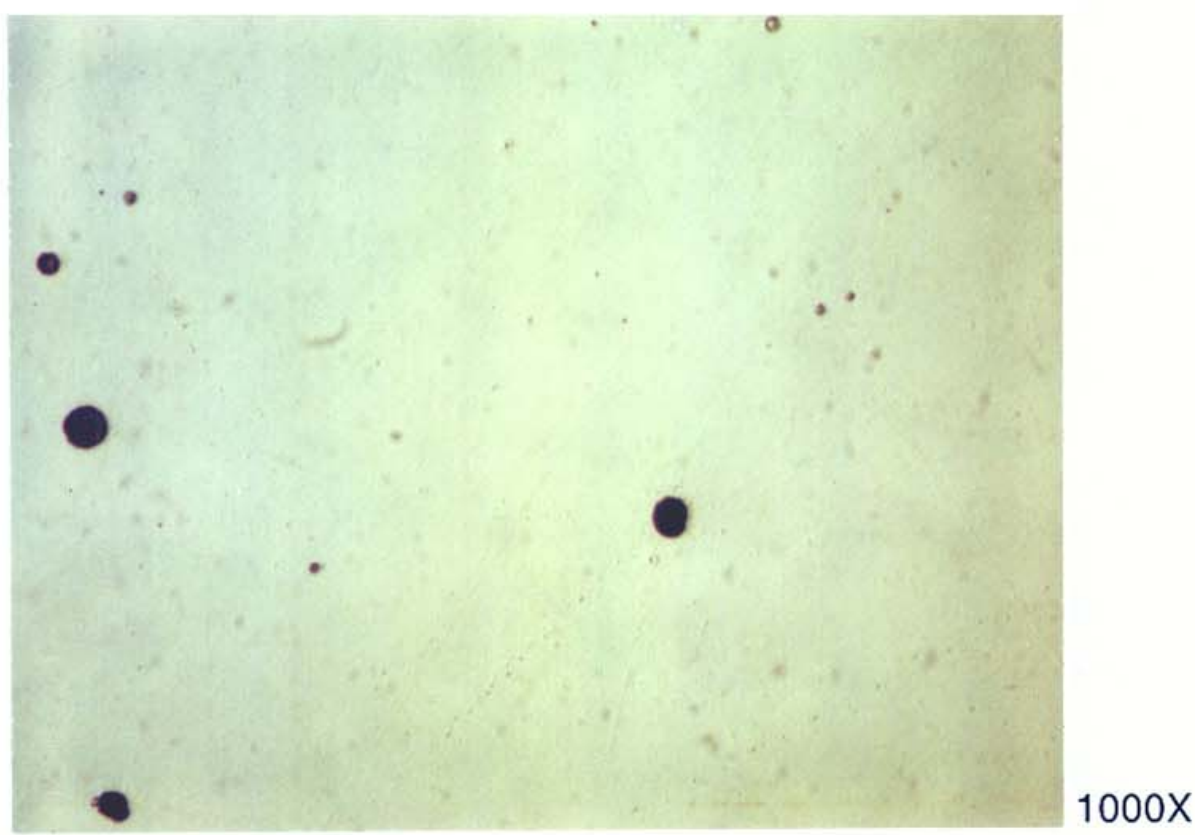

Figure 25. Microstructure of stain-etched CK-3MCuN Heat K3GAO in SA condition $\left(2300^{\circ} \mathrm{F}+\mathrm{WQ}\right)$ 


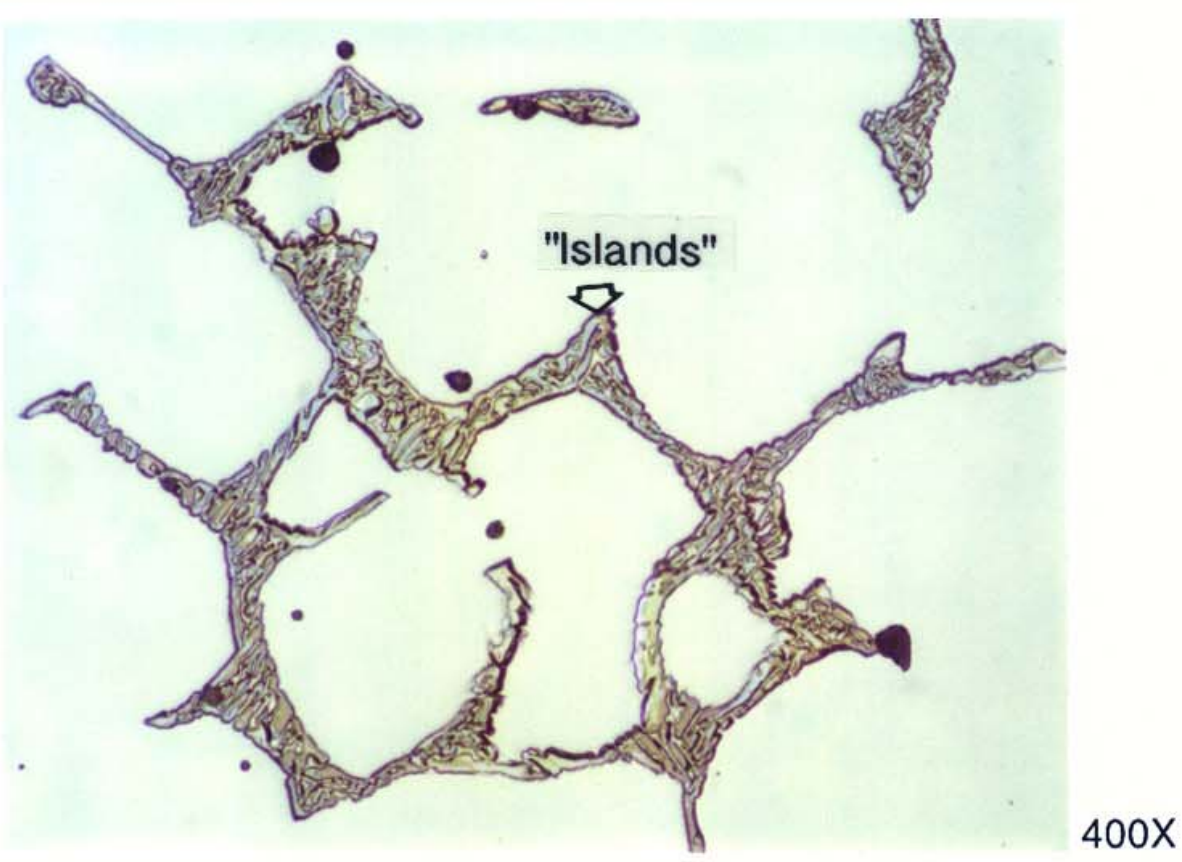

Figure 26. Microstructure of stain-etched CK-3MCuN Heat 3 in as-cast condition

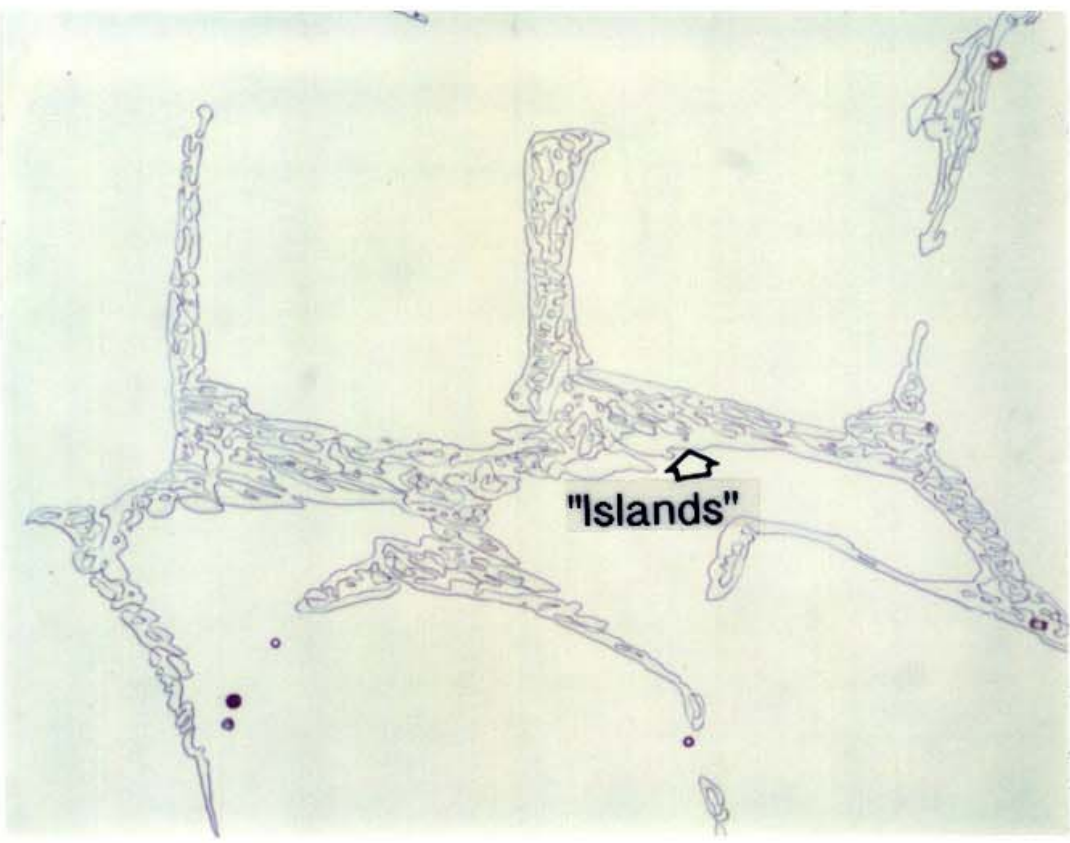

$400 X$

Figure 27. Microstructure of stain-etched CK-3MCuN Heat 3 in SA condition $\left(2100^{\circ} \mathrm{F}+\mathrm{WQ}\right)$ 


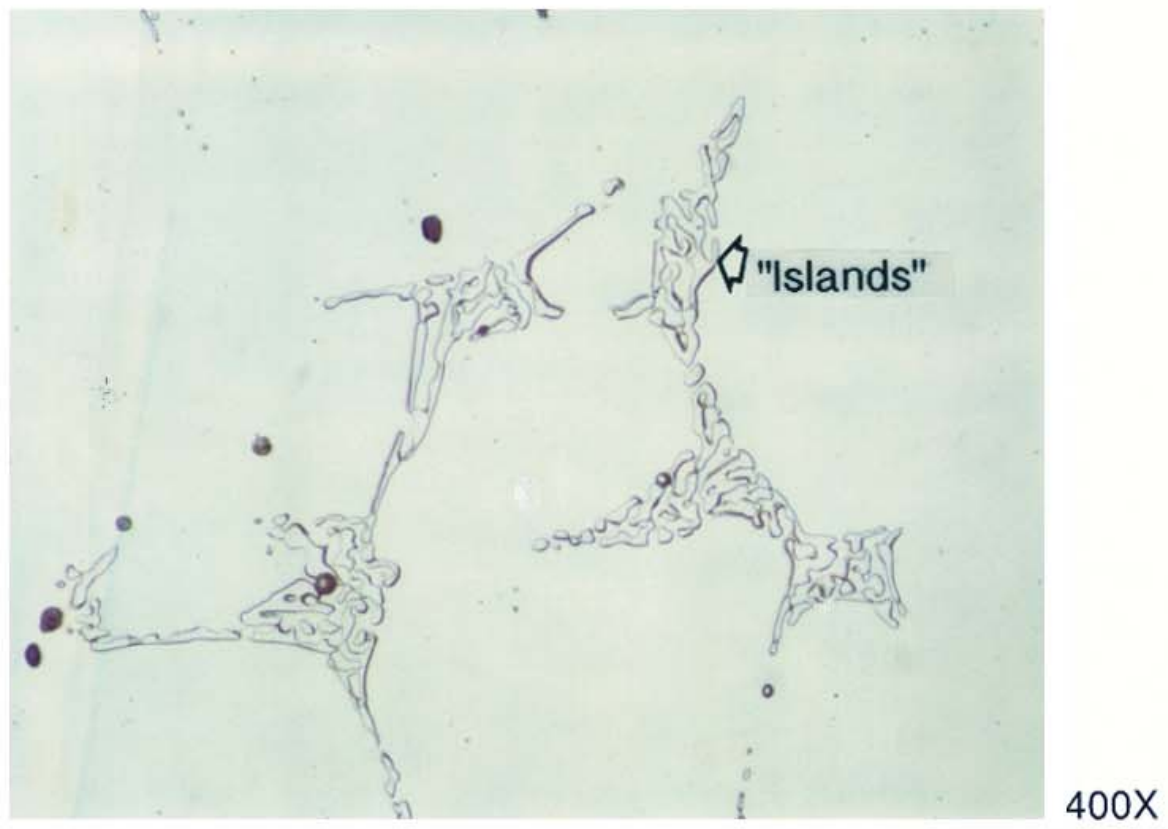

Figure 28. Microstructure of stain-etched CK-3MCuN Heat 3 in SA condition $\left(2200^{\circ} \mathrm{F}+\mathrm{WQ}\right)$

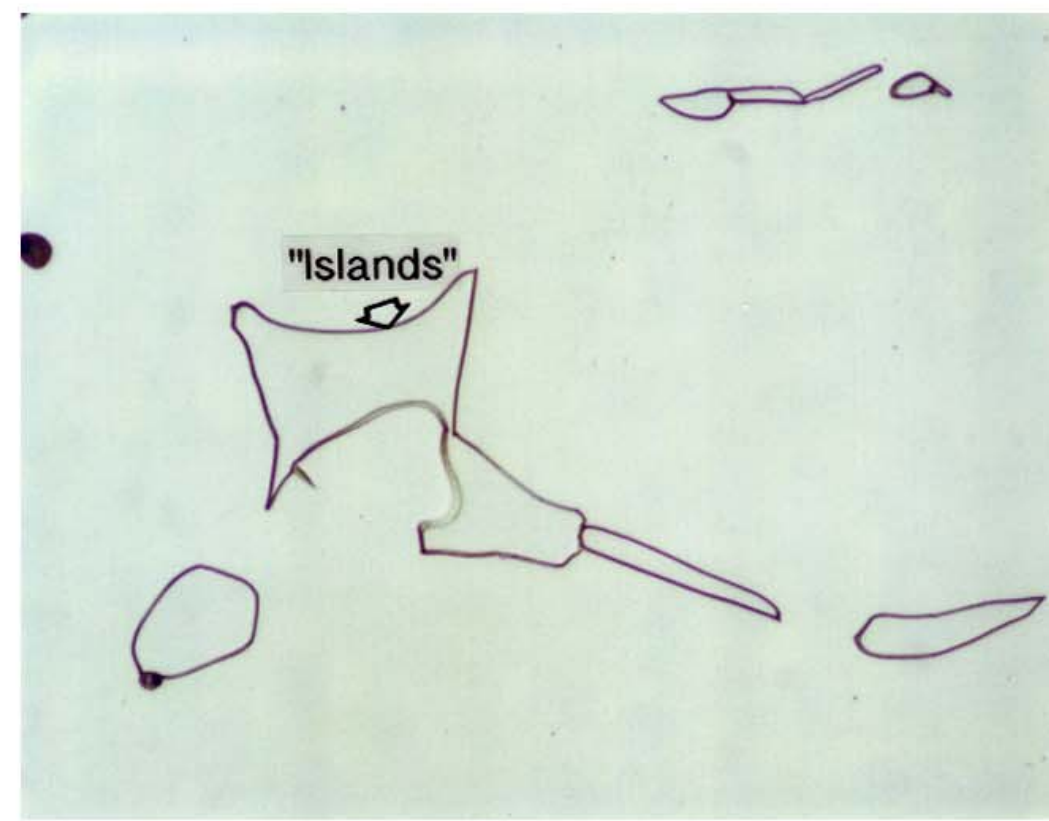

$400 X$

Figure 29. Microstructure of stain-etched CK-3MCuN Heat 3 in SA condition $\left(2300^{\circ} \mathrm{F}+\mathrm{WQ}\right)$ 
In order to understand the effect of cooling rate on microstructure of CK$3 \mathrm{MCuN}$, solution annealing at $2300^{\circ} \mathrm{F} / 1260^{\circ} \mathrm{C}$ with a slow cooling was conducted at UT for Heat K3GAO and Heat 3. (The heat treatment procedure was described previously). The comparison of microstructure between water quenching and slow cooling is shown in Figures 30 and 31 for Heat K3GAO and Heat 3, respectively. For Heat K3GAO, it is evident that, except for the dark globular particles, there are no secondary phases observed after slow cooling from $2300^{\circ} \mathrm{F} / 1260^{\circ} \mathrm{C} \mathrm{SA}$ (see Figure $30 \mathrm{~b}$ ). It should be recalled that the secondary phases in this heat were completely dissolved after $2300^{\circ} \mathrm{F} / 1260^{\circ} \mathrm{C}$ SA (see Figure 30a). Therefore, slow cooling (from $2300^{\circ} \mathrm{F} / 1260^{\circ} \mathrm{C}$ ) does not appear to cause re-precipitation in the matrix which is free of secondary phases. On the other hand, the microstructure of slow cooled Heat 3 shown in Figure 31b indicates the occurrence of re-precipitation during the slow cooling (SC). Fine and coarse irregular shaped precipitates within the "islands" are evident in interdendritic regions and along grain boundaries (Figure 31b). It must recalled that, after the $2300^{\circ} \mathrm{F} / 1260^{\circ} \mathrm{C}$ solution annealed with a WQ, this heat (Heat 3) showed no $\sigma$ phase, but only the "empty islands," which are considered to be ferrite islands as discussed previously. It is believed that the formation of these fine precipitates within the "islands" in Heat 3 occurred during slow cooling, and the re-precipitation during $\mathrm{SC}$ is associated with the remaining ferrite. The stain etching reveals that the fine precipitates within the "islands" formed during SC are $\sigma$ phase as shown Figure 32. This result indicates that remaining secondary phases can possibly trigger a re-precipitation during slow cooling. 


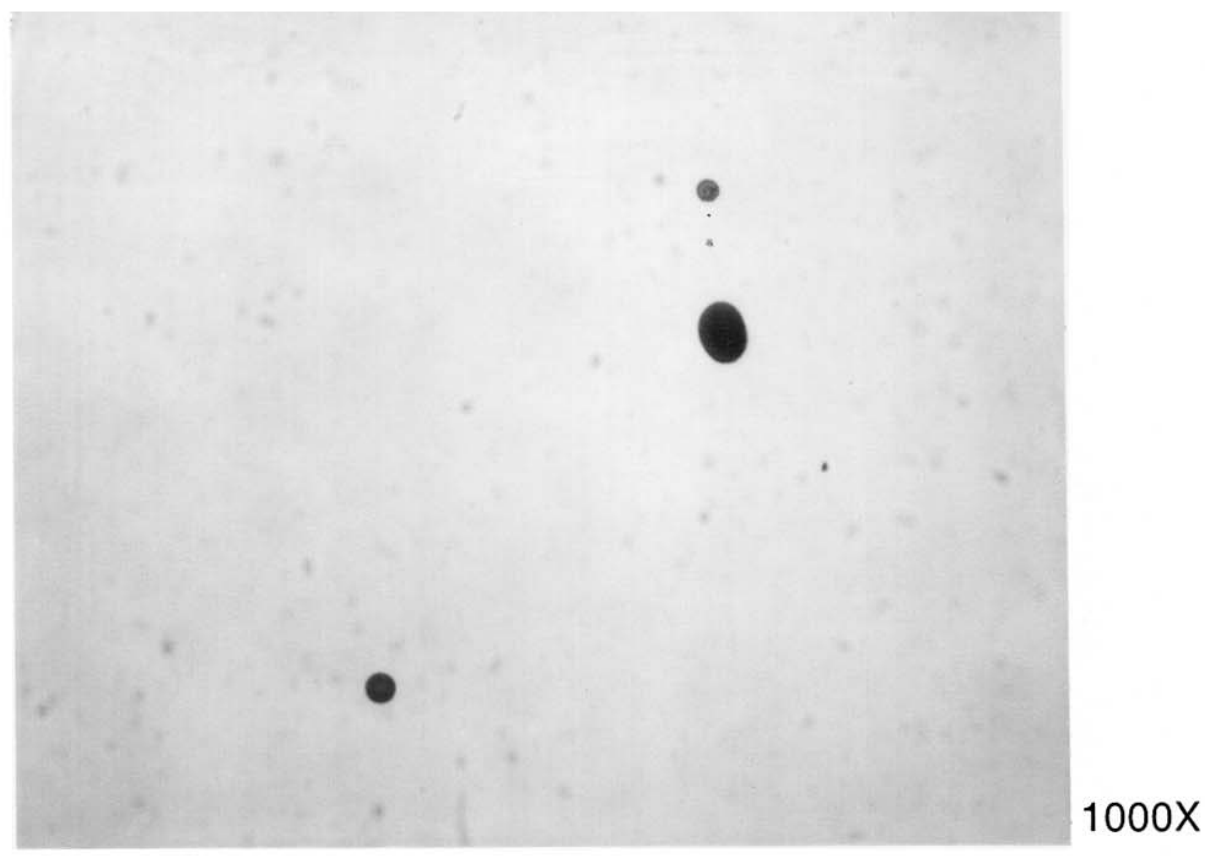

(a) $2300^{\circ} \mathrm{F} \mathrm{SA}+\mathrm{WQ}$

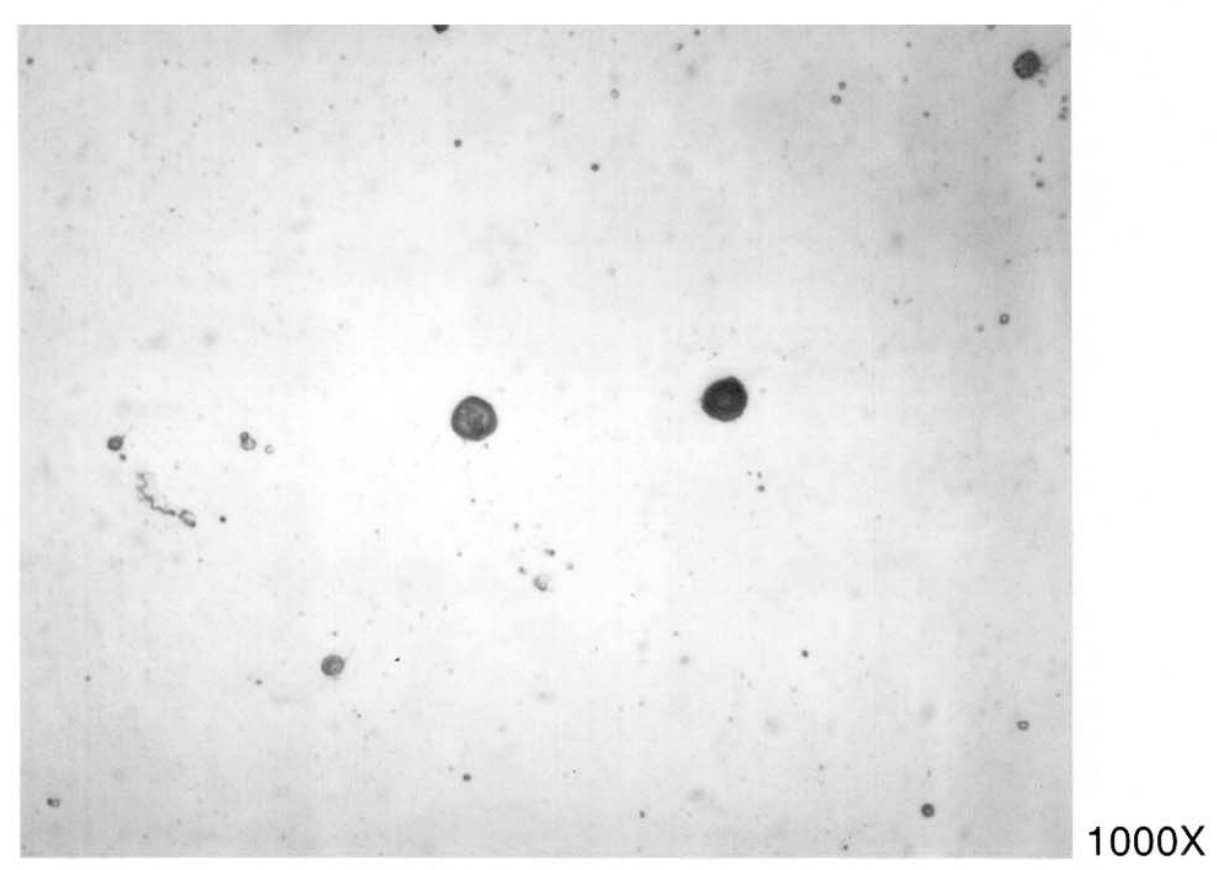

(b) $2300^{\circ} \mathrm{F} \mathrm{SA}+\mathrm{SC}$

Figure 30 Comparison of microstructure between water quenched and slow cooled CK-3MCuN Heat K3GAO 


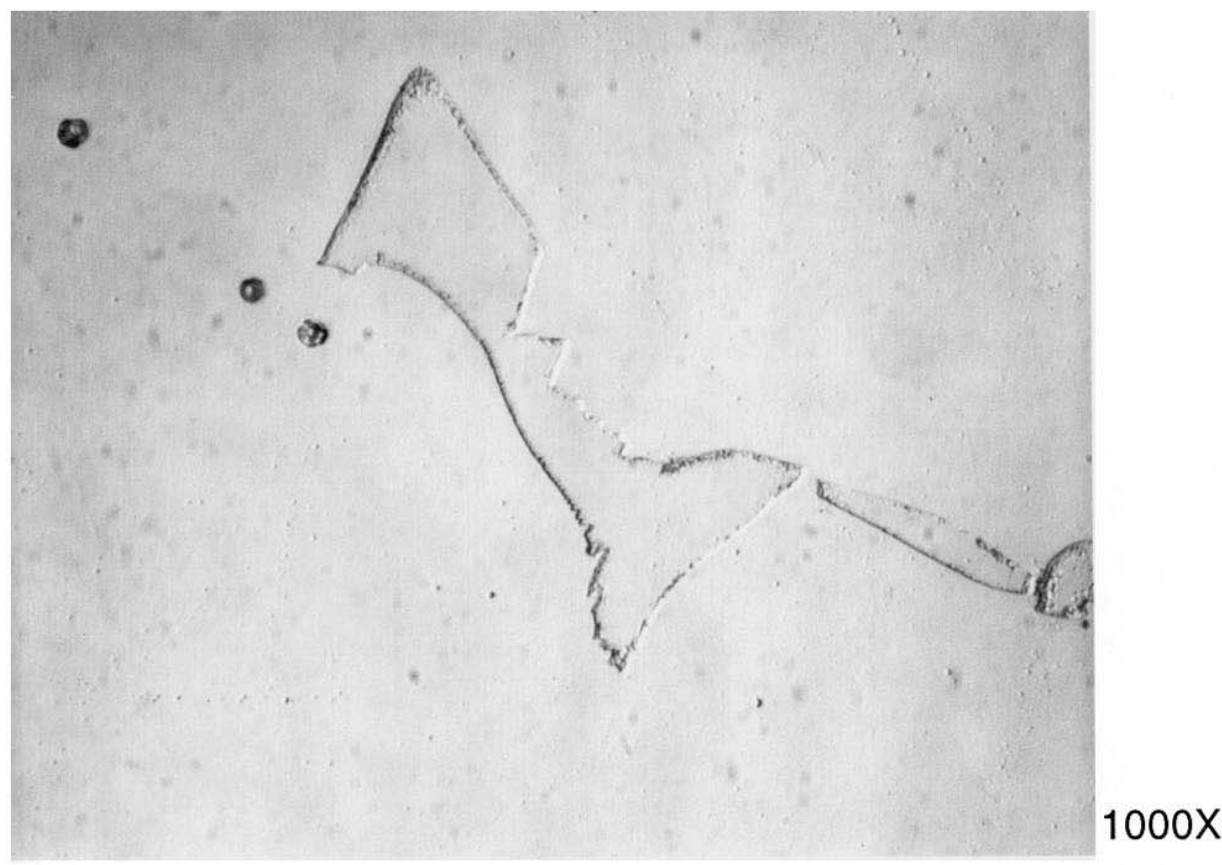

(a) $2300^{\circ} \mathrm{F} \mathrm{SA}+\mathrm{WQ}$

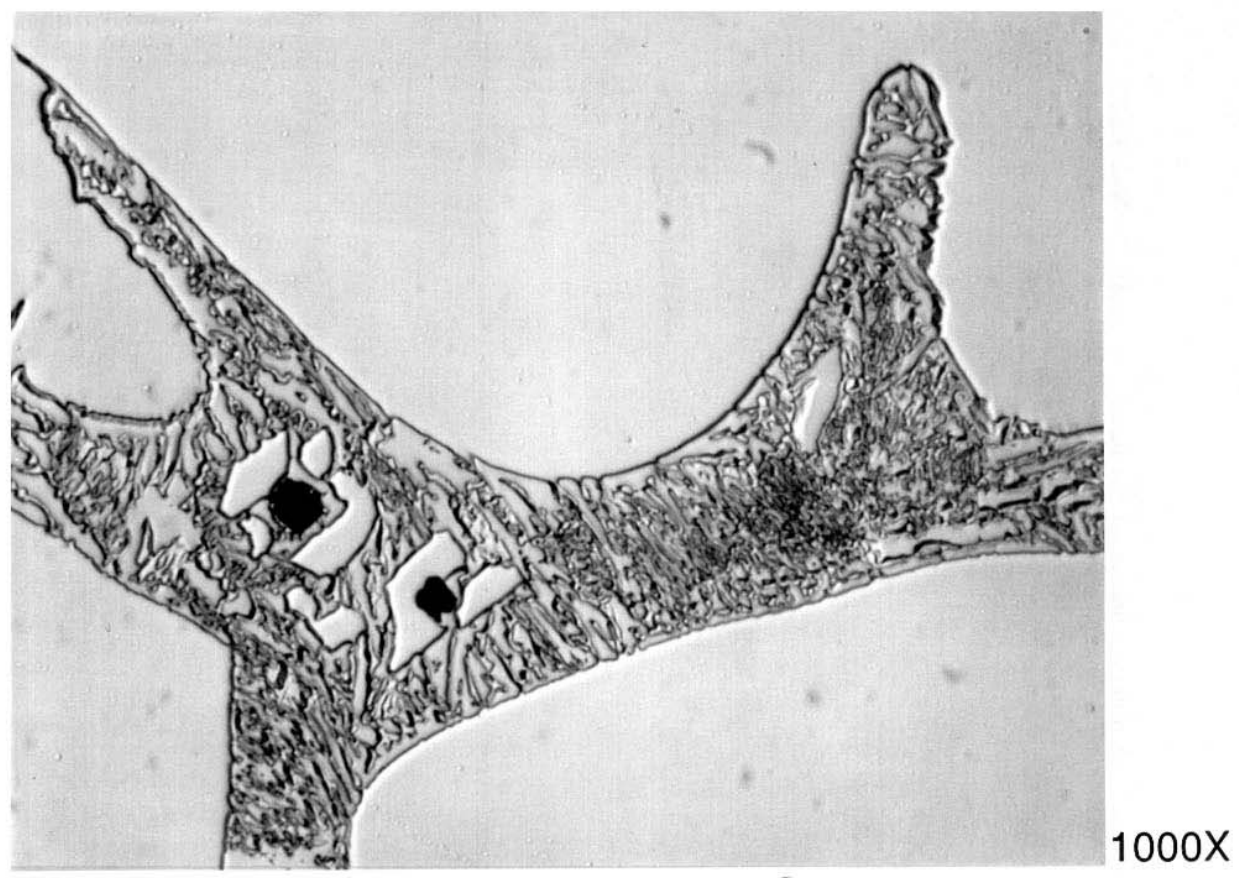

(b) $2300^{\circ} \mathrm{F} \mathrm{SA}+\mathrm{SC}$

Figure 31 Comparison of microstructure between water quenched and slow cooled CK-3MCuN Heat 3 


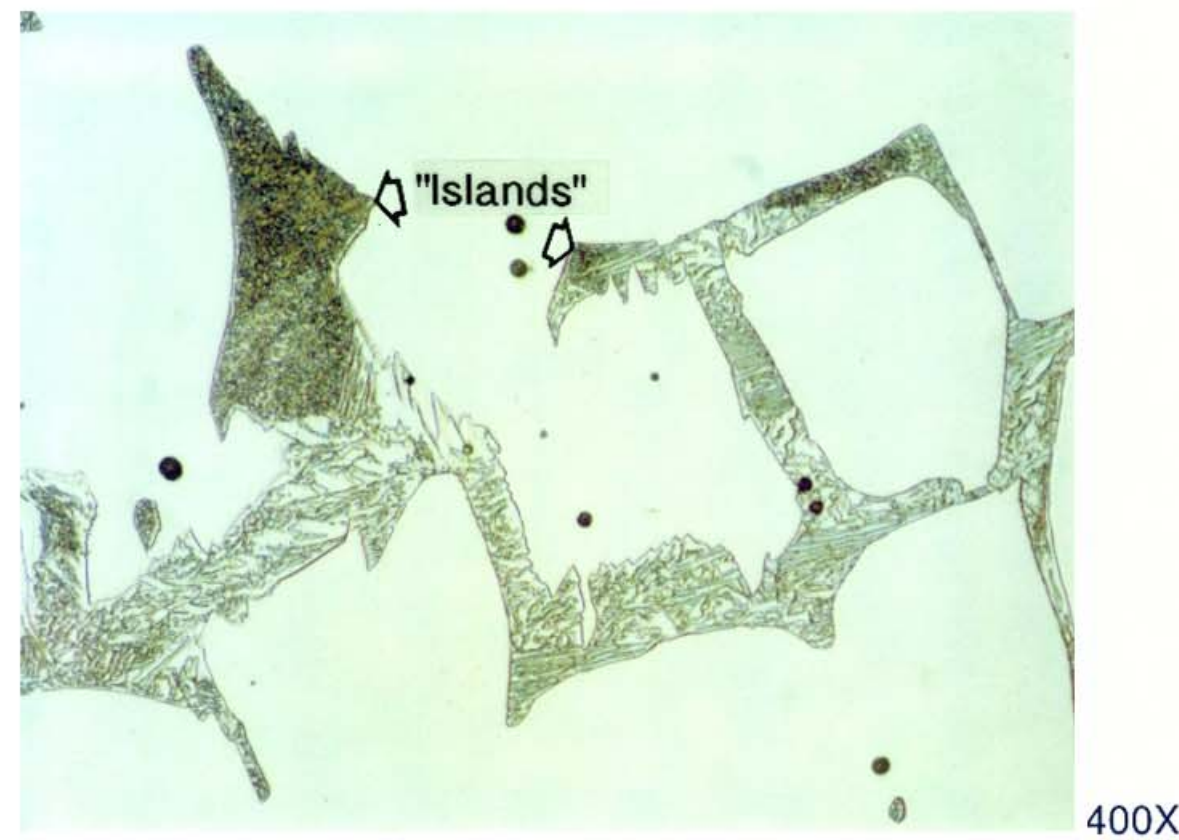

Figure 32 Microstructure of stain-etched CK-3MCUN Heat 3 in UT SA condition $\left(2300^{\circ} \mathrm{F}+\mathrm{SC}\right)$ 


\section{- SEM/EDS Analysis}

In order to provide an expanded data base, three heats of $\mathrm{CK}-3 \mathrm{MCuN}-\mathrm{Heat}$ K3GAO, Heat 2, and Heat 3-were selected for SEM/EDS evaluation. The wrought counterpart 254SMO was also used in SEM/EDS evaluation for comparison. The SEM/EDS analysis was conducted on both the as-cast and solution-annealed material for each heat.

\section{i) $\underline{\text { KK-3MCUN Heat K3GAO }}$}

SEM microstructural morphology of CK-3MCuN Heat K3GAO in the ascast condition is shown in Figure 33 (a) as a secondary electron image and (b) as a back scattered electron image at 1000X. The typical microstructure of the as-cast $\mathrm{CK}-3 \mathrm{MCuN}$ includes the fine irregular-shaped secondary phase (Location B) and the coarse irregular-shaped secondary phase (Location C) within the "islands" in the matrix in addition to dark globular particles (Location D). EDS analysis was performed at the locations marked by arrows and letters (A through D) in Figure 33. EDS analysis was also conducted on the matrix of the wrought counterpart 254 SMO for comparison. The EDS spectra for the matrix of as-cast CK-3MCuN (Location A in Figure 33) and the wrought 254SMO are presented in Figures 34 and 35, respectively. It is evident that the matrix of the as-cast CK$3 \mathrm{MCuN}$ and the wrought $254 \mathrm{SMO}$ reveal basically identical EDS spectra.

Figures 36 and 37 show the EDS results for locations $B$ and $C$ where the fine and coarse irregular-shaped secondary phases within the "islands" were generally 


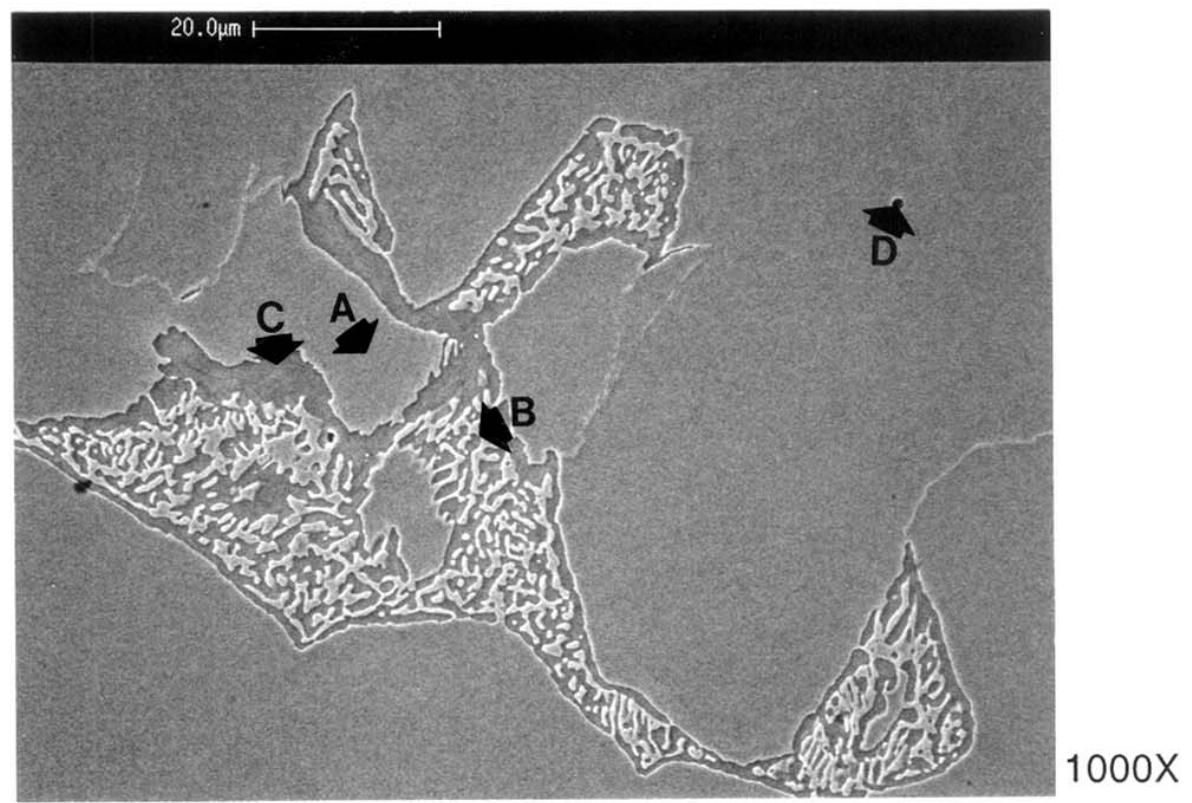

(a) Secondary image

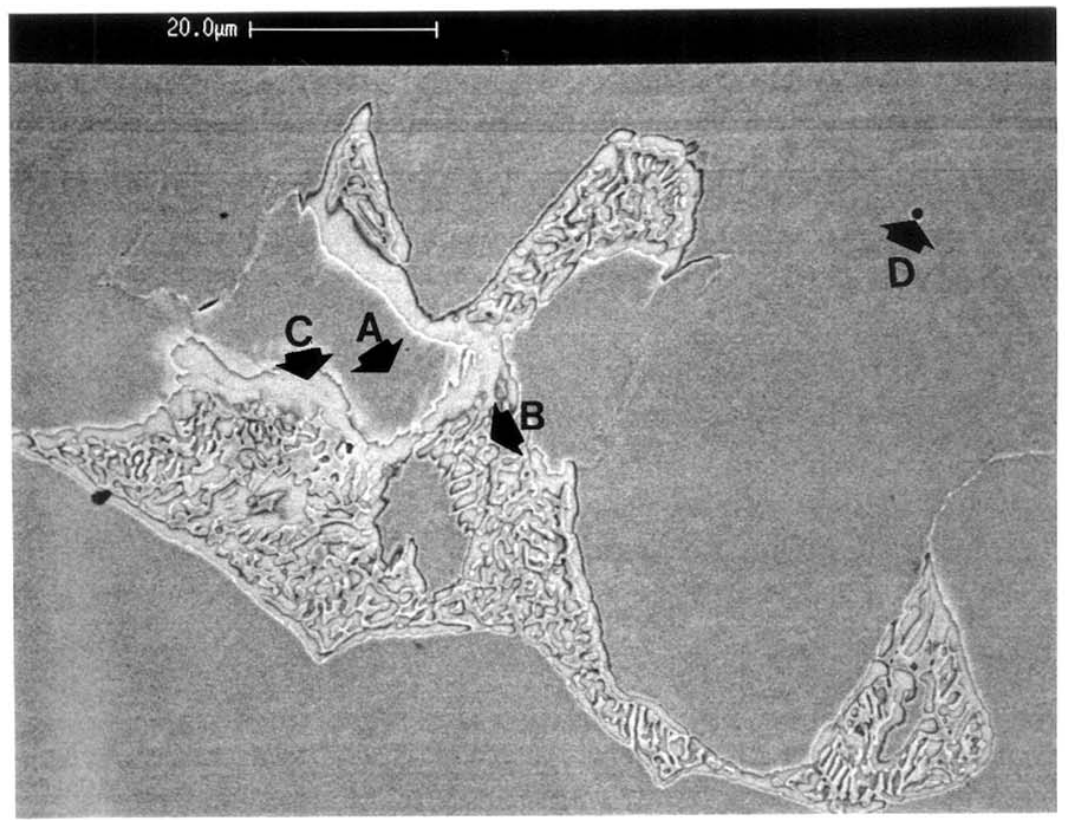

$1000 X$

(b) Back scattered image

Figure 33. SEM photomicrograph of as-cast CK-3MCUN Heat K3GAO, EDS analysis at locations marked by letters 


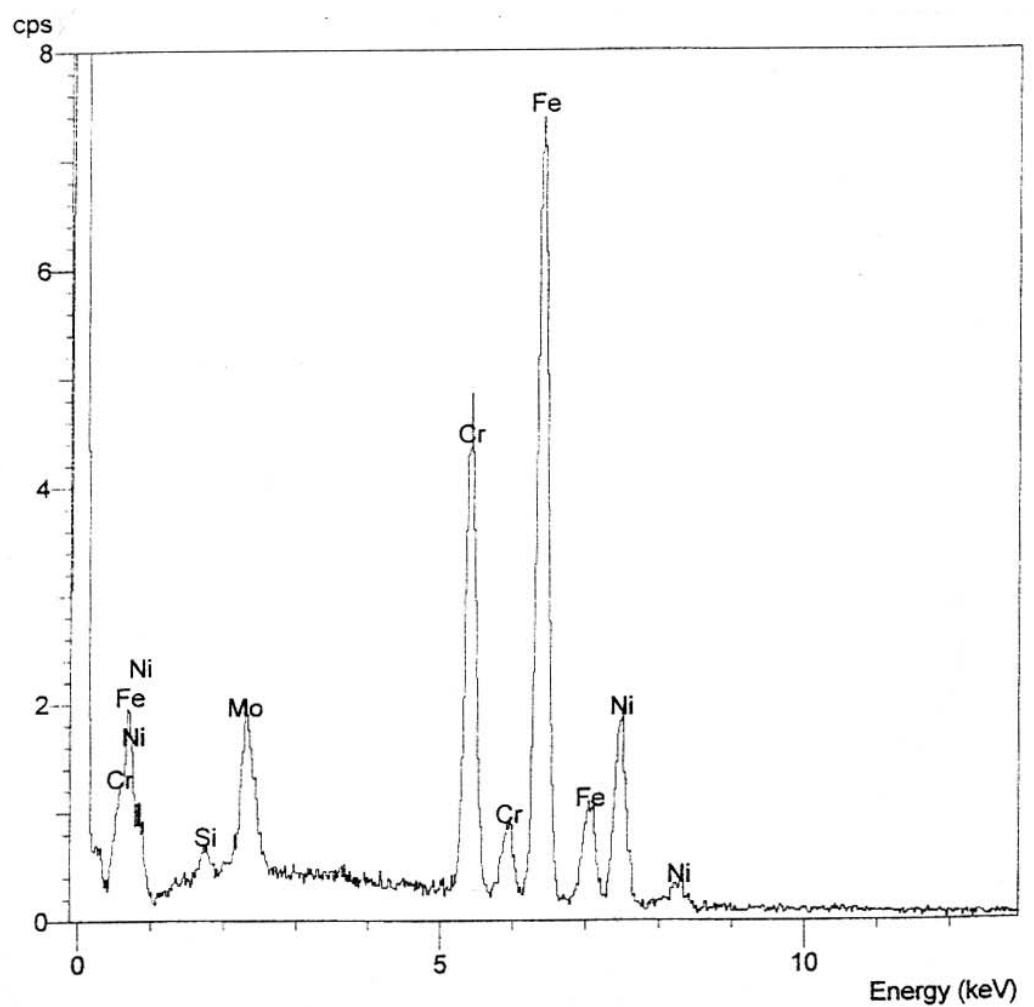

Figure 34. EDS spectrum at Location $A$ (matrix) in Figure 33, as-cast CK-3MCuN Heat K3GAO

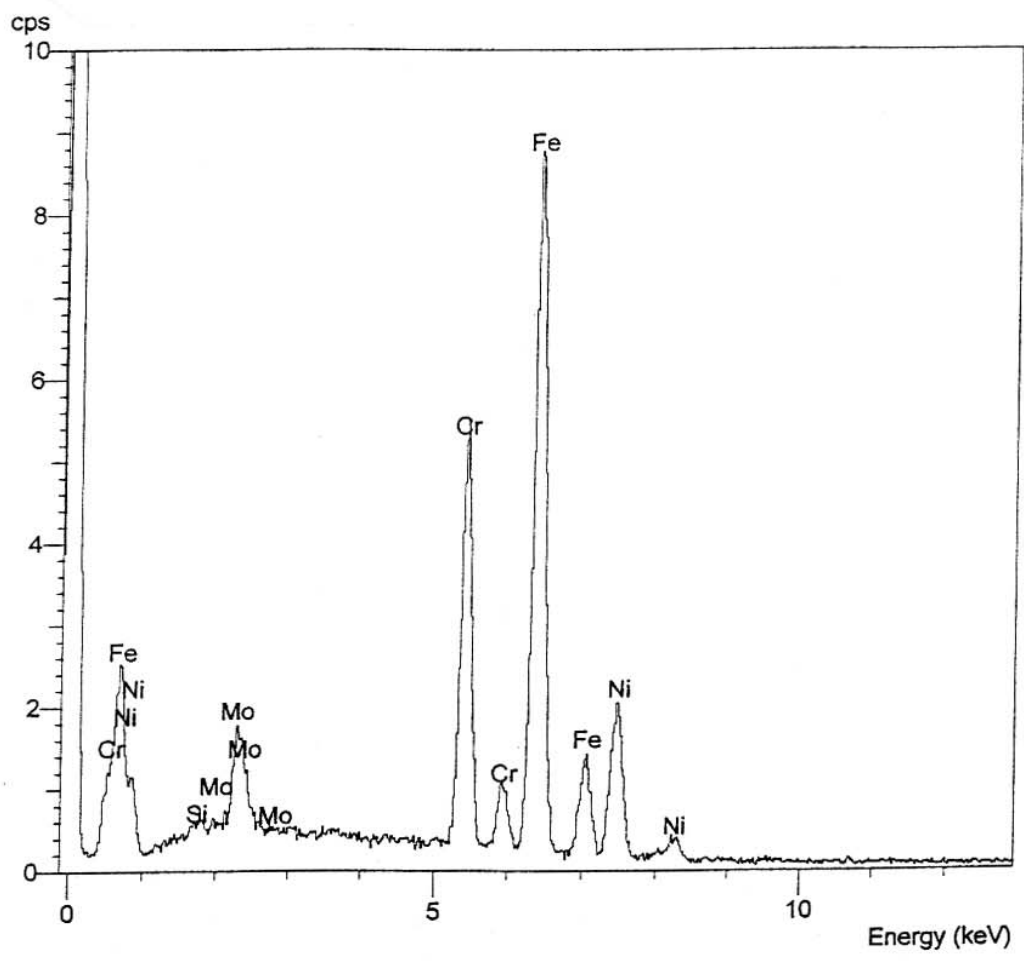

Figure 35. EDS spectrum of wrought alloy 254 SMO 
observed. Compared to the matrix (Location A), it is evident that the fine irregularshaped secondary phases within the "islands" (Location B) are richer in $\mathrm{Mo}$ and $\mathrm{Cr}$ as shown in Figure 36. In addition to the fact that these fine irregular-shaped secondary phases within the "islands" were stained blue or tan by stain etching, they are additionally defined to be $\sigma$ phase (FeCrMo). For the coarse irregularshaped secondary phases within the "islands" (Location C), EDS results (see Figure 37) indicate that they contain higher Mo and Cr than the "fine" secondary phase within the same "islands" (Location B). As stated previously, the coarse irregular-shaped secondary phases within the "islands" remain un-stained after stain-etching practice. Based on EDS and stain-etching results, these coarse irregular-shaped secondary phases were considered to be $\mathrm{Cr} / \mathrm{Mo}$ carbides. In addition to $\sigma$ phase and $\mathrm{Cr} / \mathrm{Mo}$ carbides, the dark globular particles in the matrix (Location D) were determined to be silicon oxides, magnesium oxides, or manganese oxides according to the EDS results presented in Figure 38.

For the lower temperature $\left(2100^{\circ} \mathrm{F} / 1150^{\circ} \mathrm{C}+\mathrm{WQ}\right)$ solution-annealed $\mathrm{CK}-3 \mathrm{MCuN}$ Heat K3GAO, the SEM microstructural morphology is presented in Figure 39 (a) as a secondary electron image and (b) as a back scattered electron image. The typical microstructure of $2100^{\circ} \mathrm{F} / 1150^{\circ} \mathrm{C}$ solution-annealed CK-3MCuN includes coarse irregular-shaped secondary phase within "islands" distributed in the matrix. EDS analysis was performed at Location A for Matrix and Location B for the remaining coarse irregular-shaped secondary phases within "islands". The EDS spectra are presented in Figures 40 and 41 for Locations A and B, 


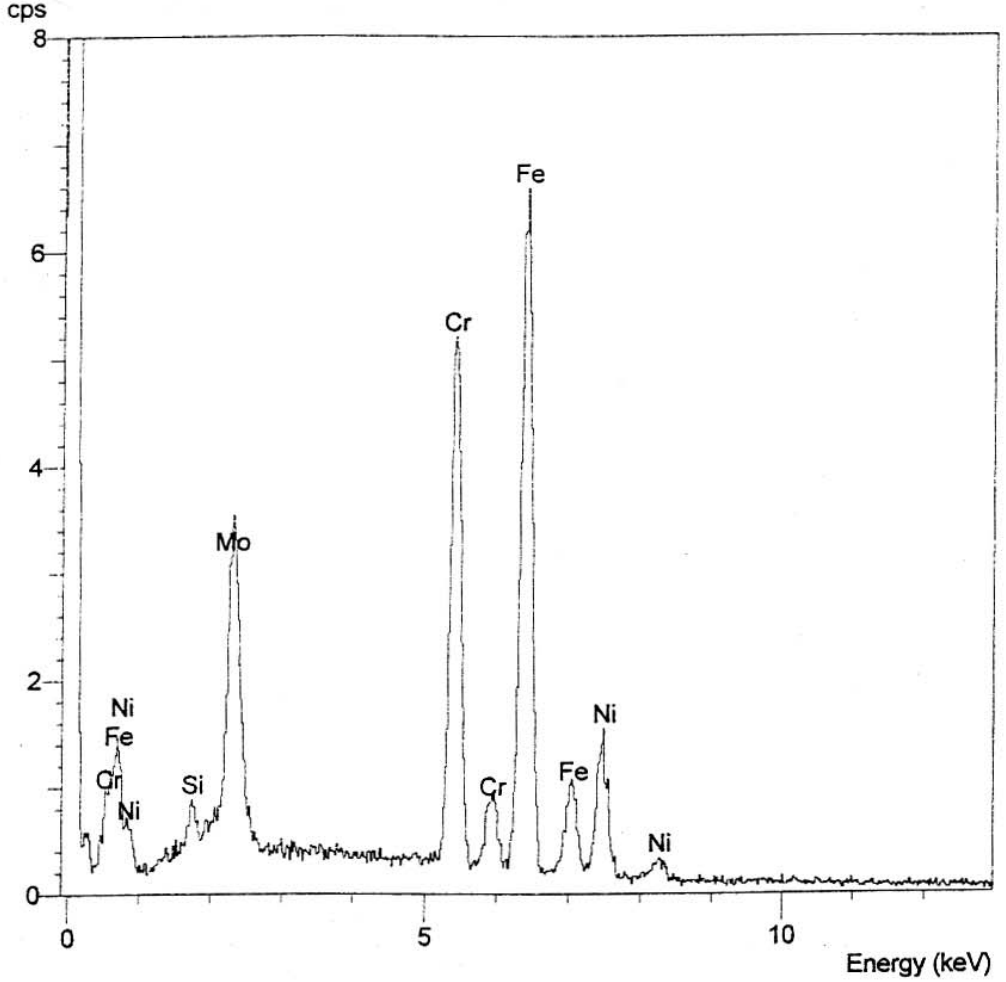

Figure 36. EDS spectrum at Location B (fine irregular shaped secondary phases within "islands") in Figure 33, as-cast CK-3MCuN Heat K3GAO

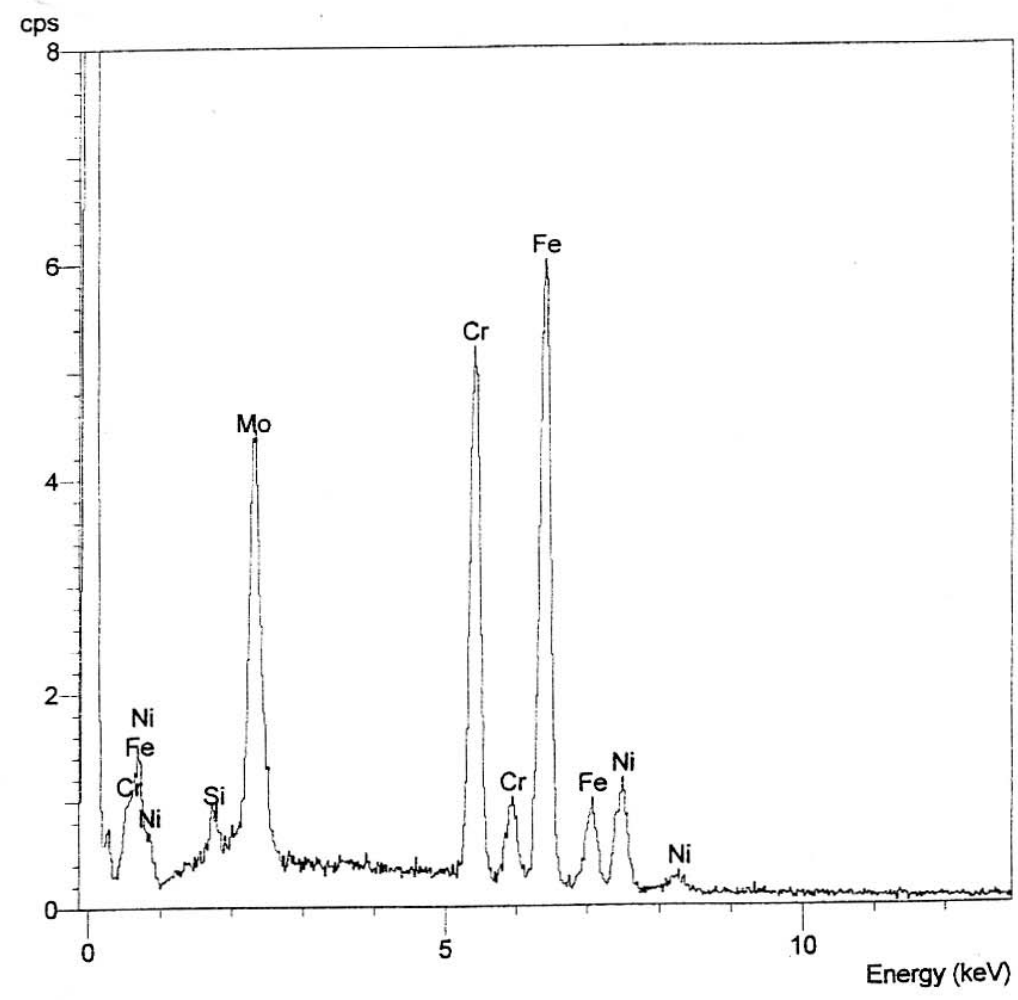

Figure 37. EDS spectrum at Location C (coarse irregular shaped secondary phases within "islands") in Figure 33, as-cast CK-3MCuN Heat K3GAO 


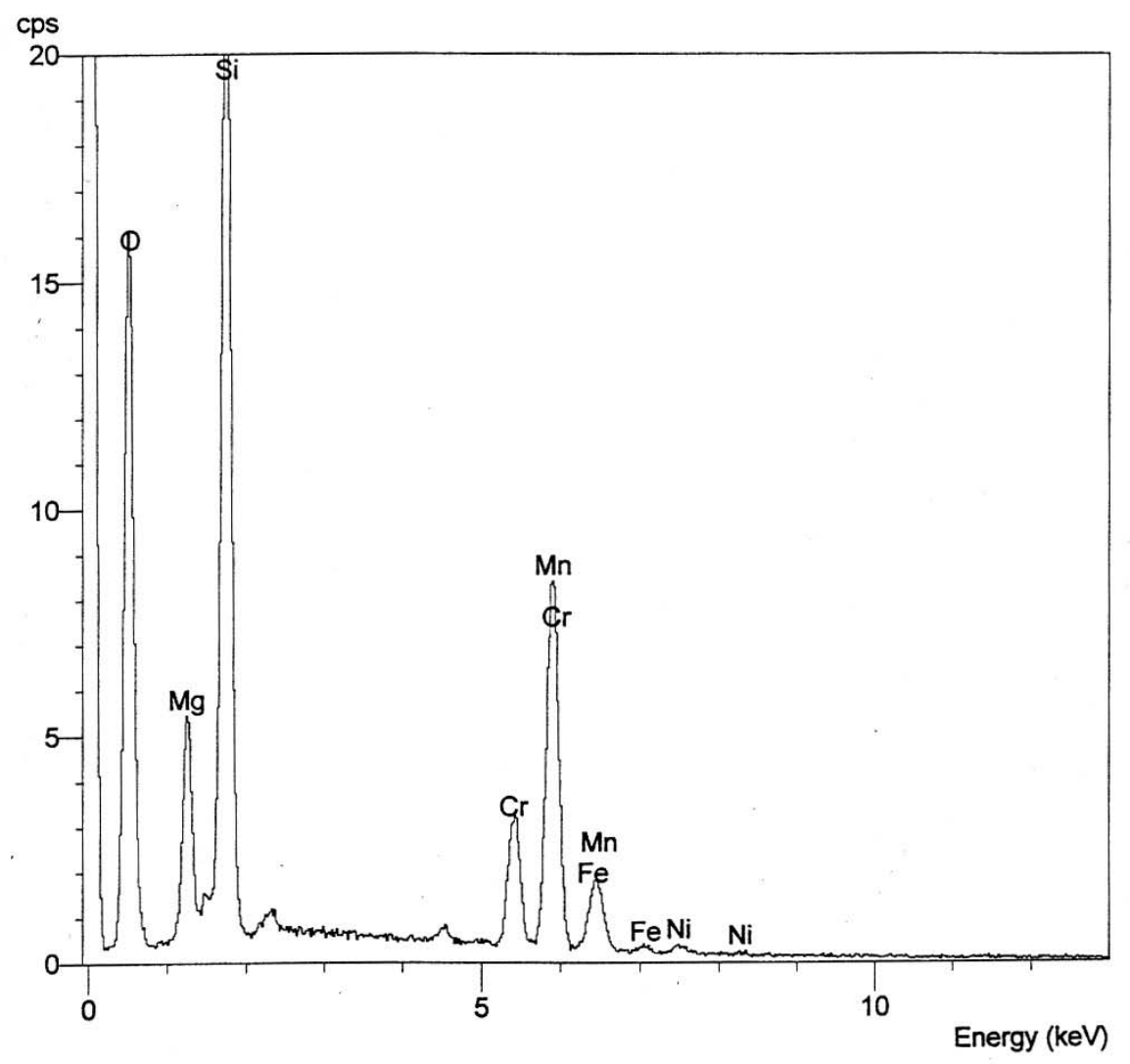

Figure 38. EDS spectrum at Location D (dark globular particles) in Figure 33, as-cast CK-3MCuN Heat K3GAO 


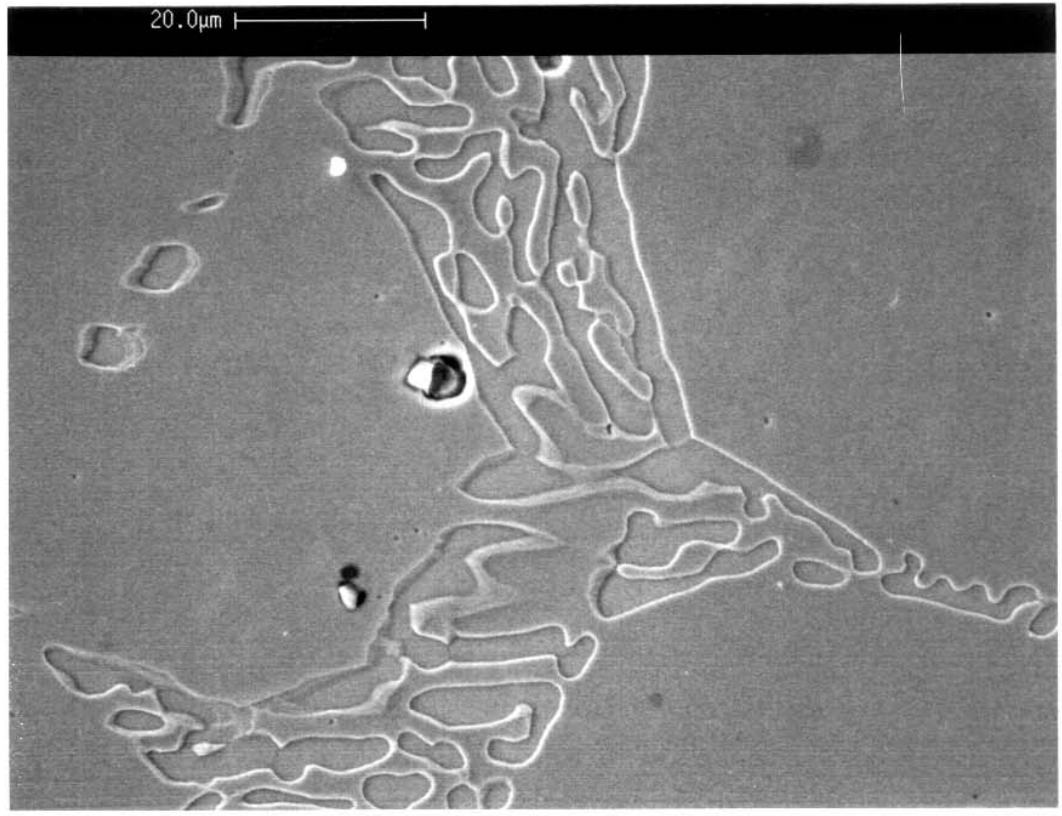

$1000 x$

(a) Secondary image

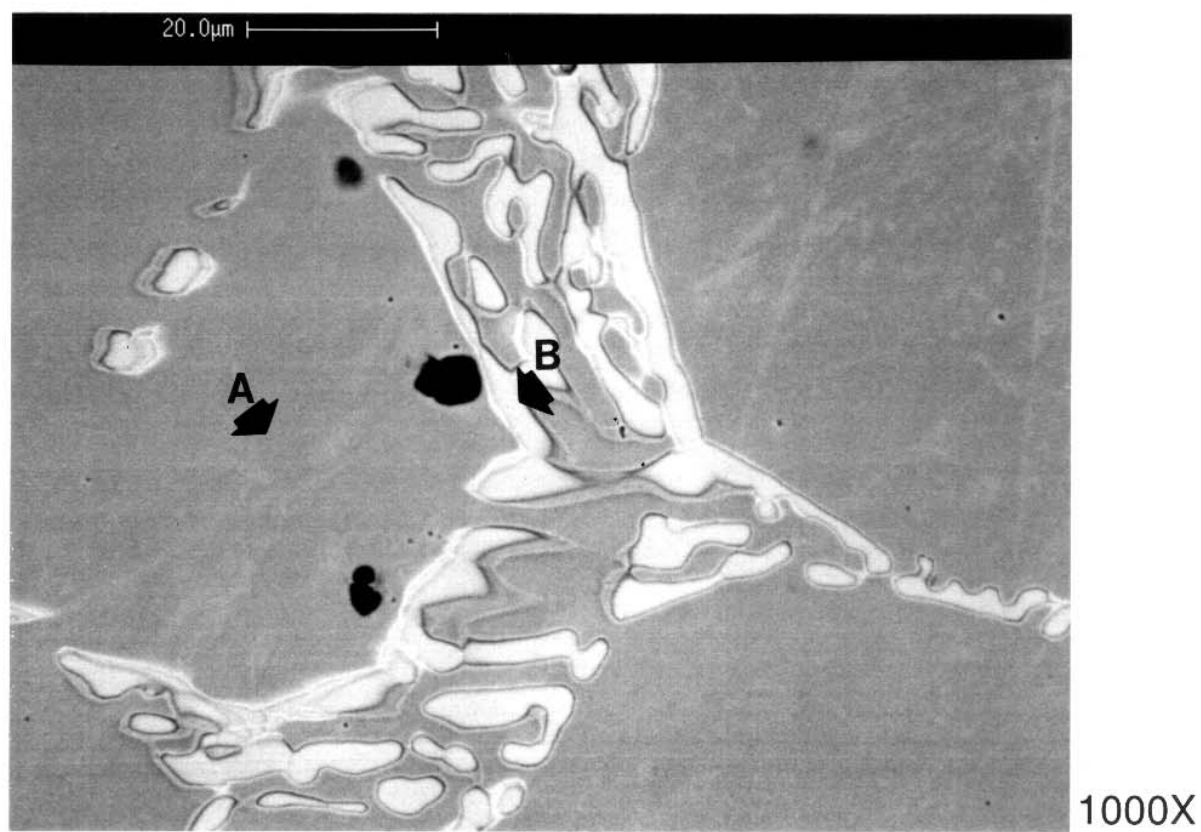

(b) Back scattered image

Figure 39. SEM photomicrograph of CK-3MCUN Heat K3GAO in SA condition $\left(2100^{\circ} \mathrm{F}+\mathrm{WQ}\right)$, EDS analysis at locations marked by letters 


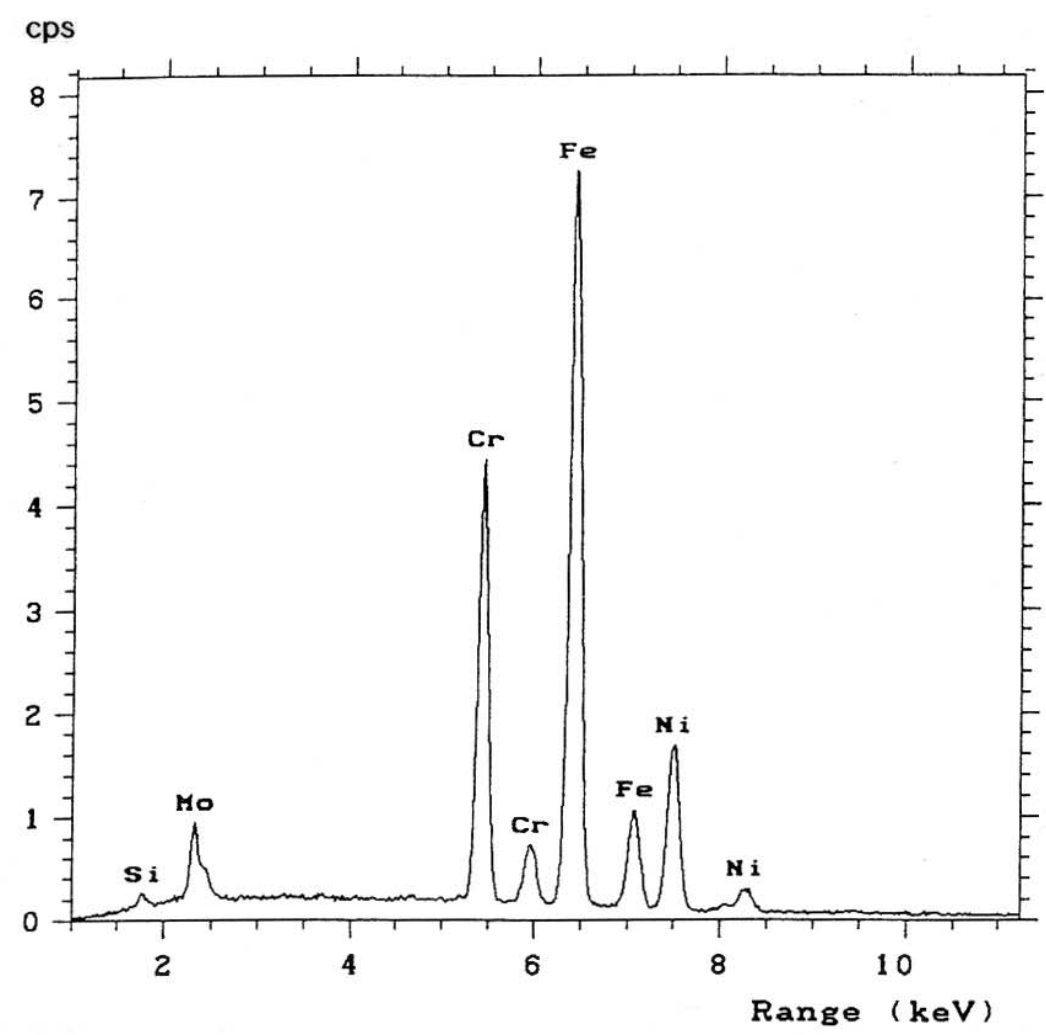

Figure 40. EDS spectrum at Location $A$ (matrix) in Figure $39,2100^{\circ} \mathrm{F}$ solution annealed (WQ) CK-3MCuN Heat K3GAO

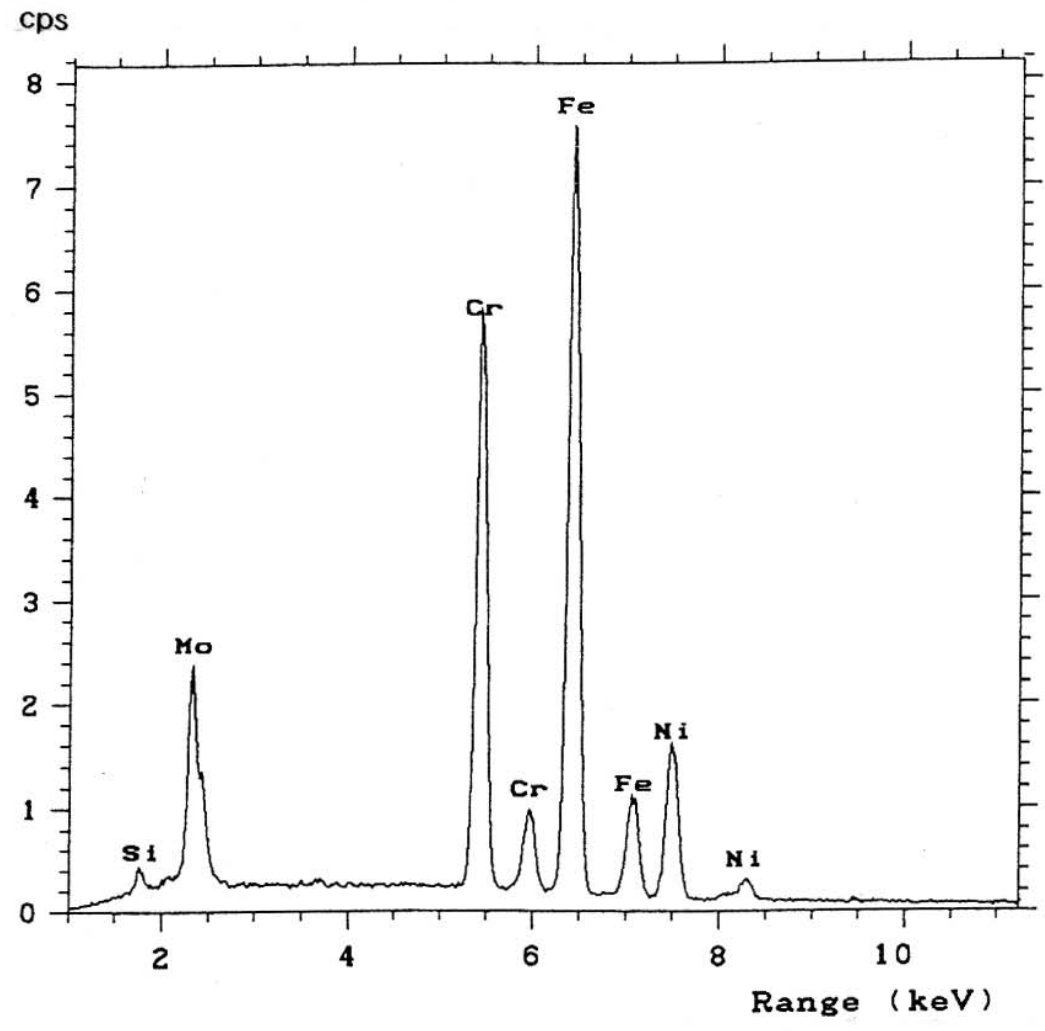

Figure 41. EDS spectrum at Location B (coarse irregular shaped secondary phases within "islands") in Figure 39, $2100^{\circ} \mathrm{F}$ solution annealed (WQ) CK-3MCuN Heat K3GAO 
respectively. EDS results show that the coarse irregular-shaped secondary phase within "islands" contain higher $\mathrm{Mo}$ and $\mathrm{Cr}$ as compared to the matrix. Again, they are considered to be $\mathrm{Cr} / \mathrm{Mo}$ carbides. It is to be noted that these coarse irregular-shaped secondary phases within "islands" " wereun-stained during stain etching. However, the peak ratios of $\mathrm{Cr} / \mathrm{Fe}$ or Mo/Fe for the coarse secondary phase were reduced after the $2100^{\circ} \mathrm{F} / 1150^{\circ} \mathrm{C}$ solution-anneal compared to that of the as-cast CK-3MCuN. This indicates that the extent of $\mathrm{Cr}$ or Mo segregation in the coarse secondary phases has decreased upon solution annealing $\left(2100^{\circ} \mathrm{F} / 1150^{\circ} \mathrm{C}+\mathrm{WQ}\right)$. The same effects were also observed for the $2200^{\circ} \mathrm{F} / 1205^{\circ} \mathrm{C}$ lowed by WQ) solution anneal for CK-3MCuN.

Figure 42 shows the typical SEM microstructural morphology of $2300^{\circ} \mathrm{F} / 1260^{\circ} \mathrm{C}$ tion annealed $\mathrm{CK}-3 \mathrm{MCuN}$ (followed by WQ). Compared to the as-cast and lower temperature $\left(2100^{\circ} \mathrm{F} / 1150^{\circ} \mathrm{C}\right.$ or $\left.2200^{\circ} \mathrm{F} / 1205^{\circ} \mathrm{C}\right)$ solution annealed CK-3MCuN, the irregular-shaped secondary phases within the "islands" were completely dissolved during the $2300^{\circ} \mathrm{F} / 1260^{\circ} \mathrm{C}$ solution anneal. Only the dark globular particles are visible in the matrix. EDS results, as shown in Figures 43 (Location A: matrix) and 44 (Location B: dark globular particles), indicate that the dark globular particles are the same type of inclusions as found in the as-cast and other solution-annealed conditions.

\section{ii) $\underline{\text { CK-3MCuN Heat } 2}$}

The typical SEM microstructural morphology of CK-3MCuN Heat 2 in the ascast condition is shown in Figure 45 (a) as a secondary electron image and (b) as a back scattered electron image at 1000X. The microstructure of 


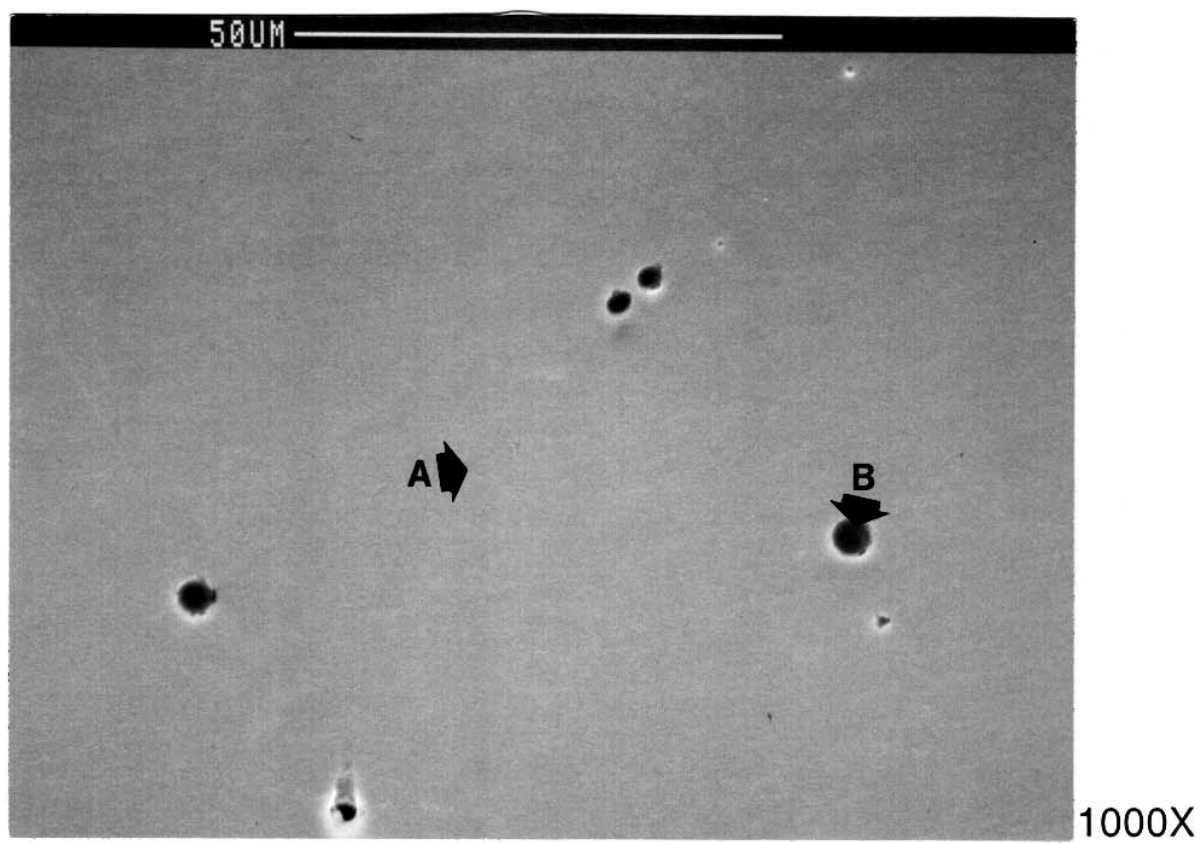

Figure 42. SEM secondary image of CK-3MCUN Heat K3GAO in SA condition $\left(2300^{\circ} \mathrm{F}+\mathrm{WQ}\right)$, EDS analysis at locations marked by letters 


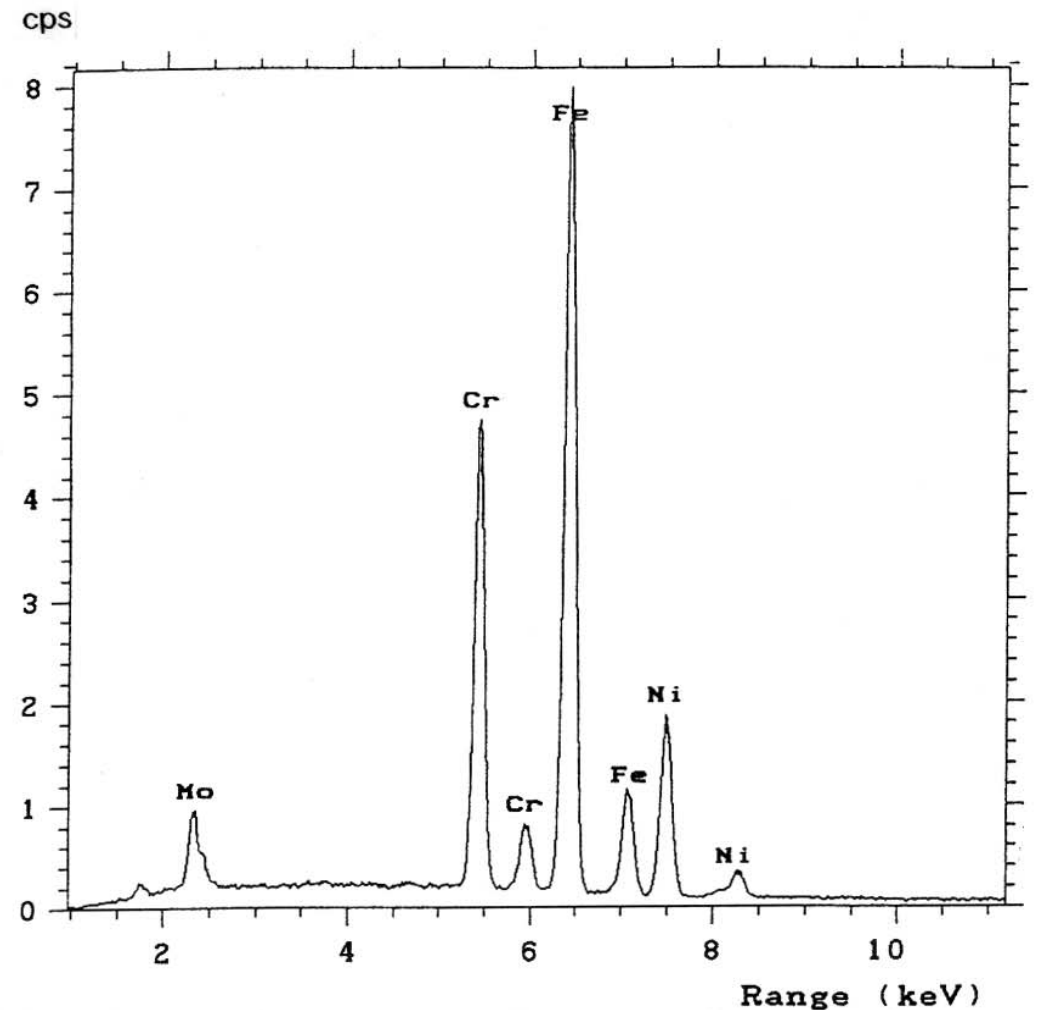

Figure 43. EDS spectrum at Location $A$ (matrix) in Figure $42,2300^{\circ} \mathrm{F}$ solution annealed (WQ) CK-3MCuN Heat K3GAO

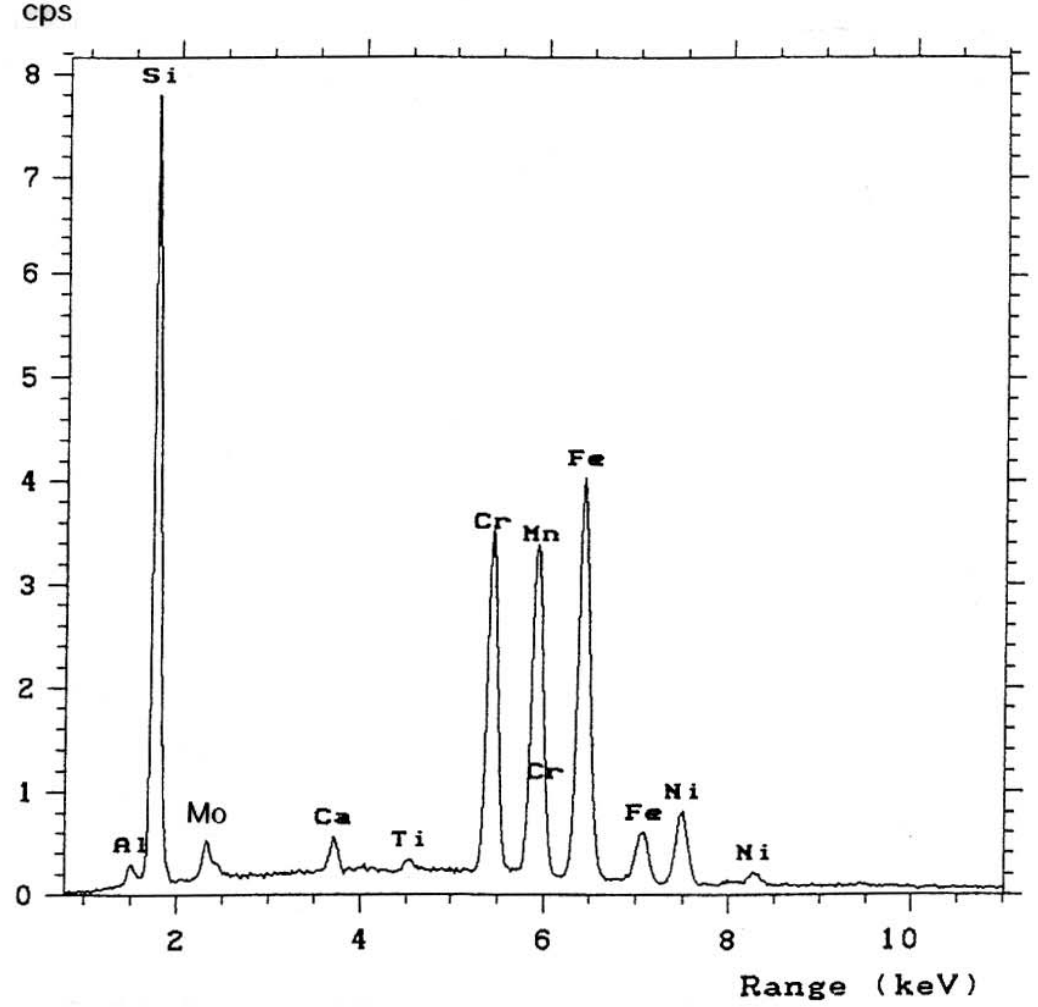

Figure 44. EDS spectrum at Location $\mathrm{B}$ (dark globular particle) in Figure $43,2300^{\circ} \mathrm{F}$ solution annealed (WQ) CK-3MCuN Heat K3GAO 


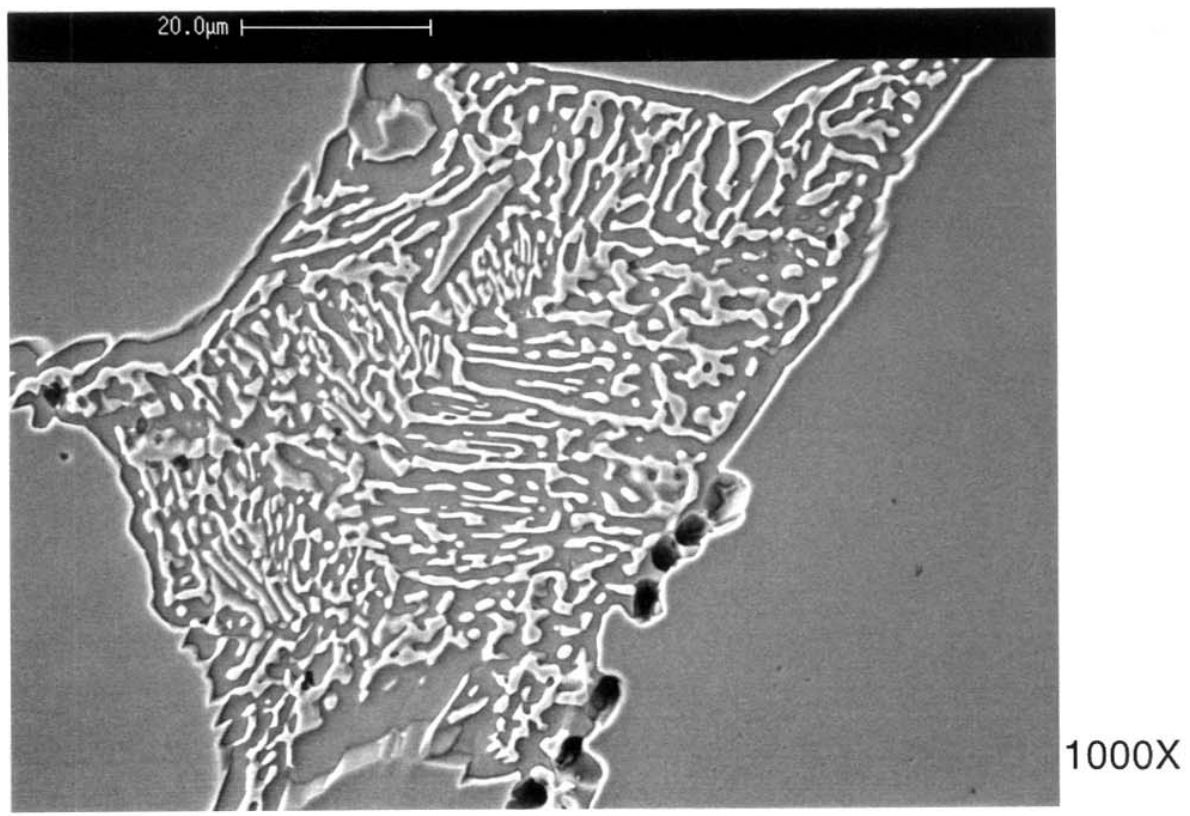

(a) Secondary image

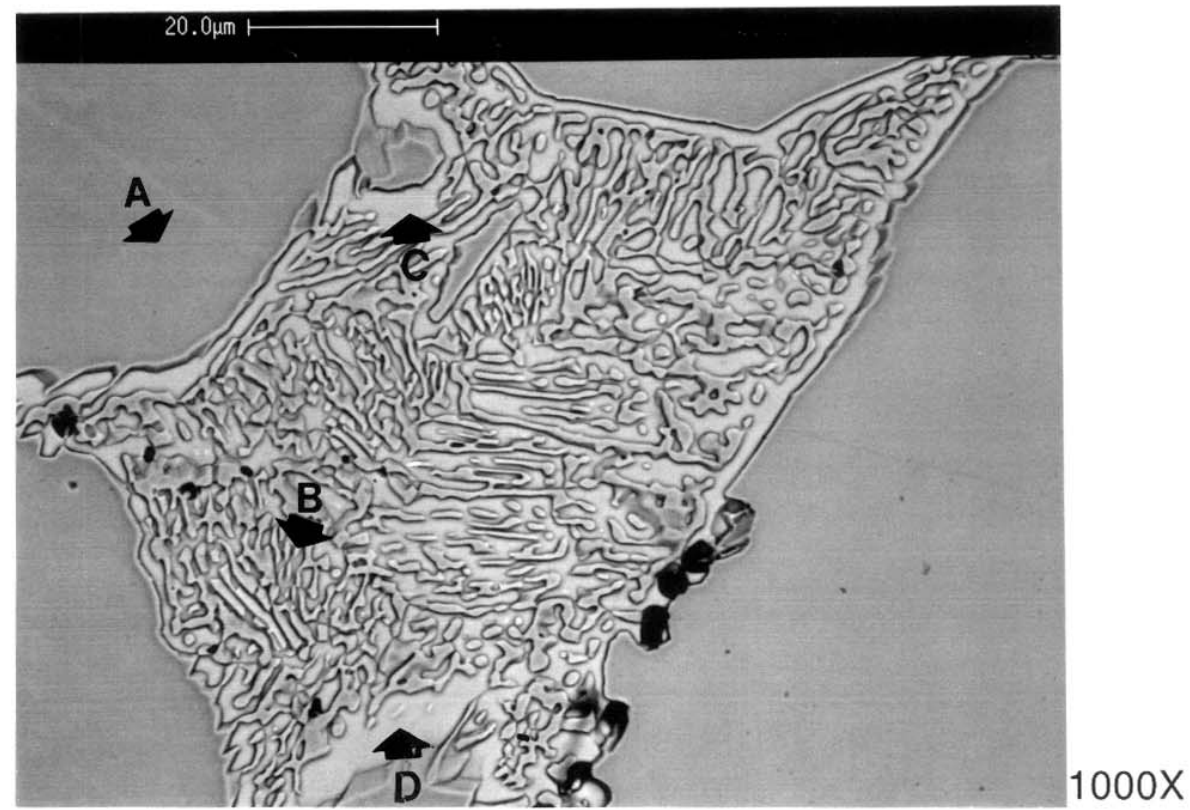

(b) Back scattered image

Figure 45. SEM photomicrograph of CK-3MCuN Heat 2 in as-cast condition, EDS analysis at locations marked by letters 
are presented in Figures 46 through 49 for Locations A through D. Figure 46 CK-3MCuN Heat 2 is basically identical to that of CK-3MCuN Heat 3 in the ascast condition. EDS analysis was performed at the locations marked by arrows and letters (A through $D$ ) in Figure 45 (b). The EDS results for the as-cast CK$3 \mathrm{MCuN}$ Heat 2shows the EDS results for the matrix (Location A). Figures 47 through 49 present the EDS results on the fine irregular-shaped precipitates (Location B) and coarse irregular-shaped precipitates (Locations C \& D) within the "islands." It is evident that these irregular-shaped precipitates (Locations B, $\mathrm{C} \& \mathrm{D})$ are all richer in Mo and $\mathrm{Cr}$ compared to the matrix. However, only the fine irregular-shaped precipitates were stained blue or tan. Thus, the fine irregular-shaped precipitates (Location B) are considered to be $\sigma$ phase, while the coarse irregular-shaped precipitates (Locations C \& D) are considered to be Cr/Mo carbides.

For $2100^{\circ} \mathrm{F} / 1150^{\circ} \mathrm{C}(\mathrm{WQ})$ solution annealed CK-3MCuN Heat 2, the typical SEM microstructural morphology is shown in Figure 50 (a) as a secondary electron image and (b) as a back-scattered electron image. EDS analysis was performed at the locations marked by arrows and letters (Locations A through $\mathrm{C}$ ) in Figure 50 (b). The EDS spectra are presented in Figures 51 through 53. Based on the EDS results, the Mo and $\mathrm{Cr}$ content at the Location B within the "islands" is greater than that in matrix, while the Mo and $\mathrm{Cr}$ content at the Location $\mathrm{C}$ within the "islands" is similar to that in matrix after solution annealing at $2100^{\circ} \mathrm{F} / 1150^{\circ} \mathrm{C}$. This indicates that secondary phases do not completely dissolve during the $2100^{\circ} \mathrm{F} / 1150^{\circ} \mathrm{C}$ solution anneal. These $\mathrm{Cr}$ and Mo rich secondary phases are, again, considered to be $\mathrm{Cr} / \mathrm{Mo}$ carbides. The gray areas (Location C) within the "islands" 


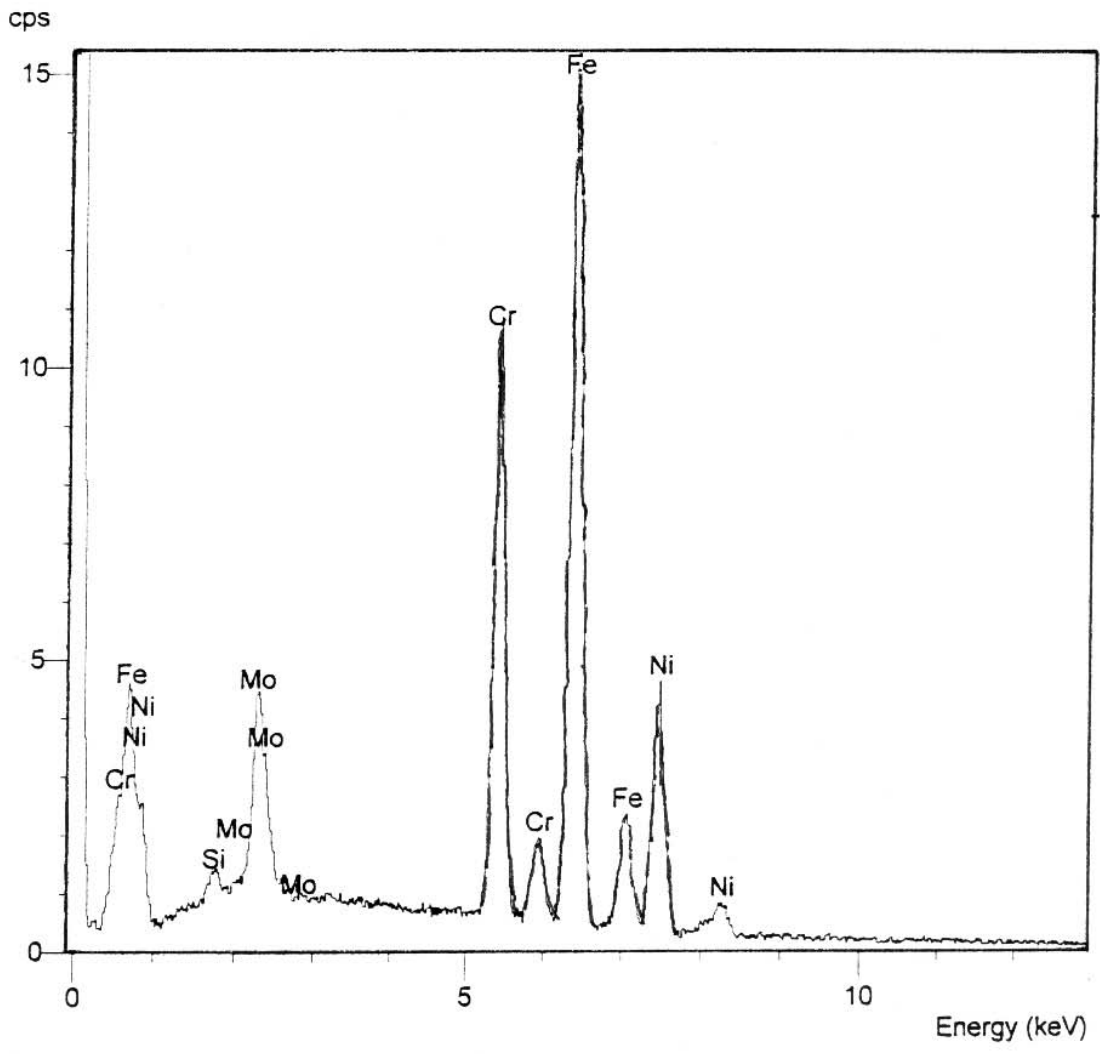

Figure 46. EDS spectrum at Location A (matrix) in Figure 45, as-cast CK-3MCuN Heat 2 


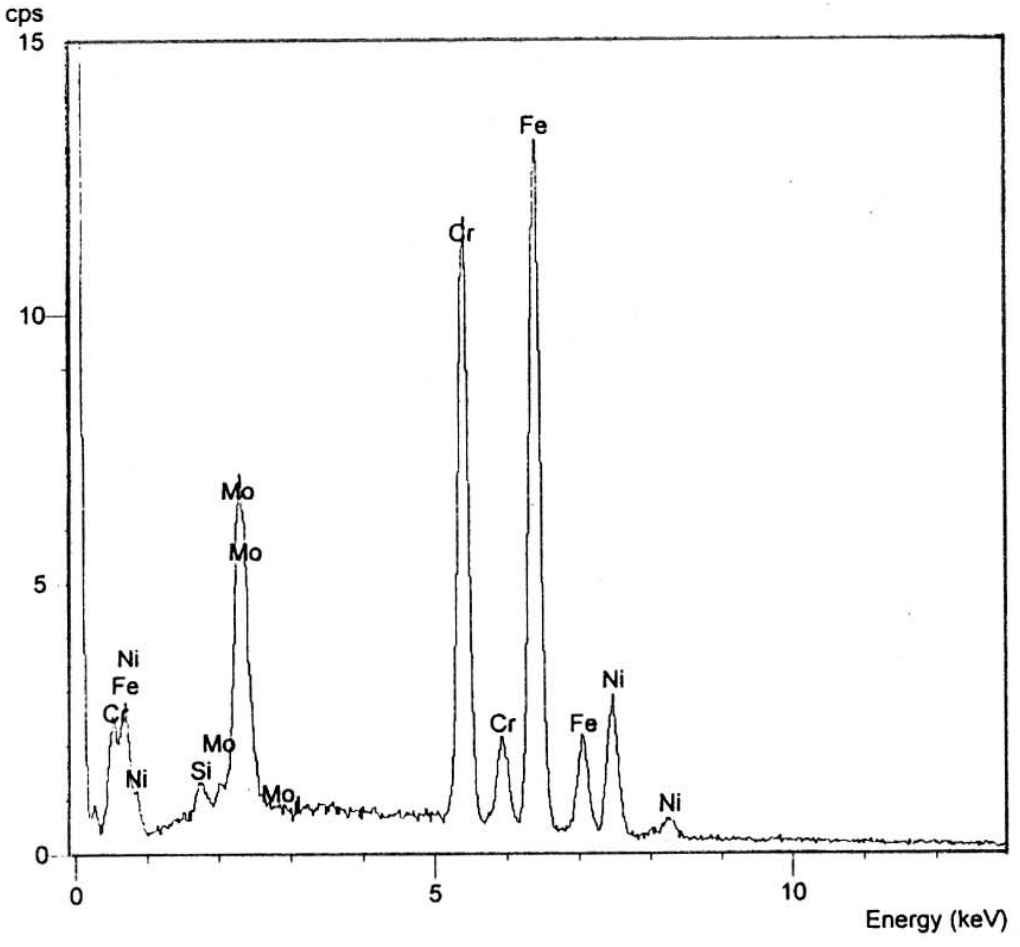

Figure 47. EDS spectrum at Location B (fine irregular shaped secondary phases within "islands") in Figure 45, as-cast CK-3MCuN Heat 2

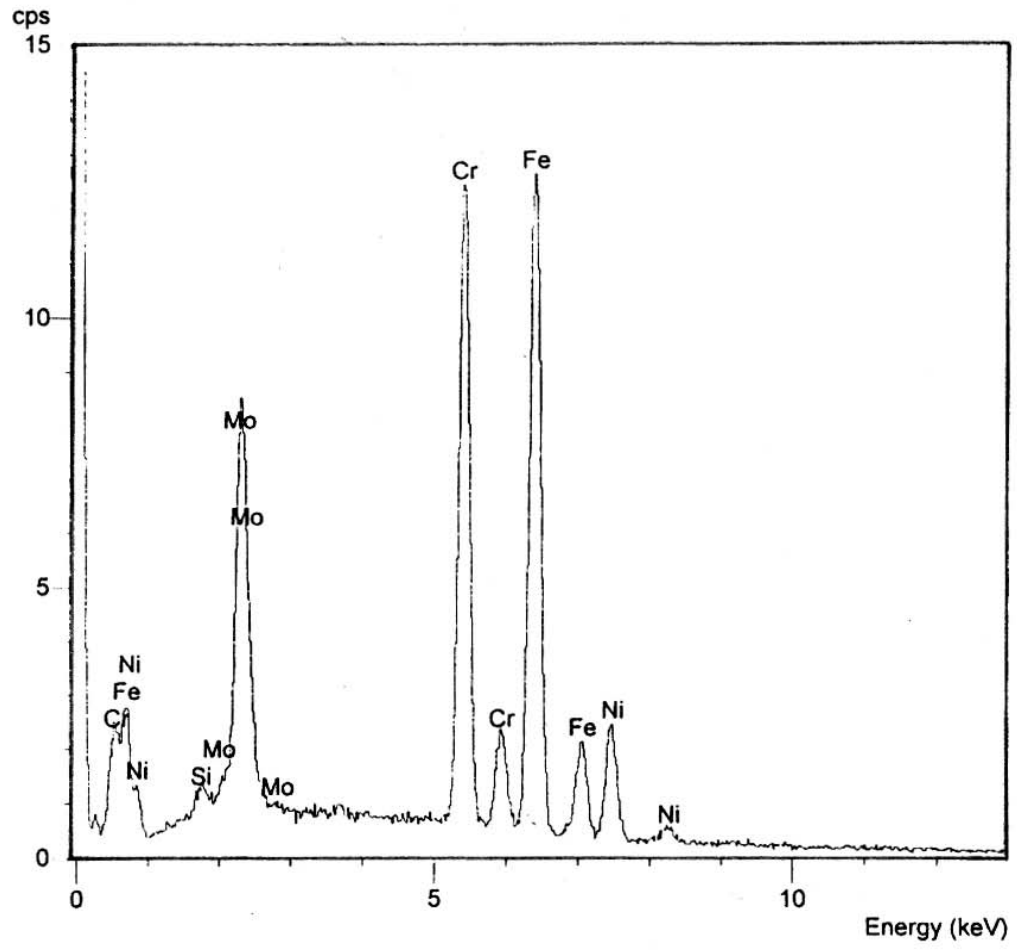

Figure 48. EDS spectrum at Location C (coarse irregular shaped secondary phases within "islands") in Figure 45, as-cast CK-3MCuN Heat 2 


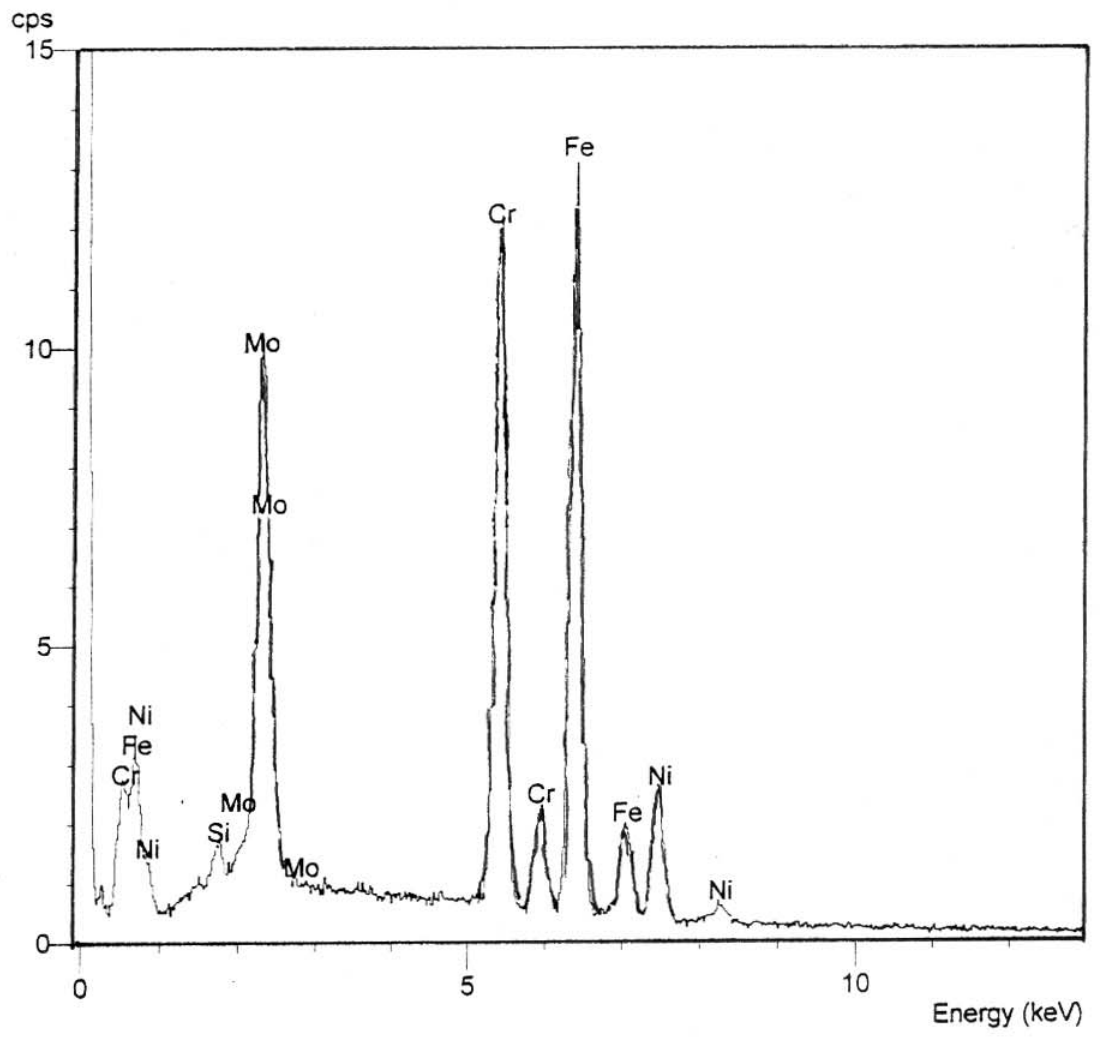

Figure 49. EDS spectrum at Location $D$ (coarse irregular shaped secondary phases), as-cast CK-3MCuN Heat 2 


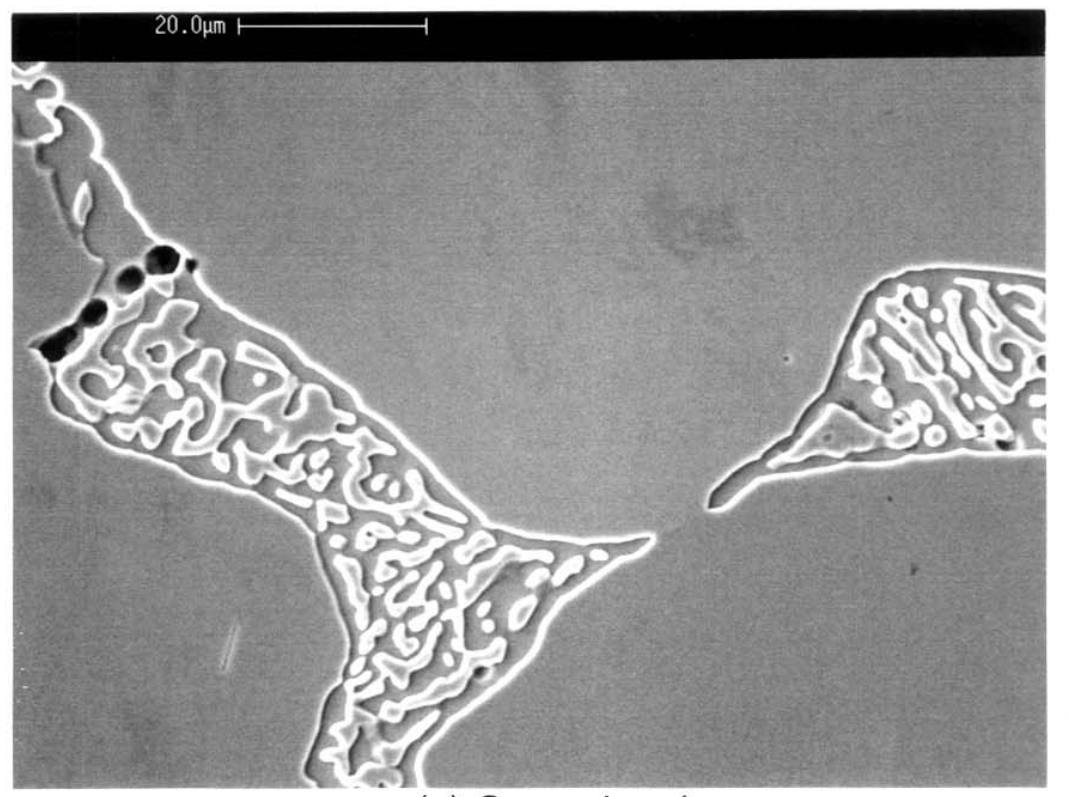

$1000 x$

(a) Secondary image

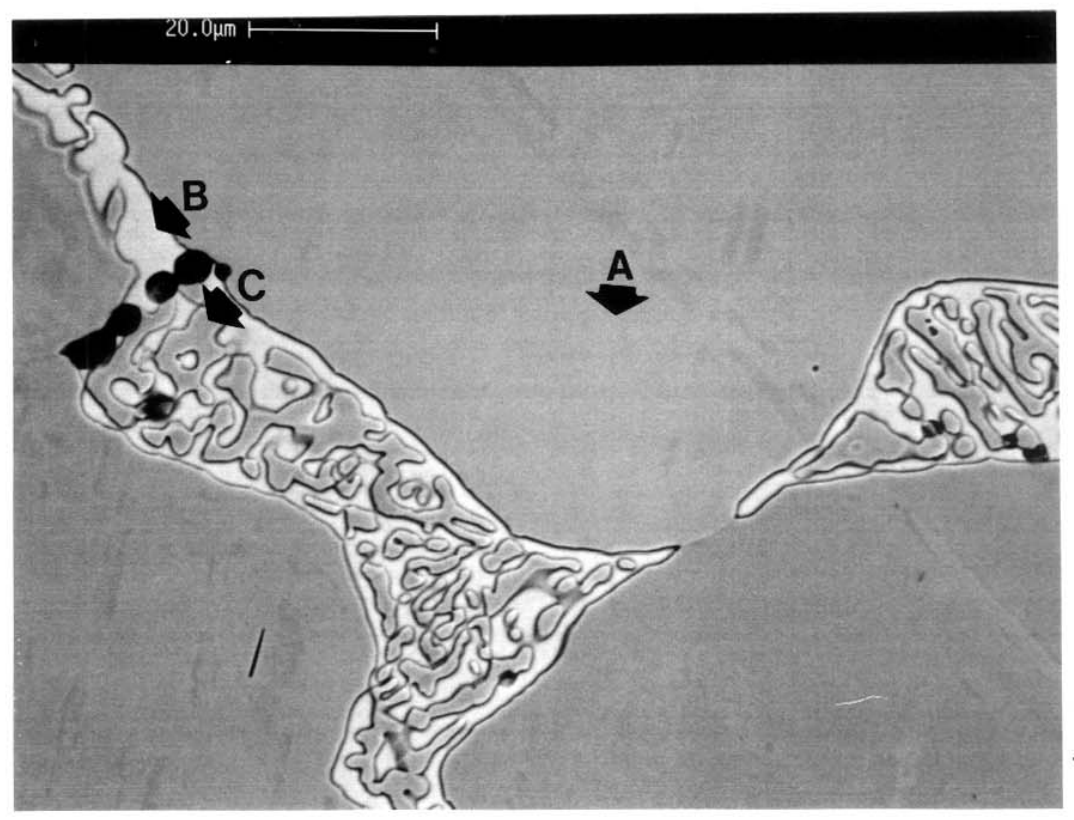

$1000 x$

(b) Back scattered image

Figure 50. SEM photomicrograph of CK-3MCuN Heat 2 in SA condition $\left(2100^{\circ} \mathrm{F}+\mathrm{WQ}\right)$, EDS analysis at locations marked by letters 


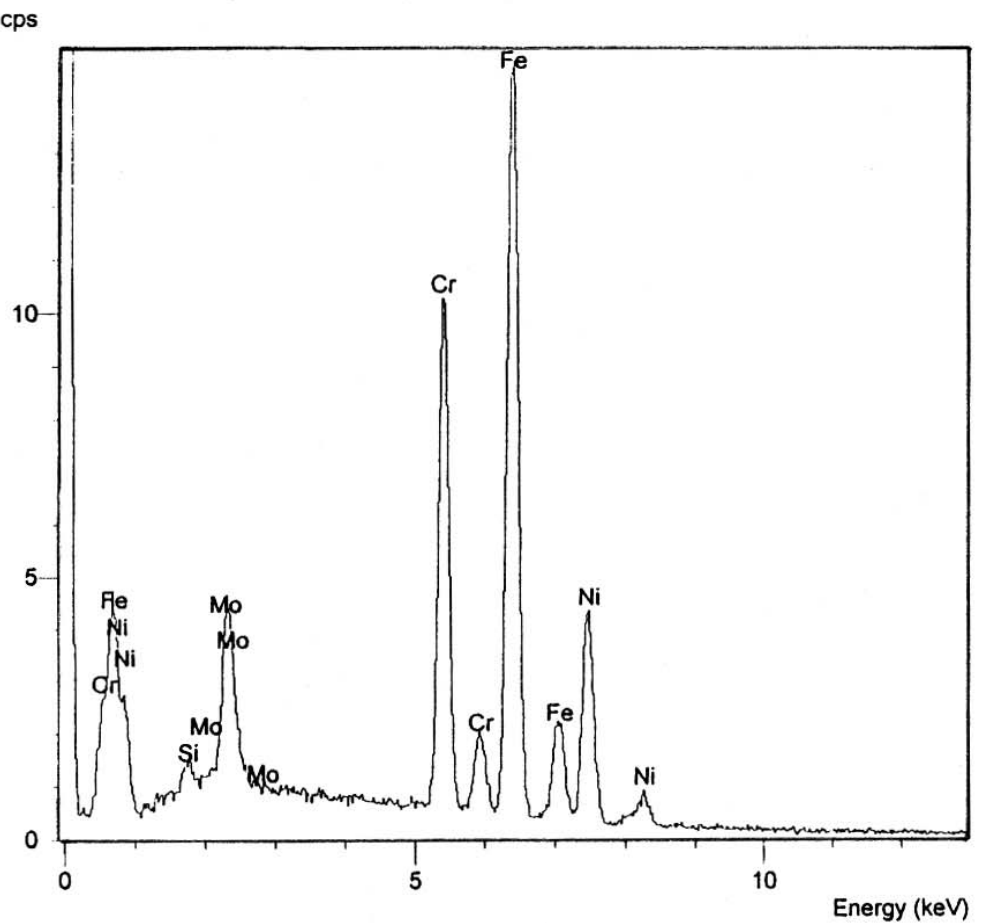

Figure 51. EDS spectrum at Location A (matrix) in Figure $50,2100^{\circ} \mathrm{F}$ solution annealed (WQ) CK-3MCuN Heat 2

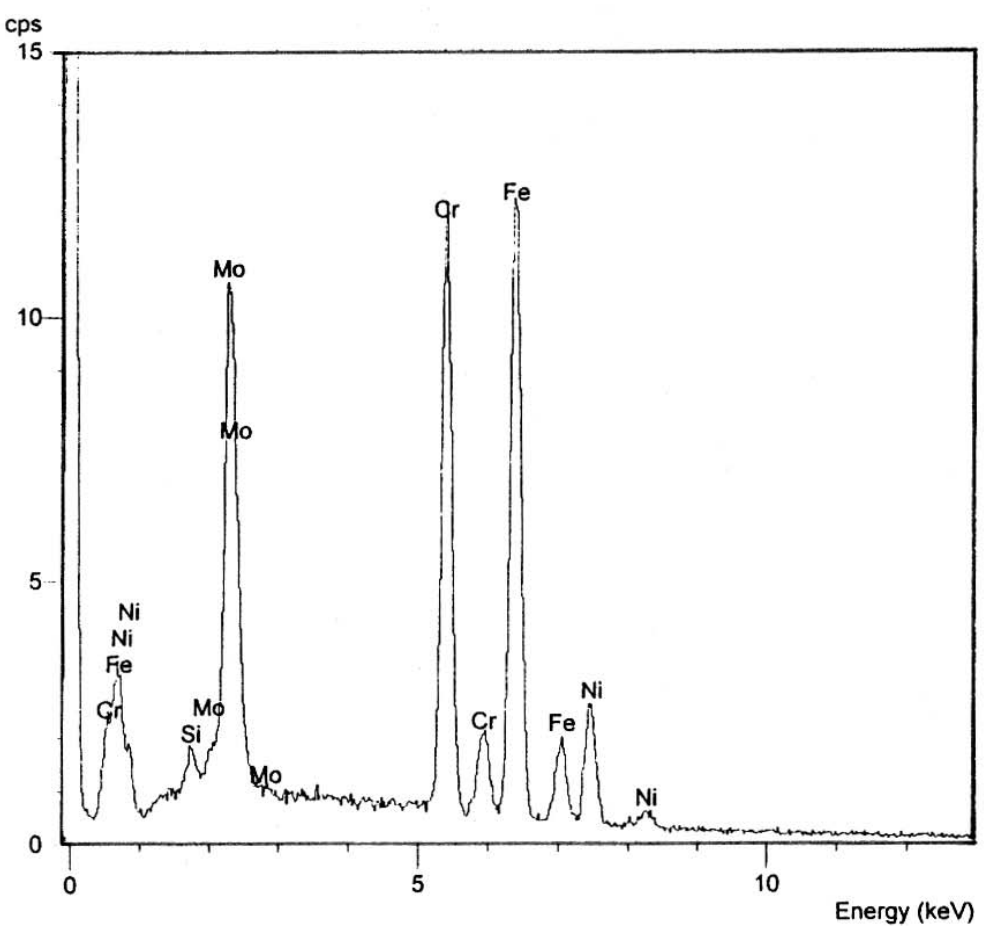

Figure 52. EDS spectrum at Location B (bright area within "islands") in Figure 50, 2100 $\mathrm{F}$ solution annealed (WQ) CK-3MCuN Heat 2 


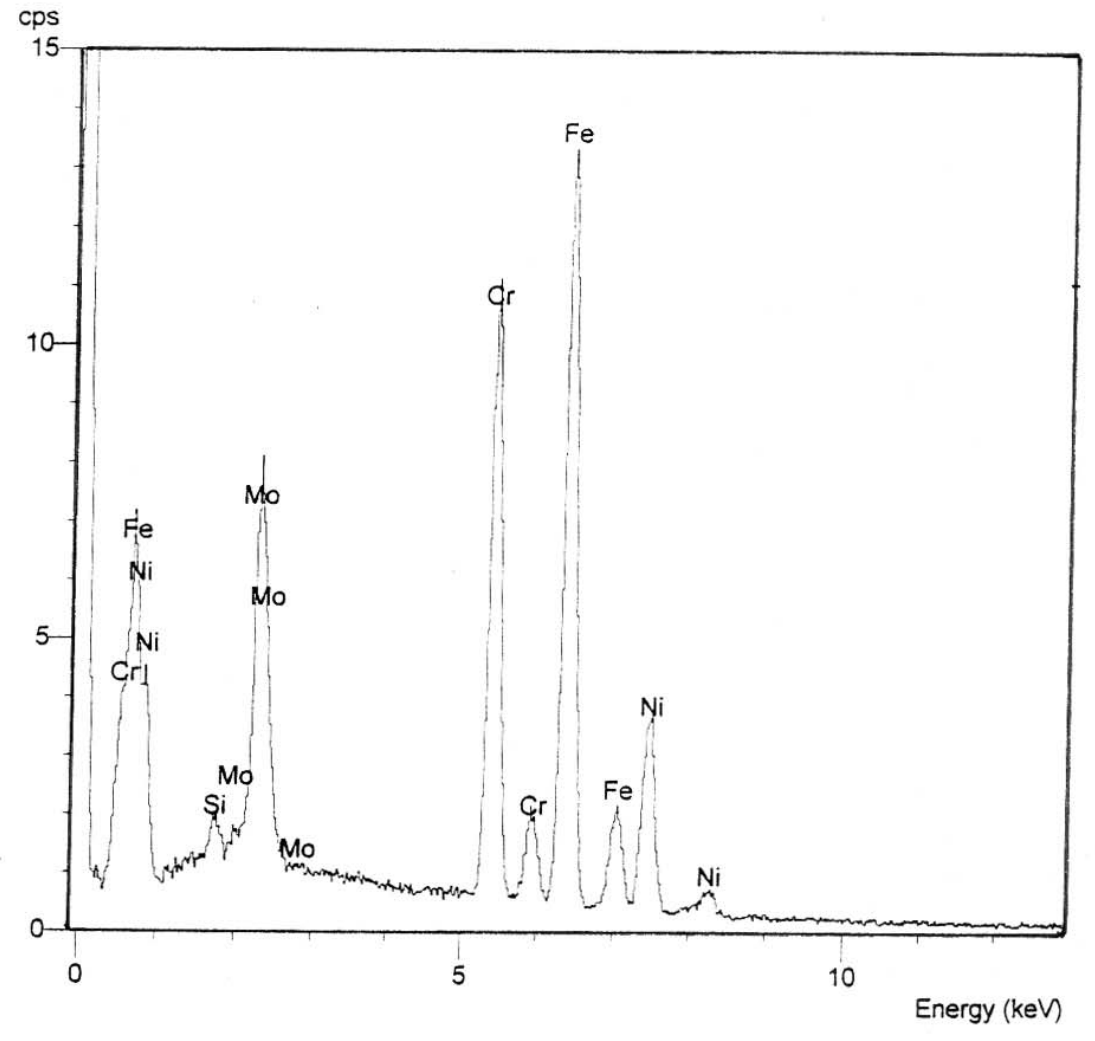

Figure 53. EDS spectrum at Location C (gray area within "islands") in Figure 50, CK-3MCuN Heat 2 in SA condition $\left(2100^{\circ} \mathrm{F}+\mathrm{WQ}\right)$ 
are considered to be an equivalent to the matrix.

However, when the solution annealing temperature was increased to $2300^{\circ} \mathrm{F} / 1260^{\circ} \mathrm{C}$, the irregular-shaped secondary phases within the "islands" still remained in the matrix of Heat 2 as shown in Figure 54. The EDS results (Figure 56) indicate that the remaining irregular-shaped secondary phases within the "islands" have a greater $\mathrm{Cr}$ and Mo content than the matrix (Figure 55). Thus, it is considered that these irregular-shaped secondary phases within the "islands" are Cr/Mo carbides.

\section{iii) $\underline{\mathrm{CK}-3 \mathrm{MCuN} \text { Heat } 3}$}

The typical SEM microstructural morphology of CK-3MCuN Heat 3 in the ascast condition is shown in Figure 57 (a) as a secondary electron image and (b) as a back scattered electron image at a magnification of 1000X. The typical microstructure of as-cast CK-3MCuN Heat 3 includes fine irregular-shaped secondary phases (Location B) and coarse irregular-shaped secondary phases (Location C) within the "islands" in the matrix (Location A). In addition, some dark globular particles (Location D) were also observed in the matrix. EDS analysis was performed at these locations marked by arrows and letters ( $\mathrm{A}$ through D) in Figure 57 (b). The EDS spectra are presented in Figures 58 through 61 for the matrix (Location A in Figure 57b), the fine irregular-shaped secondary phases within the "islands" (Location B), the coarse irregular-shaped secondary phases within the "islands" (Location C) and the dark globular particles (Location $\mathrm{D}$ ), respectively. From the EDS result on the fine irregular-

shaped secondary phases within the "islands" (Location B), it is evident that 


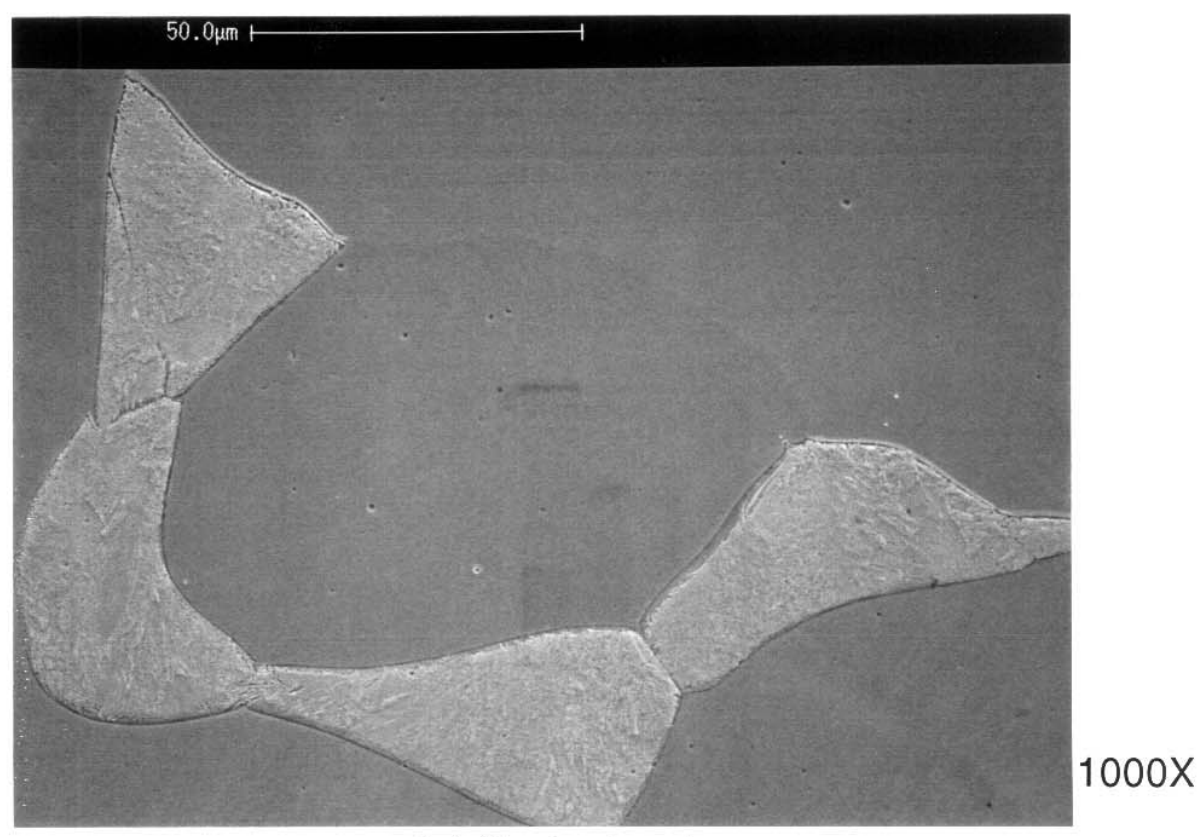

(a) Secondary image

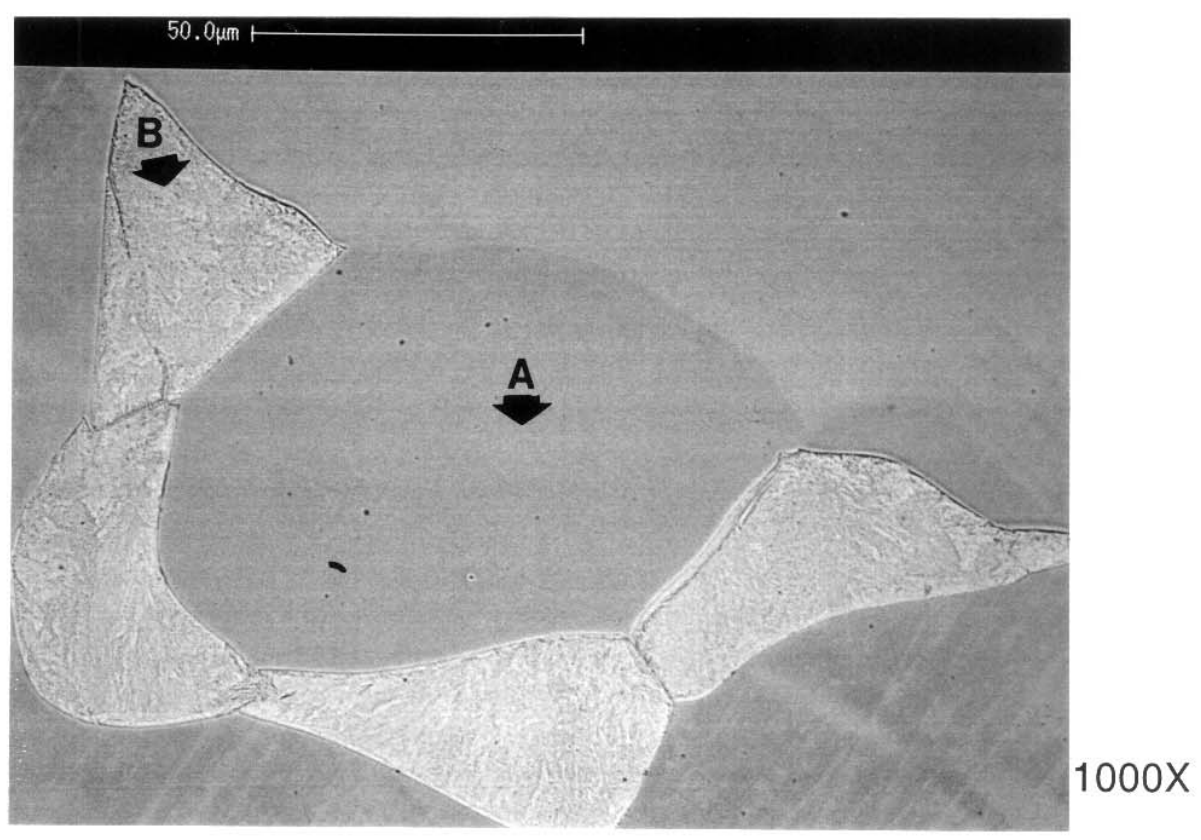

(b) Back scattered image

Figure 54. SEM photomicrograph of CK-3MCUN Heat 2 in SA condition $\left(2300^{\circ} \mathrm{F}+\mathrm{WQ}\right)$, EDS analysis at locations marked by letters 


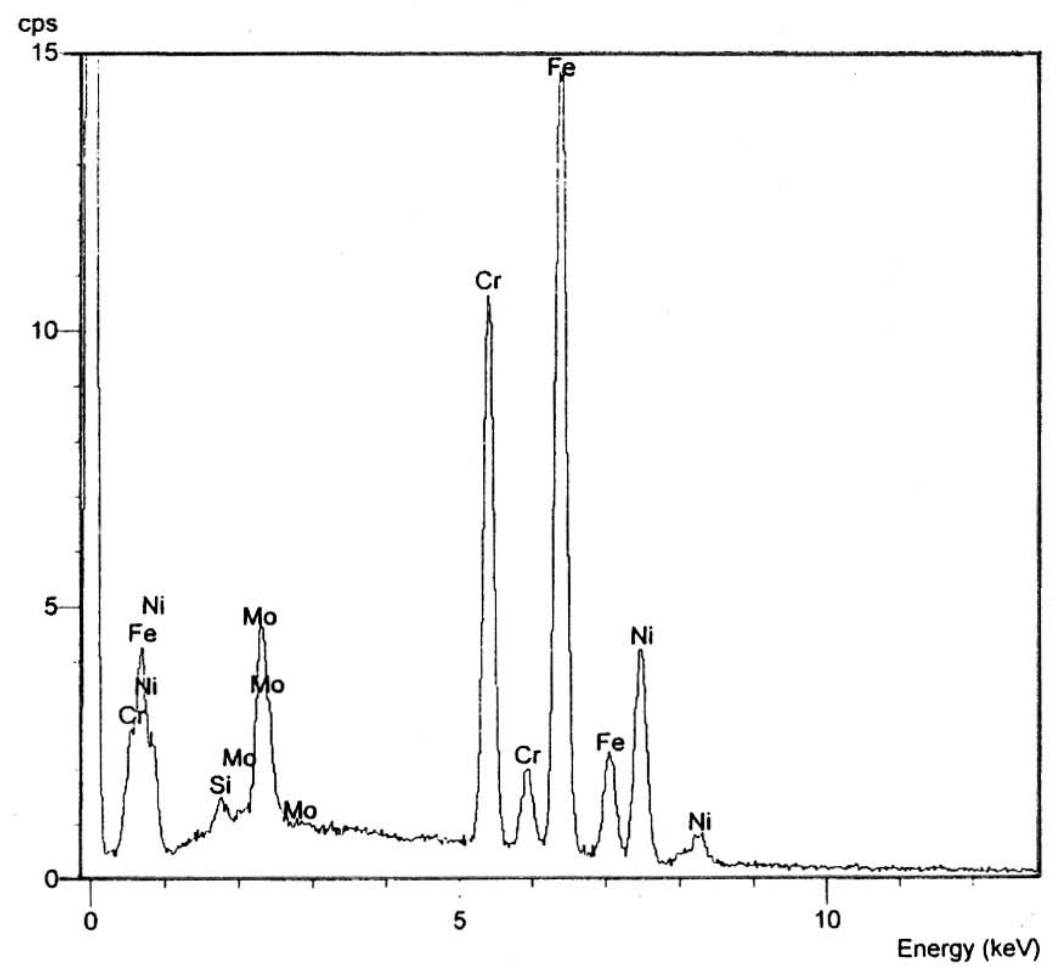

Figure 55. EDS spectrum at Location A (matrix) in Figure $54,2300^{\circ} \mathrm{F}$ solution annealed (WQ) CK-3MCuN Heat 2

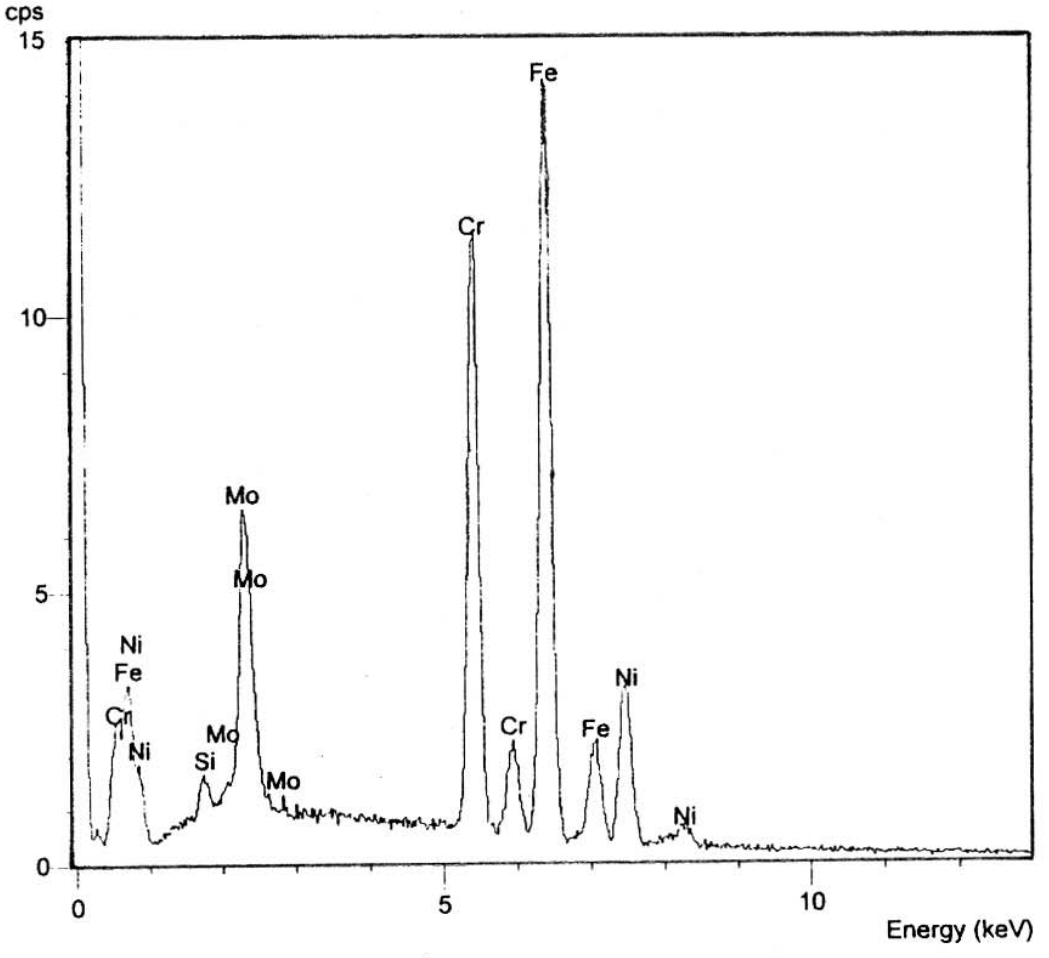

Figure 56. EDS spectrum at Location B (fine irregular shaped secondary phases within "islands") in Figure $54,2300^{\circ} \mathrm{F}$ solution annealed (WQ) CK-3MCuN Heat 2 


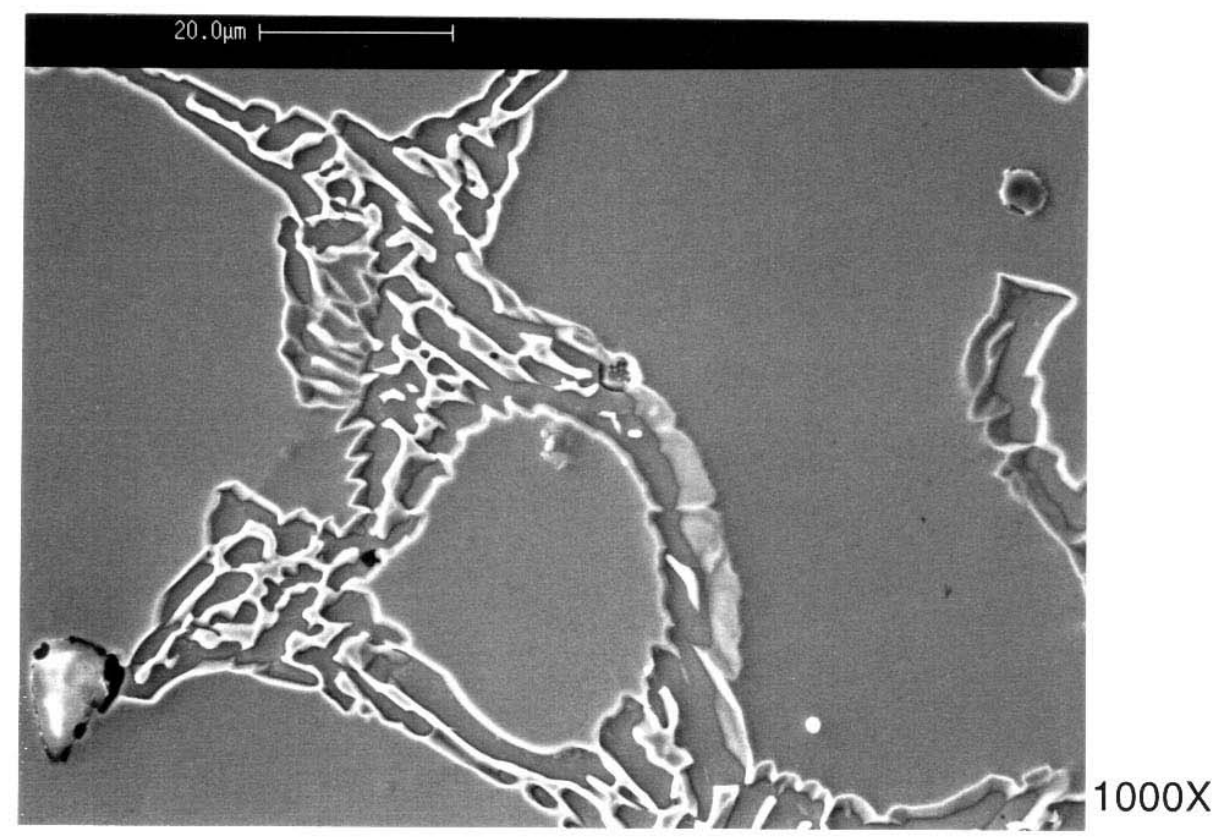

(a) Secondary image

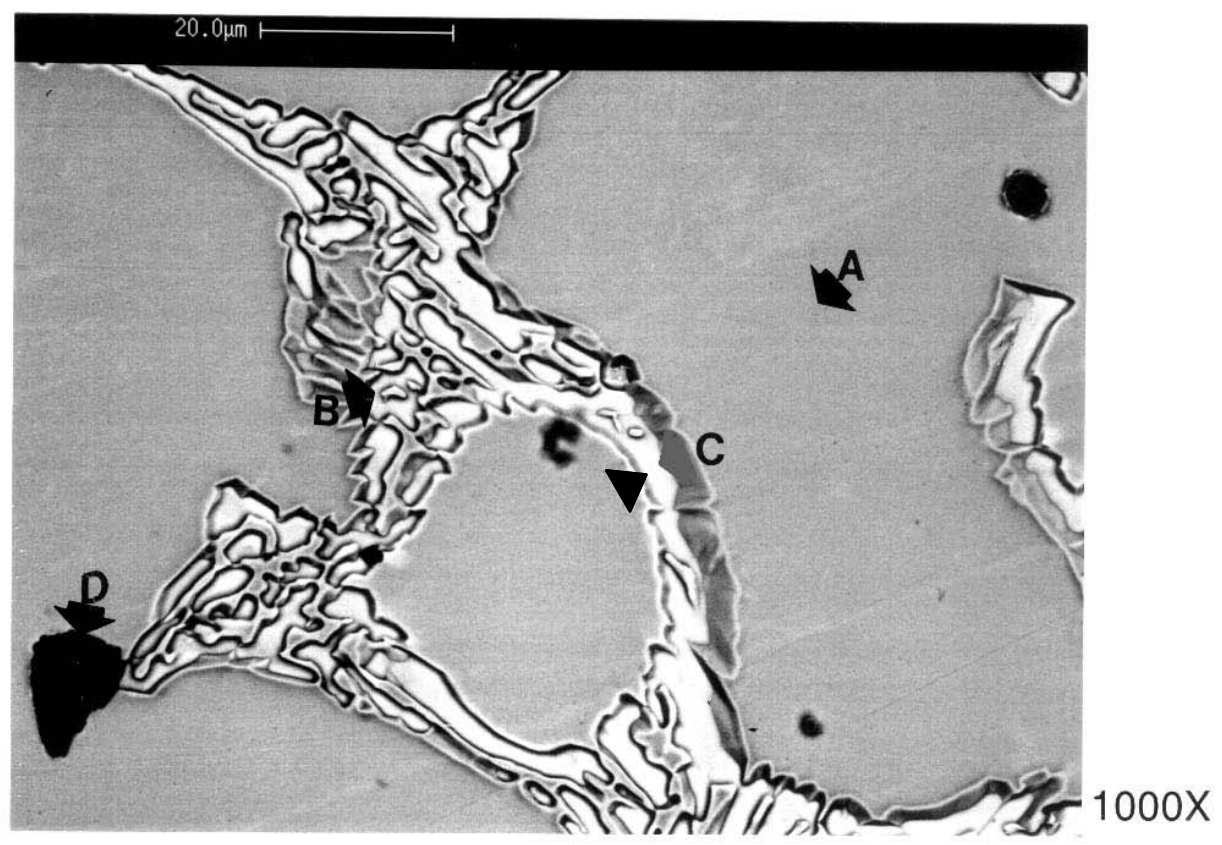

(b) Back scattered image

Figure 57. SEM photomicrograph of CK-3MCuN Heat 3 in as-cast condition, EDS analysis at locations marked by letters 


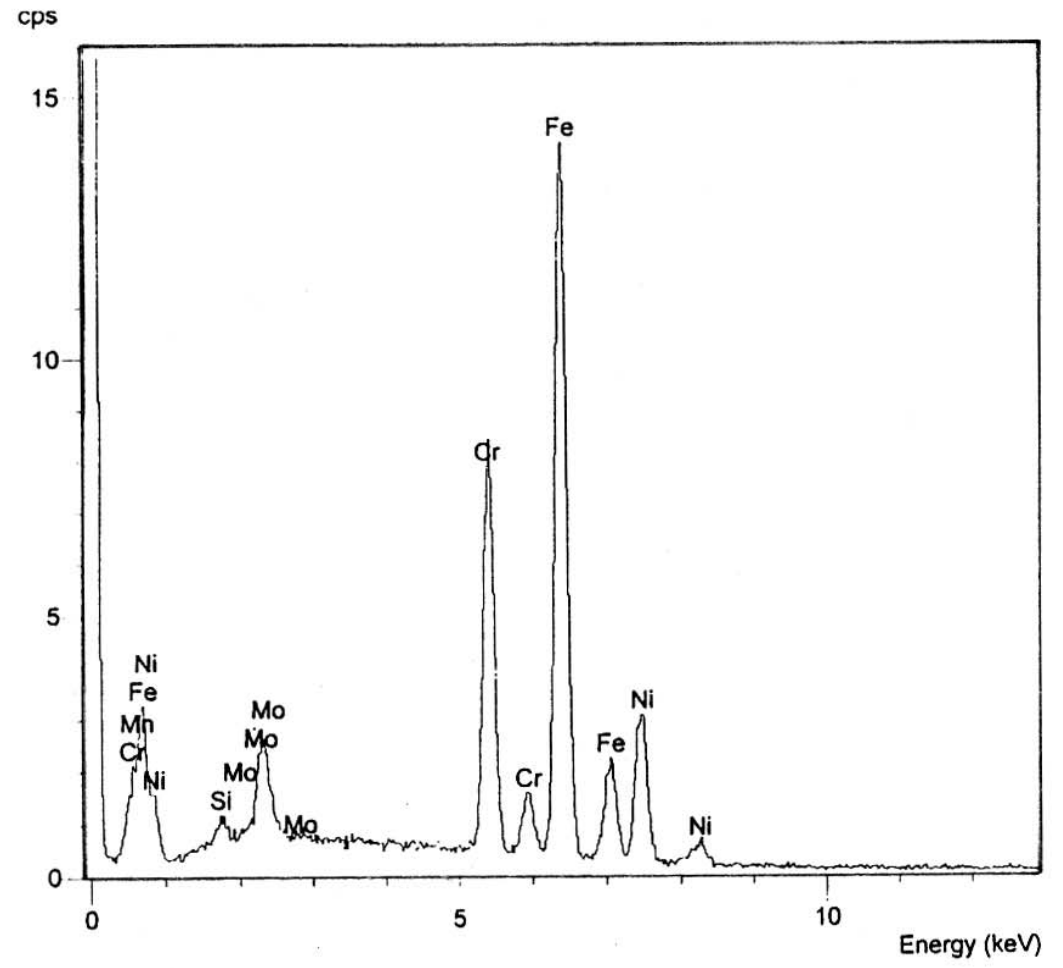

Figure 58. EDS spectrum at Location $A$ (matrix) in Figure 57, as-cast CK-3MCuN Heat 3

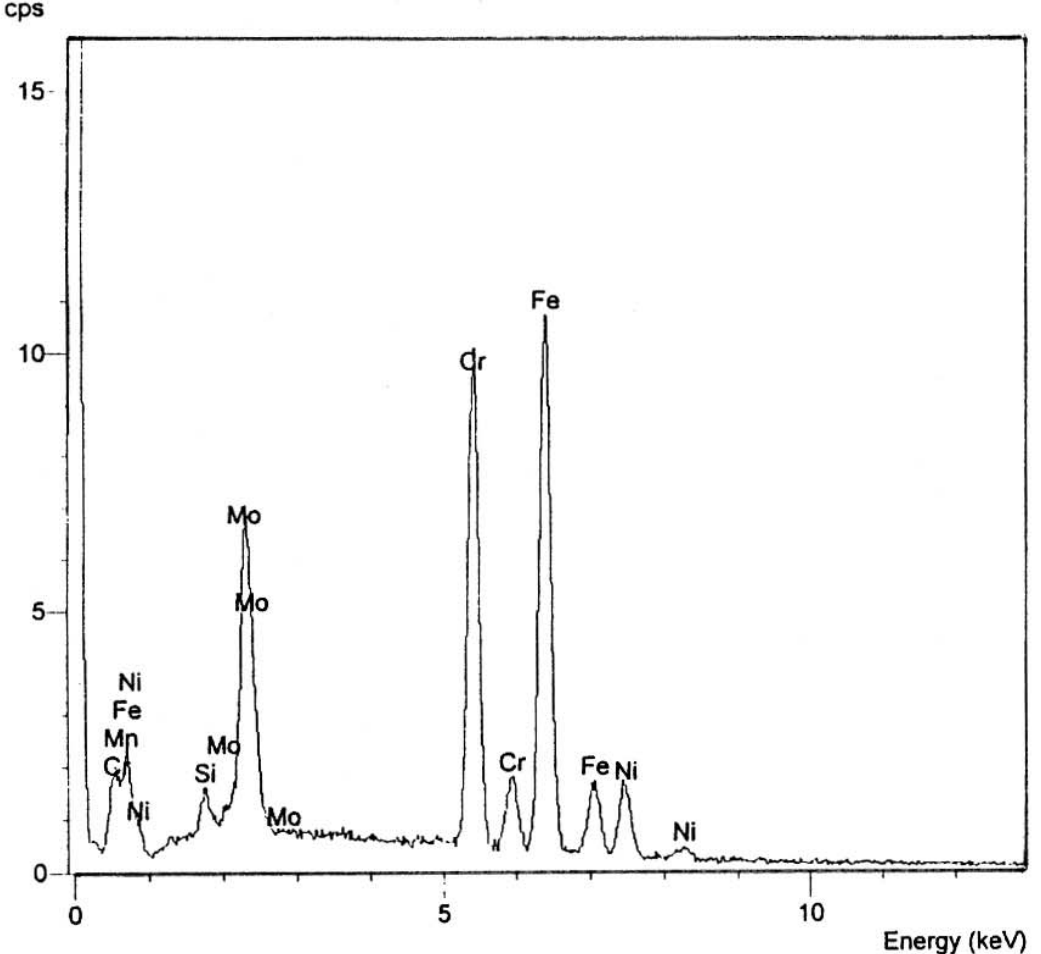

Figure 59. EDS spectrum at Location B (fine irregular shaped secondary phases within "islands") in Figure 57, as-cast CK-3MCuN Heat 3 


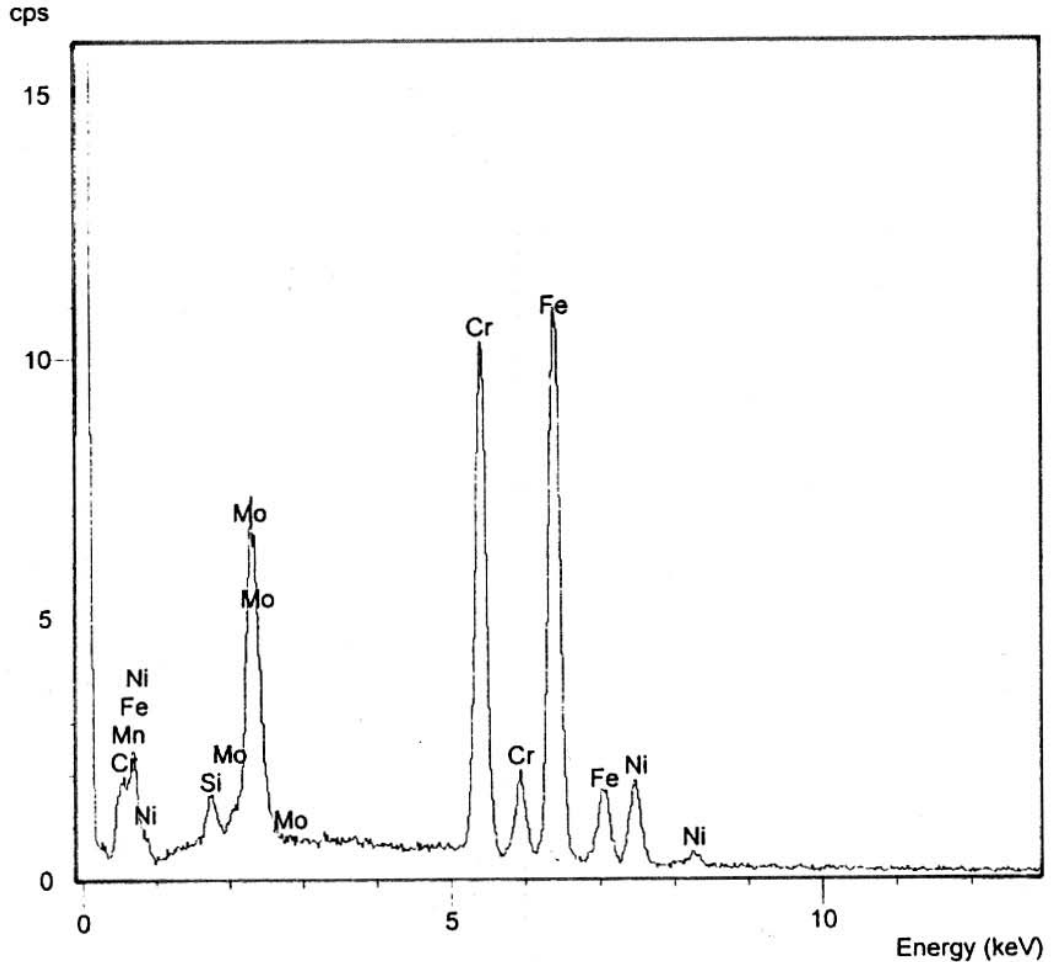

Figure 60. EDS spectrum at Location C (coarse irregular shaped secondary phases within "islands") in Figure 57, as-cast CK-3MCuN Heat 3

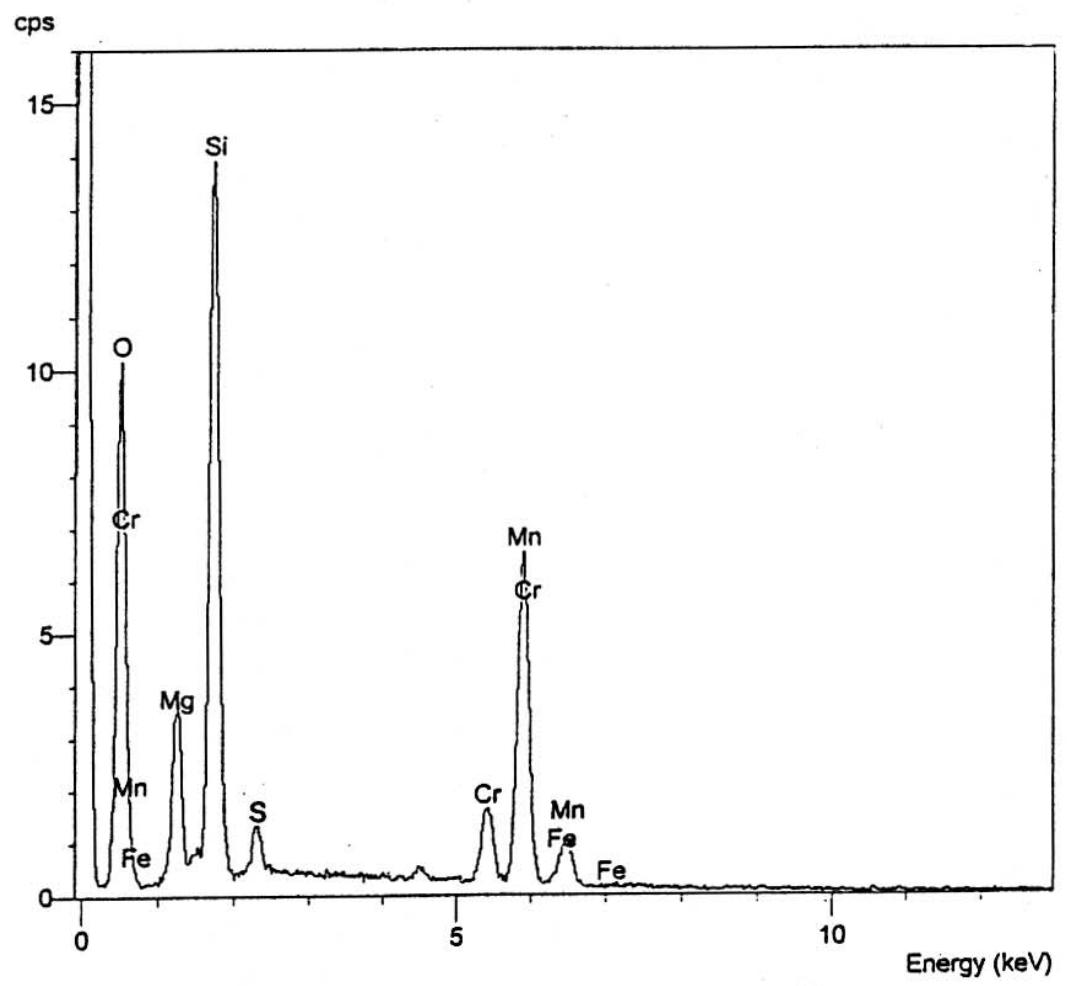

Figure 61. EDS spectrum at Location D (dark globular particles) in Figure 57, as-cast CK-3MCuN Heat 3 
these secondary phases are richer in Mo and $\mathrm{Cr}$ (Figure 59) compared to the matrix (Figure 58). It should be recalled that these fine irregular-shaped precipitates within the "islands" were stained as blue or tan by stain etching. Therefore, they are considered to be $\sigma$ phase (FeCrMo). On the other hand, the EDS result for Location C, shown in Figure 60, indicates that the coarse irregular-shaped secondary phases contain even higher Mo and $\mathrm{Cr}$ than the "fine" secondary phases within the same "islands" (Location B). It should be recalled that these coarse irregular-shaped secondary phases within the "islands" (Location C) remained unstained after stain etching practice. Based on the EDS results and unstained etching appearance, these coarse irregular-shaped secondary phases within "islands" are considered to be $\mathrm{Cr} / \mathrm{Mo}$ carbides. In addition to $\sigma$ phase and $\mathrm{Cr} / \mathrm{Mo}$ carbides, the dark globular particles in the matrix (Location D) are determined to be silicon oxides, magnesium oxides or manganese oxides based on the EDS result present in Figure 61.

The SEM microstructural morphology of CK-3MCUN Heat 3, in the solution annealed condition $\left(2100^{\circ} \mathrm{F} / 1150^{\circ} \mathrm{C}+\mathrm{WQ}\right)$, is shown in Figure 62 (a) as a secondary electron image and (b) as a back-scattered electron image. The typical microstructure of the $2100^{\circ} \mathrm{F} / 1150^{\circ} \mathrm{C}$ solution annealed $\mathrm{CK}-3 \mathrm{MCuN}$ Heat 3 includes bright and gray areas within "islands" distributed in the matrix. EDS analysis was performed at the locations marked by arrows and letters (A through C) as shown in Figure 62 (b). The EDS spectra are presented in Figures 63 through 65 for the matrix (Location A) and bright (Location B) and gray (Location 


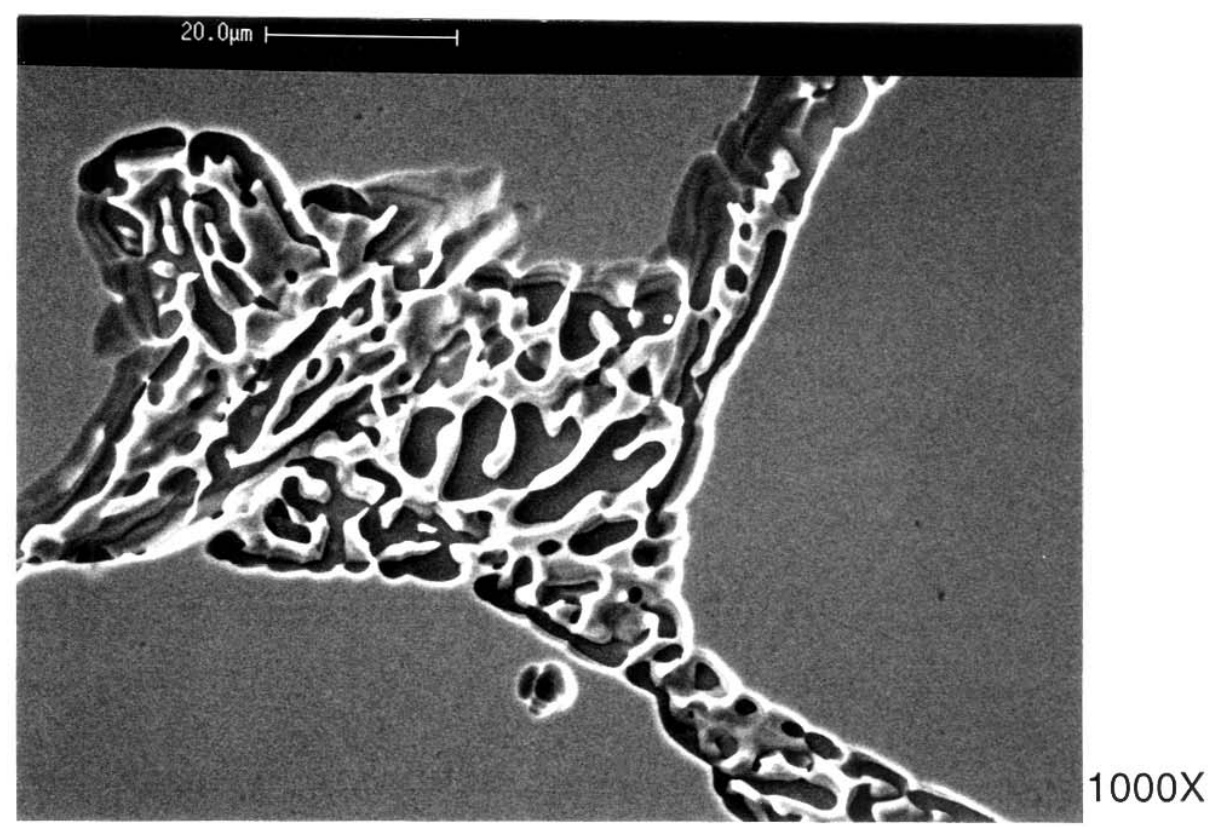

(a) Secondary image

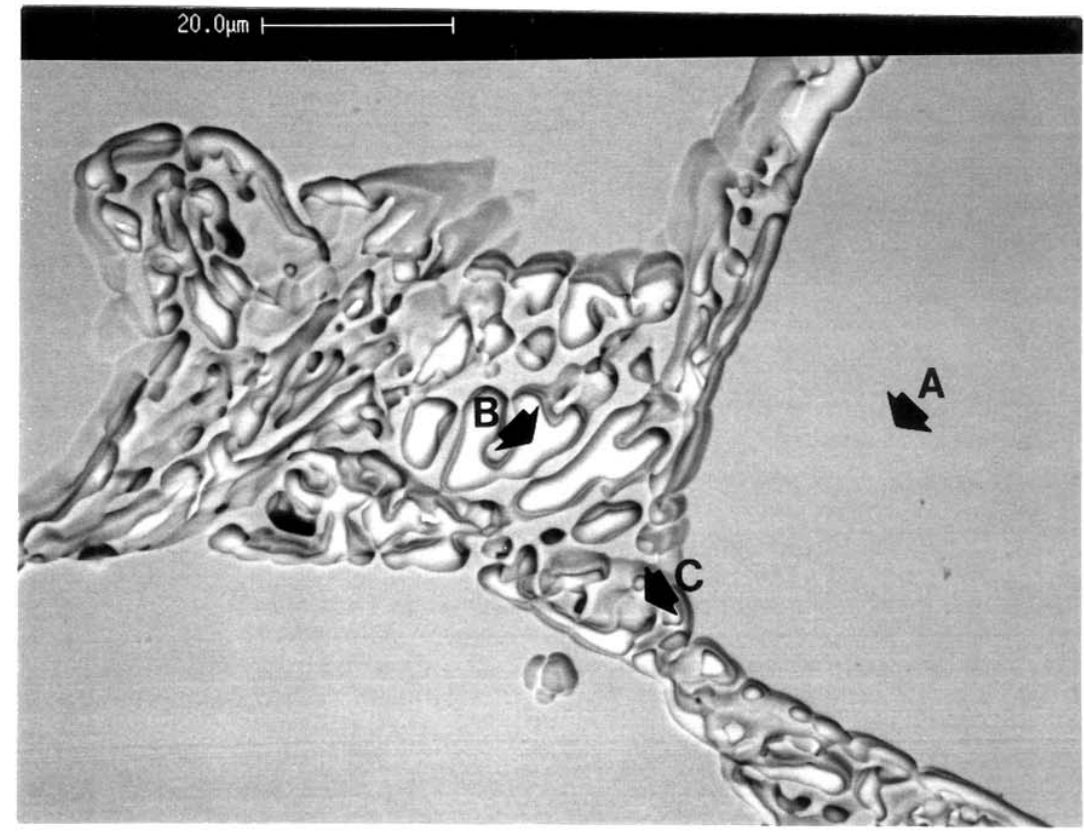

$1000 x$

(b) Back scattered image

Figure 62. SEM photomicrograph of CK-3MCUN Heat 3 in SA condition $\left(2100^{\circ} \mathrm{F}+\mathrm{WQ}\right)$, EDS analysis at locations marked by letters 


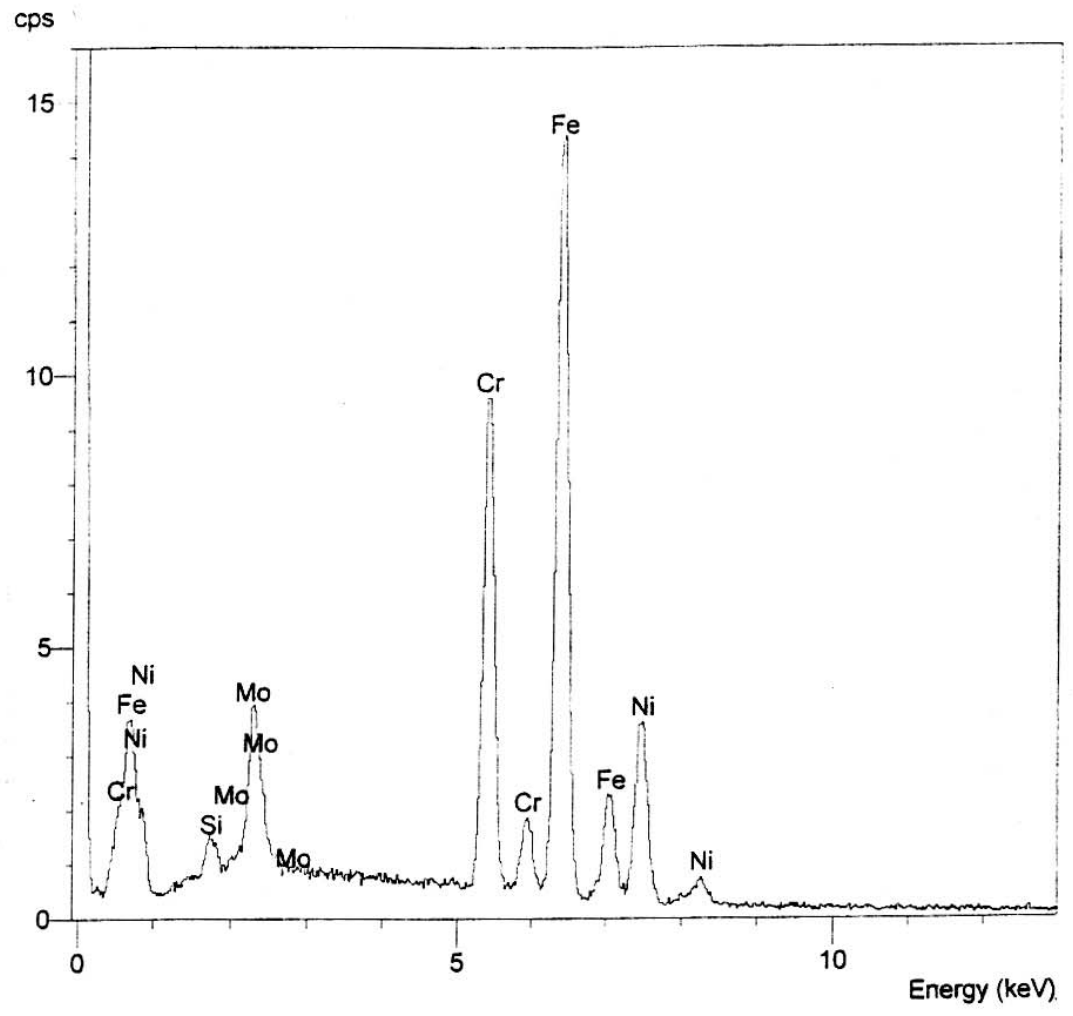

Figure 63. EDS spectrum at Location $A$ (matrix) in Figure 62, CK-3MCuN Heat 3 in $S A$ condition $\left(2100^{\circ} \mathrm{F}+\mathrm{WQ}\right)$ 


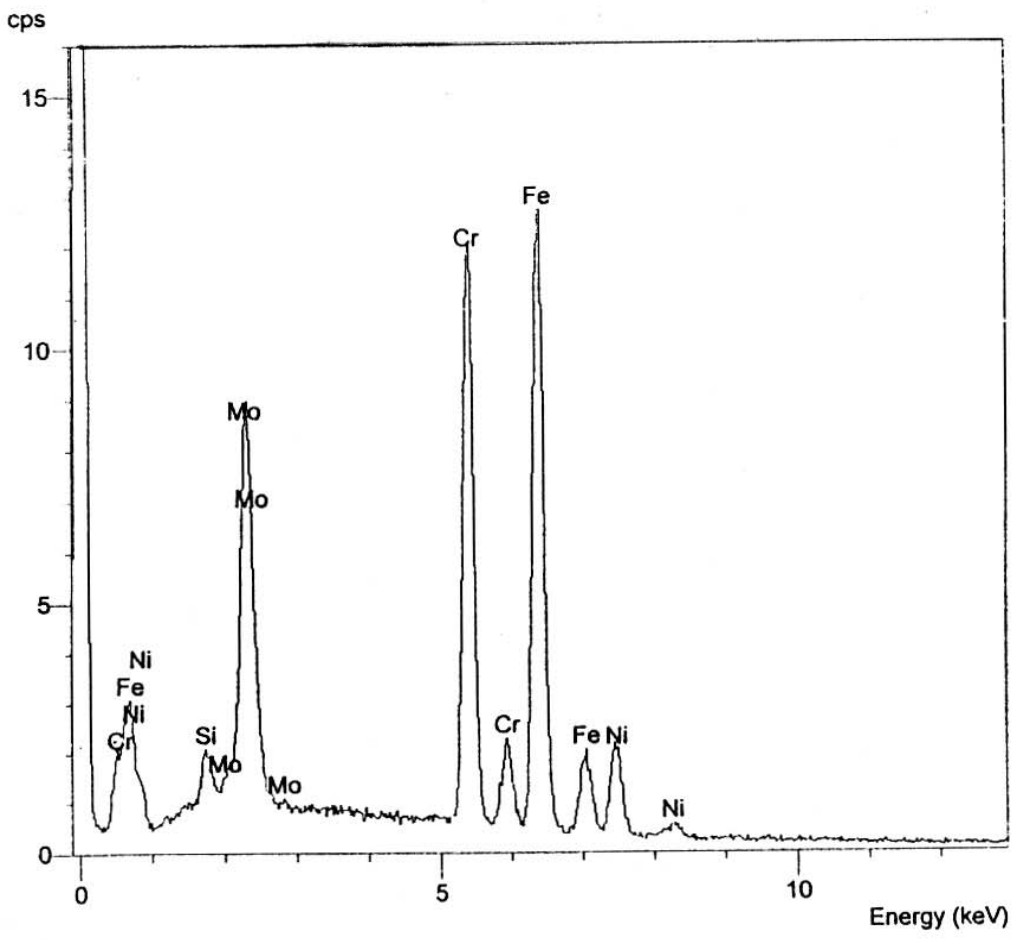

Figure 64. EDS spectrum at Location B (bright area within "islands") in Figure $62,2100^{\circ} \mathrm{F}$ solution annealed (WQ) CK-3MCuN Heat 3

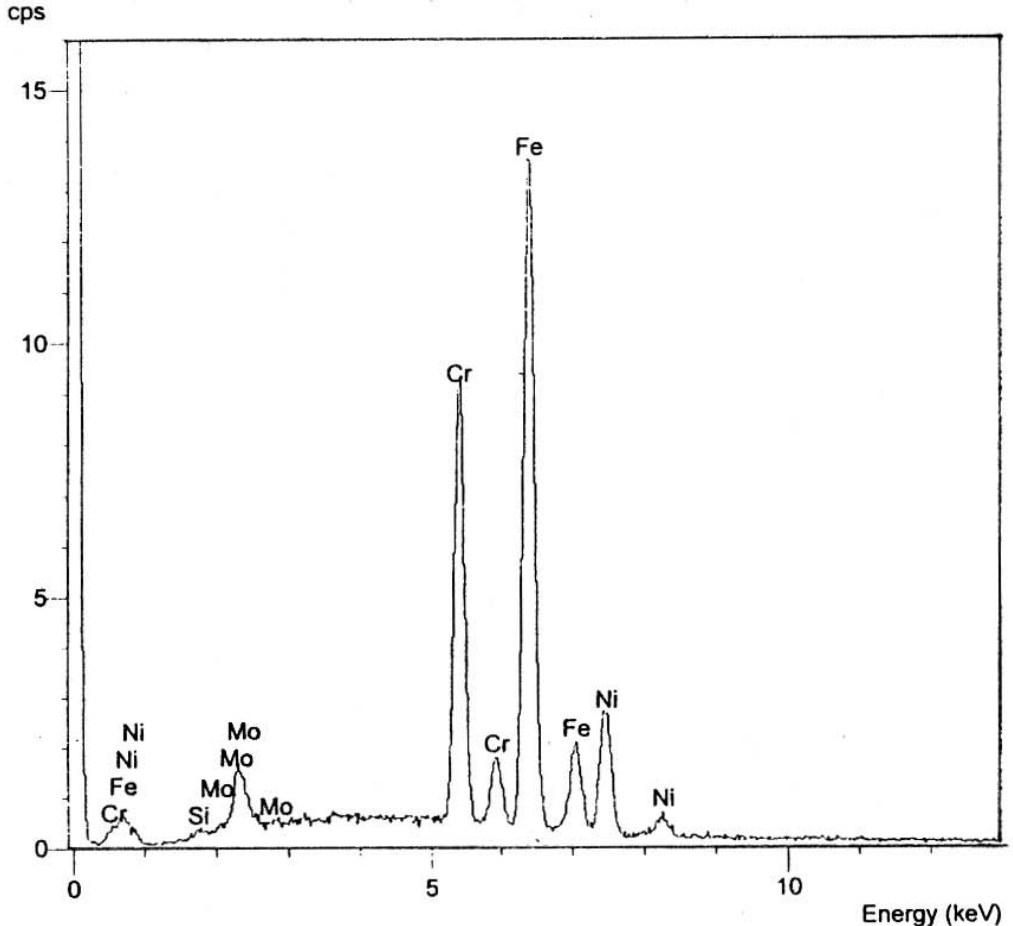

Figure 65. EDS spectrum at Location C (gray area within "islands") in Figure 62, 2300 $\mathrm{F}$ solution annealed (WQ) CK-3MCuN Heat 3 
C) areas within "islands", respectively. It is evident that Location B (bright area within "island" - Figure 64) reveals greater Mo and Cr content as compared to Location A (matrix - Figure 63) as well as Location C (gray area within "island" Figure 65). Location $\mathrm{C}$ exhibits almost the same $\mathrm{Mo}$ and $\mathrm{Cr}$ content as the matrix. In addition, both bright and gray areas within "islands" were unstained after the stain etching. This indicates that the segregation extent of $\mathrm{Cr}$ and $\mathrm{Mo}$ within the "islands" has been decreased upon solution annealing $\left(2100^{\circ} \mathrm{F} / 1150^{\circ} \mathrm{C}\right.$ + WQ) compared to the as-cast Heat 3. The bright areas (Locations B) are considered to be $\mathrm{Cr} / \mathrm{Mo}$ carbides. The gray areas (Location $\mathrm{C}$ ) are considered to be equivalent to the matrix.

Figure 66 shows the typical SEM microstructural morphology of solutionannealed CK-3MCuN Heat 3 at a higher temperature $\left(2300^{\circ} \mathrm{F} / 1260^{\circ} \mathrm{C}+\mathrm{WQ}\right)$. The response is different than that of Heat K3GAO and Heat 2. It is evident that the irregular-shaped secondary phases (present in as-cast condition) disappear from the "islands" after $2300^{\circ} \mathrm{F} / 1260^{\circ} \mathrm{C} \mathrm{SA}(\mathrm{WQ})$, but the boundary between "islands" and the matrix is still visible. The EDS results are presented in Figures 67 and 68 for the solution-annealed CK-3MCuN Heat 3 at the locations marked as $\mathrm{A}$ (matrix) and B ("empty islands") in Figure 66b. The Mo and $\mathrm{Cr}$ content within the "empty islands" are slightly higher compared to that in the matrix. It should be recalled that the ferrite measurement discussed previously indicates $1.2 \%$ ferrite in this sample, and these "empty islands" do not respond to stain etching. Thus, these "empty islands" are considered to be ferrite islands after complete dissolution of the $\sigma$ phase.

In order to define the effect of cooling rate on microstructure of high 


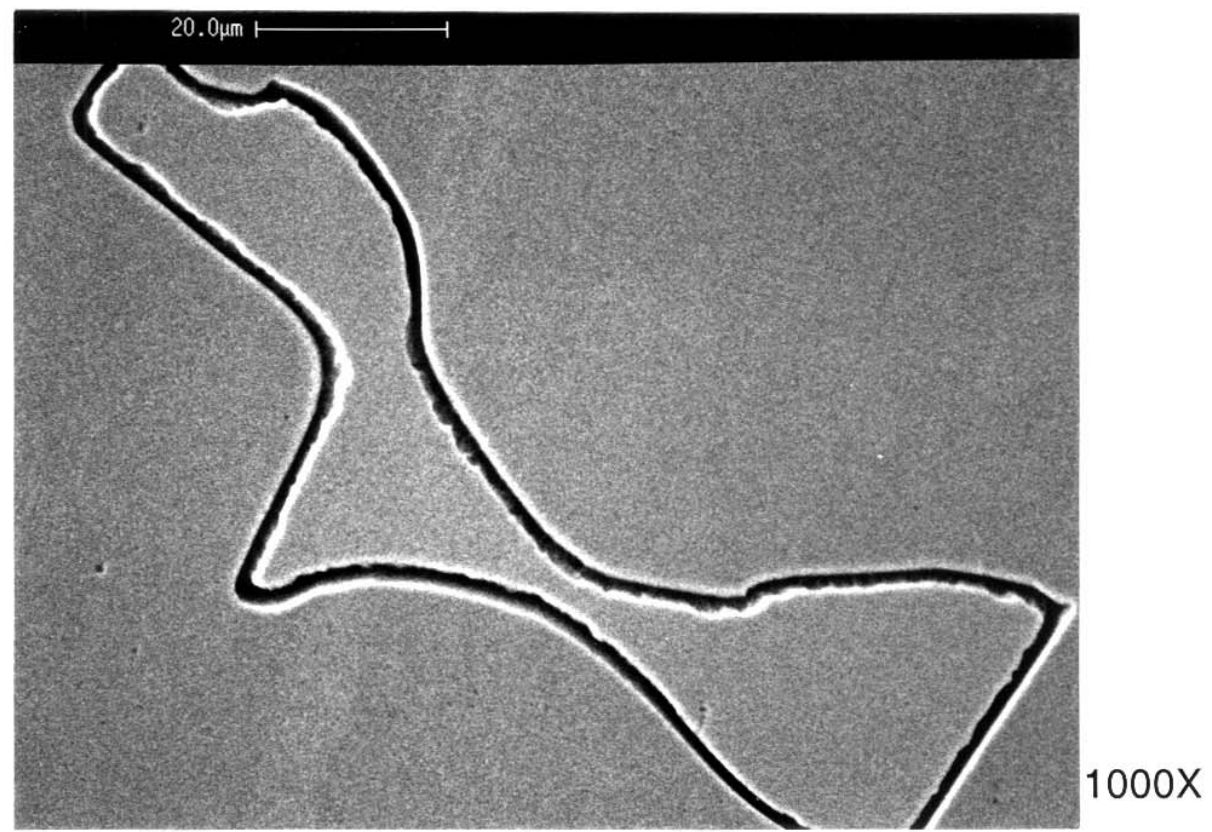

(a) Secondary image

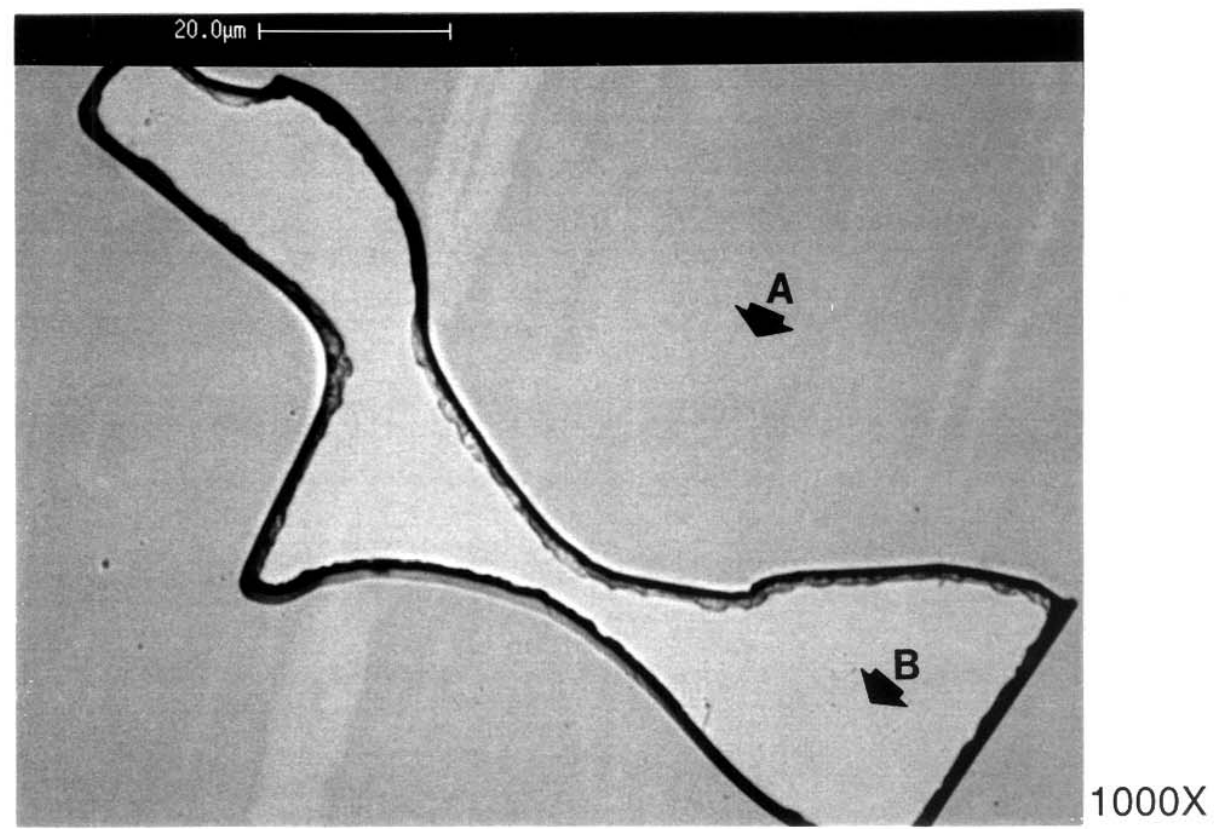

(b) Back scattered image

Figure 66. SEM photomicrograph of CK-3MCuN Heat 3 in SA condition $\left(2300^{\circ} \mathrm{F}+\mathrm{WQ}\right)$, EDS analysis at locations marked by letters 


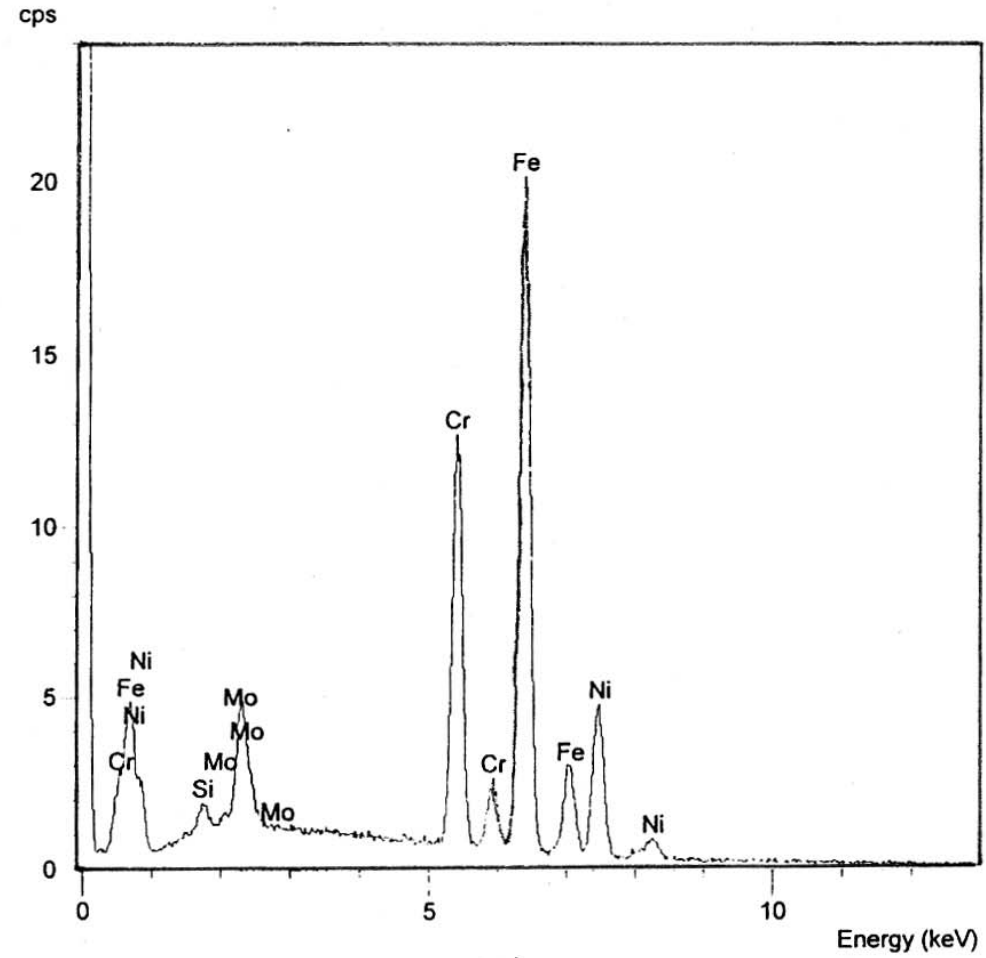

Figure 67. EDS spectrum at Location A (matrix) in Figure $66,2300^{\circ} \mathrm{F}$ solution annealed (WQ) CK-3MCuN Heat 3

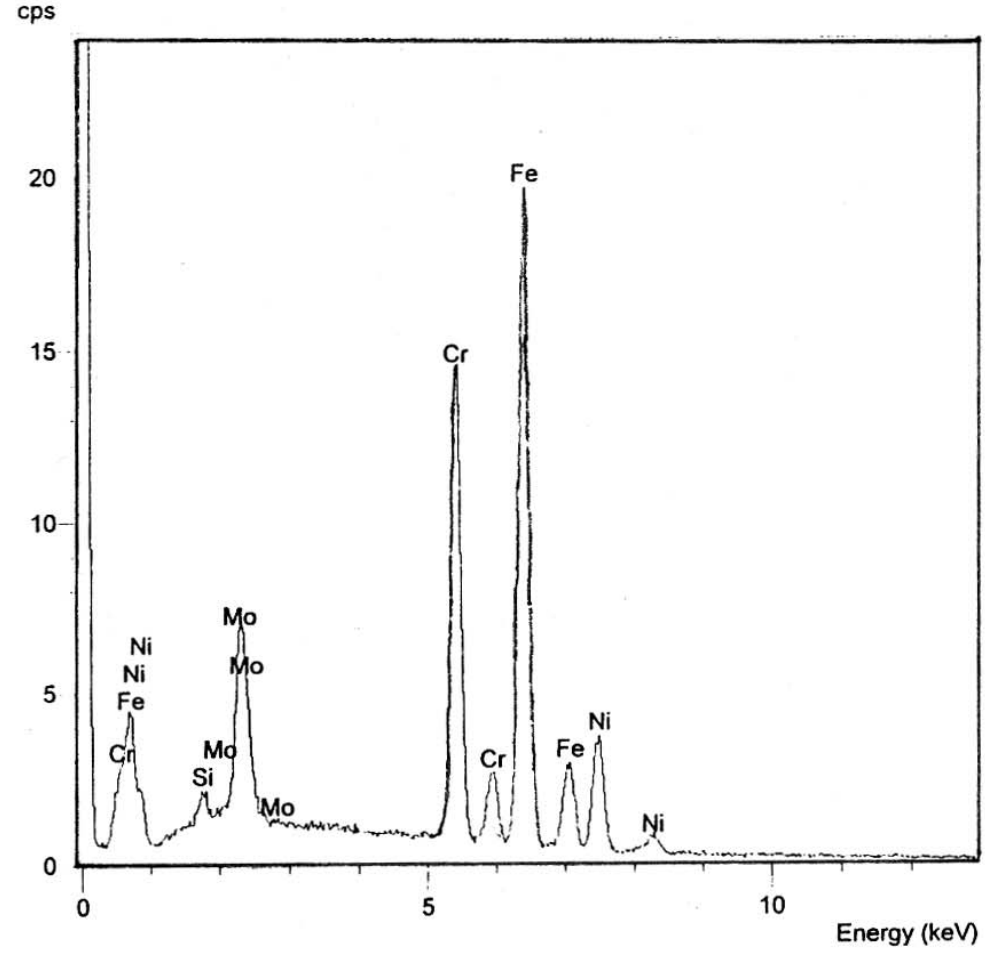

Figure 68. EDS spectrum at Location B (within "empty islands") in Figure $66,2300^{\circ} \mathrm{F}$ solution annealed (WQ) CK-3MCuN Heat 3 
Mo stainless steel castings, a solution-annealing treatment $\left(2300^{\circ} \mathrm{F} / 1260^{\circ} \mathrm{C}\right)$ followed by a slow cooling (SC) was conducted at UT. The EDS specimen extracted from

CK-3MCuN Heat 3 was selected for the slow cooling evaluation. Figure 69 shows the typical SEM morphology of slowly cooled CK-3MCuN Heat 3 (from $2300^{\circ} \mathrm{F} / 1260^{\circ} \mathrm{C}$ ). It is evident that the microstructure of $\mathrm{CK}-3 \mathrm{MCuN}$ Heat 3 in the slow cooled condition is identical to that in the as-cast condition. Fine irregularshaped secondary phases (Location B) and the coarse irregular-shaped secondary phases (Location C) with the "islands" are found in the matrix. Figures 70 through 73 present the EDS results at Locations A through D. It should be recognized that the area for the EDS analysis is previously the same area selected for the stain etching (Figure 32). Location B (fine irregular-shaped secondary phase within the "islands") was stained as blue or tan after stain etching, and the EDS spectrum at this location reveals a higher $\mathrm{Cr}$ and $\mathrm{Mo}$ content than the matrix. Thus, these fine irregular-shaped secondary phases within the "islands" are considered to be $\sigma$ phase. On the other hand, the coarse irregular-shaped precipitates within the "islands" (Location C) were not stained by stain etching (Figure 32), and the EDS results indicate that the $\mathrm{Cr}$ and $\mathrm{Mo}$ contents are greater than the fine irregular-shaped precipitates (Location B) as well as the matrix (Location A). Therefore, these coarse irregular-shaped secondary phases within the "islands" are considered to be Cr/Mo carbides. In addition, the dark globular particles in the matrix (Location D) are determined to be inclusions (Si/Mg/Mn oxides) based on EDS results as presented in Figure 73. 


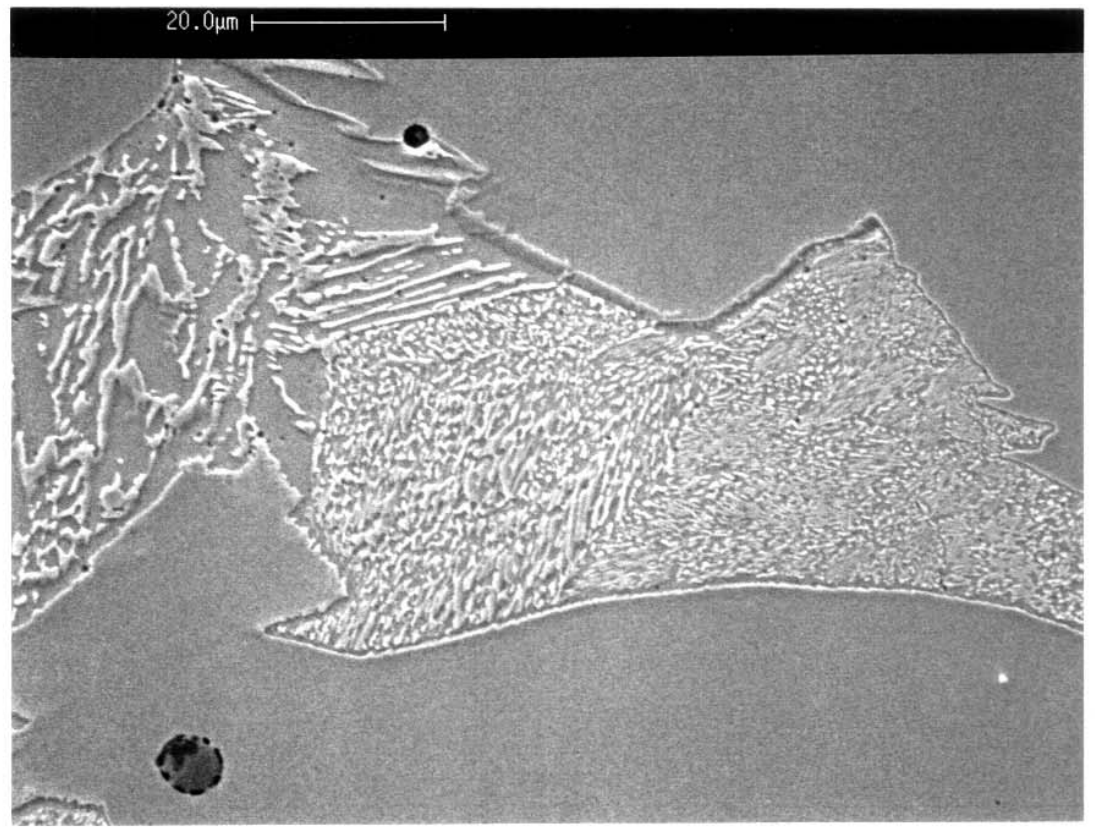

$1000 x$

(a) Secondary image

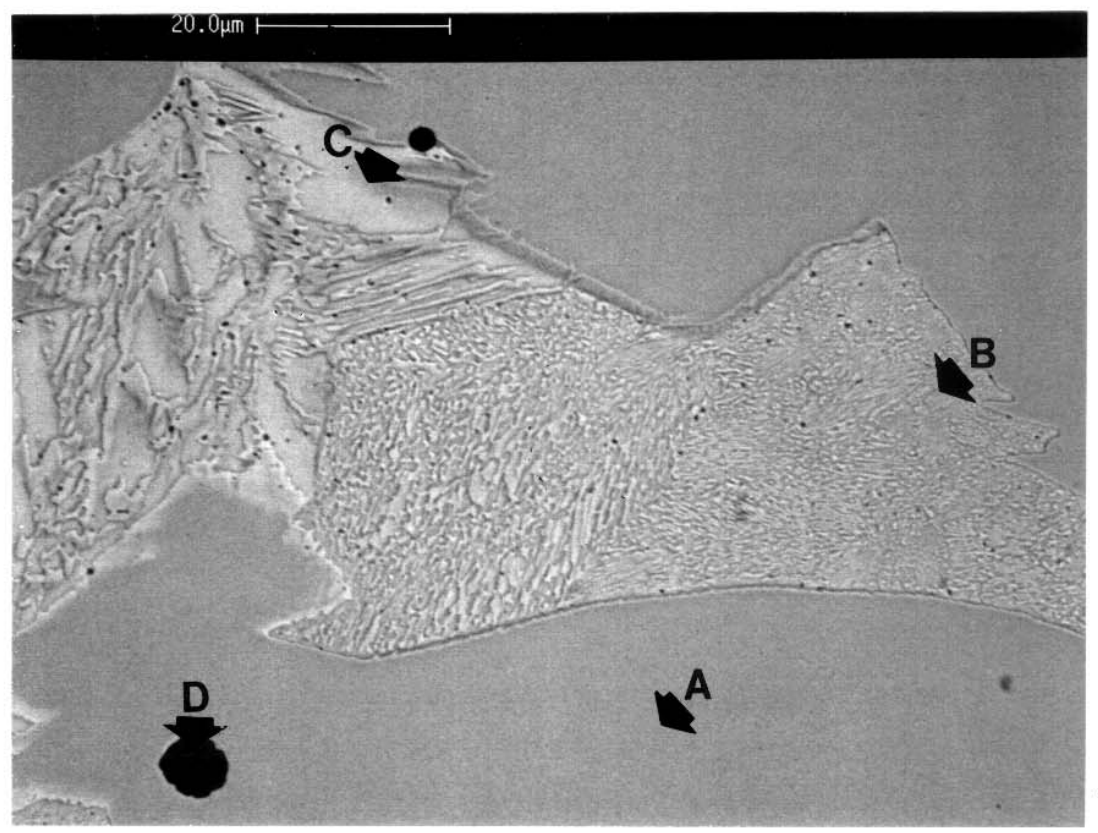

$1000 X$

(b) Back scattered image

Figure 69. SEM photomicrograph of CK-3MCuN Heat 3 in SA condition $\left(2300^{\circ} \mathrm{F}+\mathrm{SC}\right), \mathrm{EDS}$ analysis at locations marked by letters 


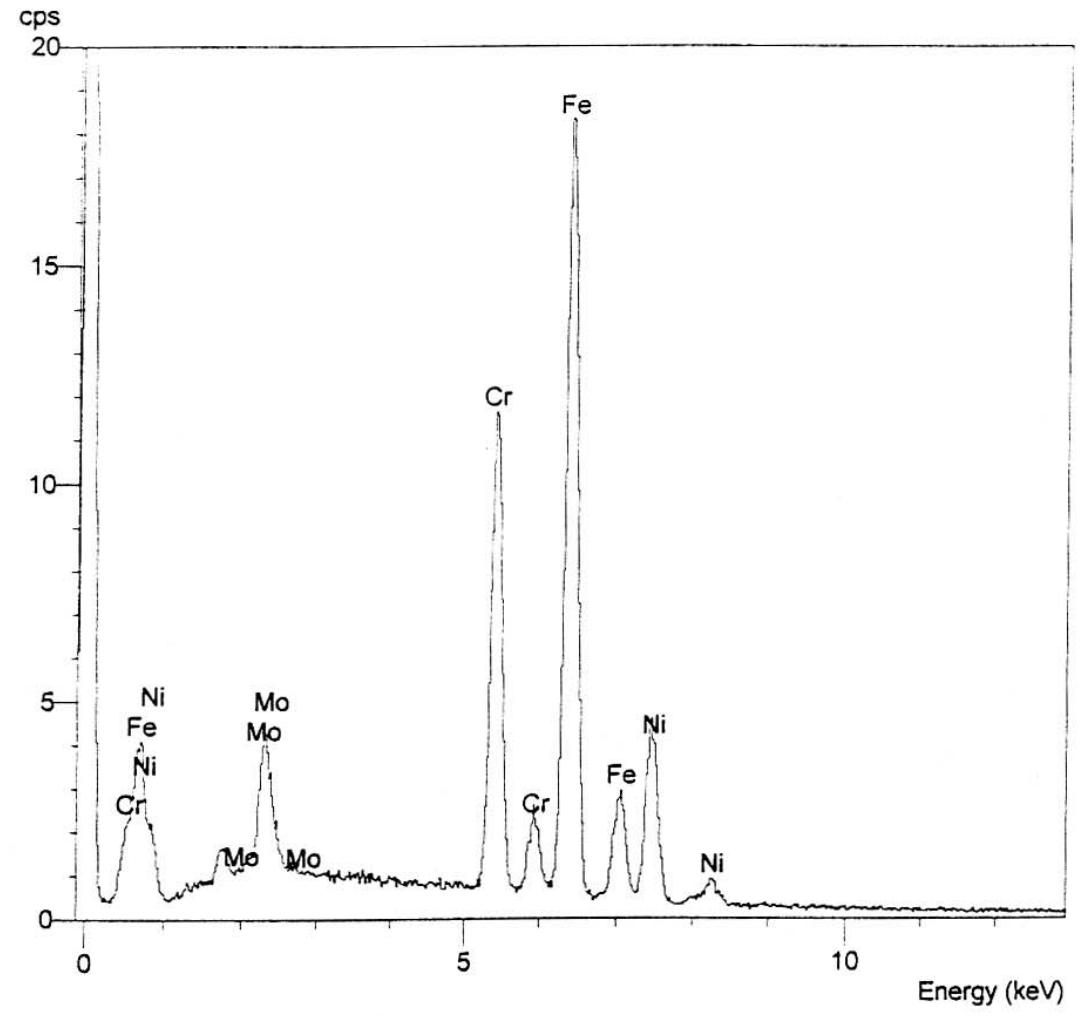

Figure 70. EDS spectrum at Location A (matrix) in Figure 69, CK-3MCuN Heat 3 in SA condition $\left(2300^{\circ} \mathrm{F}+\mathrm{SC}\right)$ 


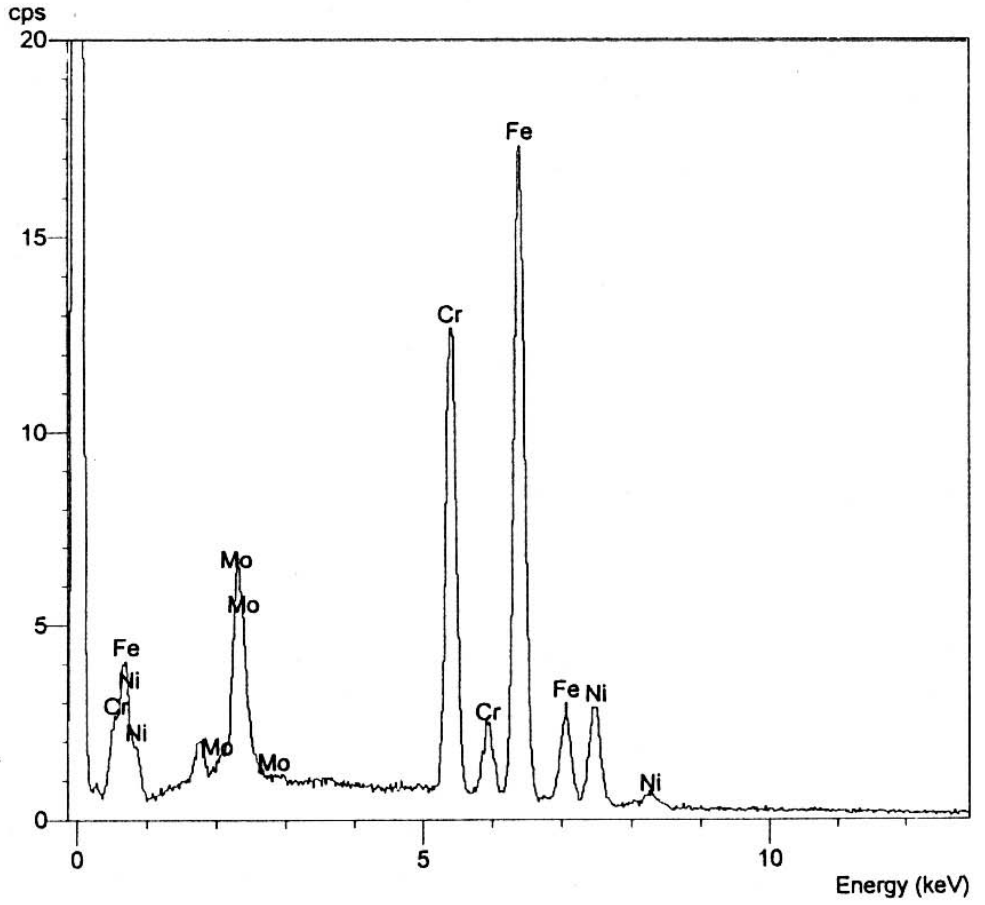

Figure 71. EDS spectrum at Location B (fine irregular shaped secondary phases within "islands") in Figure 69, 2300F solution annealed (SC) CK-3MCuN Heat 3

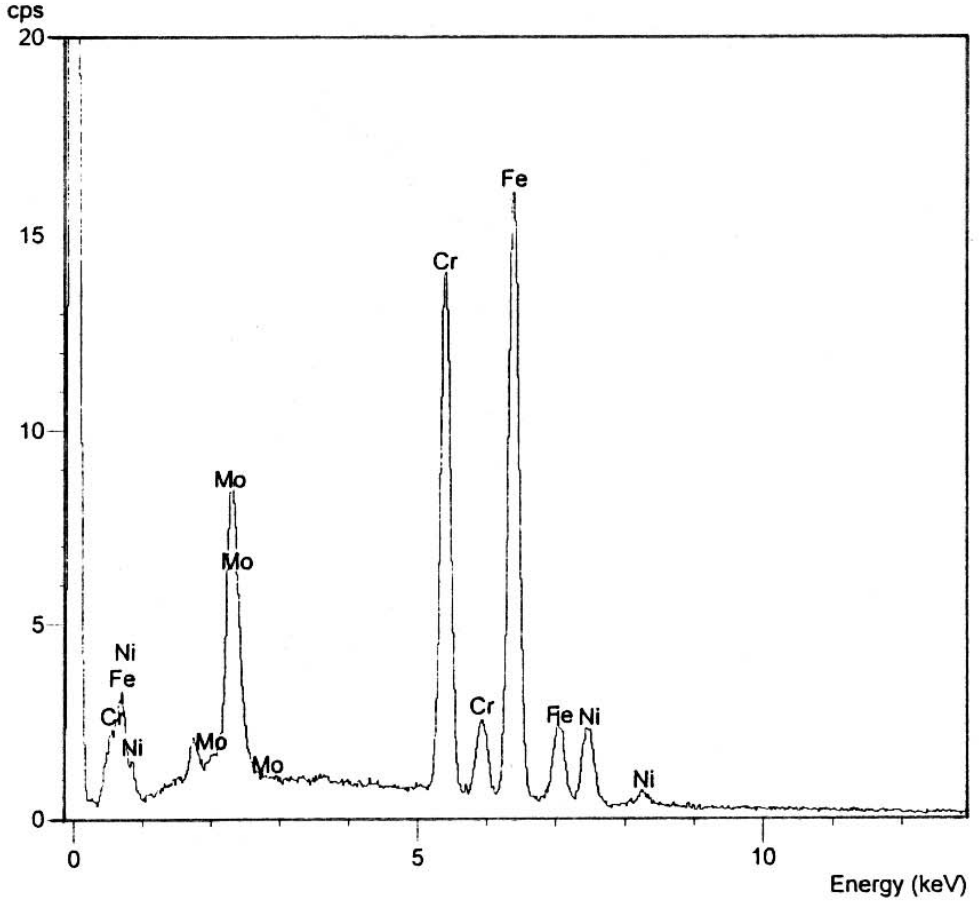

Figure 72. EDS spectrum at Location C (coarse irregular shaped secondary phases within "islands") in Figure $69,2300^{\circ} \mathrm{F}$ solution annealed (SC) CK-3MCuN Heat 3 


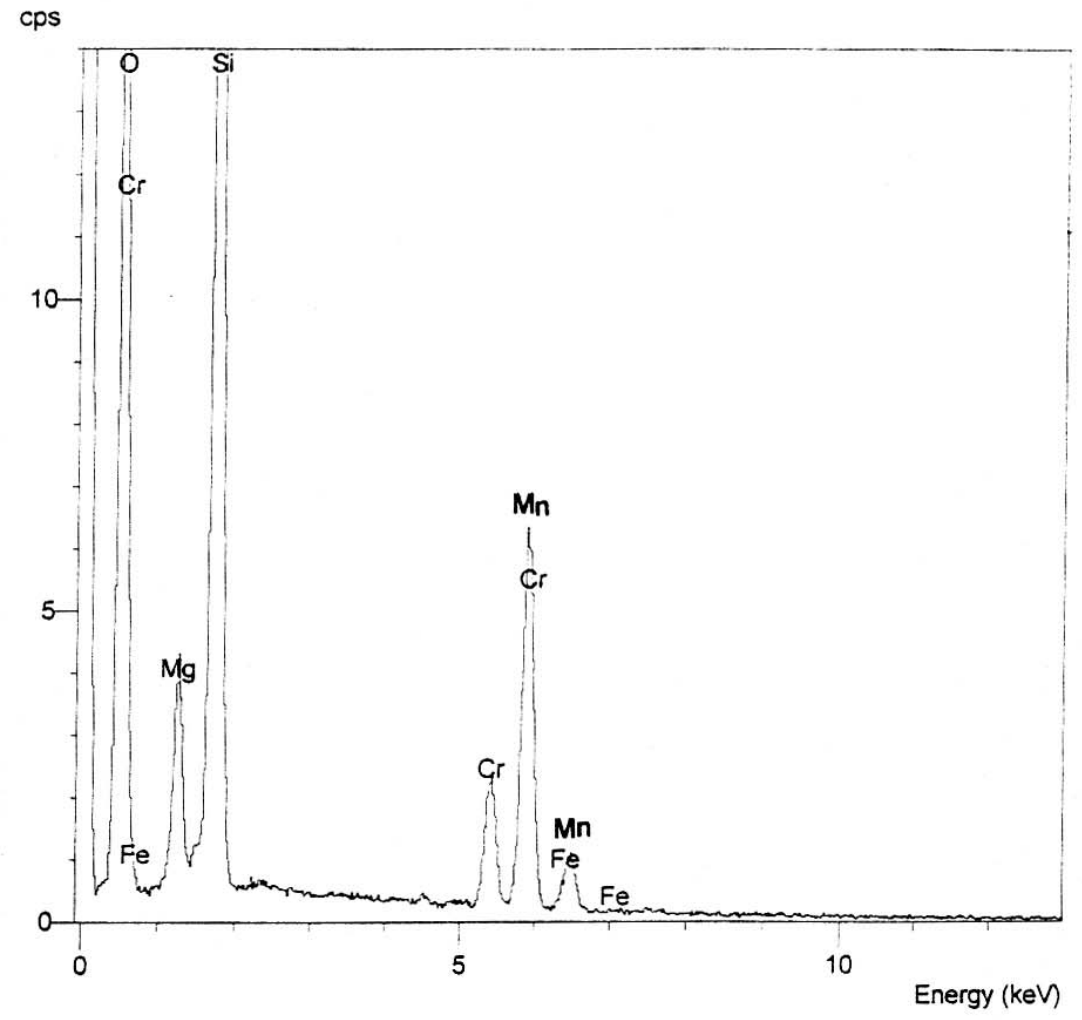

Figure 73. EDS spectrum at Location $D$ (dark globular particles) in Figure 69, CK-3MCuN Heat 3 in SA condition $\left(2300^{\circ} \mathrm{F}+\mathrm{SC}\right)$ 


\section{- X-ray Diffraction Analysis}

To confirm the results of OLM and EDS analysis, two heats of CK-3McuN Heat 2 and Heat 3 were selected for X-ray diffraction analysis in both the as-cast and solution-annealed condition. The wrought counterpart 254SMO was also used for comparison. The precipitates were extracted from the selected specimens using an electrolytic precipitate extraction technique as described previously.

\section{i) $\underline{\mathrm{CK}-3 \mathrm{MCuN} \text { Heat } 2}$}

The X-ray diffraction analyses were conducted on CK-3MCuN Heat 2 in the as-cast and two UT solution-annealed conditions $\left(2100^{\circ} \mathrm{F} / 1150^{\circ} \mathrm{C}\right.$ \& $2300^{\circ} \mathrm{F} / 1260^{\circ} \mathrm{C}+\mathrm{WQ}$ ). It should be noted that material in foundry solutionannealed condition $\left(2250^{\circ} \mathrm{F} / 1230^{\circ} \mathrm{C}+\mathrm{WQ}\right)$ was not available. The X-ray diffraction results are shown in Figure 74 for the as-cast Heat 2 and in Figures 75 and 76 for Heat 2 solution annealed at $2100^{\circ} \mathrm{F} / 1150^{\circ} \mathrm{C}$ and $2300^{\circ} \mathrm{F} / 1260^{\circ} \mathrm{C}$, respectively. For the as-cast condition, it is evident that the primary precipitates are $\mathrm{Cr}$ carbides $\left(\mathrm{Cr}_{23} \mathrm{C}_{6}\right)$ and $\sigma$ phase. Small amounts of Fe carbide $\left(\mathrm{Fe}_{3} \mathrm{C}\right)$ and $\mathrm{Ni}$ nitride $\left(\mathrm{Ni}_{3} \mathrm{~N}\right)$ were also detected. It should be recalled that the existence of $\sigma$

phase in the as-cast CK-3MCuN Heat 2 was determined by a color stain etching. This X-ray diffraction result further confirms the color stain etching and EDS results.

Figures 75 and 76 present the X-ray diffraction results for CK-3MCuN Heat 2 solution annealed at $2100^{\circ} \mathrm{F} / 1150^{\circ} \mathrm{C}$ and $2300^{\circ} \mathrm{F} / 1260^{\circ} \mathrm{C}$, respectively. 


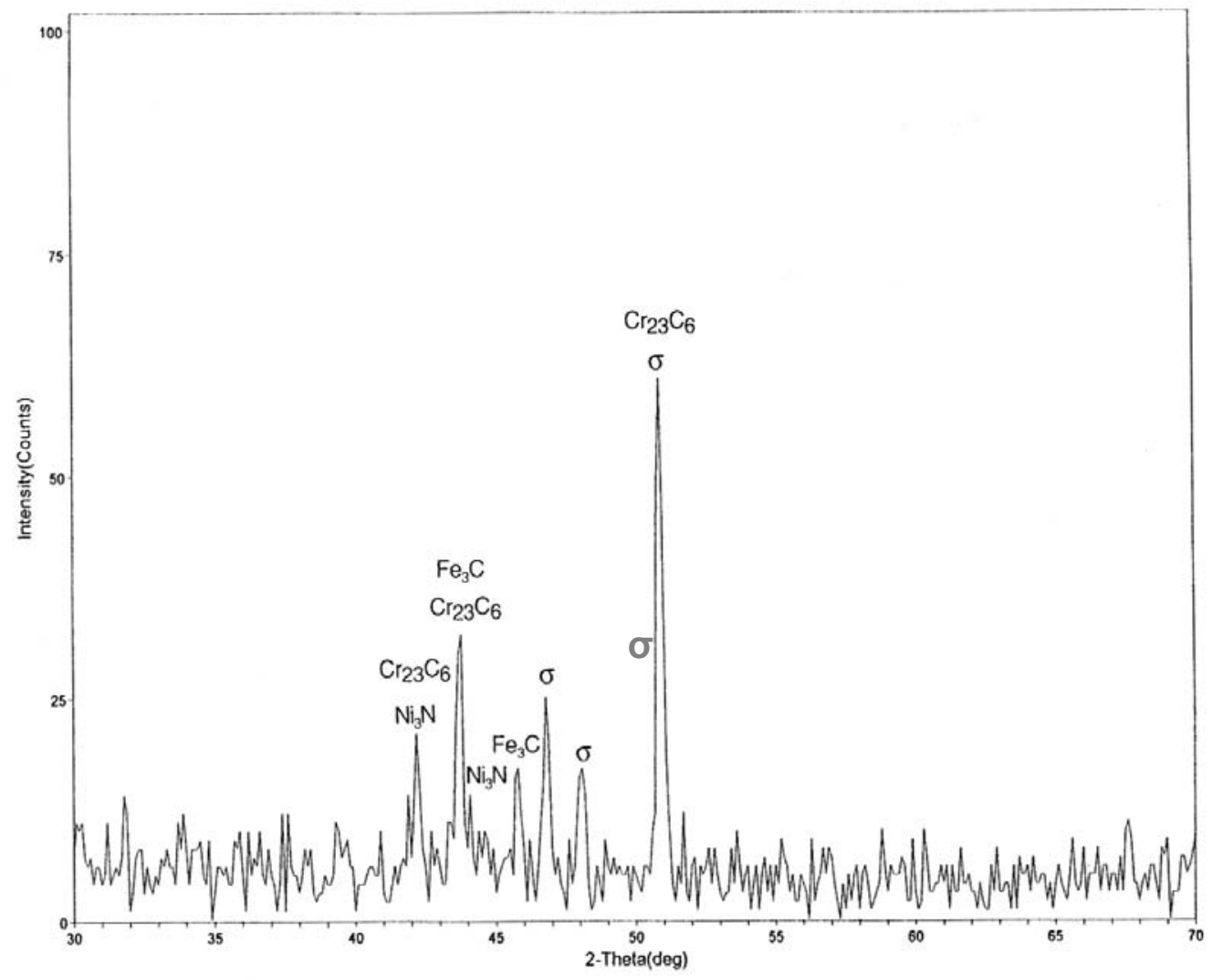

Figure 74. X-ray diffraction spectrum of particles extracted from as-cast CK-3MCuN Heat 2 


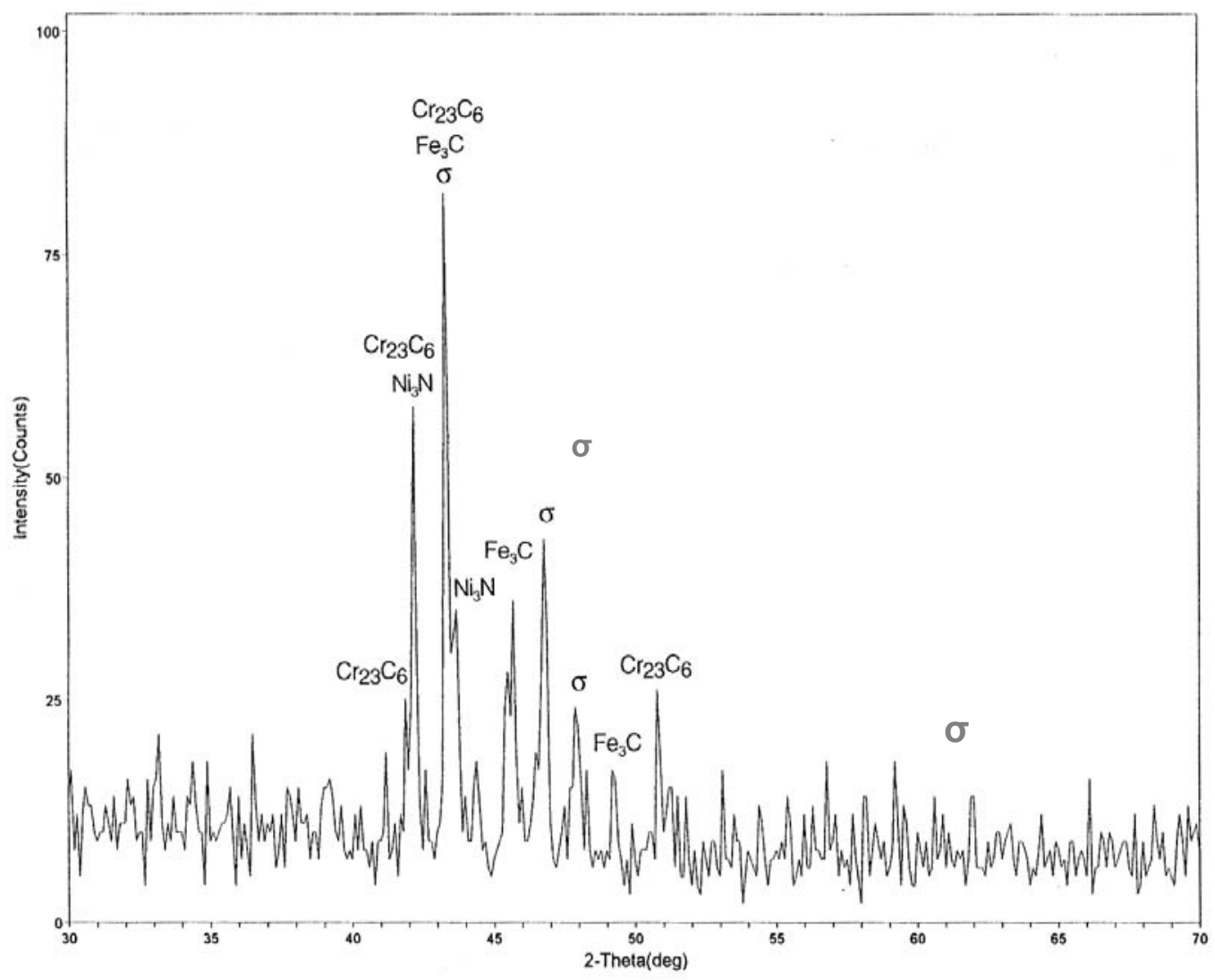

Figure 75. X-ray diffraction spectrum of particles extracted from solution annealed $\left(2100^{\circ} \mathrm{F}+\mathrm{WQ}\right)$ CK-3MCuN Heat 2 


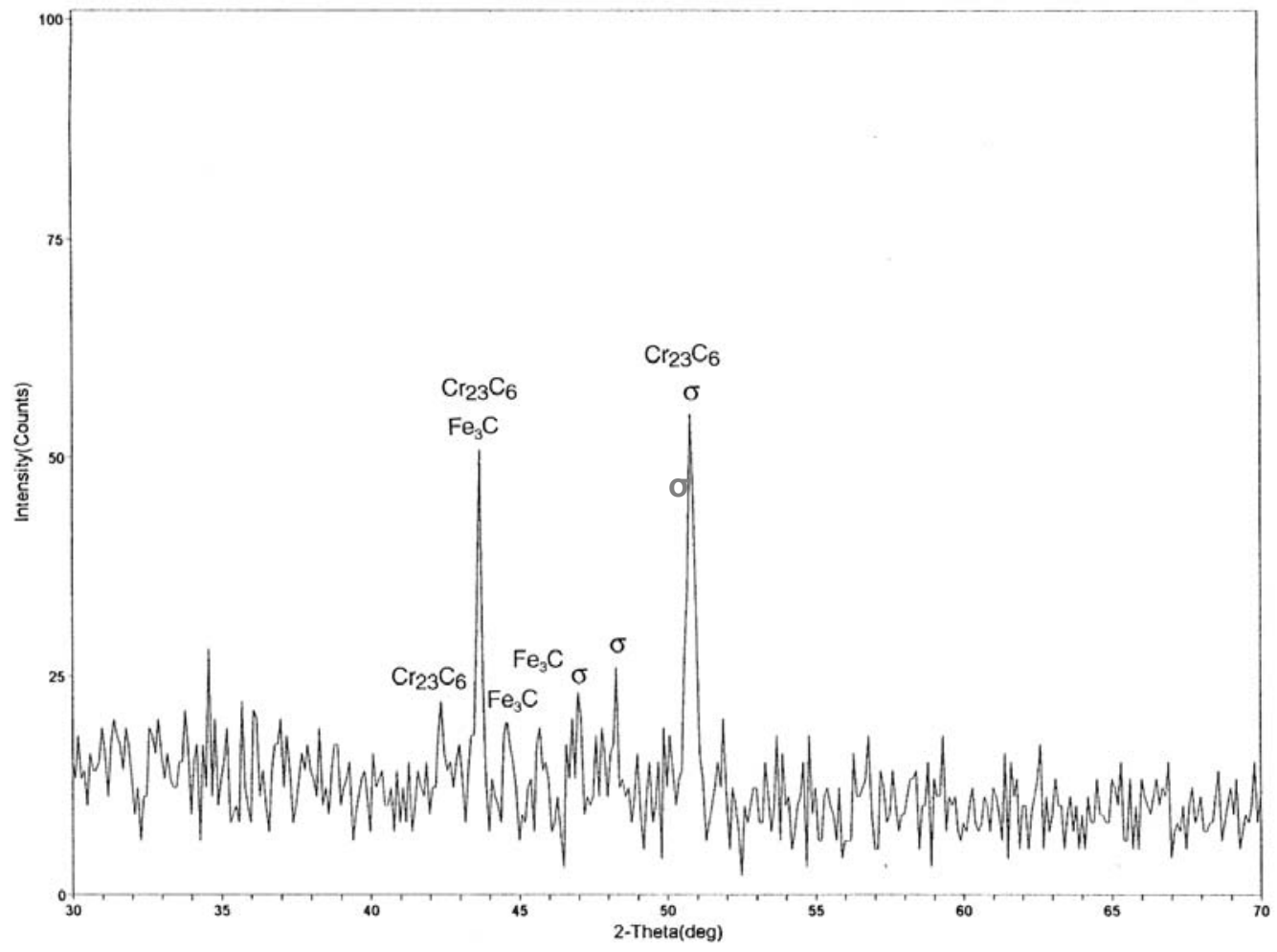

Figure 76. X-ray diffraction spectrum of particles extracted from solution annealed $\left(2300^{\circ} \mathrm{F}+\mathrm{WQ}\right)$ CK-3MCuN Heat 2 
According to the X-ray analysis, it is evident that $\mathrm{Cr}$ or Fe carbides still remained after the $2100^{\circ} \mathrm{F} / 1150^{\circ} \mathrm{C}$ and $2300^{\circ} \mathrm{F} / 1260^{\circ} \mathrm{C}$ solution anneals. Possibly, a small amount of $\sigma$ phase remains as well.

\section{ii) $\underline{\text { CK-3MCuN Heat } 3}$}

The X-ray diffraction analysis was further conducted on CK-3MCuN Heat 3. The results (spectra) are shown in Figures 77 through 81 for CK-3MCuN Heat 3 in the as-cast and several SA conditions $\left(2100^{\circ} \mathrm{F} / 1150^{\circ} \mathrm{C}+\mathrm{WQ}, 2200^{\circ} \mathrm{F} / 1205^{\circ} \mathrm{C}\right.$ $+\mathrm{WQ}, 2300^{\circ} \mathrm{F} / 1260^{\circ} \mathrm{C}+\mathrm{WQ}$ and $\left.2300^{\circ} \mathrm{F} / 1260^{\circ} \mathrm{C}+\mathrm{SC}\right)$. For the as-cast CK$3 \mathrm{MCuN}$ Heat 3 as shown in Figure 77, the X-ray diffraction result shows that the major precipitates are $\mathrm{Cr}$ carbide $\left(\mathrm{Cr}_{23} \mathrm{C}_{6}\right)$, Fe carbide $\left(\mathrm{Fe}_{3} \mathrm{C}\right)$ and $\sigma$ phase (FeCrMo, CrNiMo or CrFeMoNi). In addition, a small amount of $\mathrm{Ni}$ nitride $\left(\mathrm{Ni}_{3} \mathrm{~N}\right)$ was also detected. Compared to the as-cast CK-3MCuN Heat 2, the same types of secondary phases was found in as-cast CK-3MCuN Heat 3. The $\sigma$ phase, which exists in the as-cast CK-3MCuN Heat 2 and Heat 3, was identified by both EDS and color stain etching techniques.

For the solution-annealed CK-3MCuN Heat 3 at $2100^{\circ} \mathrm{F} / 1150^{\circ} \mathrm{C}$ and $2200^{\circ} \mathrm{F} / 1205^{\circ} \mathrm{C}$ followed by water quench (Figures 78 and 79 ), it is evident that the type of precipitates present in the solution-annealed CK-3MCuN Heat 3 (at $2100^{\circ} \mathrm{F} / 1150^{\circ} \mathrm{C}$ and $2200^{\circ} \mathrm{F} / 1205^{\circ} \mathrm{C}$ ) are generally the same in comparison with

those presented in the as-cast CK-3MCuN Heat 3 (Figure 1). They are primarily Cr carbide, Fe carbide and $\sigma$ phase. It is to be noted that there are three 


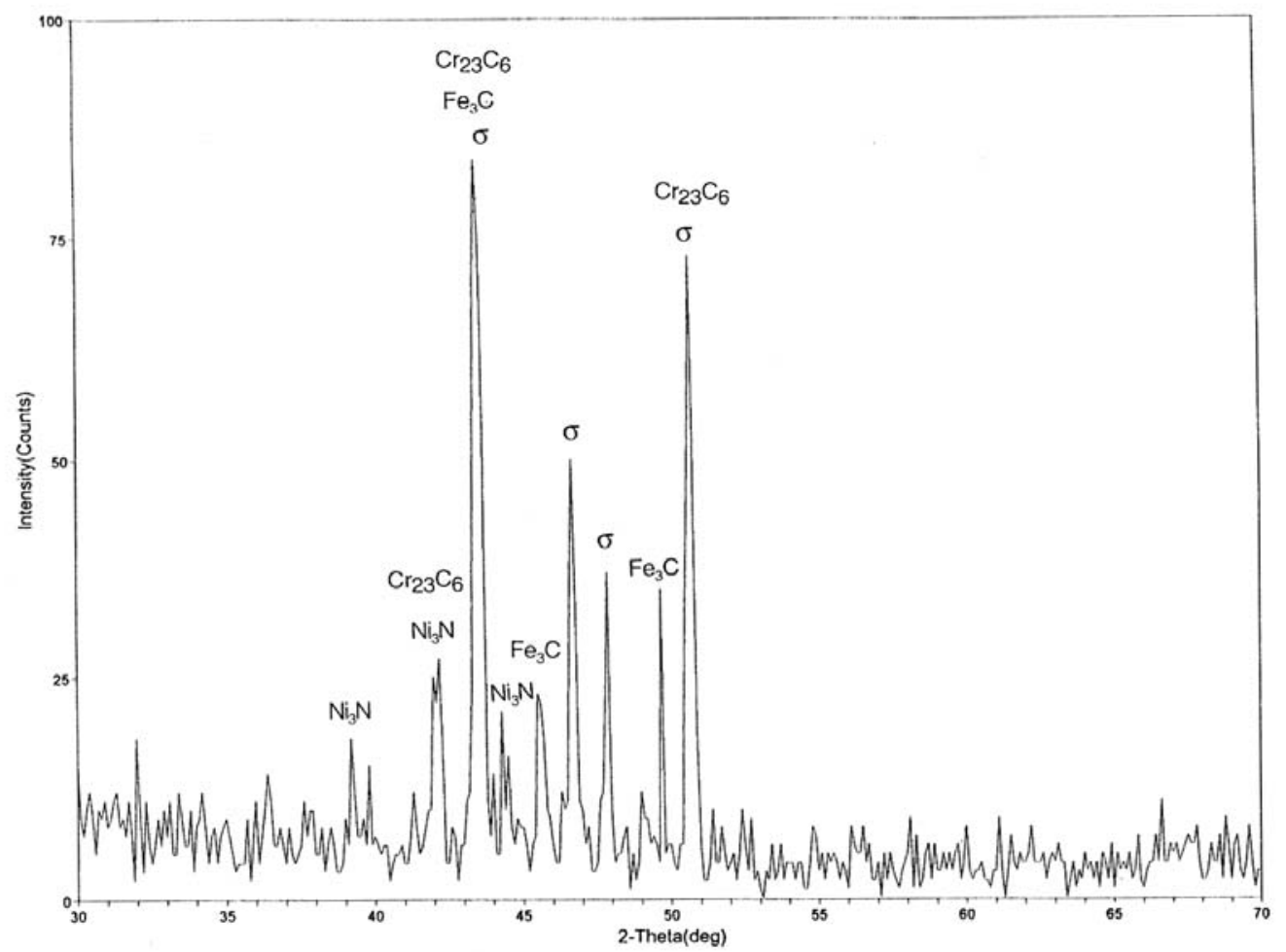

Figure 77. X-ray diffraction spectrum of particles extracted from as-cast CK-3MCuN Heat 3 


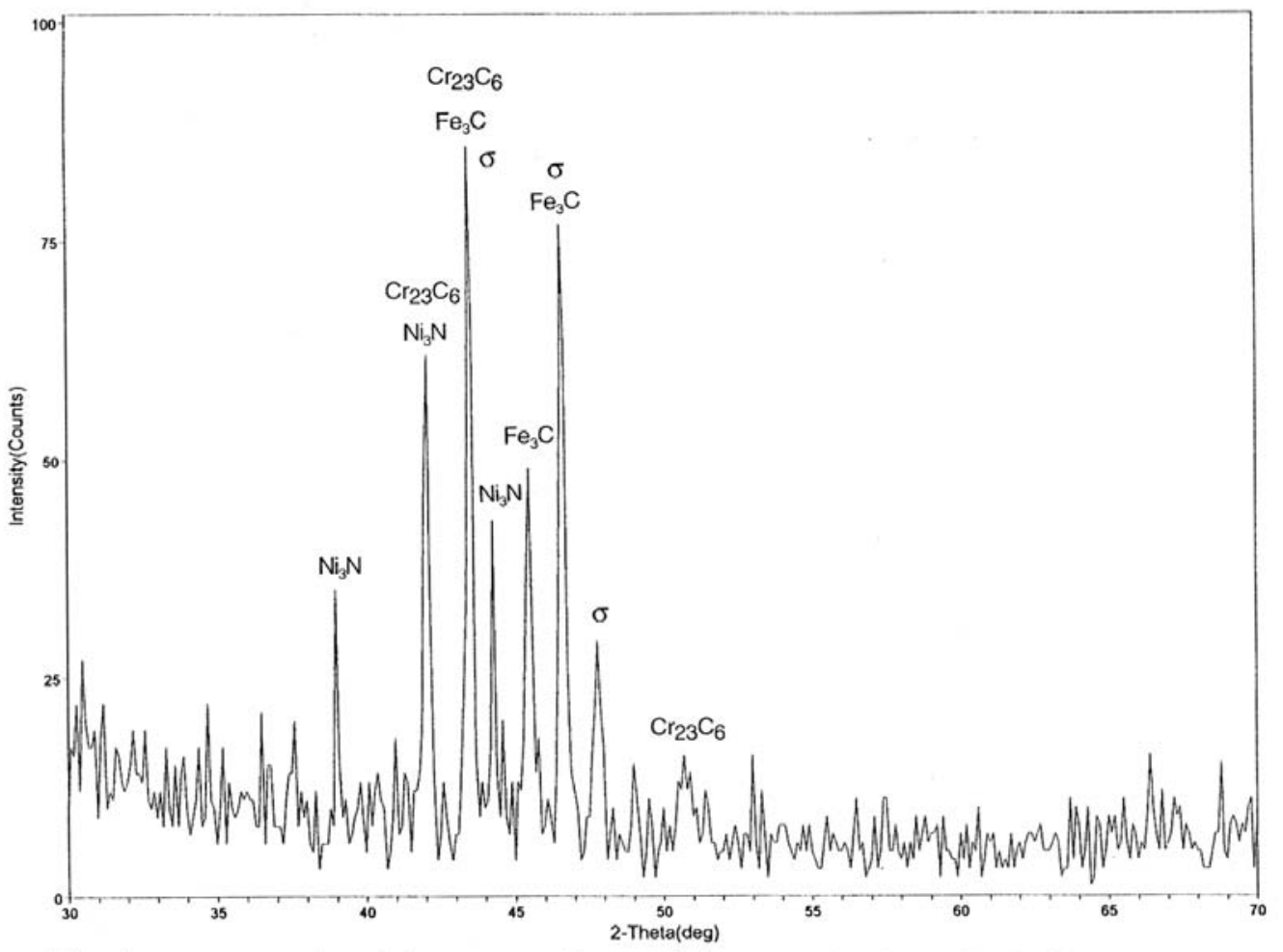

Figure 78. X-ray diffraction spectrum of particles extracted from solution annealed $\left(2100^{\circ} \mathrm{F}+\mathrm{WQ}\right)$ CK-3MCuN Heat 3 


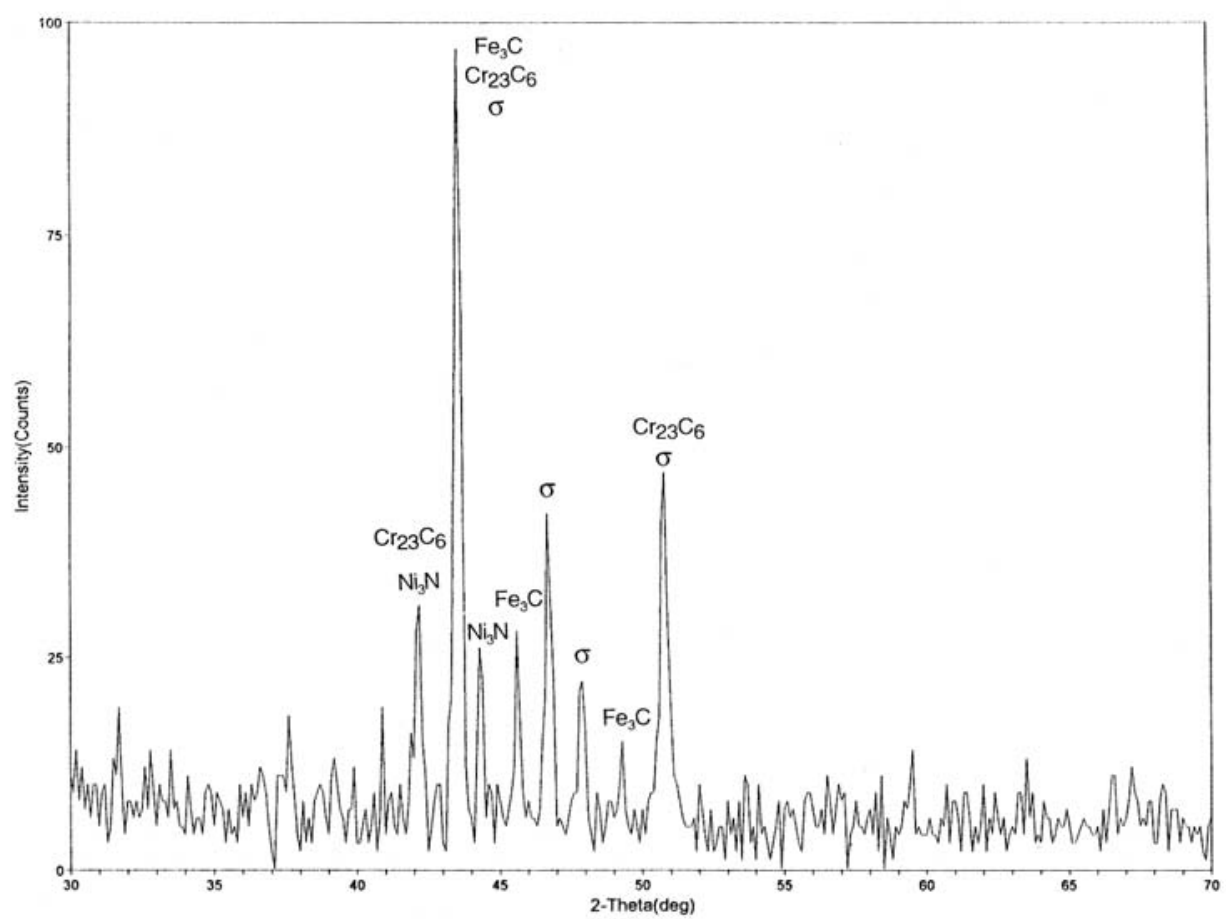

Figure 79. X-ray diffraction spectrum of particles extracted from solution annealed $\left(2200^{\circ} \mathrm{F}+\mathrm{WQ}\right)$ CK-3MCuN Heat 3 


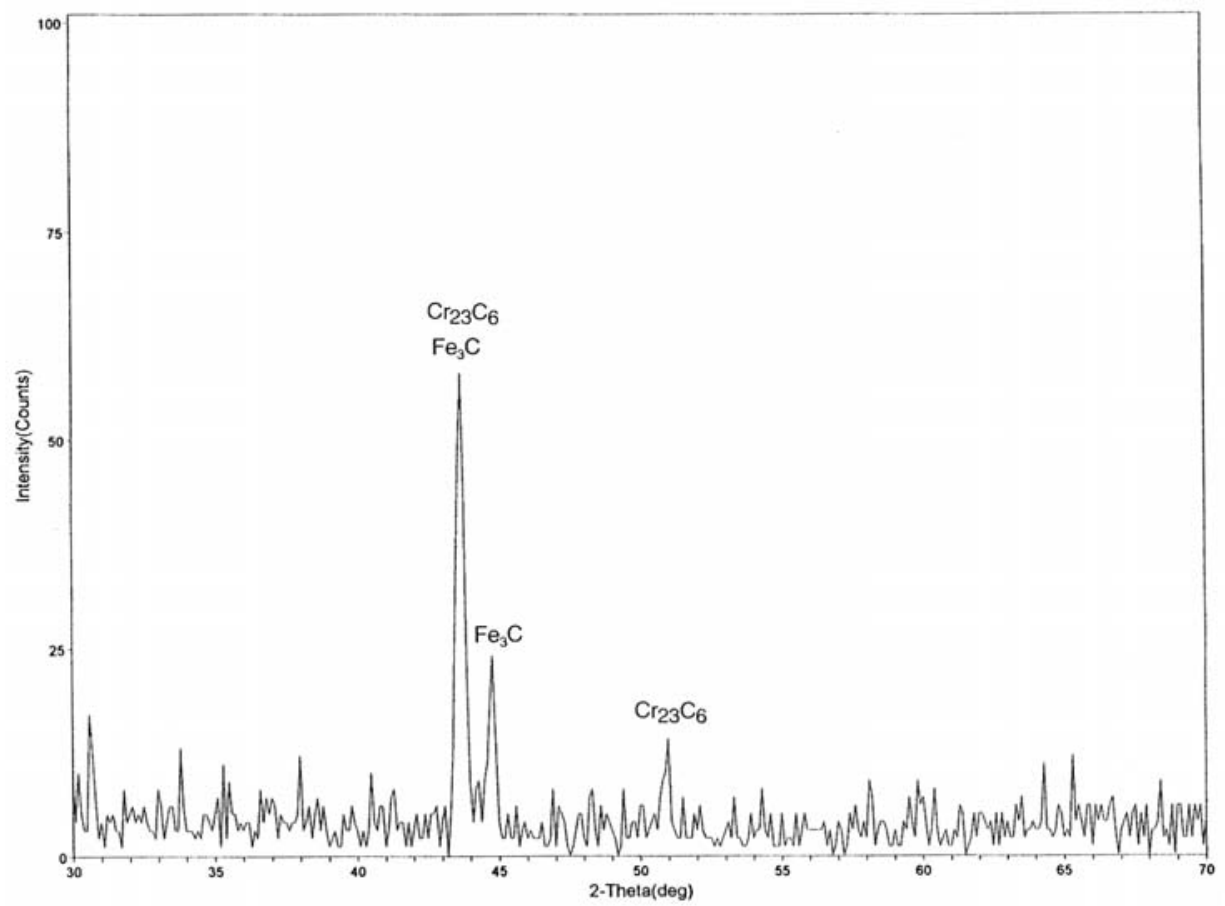

Figure 80. X-ray diffraction spectrum of particles extracted from solution annealed $\left(2300^{\circ} \mathrm{F}+\mathrm{WQ}\right)$ CK-3MCuN Heat 3 


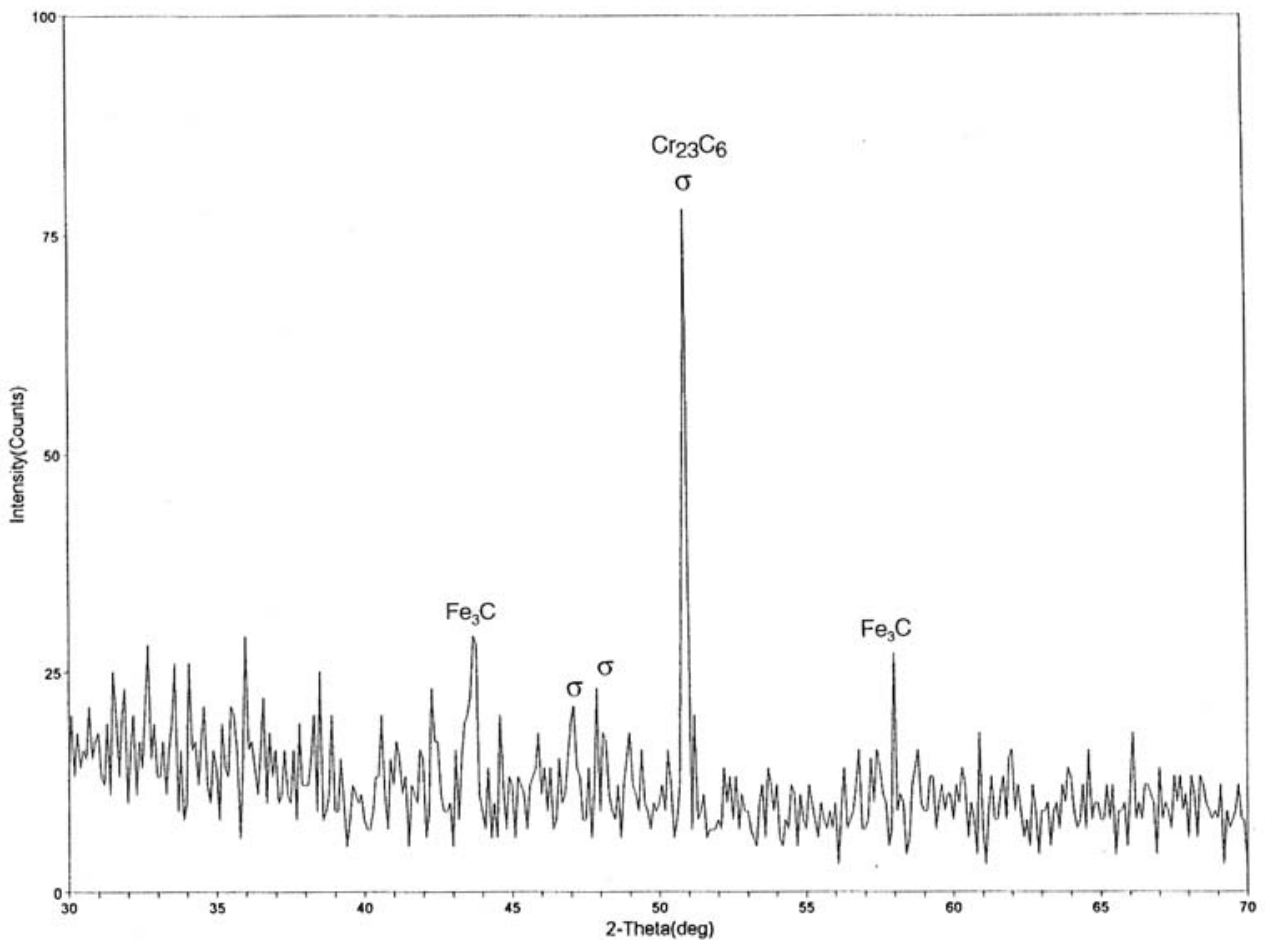

Figure 81. X-ray diffraction spectrum of particles extracted from solution annealed $\left(2300^{\circ} \mathrm{F}+\mathrm{SC}\right)$ CK-3MCuN Heat 3 
possible types of $\sigma$ phases (FeCrMo, CrFeMoNi \& CrNiMo) present in CK$3 \mathrm{MCuN}$. Each type of $\sigma$ phase has its own characteristic diffraction pattern (spectrum) in terms of interplanar spacing (d) and relative peak intensity $\left(I / I_{\mathrm{i}}\right)$. Since the spectra for the three $\sigma$ phases overlap at their characteristic peak locations, it is difficult to uniquely distinguish the three types of $\sigma$ phase. Compared to the spectrum for as-cast CK-3MCuN Heat 3 (Figure 77), the type of $\sigma$ phase present in the solution-annealed $\mathrm{CK}-3 \mathrm{MCuN}$ appears to be different from that present in the as-cast CK-3MCuN (Figure 78 for SA at $2100^{\circ} \mathrm{F} / 1150^{\circ} \mathrm{C}$ / and Figure 79 for SA at $2200^{\circ} \mathrm{F} / 1205^{\circ} \mathrm{C}$ ). As previously stated, for the $2100^{\circ} \mathrm{F} / 1150^{\circ} \mathrm{C}$ and $2200^{\circ} \mathrm{F} / 1205^{\circ} \mathrm{C}$ solution-annealed CK-3MCuN Heat $3, \sigma$ phase was not observed upon stain etching. However, $\sigma$ phase was identified by X-ray diffraction. Several factors can be involved to cause this inconsistency in results. First, since $\sigma$ phase can vary in type and chemical composition over a wide range, it may have different responses to color stain etching. In another words, it can be possible that some types of $\sigma$ phase may be stained, while others are not. Secondly, it is believed that the amount, size, and distribution of $\sigma$ phase also has an influence on stain-etching appearance. Thus, a material with a small amount of fine and widely dispersed $\sigma$ phase may not respond optimally to stain-etching techniques. Third, it should be recognized that the secondary precipitates can be partially dissolved during SA treatments. The homogenization of alloying elements between the secondary phases and the bulk material by diffusion during solution annealing may also influence the results of stain etching. Regarding the identification of $\sigma$ phase, no references 
are available for the effect of type, size, distribution, or chemical composition of $\sigma$ phase on the results of the color stain etching. Additional study is needed to enhance understanding of the color stain-etching technique. Although $\mathrm{Cr}$ carbides and $\sigma$ phase still remain after solution annealing at $2100^{\circ} \mathrm{F} / 1150^{\circ} \mathrm{C}$ and $2200^{\circ} \mathrm{F} / 1205^{\circ} \mathrm{C}$, it is considered that the extent of $\mathrm{Cr}$ and/or Mo depletion in the regions surrounding $\mathrm{Cr}$ carbides or $\sigma$ phase is reduced after solution annealing. Therefore, the localized corrosion resistance is significantly improved after solution annealing (see Table A1 in Appendix A).

Figure 80 presents the $\mathrm{X}$-ray diffraction results for the solution-annealed CK$3 \mathrm{MCuN}$ Heat $3 \mathrm{SA}$ at $2300^{\circ} \mathrm{F} / 1260^{\circ} \mathrm{C}$ (followed by water quenching). It is evident that only $\mathrm{Cr}$ carbides and Fe carbides are present. There is no evidence for the presence of $\sigma$ phase. This X-ray diffraction result is consistent with the results of the microstructural evaluation.

In order to define the effect of cooling rate on microstructure of the high Mo stainless steel castings, a solution-annealing treatment $\left(2300^{\circ} \mathrm{F} / 1260^{\circ} \mathrm{C}\right)$ with slow cooling was conducted at UT. The X-ray diffraction specimen for the slow cooling study was also extracted from $\mathrm{CK}-3 \mathrm{MCuN}$ Heat 3 . Figure 81 shows the X-ray diffraction results for CK-3MCuN Heat 3 after $2300^{\circ} \mathrm{F} / 1260^{\circ} \mathrm{C}$ solution annealing followed by slow cooling. As presented in Figure 81, the major precipitates in the slowly cooled $\mathrm{CK}-3 \mathrm{MCuN}$ Heat 3 are $\mathrm{Cr}$ carbides and $\sigma$ phase, in addition to Fe carbides. It is to be noted that $\sigma$ phase was also identified using stain etching for the $\mathrm{CK}-3 \mathrm{MCuN}$ in the slow cooled condition. However, it should be recalled that the water quenched CK-3MCuN Heat 3 , after $2300^{\circ} \mathrm{F} / 1260^{\circ} \mathrm{C}$ 
solution annealing, shows no $\sigma$ phase. Thus, the results indicate that the formation of $\sigma$ phase in CK-3MCuN Heat 3 occurred during slow cooling from $2300^{\circ} \mathrm{F} / 1260^{\circ} \mathrm{C}$.

iii) $\underline{254 \text { SMO }}$

To compare the CK-3MCuN with its wrought counterpart 254SMO, the X-ray diffraction was conducted on $254 \mathrm{SMO}$, and the X-ray diffraction results are shown in Figure 82. For the wrought 254SMO, the two peaks shown in the X-ray diffraction spectrum were identified as $\mathrm{Fe}$ carbide $\left(\mathrm{Fe}_{3} \mathrm{C}\right)$. Based on the $\mathrm{X}$-ray diffraction results, only Fe carbides were found and there were no $\sigma$ phase, $\mathrm{Cr}$ carbides or any other secondary phases present. Without the precipitation of detrimental secondary phases (such as $\sigma$ phase and/or $\mathrm{Cr}$ carbides), excellent localized corrosion resistance should be expected.

\section{4-2 Microstructural Characterization of $\mathrm{CN}-3 \mathrm{MN}$}

\section{- Evaluation Using Optical Light Microscopy (OLM)}

Two heats of CN-3MN - N3GAO and N3GBO - extracted from cast bars, and three heats of $\mathrm{CN}-3 \mathrm{MN}$ - Heat 1, Heat 4, and Heat 5 - extracted from cast wedge blocks, were used in this study. Microstructural evaluation was conducted in the as-cast and solution-annealed (SA) condition for each heat. It is to be noted that the UT solution annealing (SA) was conducted at temperatures of 


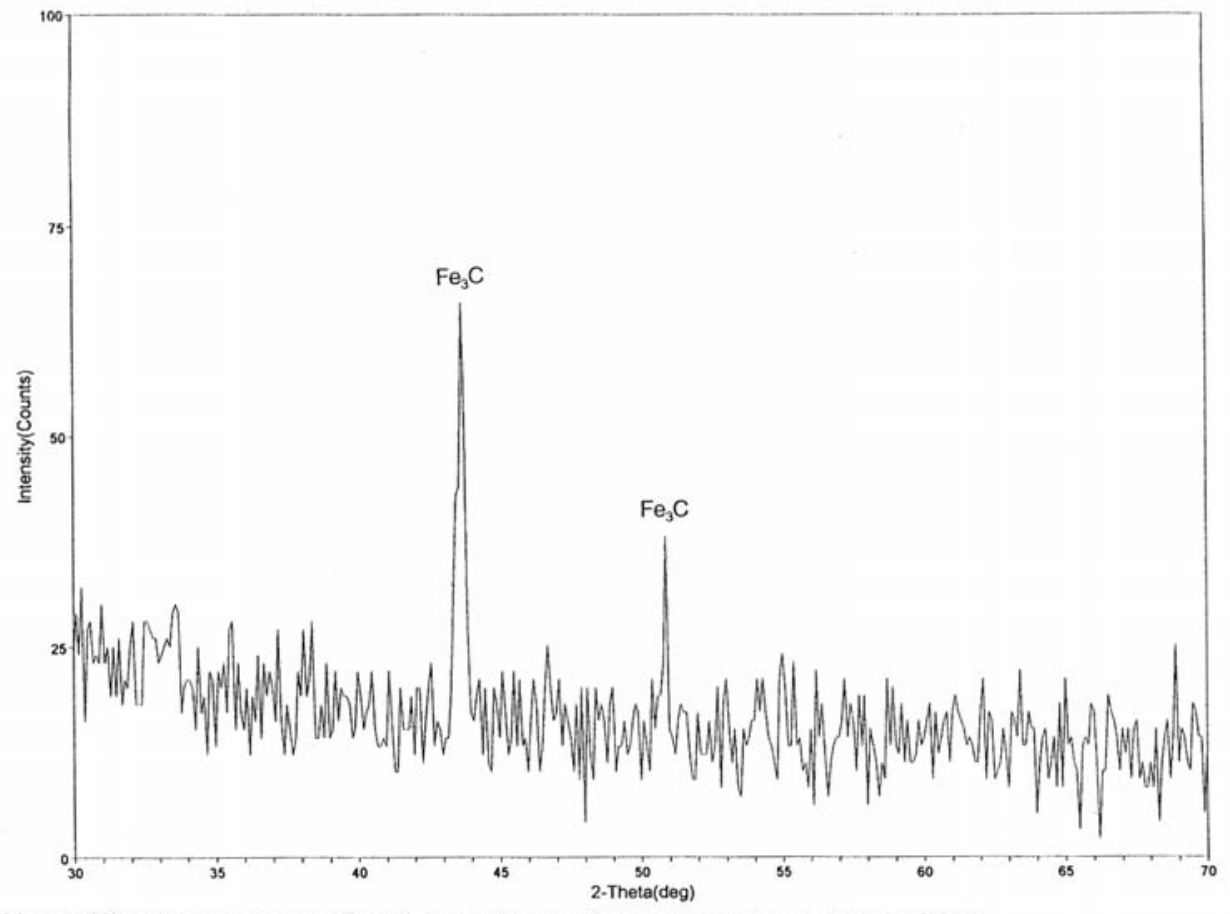

Figure 82. X-ray diffraction spectrum of particles extracted from wrought material 254SMO. 
and $2300^{\circ} \mathrm{F} / 1260^{\circ} \mathrm{C}$ followed by water quenching (WQ) for all five heats and followed by slow cooling (SC, from $2300^{\circ} \mathrm{F} / 1260^{\circ} \mathrm{C}$ only) for Heat N3GAO. Foundry solution annealing was conducted at the temperatures of $2150^{\circ} \mathrm{F} / 1180^{\circ} \mathrm{C}, 2135^{\circ} \mathrm{F} / 1170^{\circ} \mathrm{C}$ and $2250^{\circ} \mathrm{F} / 1230^{\circ} \mathrm{C}$ followed by $\mathrm{WQ}$ for Heats 1,4 , and 5 , respectively. The UT SA was also conducted at $2200^{\circ} \mathrm{F} / 1205^{\circ} \mathrm{C}$ (WQ) for Heat N3GAO and Heat N3GBO to simulate the foundry SA. Solution annealing temperatures used by UT and foundries for $\mathrm{CN}-3 \mathrm{MN}$ are listed in Table 4. Metallographic evaluation was initiated using OLM and stain-etching techniques.

The microstructure of the as-cast $\mathrm{CN}-3 \mathrm{MN}$ is shown in Figures 83 through 87 for Heat N3GCOA, N3GCOB, Heat 1 , Heat 4 , and Heat 5 , respectively. It is evident that the microstructures are identical for Heat N3GCOA, N3GCOB, Heat 1 and Heat 4 in the as-cast condition. The irregular-shaped secondary phases within the "islands" were observed in interdendritic regions and along grain boundaries. A cluster of block-like and/or irregular-shaped secondary phases, as well as dark globular particles, were also observed in the matrix for both heats. Compared to the four heats above, as-cast Heat 5 shows no irregular- shaped secondary phases within the "islands" and only dark globular particles were found in the matrix of this heat as shown in Figure 87. It is to be noted that, compared to the other four heats [Heat N3GAO $(0.027 \% \mathrm{C}, 6.65 \% \mathrm{Mo}, 0.14 \% \mathrm{Cu}$ \& $0.50 \% \mathrm{Mn})$, Heat N3GBO $(0.023 \% \mathrm{C}, 6.14 \% \mathrm{Mo}, 0.25 \% \mathrm{Cu} \& 0.59 \% \mathrm{Mn}$, Heat 1 (0.026\%C, 7.17\%Mo, 0.48\%Cu \& 0.73\%Mn) and Heat 4 (0.019\% C, 7.24\% Mo, $0.20 \% \mathrm{Cu} \& 0.80 \% \mathrm{Mn})$, Heat 5 shows the lowest $\mathrm{C}, \mathrm{Mo}, \mathrm{Cu}$ and $\mathrm{Mn}$ content 


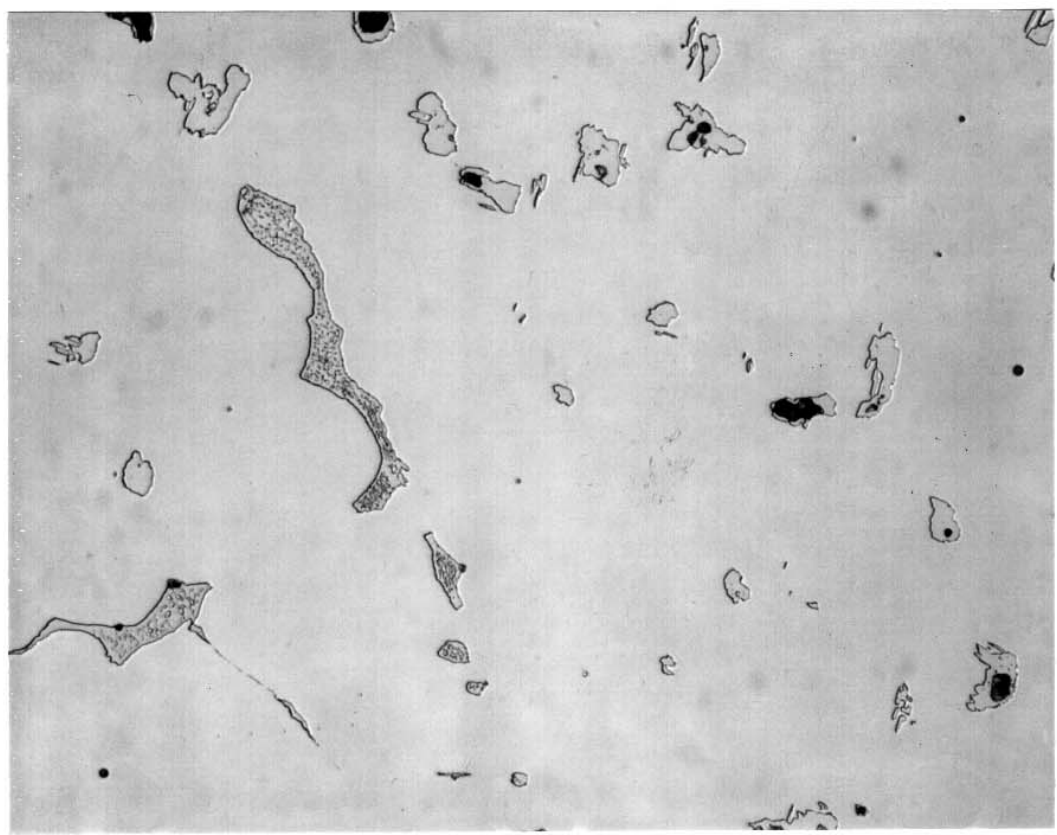

$400 x$

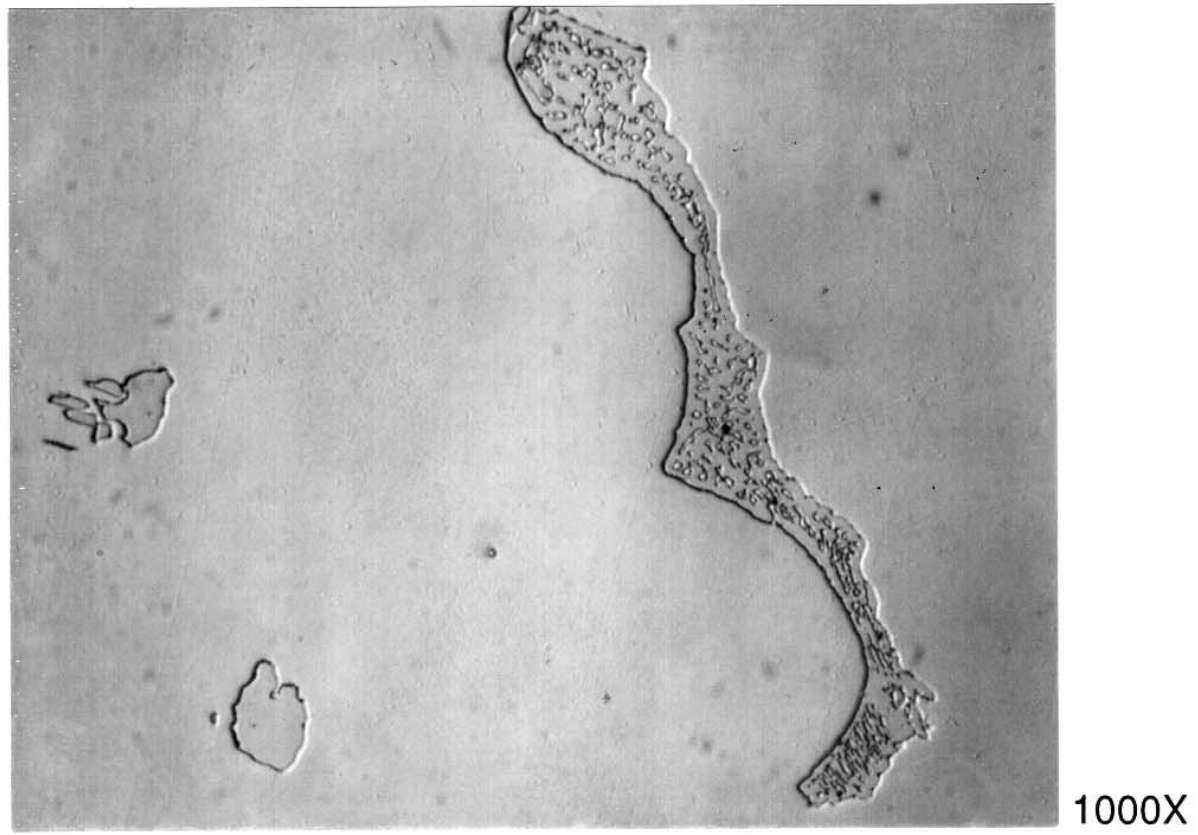

Figure 83. Microstructure of as-cast CN-3MN Heat N3GAO 

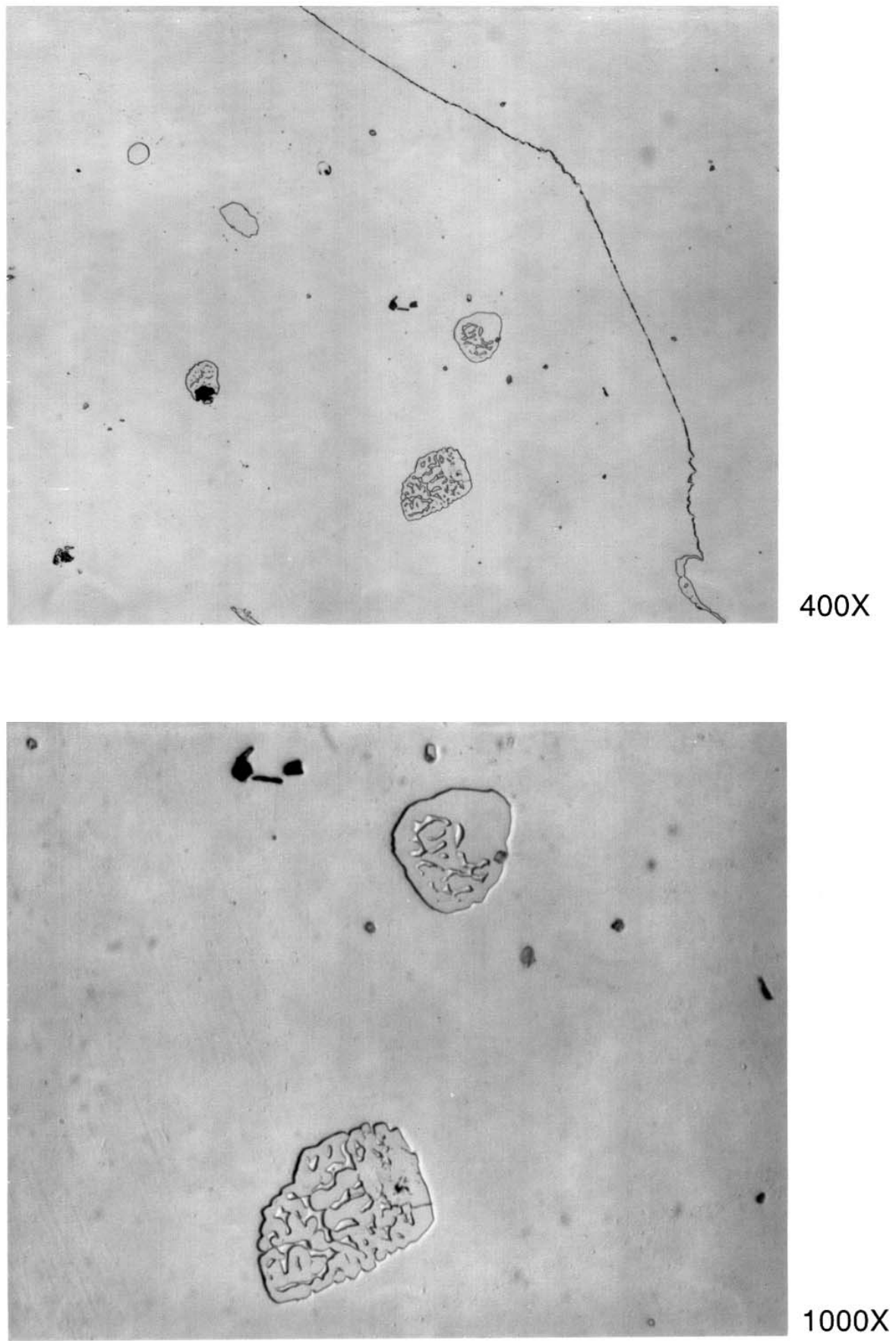

Figure 84. Microstructure of as-cast CN-3MN Heat N3GBO 


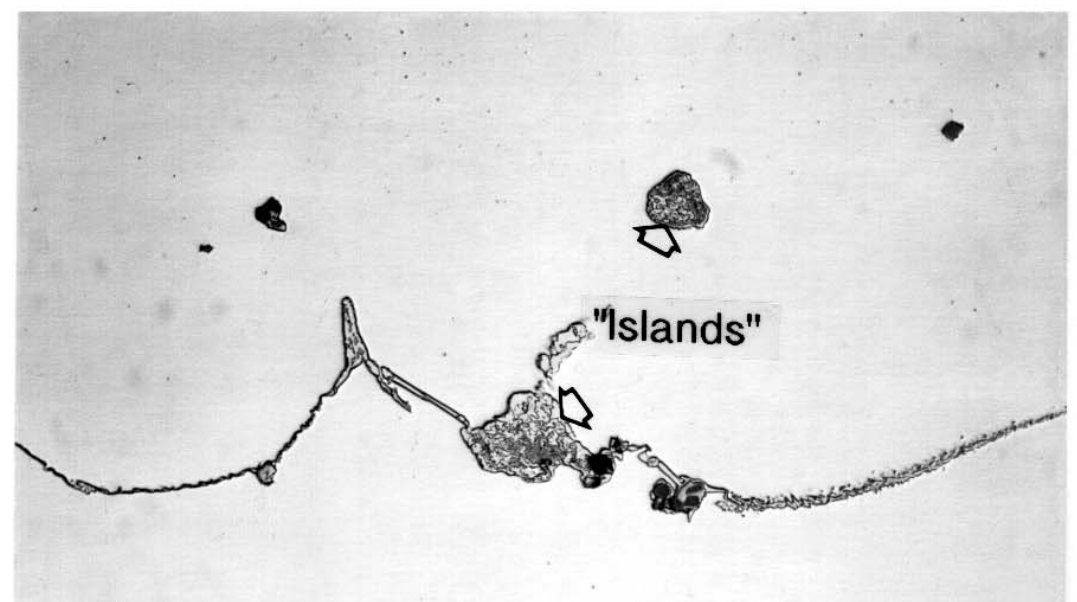

6

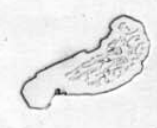

$400 X$

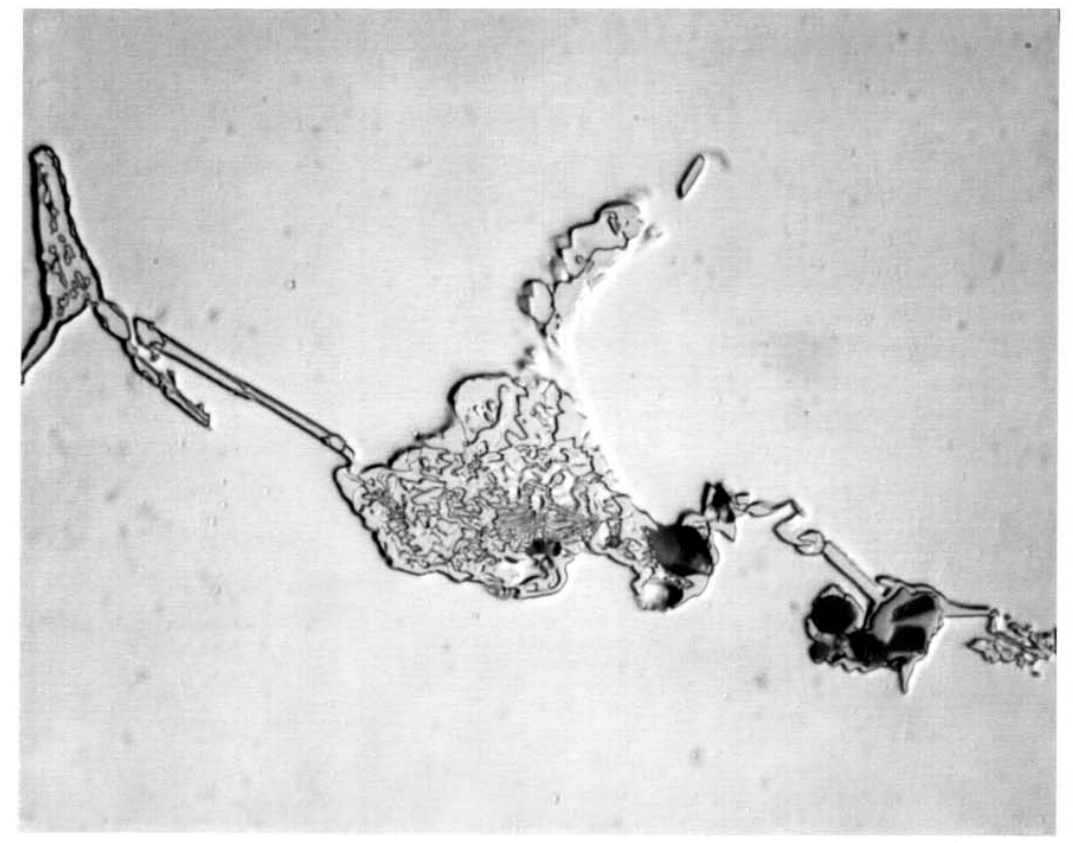

$1000 X$

Figure 85. Microstructure of as-cast $\mathrm{CN}-3 \mathrm{MN}$ Heat 1 

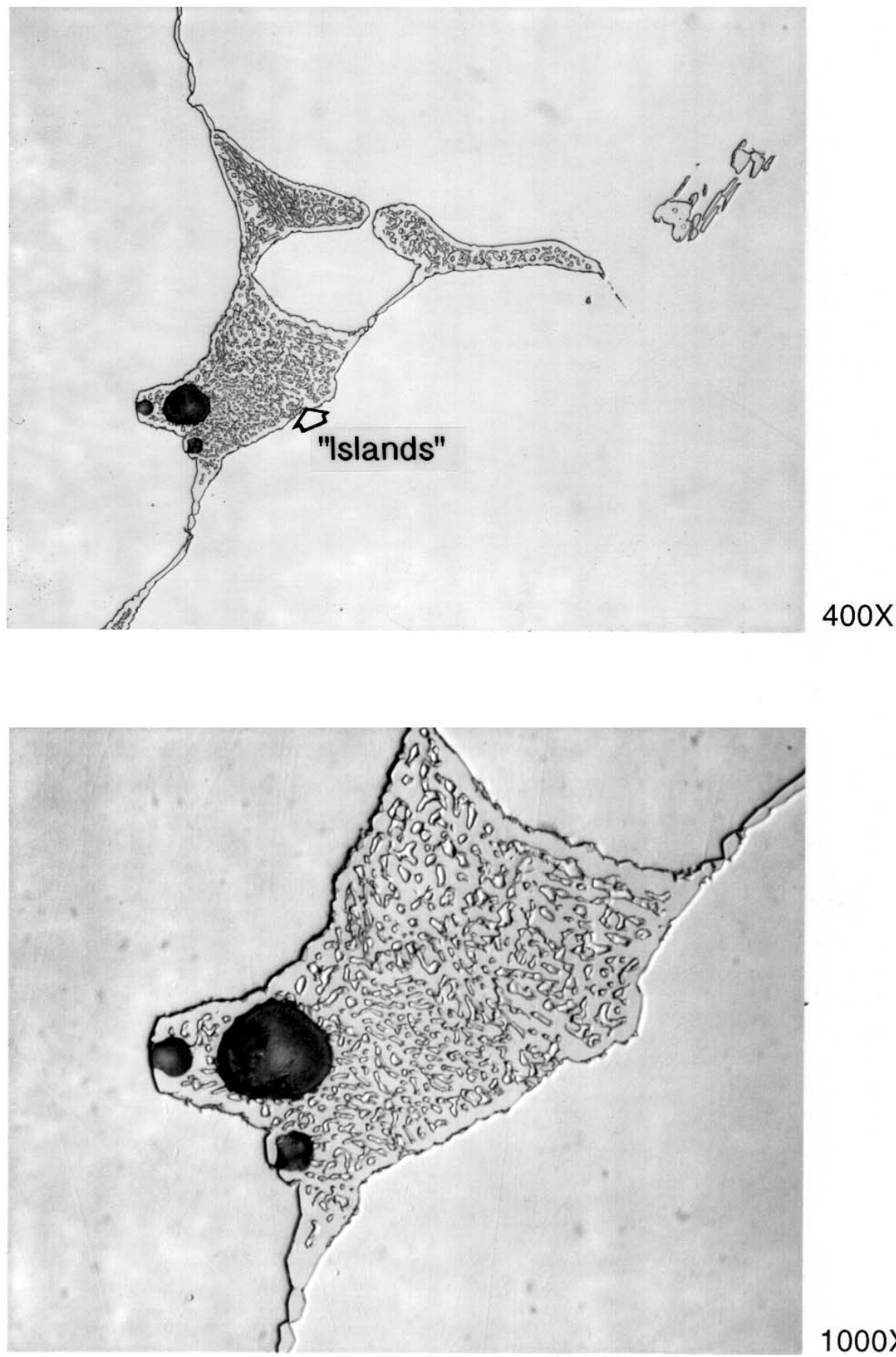

Figure 86. Microstructure of as-cast $\mathrm{CN}-3 \mathrm{MN}$ Heat 4 


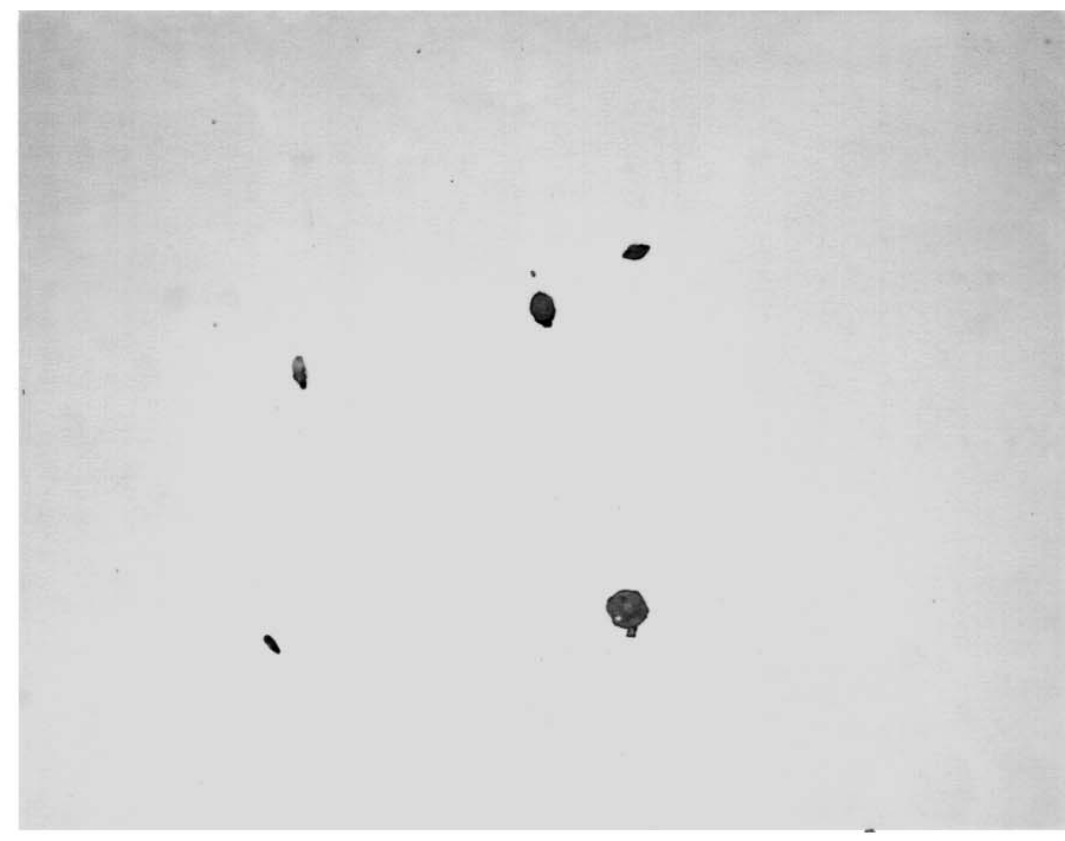

$400 X$

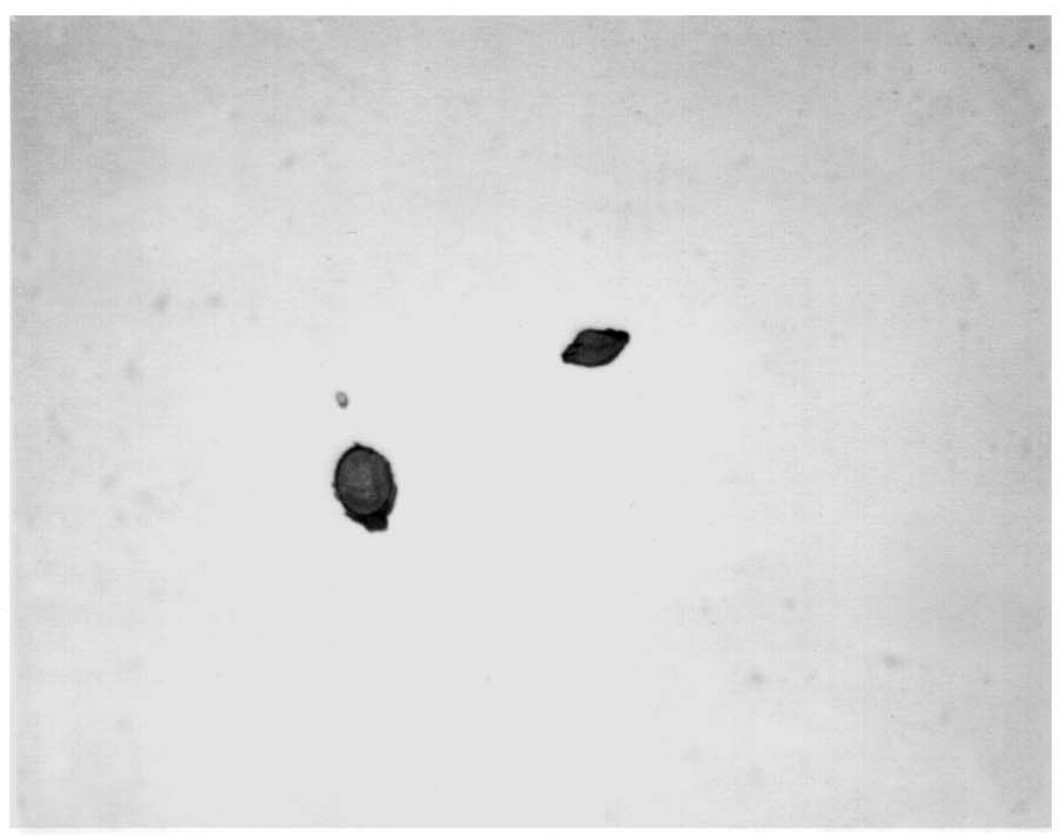

$1000 X$

Figure 87. Microstructure of as-cast CN-3MN Heat 5 
$(0.017 \% \mathrm{C}, 5.94 \% \mathrm{Mo}, 0.05 \% \mathrm{Cu} \& 0.15 \% \mathrm{Mn})$ as illustrated in Table 2 . It is believed that the chemical composition has a significant influence on the formation of secondary precipitates in the castings. However, more detailed studies are necessary to understand the effect of alloying elements on the formation of secondary phases in this alloy system.

For $2100^{\circ} \mathrm{F} / 1150^{\circ} \mathrm{C}$ solution-annealed $\mathrm{CN}-3 \mathrm{MN}$, Figures 88 though 92 present the microstructure for the five heats, respectively. In comparison with the microstructure of the as-cast $\mathrm{CN}-3 \mathrm{MN}$, the secondary phases were partially dissolved during $2100^{\circ} \mathrm{F} / 1150^{\circ} \mathrm{C} \mathrm{SA}$. A certain amount of irregular-shaped secondary phases are still observed after the $2100^{\circ} \mathrm{F} / 1150^{\circ} \mathrm{C} \mathrm{SA}$ for the four heats (Heat N3GCOA, N3GCOB, Heat 1 \& Heat 4) as shown in Figures 88 through 91 . The dark globular particles remain un-changed for these four heats after a $2100^{\circ} \mathrm{F} / 1150^{\circ} \mathrm{C}$ SA. On the other hand, no change was found in microstructure of $2100^{\circ} \mathrm{F} / 1150^{\circ} \mathrm{C}$ solution- annealed Heat 5 compared to that of the as-cast Heat 5 as shown in Figure 92.

The microstructure of $2200^{\circ} \mathrm{F} / 1205^{\circ} \mathrm{C}$ solution-annealed (by the UT) $\mathrm{CN}-3 \mathrm{MN}$ is shown in Figures 93 and 94 for Heat N3GCOA and Heat N3GCOB, while the microstructure of $2150^{\circ} \mathrm{F} / 1180^{\circ} \mathrm{C}, 2135^{\circ} \mathrm{F} / 1170^{\circ} \mathrm{C}$ and $2250^{\circ} \mathrm{F} / 1230^{\circ} \mathrm{C}$ solutionannealed (by foundries) $\mathrm{CN}-3 \mathrm{MN}$ is shown in Figures 95 through 97 for Heat 1 $\left(2150^{\circ} \mathrm{F} / 1180^{\circ} \mathrm{C}+\mathrm{WQ}\right)$, Heat $4\left(2135^{\circ} \mathrm{F} / 1170^{\circ} \mathrm{C}+\mathrm{WQ}\right)$ and Heat $5\left(2250^{\circ} \mathrm{F}\right.$ $/ 1230^{\circ} \mathrm{C}+\mathrm{WQ}$ ). Compared to $2100^{\circ} \mathrm{F} / 1150^{\circ} \mathrm{C} \mathrm{SA}$, a similar microstructural morphology was revealed, but the amount of the secondary phase 

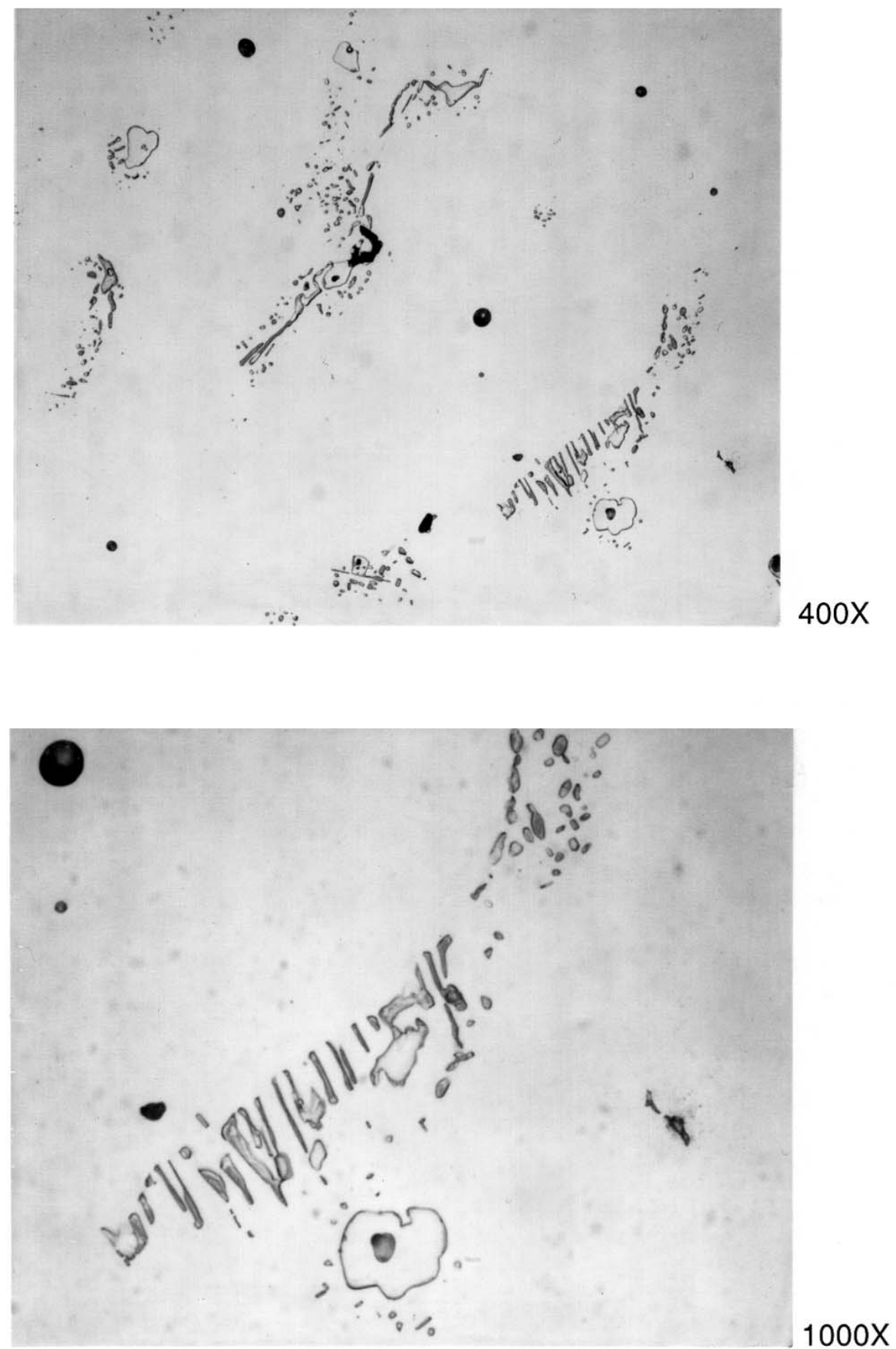

Figure 88. Microstructure of UT solution annealed $\left(2100^{\circ} \mathrm{F}+\mathrm{WQ}\right)$ $\mathrm{CN}-3 \mathrm{MN}$ Heat N3GAO 


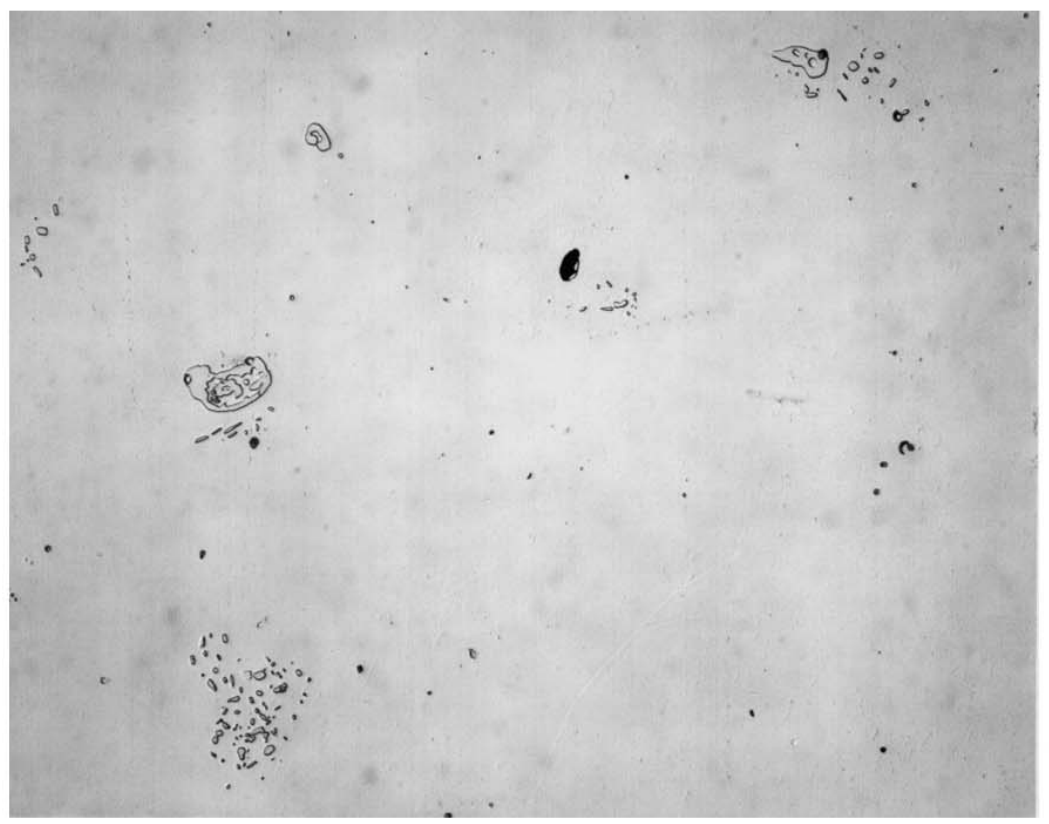

$400 x$

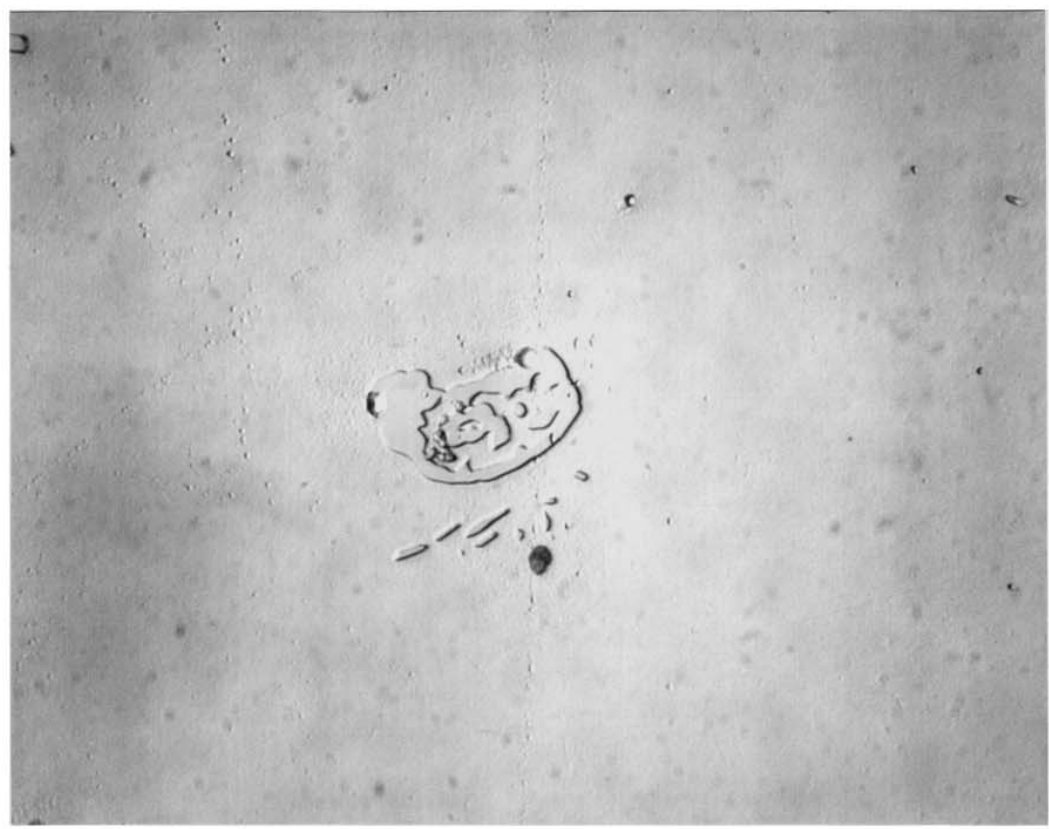

$1000 X$

Figure 89. Microstructure of UT solution annealed $\left(2100^{\circ} \mathrm{F}+\mathrm{WQ}\right)$ CN-3MN Heat N3GBO 

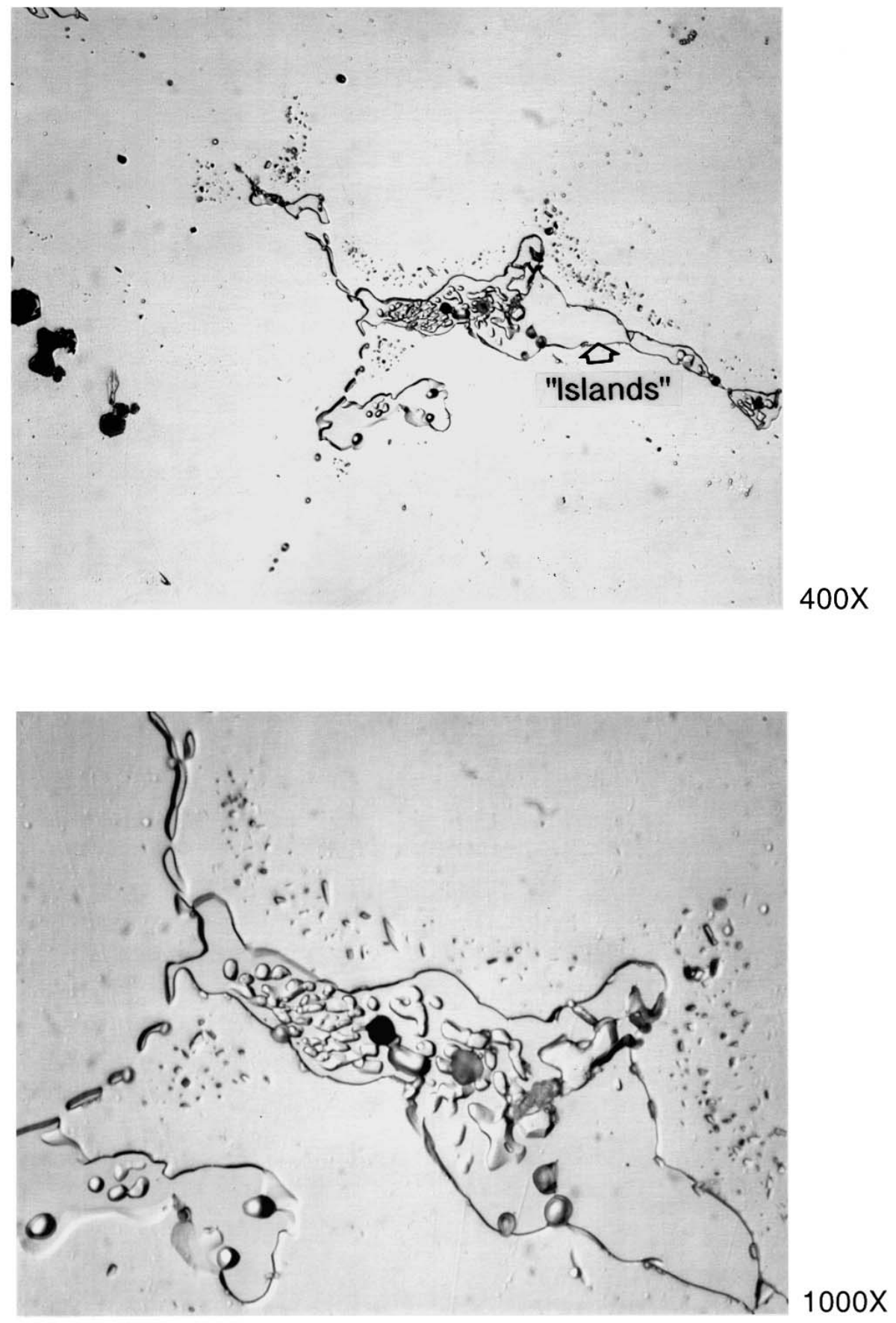

Figure 90. Microstructure of UT solution annealed $\left(2100^{\circ} \mathrm{F}+\mathrm{WQ}\right)$ $\mathrm{CN}-3 \mathrm{MN}$ Heat 1 


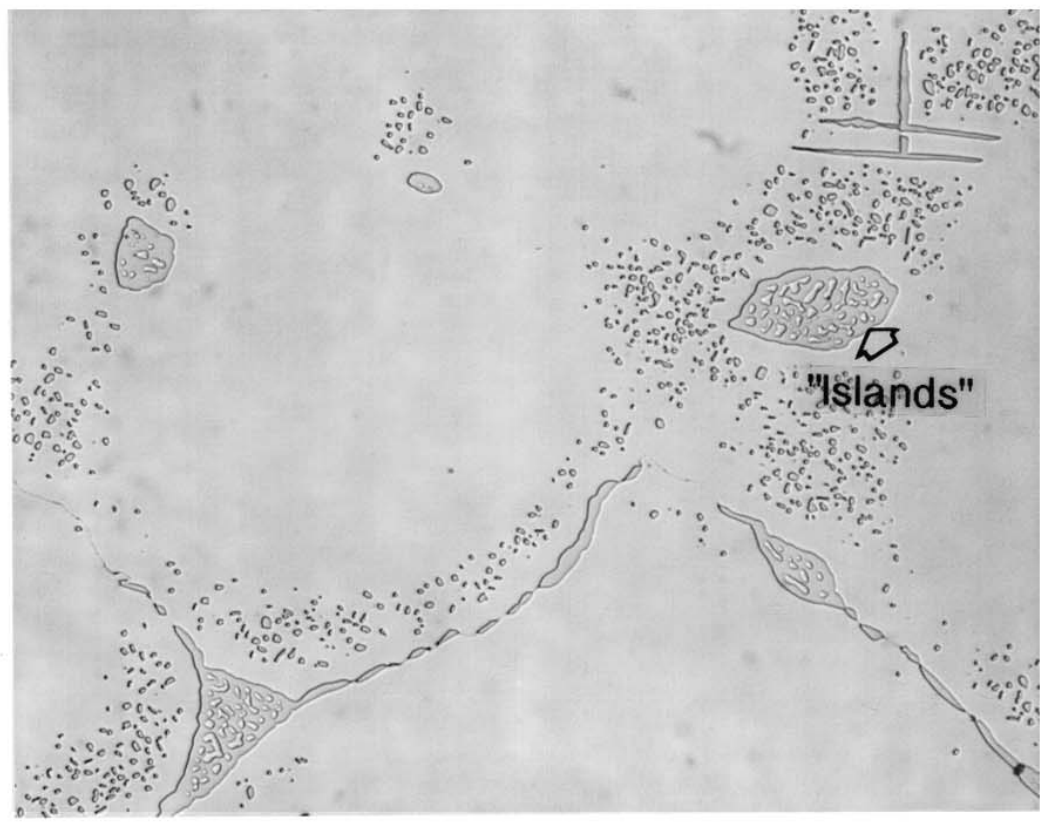

$400 X$

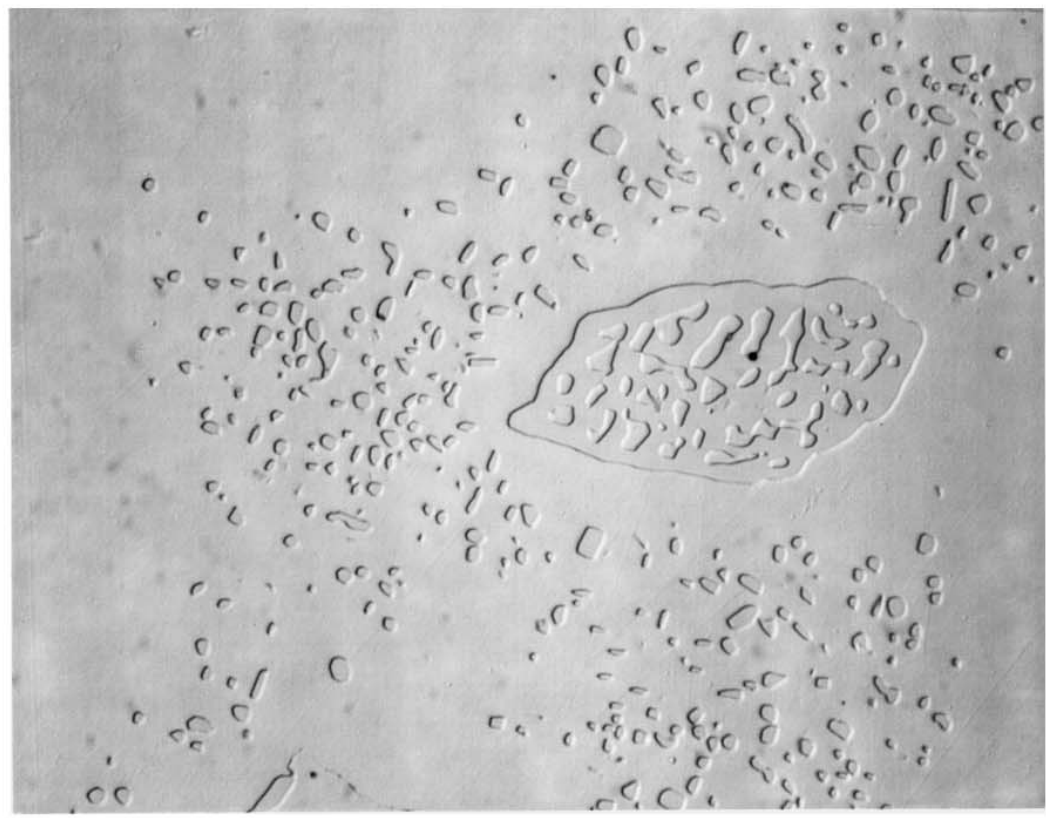

$1000 \mathrm{X}$

Figure 91. Microstructure of UT solution annealed $\left(2100^{\circ} \mathrm{F}+\mathrm{WQ}\right)$ $\mathrm{CN}-3 \mathrm{MN}$ Heat 4 

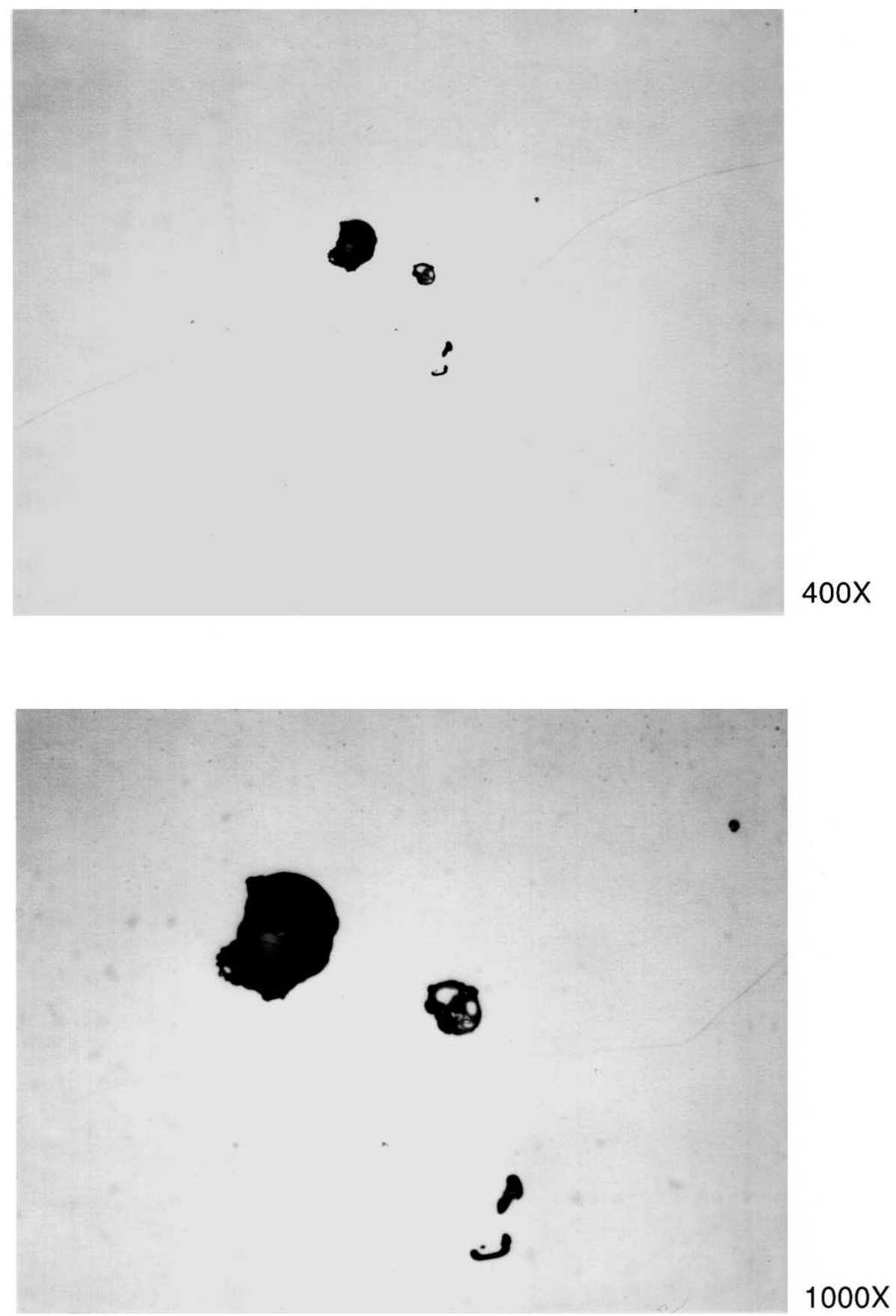

Figure 92. Microstructure of UT solution annealed (2100 $\left.{ }^{\circ} \mathrm{F}+\mathrm{WQ}\right)$ $\mathrm{CN}-3 \mathrm{MN}$ Heat 5 

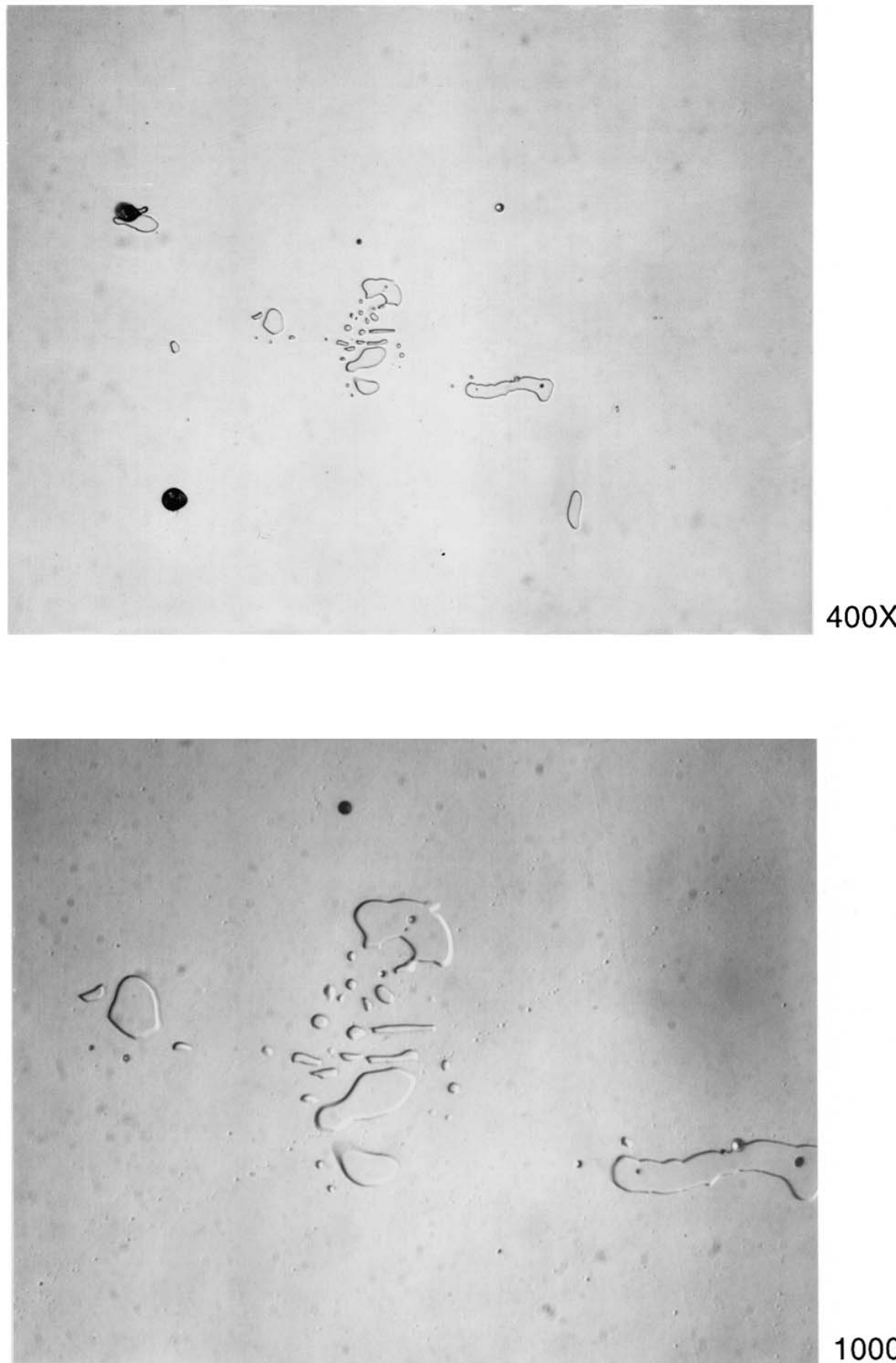

$1000 x$

Figure 93. Microstructure of UT solution annealed $\left(2200^{\circ} \mathrm{F}+\mathrm{WQ}\right)$ $\mathrm{CN}-3 \mathrm{MN}$ Heat N3GAO 

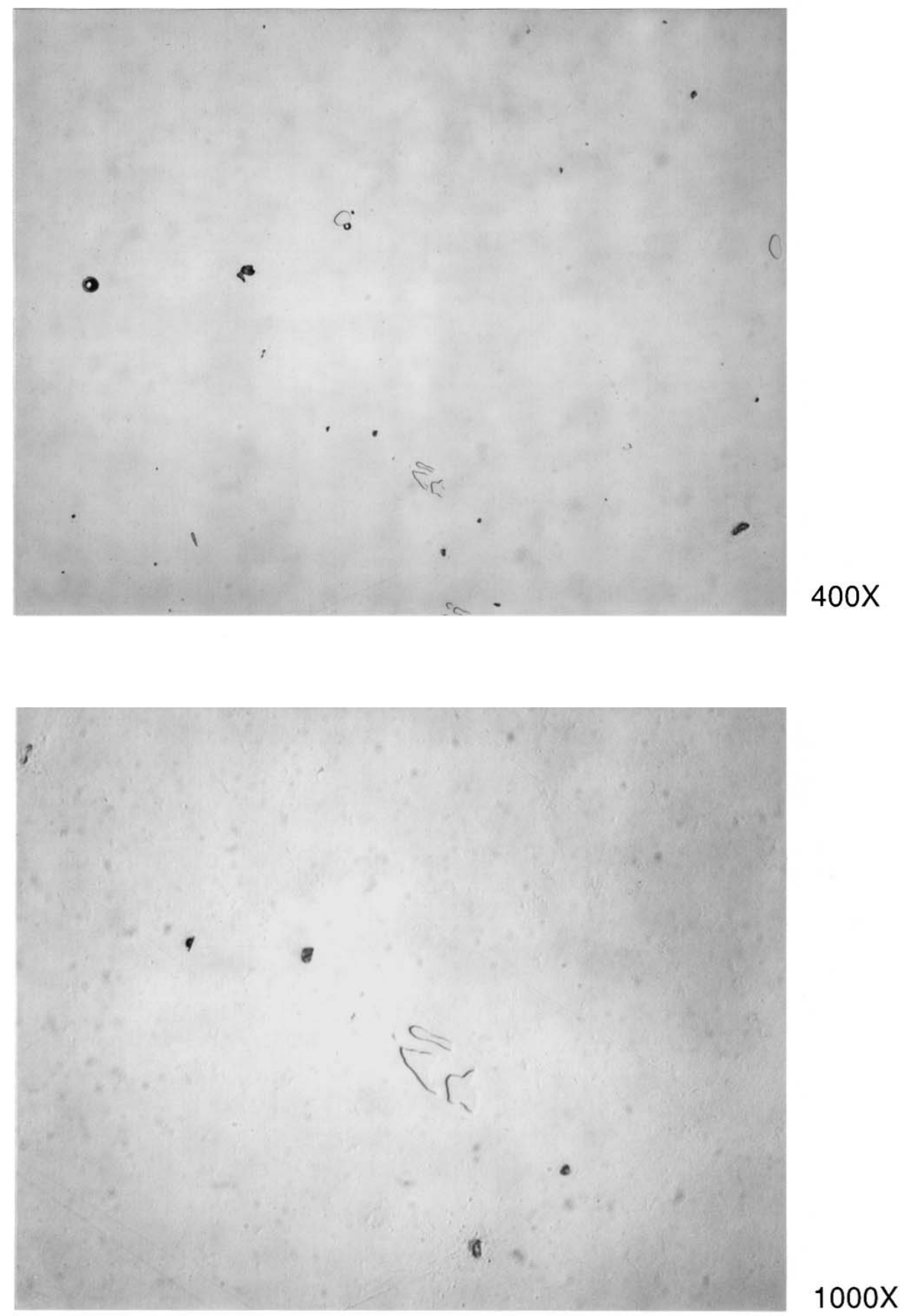

Figure 94. Microstructure of UT solution annealed $\left(2200^{\circ} \mathrm{F}+\mathrm{WQ}\right)$ $\mathrm{CN}-3 \mathrm{MN}$ Heat K3GBO 

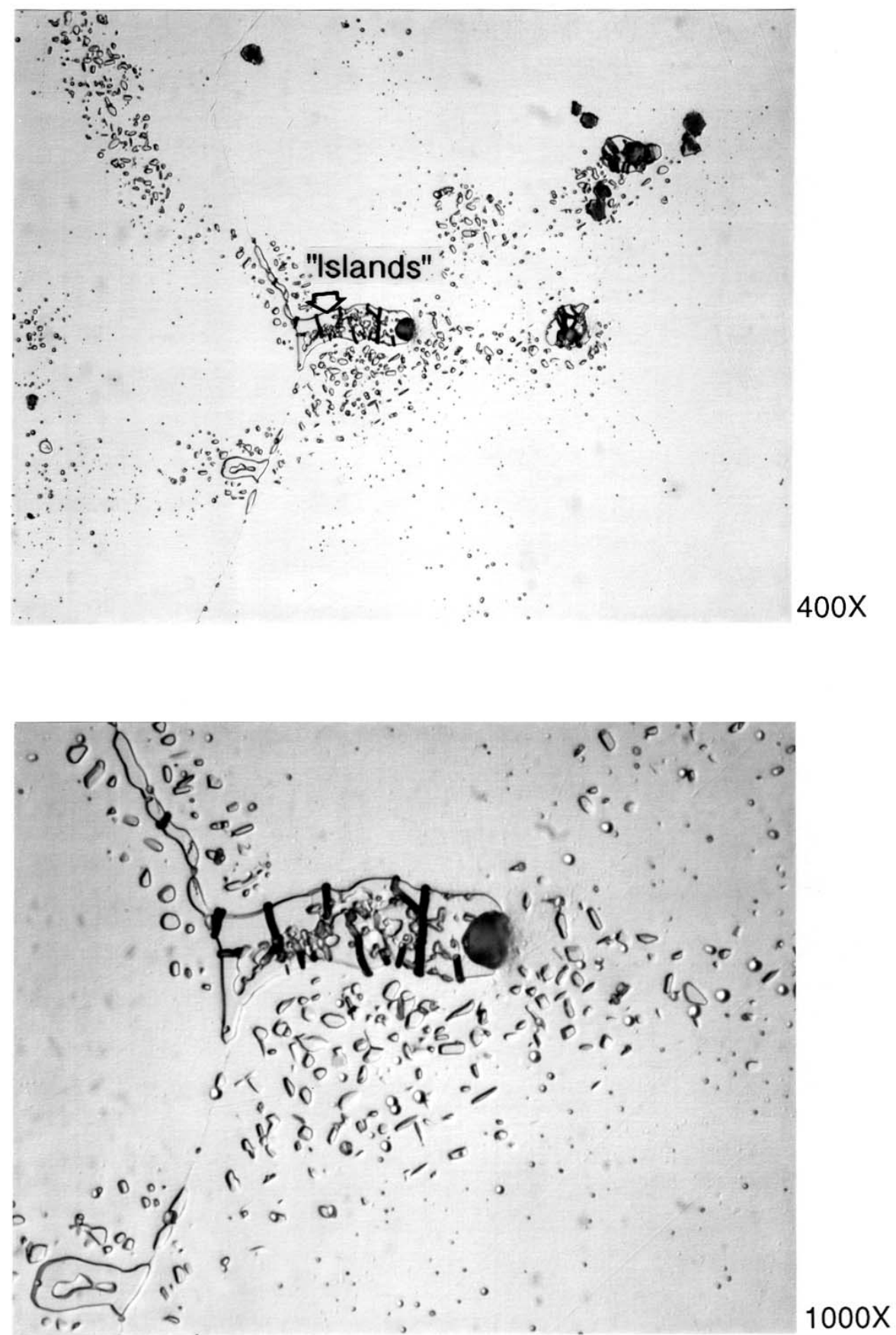

Figure 95. Microstructure of foundry solution annealed $\left(2150^{\circ} \mathrm{F}+\mathrm{WQ}\right)$ $\mathrm{CN}-3 \mathrm{MN}$ Heat 1 

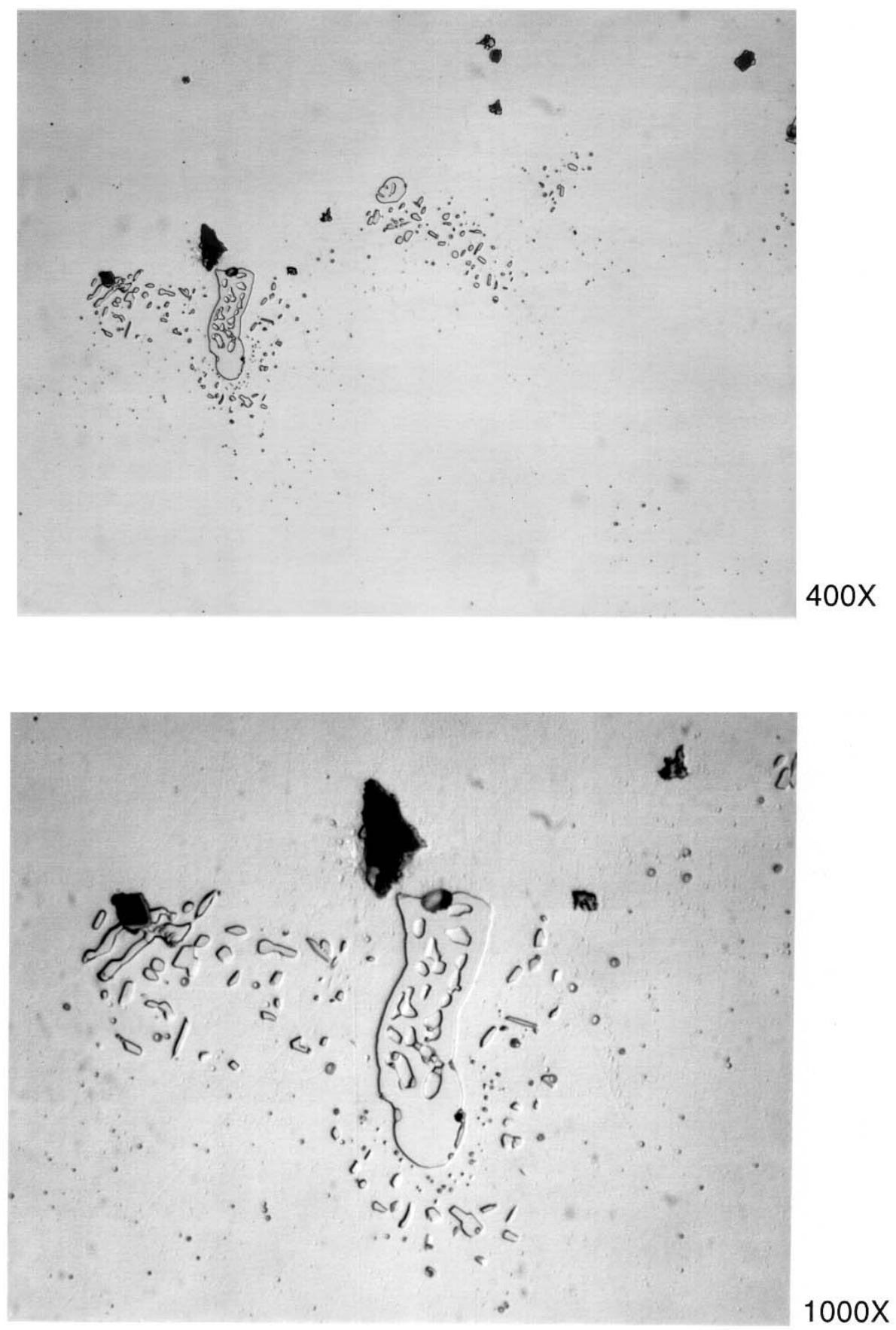

Figure 96. Microstructure of foundry solution annealed $\left(2135^{\circ} \mathrm{F}+\mathrm{WQ}\right)$ $\mathrm{CN}-3 \mathrm{MN}$ Heat 4 

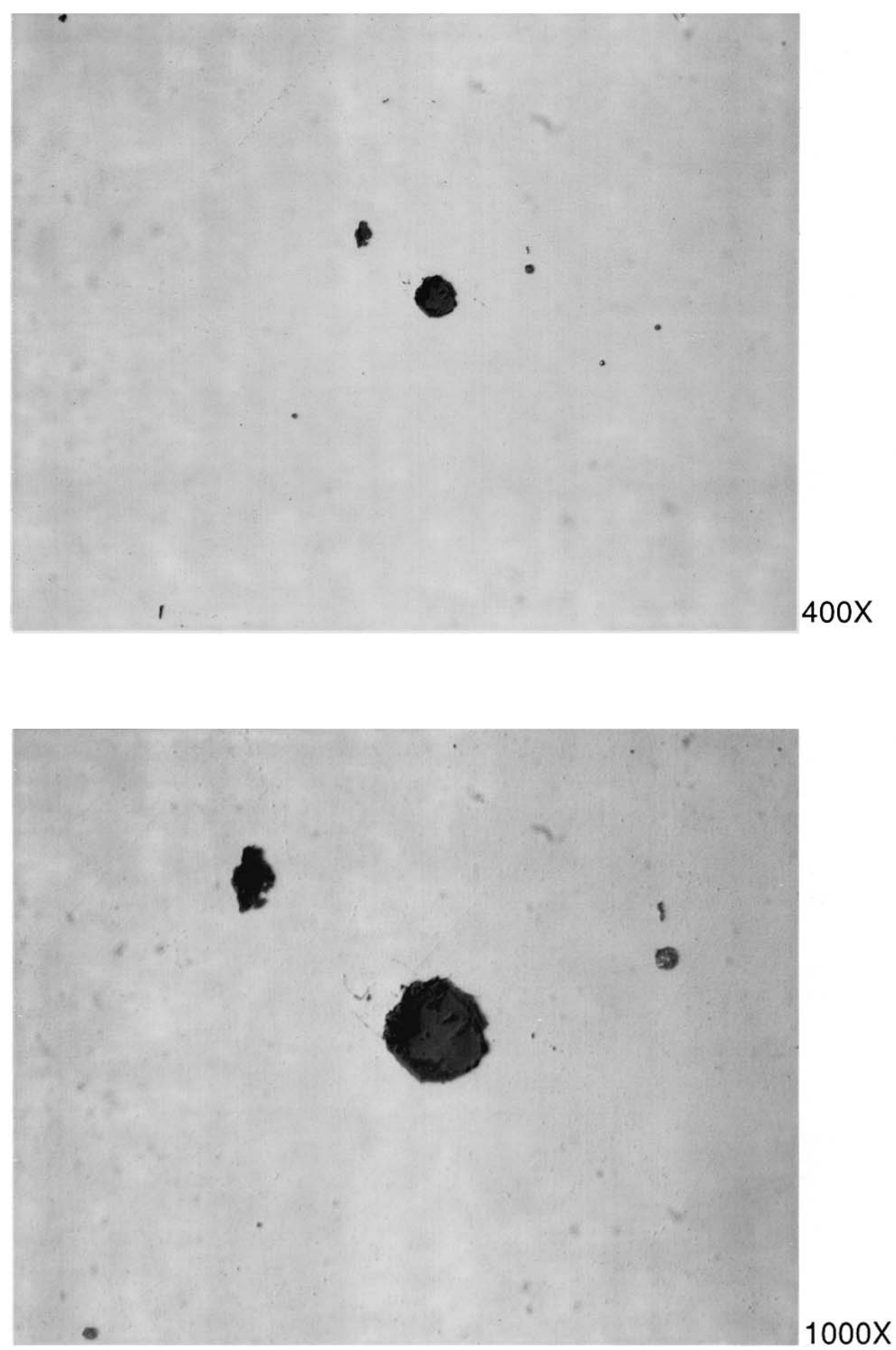

Figure 97. Microstructure of foundry solution annealed $\left(2250^{\circ} \mathrm{F}+\mathrm{WQ}\right)$ $\mathrm{CN}-3 \mathrm{MN}$ Heat 5 
is generally reduced after SA in the temperature range of 2150 to $2250^{\circ} \mathrm{F}$ $\left(1180^{\circ} \mathrm{C}\right.$ to $\left.1230^{\circ} \mathrm{C}\right)$.

When the SA temperature was increased to $2300^{\circ} \mathrm{F} / 1260^{\circ} \mathrm{C}$, the secondary phases were completely dissolved, only dark globular particles were observed in the matrix for the most heats (Heat N3GAO, Heat N3GBO and Heat 1) as present in Figures 98 through 100. However, the secondary phases were still observed in Heat 4 after $2300^{\circ} \mathrm{F} / 1260^{\circ} \mathrm{C}$ SA (see Figure 101). This implies that solution-annealing temperature has a significant influence on the microstructure of SA cast materials. It should be noted that the microstructure of Heat 5 remain unchanged regardless the solution anneal conditions (see Figures 92, 97 \&102).

To determine the ferrite level in the $\mathrm{CN}-3 \mathrm{MN}$ cast materials, ferrite measurement was conducted on all five heats of $\mathrm{CN}-3 \mathrm{MN}$ in the as-cast and solution-annealed conditions using the Fisher Feritscope. The results show no ferrite detected in $\mathrm{CN}-3 \mathrm{MN}$ under any conditions.

The microstructure of wrought counterpart $(A L-6 X N)$ is presented in Figure 103. It is evident that austenite (with annealing twins) is the predominant microstructural constituent for AL-6XN without the presence of any secondary phases. Ferrite measurement shows $0 \%$ ferrite in AL-6XN.

To identify $\sigma$ phase, stain-etching techniques were applied to two heats of CN-3MN (Heat N3GAO \& Heat 4) in both the as-cast and solution-annealed conditions. The microstructure of the stain-etched Heat N3GAO is shown in Figures 104 through 106 for the as-cast, $2100^{\circ} \mathrm{F} / 1150^{\circ} \mathrm{C}$ SA (WQ) and $2300^{\circ} \mathrm{F} / 1260^{\circ} \mathrm{C} \mathrm{SA}(\mathrm{WQ})$ conditions. For the as-cast condition, the irregular- 

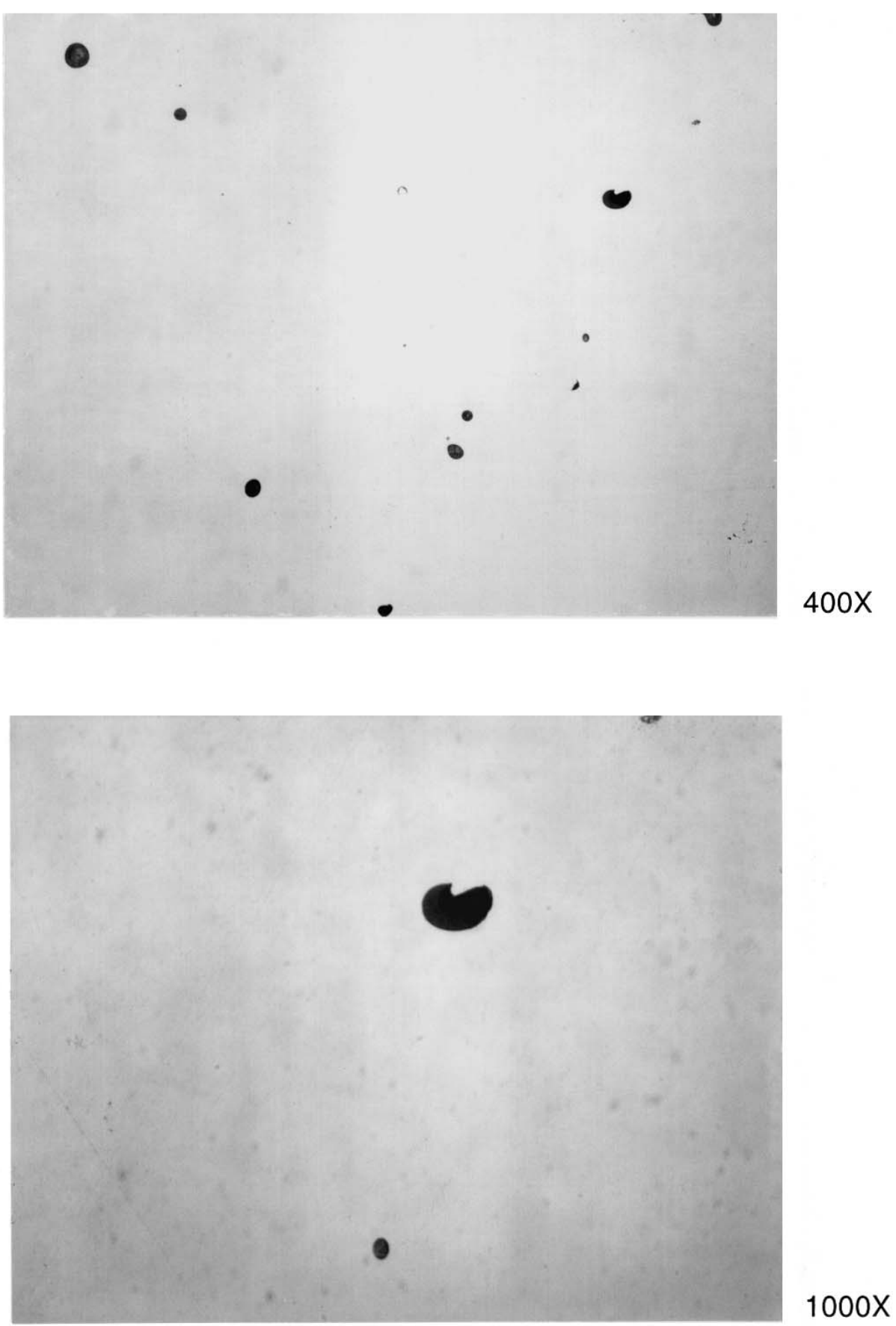

Figure 98. Microstructure of UT solution annealed $\left(2300^{\circ} \mathrm{F}+\mathrm{WQ}\right)$ CN-3MN Heat N3GAO 

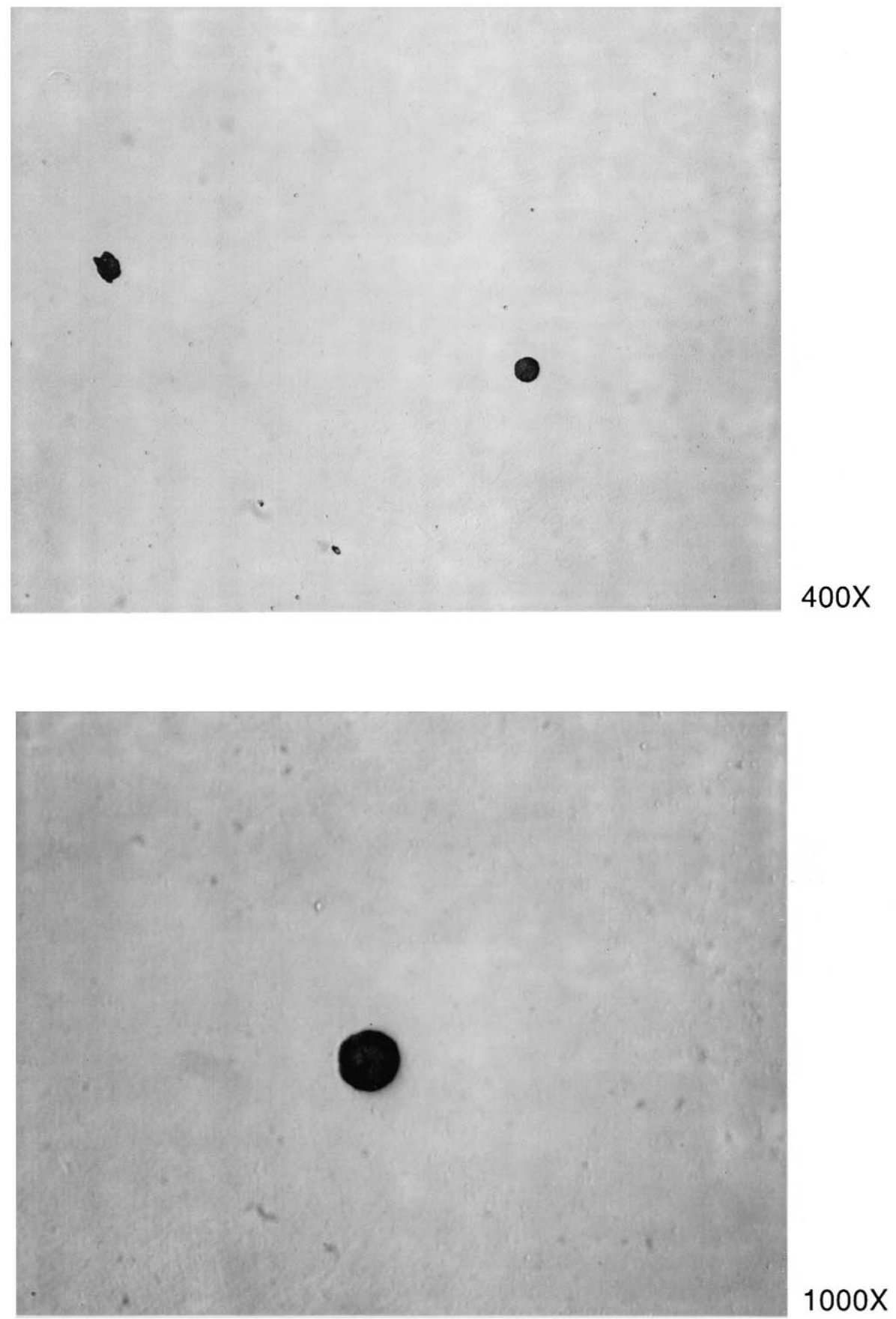

Figure 99. Microstructure of UT solution annealed $\left(2300^{\circ} \mathrm{F}+\mathrm{WQ}\right)$ CN-3MN Heat N3GBO 

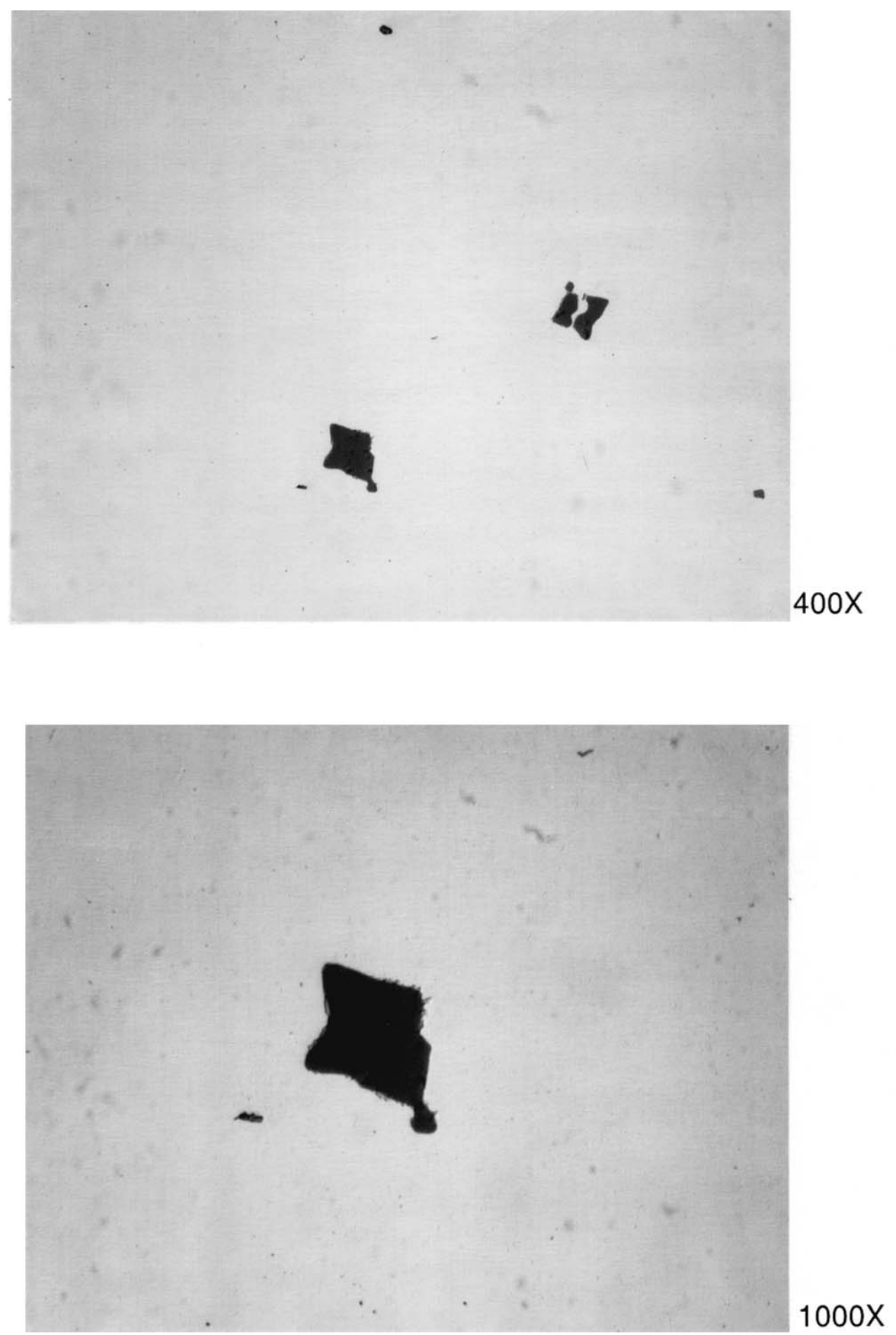

Figure 100. Microstructure of UT solution annealed $\left(2300^{\circ} \mathrm{F}+\mathrm{WQ}\right)$ $\mathrm{CN}-3 \mathrm{MN}$ Heat 1 

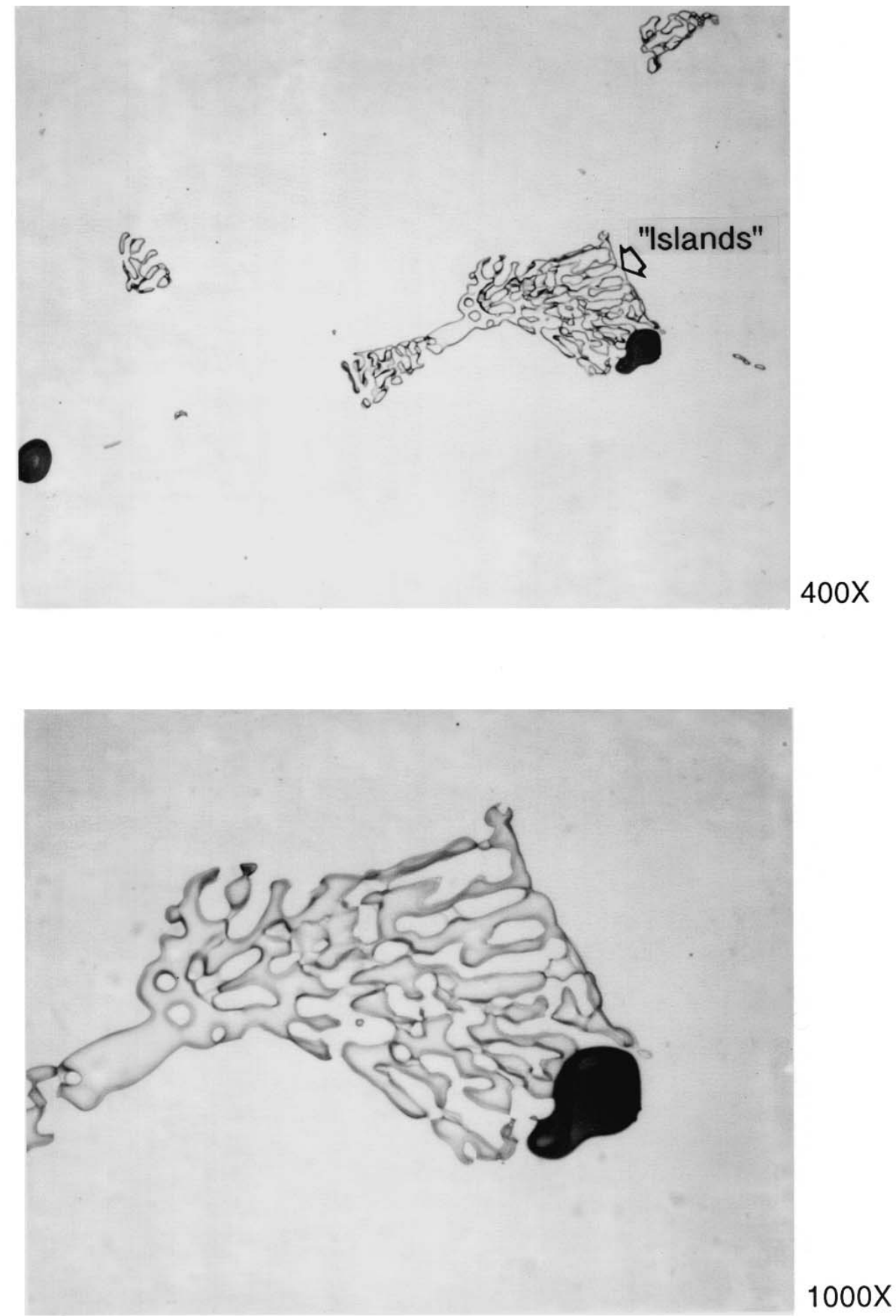

Figure 101. Microstructure of UT solution annealed $\left(2300^{\circ} \mathrm{F}+\mathrm{WQ}\right)$ $\mathrm{CN}-3 \mathrm{MN}$ Heat 4 

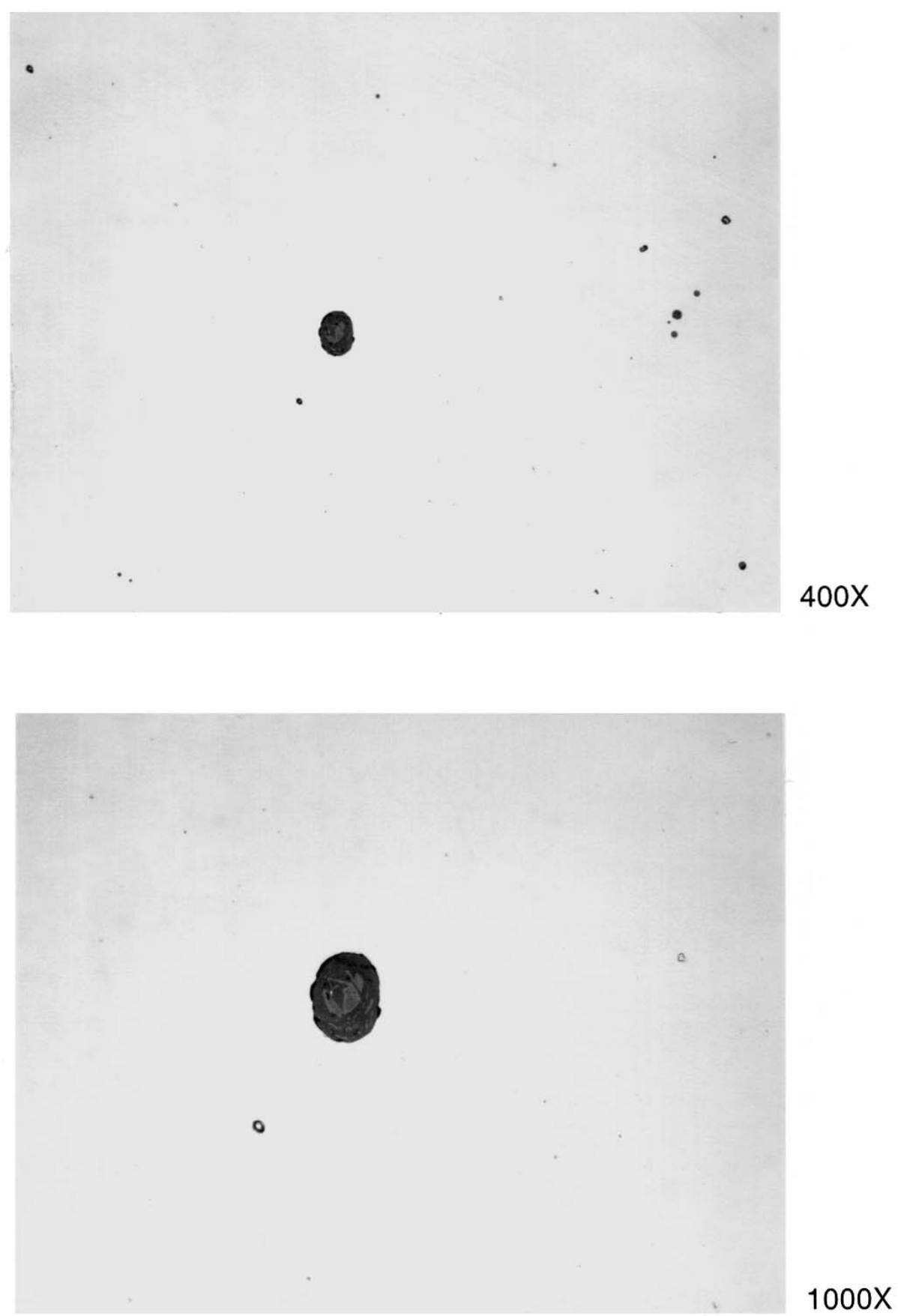

Figure 102. Microstructure of UT solution annealed $\left(2300^{\circ} \mathrm{F}+\mathrm{WQ}\right)$ $\mathrm{CN}-3 \mathrm{MN}$ Heat 5 


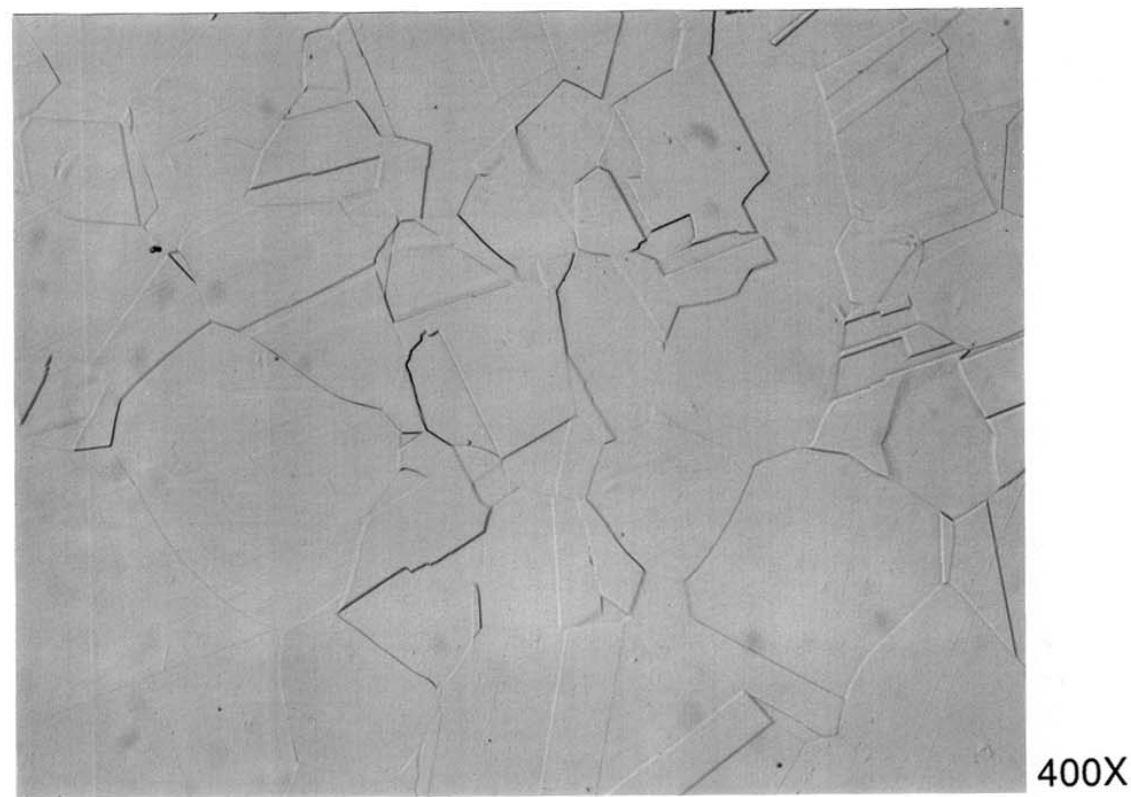

Figure 103. Microstructure of wrought counterpart alloy AL-6XN. 


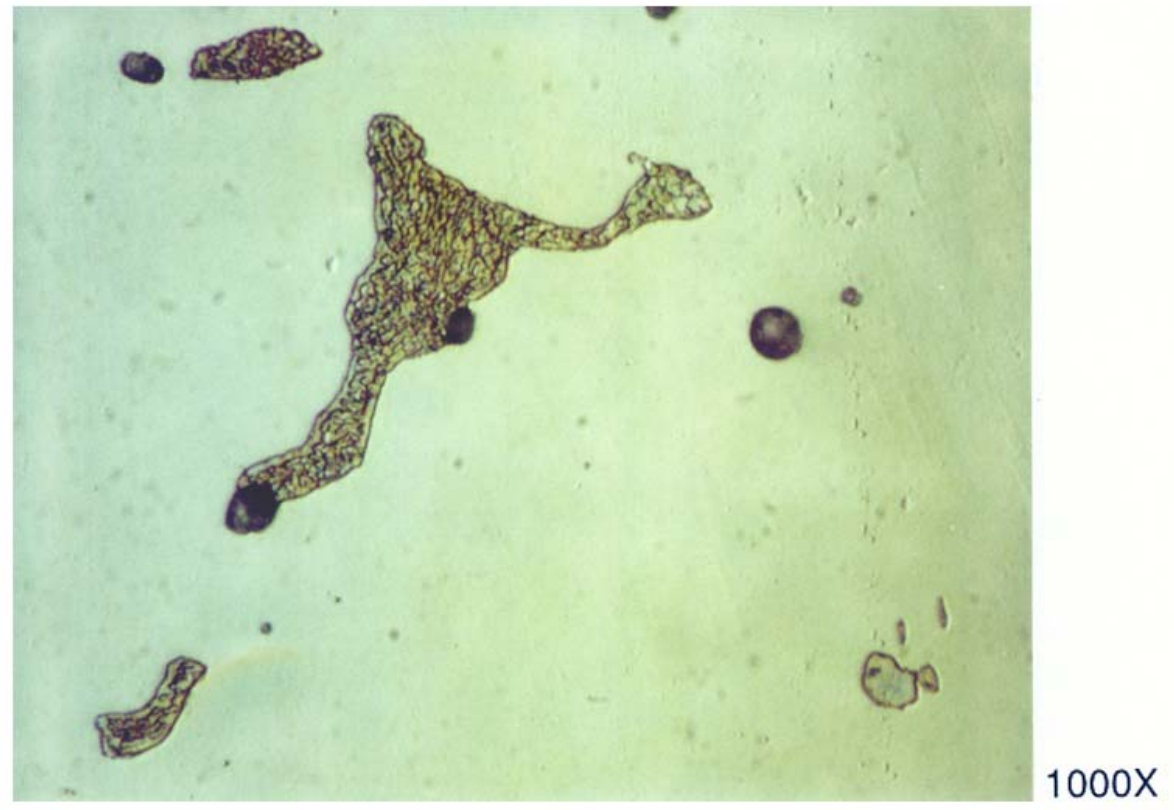

Figure 104. Microstructure of stain-etched CN-3MN Heat N3GAO in as-cast condition 


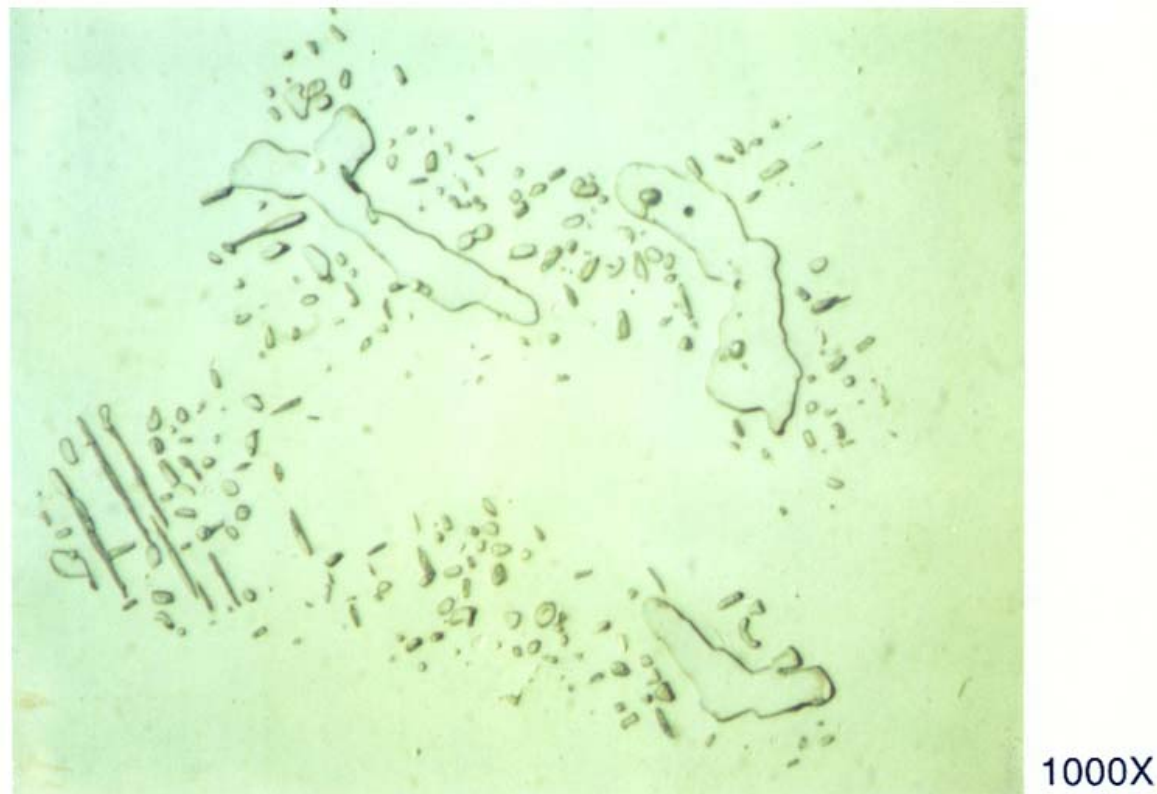

Figure 105. Microstructure of stain-etched CN-3MN Heat N3GAO in SA condition $\left(2100^{\circ} \mathrm{F}+\mathrm{WQ}\right)$

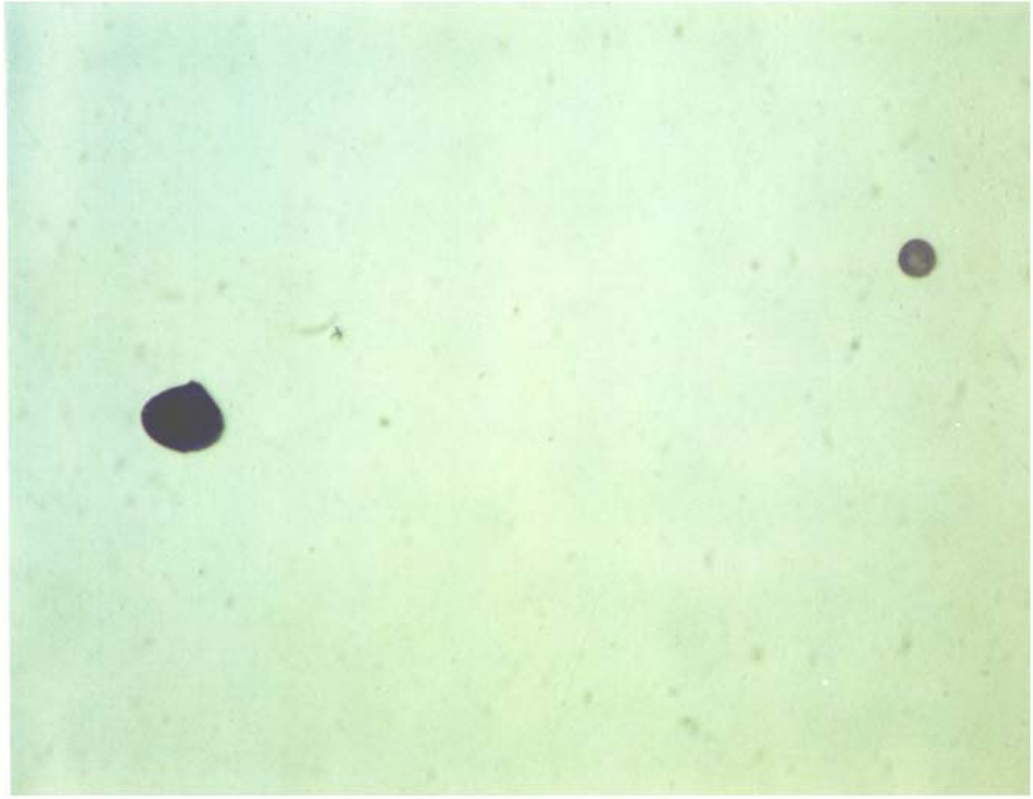

$1000 x$

Figure 106. Microstructure of stain-etched CN-3MN Heat N3GAO in SA condition $\left(2300^{\circ} \mathrm{F}+\mathrm{WQ}\right)$ 
shaped secondary phase within the "islands" was stained a blue or tan color (see Figure 104). The stain-etching results indicate that the irregular-shaped secondary phases within the "islands" in the as-cast condition are $\sigma$ phase. However, the block-like and/or irregular-shaped secondary phases observed in the as-cast condition were not effected by the stain etching. For the $2100^{\circ} \mathrm{F} / 1150^{\circ} \mathrm{C}$ solution-annealed Heat N3GAO, the microstructure after the stain etching was presented in Figure 105. It is obvious that the remaining secondary phases are not stained. This result indicates that the remaining secondary phases after $2100^{\circ} \mathrm{F} / 1150^{\circ} \mathrm{C} \mathrm{SA}$ are not $\sigma$ phase. This is also true for $2200^{\circ}$ F SA Heat N3GAO. The microstructure of stain-etched Heat N3GAO after $2300^{\circ} \mathrm{F} / 1260^{\circ} \mathrm{C} \mathrm{SA}(\mathrm{WQ})$ is shown in Figure 106 . No ferrite was found in this solution-annealed condition.

Stain etching was also conducted on $\mathrm{CN}-3 \mathrm{MN}$ Heat 4 in the as-cast and solution-annealed condition. The microstructure of the stain-etched Heat 4 are shown in Figures 107 through 109 for the as-cast, $2100^{\circ} \mathrm{F} / 1150^{\circ} \mathrm{C} \mathrm{SA}$ (WQ) and $2300^{\circ} \mathrm{F} / 1260^{\circ} \mathrm{C} \mathrm{SA}(\mathrm{WQ})$ conditions, respectively. It is evident that the irregularshaped secondary phases within the "islands" in the as-cast Heat 4 only were stained as blue or tan color (see Figure 107). Stain etching reveals no $\sigma$ phase in Heat 4 in any of the SA conditions $\left(2100 \mathrm{~F} / 1150^{\circ} \mathrm{C}, 2135^{\circ} \mathrm{F} / 1170^{\circ} \mathrm{C} \&\right.$ $2300^{\circ} \mathrm{F} / 1260^{\circ} \mathrm{C}+\mathrm{WQ}$ ). The microstructure of the $2100^{\circ} \mathrm{F} / 1150^{\circ} \mathrm{C}$ (the lowest SA temperature selected in this study) and $2300^{\circ} \mathrm{F} / 1260^{\circ} \mathrm{C}$ (the highest SA temperature selected in this study) solution-annealed Heat 4 after the stain etching are presented in Figures 108 and 109. 


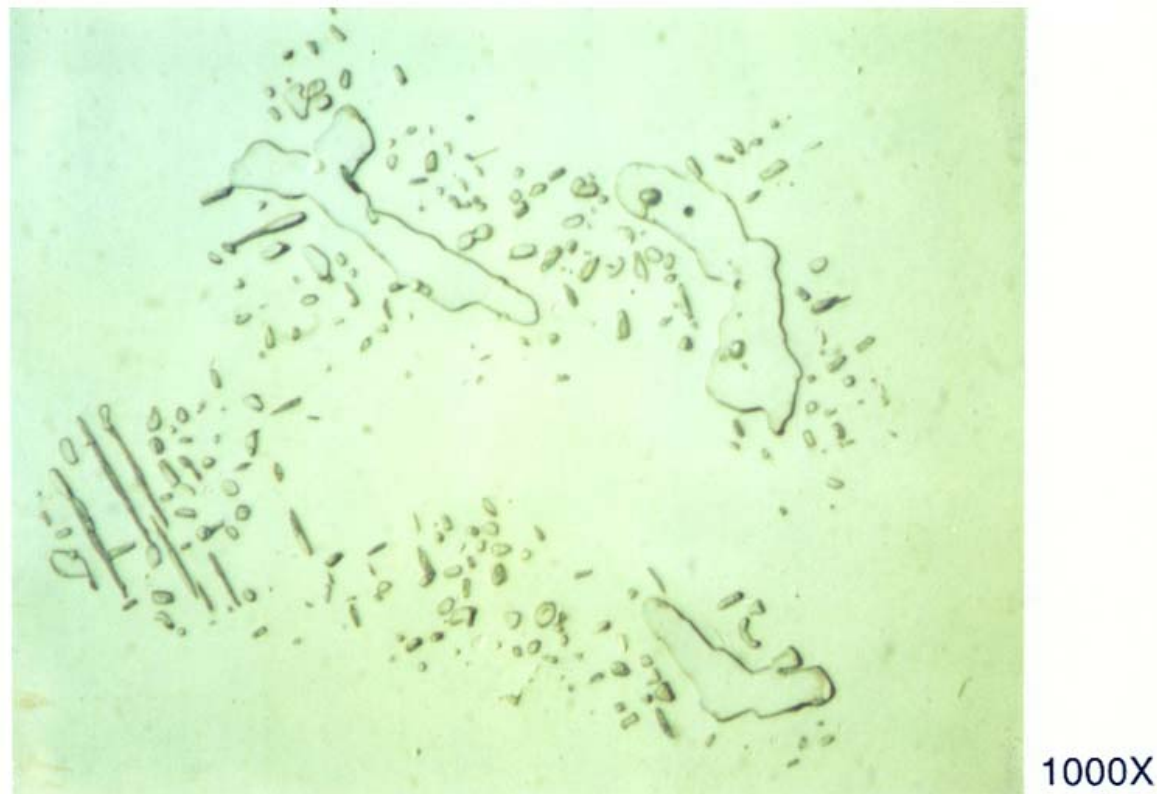

Figure 105. Microstructure of stain-etched CN-3MN Heat N3GAO in SA condition $\left(2100^{\circ} \mathrm{F}+\mathrm{WQ}\right)$

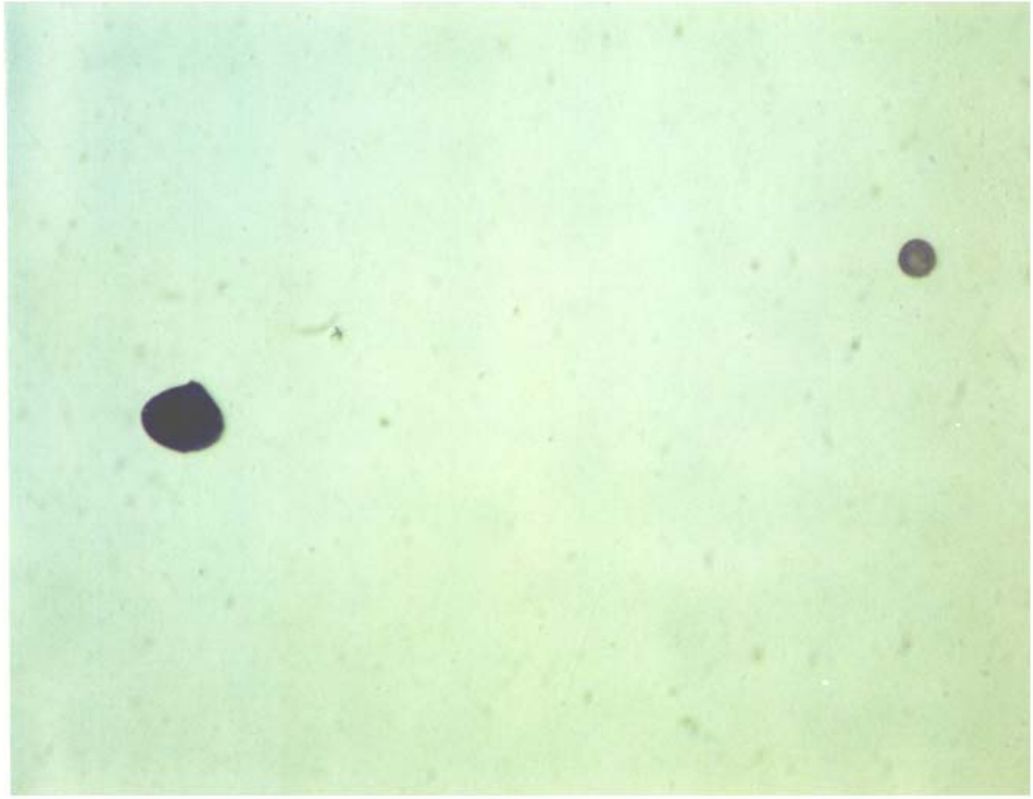

$1000 x$

Figure 106. Microstructure of stain-etched CN-3MN Heat N3GAO in SA condition $\left(2300^{\circ} \mathrm{F}+\mathrm{WQ}\right)$ 


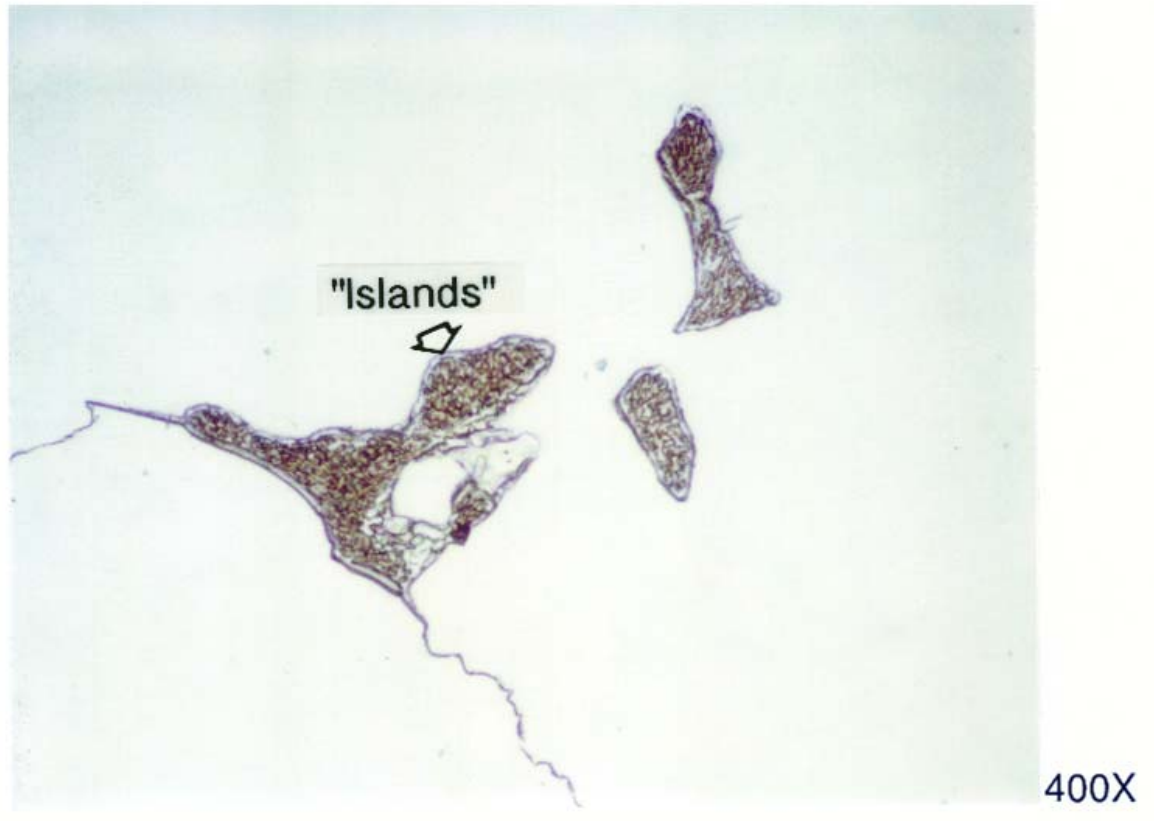

Figure 107. Microstructure of stain-etched $\mathrm{CN}-3 \mathrm{MN}$ Heat 4 in as-cast condition 


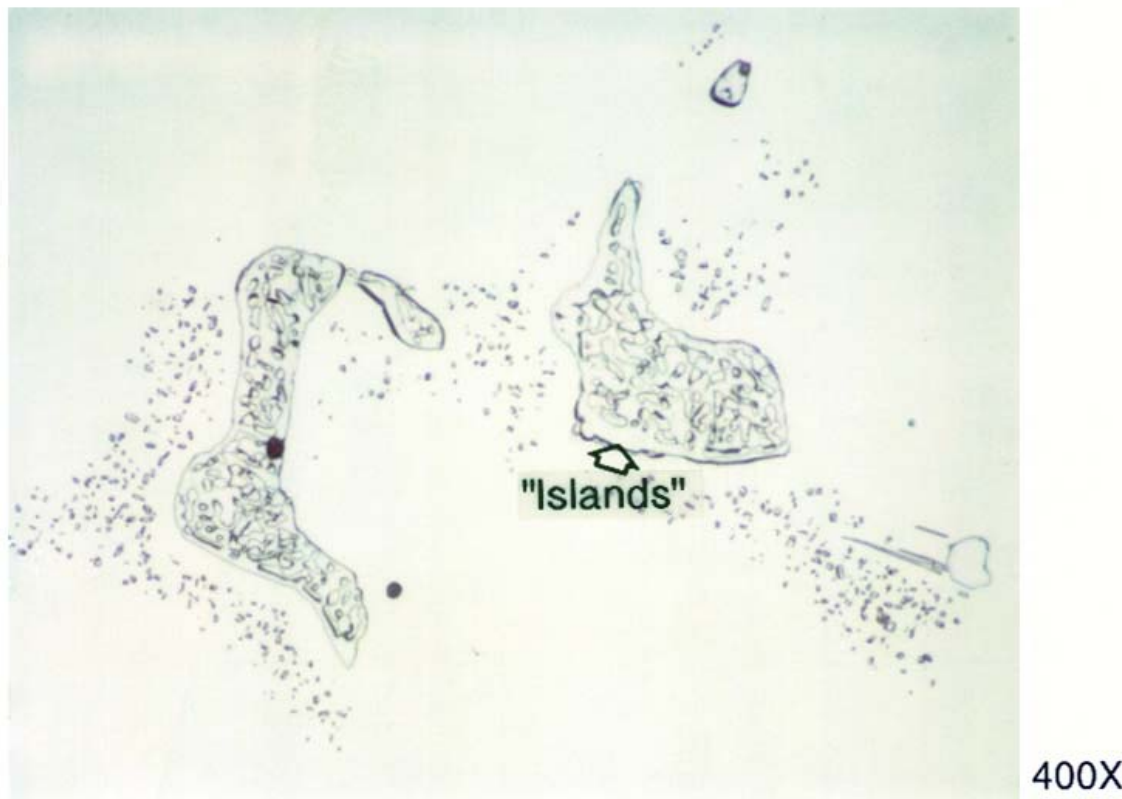

Figure 108. Microstructure of stain-etched $\mathrm{CN}-3 \mathrm{MN}$ Heat 4 in SA condition $\left(2100^{\circ} \mathrm{F}+\mathrm{WQ}\right)$

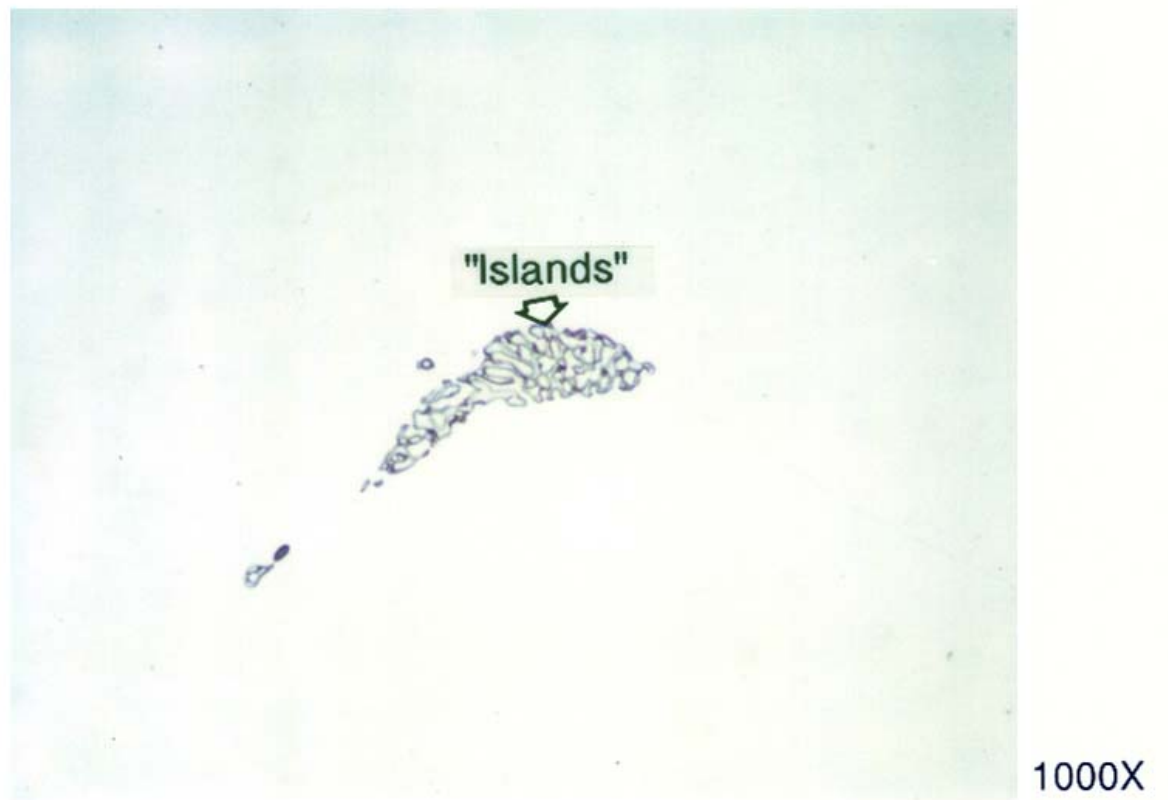

Figure 109. Microstructure of stain-etched $\mathrm{CN}-3 \mathrm{MN}$ Heat 4 in SA condition $\left(2300^{\circ} \mathrm{F}+\mathrm{WQ}\right)$ 
Optical microstructural evaluation was also conducted on a slow-cooled (from $2300^{\circ} \mathrm{F} / 1260^{\circ} \mathrm{C} \mathrm{SA}$ ) $\mathrm{CN}-3 \mathrm{MN}$ (Heat N3GAO) sample in order to understand the effect of cooling rate on the microstructure. The microstructure of the slowcooled $\mathrm{CN}-3 \mathrm{MN}$ is shown in Figure 110. It is evident that, except for the dark globular particles, there are no secondary phases observed in the slow-cooled CN-3MN Heat N3GAO sample. Therefore, slow cooling apparently does not cause the re-precipitation of secondary phases in this heat when SA at $2300^{\circ} \mathrm{F} / 1260^{\circ} \mathrm{C}$. It should be recalled that all secondary phases in Heat N3GAO were completely dissolved after the $2300^{\circ} \mathrm{F} / 1260^{\circ} \mathrm{C} \mathrm{SA}$.

\section{- SEM/EDS Analysis}

Three heats of CN-3MN-Heat N3GAO, Heat 4, and Heat 5-were selected for SEM/EDS evaluation. The wrought counterpart AL-6XN was also used for comparison. The SEM/EDS analysis was conducted in both the as-cast and solution-annealed condition. The results of SEM/EDS analysis will be discussed for each heat as follows:

\section{i) $\underline{\mathrm{CN}-3 \mathrm{MN} \text { Heat N} 3 \mathrm{GAO}}$}

Figure 111 shows the SEM microstructural morphology of CN-3MN Heat N3GAO in the as-cast condition as a secondary electron image. It should be recognized that the typical microstructure of the as-cast CN-3MN Heat N3GAO includes the austenitic matrix (Location A), irregular shaped secondary phase within the "islands" (Location B), a cluster of block-like and/or irregular shaped 

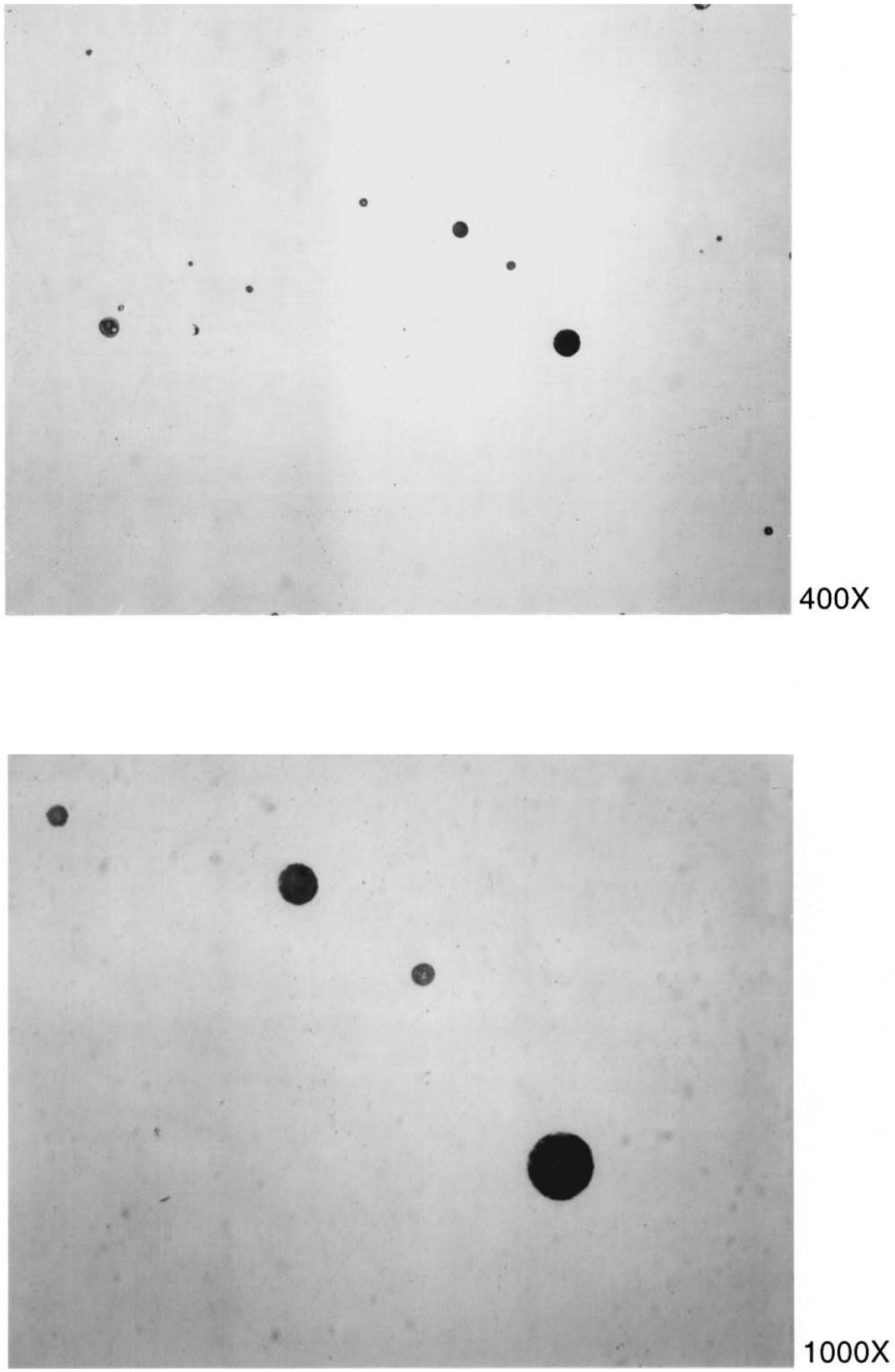

Figure 110 Microstructure of CN-3MN Heat N3GAO in SA plus slow cooled (from $2300^{\circ} \mathrm{F}$ ) condition 


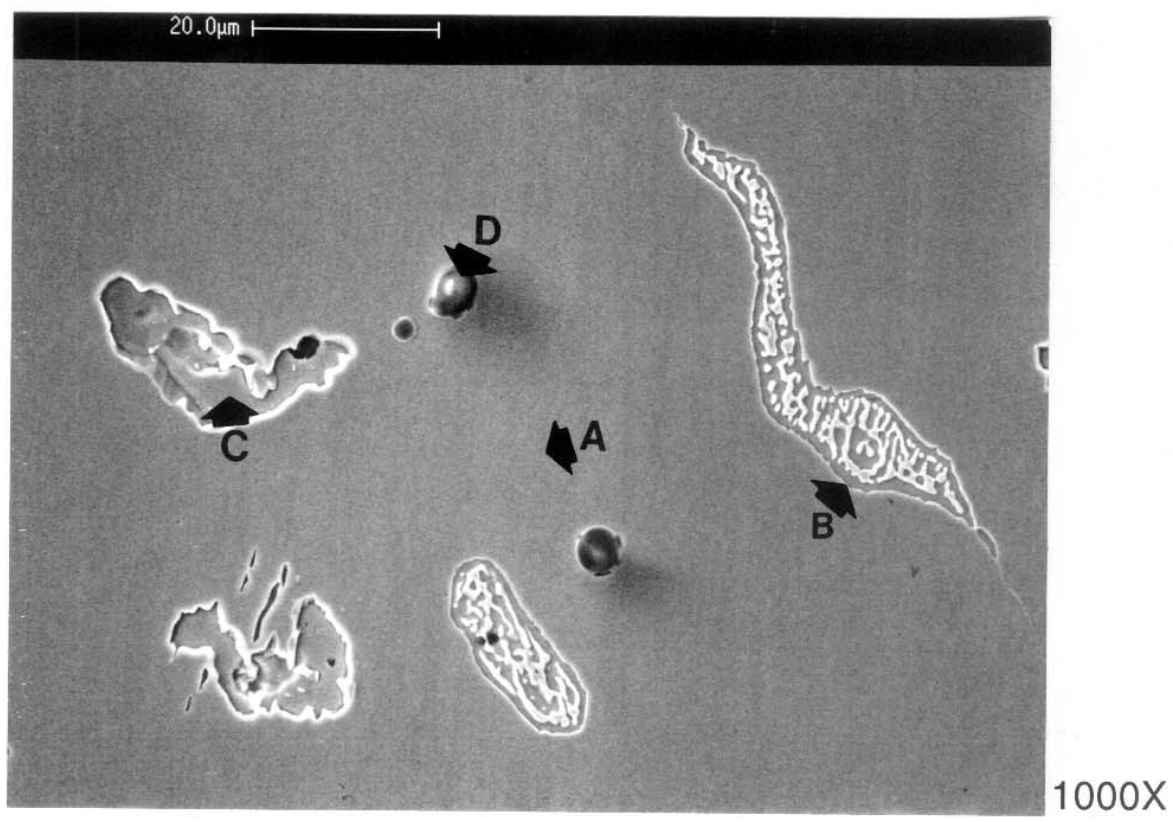

Figure 111. Secondary image of CN-3MN Heat N3GAO in as-cast condition, EDS analysis at locations marked by letters 
secondary phase (Location C) and a dark globular particle (Location D). EDS analysis was performed at the locations marked by arrows and letters (A through D) in Figure 111. EDS analysis was also conducted on the wrought counterpart AL-6XN for comparison.

The EDS spectra for the matrix of as-cast CN-3MN Heat N3GAO (Location A in Figure 111) and wrought AL-6XN are presented in Figures 112 and 113, respectively. It is evident that the matrix of as-cast CN-3MN Heat N3GAO and wrought AL-6XN reveal identical EDS spectra in terms of detection of alloying elements and count ratio between major elements. Figures 114 and 115 show the EDS results for the irregular-shaped secondary phase within the "islands" (Location B) and the cluster of block-like and/or irregular-shaped secondary phase (Location C). Compared to the matrix (Location A), it is evident that the irregular-shaped secondary phase within the "islands" revealed a greater Mo and Cr content than the matrix. In addition, the fact that these irregular shaped secondary phase particles within the "islands" were stained blue or tan by stain etching, indicates that these are $\sigma$ phase (FeCrMo). On the other hand, as shown in Figure 115, the cluster of block-like and/or irregular-shaped secondary phases (Location C) reveals an even higher Mo and $\mathrm{Cr}$ content than Location $\mathrm{B}$. It should be recalled that these block-like and/or irregular-shaped secondary phases (Location C) were not effected by the stain etching. Based on the EDS and stain-etching results, the cluster of block-like and/or irregular-shaped secondary phases are considered to be primarily $(\mathrm{Cr}, \mathrm{Mo})$ carbides/nitrides. In addition, the dark globular particles in the matrix (Location $\mathrm{D}$ ) were determined to 


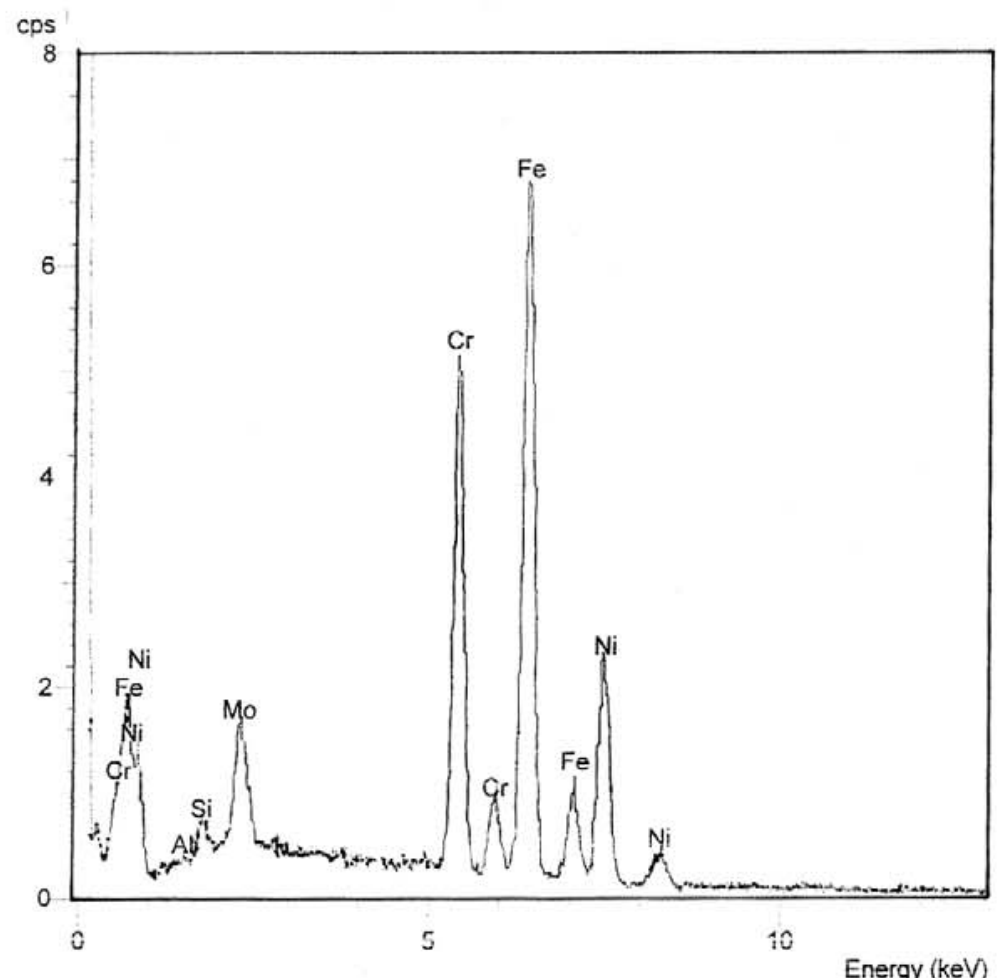

Figure 112.EDS spectrum at Location $A$ (matrix) in Figure 111, as-cast CN-3MN Heat N3GAO

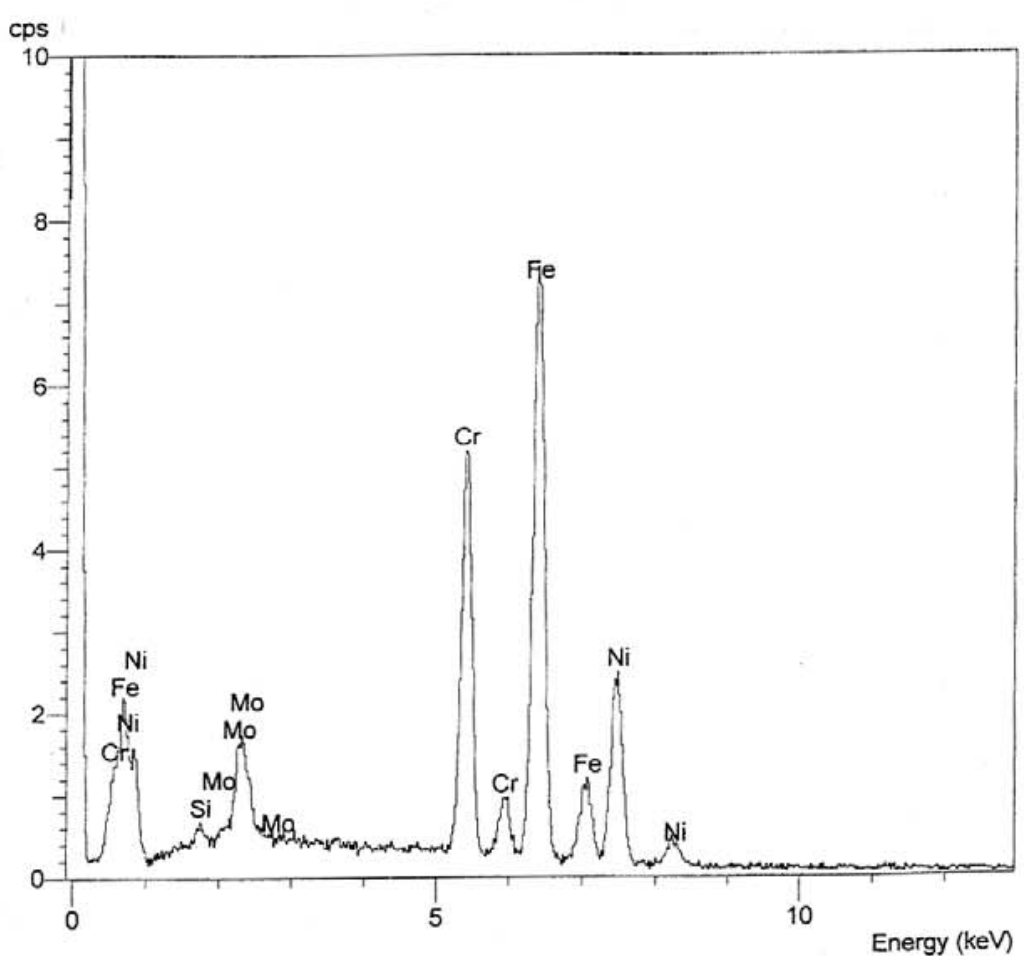

Figure 113. EDS spectrum of wrought alloy AL-6XN 


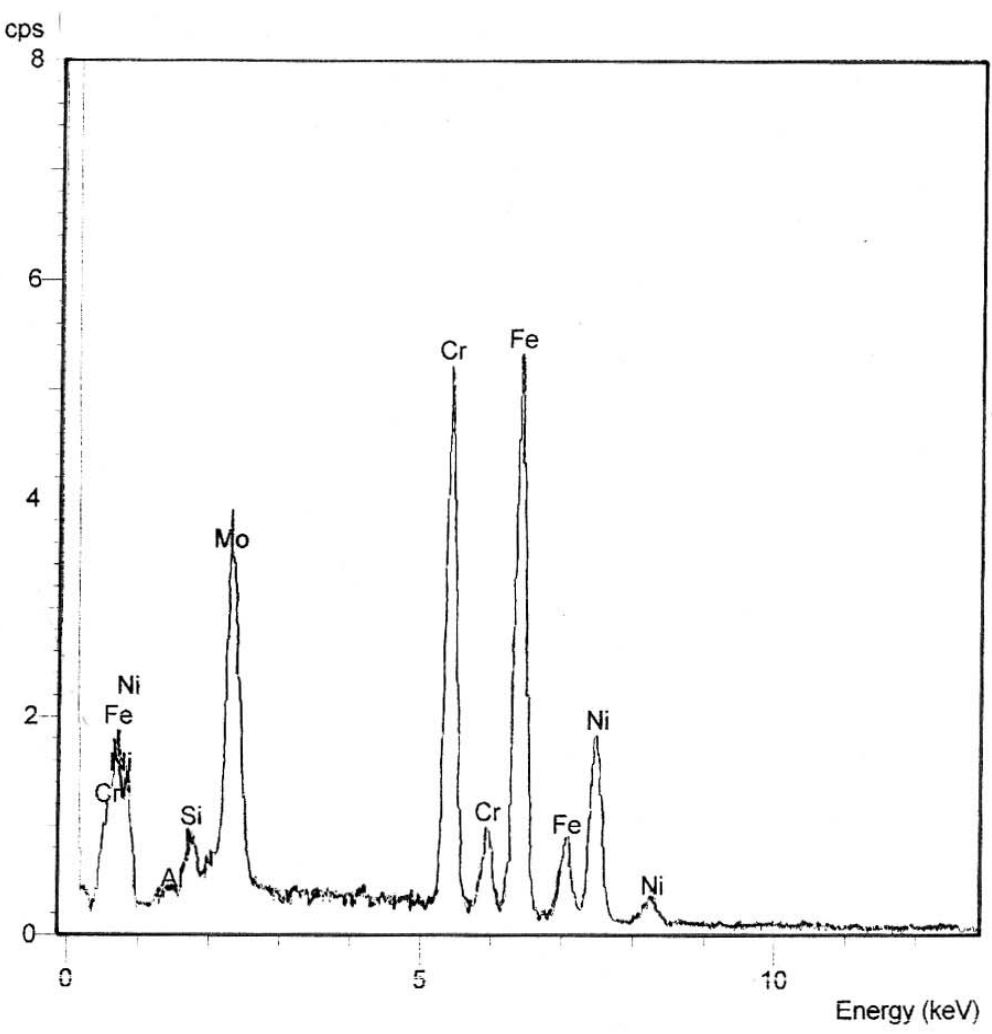

Figure 114. EDS spectrum at Location B (irregular shaped secondary phases within "islands") in Figure 111, as-cast CN-3MN Heat N3GAO

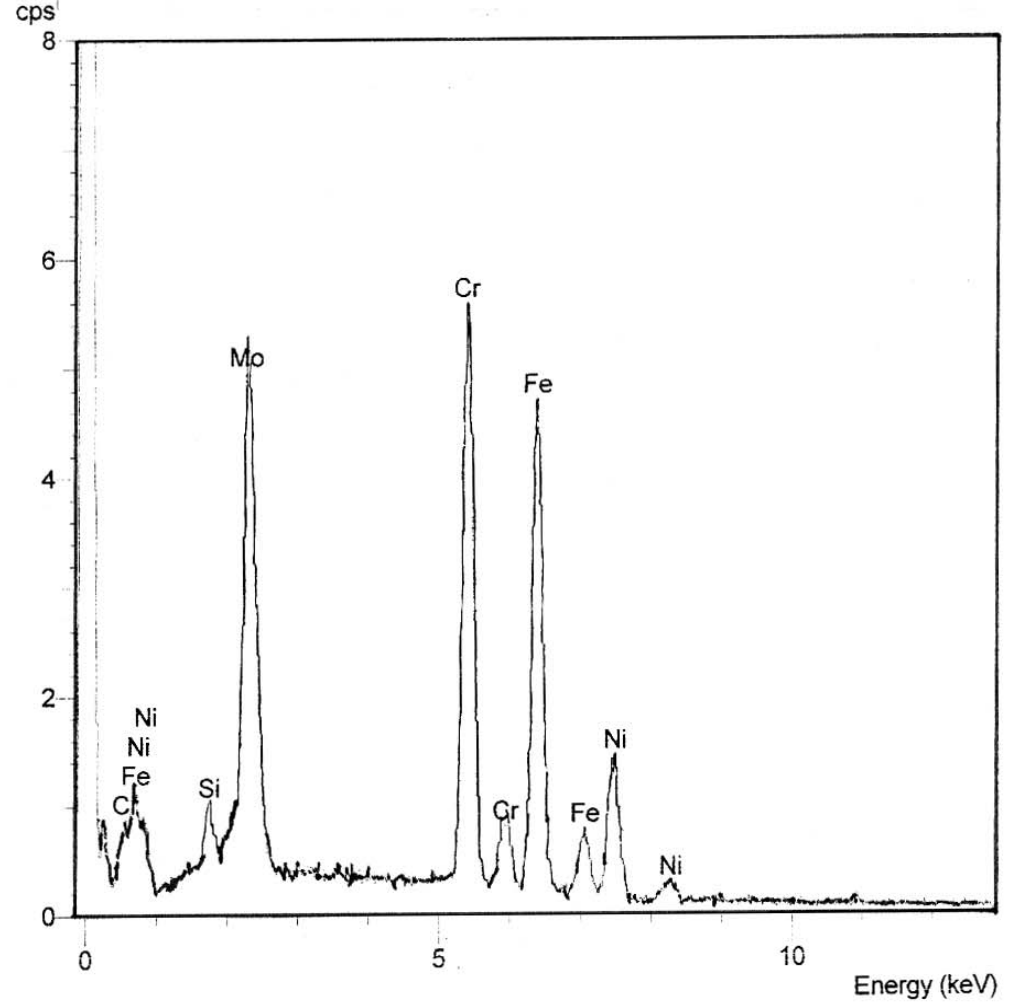

Figure 115. EDS spectrum at Location C (a cluster of block-like or irregular shaped secondary phases) in Figure 111, as-cast CN-3MN Heat N3GAO 
be silicon and/or manganese oxides according to the EDS results presented in Figure 116.

For the $2100^{\circ} \mathrm{F} / 1150^{\circ} \mathrm{C} \mathrm{SA}(\mathrm{WQ}) \mathrm{CN}-3 \mathrm{MN}$ Heat N3GAO, the SEM microstructural morphology is presented in Figure 117 as a secondary electron image. The typical microstructure includes the irregular-shaped secondary phases in various sizes distributed in the matrix. EDS analysis was performed at Location A for Matrix and Location B for the irregular-shaped secondary phases. The EDS spectra are presented in Figures 118 and 119 for Locations A and B, respectively. The EDS results show that the irregular-shaped secondary phases contains higher $\mathrm{Mo}$ and $\mathrm{Cr}$ as compared to the matrix. It is to be noted that, after $2100^{\circ} \mathrm{F} / 1150^{\circ} \mathrm{C} \mathrm{SA}(\mathrm{WQ})$, these irregular-shaped secondary phases were not effected by the stain etching. They are considered to be (Cr, Mo) carbides/ nitrides. This is also true for $2200^{\circ} \mathrm{F} / 1205^{\circ} \mathrm{C}$ solution-annealed $\mathrm{CN}-3 \mathrm{MN}$. It is to be noted that the small irregular-shaped secondary phase presented in $\mathrm{CN}-3 \mathrm{MN}$ matrix after 2100 and $2200^{\circ} \mathrm{F}\left(1150^{\circ} \mathrm{C}\right.$ and $\left.1205^{\circ} \mathrm{C}\right) \mathrm{SA}$ is not large enough for EDS analysis.

Figure 120 shows the typical SEM microstructural morphology of $2300^{\circ} \mathrm{F} / 1260^{\circ} \mathrm{C}$ SA (WQ) CN-3MN Heat N3GAO. Compared to the as-cast and lower temperature $\left(2100^{\circ} \mathrm{F} / 1150^{\circ} \mathrm{C}\right.$ or $\left.2200^{\circ} \mathrm{F} / 1205^{\circ} \mathrm{C}\right)$ solution-annealed $\mathrm{CK}$ $3 \mathrm{MCuN}$, the irregular-shaped secondary phases are completely dissolved during the $2300^{\circ} \mathrm{F} / 1260^{\circ} \mathrm{C}$ solution anneal. Only dark globular particles are visible in the matrix. The EDS results, as shown in Figures 121 (Location A: matrix) and 122 


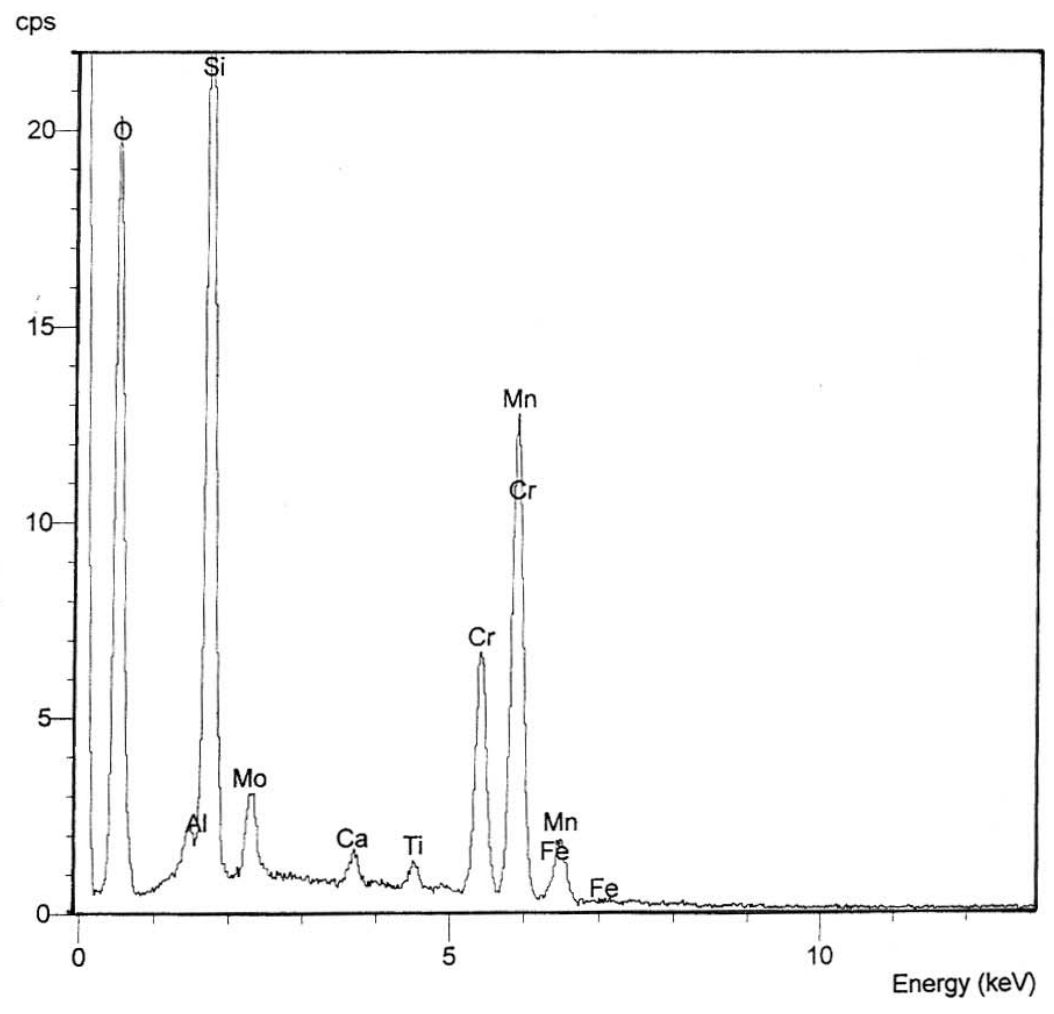

Figure 116. EDS spectrum at Location D (dark globular particles) in Figure 111, as-cast CN-3MN Heat N3GAO 


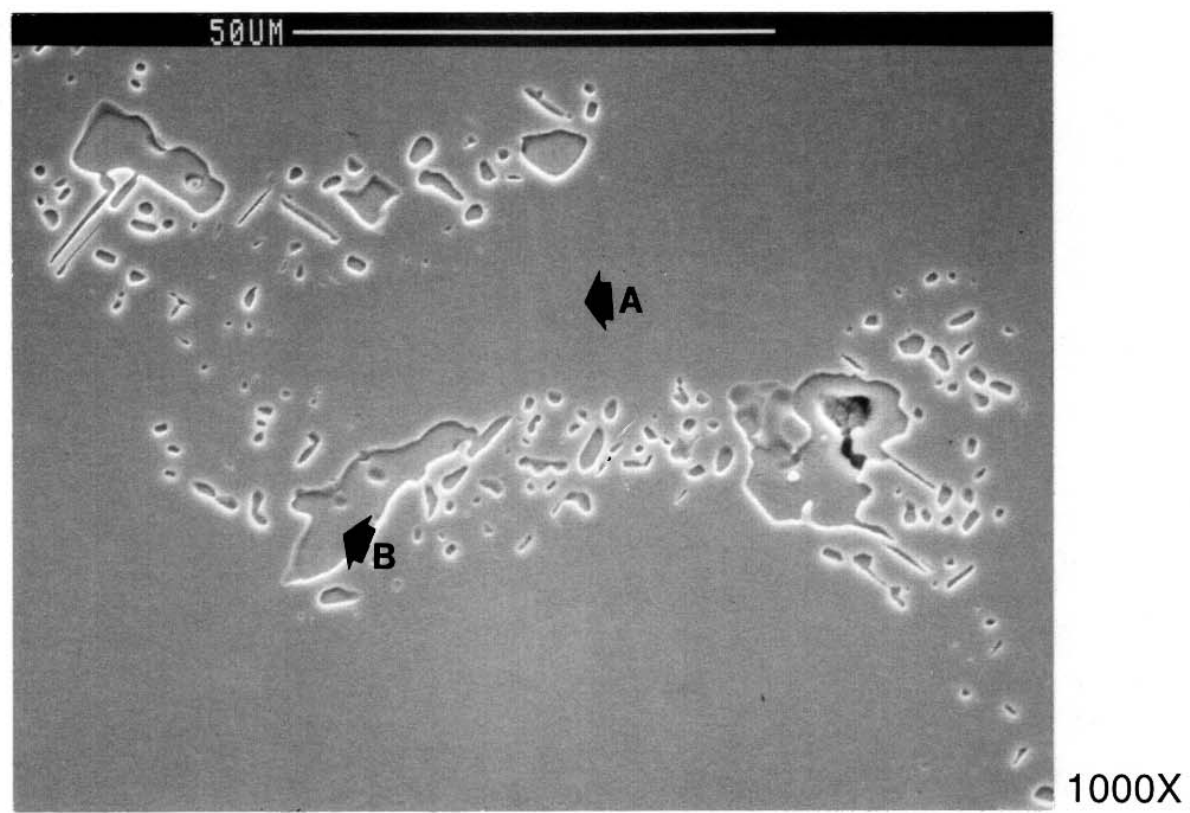

Figure 117. Secondary image of CN-3MN Heat N3GAO in SA condition $\left(2100^{\circ} \mathrm{F}+\mathrm{WQ}\right)$, EDS analysis at locations marked by letters 


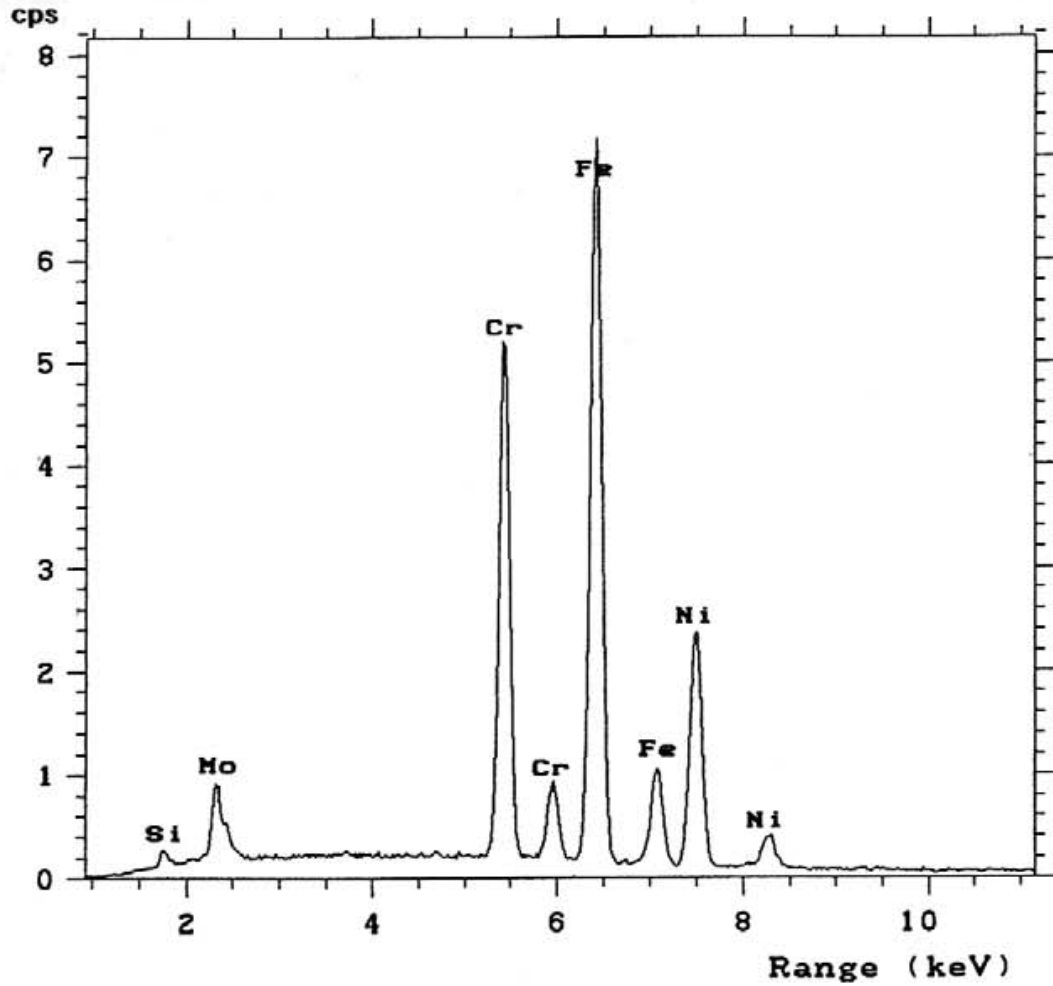

Figure 118. EDS spectrum at Location $\mathrm{A}$ (matrix) in Figure $117,2100^{\circ} \mathrm{F}$ solution annealed (WQ) $\mathrm{CN}-3 \mathrm{MN}$ Heat N3GAO

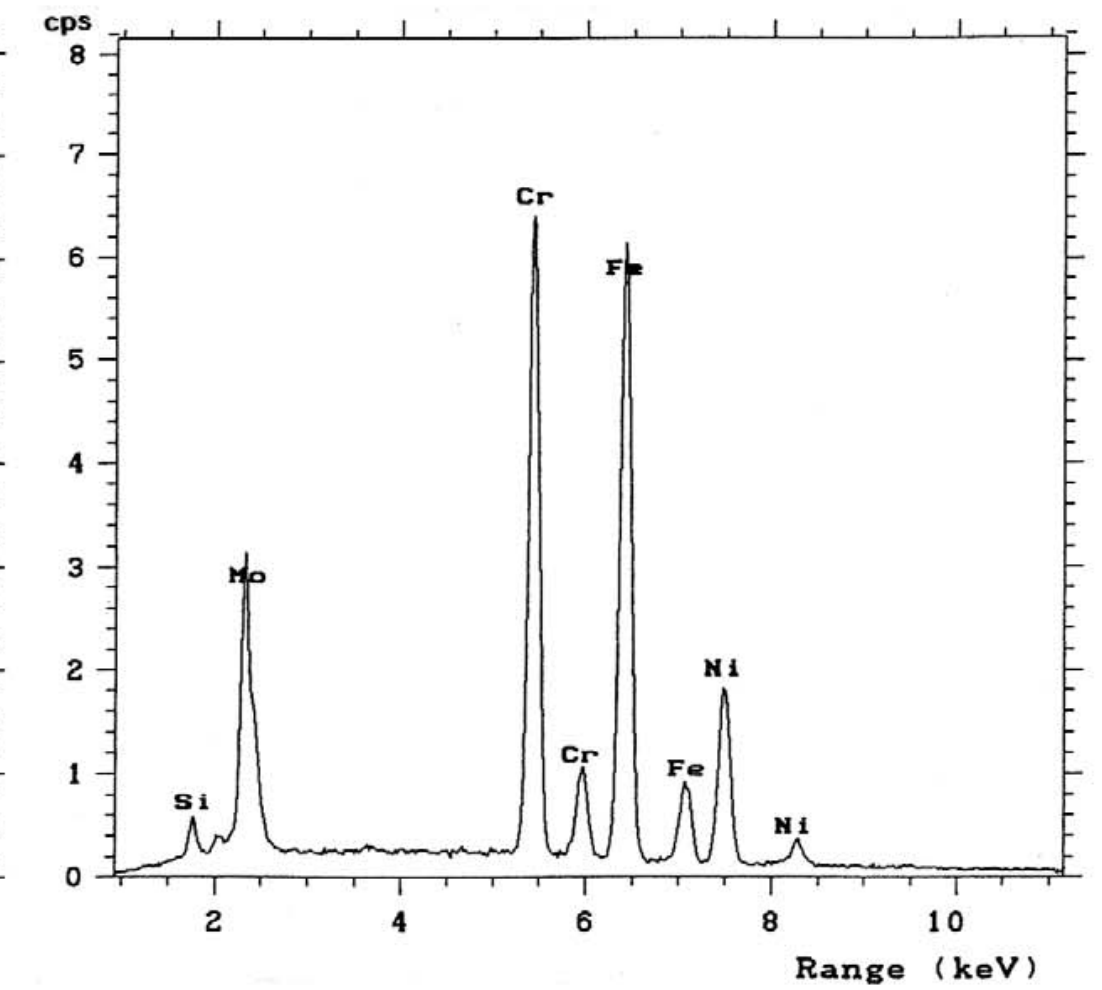

Figure 119.EDS spectrum at Location B (irregular shaped secondary phases) in Figure 117, $2100^{\circ} \mathrm{F}$ solution annealed (WQ) CN-3MN Heat N3GAO 


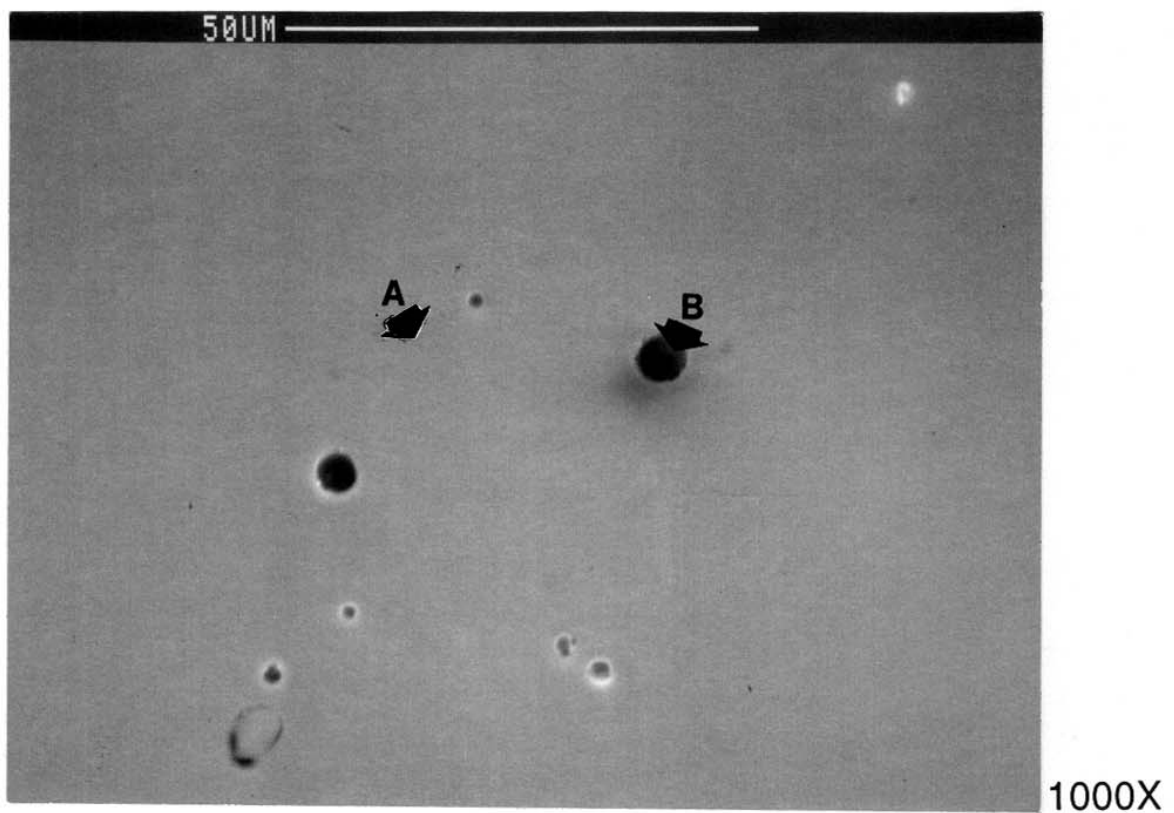

Figure 120. Secondary image of CN-3MN Heat N3GAO in SA condition $\left(2300^{\circ} \mathrm{F}+\mathrm{WQ}\right)$, EDS analysis at locations marked by letters 


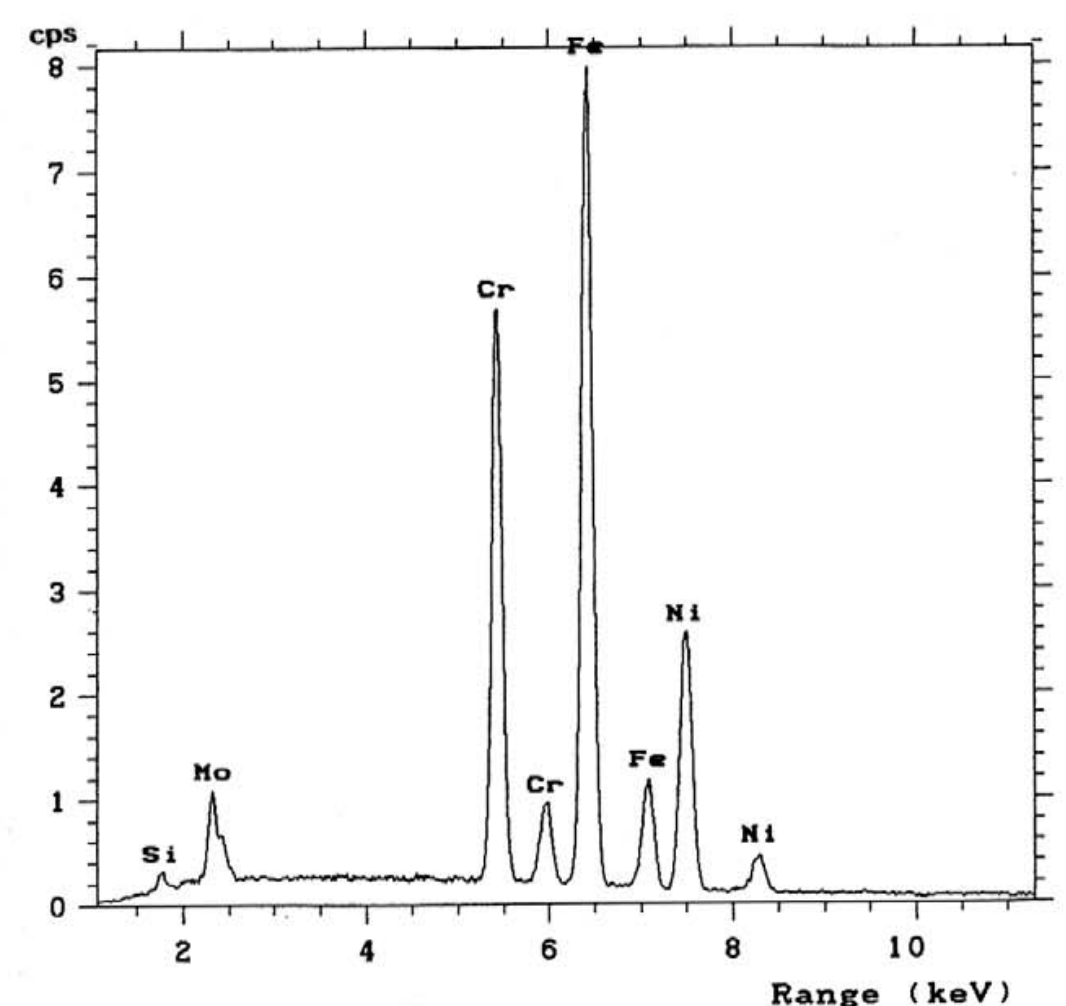

Figure 121.EDS spectrum at Location $A$ (matrix) in Figure $120,2300^{\circ} \mathrm{F}$ solution annealed (WQ) $\mathrm{CN}-3 \mathrm{MN}$ Heat N3GAO

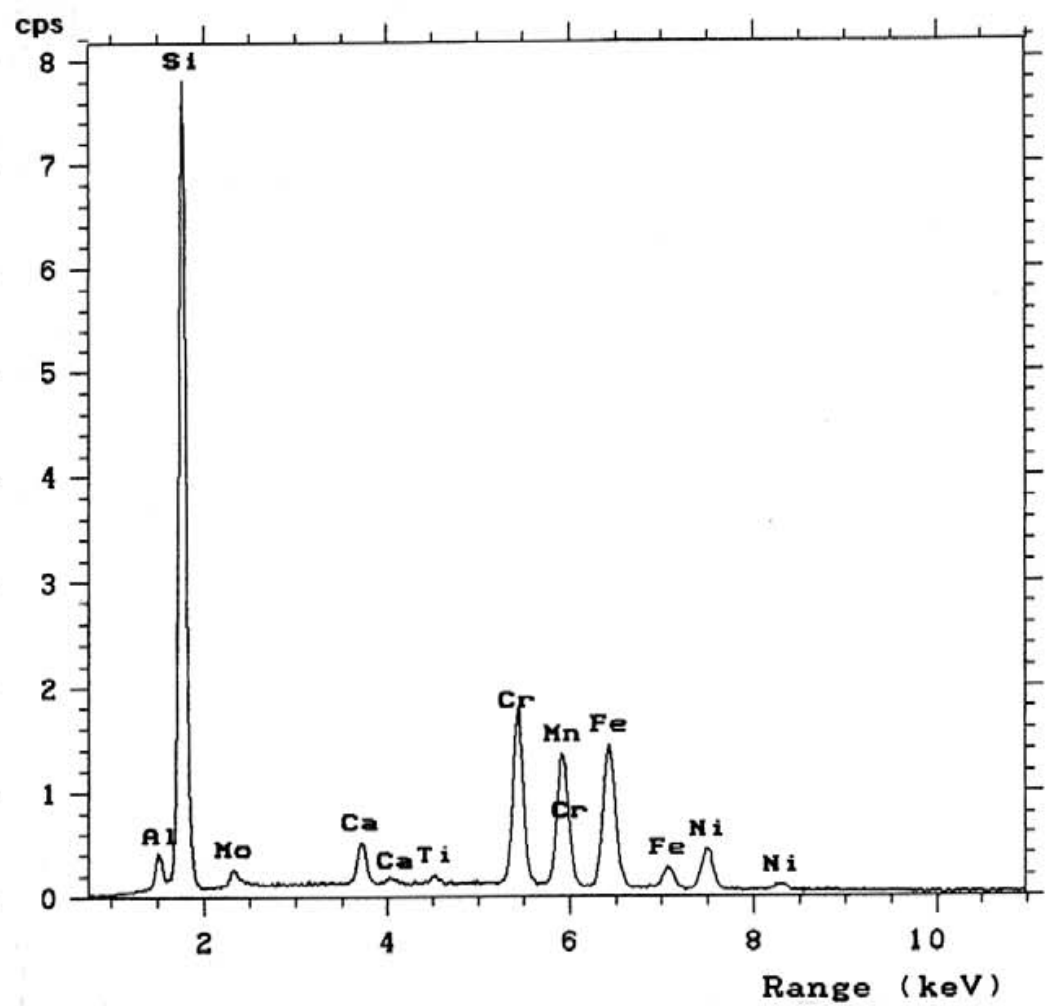

Figure 122. EDS spectrum at Location B (dark globular particle) in Figure $120,2300^{\circ} \mathrm{F}$ solution annealed (WQ) CN-3MN Heat N3GAO 
(Location B: dark globular particles), indicate that the dark globular particles are the same type of inclusions ( $\mathrm{Si}$ and/or Mn oxides) as found in the as-cast and other solution-annealed conditions.

\section{ii) $\underline{\mathrm{CN}-3 \mathrm{MN} \text { Heat } 4}$}

The SEM microstructural morphology of $\mathrm{CN}-3 \mathrm{MN}$ Heat 4 in the as-cast condition is shown in Figure 123 (a) as a secondary electron image and (b) as a back scattered electron image. Similar to the as-cast CN-3MN Heat N3GAO, the typical microstructure of as-cast $\mathrm{CN}-3 \mathrm{MN}$ Heat 4 also includes the austenitic matrix (Location A), irregular-shaped secondary phase particles within the "islands" (Location B), a cluster of block-like and/or irregular-shaped secondary phase (Location C) and a dark globular particle (Location D). EDS analysis was performed at the locations marked by arrows and letters (A through D) in Figure 123 (b). The EDS spectrum for the matrix of the as-cast CN-3MN Heat 4 (Location A) is presented in Figure 124. It is evident that the matrix of the ascast CN-3MN Heat 4 and the wrought AL-6XN (see Figure 113) reveal basically identical EDS spectra. Figures 125 and 126 show the EDS results for the locations within the "islands" (Location B) and location where a cluster of blocklike and/or irregular-shaped secondary phase (Location C) was found in this heat. From the EDS result on Location B, the irregular-shaped secondary phases within the "islands" are richer in Mo and $\mathrm{Cr}$ (Figure 125) compared to the matrix (Figure 124). In addition, it should be recalled that these irregular-shaped secondary phases within the "islands" were stained blue or tan by stain etching. 


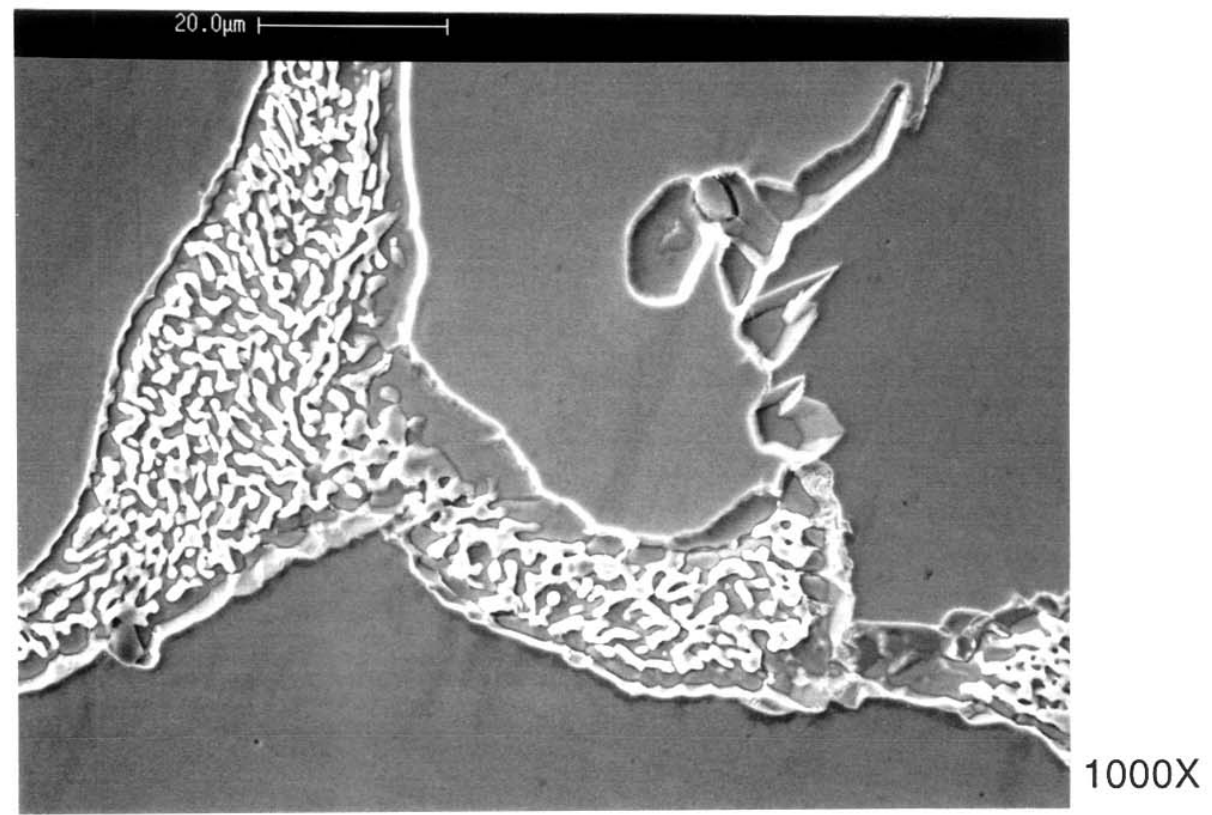

(a) Secondary image

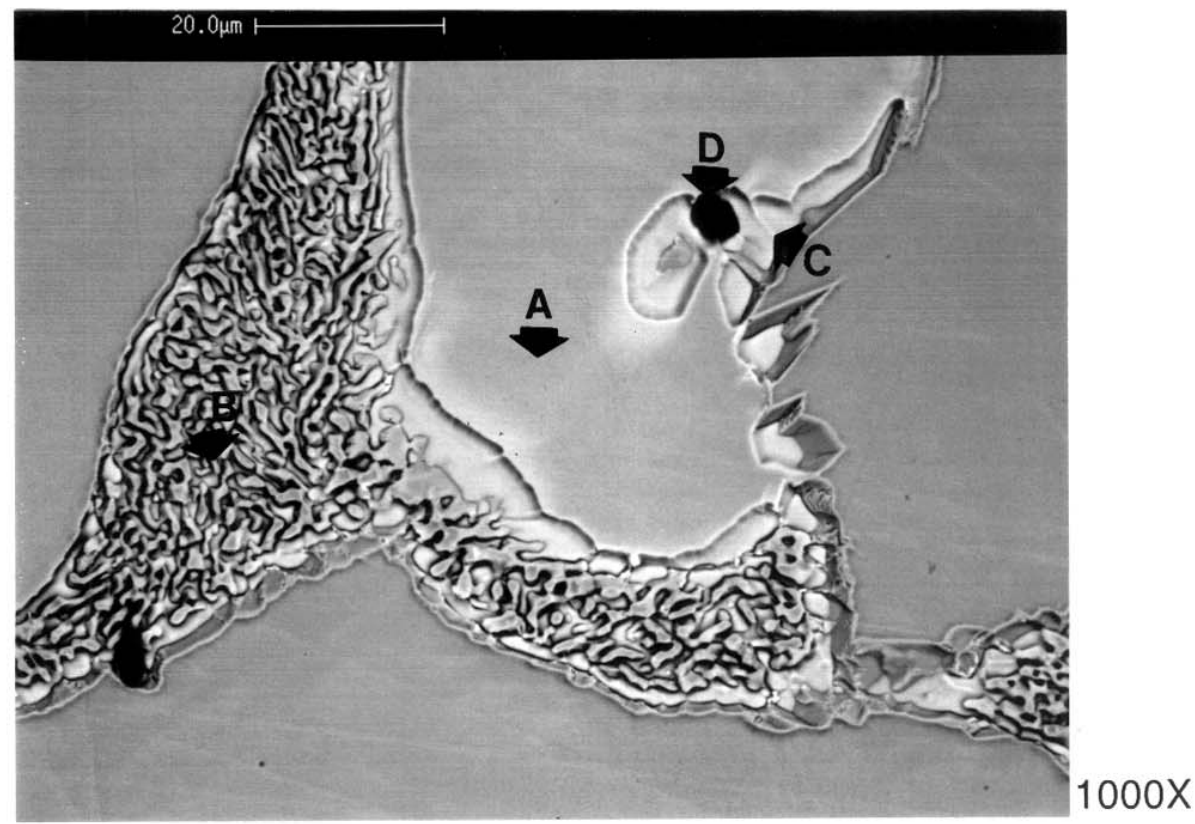

(b) Back scattered image

Figure 123. SEM photomicrograph of CN-3MN Heat 4 in as-cast condition, EDS analysis at locations marked by letters 


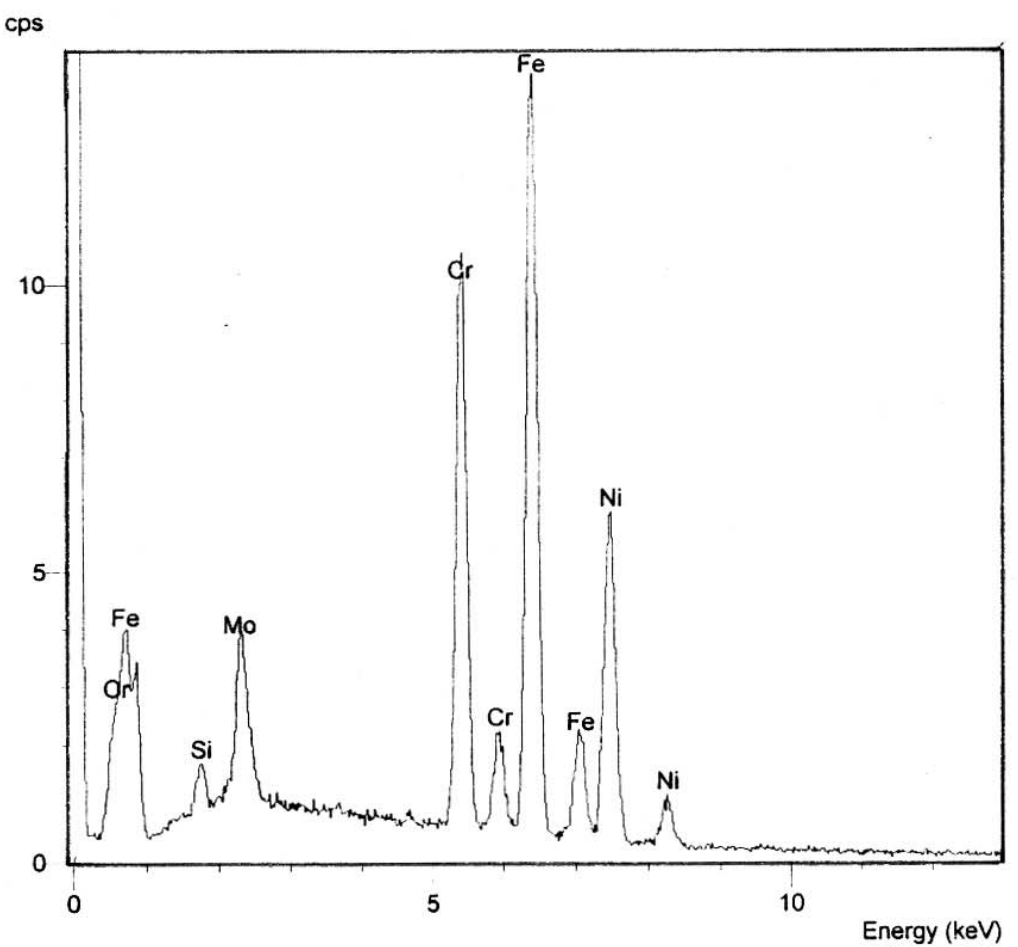

Figure 124.EDS spectrum at Location A (matrix) in Figure 123, as-cast CN-3MN Heat 4

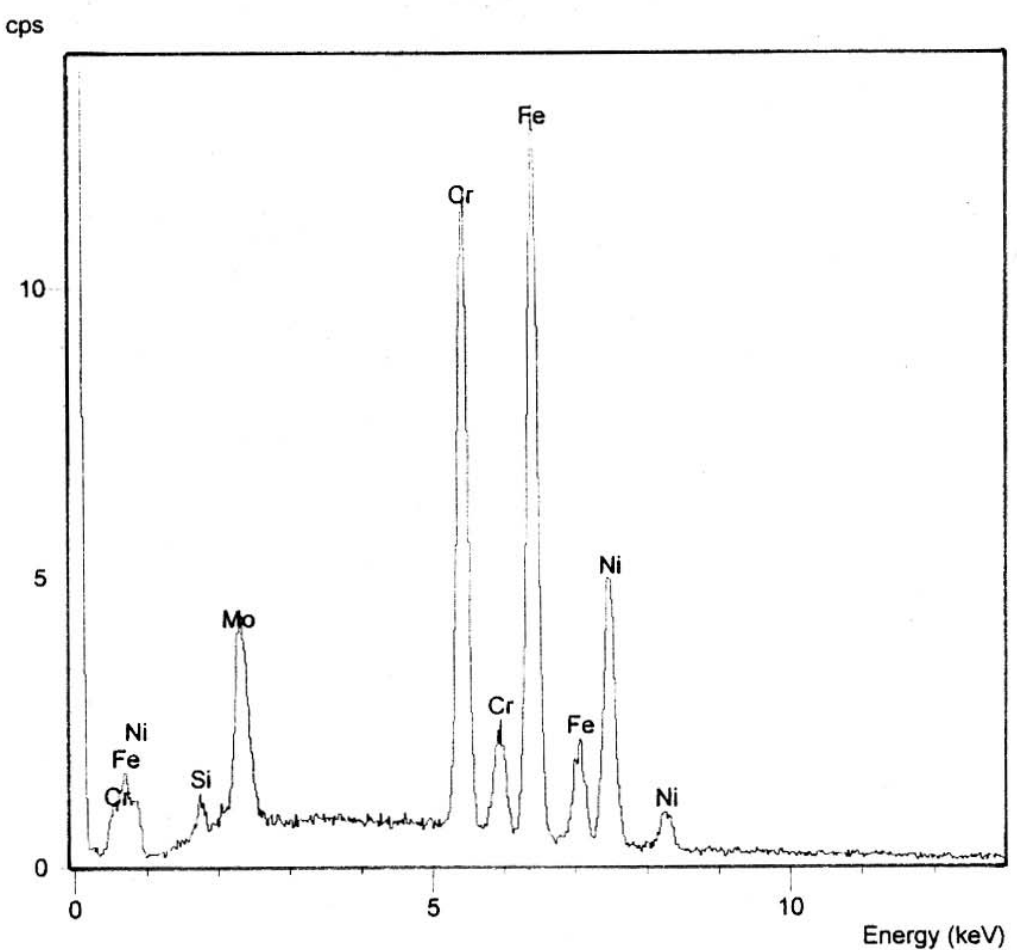

Figure 125. EDS spectrum at Location B (fine irregular shaped secondary phases within "islands") in Figure 123, as-cast CN-3MN Heat 4 


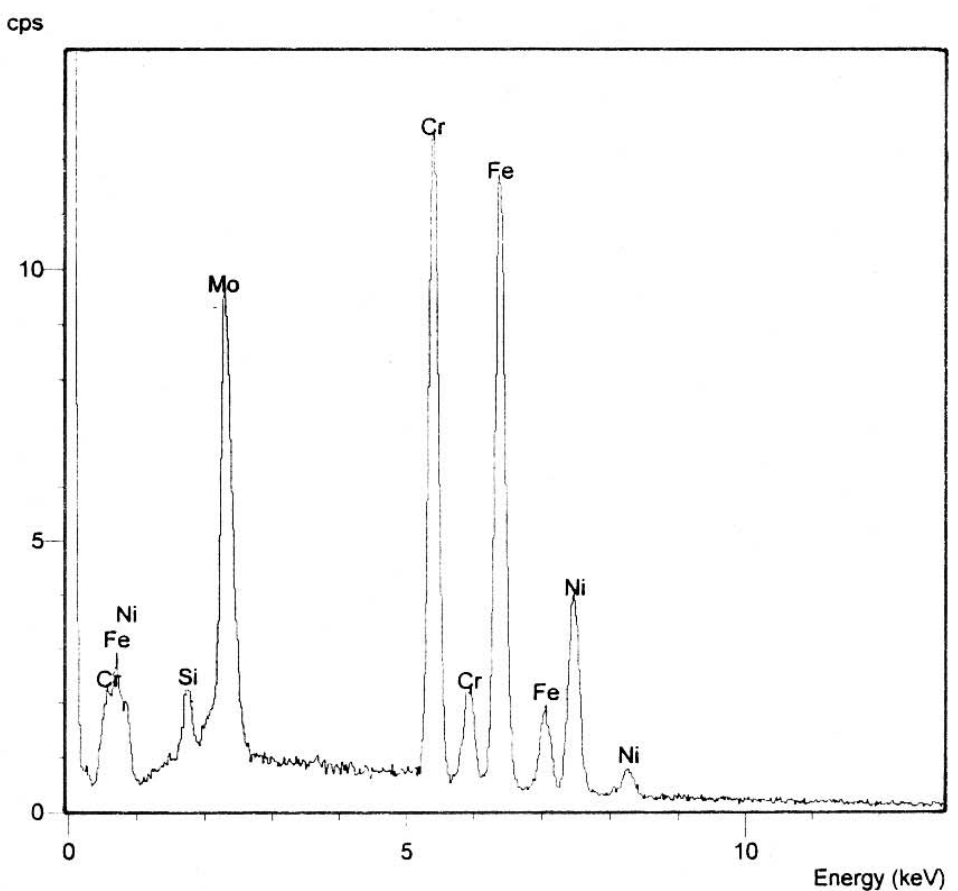

Figure 126. EDS spectrum at Location C (coarse irregular shaped secondary phases within "islands") in Figure 123, as-cast CN-3MN Heat 4

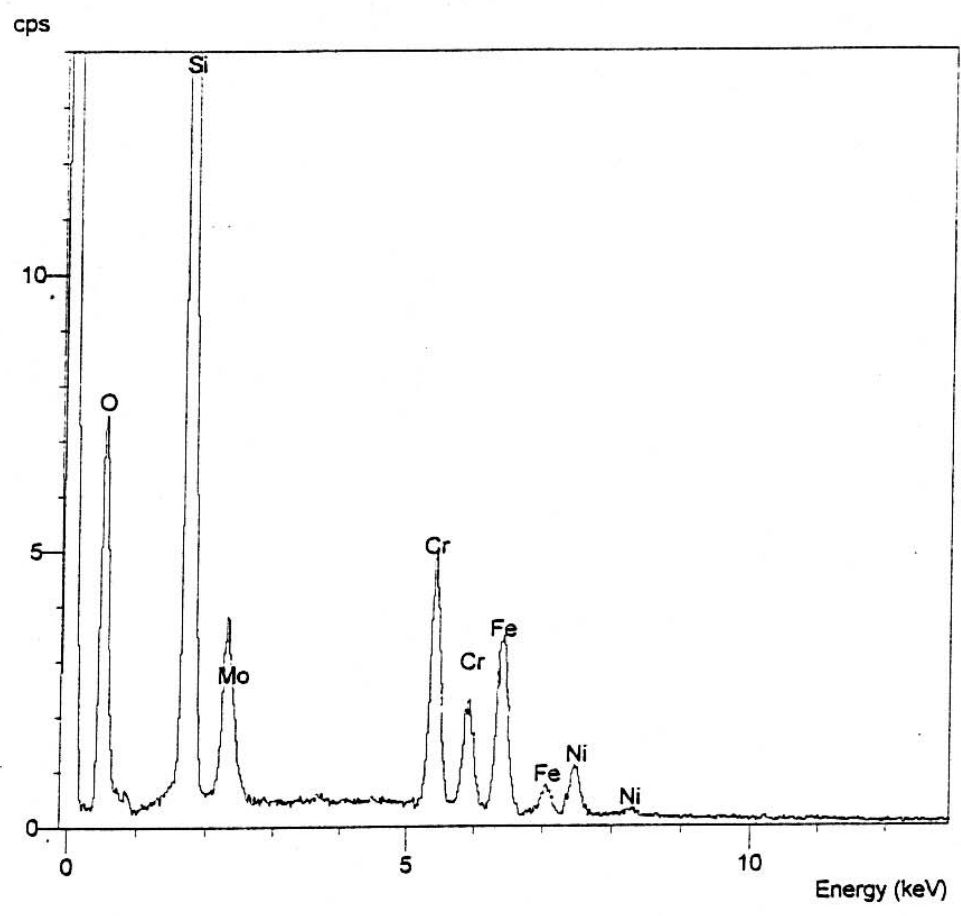

Figure 127. EDS spectrum at Location D (dark globular particles) in Figure 123, as-cast CN-3MN Heat 4 
Therefore, they are considered to be $\sigma$ phase. On the other hand, the cluster of block-like and/or irregular-shaped secondary phase (Location C) remained unstained after stain etching. The EDS result for Location C, shown in Figure 126 , indicates that these secondary phase particles contain even higher Mo and Cr content than the irregular-shaped secondary phase within the "islands" (Location B). Based on the EDS results and unstained etching appearance in previous study, the small amount of coarse irregular-shaped precipitates within the "islands" are considered to be $\mathrm{Cr} / \mathrm{Mo}$ carbides/nitrides. In addition to $\sigma$ phase and $\mathrm{Cr} / \mathrm{Mo}$ carbides/nitrides, the dark globular particles in the matrix (Location D) were determined to be silicon and/or manganese oxides based on the EDS results present in Figure 127.

The SEM microstructural morphology of $2100^{\circ} \mathrm{F} / 1150^{\circ} \mathrm{C} S A(W Q) \mathrm{CN}-$ $3 \mathrm{MN}$ Heat 4 is shown in Figure 128 (a) as a secondary electron image and (b) as a back-scattered electron image. The typical microstructure of solution-annealed $\mathrm{CN}-3 \mathrm{MN}$ Heat 4 includes bright and gray areas within "islands" distributed in the matrix in addition to fine particles surrounding the "islands". EDS analysis was performed at the locations marked by arrows and letters (A through $\mathrm{C}$ ) as shown in Figure 128 (b). The EDS spectra are presented in Figures 129 through 131 for the matrix (Location A) and bright (Location B) and gray (Location C) areas within "islands", respectively. It is evident that Location B (bright area within "island" Figure 130) reveals greater Mo and $\mathrm{Cr}$ as compared to Location A (matrix Figure 129) as well as Location C (gray area within "island" - Figure 131). Location $\mathrm{C}$ exhibits almost the same $\mathrm{Mo}$ and $\mathrm{Cr}$ content as the matrix. This 


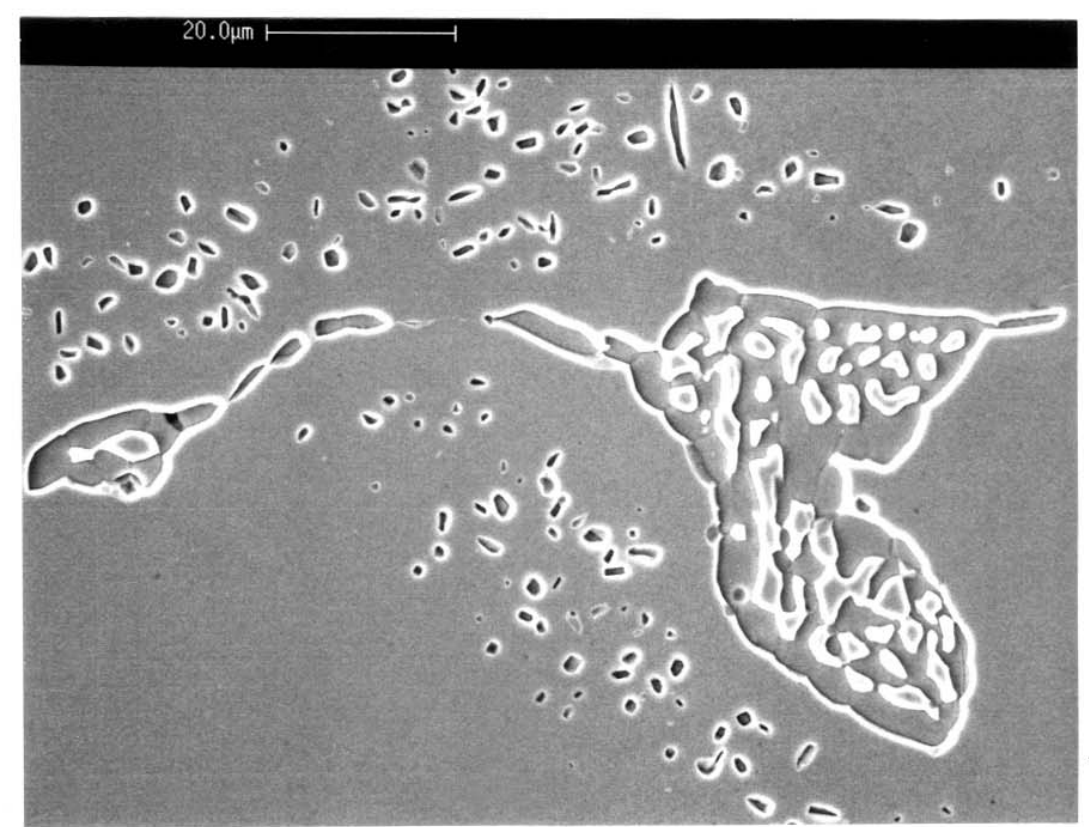

$1000 x$

(a) Secondary image

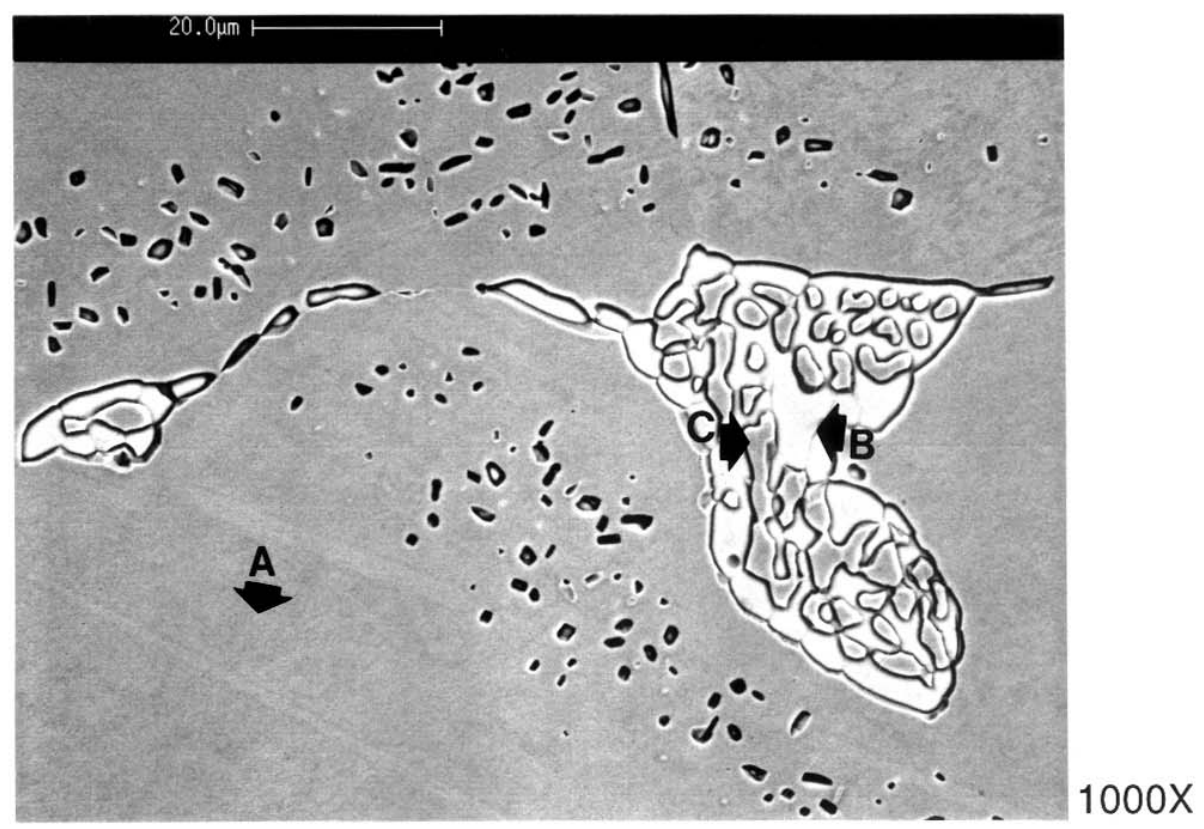

(b) Back scattered image

Figure 128. SEM photomicrograph of CN-3MN Heat 4 in SA condition, $\left(2100^{\circ} \mathrm{F}+\mathrm{WQ}\right)$, EDS analysis at locations marked by letters 


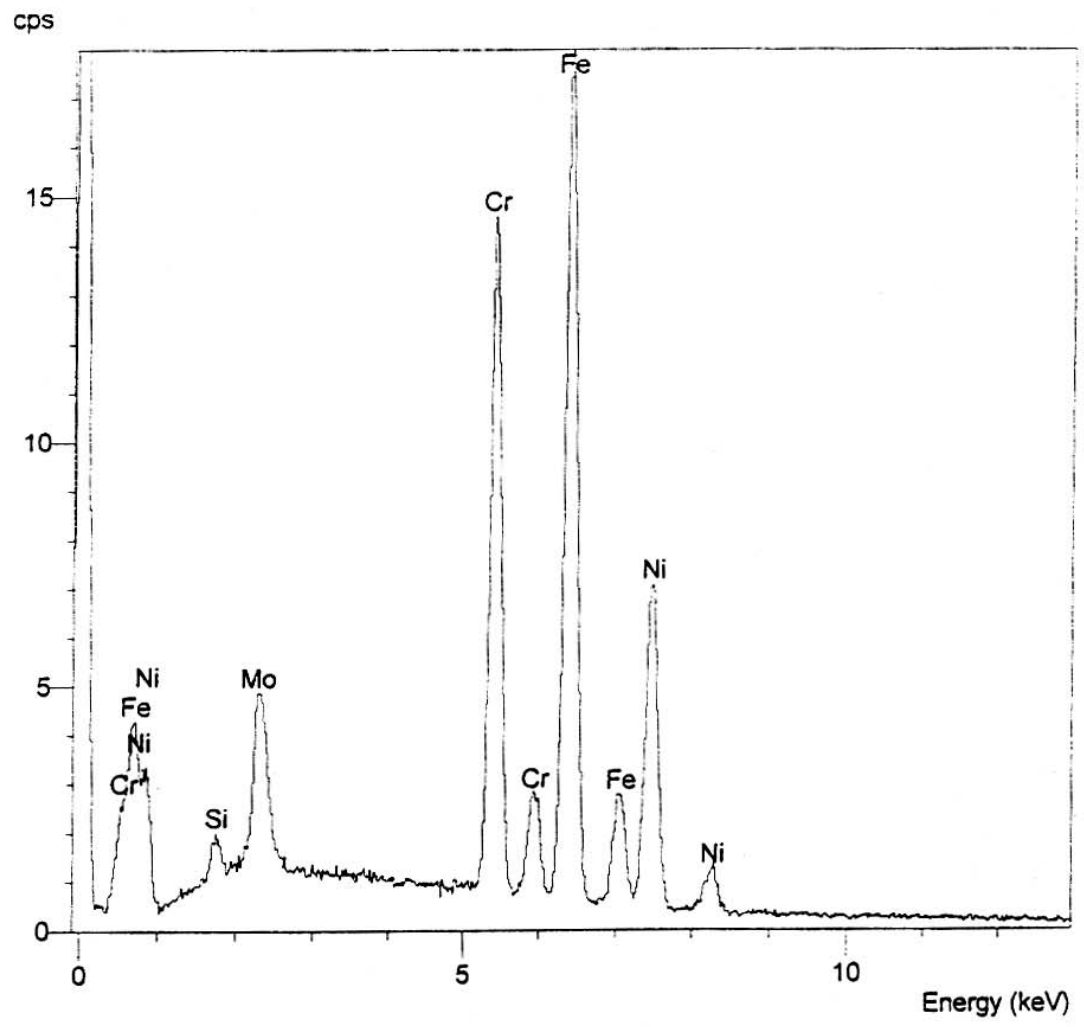

Figure 129. EDS spectrum at Location A (matrix) in Figure 128, $\mathrm{CN}-3 \mathrm{MN}$ Heat 4 in SA condition (2100 $\mathrm{F}+\mathrm{WQ})$ 
cps

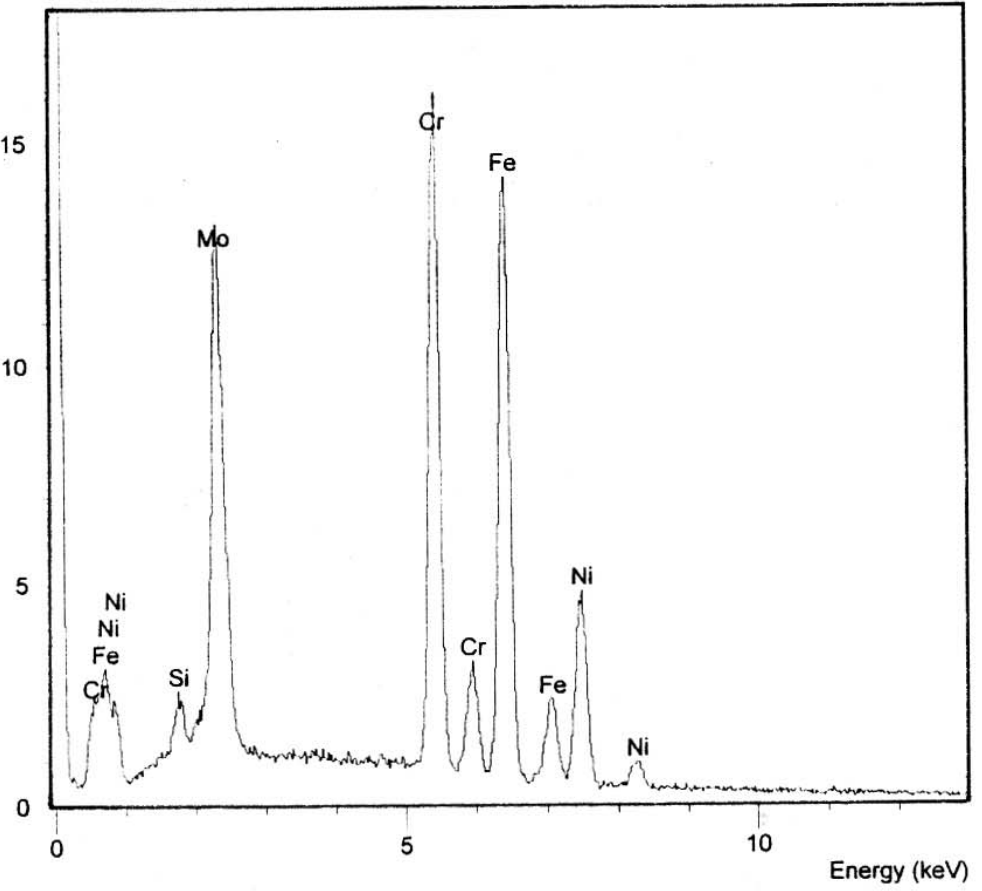

Figure 130. EDS spectrum at Location B (bright area within "islands") in Figure $128,2100^{\circ} \mathrm{F}$ solution annealed (WQ) $\mathrm{CN}-3 \mathrm{MN}$ Heat 4

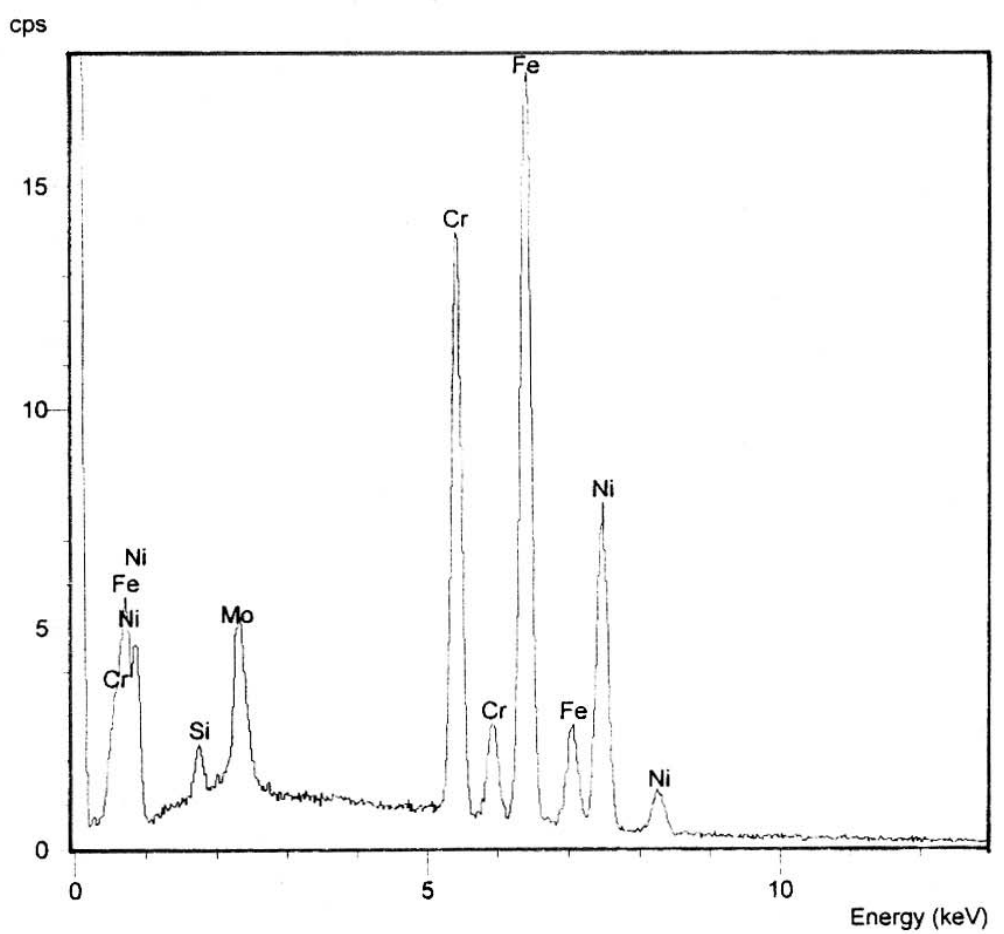

Figure 131. EDS spectrum at Location C (gray area within "islands") in Figure $128,2100^{\circ} \mathrm{F}$ solution annealed (WQ) CN-3MN Heat 4 
indicates that the segregation extent of $\mathrm{Cr}$ and Mo within the "islands" has been decreased upon solution annealing $\left(2100^{\circ} \mathrm{F} / 1150^{\circ} \mathrm{C}+\mathrm{WQ}\right)$, compared to the ascast condition. In addition, the majority of the area, both bright and gray areas within "islands", was unstained during stain etching. The bright areas (Locations B) are considered to be $\mathrm{Cr} / \mathrm{Mo}$ carbides/nitrides. The gray areas are considered to be equivalent to the matrix.

Figure 132 shows the typical SEM microstructural morphology of $2300^{\circ} \mathrm{F} / 1260^{\circ} \mathrm{C}(\mathrm{WQ})$ solution annealed $\mathrm{CN}-3 \mathrm{MN}$ Heat 4 . It is evident that the bright irregular- shaped secondary phases within the "islands" (present in the ascast and $2100^{\circ} \mathrm{F} / 1150^{\circ} \mathrm{C} \mathrm{SA}$ conditions) are still visible. It should be recalled that these bright irregular-shaped secondary phases did not respond to stain etching. The EDS results are presented in Figures 133 through 136 at the locations marked as A (matrix), B (bright area within "islands"), C (gray area within “islands") and D (dark globular particles) for $2300^{\circ} \mathrm{F} / 1260^{\circ} \mathrm{C}$ solution-annealed $\mathrm{CN}-3 \mathrm{MN}$ Heat 4. Compared to the EDS results for $2100^{\circ} \mathrm{F} / 1150^{\circ} \mathrm{C}$ solutionannealed CN-3MN, Location B (bright area) within the "islands" revealed an identical spectrum to that for $2300^{\circ} \mathrm{F} / 1260^{\circ} \mathrm{C}$ solution annealed $\mathrm{CN}-3 \mathrm{MN}$. This is also true for Location C (gray area within the "islands"). The Mo and $\mathrm{Cr}$ content in the bright areas within the "islands" is greater compared to that in the matrix. Therefore, the remaining secondary phases within the "islands" (Location B) are considered to be $\mathrm{Cr} / \mathrm{Mo}$ carbides/nitrides. The gray areas within the "islands" exhibit a similar Mo and $\mathrm{Cr}$ content to the matrix. Therefore, the gray areas within the "islands" (Location C) are considered to be equivalent to the matrix. 


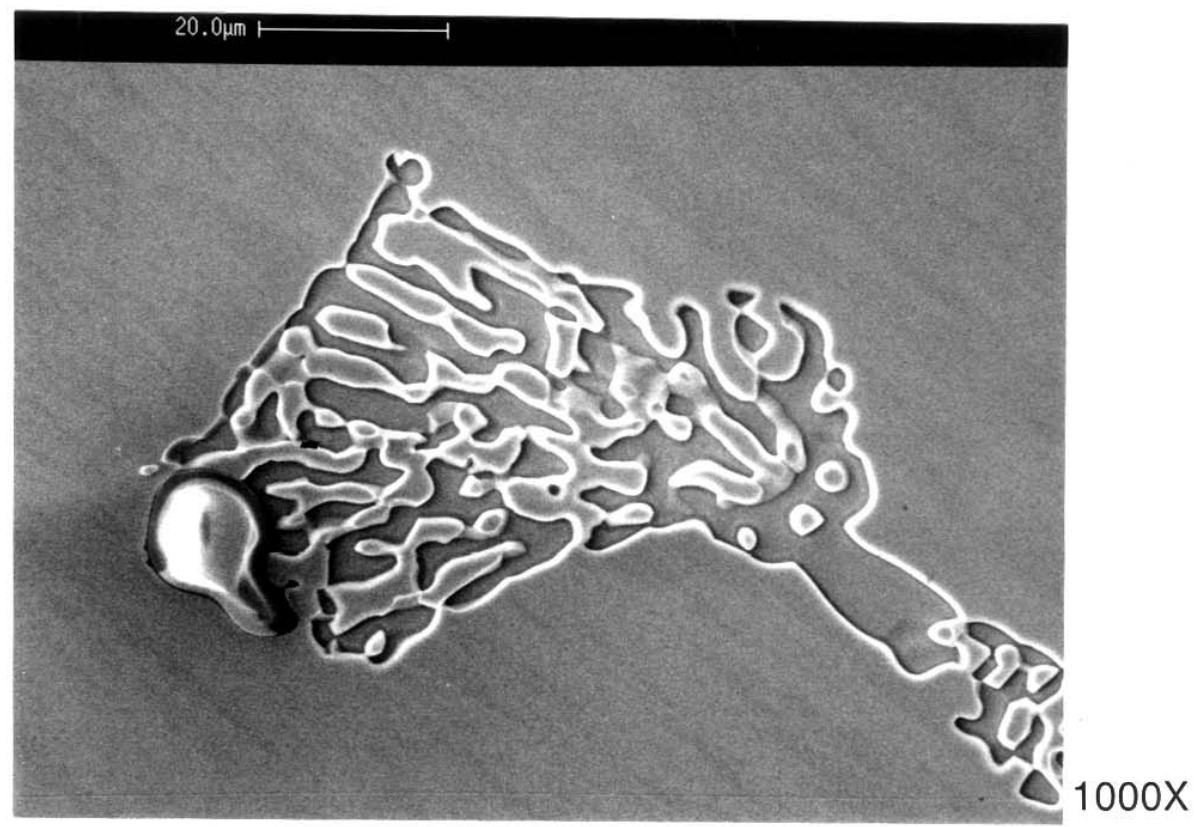

(a) Secondary image

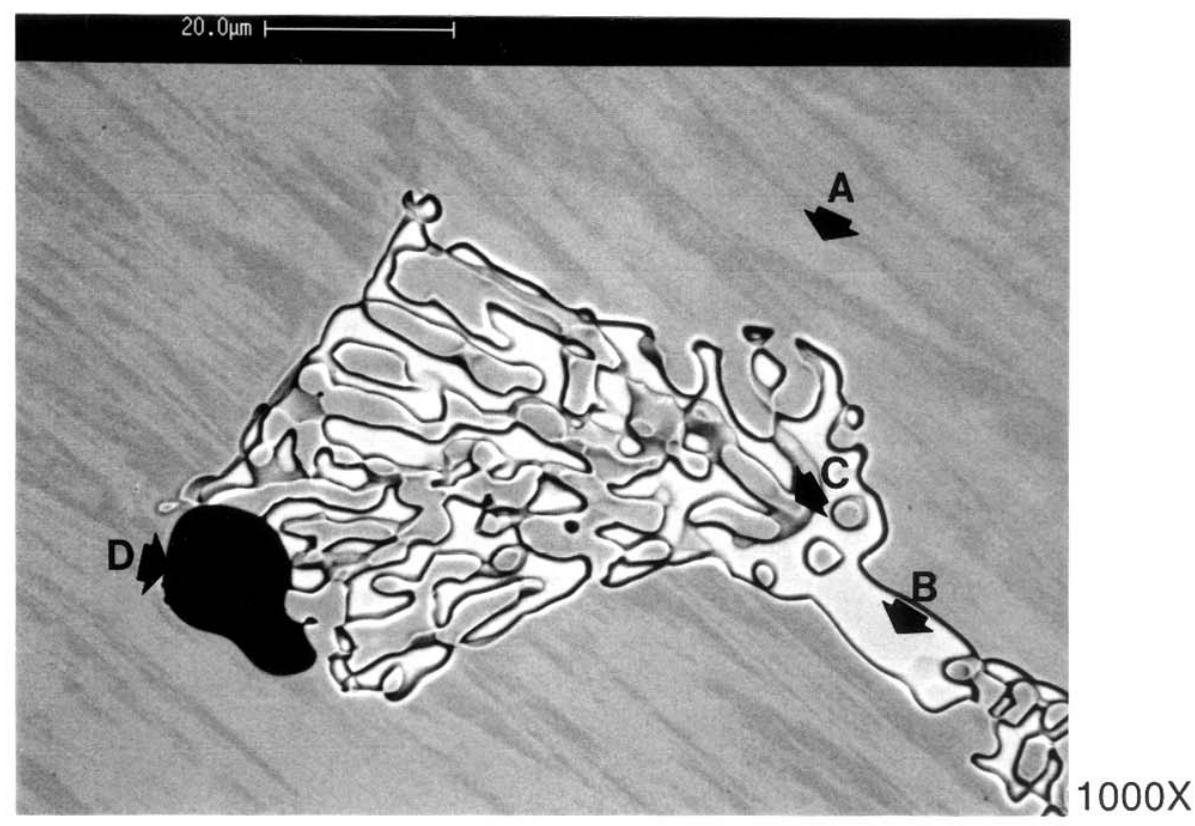

(b) Back scattered image

Figure 132. SEM photomicrograph of CN-3MN Heat 4 in SA condition, $\left(2300^{\circ} \mathrm{F}+\mathrm{WQ}\right)$, EDS analysis at locations marked by letters 


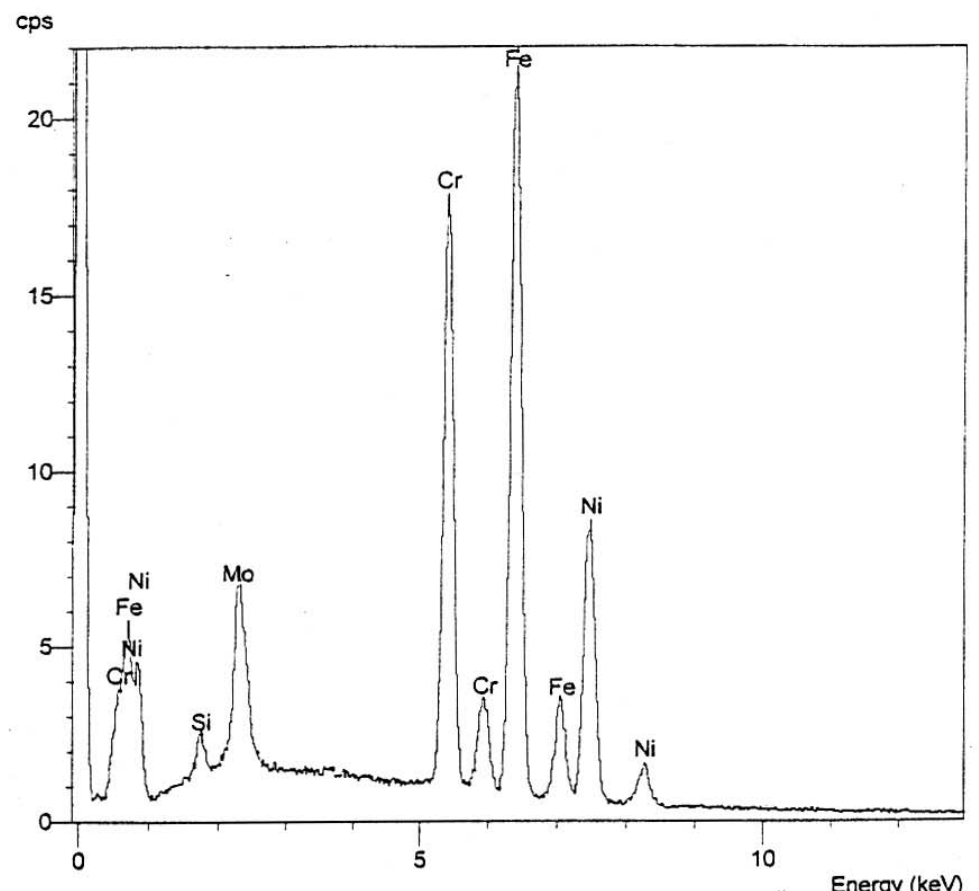

Figure 133. EDS spectrum at Location A (matrix) in Figure $132,2300^{\circ} \mathrm{F}$ solution annealed (WQ) CN-3MN Heat 4

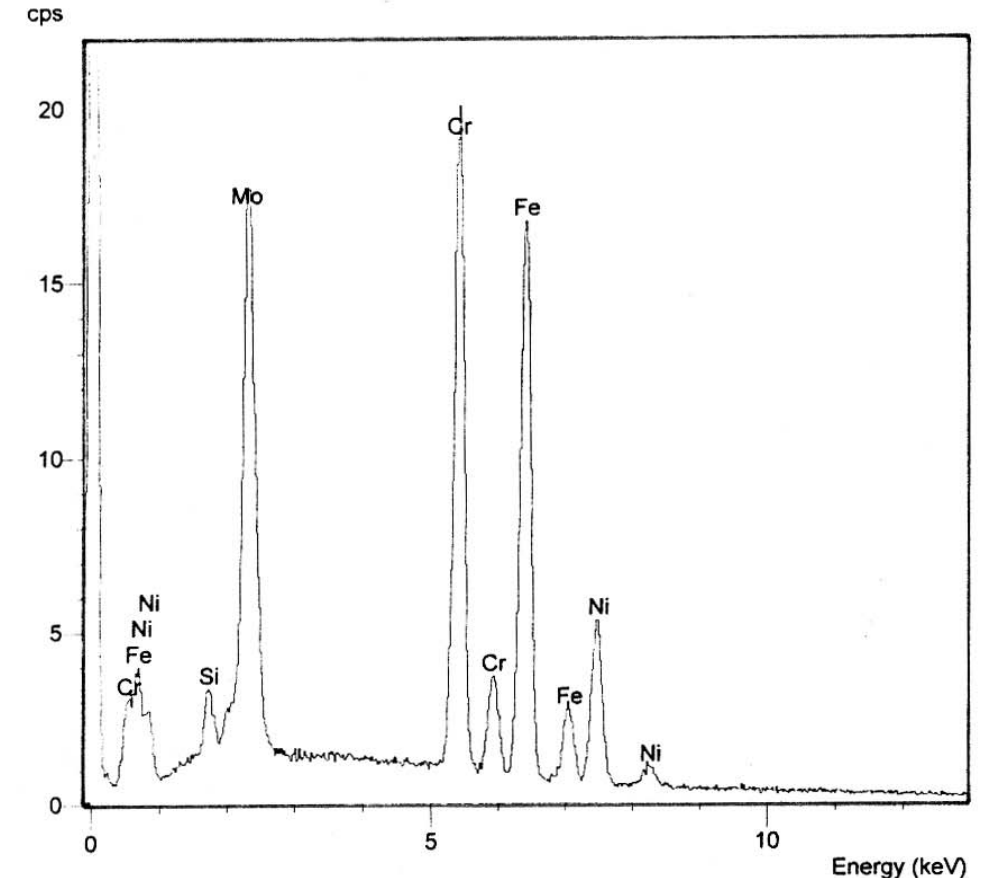

Figure 134.EDS spectrum at Location B (fine irregular shaped secondary phases within "islands") in Figure $132,2300^{\circ} \mathrm{F}$ solution annealed (WQ) CN-3MN Heat 4 
cps

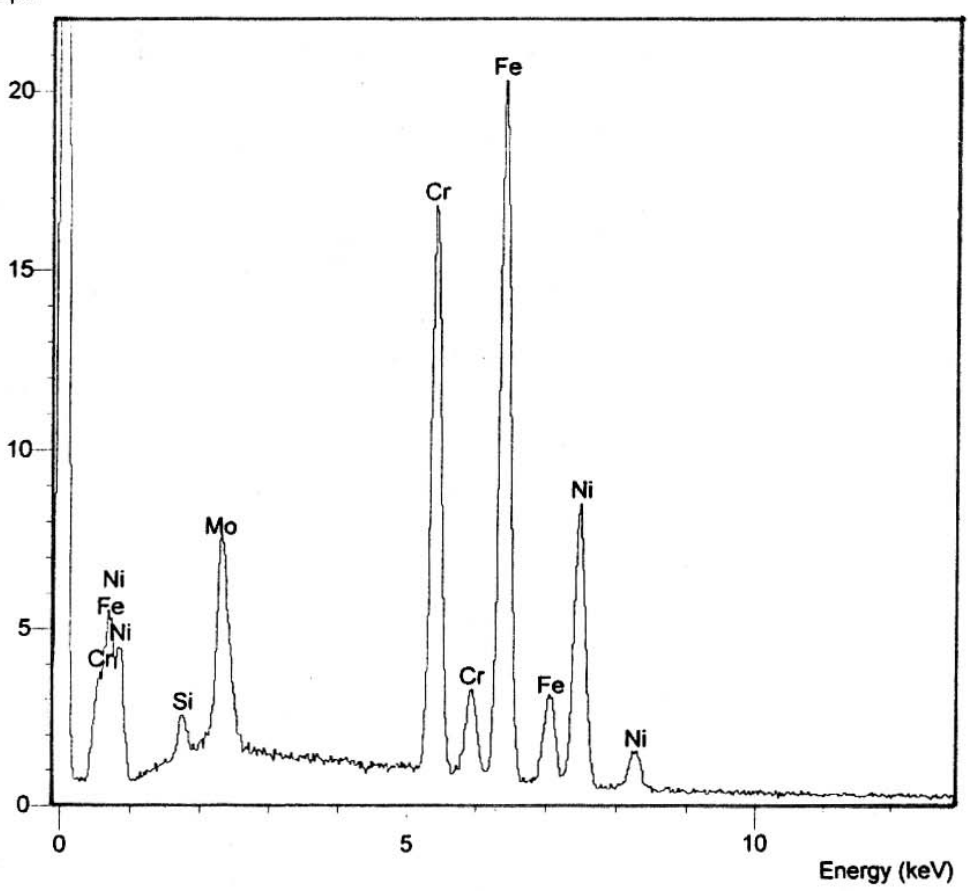

Figure 135. EDS spectrum at Location C (gray area within "islands") in Figure $132,2300^{\circ} \mathrm{F}$ solution annealed $\mathrm{CN}-3 \mathrm{MN}$ Heat 4

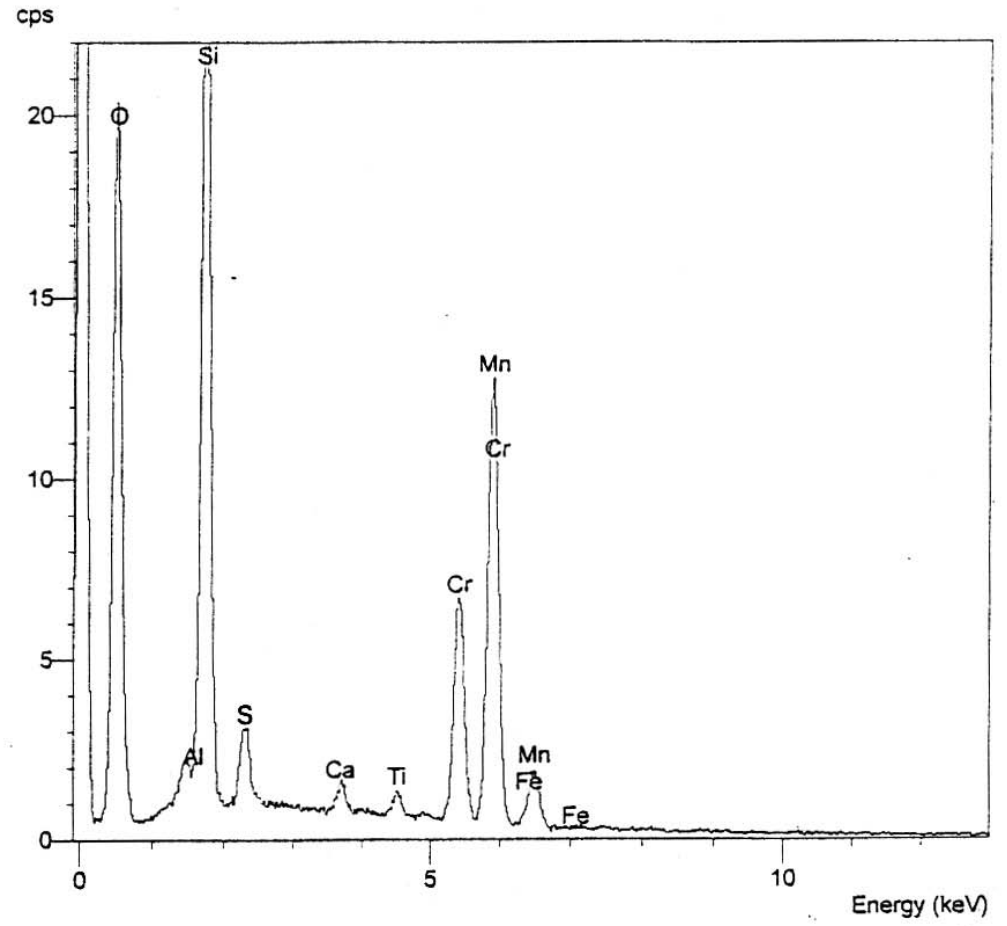

Figure 136. EDS spectrum at Location $D$ (dark globular particles) in Figure $132,2300^{\circ} \mathrm{F}$ solution annealed $\mathrm{CN}-3 \mathrm{MN}$ Heat 4 
In addition, the dark globular particles (location $\mathrm{D}$ ) are primarily Si and/or $\mathrm{Mn}$ oxides.

iii) $\underline{\mathrm{CN}-3 \mathrm{MN} \text { Heat } 5}$

CN-3MN Heat 5 was also selected for SEM/EDS evaluation in the as-cast condition and solution-annealed conditions $\left(2100^{\circ} \mathrm{F} / 1150^{\circ} \mathrm{C} \& 2300^{\circ} \mathrm{F} / 1260^{\circ} \mathrm{C}+\right.$ WQ). The typical SEM microstructural morphology of the as-cast $C N-3 M N$ Heat 5 is shown in Figure 137 (a) as a secondary electron image and (b) as a back scattered electron image. It is evident that the SEM microstructural morphology of this heat is different from the above two heats (Heat N3GAO \& Heat 4) in the as-cast condition. In as-cast Heat 5 , only bright globular particles with various sizes are observed as shown in Figure 137, and the microstructure of $\mathrm{CN}-3 \mathrm{MN}$ Heat 5 does not change after solution annealing at all selected SA temperatures $\left(2100 / 1150^{\circ} \mathrm{C}, 2250 / 1230^{\circ} \mathrm{C} \& 2300^{\circ} \mathrm{F} / 1260^{\circ} \mathrm{C}\right)$. To identify these bright globular particles, EDS analysis was performed at the locations A (matrix) and B (bright globular particles) as marked in Figure 137 (b). The EDS results for the as-cast CN-3MN Heat 5 are presented in Figures 138 (locations A - matrix) and 139 (location B - bright globular particles). It is evident that these bright globular particles are primarily Ce, La, Al and O-rich particles (see Figure 139). These bright globular particles are considered to be Ce/La/Al oxides. 


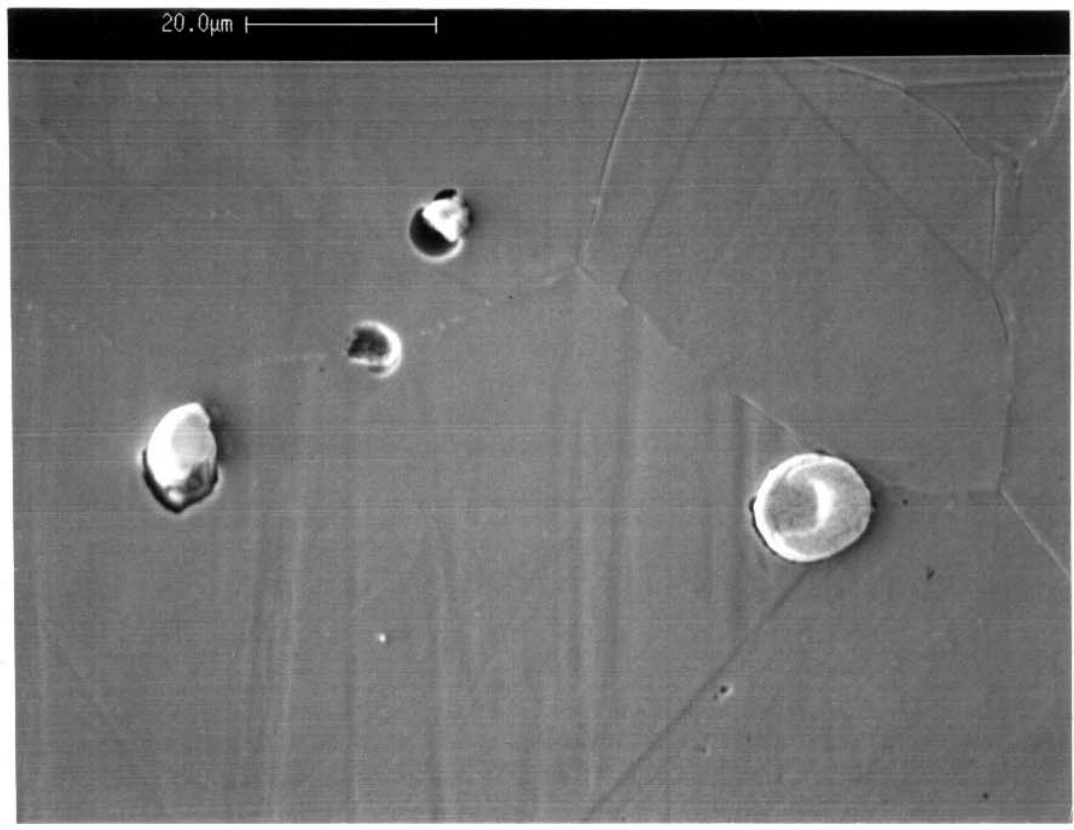

$1000 X$

(a) Secondary image

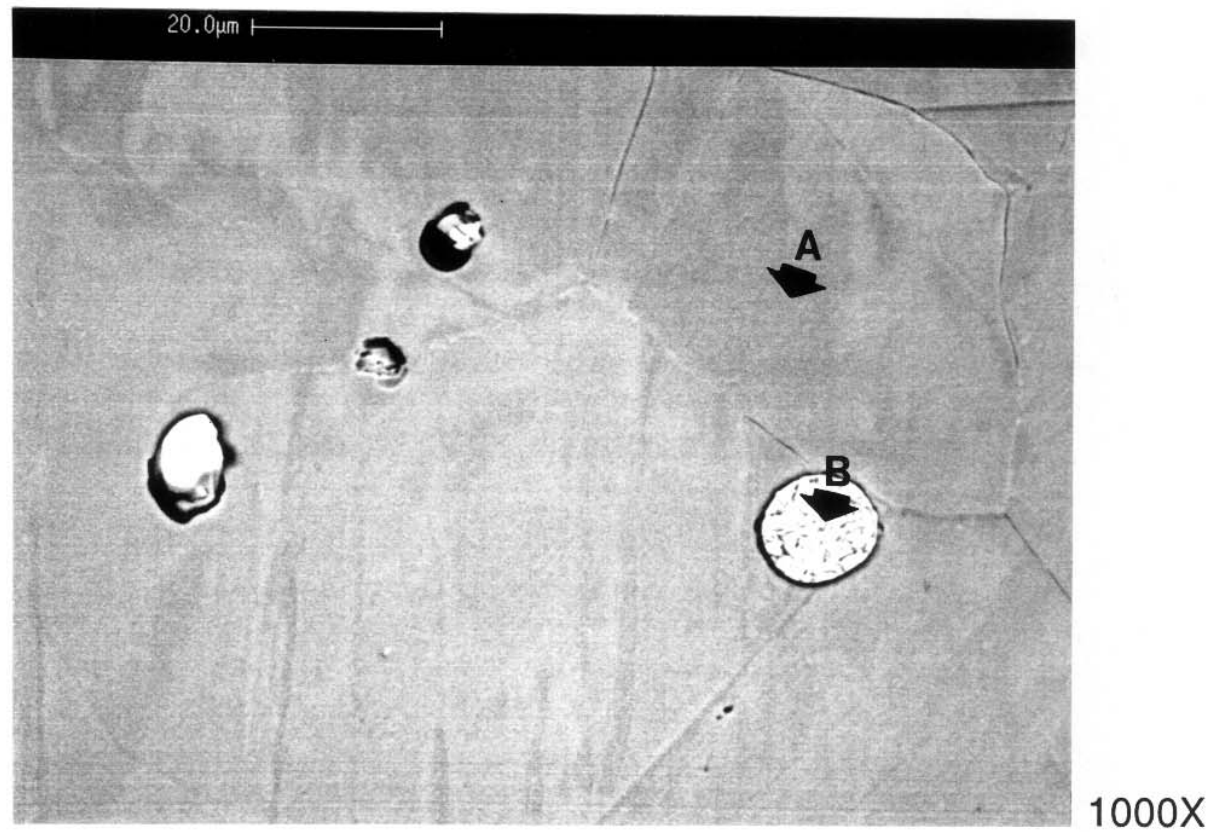

(b) Back scattered image

Figure 137. SEM photomicrograph of CN-3MN Heat 5 in as-cast condition, EDS analysis at locations marked by letters 
cps

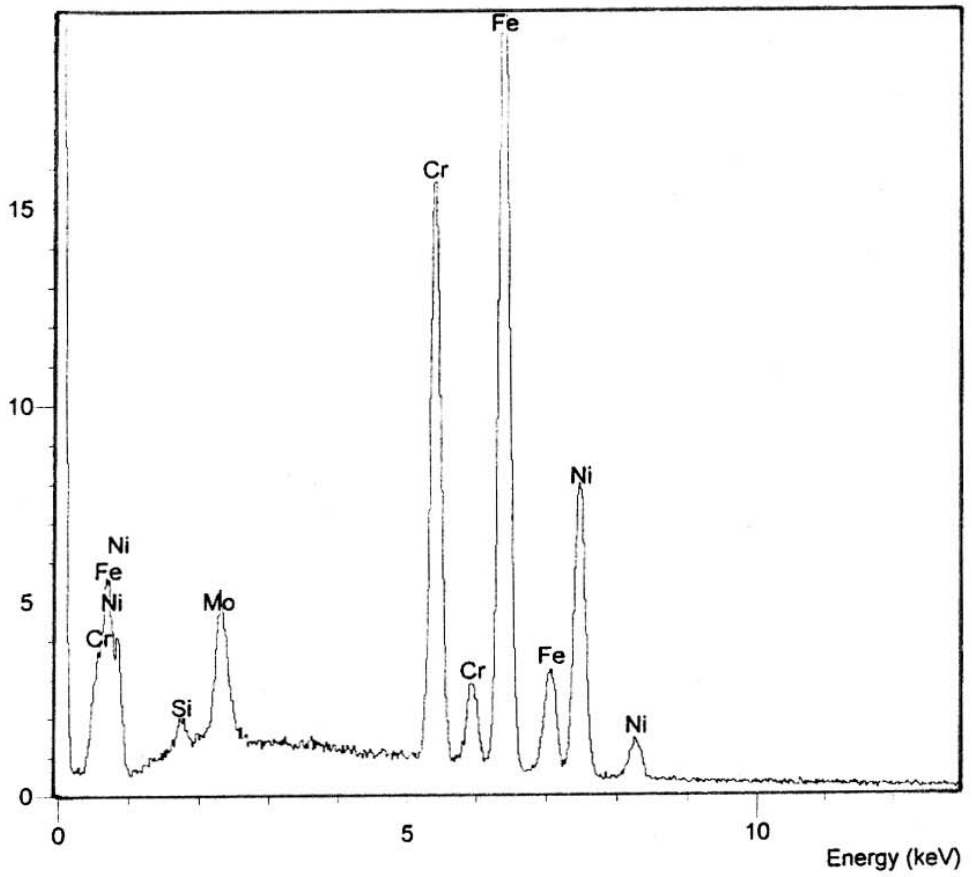

Figure 138. EDS spectrum at Location A (matrix) in Figure 137, as-cast CN-3MN Heat 5

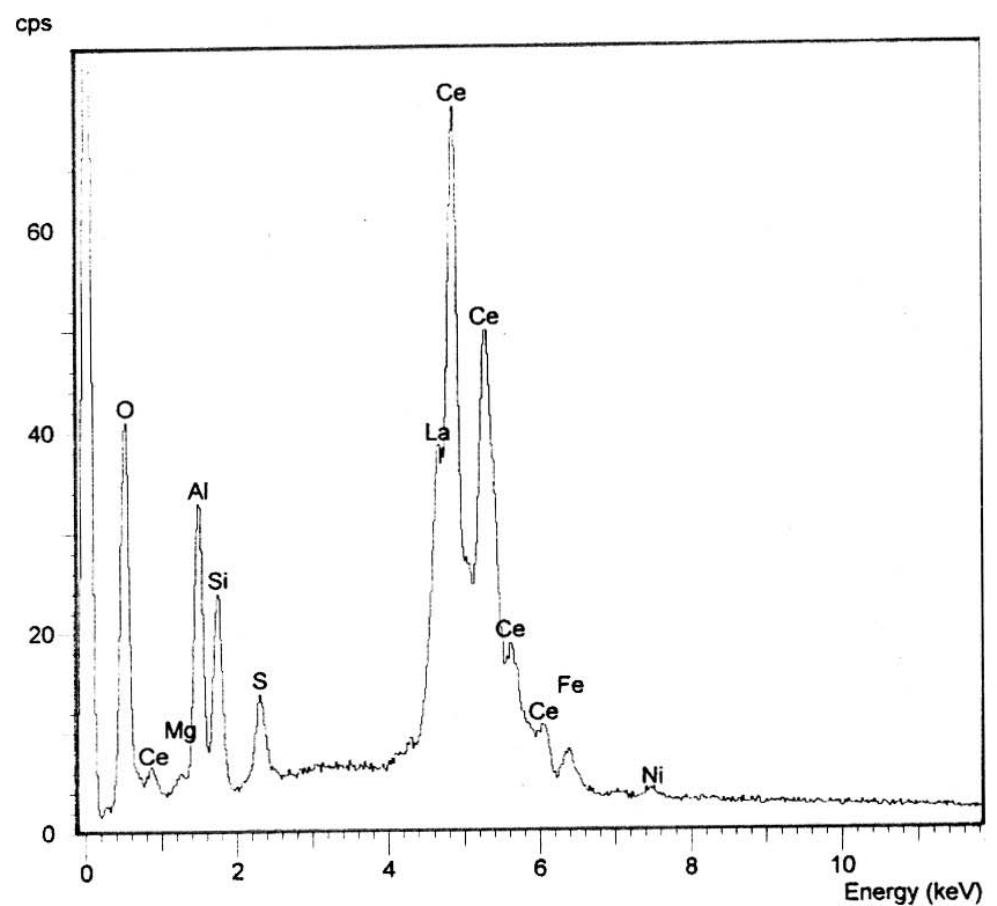

Figure 139. EDS spectrum at Location B (bright globular particles) in Figure 137, as-cast $\mathrm{CN}-3 \mathrm{MN}$ Heat 5 


\section{- $\underline{\text { X-ray Diffraction Analysis }}$}

To further verify the results of stain-etching and EDS analysis, X-ray diffraction analysis was conducted on two heats of CN-3MN (Heat 4 \& Heat 5) in both the as-cast and solution-annealed condition. The secondary phases were extracted from the cast materials using the electrolytic precipitate extraction technique. For comparison, X-ray diffraction was also conducted on the wrought counterpart AL-6XN.

\section{i) $\underline{\mathrm{CN}}-3 \mathrm{MN}$ Heat 4}

The X-ray diffraction results are shown in Figures 140 through 142 for the $\mathrm{CN}-3 \mathrm{MN}$ Heat 4 in the as-cast and solution-annealed conditions $\left(2100^{\circ} \mathrm{F} / 1150^{\circ} \mathrm{C}\right.$ and $2300^{\circ} \mathrm{F} / 1260^{\circ} \mathrm{C}+\mathrm{WQ}$ ). As identified in Figure 140 , the major precipitates in the as-cast $\mathrm{CN}-3 \mathrm{MN}$ Heat 4 are $\mathrm{Cr}$ carbides $\left(\mathrm{Cr}_{23} \mathrm{C}_{6}\right)$ and/or Fe carbides $\left(\mathrm{Fe}_{3} \mathrm{C}\right)$.

For solution annealed $\mathrm{CN}-3 \mathrm{MN}$ Heat 4, the X-ray diffraction results are presented in Figures 141 and 142 for $2100^{\circ} \mathrm{F} / 1150^{\circ} \mathrm{C}$ and $2300^{\circ} \mathrm{F} / 1260^{\circ} \mathrm{C}$, respectively. Compared to the as-cast $\mathrm{CN}-3 \mathrm{MN}$ Heat 4, two major peaks were revealed for the SA CN-3MN Heat $4\left(2100^{\circ} \mathrm{F} / 1150^{\circ} \mathrm{C} \& 2300^{\circ} \mathrm{F} / 1260^{\circ} \mathrm{C}\right)$ at the same locations as those of the as-cast $\mathrm{CN}-3 \mathrm{MN}$ Heat 4 . It is indicated that the major precipitates in the SA CN-3MN Heat 4 are $\mathrm{Cr}$ carbides $\left(\mathrm{Cr}_{23} \mathrm{C}_{6}\right)$ and/or $\mathrm{Fe}$ carbides $\left(\mathrm{Fe}_{3} \mathrm{C}\right)$. 


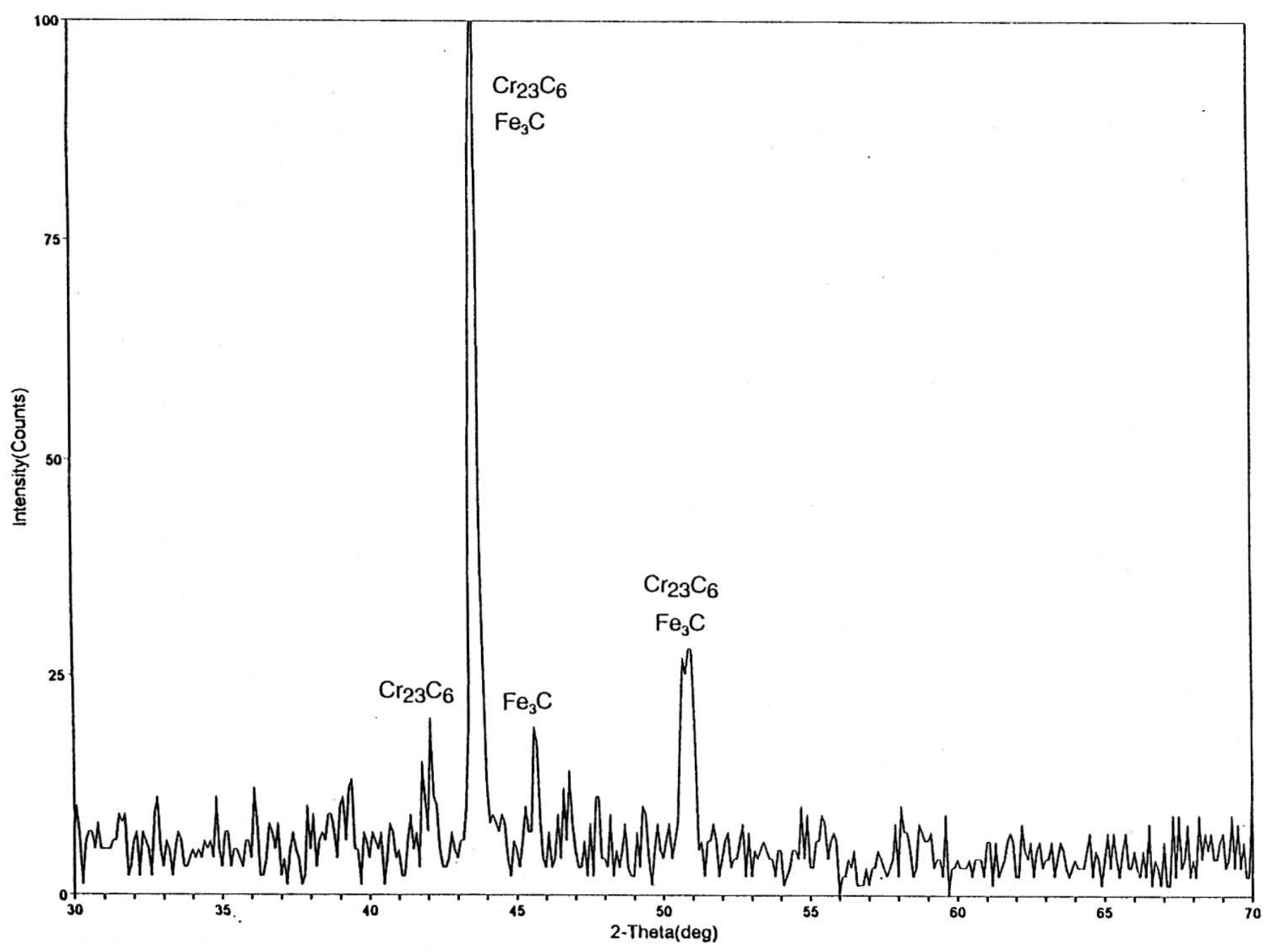

Figure 140. X-ray diffraction spectrum of particles extracted from as-cast CN-3MN Heat 4 . 


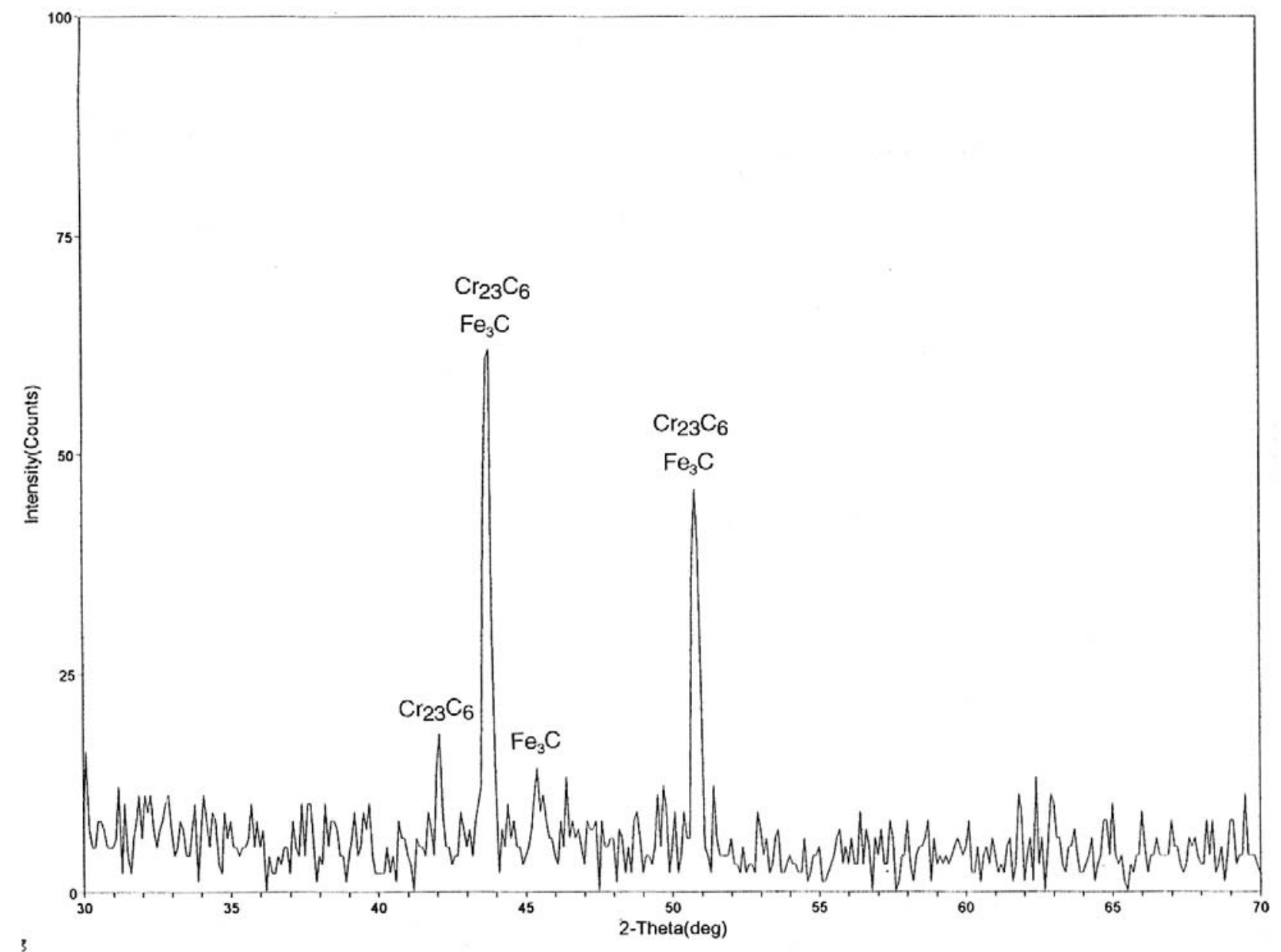

Figure 141. X-ray diffraction spectrum of particles extracted from solution annealed $\left(2100^{\circ} \mathrm{F}+\mathrm{WQ}\right)$ $\mathrm{CN}-3 \mathrm{MN}$ Heat 4 


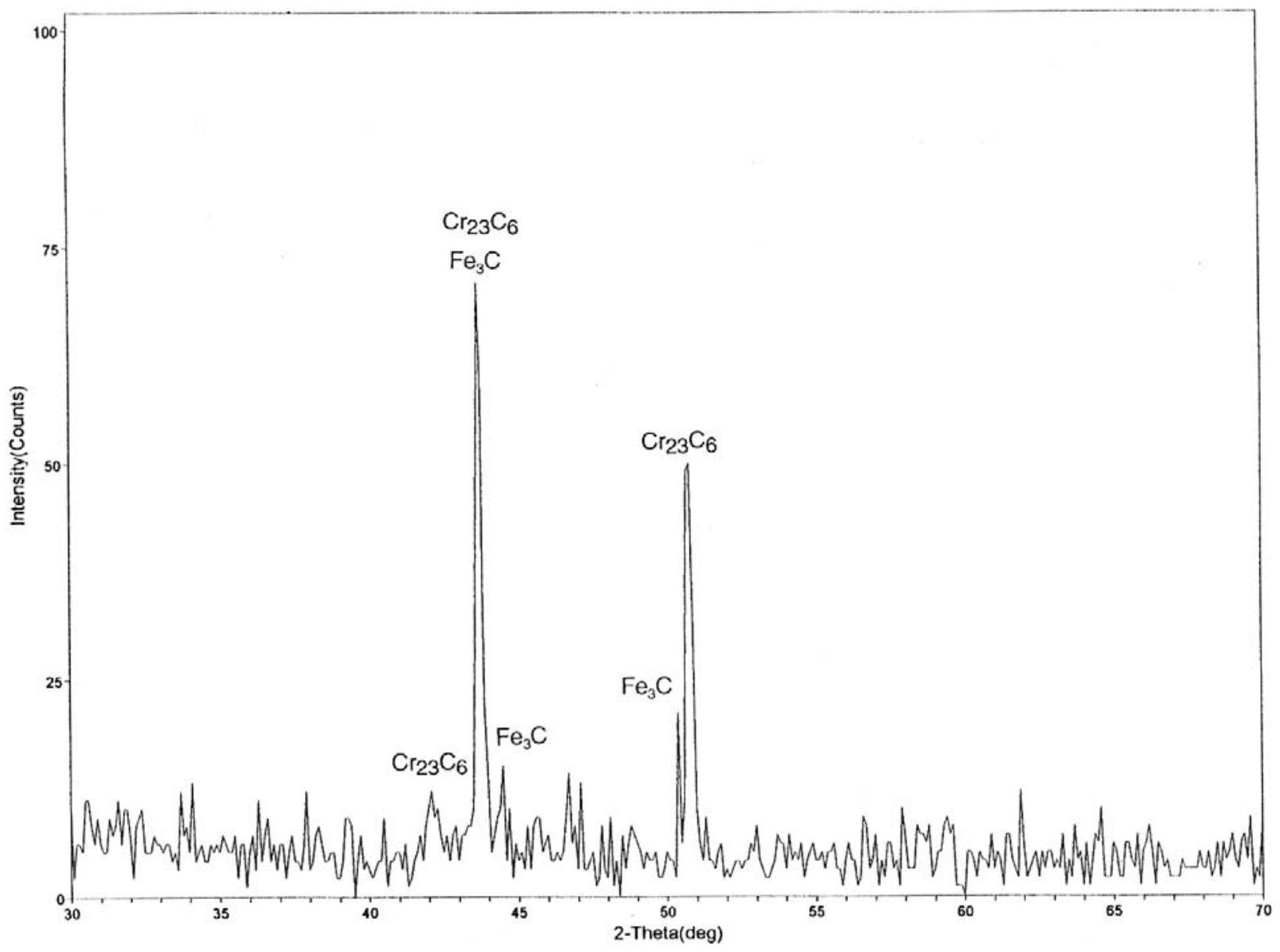

Figure 142. X-ray diffraction spectrum of particles extracted from solution annealed $\left(2300^{\circ} \mathrm{F}+\mathrm{WQ}\right)$ $\mathrm{CN}-3 \mathrm{MN}$ Heat 4 


\section{ii) $\underline{\mathrm{CN}-3 \mathrm{MN} \text { Heat } 5}$}

For the case of $\mathrm{CN}-3 \mathrm{MN}$ Heat 5, Figures 143 through 145 present the X-ray diffraction results in the as-cast, $2100^{\circ} \mathrm{F} / 1150^{\circ} \mathrm{C}$ and $2300^{\circ} \mathrm{F} / 1260^{\circ} \mathrm{C}$ solutionannealed conditions. It is evident that the spectra of X-ray diffraction for the ascast and solution-annealed CN-3MN Heat 5 are basically identical (see Figures 143 through 145). The secondary phases were determined for the as-cast and solution-annealed $\mathrm{CN}-3 \mathrm{MN}$ Heat 5 are $\mathrm{Cr} / \mathrm{Fe}$ carbides. It should be recalled that the metallographic study revealed only a small amount of globular particles (Ce/La/Al oxides By EDS analysis) in CN-3MN Heat 5 and no other secondary phases were found at magnification of $1,000 \mathrm{X}$ in both the as-cast or solutionannealed condition. It is believed that the fine $\mathrm{Cr}$ and Fe carbides in $\mathrm{CN}-3 \mathrm{MN}$ Heat 5 may be too small in size to be identified using OLM at 1,000X. However, a significant amount of fine $\mathrm{Cr}$ and $\mathrm{Fe}$ carbides can be extracted from the bulk material using electrolytic precipitate extraction technique. On the other hand, the small amount of globular particles (Ce/La/Al oxides) may not be revealed clearly using X-ray diffraction due to an insufficient amount.

The wrought counterpart AL-6XN was also used for X-ray diffraction and the results are shown in Figure 146. For the wrought material AL-6XN, the precipitates are identified as $\mathrm{Fe}$ carbide $\left(\mathrm{Fe}_{3} \mathrm{C}\right)$. No $\sigma$ phase, $\mathrm{Cr}$ carbides, or any other secondary phases were found in AL-6XN. 


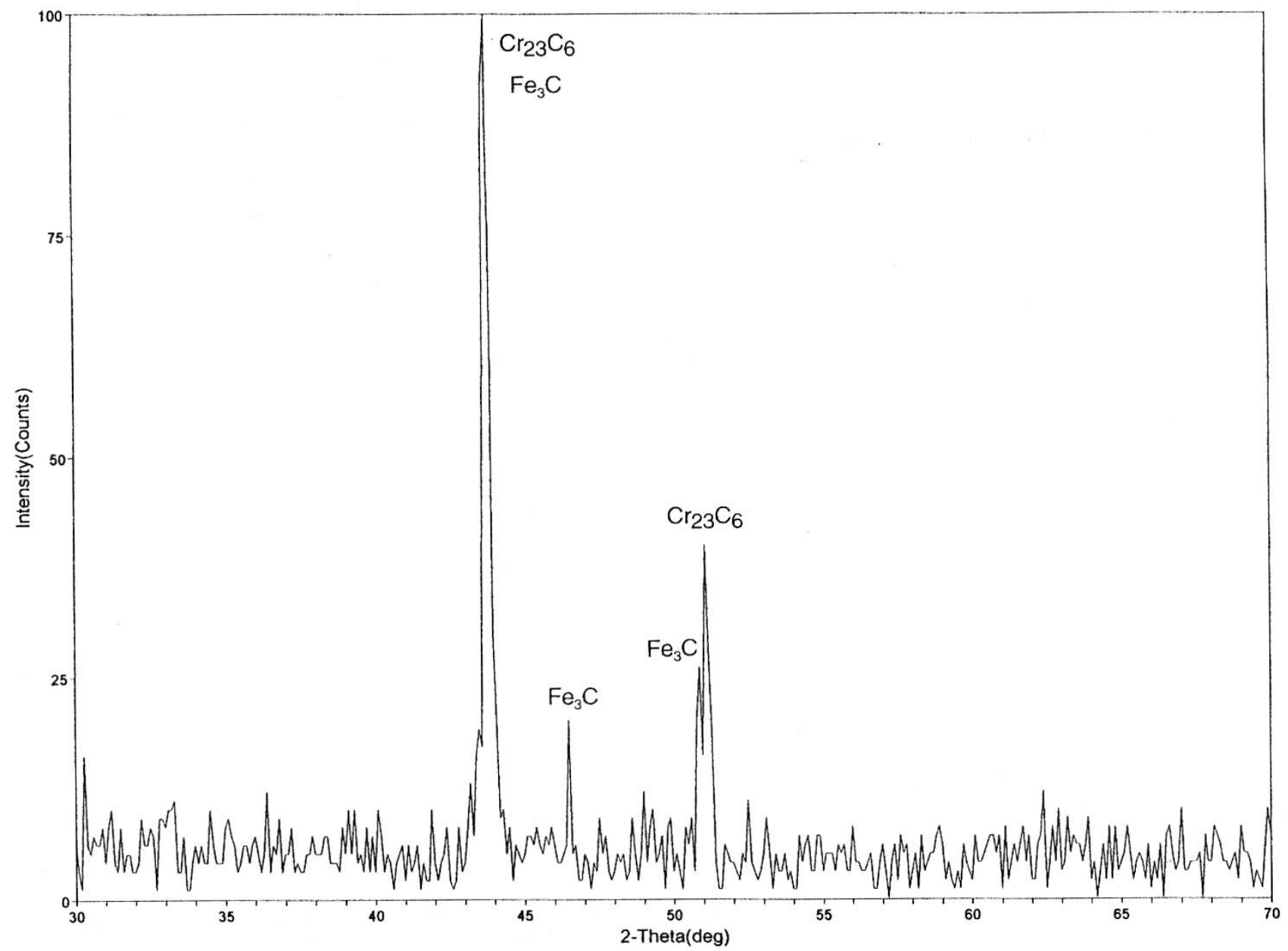

Figure 143. X-ray diffraction spectrum of particles extracted from as-cast CN-3MN Heat 5 . 


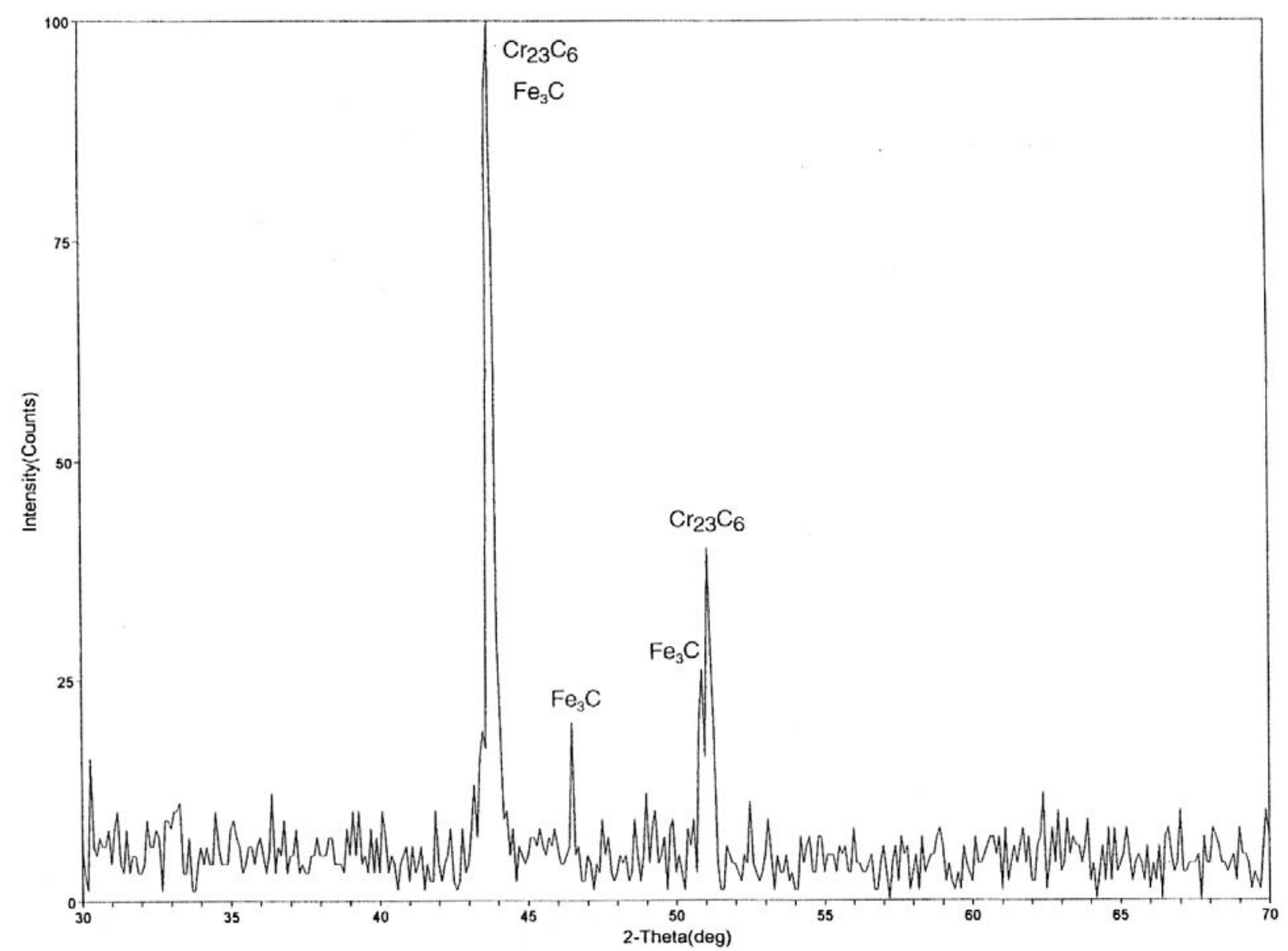

Figure 143. X-ray diffraction spectrum of particles extracted from as-cast $\mathrm{CN}-3 \mathrm{MN}$ Heat 5. 


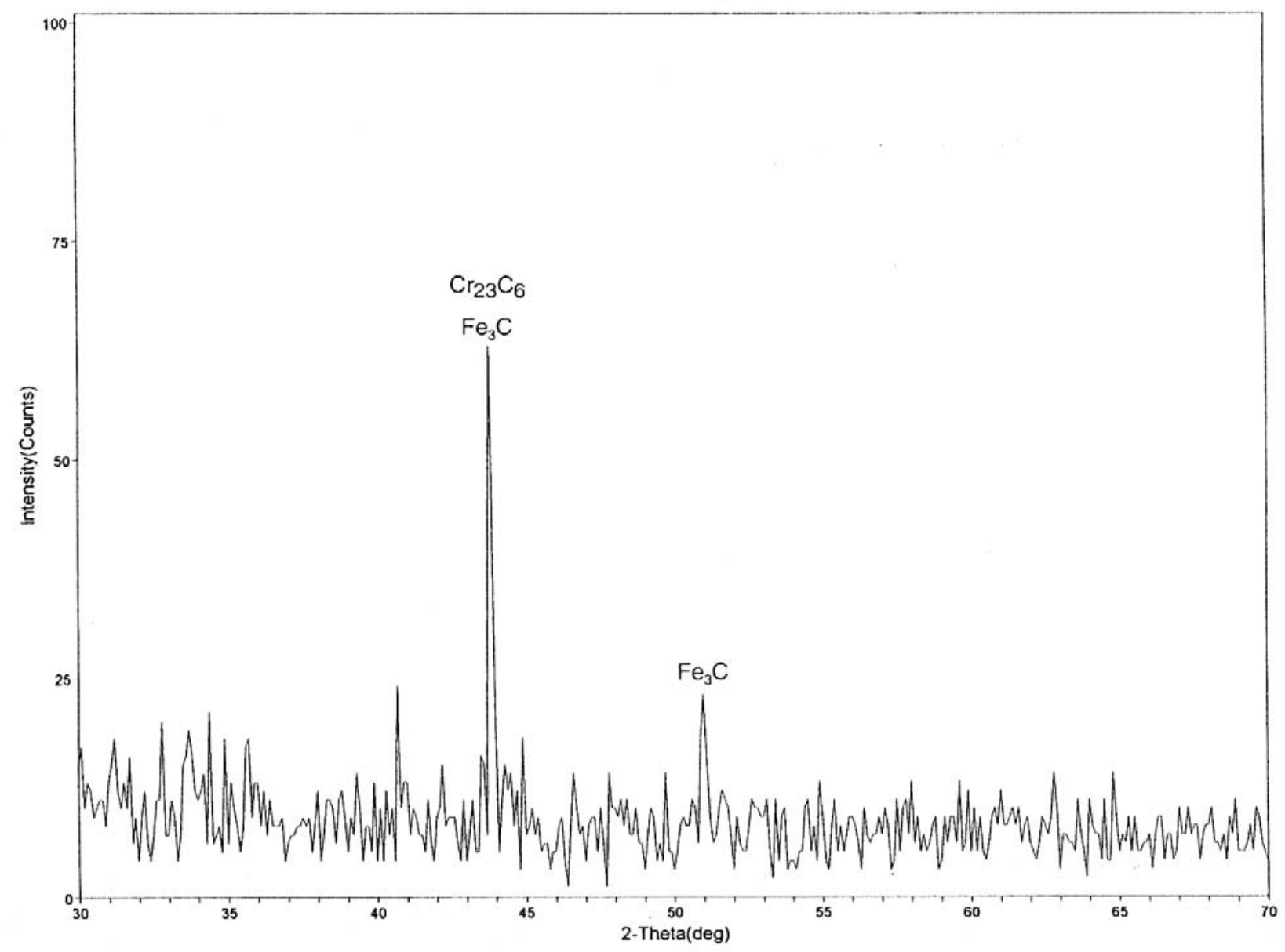

Figure 145. X-ray diffraction spectrum of particles extracted from solution annealed $\left(2300^{\circ} \mathrm{F}+\mathrm{WQ}\right)$ $\mathrm{CN}-3 \mathrm{MN}$ Heat 5 


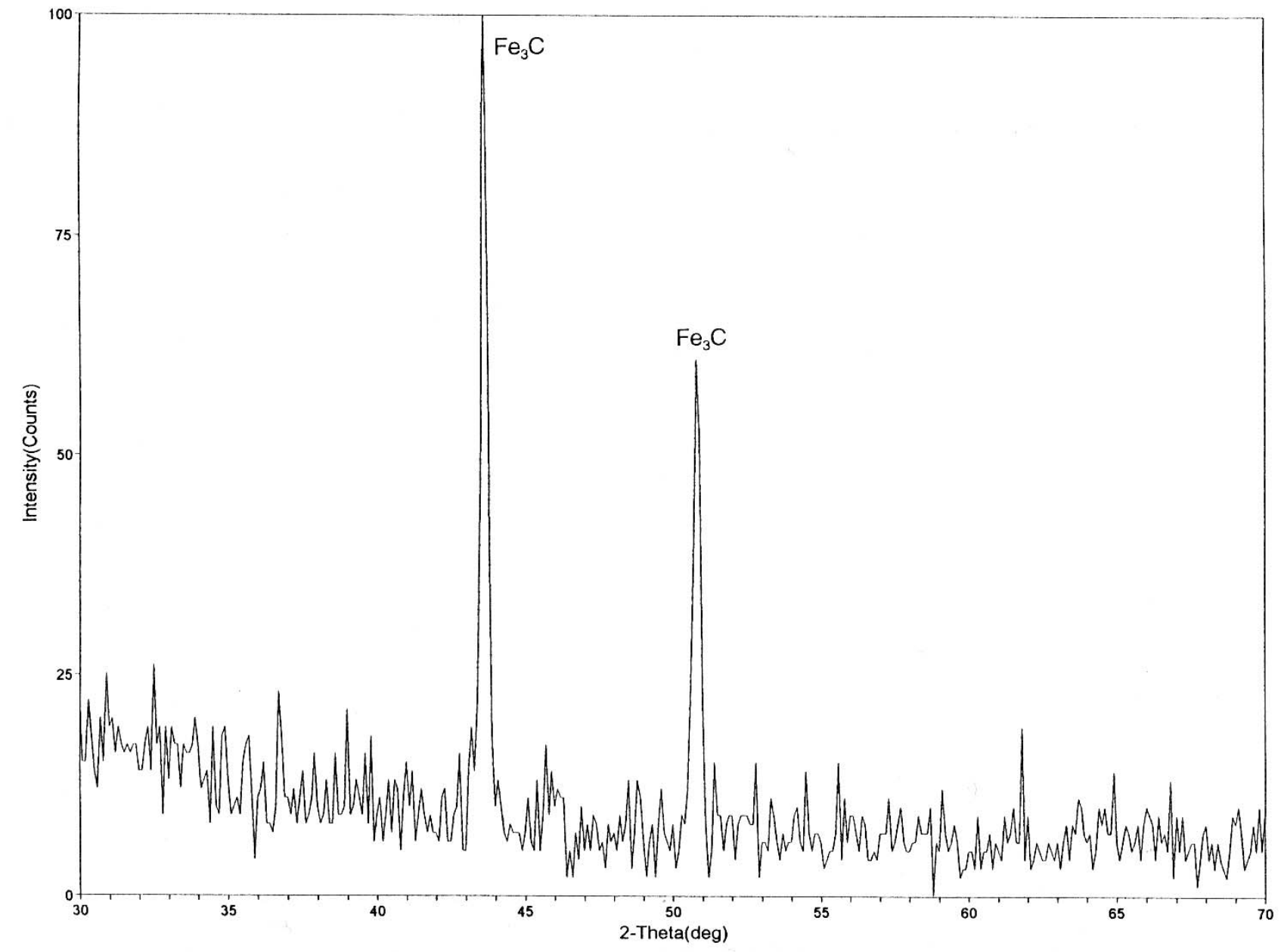

Figure 146. X-ray diffraction spectrum of particles extracted from wrought material AL-6XN. 


\section{4-3. Results of Inclusion Study}

In the microstructural inclusion evaluation, three heats of CK-3MCuN (reported as Heats 2, 3, \& 5 in the Phase I program) and CN-3MN (reported Heats as 1, 4, $\& 5$ in the Phase I program) were used in the as-cast condition. In addition, the foundry solution-annealed $\mathrm{CN}-3 \mathrm{MN}$ (Heat 4) was also selected to determine the effect of solution annealing on inclusion density and distribution. Two specimens $(3 / 4 " X 3 / 4 ")$ from each heat were extracted from the locations in the casting as shown in Figure 147. These two locations are identified as " $U$ " for the location under the riser and "B" for the location near the bottom edge. The specimens were mounted and polished to $0.05 \mu \mathrm{m}$ and were not etched prior to examination. For comparison, the wrought counterparts $254 \mathrm{SMO}$ and $\mathrm{AL}-6 \mathrm{XN}$, were also evaluated. Quantitative metallographic techniques were applied to determine inclusion distribution and density optically using the "Image-Pro Plus" image analysis system. It is to be noted that the cross-sectional area of inclusions, exposed on the polished surface, was used as a parameter to define "inclusion size" in this study. Some of the inclusions reveal irregular shapes instead of a more typical spherical shape in these high Mo castings, thus, it is more reasonable to use the cross-sectional area of the inclusions to define "inclusion size" as opposed to an inclusion diameter.

For CK-3MCuN, the inclusion areal density (the number of inclusions per square millimeter) as a function of inclusion size is presented in Figures 148 (a), (b) and (c) for Heats 2, 3, and 5 at Locations " $\mathrm{U}$ " and " $\mathrm{B}$ ". It is evident that, for all three heats, the majority of inclusions are within the area range of $2.2-20 \mu \mathrm{m}^{2}$ 


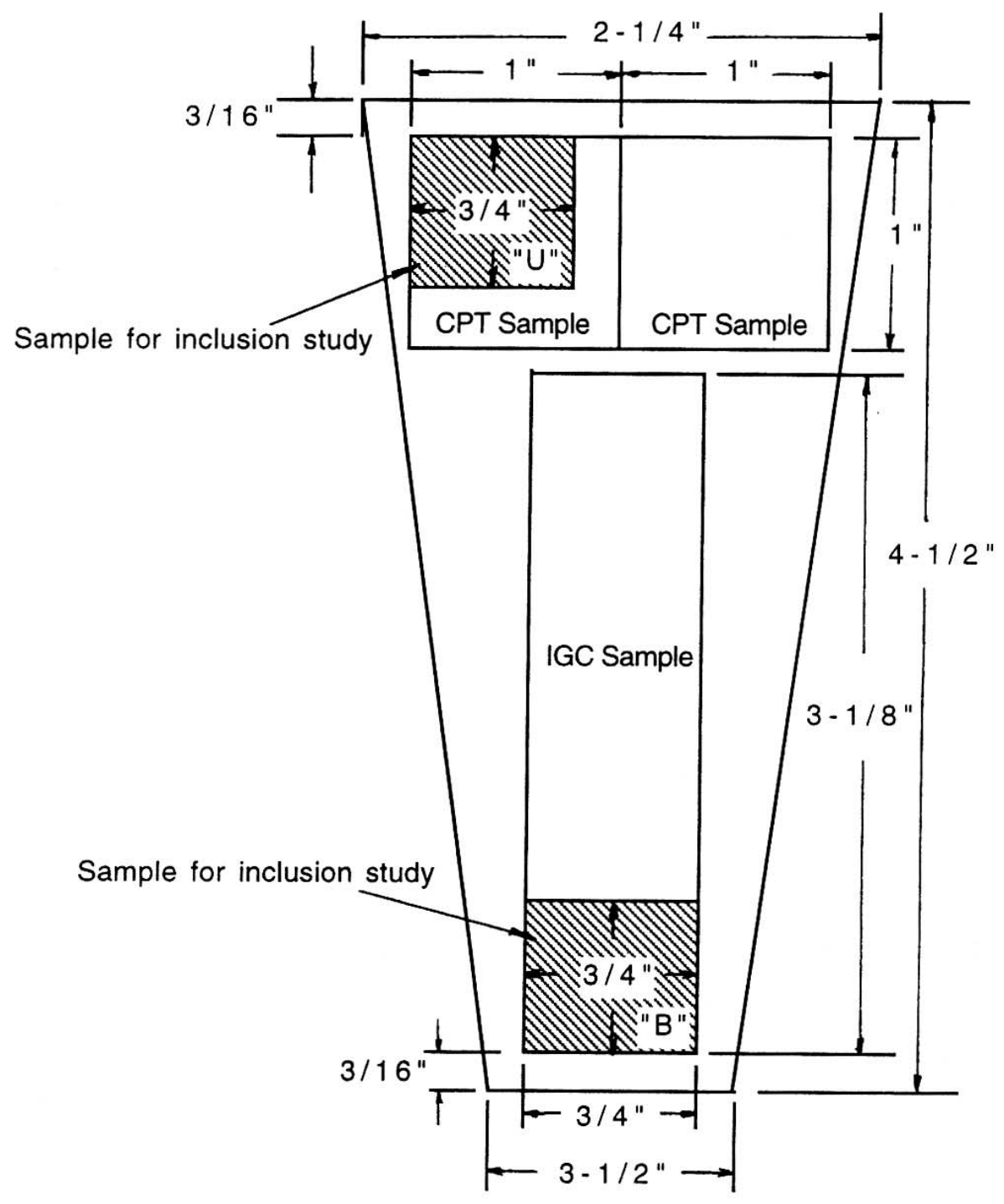

Figure 147. Sketch for showing location of sample extraction 


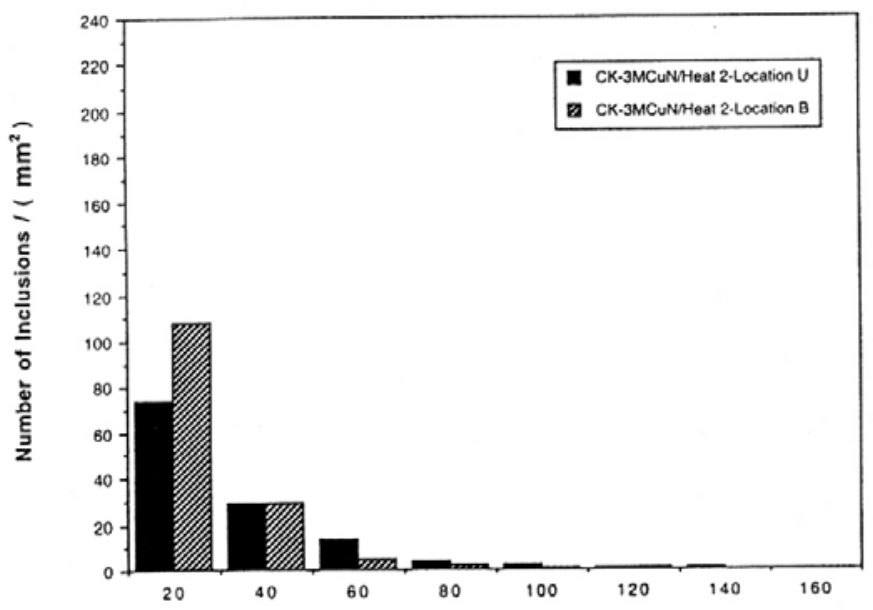

(a)

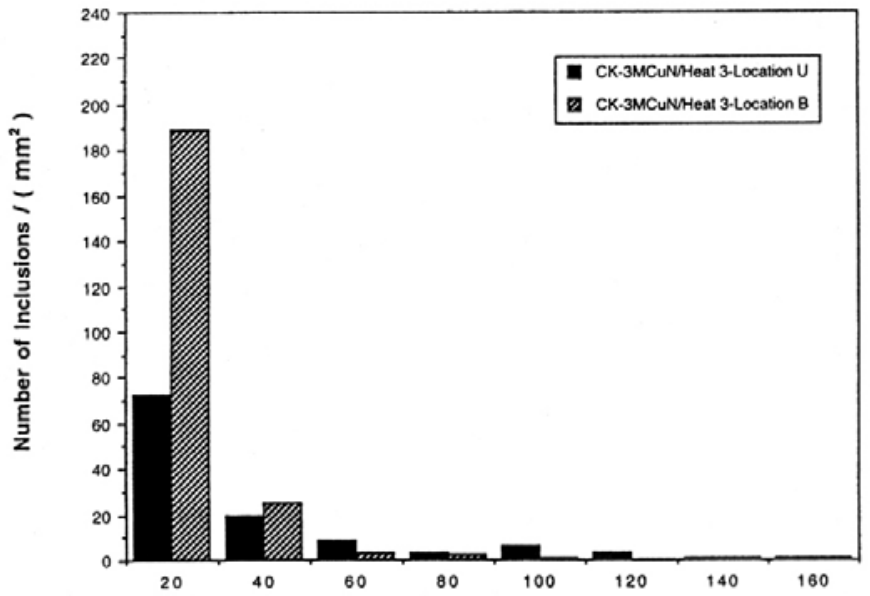

(b)

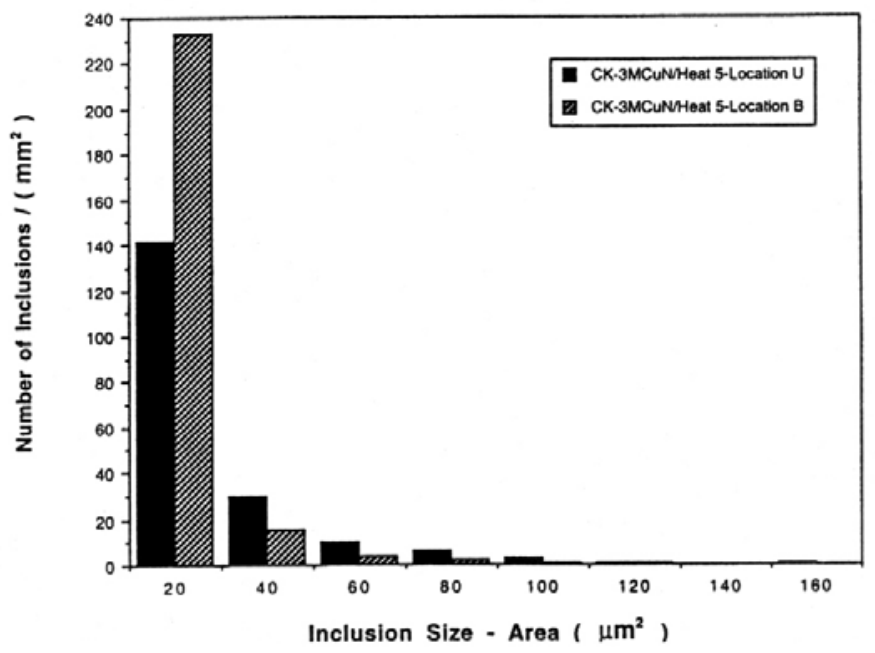

(c)

Figure 148. Inclusion distribution in as-cast CK-3MCuN, (a). for Heat 2, (b). for Heat 3, (c). for Heat 5 
(approximately $1.7-5.0 \mu \mathrm{m}$ in diameter, assuming that inclusions are spherical). A small portion of inclusions exhibit a cross-sectional area greater than $20 \mu \mathrm{m}^{2}(>$ $5.0 \mu \mathrm{m}$ in diameter). This is true at both locations ("U" and "B") for all three heats. In addition, Location "U" reveals more inclusions with a cross-sectional area $>20 \mu \mathrm{m}^{2}(>5.0 \mu \mathrm{m}$ in diameter) than Location "B" for all three heats of CK3MCuN.

Three heats of $\mathrm{CN}-3 \mathrm{MN}$ (Heats 1, 4, \& 5) were also used for the inclusion study. The results are presented in Figure 149 (a), (b), and (c) for Heats 1, 4, \& 5 , respectively. It is evident that $\mathrm{CN}-3 \mathrm{MN}$ reveals the same inclusion distribution pattern as CK-3MCuN.

It is generally believed that heat treatment has no effect on inclusion distribution and density. In order to confirm this, foundry solution annealed CN$3 \mathrm{MN}$ Heat 4 was used for comparison with as-cast $\mathrm{CN}-3 \mathrm{MN}$ Heat 4 . It is to be noted that $\mathrm{CN}-3 \mathrm{MN}$ Heat 4 was solution annealed at $2135^{\circ} \mathrm{F} / 1170^{\circ} \mathrm{C}$ followed by a water quench. The quantitative metallographic evaluation results for $\mathrm{CN}-3 \mathrm{MN}$ Heat 4 in the as-cast and the solution-annealed condition are presented in Figure 150. Figure 150 a shows the inclusion density of as-cast $\mathrm{CN}-3 \mathrm{MN}$ Heat 4 as a function of inclusion size while Figure $150 \mathrm{~b}$ reveals the inclusion density in solution-annealed $\mathrm{CN}-3 \mathrm{MN}$ Heat 4 . It is evident that inclusion density, as a function of inclusion size, is identical between the as-cast and solution-annealed condition ( $\mathrm{CN}-3 \mathrm{MN}$ Heat 4$)$. In addition, the total inclusion density of as-cast $\mathrm{CN}$ 3MN Heat $4\left(49 / \mathrm{mm}^{2}\right.$ at Location "U", 118/ $\mathrm{mm}^{2}$ at Location "B") is identical to that 


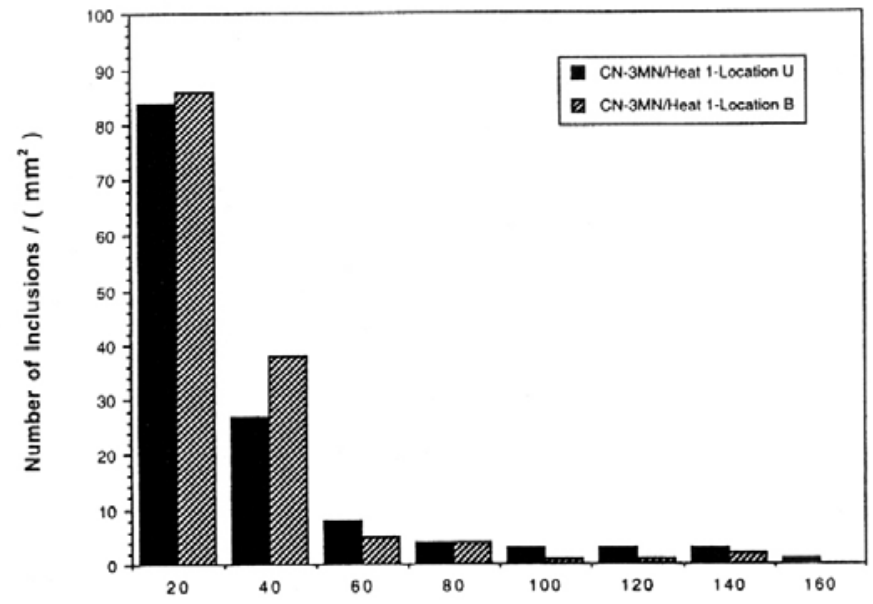

(a)

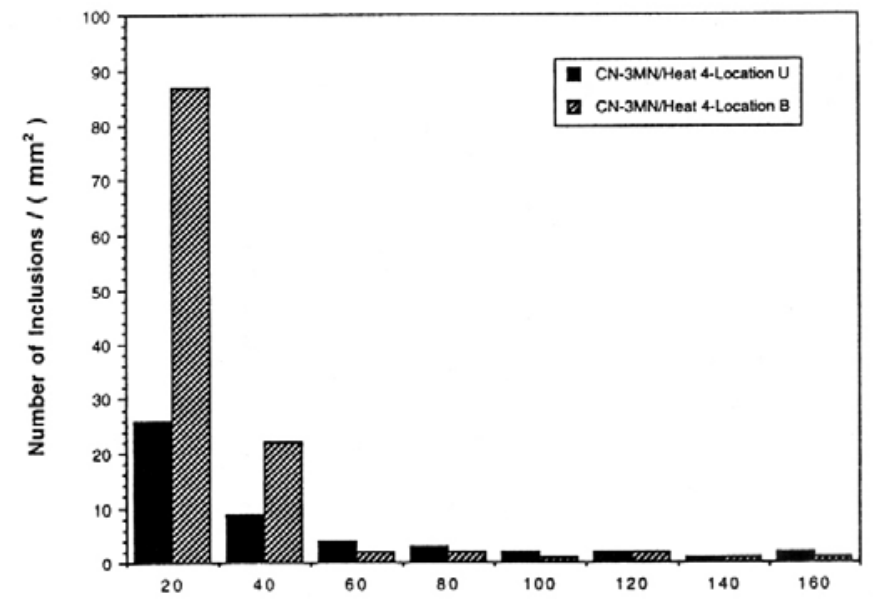

(b)

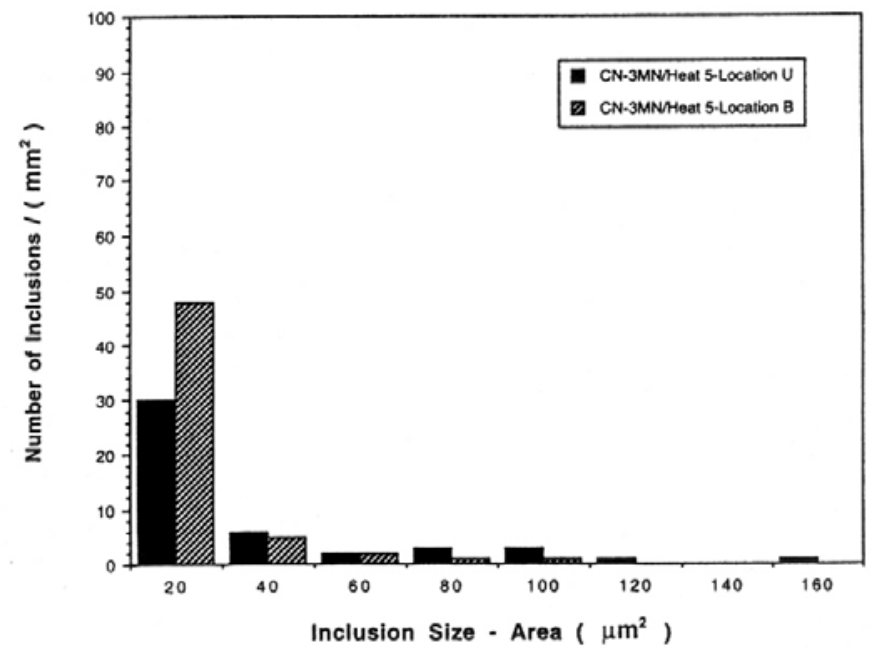

(c)

Figure 149. Inclusion distribution in as-cast $\mathrm{CN}-3 \mathrm{MN}$, (a). for Heat 1, (b). for Heat 4, (c). for Heat 5 


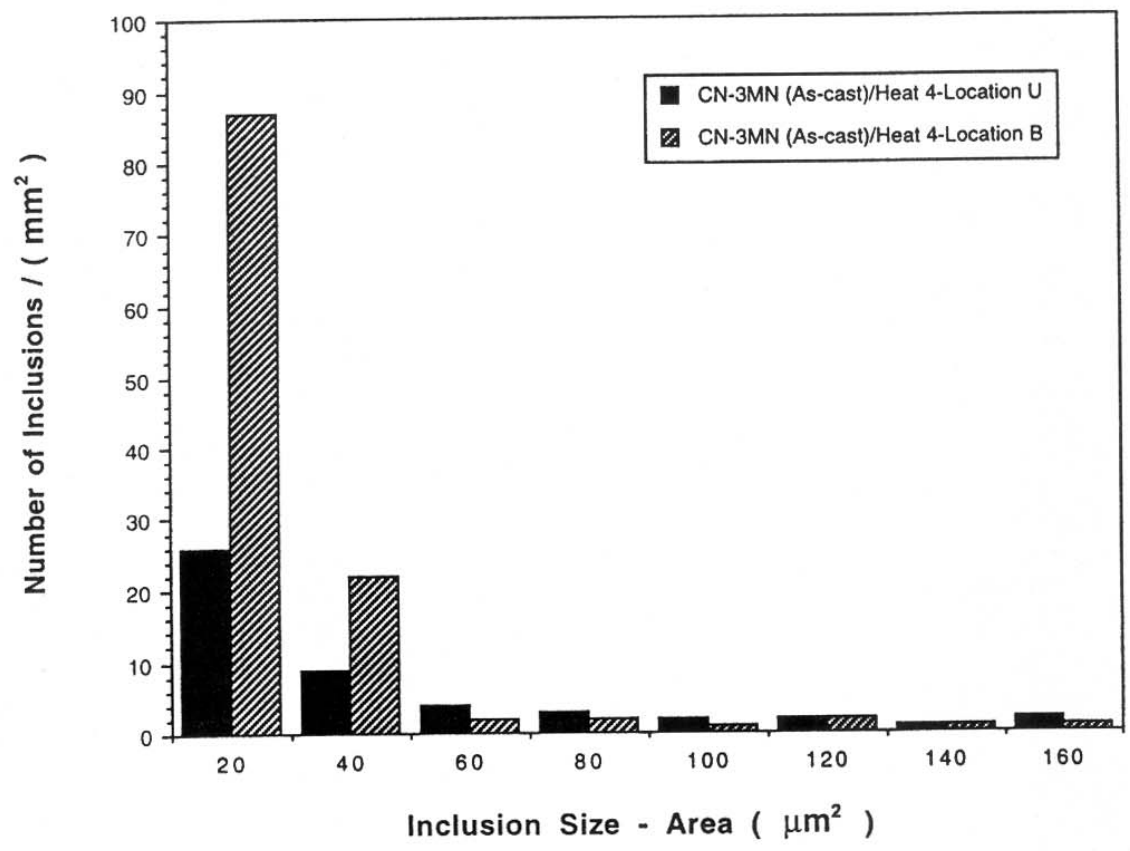

(a)

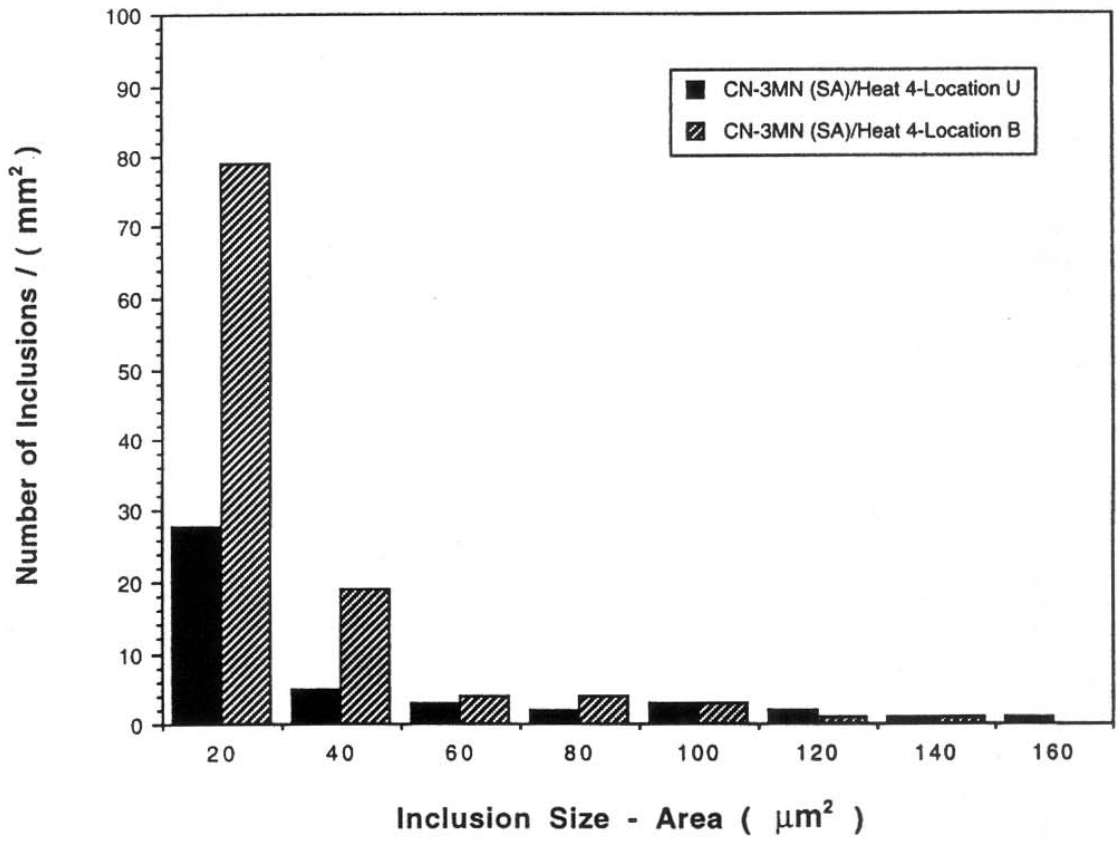

(b)

Figure 150. Comparison of inclusion distribution between as-cast and solution annealed $\mathrm{CN}-3 \mathrm{MN}$ Heat 4, (a). as-cast, (b). solution annealed 
of solution-annealed CN-3MN Heat $4\left(45 / \mathrm{mm}^{2}\right.$ at Location "U", $111 / \mathrm{mm}^{2}$ at Location "B"). This result indicates that solution heat treatment had no influence on inclusion distribution and density.

In order to understand the effect of inclusions on corrosion behavior of these high Mo castings, the total number of inclusions per square millimeter (at Location "U") is summarized together with the measured CPT values in Figures 151 and 152 for CK-3MCuN (Heats 2, 3, \& 5) and CN-3MN (Heats 1, 4, \& 5) as well as $254 \mathrm{SMO}$ and $\mathrm{AL}-6 \mathrm{XN}$ for comparison. It should be noted that the evaluation of corrosion behavior on these wedge block castings $\mathrm{CK}-3 \mathrm{MCuN}$ (Heats 2, 3, \& 5) and CN-3MN (Heats 1, 4, \& 5) has been completed previously in the Phase I Program in UT. The measured critical pitting temperature (CPT) and corrosion rate for each heat of the CK-3MCuN (Heats 2, 3, \& 5) and CN3MN (Heats 1, 4, \& 5) reported in the Technical Report of Phase I Program (entitled "Improved Process Procedures for Upgrading \& Repair of High Alloy \& Stainless Castings") are cited in this report as shown in Tables A1 and A2 in appendix $\mathrm{A}$. It is evident that there is no clear correlation between the inclusion density and CPT for each heat. This result indicates that the inclusions may have an influence on general corrosion behavior but do not necessarily dominant localized corrosion behavior. 


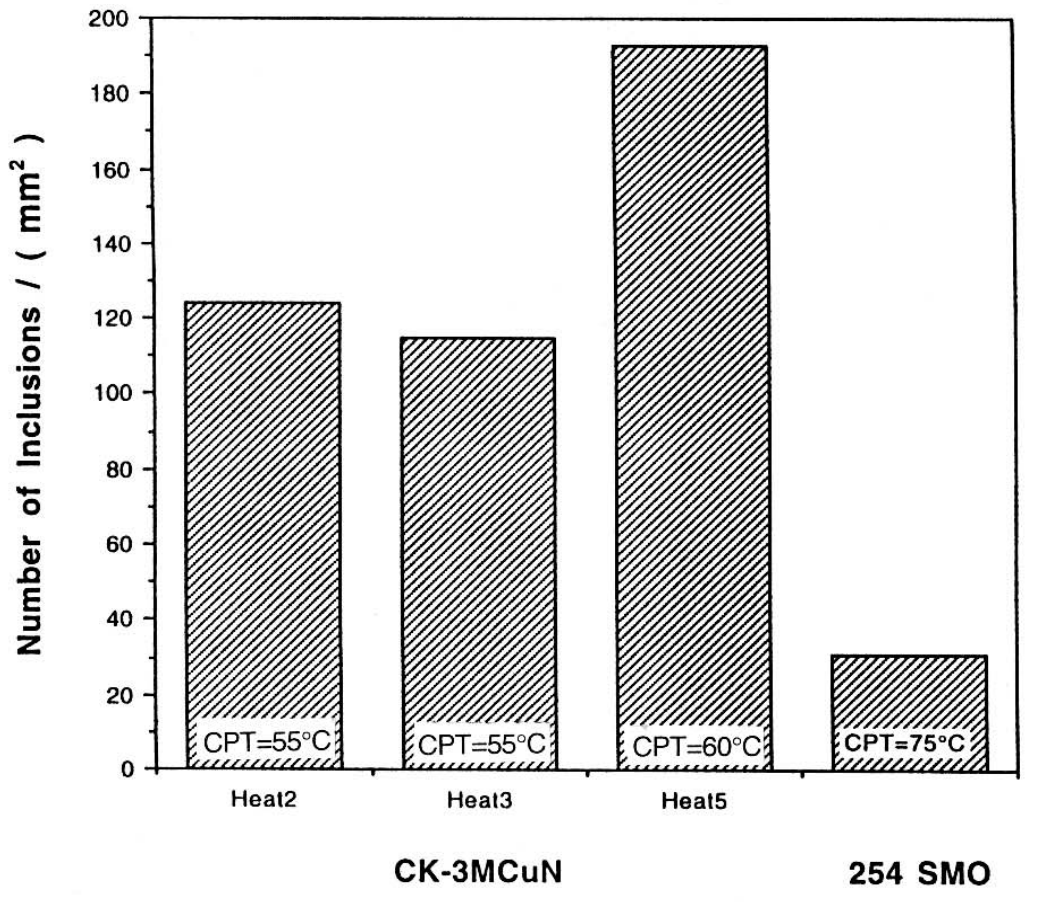

Figure 151. Number of Inclusion per square millimeter in as-cast CK-3MCuN Heat 2, Heat 3 and Heat 5

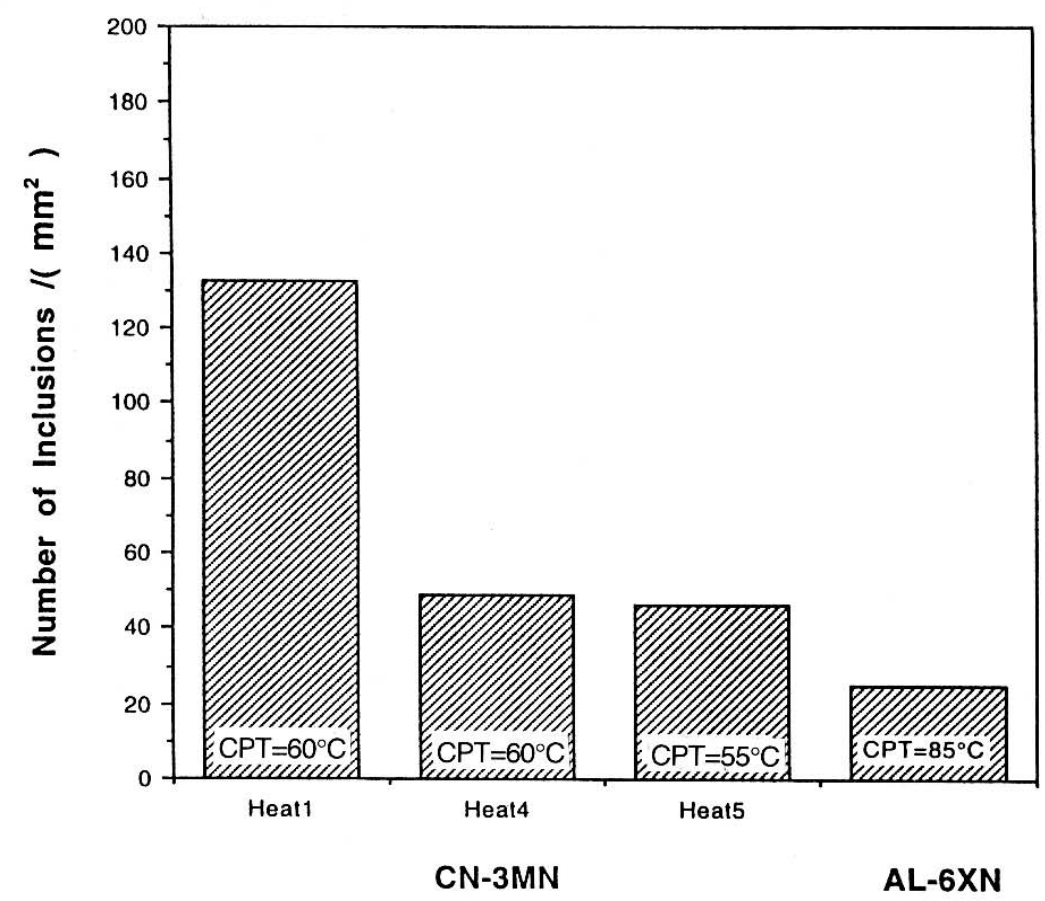

Figure 152. Number of Inclusion per square millimeter in as-cast CN-3MN Heat 1, Heat 4 and Heat 5 


\section{4-4 Localized Corrosion Behavior of CK-3MCuN and CN-3MN}

In addition to corrosion evaluation on CK-3MCuN Heats 2, 3, \& 5, and CN-3MN Heats $1,4, \& 5$ in previous Phase I study, the evaluation of localized corrosion behavior of high Mo stainless steel castings-CK-3MCuN (Heats K3GAO \& K3GCO) and CN-3MN (Heats N3GAO \& N3GBO) - was, again, conducted in the current study. Three individual immersion corrosion tests, including pitting (ASTM G48 C), general corrosion (ASTM G28 A), and NORSOK corrosion tests, were conducted to investigate the localized corrosion behavior of high Mo stainless steel castings. The procedure for each corrosion test is described in detail in this report. It is to be noted that an additional bend-testing was applied to corrosion specimens after ASTM G28 A practice to enhance the evaluation. All test results, in terms of critical pitting temperature (CPT), corrosion rate, as well as intergranular corrosion appearance revealed by bending and NORSOK corrosion test results, are presented in Tables 5 and 6 for $\mathrm{CK}-3 \mathrm{MCuN}$ and $\mathrm{CN}-3 \mathrm{MN}$, respectively. The results for the wrought counterparts (254 SMO and AL-6XN) are also included in Tables 5 and 6 for comparison.

\section{- Pitting Corrosion}

Figure 153 shows the CPTs of CK-3MCuN and CN-3MN (two heats of each) as a function of material conditions (as-cast, $2100^{\circ} \mathrm{F} / 1150^{\circ} \mathrm{C}, 2200^{\circ} \mathrm{F} / 1205^{\circ} \mathrm{C}$, and $2300^{\circ} \mathrm{F} / 1260^{\circ} \mathrm{C} \mathrm{SA}+\mathrm{WQ}$ ). Compared to the as-cast condition, solution annealing heat treatment $\left(2100^{\circ} \mathrm{F} / 1150^{\circ} \mathrm{C}, 2200^{\circ} \mathrm{F} / 1205^{\circ} \mathrm{C}\right.$, and $2300^{\circ} \mathrm{F} / 1260^{\circ} \mathrm{C}$ $\mathrm{SA}+\mathrm{WQ}$ ) improves the CPTs of CK-3MCuN by $30-45 \mathrm{C}^{\circ}$ and the CPTs of $\mathrm{CN}$ - 


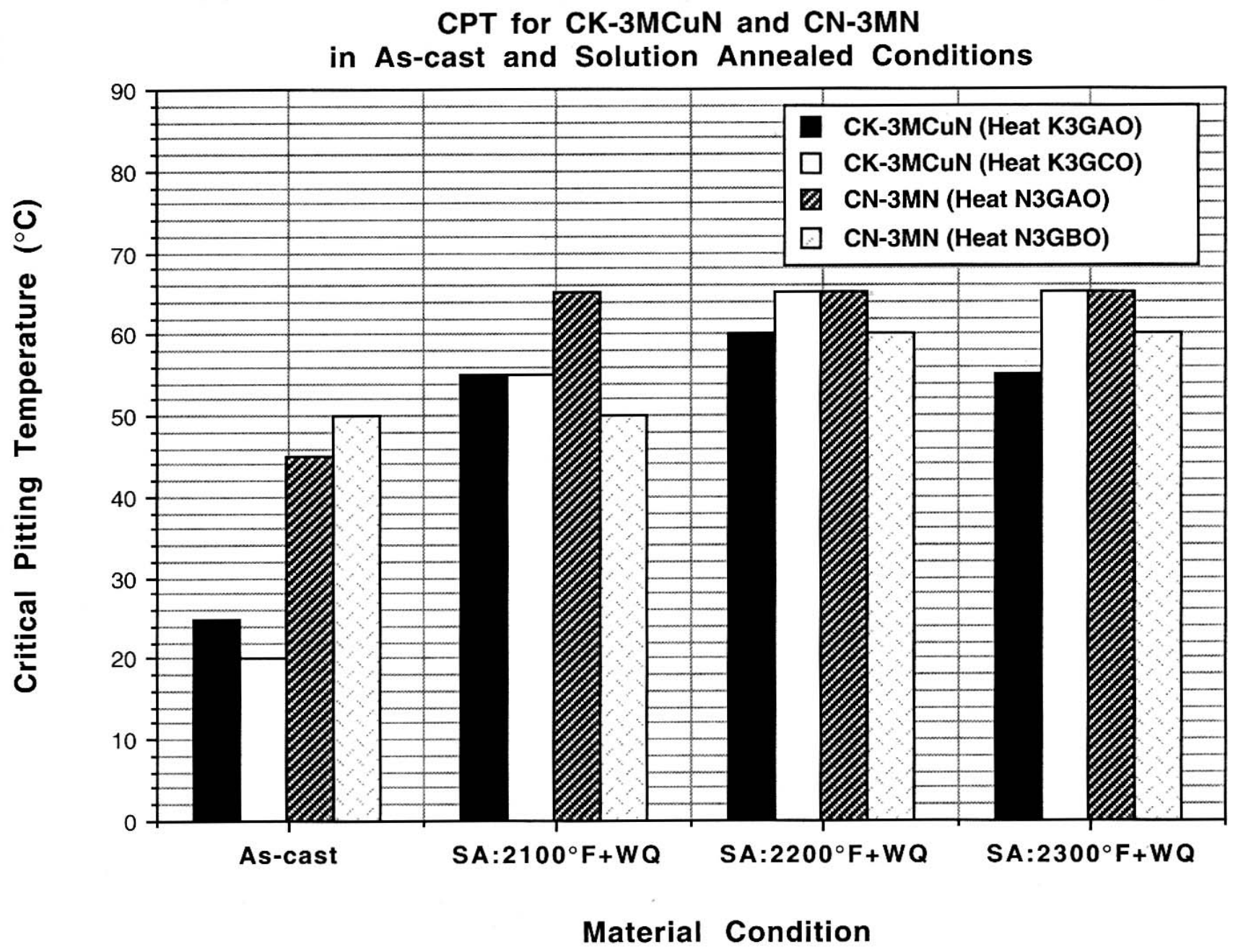

Figure 153. Pitting corrosion test results for $\mathrm{CK}-3 \mathrm{MCuN}$ and $\mathrm{CN}-3 \mathrm{MN}$ in as-cast and solution annealed conditions 
$3 \mathrm{MN}$ by $10-20 \mathrm{C}^{\circ}$. In general, as the solution-annealing temperature rises, so does the CPT. In addition, the CPTs after $2200^{\circ} \mathrm{F} / 1205^{\circ} \mathrm{C}$ and $2300^{\circ} \mathrm{F} / 1260^{\circ} \mathrm{C}$ $S A+W Q$ are basically the same for each heat of both casting materials and reach to the optimum CPT level in the solution-annealed condition.

It should be recalled that a certain amount of secondary phases $(\mathrm{Cr} / \mathrm{Mo}$ carbides/nitrides) still remain in $2100^{\circ} \mathrm{F} / 1150^{\circ} \mathrm{C}$ SA materials, and this is believed to be responsible for the reduction in the CPT in comparison with the $2200^{\circ} \mathrm{F} / 1205^{\circ} \mathrm{C}$ and $2300^{\circ} \mathrm{F} / 1260^{\circ} \mathrm{C} \mathrm{SA}$. From the microstructural view point, the elimination of $\sigma$ phase and the reduction in the extent of $\mathrm{Cr}$ and Mo segregation are at the root-cause in the improvement of the CPT. Therefore, based upon the evaluation results in this study, $2200^{\circ} \mathrm{F} / 1205^{\circ} \mathrm{C}$ is recommended as a minimum SA temperature for both $\mathrm{CK}-3 \mathrm{MCuN}$ and $\mathrm{CN}-3 \mathrm{MN}$.

Solution annealing at $2300^{\circ} \mathrm{F} / 1260^{\circ} \mathrm{C}$ followed by slow cooling (from $2300^{\circ} \mathrm{F} / 1260^{\circ} \mathrm{C}$ ) was applied to $\mathrm{CK}-3 \mathrm{MCuN}$ Heat K3GAO and CN-3MN Heat N3GAO to evaluate the effect of cooling rate on pitting corrosion behavior. Figure 154 shows the comparison of the CPTs between the water quenching and slow cooling for CK-3MCuN Heat K3GAO and CN-3MN Heat N3GAO. It is evident that there is no difference in the CPT between water quenched and slow cooled conditions. This indicates that slow cooling after $2300^{\circ} \mathrm{F} / 1260^{\circ} \mathrm{C}$ SA does not reduce the pitting corrosion resistance.

To reveal pit initiation behavior, specimens pitting corrosion tested at $25^{\circ} \mathrm{C}$ (CPT of the as-cast condition) were further microstructurally evaluated using OLM. The pitting appearance of the as-cast CK-3MCuN is presented in Figure 
Comparison of CPT between

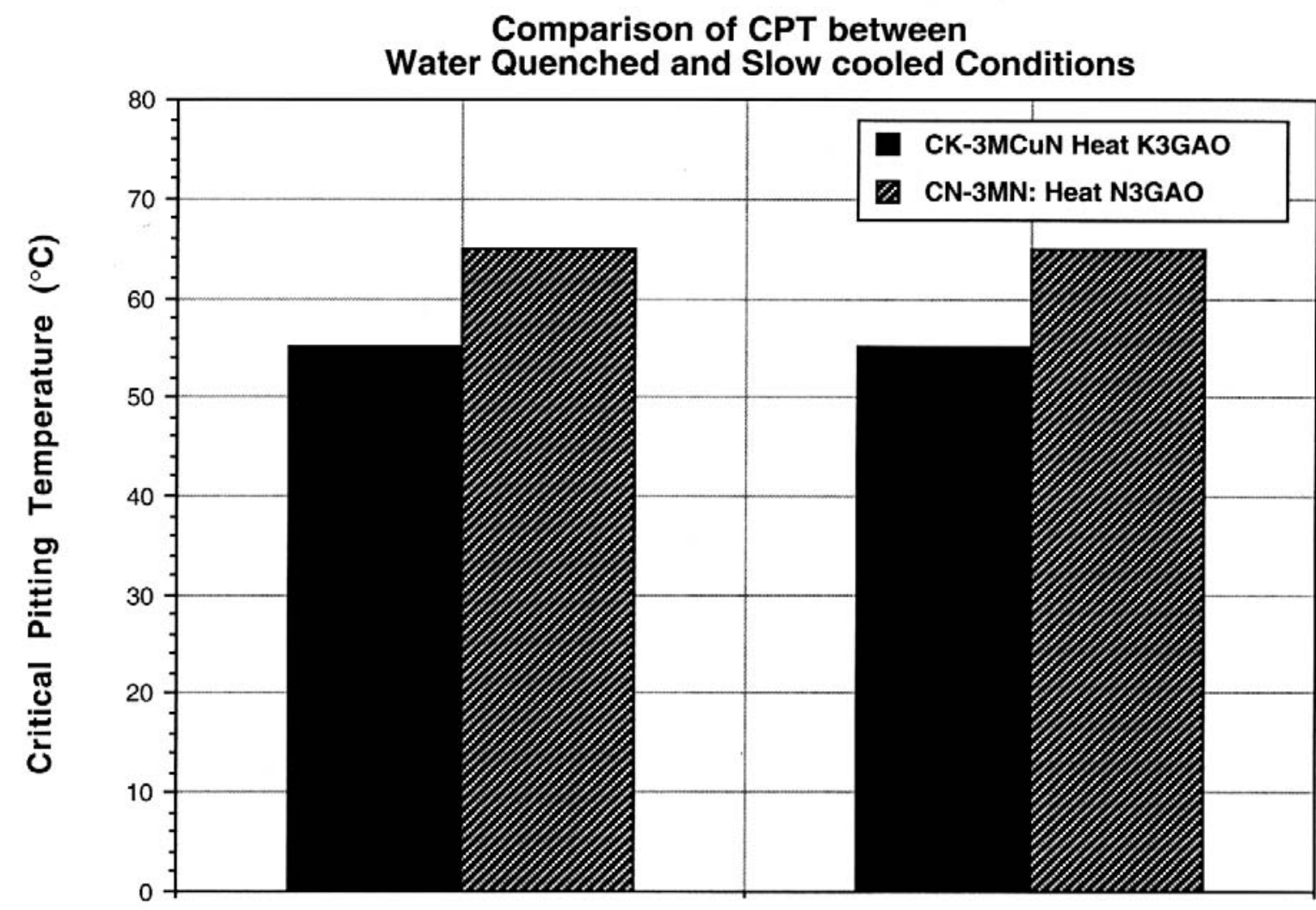

WQ from $2300^{\circ} \mathrm{F}$

SC from $2300^{\circ} \mathrm{F}$

\section{Cooling Condition}

Figure 154. Comparison CPT between WQ and SC conditions for CK-3MCuN Heat K3GAO and CN-3MN Heat N3GAO 
155 (a \& b). From an overview of the pitted surface (see Figure 155a), it is clear that pit initiation is strongly associated with the secondary phases. The preferential location for pit initiation is an area either adjacent to the coarse $\mathrm{Cr} / \mathrm{Mo}$ carbides at the outer boundary of the "islands" (marked by letters a \& $\mathrm{b}$ in Figure 155b) or adjacent to the $\sigma$ phase within the "islands" (marked by letters c and $d$ in Figure 155b). A large number of pits initiate simultaneously on the surface since the as-cast $\mathrm{CK}-3 \mathrm{MCuN}$ provides a number of preferential locations.

The specimens, tested at the CPT of $55^{\circ} \mathrm{C}$ for both the $2100^{\circ} \mathrm{F} / 1150^{\circ} \mathrm{C}$ and $2300^{\circ} \mathrm{F} / 1260^{\circ} \mathrm{C}$ solution-annealed (followed by WQ) conditions, were also selected for microstructural evaluation. The pitting appearances of the $2100^{\circ} \mathrm{F} / 1150^{\circ} \mathrm{C}$ and $2300^{\circ} \mathrm{F} / 1260^{\circ} \mathrm{C}$ solution-annealed (followed by WQ) CK$3 \mathrm{MCuN}$ are presented in Figures 156 and 157, respectively. As contrasted to the as-cast condition, the pit initiation locations dramatically decrease for the solution-annealed $\mathrm{CK}-3 \mathrm{MCuN}$. Even with the secondary phases remaining in the matrix after the $2100^{\circ} \mathrm{F} / 1150^{\circ} \mathrm{C}$ SA CK-3MCuN (see Figure 156), only a few pits were observed to initiate in association with secondary phases. This microstructural evidence verifies that a reduction of $\mathrm{Cr}$ and Mo segregation in secondary phases during SA most likely plays an important role in restoring the pitting corrosion resistance of the cast material.

\section{- Intergranular Corrosion}

Figure 158 presents the corrosion results for CK-3MCuN and CN-3MN (two heats of each) as a function of material conditions (as-cast, $2100^{\circ} \mathrm{F} / 1150^{\circ} \mathrm{C}$, 


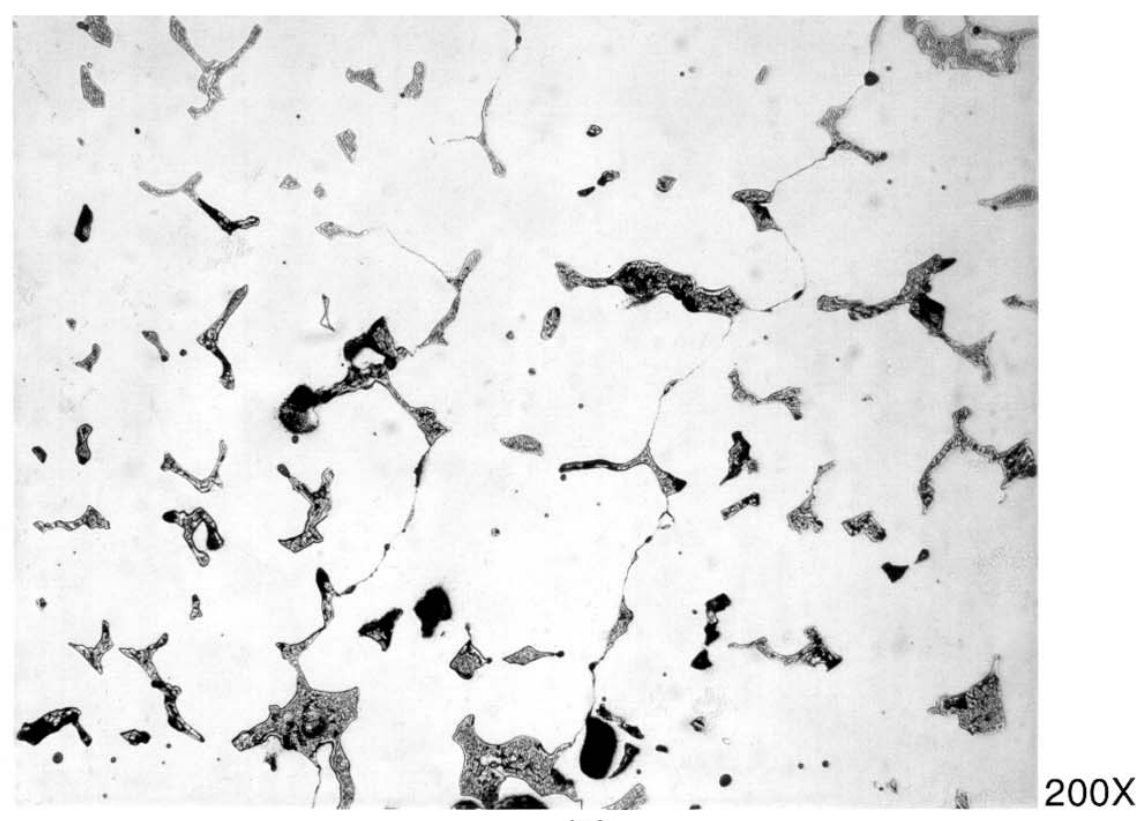

(a)

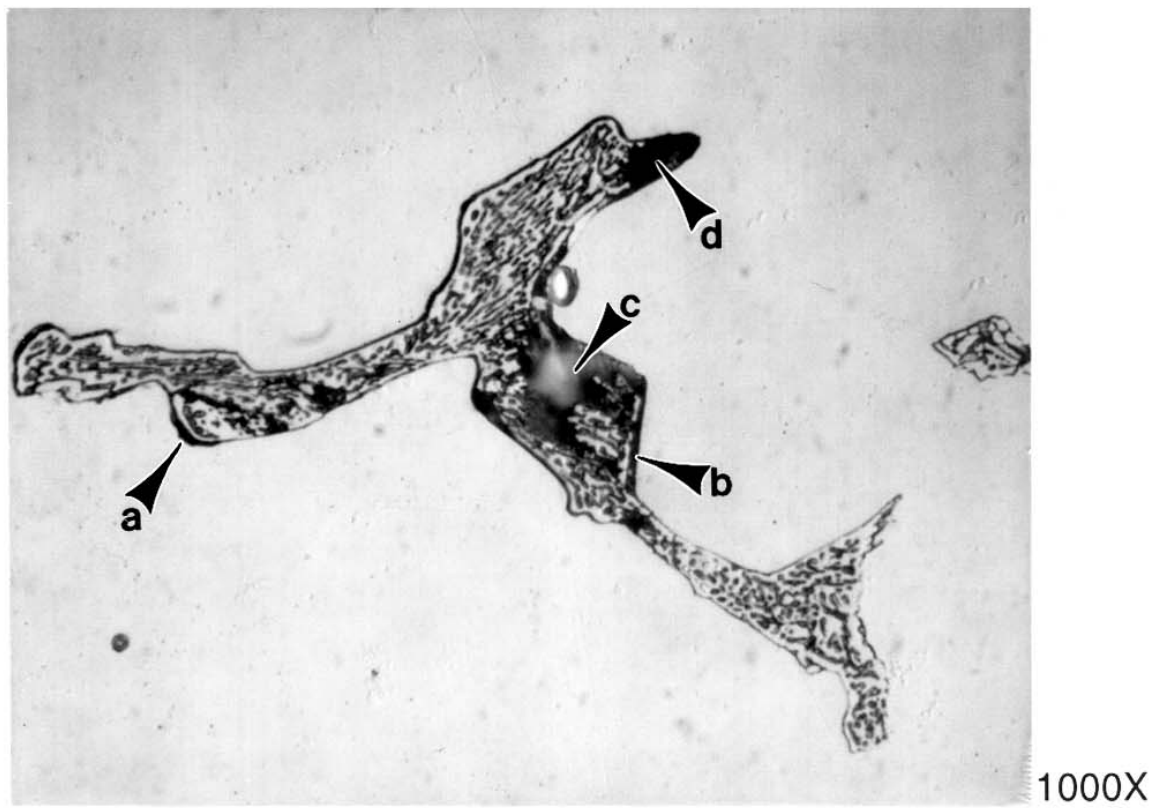

(b)

Figure 155. Pitting corrosion tested CK-3MCuN Heat K3GAO, as-cast, CPT: $25^{\circ} \mathrm{C}$ 


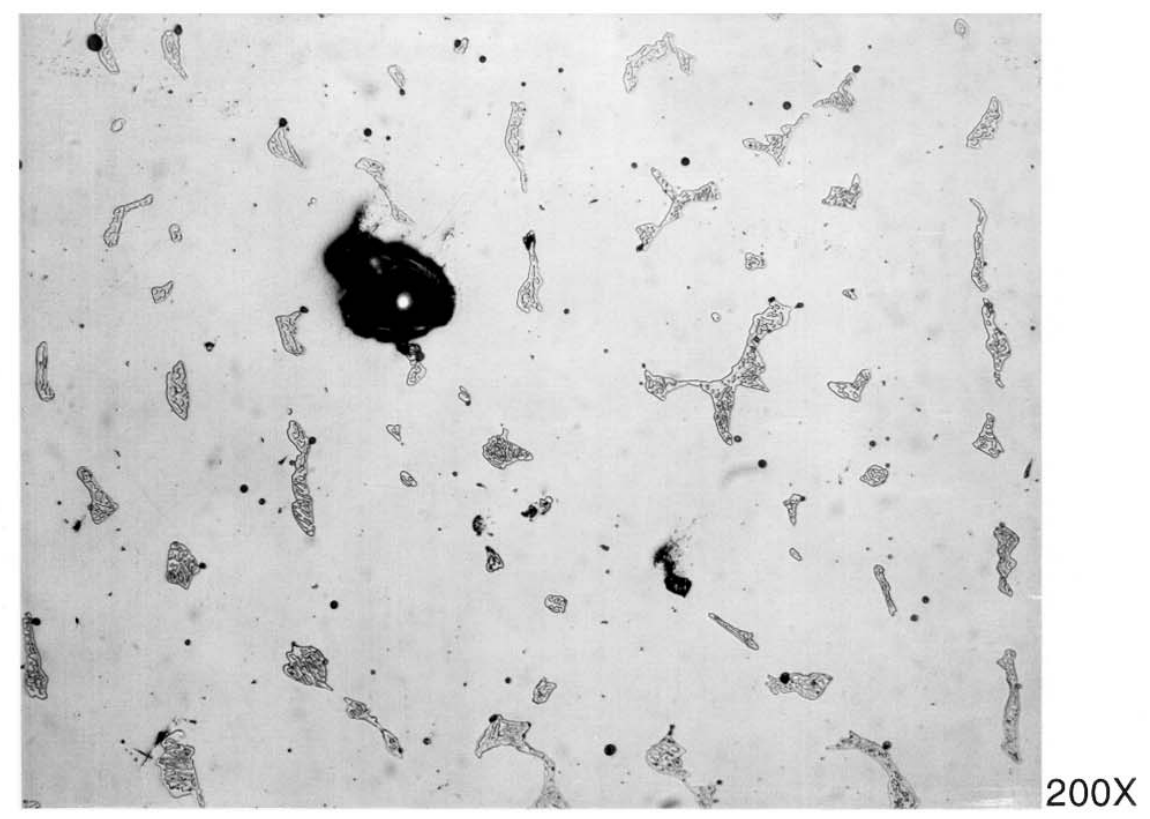

Figure 156. Pitting corrosion tested CK-3MCuN Heat K3GAO, $2100^{\circ} \mathrm{F}+\mathrm{WQ}$, CPT: $55^{\circ} \mathrm{C}$

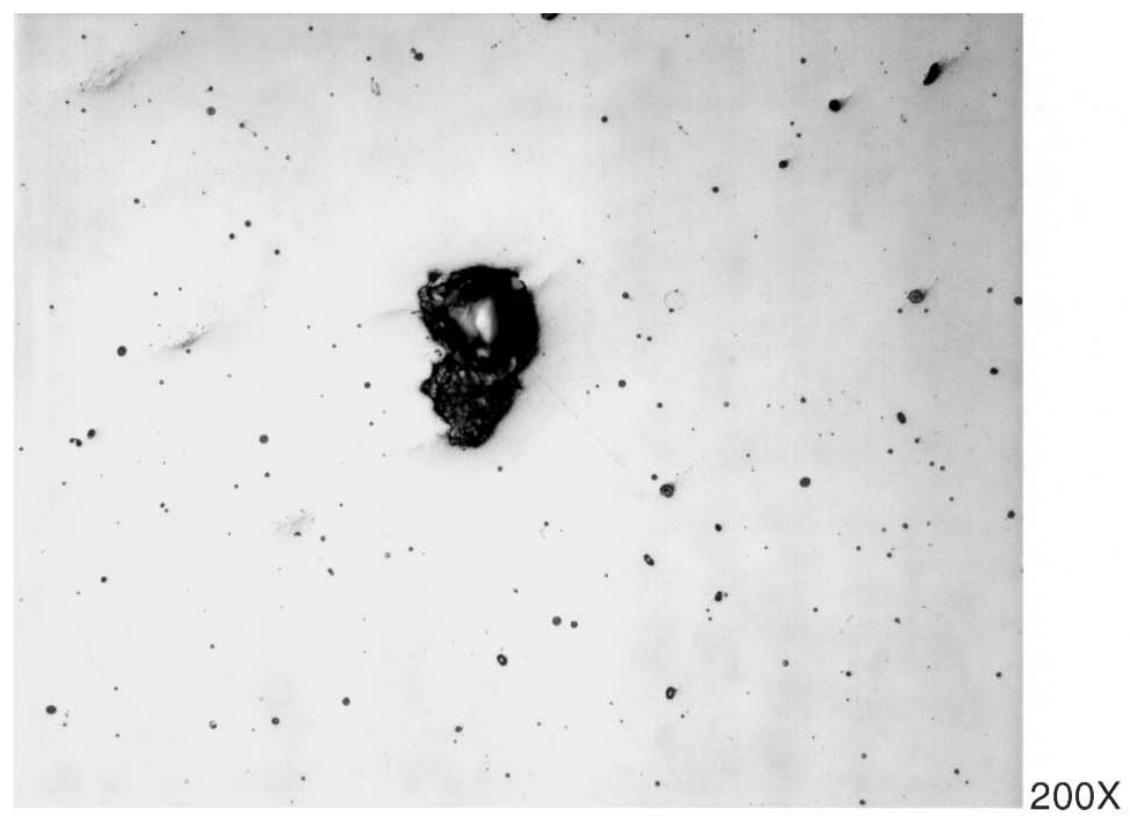

Figure 157. Pitting corrosion tested CK-3MCuN Heat K3GAO, $2300^{\circ} \mathrm{F}+\mathrm{WQ}$, CPT: $55^{\circ} \mathrm{C}$ 


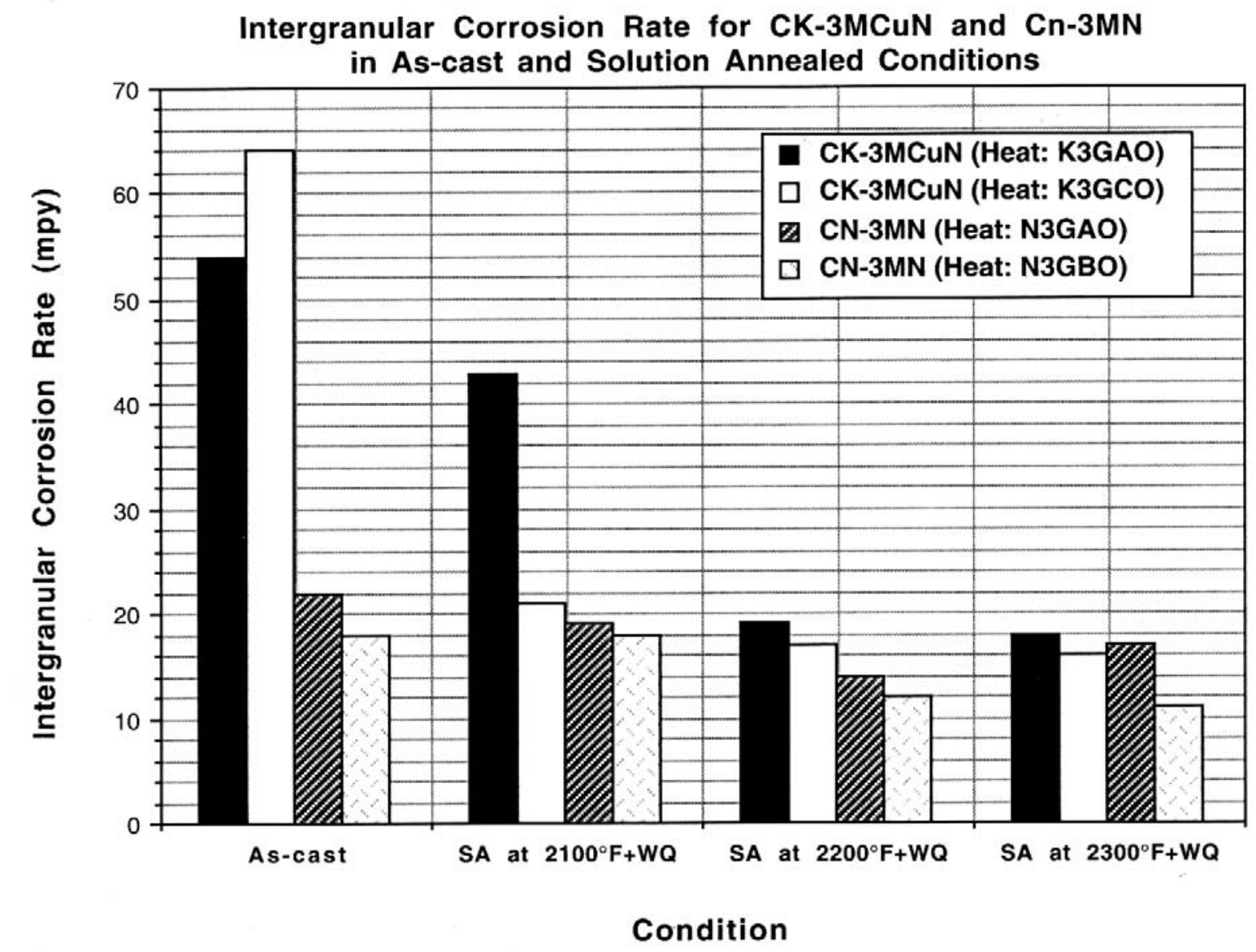

Figure 158. Intergranular corrosion test results for $\mathrm{CK}-3 \mathrm{MCuN}$ and $\mathrm{CN}-3 \mathrm{MN}$ in as-cast and solution annealed conditions 
$2200^{\circ} \mathrm{F} / 1205^{\circ} \mathrm{C}$ and $2300^{\circ} \mathrm{F} / 1260^{\circ} \mathrm{C} \mathrm{SA}$ ). It is evident that the solution-annealing heat treatment at all three SA temperatures, improves the intergranular corrosion resistance (reduces the corrosion rate) compared to the as-cast condition. The maximum reduction in the corrosion rate is $48 \mathrm{mpy}$ for CK-3MCuN and $8 \mathrm{mpy}$ for $\mathrm{CN}-3 \mathrm{MN}$. However, by comparing the corrosion rate for the three SA temperatures, the higher the SA temperature, the lower the corrosion rate. This corresponds to the microstructural evaluation results in terms of presence of secondary phases and extent of alloy element segregation as a function of SA temperature. According to corrosion results presented in Figure 158, it is to be noted that $2200^{\circ} \mathrm{F} / 1205^{\circ} \mathrm{C}$ and $2300^{\circ} \mathrm{F} / 1260^{\circ} \mathrm{C} \mathrm{SA}$ (followed by WQ) reveal identical corrosion rates for each heat and this is the minimum level of the corrosion rates in the SA conditions. Therefore, from the corrosion standpoint, $2200^{\circ} \mathrm{F} / 1205^{\circ} \mathrm{C}$ is recommended as the minimum solution-annealing temperature for both CK-3MCuN and CN-3MN.

The effect of cooling rate on corrosion behavior was also determined on CK$3 M C u N$ Heat K3GAO and CN-3MN Heat N3GAO. Figure 159 shows the comparison in the corrosion rate between the WQ and SC. It is evident that the slow cooling increases the corrosion rate as compared to the water quenched condition. The corrosion rate for slow cooled CK-3MCuN is 6 mpy greater than the water quenched CK-3MCuN, while the CORROSION rate for slow cooled $\mathrm{CN}-3 \mathrm{MN}$ is 12 mpy greater than the water quenched $\mathrm{CN}-3 \mathrm{MN}$. It should be recalled that there is no difference in the microstructure between WQ and SC conditions. Thus, it may be that the alloy element (such as $\mathrm{Cr}$ and $\mathrm{Mo}$ ) 


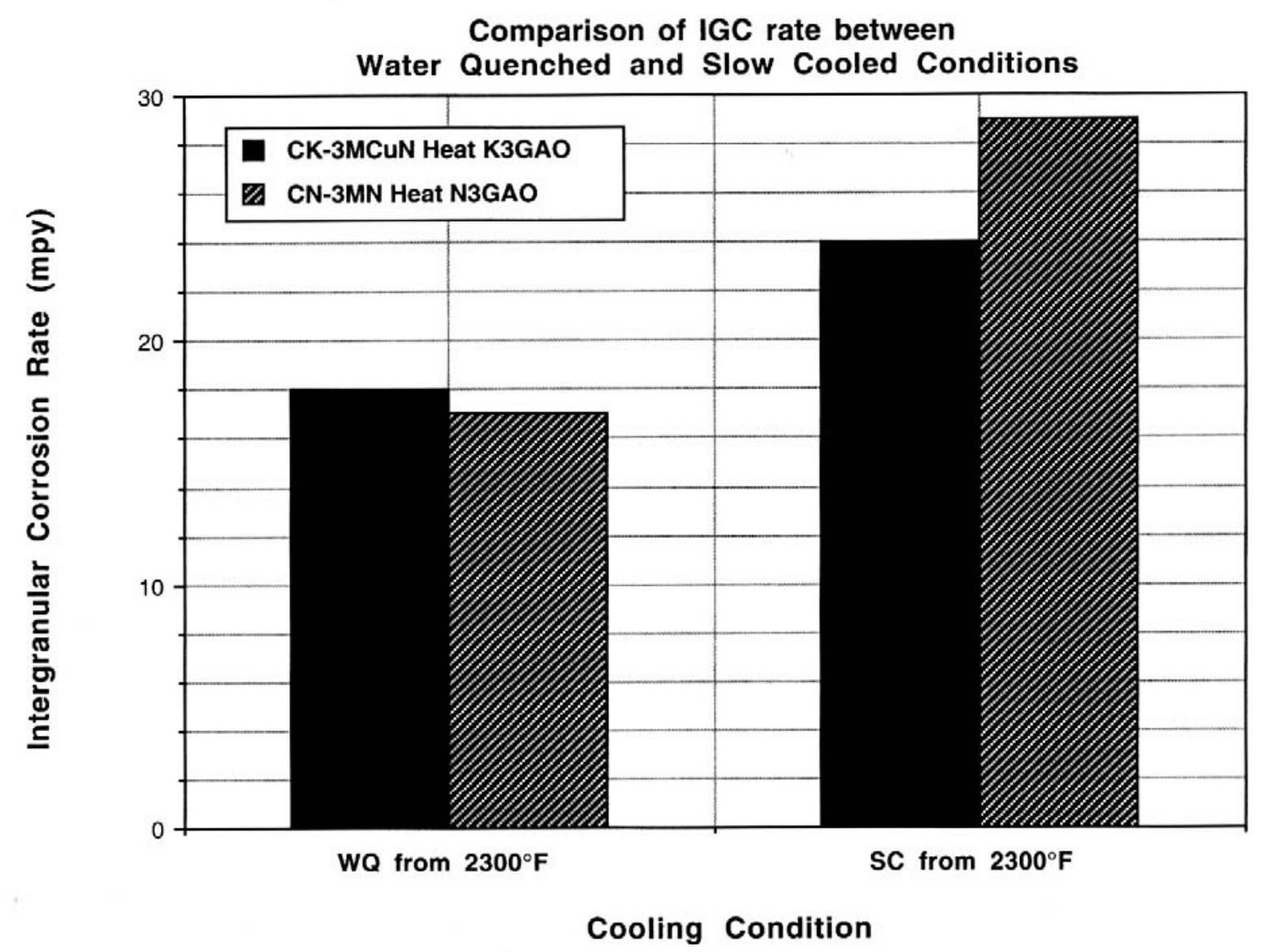

Figure 159. Comparison IGC rate between WQ and SC conditions for CK-3MCuN Heat K3GAO and CN-3MN Heat N3GAO 
segregation to grain boundaries during slow cooling may be responsible for the reduction in corrosion resistance.

For enhanced understanding, a microstructural evaluation was conducted on the corrosion tested specimens. Figures 160 through 163 show the microstructure of the as-cast and solution-annealed (followed by WQ) samples of CK-3MCuN (cross-section orientation). It is evident that corrosion occurred preferentially not only within the secondary phases along grain boundaries but also within the secondary phases in the interdendritic regions for the as-cast condition (see Figure 160). The same corrosion morphology was observed for the $2100^{\circ} \mathrm{F} / 1150^{\circ} \mathrm{C} \mathrm{SA}$ condition, but to a decreased extent compared to as-cast condition (see Figure 161). However, upon increasing the solution annealing temperature, only slight corrosion occurred for the $2200^{\circ} \mathrm{F} / 1205^{\circ} \mathrm{C}$ and $2300^{\circ} \mathrm{F} / 1260^{\circ} \mathrm{C} \mathrm{SA}$ conditions (see Figures 162 and 163 ), since only a small amount of secondary phases remained after the $2200^{\circ} \mathrm{F} / 1205^{\circ} \mathrm{C} \mathrm{SA}$ and no secondary phases remained after the $2300^{\circ} \mathrm{F} / 1260^{\circ} \mathrm{C}$ SA. Therefore, intergranular corrosion for $\mathrm{CK}-3 \mathrm{MCuN}$ is strongly associated with secondary phases ( $\sigma$ phase and/or $\mathrm{Cr} /$ Mo carbides) formed within the "islands" along grain boundaries and in the interdendritic regions.

For the slow-cooled (from $2300^{\circ} \mathrm{F} / 1260^{\circ} \mathrm{C}$ ) $\mathrm{CK}-3 \mathrm{MCuN}$, the corrosion rate was determined to be $24 \mathrm{mpy}$, which is slightly higher than that of waterquenched CK-3MCuN (18 mpy). To more completely understand these effects, a microstructural evaluation was also conducted on the CORROSION coupons tested with a slow cooling rate. The results are shown in Figure 168. 


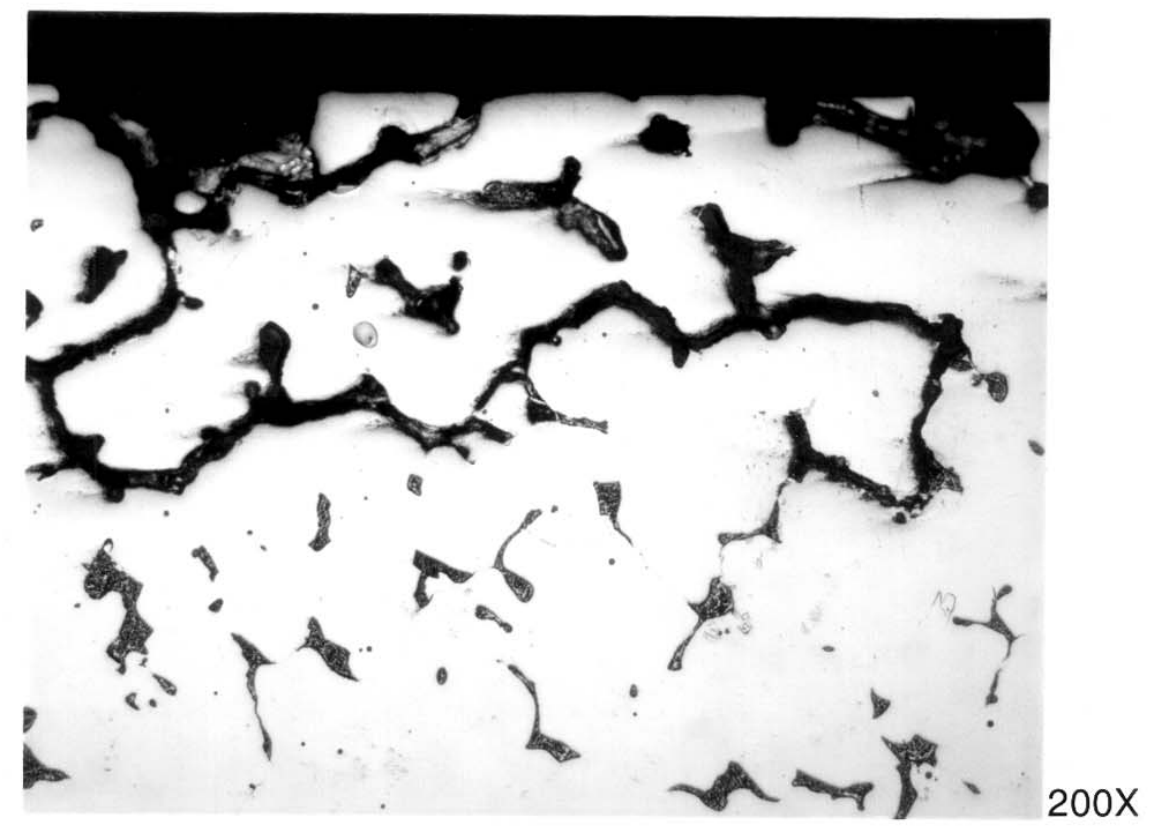

Figure 160. Intergranular corrosion tested CK-3MCuN Heat K3GAO, as-cast, IGC rate: 45 mpy

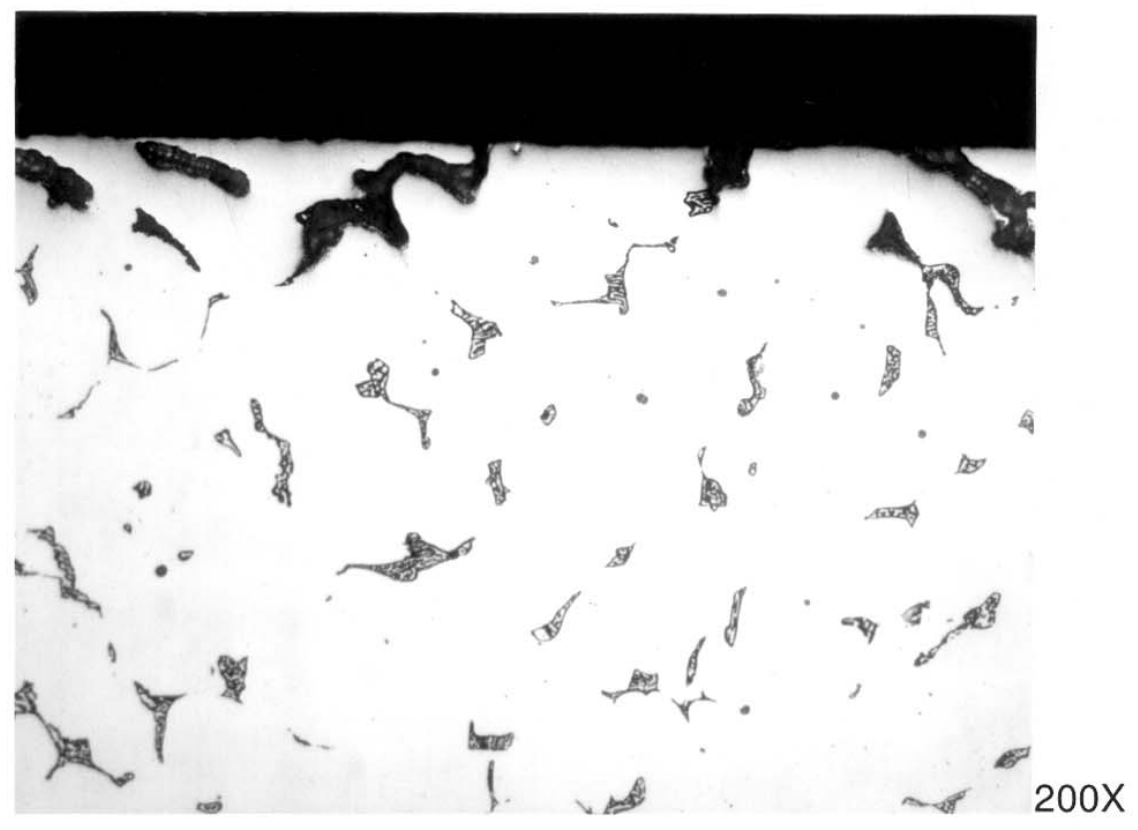

Figure 161. Intergranular corrosion tested CK-3MCuN Heat K3GAO, $2100^{\circ} \mathrm{F}+\mathrm{WQ}$, IGC rate: $43 \mathrm{mpy}$ 


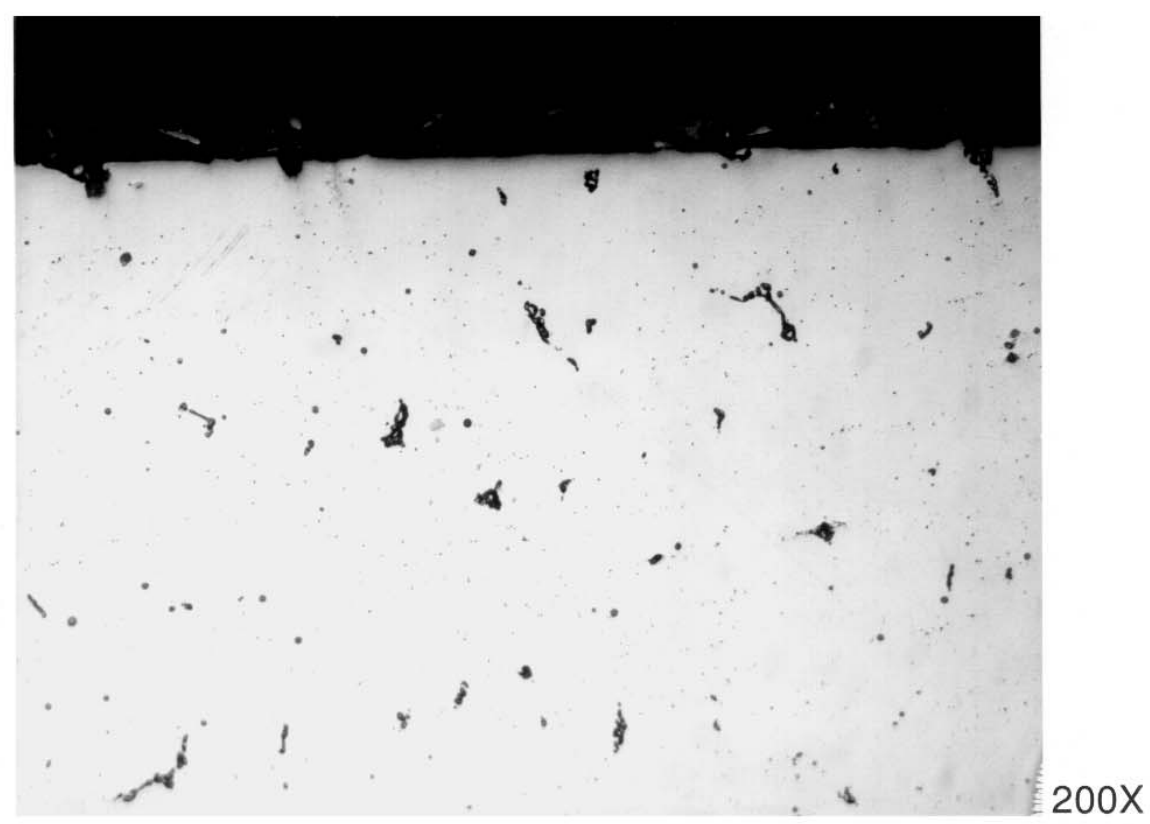

Figure 162. Intergranular corrosion tested CK-3MCuN Heat K3GAO, $2200^{\circ} \mathrm{F}+\mathrm{WQ}$, IGC rate: $18 \mathrm{mpy}$

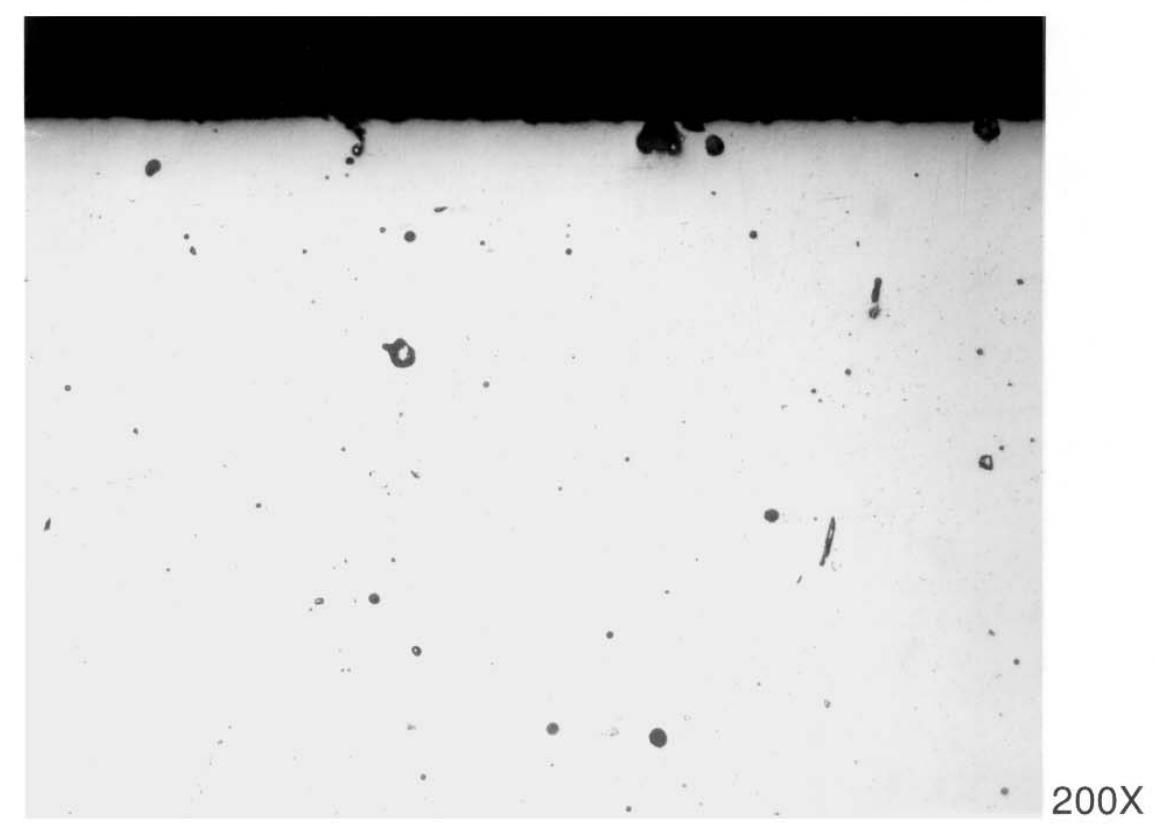

Figure 163. Intergranular corrosion tested CK-3MCuN Heat K3GAO, $2300^{\circ} \mathrm{F}+\mathrm{WQ}$, IGC rate: $18 \mathrm{mpy}$ 
It is evident that corrosion occurred primarily along grain boundaries for the slowcooled CK-3MCuN. Compared to water-quenched CK-3MCuN (see Figure 163), it is considered that some precipitates may have formed at grain boundaries during slow cooling, which resulted in a degradation of the intergranular corrosion resistance. However, the size of precipitates must be too small to be observed using OLM.

Additional bend-testing was applied to the corrosion-tested specimens to enhance the evaluation of the corrosion behavior. The observations of the CORROSION-tested samples after bending are included in Tables 5 and 6 . The surface appearance of bent corrosion samples are classified in four levels: 1) fractured, 2) intergranular and interdendritic separated, 3) minor intergranular separated, and 4) non - separated as shown in Figure 165. It is evident that, for the $2200^{\circ} \mathrm{F} / 1205^{\circ} \mathrm{C}$ or $2300^{\circ} \mathrm{F} / 1260^{\circ} \mathrm{C} \mathrm{SA}(\mathrm{WQ})$ condition, only minor intergranular separation or no-separation was observed for both $\mathrm{CK}-3 \mathrm{MCuN}$ and $\mathrm{CN}-3 \mathrm{MN}$ materials. In addition, slow cooling after $2300^{\circ} \mathrm{F} / 1260^{\circ} \mathrm{C} \mathrm{SA}$ reveals intergranular and interdendritic separation for CK-3MCuN Heat K3GAO and CN3MN Heat N3GAO compared to only minor intergranular separation for the $2300^{\circ} \mathrm{F} / 1260^{\circ} \mathrm{C}+\mathrm{WQ}$. The observations on the bent corrosion samples reveals an identical intergranular corrosion relationship to intergranular corrosion rate as determined according to ASTM G28 A. 


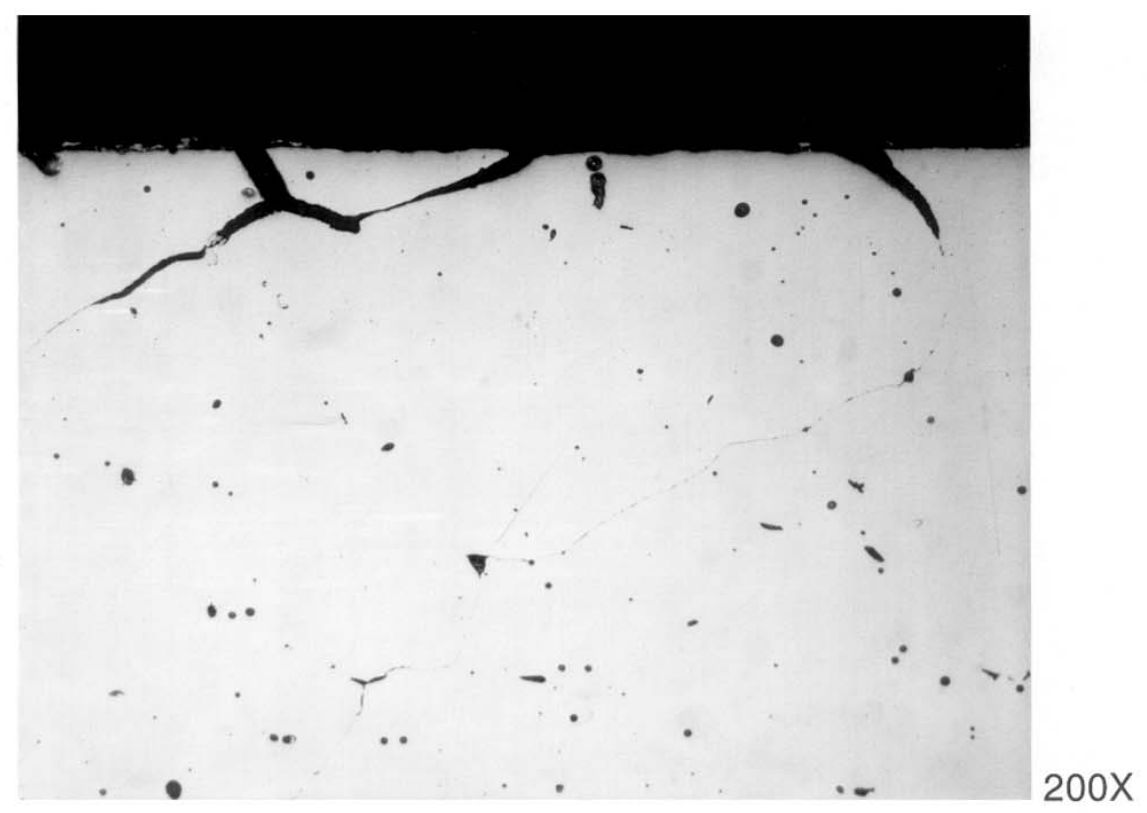

Figure 164. Intergranular corrosion tested CK-3MCuN Heat K3GAO, $2100^{\circ} \mathrm{F}+\mathrm{SC}, \mathrm{IGC}$ rate: $24 \mathrm{mpy}$ 


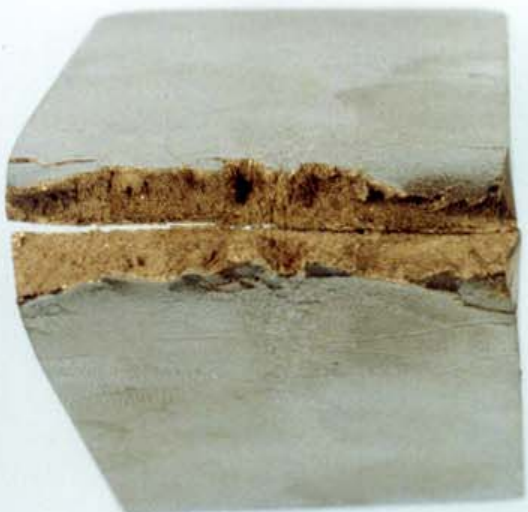

1) Fractured

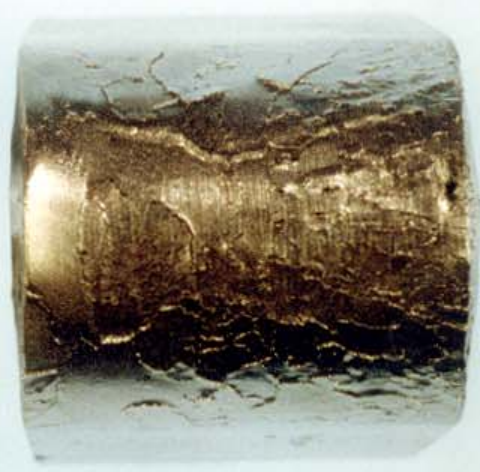

2) Intergranular \& Interdendritic Separation

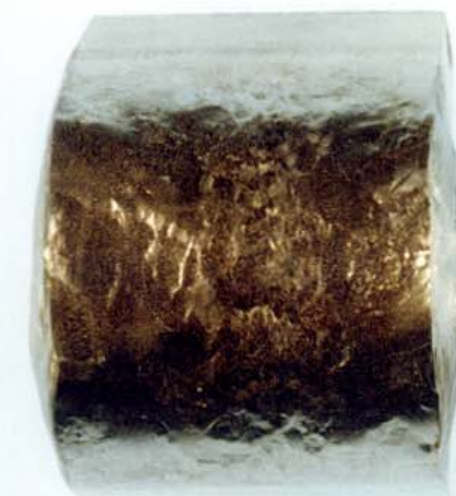

3) Minor Intergranular Separation

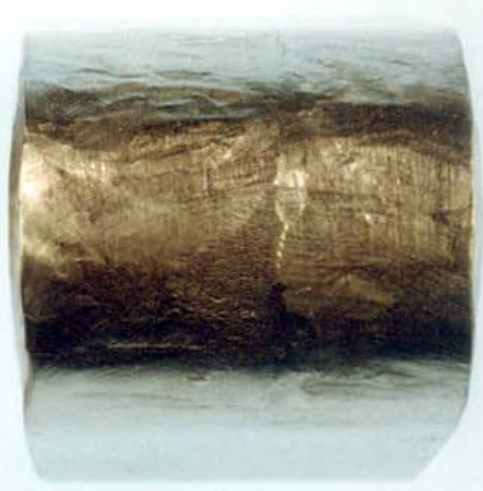

4) No Separation

Figure 165. Typical IGC appearance after bending for cast material 


\section{- NORSOK Corrosion Testing}

The NORSOK corrosion test is a commonly used method to screen high Mo stainless steels. Therefore, NORSOK corrosion testing was selected as a candidate method in this study. All four heats of $\mathrm{CK}-3 \mathrm{MCuN}$ and $\mathrm{CN}-3 \mathrm{MN}$ were evaluated using NORSOK method in the as-cast and solution-annealed conditions. The results are summarized in Tables 5 and 6 together with the CPT and CORROSION test results. Regardless of SA temperature and cooling condition, all four heats in all SA conditions pass the NORSOK corrosion test, while all four heats in the as-cast condition fail the NORSOK corrosion test. Therefore, at a minimum, the NORSOK corrosion test is considered as a suitable method to distinguish between the as-cast and solution-annealed materials.

\section{4-5 Non-uniform Microstructure of Cast Bar}

It was found that the microstructure in the cast bars provided for study was non-uniform with regard to position along the bar (along length or round-cross section across diameter). In addition, the extent of non-uniformity in microstructure is significantly greater in $\mathrm{CK}-3 \mathrm{MCuN}$ than in the $\mathrm{CN}-3 \mathrm{MN}$ in the solution-annealed condition $\left(2300^{\circ} \mathrm{F} / 1260^{\circ} \mathrm{C}+\mathrm{WQ}\right)$. The initial detection of the non-uniform microstructure in the cast bars was reflected in the corrosion testing. A CK-3MCuN corrosion sample (extracted from near the riser) in the $2300^{\circ} \mathrm{F} / 1260^{\circ} \mathrm{C} \mathrm{SA}$ condition showed the CPT of $45^{\circ} \mathrm{C}$, compared to the CPTs of $55 \sim 60^{\circ} \mathrm{C}$ for the same material in the $2100^{\circ} \mathrm{F} / 1150^{\circ} \mathrm{C}$ and $2200^{\circ} \mathrm{F} / 1205^{\circ} \mathrm{C} \mathrm{SA}$ conditions but extracted remote from the riser. In another case of SA CK-3MCuN corrosion testing, it was found that a majority of pits formed in the center 
region of the corrosion sample. Therefore, a suspicion was raised regarding the uniformity in microstructure along the length or through the cross-section of the cast bars. For preliminary evaluation of the non-uniformity in microstructure of cast bar, both heats of $\mathrm{CK}-3 \mathrm{MCuN}\left(2300^{\circ} \mathrm{F} / 1260^{\circ} \mathrm{C}+\mathrm{WQ}\right)$ were selected since a greater non-uniformity in microstructure was found in $\mathrm{CK}-3 \mathrm{MCuN}$ than in $\mathrm{CN}$ $3 \mathrm{MN}$.

It should be noted that the bars were provided in two forms: 1" diameter bar with riser and 1.75" diameter (wide end) tapered bar without a riser. A sketch of the 1" bar (Heat K3GAO, $\left.2300^{\circ} \mathrm{F} / 1260^{\circ} \mathrm{C} \mathrm{SA}+\mathrm{WQ}\right)$ is shown in Figure 166. First, a macrostructural specimen was extracted with one-half length of the cast bar and then longitudinally sectioned. It is to be noted that the longitudinal sectioning plane (Plane $A$ ) is through the riser longitudinal axis as shown in Figure 166. The macrostructure is shown in Figure 167. It is evident that the solidification pattern gradually changes from the area remote from riser to the area under riser. Cellular dendrites were observed in the area remote from riser, while coarse columnar dendrites were observed at the area under riser. This change in the solidification pattern implies that more segregation (slower cooling) occurred in the area under riser than in the area remote from riser, which may result in the more stable secondary phases in the area under riser. Three metallographic specimens were also extracted from the bar (CK-3MCuN, Heat $\mathrm{K} 3 \mathrm{GAO}, 2300^{\circ} \mathrm{F} / 1260^{\circ} \mathrm{C} \mathrm{SA}+\mathrm{WQ}$ ) at Locations 1,2 , and 3 as shown in Figure 166. It is to be noted that Location 1 is remote from the riser, Location 3 is under the riser, and Location 2 is between Locations 1 and 3 . The typical 


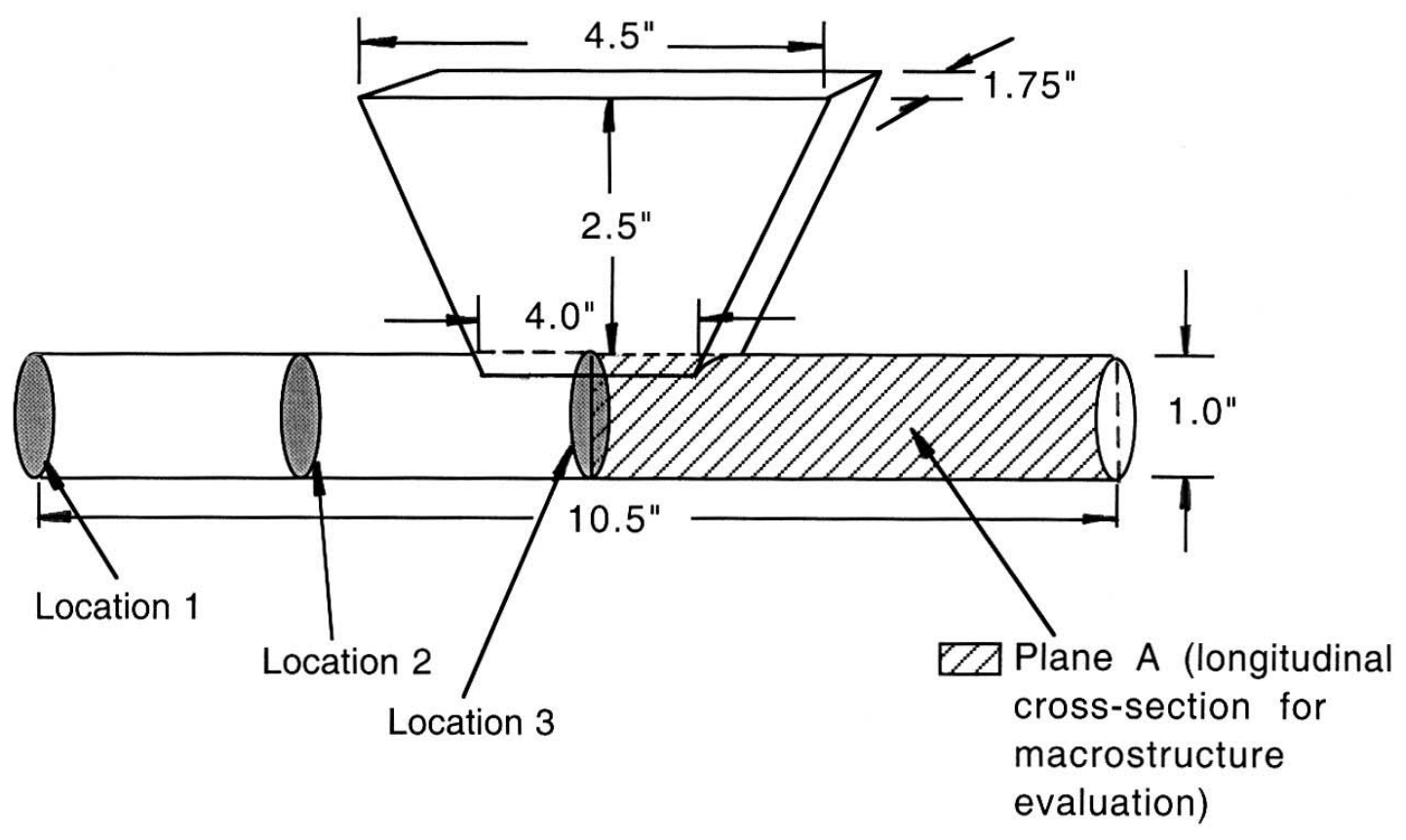

Figure 166. Sketch of a 1" diameter bar, metallographic and chemical analysis specimen extracted from Locations 1, 2 and 3 


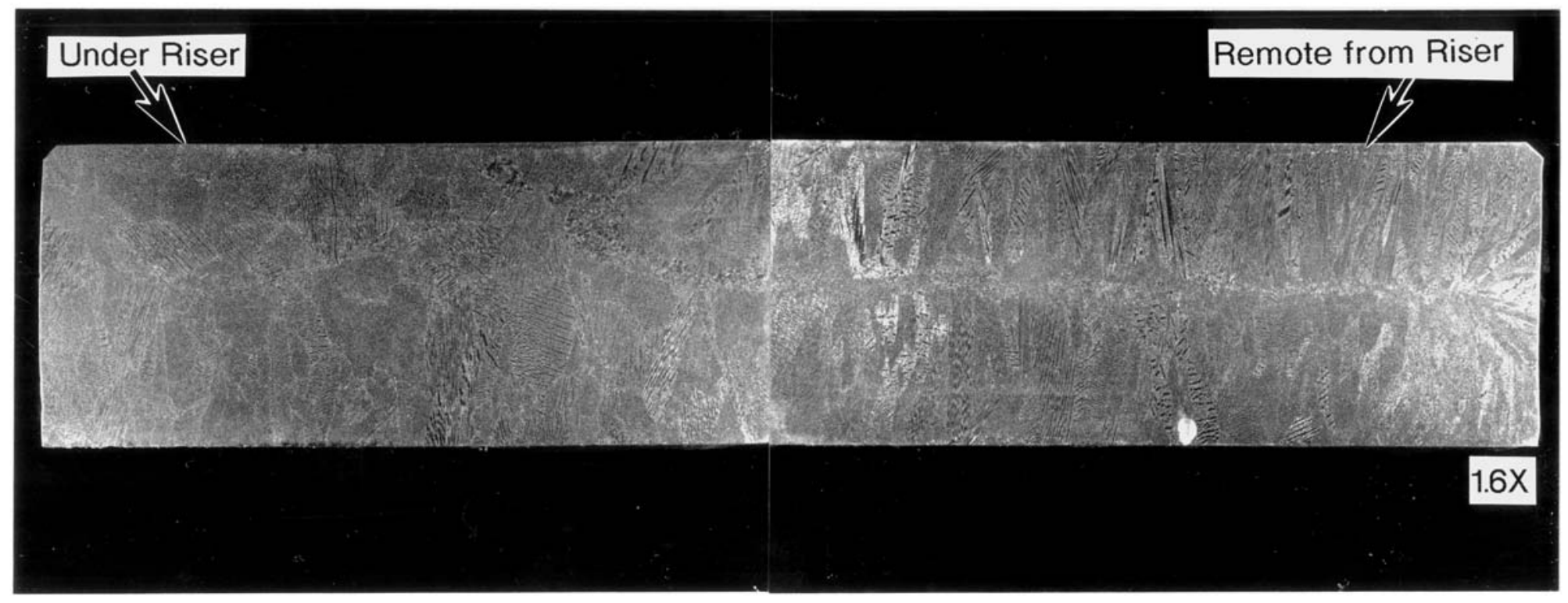

Figure 167. Typical microstructure of longitudinal cross-section of 1" diameter cast bar (one half of the length) 
microstructures are presented in Figures 168 through 170 for Locations 1, 2, and 3 , respectively. It is evident that no secondary phase was observed at Location 1 (see Figure 168), a small amount of secondary phase was found at Location 2 (see Figure 169), and a large amount of secondary phase was observed at Location 3 (see Figure 170). It is believed that the extent of secondary phase at Location 3 is responsible for the decrease in CPT in comparison to the other locations in the same bar. In order to properly determine the corrosion behavior, all corrosion samples were extracted from locations remote from the riser. In addition, chemical analysis was conducted at the three locations as presented in Table 7. It is evident that there is only a slight difference in $\mathrm{Cr}$ and Mo contents among these three locations $(19.89 \mathrm{wt} \% \mathrm{Cr}$ and $7.39 \mathrm{wt} \%$ Mo for Location 1 , 19.87 wt\% Cr and 7.37 wt\% Mo for Location 2 and 19.90 wt\% $\mathrm{Cr}$ and 7.46 wt\% Mo for Location 3).

Figure 171 shows a sketch of the tapered cast bar (Heat K3GCO, $\left.2300^{\circ} \mathrm{F} / 1260^{\circ} \mathrm{C} \mathrm{SA}+\mathrm{WQ}\right)$. A transverse cross-section specimen $\left(\phi 1.3^{\prime \prime} \mathrm{X} 1 / 8^{\prime \prime}\right.$ disk) for macrostructural evaluation was extracted from the mid-length of the cast bar. The macrostructure is shown in Figure 172. A change in solidification pattern is evident from the edge area to the center region of the bar. Cellular dendrites were observed at the edge area of the cast bar, while coarse columnar dendrites were observed in the center region of the cast bar. From the change in the solidification pattern, it is believed that more segregation occurs in the center region than at the edge area of the cast bar. This segregation may cause more stable secondary phases to be formed in the center region of the cast bar. The 

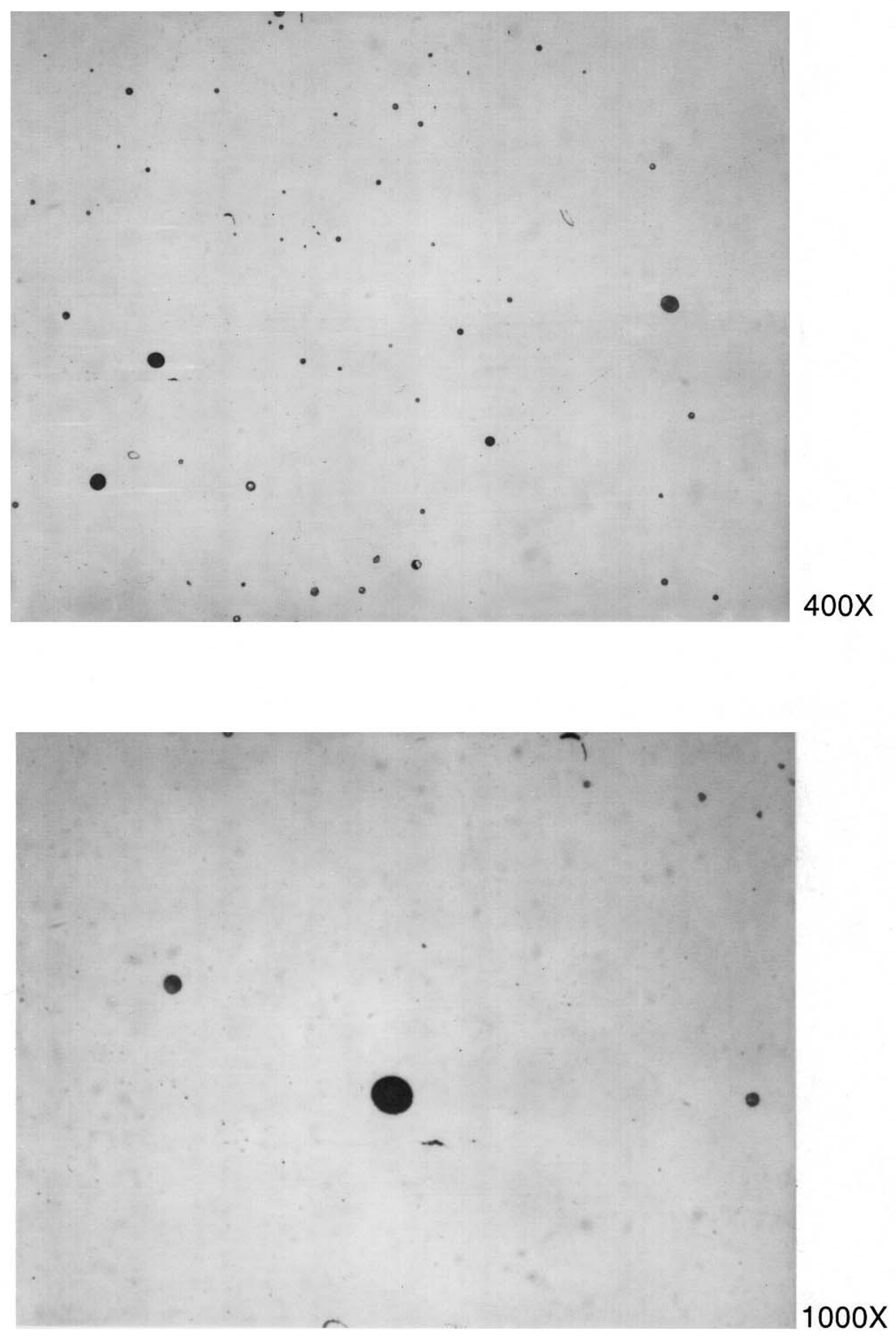

Figure 168. Microstructure of CK-3MCuN Heat K3GAO $\left(2300^{\circ} \mathrm{F}+\mathrm{WQ}\right)$ at Location 1 in Figure 166 

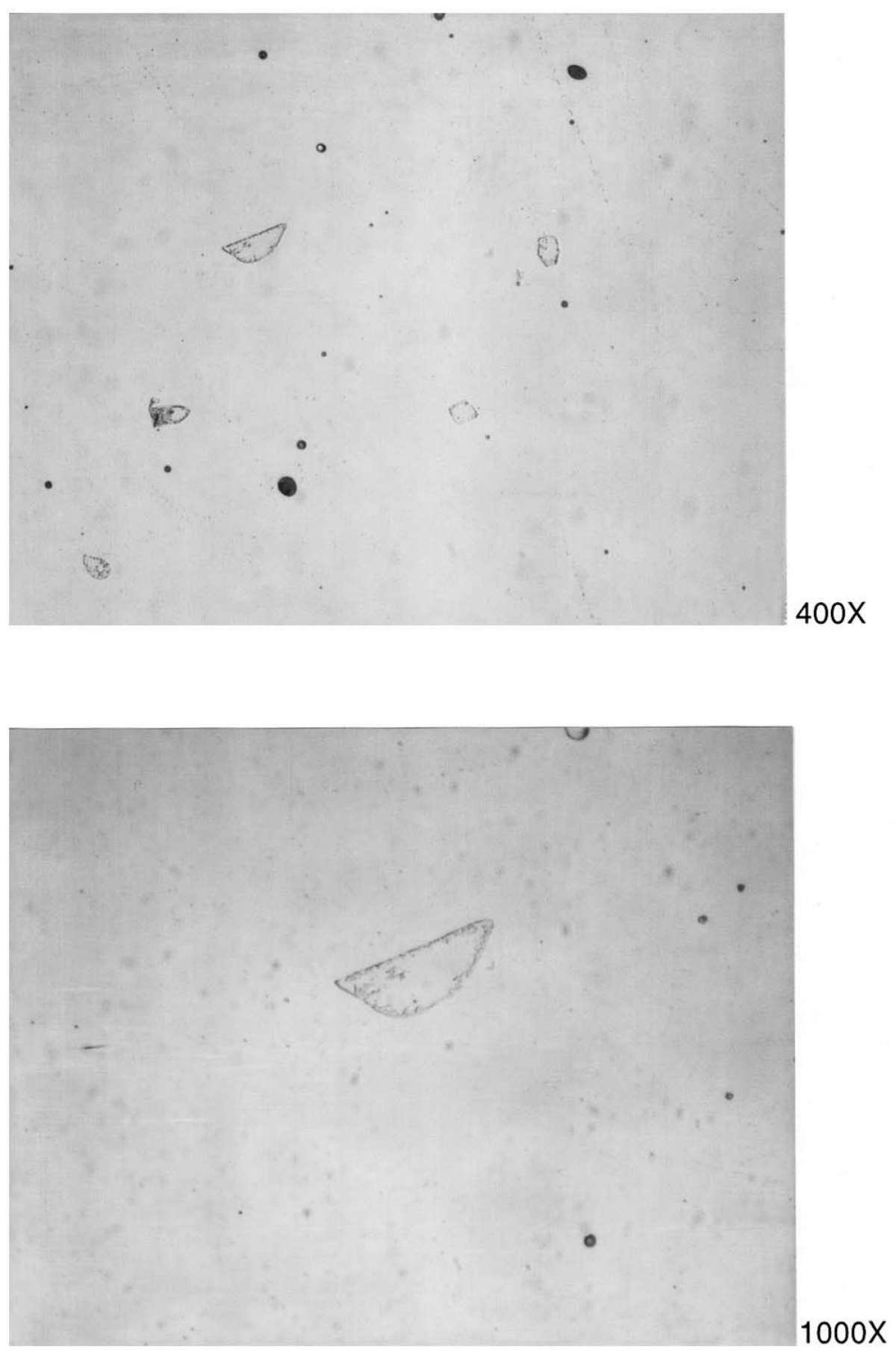

Figure 169. Microstructure of CK-3MCuN Heat K3GAO $\left(2300^{\circ} \mathrm{F}+\mathrm{WQ}\right)$ at Location 2 in Figure 166 

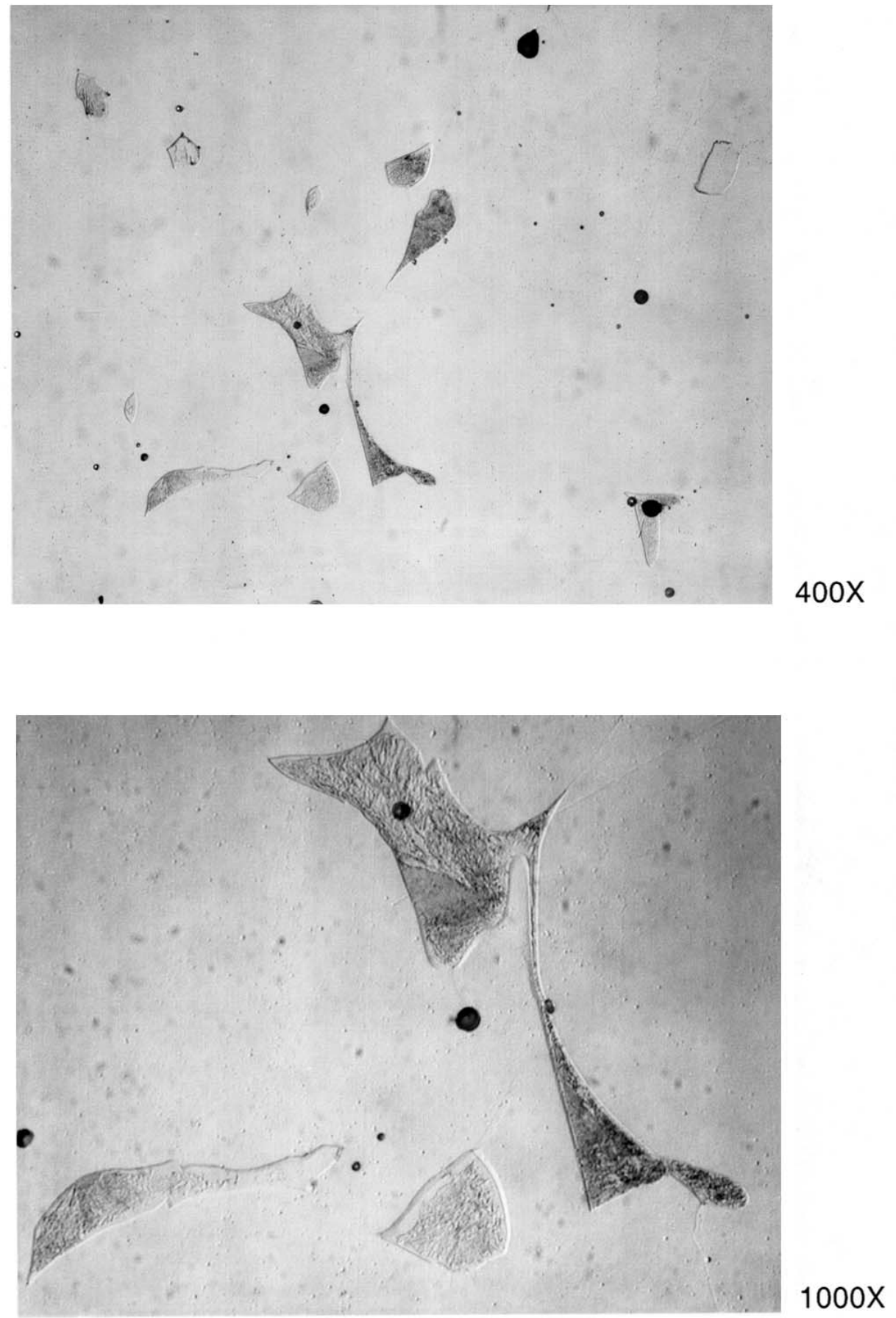

Figure 170. Microstructure of CK-3MCuN Heat K3GAO $\left(2300^{\circ} \mathrm{F}+\mathrm{WQ}\right)$ at Location 3 in Figure 166 


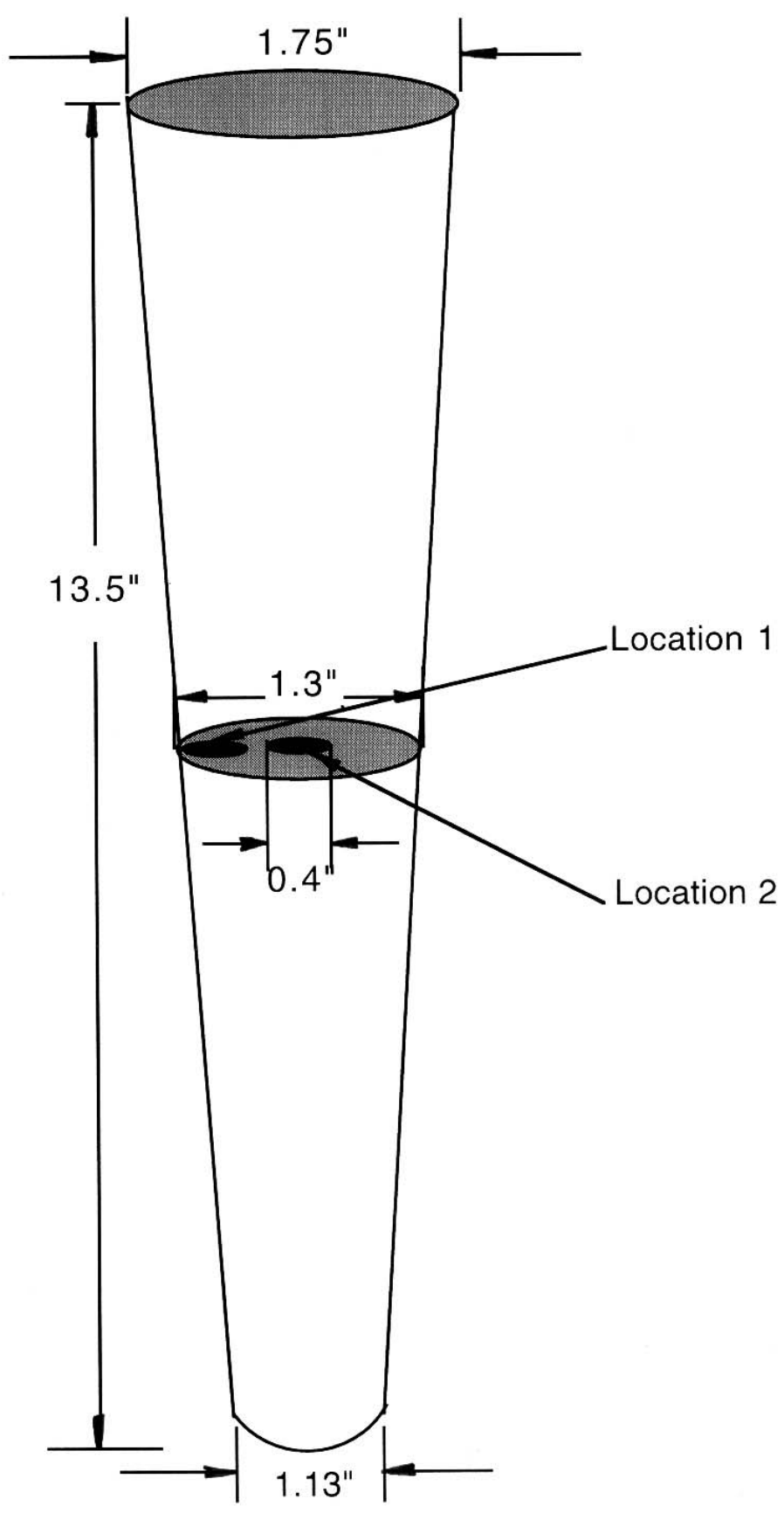

Figure 171. Sketch of a tapered bar, metallographic and chemical analysis specimen extracted from Locations 1 and 2 


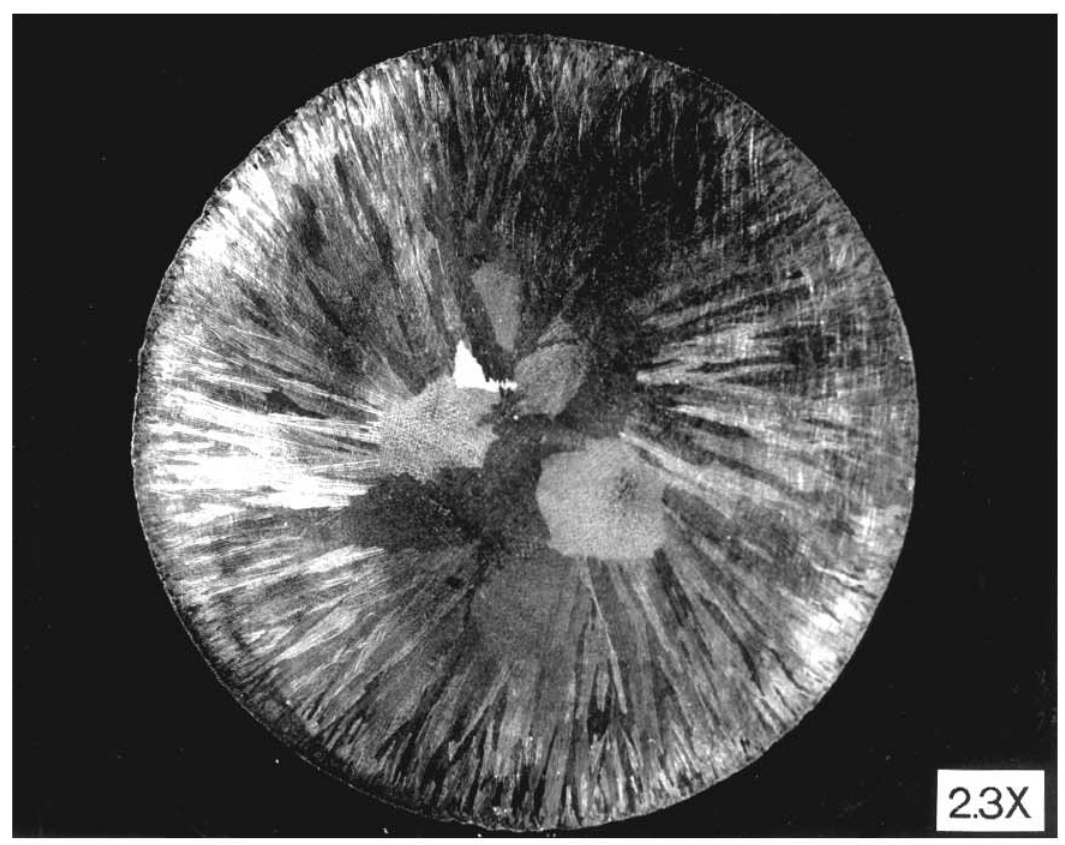

Figure 172. Typical macrostructure of transverse cross-section of tapered cast bar (middle length of the bar) 
same specimen was also used for microstructural evaluation. As shown in Figure 171, microstructural evaluation focused on the difference in microstructure at the locations between the center region and edge area (Location 1 for the edge area and Location 2 for the center region). The typical microstructures are shown in Figure 173 for the edge area and Figures 174 and 175 for the center region. It is evident that in a 0.4 " diameter center region, a significant amount of secondary phase exists (Figure 174), compared to the edge area (free of secondary phases, see Figure 173). In addition, some areas of shrinkage were also observed in the center region of the sample, as illustrated in Figure 175. Therefore, the corrosion samples were extracted longitudinally along the length away from the center region instead of transverse cross-sections. (It is to be noted that the CPT of the transverse cross-section sample, containing the center region, was not determined). The chemical analysis results (see Table 8 ) shows that the center region contains slightly lower carbon (0.021 wt\%), higher $\mathrm{Cr}$ (20.43 wt\%) and Mo (7.02 wt\%) in comparison with the edge area $(0.031 \mathrm{wt} \% \mathrm{C}$, $20.22 \mathrm{wt} \% \mathrm{Cr} \& 6.53 \mathrm{wt} \% \mathrm{Mo})$.

Based on the evaluation above, it is evident that the secondary phases remain (un-dissolved) at the location under the riser for CK-3MCuN Heat K3GAO or in the center region for $\mathrm{CK}-3 \mathrm{MCuN}$ Heat $\mathrm{K} 3 \mathrm{GCO}$ are more stable than those in other areas of the cast bars. These secondary phases at the location under the riser for $\mathrm{CK}-3 \mathrm{MCUN}$ Heat K3GAO or in the center region for $\mathrm{CK}-3 \mathrm{MCuN}$ Heat K3GCO were not dissolved by the one-hour-SA at $2300^{\circ} \mathrm{F} / 1260^{\circ} \mathrm{C}$. For further investigation, in addition to a one-hour-SA, a four-hour-SA at $2300^{\circ} \mathrm{F} / 1260^{\circ} \mathrm{C}$ 

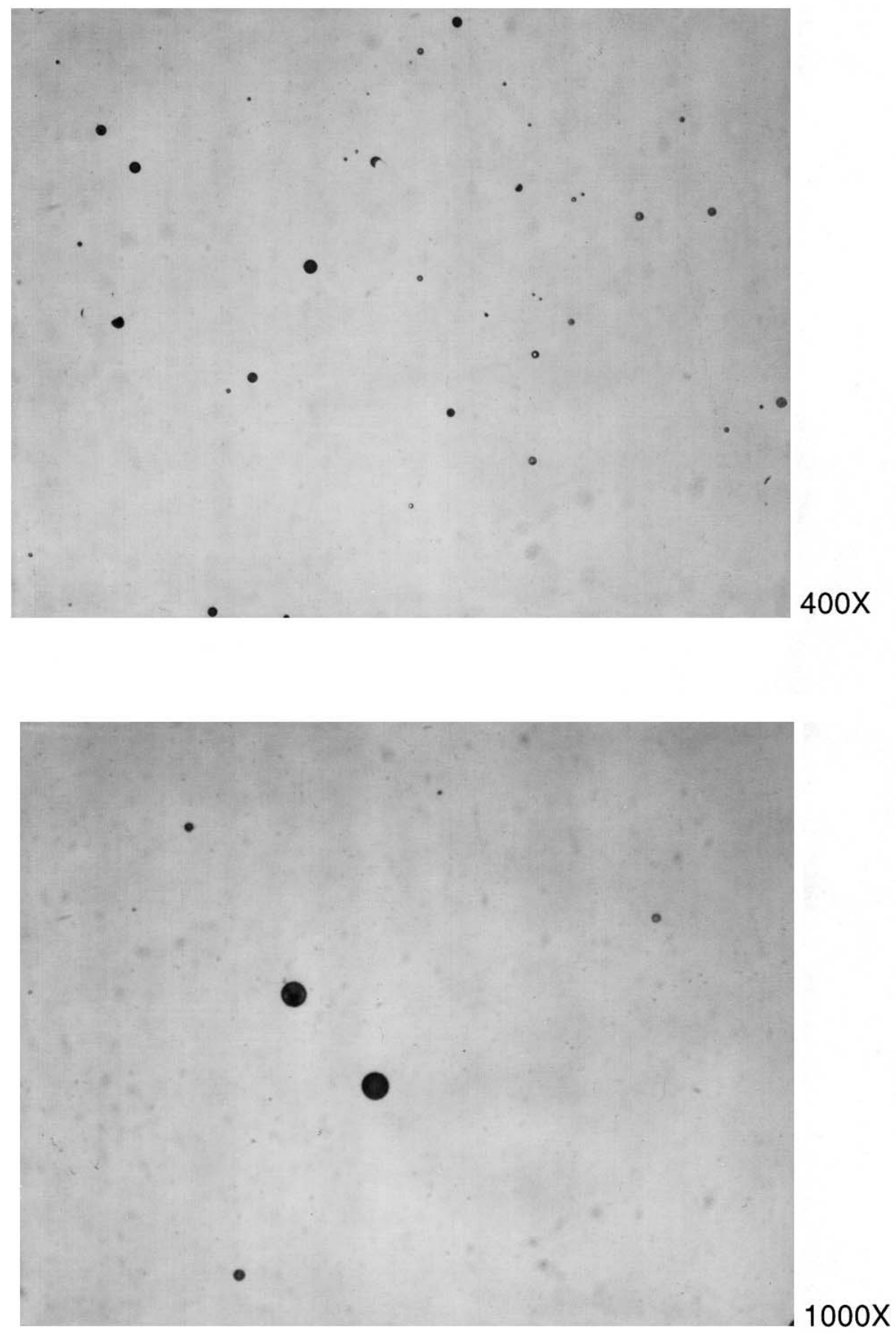

Figure 173. Microstructure of CK-3MCuN Heat K3GCO $\left(2300^{\circ} \mathrm{F}+\mathrm{WQ}\right)$ at Location 1 in Figure 171 

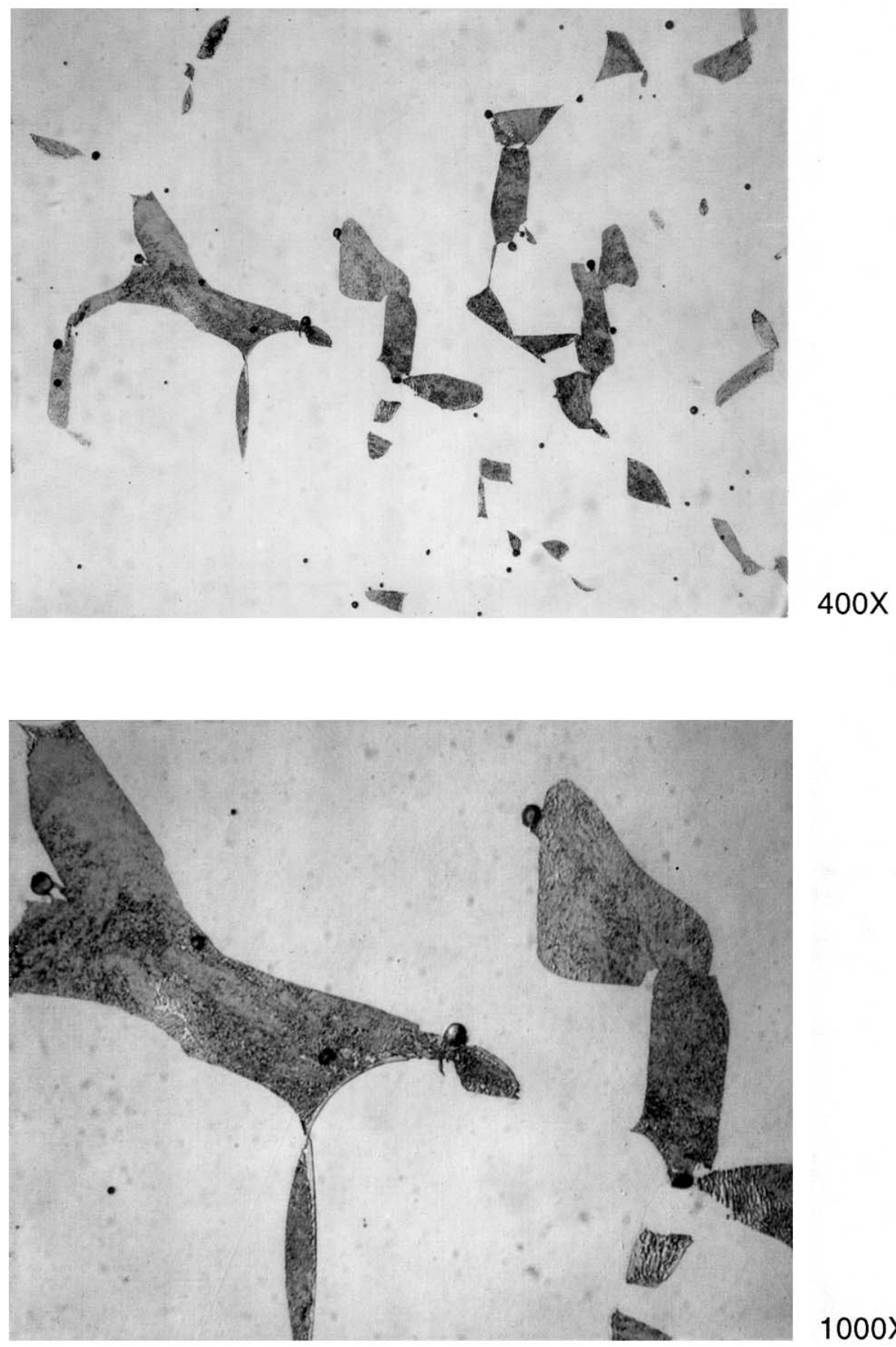

$1000 X$

Figure 174. Microstructure of CK-3MCuN Heat K3GCO $\left(2300^{\circ} \mathrm{F}+\mathrm{WQ}\right)$ at Location 2 in Figure 29 

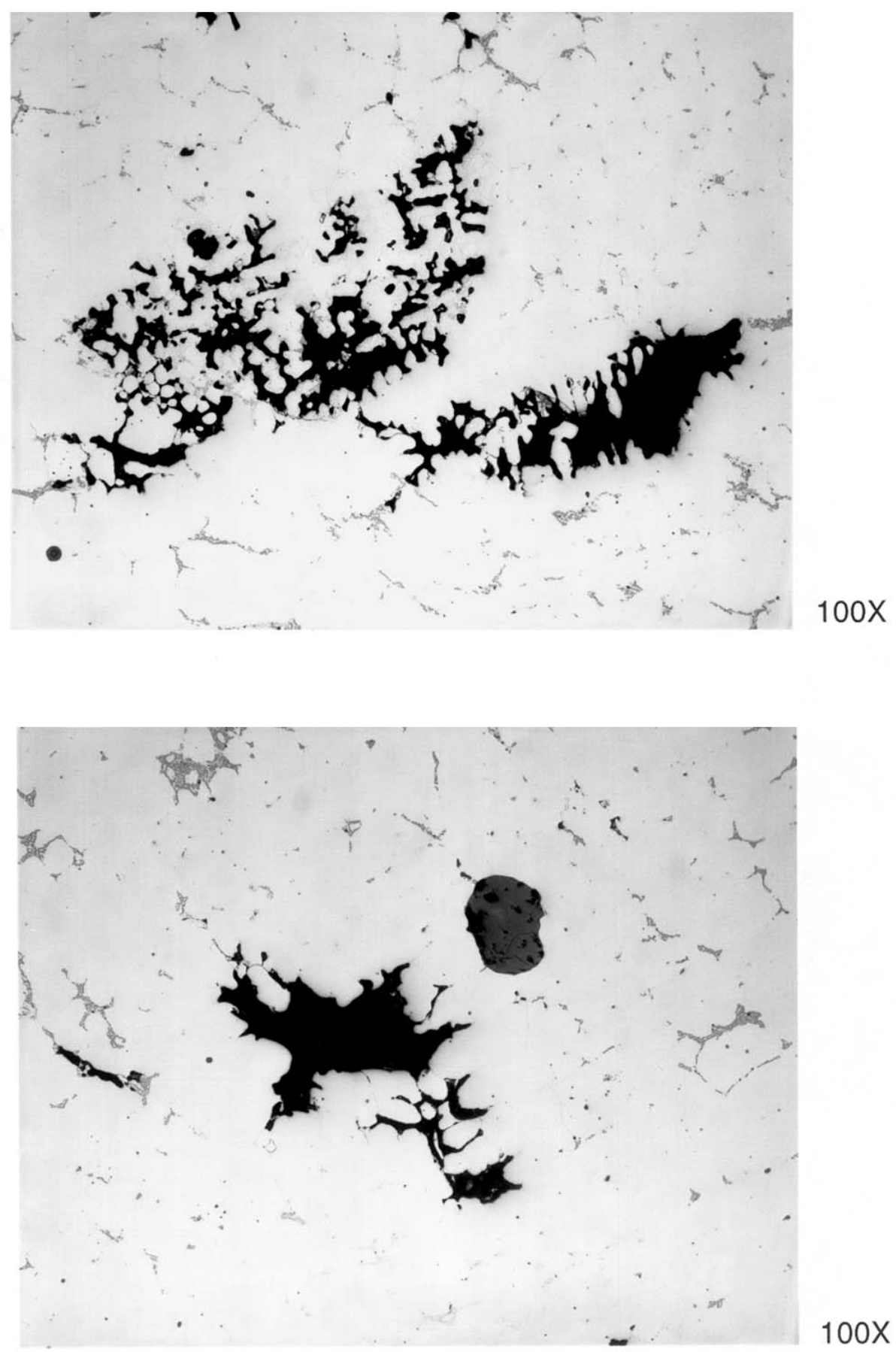

Figure 175. Microstructure of CK-3MCuN Heat K3GCO $\left(2300^{\circ} \mathrm{F}+\mathrm{WQ}\right)$ at Location 2 in Figure 29 

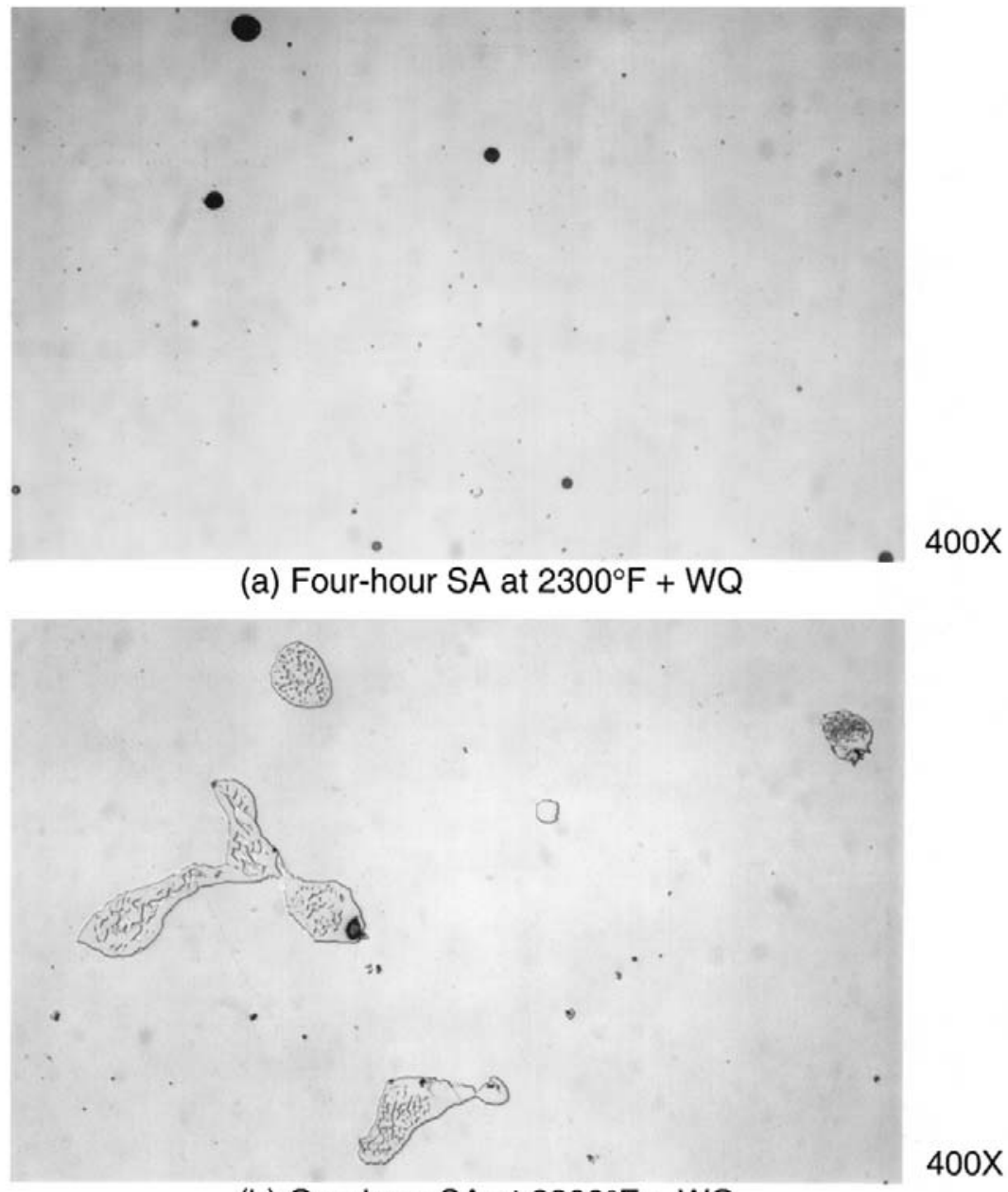

$400 x$

(b) One-hour SA at $2300^{\circ} \mathrm{F}+\mathrm{WQ}$

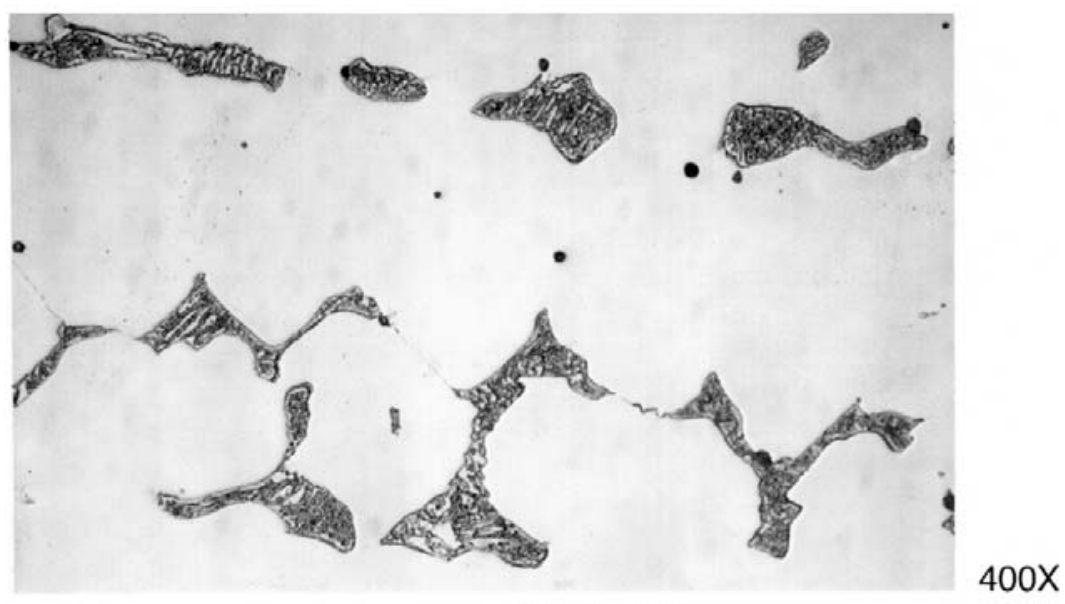

(c) As-cast

Figure 176. Microstructure of CK-3MCuN Heat K3GAO 
(WQ) was conducted on the specimen (Heat K3GAO) extracted from the area under the riser. Microstructural evaluation was conducted on the four-hour solution-annealed specimen. The microstructure of Heat K3GAO after the fourhour SA (at $2300^{\circ} \mathrm{F} / 1260^{\circ} \mathrm{C}+\mathrm{WQ}$ ) is presented in Figure $176 \mathrm{a}$, in comparison with the microstructure of the same heat after one hour SA (at $2300^{\circ} \mathrm{F} / 1260^{\circ} \mathrm{C}+$ WQ, Figure $176 \mathrm{~b}$ ) and the microstructure in the as-cast condition (Figure $176 \mathrm{c}$ ). It is evident that the secondary phases in the area under the riser were completely dissolved when the time for SA (at $2300^{\circ} \mathrm{F} / 1260^{\circ} \mathrm{C}$ ) was increased from one hour to four hours (see Figure 176 a). 


\section{CONCLUSIONS}

\section{- Microstructural Characterization of CK-3MCuN:}

1) For as-cast $\mathrm{CK}-3 \mathrm{MCuN}$, fine and coarse irregular-shaped secondary phases observed within the "islands" along grain boundaries and in interdendritic regions are identified as $\sigma$ phase and $\mathrm{Cr} /$ Mo carbides, respectively, by SEM/EDS and X-ray analysis. The existence of $\sigma$ phase is confirmed by the stain etching. The dark globular particles observed in the matrix are defined to be inclusions (Si/Mn/Mg oxides).

2) The effect of the solution-annealing temperature on the microstructure of CK$3 \mathrm{MCuN}$ was defined. After SA in the temperature range of 2100 to $2250^{\circ} \mathrm{F}$ $\left(1150\right.$ to $\left.1230^{\circ} \mathrm{C}\right)$ followed by water quenching, the $\sigma$ phase within the "islands" is completely dissolved, while Cr/Mo carbides within the "islands" remain. The amount of remaining $\mathrm{Cr} / \mathrm{Mo}$ carbides is reduced with an increase in SA temperature.

3) A higher temperature $\left(2300^{\circ} \mathrm{F} / 1260^{\circ} \mathrm{C}\right)$ solution anneal followed by a water quench results in complete dissolution of secondary phases for both Heat K3GAO and K3GCO, but not for Heats 2, 3, and 5. The "empty islands" remaining in Heat 2, 3, and 5 are considered to be ferrite islands.

4) Re-formation of secondary phases ( $\sigma$ phase and $\mathrm{Cr} / \mathrm{Mo}$ carbides ) occurs during slow cooling (from $2300^{\circ} \mathrm{F} / 1260^{\circ} \mathrm{C}$ ) only if secondary phases are not completely dissolved during solution annealing (at $2300^{\circ} \mathrm{F} / 1260^{\circ} \mathrm{C}$ ).

5) No $\sigma$ phase or $\mathrm{Cr} /$ Mo carbides were found in wrought 254 SMO by SEM/EDS, X-ray diffraction analysis and stain-etching. 


\section{- Microstructural Characterization of CN-3MN:}

1) For as-cast $\mathrm{CN}-3 \mathrm{MN}$ (except Heat 5), irregular-shaped secondary phases observed within the "islands" (in interdendritic regions and along grain boundaries) and a cluster of block-like and/or irregular shaped secondary phases observed in the matrix are identified as $\sigma$ phase and $\mathrm{Cr} / \mathrm{Mo}$ carbides/nitrides, respectively, by SEM/EDS and X-ray analysis. The existence of $\sigma$ phase is confirmed by a stain etching. The dark globular particles observed in the matrix are defined to be inclusions (Si/Mn/Al oxides). For as-cast $\mathrm{CN}-3 \mathrm{MN}$ Heat 5 , only globular or block-like particles were observed in the matrix. They are identified as inclusions (Ce/La/Al oxides) which remain un-changed regardless of material condition (as-cast or in various SA conditions).

2) The effect of solution-annealing temperature on the microstructure of $\mathrm{CN}$ $3 \mathrm{MN}$ was defined. After SA at the temperature range of 2100 to $2200^{\circ} \mathrm{F}$ $\left(1150\right.$ to $\left.1205^{\circ} \mathrm{C}\right)$ followed by water quenching, $\sigma$ phase within the "islands" are completely dissolved, while $\mathrm{Cr} / \mathrm{Mo}$ carbides/nitrides still remain. The amount of remaining $\mathrm{Cr} /$ Mo carbides/nitrides is reduced with increasing in SA temperature.

3) At a higher temperature $\left(2300^{\circ} \mathrm{F} / 1260^{\circ} \mathrm{C}\right)$ solution anneal followed by $\mathrm{WQ}$, the complete dissolution of $\mathrm{Cr} / \mathrm{Mo}$ carbides/nitrides is observed for the most heats of CN-3MN (Heat N3GAO, Heat N3GBO and Heat 1, but not for Heat 4).

4) No re-formation of secondary phases occurs during slow cooling (from 
$2300^{\circ} \mathrm{F} / 1260^{\circ} \mathrm{C}$ ) when secondary phases ( $\sigma$ phase and $\mathrm{Cr} /$ Mo carbides) are completely dissolved after solution annealing (at $2300^{\circ} \mathrm{F} / 1260^{\circ} \mathrm{C}$ ).

5) No $\sigma$ phase or $\mathrm{Cr} / \mathrm{Mo}$ carbides/nitrides were found in wrought AL-6XN by SEM/EDS, X-ray diffraction analysis, and stain etching.

\section{- Results of Inclusion Study}

1) The majority of the inclusions (cross-sectional area) are within the range of $2.2-20 \mu \mathrm{m}^{2}$ (as polished surface). This was determined to be the case for all six heats evaluated ( 3 from $\mathrm{CK}-3 \mathrm{MCuN}$ and 3 from $\mathrm{CN}-3 \mathrm{MN}$ ).

2) The large inclusions (cross-sectional area greater than $20 \mu \mathrm{m}^{2}$ ) appear to be more generally located near the top of the cast blocks (under the riser). This is true for all six heats evaluated.

3) No clear correlation was found between the number of inclusions (per square millimeter) and CPT for each type of castings. This result indicates that while the inclusions may have an influence on corrosion behavior, they are not dominant in localized corrosion behavior (pitting). 


\section{- Localized Corrosion Behavior of CK-3MCuN and CN-3MN}

\section{Pitting Corrosion:}

1) Solution annealing, at three selected temperatures $\left(2100^{\circ} \mathrm{F} / 1150^{\circ} \mathrm{C}\right.$, $2200^{\circ} \mathrm{F} / 1205^{\circ} \mathrm{C}$, and $2300^{\circ} \mathrm{F} / 1260^{\circ} \mathrm{C}$ ), is effective in improving pitting corrosion resistance of high Mo castings. The CPT of solution-annealed CK-3MCuN is 30$45 \mathrm{C}^{\circ}\left(54-81 \mathrm{~F}^{\circ}\right)$ higher than that of the as-cast condition, while the CPT of solution-annealed $\mathrm{CN}-3 \mathrm{MN}$ is $10-20 \mathrm{C}^{\circ}\left(18-36 \mathrm{~F}^{\circ}\right)$ higher than that of the as-cast condition. In general, as the SA temperature increases, the CPT increases.

2) Slow cooling after $2300^{\circ} \mathrm{F} / 1260^{\circ} \mathrm{C} \mathrm{SA}$ revealed no effect on pitting corrosion resistance for both $\mathrm{CK}-3 \mathrm{MCUN}$ and $\mathrm{CN}-3 \mathrm{MN}$.

3) The pitting corrosion behavior is strongly related to secondary phases ( $\sigma$ phase and $\mathrm{Cr} / \mathrm{Mo}$ carbides/nitrides) in these high Mo castings. The preferential location for pit initiation is the area either adjacent to the coarse Cr/Mo carbides/nitrides at the outer boundary of the "islands" or adjacent to the $\sigma$ phase within the "islands".

\section{Intergranular Corrosion:}

1) Solution annealing, at the three SA temperatures employed, improves the intergranular corrosion resistance compared to the as-cast condition. The maximum reduction in the CORROSION rate is $48 \mathrm{mpy}$ for $\mathrm{CK}-3 \mathrm{MCuN}$ and 8 mpy for $\mathrm{CN}-3 \mathrm{MN}$. In general, the higher the SA temperature, the lower the corrosion rate.

2) Slow cooling after a $2300^{\circ} \mathrm{F} / 1260^{\circ} \mathrm{C} \mathrm{SA}$ decreases the intergranular corrosion 
resistance compared to water quenching after a $2300^{\circ} \mathrm{F} / 1260^{\circ} \mathrm{C}$ SA for both CK-3MCuN and CN-3MN.

3) Intergranular corrosion is strongly related to secondary phases ( $\sigma$ phase and Cr/Mo carbides/nitrides) formed within the "islands" along grain boundaries and in interdendritic regions of these high Mo castings.

4) Bend testing after corrosion testing enhances the evaluation of intergranular corrosion behavior and reveals an identical intergranular corrosion tendency compared to corrosion rate.

\section{NORSOK Corrosion Testing:}

1) All heats in the solution-annealed conditions passed the NORSOK corrosion test criteria, while all heats in the as-cast condition failed the NORSOK corrosion test.

2) Slow cooling after $2300^{\circ} \mathrm{F} / 1260^{\circ} \mathrm{C} \mathrm{SA}$ produced no effect on NORSOK corrosion test results for both $\mathrm{CK}-3 \mathrm{MCuN}$ and $\mathrm{CN}-3 \mathrm{MN}$. 


\section{RECOMMENDATION}

Based on the microstructural and corrosion evaluation results, a minimum SA temperature of $2300^{\circ} \mathrm{F} / 1260^{\circ} \mathrm{C}$ is recommended for both $\mathrm{CK}-3 \mathrm{MCuN}$ and $\mathrm{CN}$ $3 \mathrm{MN}$ high Mo stainless steel castings. 


\section{REFERENCES}

[1] ASM International, "Stainless Steels", ASM International ${ }^{\circledR}$, Metals Park, Ohio 44073, 1994.

[2] Lundin, C. D., Li, L., Lu, G. and Liu, W., "A State-of-Art Review: Fabrication and Corrosion Behavior of High Alloy Cast Materials", The University of Tennessee, November 1995.

[3] Lundin, C. D., Liu, W., Qiao, C. Y. P. and Khan, K. K. "Evaluation of Cracking and Corrosion Sensitivity of A CN-3MN Casting / SMA Beadon-plate Welding Using Inconel 112 Electrodes", Technical Service Report 121 to Steel Founders' Society of America, April 1995.

[4] Lundin, C. D., Lu, L, Shi, C. J. and Liu, W. "Improved Process Procedures for Upgrading and Repair of High Alloy and Stainless Castings", Technical Report, December 1996.

[5] ASM International, "Metallography and Microstructures", Metals Handbook ${ }^{\circledR}$ Ninth Edition, Vol. 9, Metals Park, Ohio 44073, 1994.

[6] Horvath, W., Prantl, W., Werner, E. and Stuwe, H. P. "Influence of Thermal Cycling on the Microstructure of a ferritic-Austenitic duplex Stainless Steel", Materials Characterization, 34: 277-285, 1995.

[7] Brandis, H. and Kiesheyer, H. "Influence of Chromium and Molybdenum on Chloride Corrosion of Stainless Steels", Proceedings of the Conference, Stainless Steels' 84, September 3-4, 1984.

[8] Mckay, "Welding Stainless Steel", Teledyne Mckay, PA 17405-1509, 1990. 
Table 1. Chemical Composition of CK-3MCuN Castings in Comparison with Wrought Counterpart 254 SMO

\begin{tabular}{|c|c|c|c|c|c|c|c|c|c|c|c|c|c|c|c|c|c|c|c|c|}
\hline & C & $\mathrm{Cr}$ & Mo & $\mathrm{Ni}$ & $\mathrm{Cu}$ & $S$ & Mn & $\mathbf{P}$ & Si & $\mathrm{Ta}$ & V & $\mathbf{w}$ & $\mathrm{Mg}$ & Co & $\mathrm{Fe}$ & $\mathrm{Nb}$ & $\mathrm{Al}$ & $\mathrm{Ti}$ & 0 & $\mathbf{N}$ \\
\hline K3GAO* & 0.024 & 19.80 & 7.53 & 18.72 & 0.61 & 0.010 & 0.52 & 0.025 & 0.71 & $<0.01$ & 0.05 & 0.17 & $<0.01$ & 0.11 & Bal & 0.01 & 0.01 & $<0.01$ & 0.043 & 0.23 \\
\hline $\mathrm{K} 3 \mathrm{GCO}^{* *}$ & 0.018 & 19.85 & 6.56 & 18.83 & 0.69 & 0.009 & 0.72 & 0.018 & 1.01 & $<0.01$ & 0.03 & $<0.01$ & $<0.01$ & 0.05 & Bal & 0.01 & $<0.01$ & $<0.01$ & 0.019 & 0.22 \\
\hline Heat 2 & 0.021 & 19.13 & 6.89 & 19.72 & 0.802 & 0.012 & 0.600 & 0.016 & 0.361 & 0.010 & 0.055 & 0.088 & 0.018 & 0.099 & 51.78 & $<0.003$ & 0.020 & ND & 0.086 & 0.244 \\
\hline Heat 3 & 0.015 & 19.48 & 6.26 & 17.60 & 0.552 & 0.008 & 0.560 & 0.019 & 0.505 & 0.009 & 0.055 & 0.253 & 0.017 & 0.232 & 54.10 & 0.026 & 0.020 & ND & 0.062 & 0.212 \\
\hline Heat 5 & 0.015 & 20.80 & 6.72 & 18.02 & 0.464 & 0.002 & 0.316 & 0.016 & 0.424 & 0.113 & 0.030 & 0.034 & 0.046 & 0.044 & 52.63 & 0.016 & $<0.003$ & ND & 0.094 & 0.212 \\
\hline $\begin{array}{l}\text { ASTM } \\
\text { A } 743\end{array}$ & $\begin{array}{c}0.025 \\
\max \end{array}$ & $\begin{array}{l}19.5- \\
20.5\end{array}$ & $\begin{array}{l}6.0- \\
7.0\end{array}$ & $\begin{array}{c}17.5- \\
19.5\end{array}$ & $\begin{array}{c}0.50- \\
1.00\end{array}$ & $\begin{array}{c}0.010 \\
\max \end{array}$ & $\begin{array}{l}1.20 \\
\max \end{array}$ & $\begin{array}{c}0.045 \\
\max \end{array}$ & $\begin{array}{l}1.00 \\
\max \end{array}$ & NS & NS & NS & NS & NS & NS & NS & NS & NS & NS & $\begin{array}{l}0.18- \\
0.24\end{array}$ \\
\hline $\begin{array}{c}254 \\
\text { SMO }\end{array}$ & 0.013 & 19.90 & 6.19 & 18.08 & 0.939 & 0.001 & 0.507 & 0.033 & 0.35 & 0.009 & 0.052 & 0.066 & 0.053 & 0.29 & 56.71 & 0.011 & 0.003 & ND & 0.006 & 0.218 \\
\hline
\end{tabular}

NS: Not Specified

ND: Not Determined

Chemical analysis conducted by The Alstom-CE for Heats K3GAO \& K3GCO

Chemical analysis conducted by The Wisconsin Centrifugal for Heats 2,3 \& 5

* Sample for chemical analysis extracted from the end (remote from riser) of 1" diameter bar in as-cast condition for Heat K3GAO

** Sample for chemical analysis extracted from the narrow end of tapered bar in as-cast condition for Heat K3GCO 
Table 2. Chemical Composition of CN-3MN Castings in Comparison with Wrought Counterpart AL-6XN

\begin{tabular}{|c|c|c|c|c|c|c|c|c|c|c|c|c|c|c|c|c|c|c|c|c|}
\hline & C & $\mathrm{Cr}$ & Mo & $\mathrm{Ni}$ & $\mathrm{Cu}$ & S & Mn & $\mathbf{P}$ & Si & $\mathrm{Ta}$ & V & $\mathbf{w}$ & $\mathrm{Mg}$ & Co & $\mathrm{Fe}$ & $\mathrm{Nb}$ & $\mathrm{Al}$ & $\mathrm{Ti}$ & 0 & $\mathbf{N}$ \\
\hline N3GAO* & 0.027 & 21.24 & 6.65 & 24.04 & 0.14 & 0.005 & 0.50 & 0.024 & 0.80 & $<0.01$ & 0.05 & 0.14 & $<0.01$ & 0.10 & Bal & $<0.01$ & 0.01 & 0.01 & 0.040 & 0.21 \\
\hline N3GBO** & 0.023 & 21.25 & 6.14 & 24.06 & 0.25 & 0.006 & 0.59 & 0.027 & 0.64 & $<0.01$ & 0.04 & 0.01 & $<0.01$ & 0.02 & Bal & 0.02 & 0.02 & 0.01 & 0.010 & 0.25 \\
\hline Heat 1 & 0.026 & 20.09 & 7.17 & 25.25 & 0.487 & 0.011 & 0.730 & 0.017 & 0.441 & 0.126 & 0.064 & 0.168 & 0.021 & 0.118 & 45.08 & ND & 0.013 & ND & 0.022 & 0.113 \\
\hline Heat 4 & 0.019 & 21.15 & 7.24 & 25.42 & 0.204 & 0.003 & 0.804 & 0.013 & 0.674 & 0.125 & 0.045 & 0.057 & 0.021 & 0.085 & 43.98 & ND & 0.008 & ND & 0.022 & 0.128 \\
\hline Heat 5 & 0.017 & 20.77 & 5.94 & 25.26 & 0.055 & 0.005 & 0.146 & 0.004 & 0.562 & 0.009 & 0.010 & 0.027 & 0.020 & 0.050 & 46.81 & $<0.003$ & 0.013 & ND & 0.078 & 0.214 \\
\hline $\begin{array}{l}\text { ASTM } \\
\text { A } 743\end{array}$ & $\begin{array}{l}0.03 \\
\max \end{array}$ & $\begin{array}{l}20.0- \\
22.0\end{array}$ & $\begin{array}{l}6.00- \\
7.00\end{array}$ & $\begin{array}{l}23.5- \\
25.5\end{array}$ & $\begin{array}{l}0.75 \\
\max \end{array}$ & $\begin{array}{c}0.010 \\
\max \end{array}$ & $\begin{array}{l}2.00 \\
\max \end{array}$ & $\begin{array}{c}0.040 \\
\max \end{array}$ & $\begin{array}{l}1.00 \\
\max \end{array}$ & NS & NS & NS & NS & NS & Bal & NS & NS & NS & NS & $\begin{array}{c}0.18- \\
0.26\end{array}$ \\
\hline AL-6XN & 0.020 & 20.07 & 6.22 & 24.28 & 0.184 & .0008 & 0.379 & 0.032 & 0.488 & 0.011 & 0.070 & 0.038 & 0.036 & 0.278 & 48.09 & $<0.003$ & 0.022 & ND & .0048 & 0.220 \\
\hline
\end{tabular}

NS: Not Specified.

ND: Not Determined.

Chemical analysis conducted by The Alstom-CE for Heats N3GAO \& N3GBO.

Chemical analysis conducted by The Wisconsin Centrifugal for Heats $1,4, \& 5$.

* Sample for chemical analysis extracted from the end (remote from riser) of 1" diameter bar in as-cast condition for Heat N3GAO.

** Sample for chemical analysis extracted from one end of Keel bar in as-cast condition for Heat K3GBO. 
Table 3. Solution-Annealing (SA) Temperatures for CK-3MCuN Materials

\begin{tabular}{|l|c|c|c|c|c|}
\hline \multicolumn{1}{|c|}{ Materials } & $\begin{array}{c}\text { Heat } \\
\text { K3GAO }\end{array}$ & $\begin{array}{c}\text { Heat } \\
\text { K3GCO }\end{array}$ & Heat 2 & Heat 3 & Heat 5 \\
\hline \multirow{3}{*}{ UT SA } & $2100^{\circ} \mathrm{F} / 1150^{\circ} \mathrm{C}$ & $2100^{\circ} \mathrm{F} / 1150^{\circ} \mathrm{C}$ & $2100^{\circ} \mathrm{F} / 1150^{\circ} \mathrm{C}$ & $2100^{\circ} \mathrm{F} / 1150^{\circ} \mathrm{C}$ & $2100^{\circ} \mathrm{F} / 1150^{\circ} \mathrm{C}$ \\
& $2200^{\circ} \mathrm{F} / 1205^{\circ} \mathrm{C}$ & $2200^{\circ} \mathrm{F} / 1205^{\circ} \mathrm{C}$ & $2300^{\circ} \mathrm{F} / 1260^{\circ} \mathrm{C}$ & $2300^{\circ} \mathrm{F} / 1260^{\circ} \mathrm{C}$ & $2300^{\circ} \mathrm{F} / 1260^{\circ} \mathrm{C}$ \\
& $2300^{\circ} \mathrm{F} / 1260^{\circ} \mathrm{C}$ & $2300^{\circ} \mathrm{F} / 1260^{\circ} \mathrm{C}$ & & & \\
\hline \multirow{2}{*}{ Foundry SA } & - & - & $2250^{\circ} \mathrm{F} / 1230^{\circ} \mathrm{C}$ & $2200^{\circ} \mathrm{F} / 1205^{\circ} \mathrm{C}$ & $2250^{\circ} \mathrm{F} / 1230^{\circ} \mathrm{C}$ \\
\hline \multirow{2}{*}{ ASTM A 743 } & \multicolumn{5}{|c|}{ Minimum $2100^{\circ} \mathrm{F} / 1150^{\circ} \mathrm{C}$} \\
\hline
\end{tabular}

Note: - Water Quench (WQ) was applied to all heats listed in above table. - Slow Cooling (SC) was also applied to Heat K3GAO \& Heat 3 (from $2300^{\circ} \mathrm{F} / 1260^{\circ} \mathrm{C} \mathrm{SA}$ ) in addition to $\mathrm{WQ}$. 
Table 4. Solution-Annealing (SA) Temperatures for CN-3MN Materials

\begin{tabular}{|c|c|c|c|c|c|}
\hline Materials & $\begin{array}{c}\text { Heat } \\
\text { N3GAO }\end{array}$ & $\begin{array}{c}\text { Heat } \\
\text { N3GBO }\end{array}$ & Heat 1 & Heat 4 & Heat 5 \\
\hline \multirow{3}{*}{ UT SA } & $2100^{\circ} \mathrm{F} / 1150^{\circ} \mathrm{C}$ & $2100^{\circ} \mathrm{F} / 1150^{\circ} \mathrm{C}$ & $2100^{\circ} \mathrm{F} / 1150^{\circ} \mathrm{C}$ & $2100^{\circ} \mathrm{F} / 1150^{\circ} \mathrm{C}$ & $2100^{\circ} \mathrm{F} / 1150^{\circ} \mathrm{C}$ \\
\hline & $2200^{\circ} \mathrm{F} / 1205^{\circ} \mathrm{C}$ & $2200^{\circ} \mathrm{F} / 1205^{\circ} \mathrm{C}$ & $2300^{\circ} \mathrm{F} / 1260^{\circ} \mathrm{C}$ & $2300^{\circ} \mathrm{F} / 1260^{\circ} \mathrm{C}$ & $2300^{\circ} \mathrm{F} / 1260^{\circ} \mathrm{C}$ \\
\hline & $2300^{\circ} \mathrm{F} / 1260^{\circ} \mathrm{C}$ & $2300^{\circ} \mathrm{F} / 1260^{\circ} \mathrm{C}$ & & & \\
\hline Foundry SA & & - & $2150^{\circ} \mathrm{F} / 1180^{\circ} \mathrm{C}$ & $2135^{\circ} \mathrm{F} / 1170^{\circ} \mathrm{C}$ & $2250^{\circ} \mathrm{F} / 1230^{\circ} \mathrm{C}$ \\
\hline ASTM A 743 & \multicolumn{5}{|c|}{ Minimum $2100^{\circ} \mathrm{F} / 1150^{\circ} \mathrm{C}$} \\
\hline
\end{tabular}

Note: - Water Quench (WQ) was applied to all heats listed in above table.

- Slow Cooling (SC) was also applied to Heat N3GAO (from $2300^{\circ} \mathrm{F} / 1260^{\circ} \mathrm{C} \mathrm{SA}$ ) in addition to $\mathrm{WQ}$. 
Table 5. $\quad$ Critical Pitting Temperature (CPT), Corrosion Rate and NORSOK Corrosion Testing Result for CK-3MCuN (K3GAO \& K3GCO) in the as-cast and solution-annealed conditions

\begin{tabular}{|c|c|c|c|c|c|}
\hline $\begin{array}{c}\text { Material } \\
\text { Code }\end{array}$ & Condition & $\mathrm{CPT}\left({ }^{\circ} \mathrm{C}\right)$ & $\begin{array}{l}\text { Corrosion } \\
\text { Rate(mpy) }\end{array}$ & $\begin{array}{c}\text { Observation } \\
\text { After } \\
\text { Bending } \\
\end{array}$ & $\begin{array}{c}\text { Test Rest } \\
\text { per } \\
\text { NORSOK } \\
\end{array}$ \\
\hline \multirow{5}{*}{ K3GAO } & As-cast & 25 & 54 & Fractured & Fail \\
\hline & $\begin{array}{c}\mathrm{SA}: 2100^{\circ} \mathrm{F}\left(1150^{\circ} \mathrm{C}\right)+ \\
W Q\end{array}$ & 55 & 43 & Fractured & Pass \\
\hline & $\begin{array}{c}\text { SA: } 2200^{\circ} \mathrm{F}\left(1205^{\circ} \mathrm{C}\right)+ \\
W Q\end{array}$ & 60 & 19 & $\begin{array}{c}\text { Minor } \\
\text { Intergranular } \\
\text { separations }\end{array}$ & Pass \\
\hline & $\begin{array}{c}S A: 2300^{\circ} \mathrm{F}\left(1260^{\circ} \mathrm{C}\right)+ \\
W Q\end{array}$ & 55 & 18 & $\begin{array}{c}\text { Minor } \\
\text { Intergranular } \\
\text { separations }\end{array}$ & Pass \\
\hline & $\mathrm{SA}: 2300^{\circ} \mathrm{F}\left(1260^{\circ} \mathrm{C}\right)+\mathrm{SC}$ & 55 & 24 & $\begin{array}{c}\text { Intergranular } \\
\text { and interdendritic } \\
\text { separations } \\
\end{array}$ & Pass \\
\hline \multirow{4}{*}{ K3GCO } & As-cast & 20 & 64 & Fractured & Fail \\
\hline & $\begin{array}{c}S A: 2100^{\circ} \mathrm{F}\left(1150^{\circ} \mathrm{C}\right)+ \\
W Q\end{array}$ & 55 & 21 & $\begin{array}{c}\text { Minor } \\
\text { Intergranular } \\
\text { separations }\end{array}$ & Pass \\
\hline & $\begin{array}{c}\mathrm{SA}: 2200^{\circ} \mathrm{F}\left(1205^{\circ} \mathrm{C}\right)+ \\
W Q\end{array}$ & 65 & 17 & $\begin{array}{c}\text { Minor } \\
\text { Intergranular } \\
\text { separations }\end{array}$ & Pass \\
\hline & $\begin{array}{c}S A: 2300^{\circ} \mathrm{F}\left(1260^{\circ} \mathrm{C}\right)+ \\
W Q\end{array}$ & 65 & 16 & $\begin{array}{c}\text { Minor } \\
\text { Intergranular } \\
\text { separations }\end{array}$ & Pass \\
\hline $254 \mathrm{SMO}$ & Wrought & 75 & 11 & No separations & Pass \\
\hline
\end{tabular}

Note:

* Pitting test condition: G48C (6\% $\mathrm{FeCl}_{3}+1 \% \mathrm{HCl}, 24$ hours, 600 grit surface).

* Corrosion test condition: G28A (Boiling in $\mathrm{Fe}_{2}\left(\mathrm{SO}_{4}\right)_{3} / \mathrm{H}_{2} \mathrm{SO}_{4}, 120 \mathrm{hr}, 120$ grit surface).

* NORSOK corrosion test condition: 1) Pickled in a solution of $20 \% \mathrm{HNO}_{3}+5 \% \mathrm{HF}$ at $60^{\circ} \mathrm{C}$ for 5 min prior to corrosion testing, 600 grit surface.

2) Immersed into a solution of $6 \% \mathrm{FeCl}_{3}+1 \% \mathrm{HCl}$ at $50^{\circ} \mathrm{C}$ for 24 hours. 
Table 6. Critical Pitting Temperature (CPT), Corrosion Rate, and NORSOK Corrosion Testing Result for CN-3MN (N3GAO \& N3GBO) in the as-cast and solution-annealed conditions

\begin{tabular}{|c|c|c|c|c|c|}
\hline $\begin{array}{l}\text { Material } \\
\text { Code }\end{array}$ & Condition & $\mathrm{CPT}\left({ }^{\circ} \mathrm{C}\right)$ & $\begin{array}{l}\text { Corrosion } \\
\text { Rate(mpy) }\end{array}$ & $\begin{array}{l}\text { Observation } \\
\text { After } \\
\text { Bending }\end{array}$ & $\begin{array}{c}\text { Test Rest } \\
\text { per } \\
\text { NORSOK }\end{array}$ \\
\hline \multirow{5}{*}{ N3GAO } & As-cast & 45 & 22 & $\begin{array}{c}\text { Intergranular } \\
\text { and interdendritic } \\
\text { separations }\end{array}$ & Fail \\
\hline & $\begin{array}{c}S A: 2100^{\circ} \mathrm{F}\left(1150^{\circ} \mathrm{C}\right)+ \\
W Q\end{array}$ & 65 & 19 & $\begin{array}{c}\text { Minor } \\
\text { Intergranular } \\
\text { separations } \\
\end{array}$ & Pass \\
\hline & $\begin{array}{c}S A: 2200^{\circ} \mathrm{F}\left(1205^{\circ} \mathrm{C}\right)+ \\
\text { WQ }\end{array}$ & 65 & 14 & No separations & Pass \\
\hline & $\begin{array}{c}\text { SA: } 2300^{\circ} \mathrm{F}\left(1260^{\circ} \mathrm{C}\right)+ \\
W Q\end{array}$ & 65 & 17 & $\begin{array}{c}\text { Minor } \\
\text { Intergranular } \\
\text { separations }\end{array}$ & Pass \\
\hline & $\mathrm{SA}: 2300^{\circ} \mathrm{F}\left(1260^{\circ} \mathrm{C}\right)+\mathrm{SC}$ & 65 & 29 & $\begin{array}{c}\text { Intergranular } \\
\text { and interdendritic } \\
\text { separations }\end{array}$ & Pass \\
\hline \multirow{4}{*}{ N3GBO } & As-cast & 50 & 18 & $\begin{array}{c}\text { Minor } \\
\text { Intergranular } \\
\text { separations }\end{array}$ & Fail \\
\hline & $\begin{array}{c}\mathrm{SA}: 2100^{\circ} \mathrm{F}\left(1150^{\circ} \mathrm{C}\right)+ \\
W Q\end{array}$ & 50 & 18 & $\begin{array}{c}\text { Minor } \\
\text { Intergranular } \\
\text { separations } \\
\end{array}$ & Pass \\
\hline & $\begin{array}{c}S A: 2200^{\circ} \mathrm{F}\left(1205^{\circ} \mathrm{C}\right)+ \\
W Q\end{array}$ & 60 & 12 & No separations & Pass \\
\hline & $\begin{array}{c}\mathrm{SA}: 2300^{\circ} \mathrm{F}\left(1260^{\circ} \mathrm{C}\right)+ \\
W Q\end{array}$ & 60 & 11 & No separations & Pass \\
\hline AL-6XN & Wrought & 85 & 12 & No separations & Pass \\
\hline
\end{tabular}

Note:

${ }^{*}$ Pitting test condition: $\mathrm{G} 48 \mathrm{C}\left(6 \% \mathrm{FeCl}_{3}+1 \% \mathrm{HCl}, 24\right.$ hours, 600 grit surface).

${ }^{*}$ Corrosion test condition: G28A (Boiling in $\mathrm{Fe}_{2}\left(\mathrm{SO}_{4}\right)_{3} / \mathrm{H}_{2} \mathrm{SO}_{4}, 120 \mathrm{hr}, 120$ grit surface).

* NORSOK corrosion test condition: 1) Pickled in a solution of $20 \% \mathrm{HNO}_{3}+5 \% \mathrm{HF}$ at $60^{\circ} \mathrm{C}$ for 5 min prior to corrosion testing, 600 grit surface.

2) Immersed into a solution of $6 \% \mathrm{FeCl}_{3}+1 \% \mathrm{HCl}$ at $50^{\circ} \mathrm{C}$ for 24 hours. 
Table 7. Chemical Composition at Three Locations of 1" Diameter Cast Bar --- CK-3MCuN Heat K3GAO

\begin{tabular}{|c|c|c|c|c|c|c|c|c|c|c|c|c|c|c|c|c|c|c|c|c|}
\hline & C & $\mathrm{Cr}$ & Mo & $\mathrm{Ni}$ & $\mathrm{Cu}$ & $\mathbf{S}$ & Mn & $\mathbf{P}$ & $\mathbf{S i}$ & $\mathrm{Ta}$ & V & $\mathbf{W}$ & Mg & Co & $\mathrm{Fe}$ & $\mathrm{Nb}$ & $\mathrm{Al}$ & $\mathrm{Ti}$ & 0 & $\mathbf{N}$ \\
\hline $\begin{array}{c}\text { Location } \\
1\end{array}$ & 0.031 & 19.89 & 7.39 & 18.25 & 0.61 & 0.009 & 0.55 & 0.011 & 0.66 & $<0.02$ & 0.05 & 0.15 & $<0.04$ & 0.11 & Bal & 0.01 & $<0.01$ & $<0.01$ & 0.033 & 0.24 \\
\hline $\begin{array}{c}\text { Location } \\
2 \\
\end{array}$ & 0.030 & 19.87 & 7.37 & 18.33 & 0.61 & 0.010 & 0.55 & 0.011 & 0.67 & $<0.02$ & 0.05 & 0.15 & $<0.04$ & 0.11 & Bal & 0.01 & $<0.01$ & $<0.01$ & 0.033 & 0.23 \\
\hline $\begin{array}{c}\text { Location } \\
3 \\
\end{array}$ & 0.030 & 19.90 & 7.46 & 18.35 & 0.61 & 0.009 & 0.55 & 0.012 & 0.68 & $<0.02$ & 0.05 & 0.15 & $<0.04$ & 0.11 & Bal & 0.01 & $<0.01$ & $<0.01$ & 0.033 & 0.24 \\
\hline $\begin{array}{l}\text { ASTM } \\
\text { A } 743 \\
\end{array}$ & $\begin{array}{c}0.025 \\
\max \end{array}$ & $\begin{array}{l}19.5- \\
20.5\end{array}$ & $\begin{array}{l}6.0- \\
7.0\end{array}$ & $\begin{array}{l}17.5- \\
19.5\end{array}$ & $\begin{array}{c}0.50- \\
1.00\end{array}$ & $\begin{array}{c}0.010 \\
\max \end{array}$ & $\begin{array}{l}1.20 \\
\max \end{array}$ & $\begin{array}{c}0.045 \\
\max \end{array}$ & $\begin{array}{l}1.00 \\
\max \end{array}$ & NS & NS & NS & NS & NS & NS & NS & NS & NS & NS & $\begin{array}{l}0.18- \\
0.24\end{array}$ \\
\hline
\end{tabular}

NS Not Specified.

Not Determined.

Chemical analysis conducted by The ABB-CE. 
Table 8. Chemical Composition at Two Locations of Tapered Bar (at 1.3" diameter) --- CK-3MCuN Heat K3GCO

\begin{tabular}{|c|c|c|c|c|c|c|c|c|c|c|c|c|c|c|c|c|c|c|c|c|}
\hline & C & $\mathrm{Cr}$ & Mo & $\mathrm{Ni}$ & $\mathrm{Cu}$ & $S$ & Mn & $\mathbf{P}$ & Si & $\mathrm{Ta}$ & V & W & Mg & Co & $\mathrm{Fe}$ & $\mathrm{Nb}$ & $\mathrm{Al}$ & $\mathrm{Ti}$ & 0 & $\mathbf{N}$ \\
\hline $\begin{array}{l}\text { Edge } \\
\text { Area }\end{array}$ & 0.031 & 20.22 & 6.53 & 18.40 & 0.63 & 0.009 & 0.73 & 0.009 & 0.98 & $<0.02$ & 0.02 & $<0.02$ & $<0.04$ & 0.03 & Bal & 0.01 & $<0.01$ & $<0.01$ & 0.018 & 0.23 \\
\hline $\begin{array}{l}\text { Center } \\
\text { Region }\end{array}$ & 0.021 & 20.43 & 7.02 & 18.59 & 0.64 & 0.010 & 0.74 & 0.009 & 1.05 & $<0.02$ & 0.02 & $<0.02$ & $<0.04$ & 0.03 & Bal & 0.01 & $<0.01$ & $<0.02$ & 0.028 & 0.22 \\
\hline $\begin{array}{l}\text { ASTM } \\
\text { A } 743\end{array}$ & $\begin{array}{c}0.025 \\
\max \end{array}$ & $\begin{array}{l}19.5- \\
20.5\end{array}$ & $\begin{array}{l}6.0- \\
7.0\end{array}$ & $\begin{array}{c}17.5- \\
19.5\end{array}$ & $\begin{array}{l}0.50- \\
1.00\end{array}$ & $\begin{array}{c}0.010 \\
\max \end{array}$ & $\begin{array}{l}1.20 \\
\max \end{array}$ & $\begin{array}{c}0.045 \\
\max \end{array}$ & $\begin{array}{l}1.00 \\
\max \end{array}$ & NS & NS & NS & NS & NS & NS & NS & NS & NS & NS & $\begin{array}{l}0.18- \\
0.24\end{array}$ \\
\hline
\end{tabular}

NS Not Specified.

- Not Determined.

Chemical analysis conducted by The ABB-CE 


\section{Appendix A}

Corrosion test results

for

CK-3MCuN and CN-3MN Cast Wedge Blocks in as-cast and solution annealed conditions [4] 
Table A1. Corrosion Test Result for CK-3MCuN

\begin{tabular}{|c|c|c|c|c|}
\hline Material & Condition & $\mathrm{CPT}\left({ }^{\circ} \mathrm{C}\right)$ & $\begin{array}{l}\text { Corrosion } \\
\text { Rate (mpy) }\end{array}$ & $\begin{array}{c}\text { Observation } \\
\text { After } \\
\text { Bending } \\
\end{array}$ \\
\hline \multirow{4}{*}{ Heat 2} & As-cast & 30 & 15 & $\begin{array}{l}\text { Intergranular } \\
\text { separations }\end{array}$ \\
\hline & $\begin{array}{c}\text { SA: } 2250^{\circ} \mathrm{F}\left(1230^{\circ} \mathrm{C}\right)+\mathrm{WQ} \\
\text { (Foundry) }\end{array}$ & 55 & 14 & No separations \\
\hline & $\begin{array}{c}\text { SA: } 2100^{\circ} \mathrm{F}\left(1150^{\circ} \mathrm{C}\right)+\mathrm{WQ} \\
(\mathrm{UT})\end{array}$ & 55 & 14 & No separations \\
\hline & $\begin{array}{c}\text { SA: } 2300^{\circ} \mathrm{F}\left(1260^{\circ} \mathrm{C}\right)+\mathrm{WQ} \\
(\mathrm{UT})\end{array}$ & 55 & 18 & separations \\
\hline \multirow{5}{*}{ Heat 3} & As-cast & 25 & 22 & $\begin{array}{l}\text { Intergranular } \\
\text { separations }\end{array}$ \\
\hline & $\begin{array}{c}\text { SA: } 2200^{\circ} \mathrm{F}\left(1205^{\circ} \mathrm{C}\right)+\mathrm{WQ} \\
\text { (Foundry) }\end{array}$ & 50 & 19 & No separations \\
\hline & $\begin{array}{c}\text { SA: } 2100^{\circ} \mathrm{F}\left(1150^{\circ} \mathrm{C}\right)+\mathrm{WQ} \\
(\mathrm{UT})\end{array}$ & 55 & - & - \\
\hline & $\begin{array}{c}\text { SA: } 2300^{\circ} F\left(1260^{\circ} \mathrm{C}\right)+W Q \\
(\text { UT) }\end{array}$ & 55 & - & - \\
\hline & $\begin{array}{c}\mathrm{SA}: 2300^{\circ} \mathrm{F}\left(1260^{\circ} \mathrm{C}\right)+\mathrm{SC} \\
(\mathrm{UT})\end{array}$ & 40 & - & - \\
\hline \multirow{4}{*}{ Heat 5} & As-cast & 40 & 13 & $\begin{array}{l}\text { Interdendritic } \\
\text { separations }\end{array}$ \\
\hline & $\begin{array}{c}\text { SA: } 2250^{\circ} \mathrm{F}\left(1230^{\circ} \mathrm{C}\right)+\mathrm{WQ} \\
\text { (Foundry) }\end{array}$ & 60 & 12 & No separations \\
\hline & $\begin{array}{c}\text { SA: } 2100^{\circ} \mathrm{F}\left(1150^{\circ} \mathrm{C}\right)+\mathrm{WQ} \\
(\mathrm{UT})\end{array}$ & 60 & 13 & No separations \\
\hline & $\begin{array}{c}\mathrm{SA}: 2300^{\circ} \mathrm{F}\left(1260^{\circ} \mathrm{C}\right)+\mathrm{WQ} \\
(\mathrm{UT})\end{array}$ & 65 & 12 & No separations \\
\hline $254 \mathrm{SMO}$ & Wrought & 75 & 11 & No separations \\
\hline
\end{tabular}

Note: Pitting test condition: $10 \% \mathrm{FeCl}_{3}$ for 24 hours.

Intergranular corrosion test condition: G28A (24 hours). 
Table A2. Corrosion Test Result for CN-3MN

\begin{tabular}{|c|c|c|c|c|}
\hline Material & Condition & $\mathrm{CPT}\left({ }^{\circ} \mathrm{C}\right)$ & $\begin{array}{l}\text { Corrosion } \\
\text { Rate (mpy) }\end{array}$ & $\begin{array}{c}\text { Observation } \\
\text { After } \\
\text { Bending }\end{array}$ \\
\hline \multirow{4}{*}{ Heat 1} & As-cast & 33 & 17 & $\begin{array}{l}\text { Intergranular } \\
\text { separations }\end{array}$ \\
\hline & $\begin{array}{c}\text { SA: } 2150^{\circ} \mathrm{F}\left(1180^{\circ} \mathrm{C}\right)+\mathrm{WQ} \\
\text { (Foundry) }\end{array}$ & 55 & 16 & No separations \\
\hline & $\begin{array}{c}\text { SA: } 2100^{\circ} F\left(1150^{\circ} \mathrm{C}\right)+W Q \\
\text { (UT) }\end{array}$ & 65 & - & - \\
\hline & $\begin{array}{c}\mathrm{SA}: 2300^{\circ} \mathrm{F}\left(1260^{\circ} \mathrm{C}\right)+\mathrm{WQ} \\
(\mathrm{UT})\end{array}$ & 60 & - & - \\
\hline \multirow{4}{*}{ Heat 4} & As-cast & 40 & 17 & $\begin{array}{c}\text { Intergranular } \\
\text { separations }\end{array}$ \\
\hline & $\begin{array}{c}\text { SA: } 2135^{\circ} \mathrm{F}\left(1170^{\circ} \mathrm{C}\right)+\mathrm{WQ} \\
\text { (Foundry) }\end{array}$ & 55 & 17 & No separations \\
\hline & $\begin{array}{c}\text { SA: } 2100^{\circ} \mathrm{F}\left(1150^{\circ} \mathrm{C}\right)+\mathrm{WQ} \\
\text { (UT) }\end{array}$ & 60 & - & - \\
\hline & $\begin{array}{c}\text { SA: } 2300^{\circ} \mathrm{F}\left(1260^{\circ} \mathrm{C}\right)+\mathrm{WQ} \\
(\mathrm{UT})\end{array}$ & 60 & - & - \\
\hline \multirow{4}{*}{ Heat 5} & As-cast & 45 & 14 & $\begin{array}{l}\text { Interdendritic } \\
\text { separations }\end{array}$ \\
\hline & $\begin{array}{c}\mathrm{SA}: 2250^{\circ} \mathrm{F}\left(1230^{\circ} \mathrm{C}\right)+\mathrm{WQ} \\
\text { (Foundry) }\end{array}$ & 55 & 13 & No separations \\
\hline & $\begin{array}{c}\text { SA: } 2100^{\circ} F\left(1150^{\circ} \mathrm{C}\right)+W Q \\
(\mathrm{UT})\end{array}$ & 55 & 14 & No separations \\
\hline & $\begin{array}{c}\text { SA: } 2300^{\circ} \mathrm{F}\left(1260^{\circ} \mathrm{C}\right)+\mathrm{WQ} \\
\text { (UT) }\end{array}$ & 55 & 12 & No separations \\
\hline AL-6XN & Wrought & 85 & 12 & No separations \\
\hline
\end{tabular}

Note: Pitting test condition: $10 \% \mathrm{FeCl}_{3}$ for 24 hours. Intergranular corrosion test condition: G28A (24 hours). 